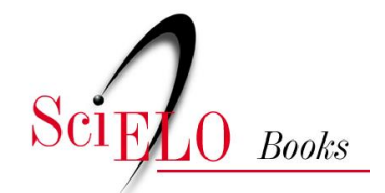

\title{
Água e Democracia na América Latina
}

\author{
José Esteban Castro
}

SciELO Books / SciELO Livros / SciELO Libros

CASTRO, J. E. Água e democracia na América Latina [online]. Campina Grande: EDUEPB, 2016, 427 p. ISBN 978-85-7879-486-6. Available from: doi: 10.7476/9788578794866. Also available in ePUB from: http://books.scielo.org/id/tn4y9/epub/castro-9788578794866.epub.

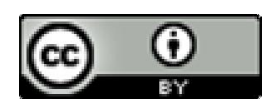

All the contents of this work, except where otherwise noted, is licensed under a Creative Commons Attribution $\underline{4.0 \text { International license. }}$

Todo o conteúdo deste trabalho, exceto quando houver ressalva, é publicado sob a licença Creative Commons Atribição 4.0.

Todo el contenido de esta obra, excepto donde se indique lo contrario, está bajo licencia de la licencia Creative Commons Reconocimento 4.0. 


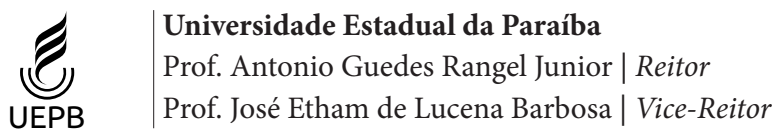

\section{eduepb}

Editora da Universidade Estadual da Paraíba

Luciano do Nascimento Silva | Diretor

Antonio Roberto Faustino da Costa | Diretor-Adjunto

\section{Conselho Editorial}

Presidente

Luciano do Nascimento Silva

\section{Conselho Científico}

Alberto Soares Melo

Cidoval Morais de Sousa

Hermes Magalhães Tavares

José Esteban Castro

José Etham de Lucena Barbosa

José Tavares de Sousa

Marcionila Fernandes

Olival Freire Jr

Roberto Mauro Cortez Motta

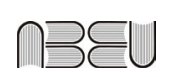

Editora filiada a ABEU

EDITORA DA UNIVERSIDADE ESTADUAL DA PARAÍBA

Rua Baraúnas, 351 - Bairro Universitário - Campina Grande-PB - CEP 58429-500

Fone/Fax: (83) 3315-3381 - http://eduepb.uepb.edu.br - email: eduepb@uepb.edu.br 


\author{
José Esteban Castro
}

(Universidade de Newcastle - Reino Unido)

\title{
Água e Democracia na América Latina
}

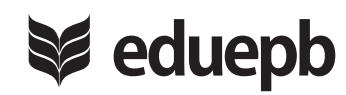

Campina Grande-PB

2016 
Copyright $\odot$ EDUEPB

A reprodução não-autorizada desta publicação, por qualquer meio, seja total ou parcial, constitui violação da Lei no 9.610/98.

Editora da Universidade Estadual da Paraíba

Luciano do Nascimento Silva | Diretor

Antonio Roberto Faustino da Costa | Diretor-Adjunto

Design Gráfico

Erick Ferreira Cabral

Jefferson Ricardo Lima Araujo Nunes

Lediana Costa

Leonardo Ramos Araujo

Comercialização e Distribução

Vilani Sulpino da Silva

Danielle Correia Gomes

\section{Divulgação}

Zoraide Barbosa de Oliveira Pereira

\section{Revisão Linguística}

Elizete Amaral de Medeiros

\section{Normalização Técnica}

Jane Pompilo dos Santos

Depósito legal na Biblioteca Nacional, conforme decreto ${ }^{\circ}$ 1.825, de 20 de dezembro de 1907.

C355a Castro, Jose Esteban.

Água e democracia na América Latina [Livro Eletrônico]. /Jose Esteban

Castro. - Campina Grande: EDUEPB, 2016.

3800 kb. 450 p.: il.

Modo de acesso: Word Wide Web

$<$ http://www.uepb.edu.br/ebooks>

ISBN: 978.85.7879.227-5

ISBN EBOOK: 978.85.7879.228-2

1. Água 2. Democracia 3. América Latina. 4. Democratização. 5. Elementos da Natureza I. Título. 


\section{Sumário}

Apresentação

Capítulo 1

Luchas sociales por el agua y el proceso de democratización en América Latina

Capítulo 2

Incertezas manufacturadas, tecnociência e as políticas da desigualdade: o caso da gestão da água

Capítulo 3

Proposiciones para el examen teórico y empírico de la privatización: el caso de los servicios de agua y saneamiento en América Latina.

\section{Capítulo 4}

Agua, democracia, y la construcción de la ciudadanía .. 100

Capítulo 5

Agua y gobernabilidad: entre la ideología neoliberal y la memoria histórica 
Capítulo 6

A normatização da prestação dos serviços de água

e esgoto, a experiência de Inglaterra e Gales. 160

Capítulo 7

A participação do setor privado nos serviços públicos de abastecimento de água e esgotamento sanitário: resposta aos fracassos do setor público?

202

Capítulo 8

Gestão democrática nos serviços de saneamento 244

Capítulo 9

Participación y control social en los servicios de agua y saneamiento 305

Capítulo 10

Los bienes comunes y la ciudadanía: contradicciones de una relación en desarrollo

Capítulo 11

A água (ainda) não é uma mercadoria: aportes para o debate sobre a mercantilização da água

\section{Capítulo 12}

Apuntes para una ecología política de la integración en América Latina y el Caribe 


\section{Agradecimento}

Quero agradecer ao Prof. Cidoval Moraes de Sousa pela iniciativa de organizar esta publicação que permite disponibilizar um conjunto de meus trabalhos publicados como artigos e capítulos num livro. Esta iniciativa forma parte de uma parceria de longo prazo com a Universidade Estadual da Paraíba, no marco das atividades da Rede WATERLAT-GOBACIT (www. waterlat.org).

Também quero agradecer à Nidia Piñeyro, colega da Universidade Nacional do Nordeste (UNNE), Resistencia, Chaco, Argentina, pelo apoio na revisão detalhada da maioria dos textos em espanhol. 


\section{Apresentação}

Este livro apresenta uma série de trabalhos publicados previamente como artigos ou capítulos. O propósito foi reunir estes diversos trabalhos numa coletânea para facilitar o acesso, já que muitos deles não estão facilmente disponíveis aos leitores em Brasil e na América Latina em geral.

Como o título indica, o eixo central dos trabalhos é o processo de democratização na América Latina, um tema que abordo desde a perspectiva da ecologia política, colocando a ênfase nos temas da política e a gestão da água e dos serviços essenciais baseados no uso da água. Pode-se dizer que os trabalhos abordam o tema da política da água como um ponto de observação privilegiado para examinar os avanços e retrocessos do processo de democratização na região, com foco nos processos de construção da cidadania substantiva. Neste sentido, um tema norteador dos trabalhos são os obstáculos e as ameaças ao processo democratizador. Entre estes obstáculos e ameaças destacam-se os ataques as formas de propriedade e de gestão comunitárias e públicas dos elementos da natureza, a água incluída, por parte das políticas neoliberais introduzidas na região desde a década de 1980. Estes obstáculos e ameaças formam parte do processo mais abrangente de mercantilização dos bens comuns e dos bens públicos, e incluem formas abertas ou encobertas da privatização, a des- e a re-regulação, e a liberalização. Também cabe mencionar os ataques aos direitos cidadãos, particularmente os direitos sociais, que apesar de ter sido consagrados formalmente nas constituições dos países da região, na prática continuam sendo inacessíveis para as grandes maiorias que nunca conseguiram beneficiar-se do seu exercício concreto. Ainda assim, para os setores dominantes nas sociedades latino-americanas a mera existência formal de esses direitos constitui uma afrenta ao status quo excludente, baseado na reprodução de desigualdades qualitativas e quantitativas, um status quo que estes atores procuram defender e consolidar. Em relação com isto, outro tema que atravessa os diferentes trabalhos é o das distintas formas e dimensões das 
lutas sociais que que procuram defender as experiências de democracia substantiva e aprofundar e consolidar o processo de democratização. $O$ foco na América Latina justifica-se porque a região tem sido um laboratório das lutas sociais pela defesa do direito a água e dos serviços públicos essenciais, incluindo confrontações dirigidas contra os processos privatizadores e mercantilizadores e contra a destruição das fontes de água pelas práticas extrativistas impulsadas por políticas que reduzem a complexidade dos processos de desenvolvimento social ao plano de mero crescimento econômico.

Apesar de que a maioria dos textos se referem a casos latino-americanos, alguns trabalhos também trazem referências a experiências europeias, particularmente do Reino Unido. Este é um ponto importante, porque no debate local e regional na América Latina existe uma tendência a desconsiderar a experiência dos países centrais, particularmente da Europa e dos Estados Unidos, em relação a estes temas. Por exemplo, a pesar do fato de que as políticas neoliberais têm sido promovidas desde esses países, é muito incomum o exame das políticas ambientais, e em particular a política da água vigentes nesses territórios. Por exemplo, o fato de que nos Estados Unidos os serviços de saneamento da maioria da população são fornecidos por empresas públicas, não privatizadas, e praticamente desconhecido na América Latina, o que contribui a obscurecer os debates sobre a política da água e as políticas de serviços públicos em geral na região.

O livro debate estes e outros temas fazendo sobre a base de exemplos empíricos, analisados em perspectiva histórica, para contribuir a estabelecer um balanço no debate que permita aprofundar nos problemas que confronta América Latina em relação aos desafios da política e a gestão da água e dos serviços públicos essenciais. Nesse sentido, os trabalhos também procuram expor alguns dos mitos que perigosamente continuam formando parte do ideário político e ideológico predominante em nossos países. Desejo ao leitor uma proveitosa leitura, esperando contribuir a fortalecer a capacidade de análise crítica de nossas realidades e inspirar a construção de forma de política e gestão da água igualitárias, inclusivas, e genuinamente democráticas.

\section{José Esteban Castro}

Newcastle upon Tyne, Reino Unido, julho de 2016 


\section{Capítulo 1}

\section{Luchas sociales por el agua y el proceso de democratización en América Latina ${ }^{1}$}

\section{Introducción}

En este artículo me propongo explorar algunas de las conexiones entre las luchas sociales por el agua y el ejercicio de la ciudadanía substantiva y la gobernabilidad democrática en América Latina, con énfasis en el período que comienza en la década de 1970. Dado lo breve de este artículo introductorio, solamente presento aquí los lineamientos más genéricos de un argumento que he desarrollado en mayor detalle en otros trabajos (ver por ejemplo Castro, 2004, 2006, 2007, 2008, 2009). También por razones de espacio no trato en detalle aquí las características de los actores de las luchas por el agua, un tema que de todas maneras ha sido objeto de una amplia gama de trabajos que consideran, por ejemplo, el impacto de las identidades sociales de clase, étnicas o de género en las luchas sociales por el agua registradas en América Latina durante las últimas décadas (véase, por ejemplo, Laurie et. al., 2002; Bennett et. al., 2005; Crespo Flores, 2009; Castro y Costa Ribeiro, 2010). Finalmente, y por las mismas razones, este trabajo trata específicamente el caso de las luchas por el agua y no examina las interconexiones entre éstas y otros conflictos, aunque desde luego un estudio comprehensivo requeriría la consideración del entramado que componen las diversas formas de lucha social que tienen lugar en América Latina en relación con el control, propiedad y gestión del territorio (tierra, agua, bosques, etc.). Más bien, el centro de atención en este artículo son algunas distinciones

1 El original en inglés de este artículo fue publicado en Development, 2008, 51, pp. 72-76. Una traducción al español fue publicada previamente en: Anuario de Estudios Americanos, Vol. 66, No 2, 2009, pp. 15-22. 
analíticas que, en mi sugerencia, permiten avanzar en la sistematización del estudio de las luchas por el agua. Finalmente, cierro el trabajo con una breve referencia a las vinculaciones que pueden establecerse entre las luchas por el agua y el proceso de democratización en América Latina.

\section{Algunos patrones reconocibles en las luchas por el agua}

Una primera categorización de los eventos de lucha social por el agua identificados en América Latina desde la década de 1970 puede hacerse dividiéndolos en dos grandes grupos: luchas por el agua a) ecocéntricas y b) antropocéntricas. Como instrumento analítico esta distinción es en cierto modo artificial, ya que en la práctica la mayoría de los eventos de lucha por el agua tienden a combinar ambos aspectos. Sin embargo, la distinción no es enteramente arbitraria y además resulta de gran utilidad para iluminar ciertos aspectos específicos clave del proceso. En primer lugar, algunos expertos han insistido tradicionalmente en la necesidad de mantener una diferenciación analítica entre el estudio de los ecosistemas acuáticos, por una parte, y la infraestructura de los servicios derivados del agua o basados en ella. Por otra parte, la diferenciación se mantuvo, entre otras razones, porque históricamente ha existido una separación entre ambas áreas de actividad. Esto se ha reflejado, por ejemplo, en una distinción de estas dos esferas de acción en relación a los sistemas legales e institucionales que las regulan, las prácticas de gestión, e incluso en las formas que ha adoptado la división del trabajo entre las distintas disciplinas científicas que producen conocimiento sobre el agua, por ejemplo, entre la hidrología y la ingeniería de infraestructuras hídricas.

En segundo lugar, otra razón para mantener esta distinción analítica entre luchas ecocéntricas y antropocéntricas es que podemos identificar una cierta divergencia entre las luchas sociales conectadas con la protección de los ecosistemas acuáticos (por ejemplo, luchas contra la contaminación y el deterioro de dichos ecosistemas o contra los impactos negativos que la intrusión humana en la forma de grandes obras de infraestructura tiene tanto sobre el ciclo del agua como sobre la biodiversidad) y aquellas luchas orientadas a la defensa de los derechos de los seres humanos contemporáneos a 
un ambiente acuático limpio o al acceso a servicios de agua que son esenciales para la sobrevivencia y para el mantenimiento de condiciones de vida digna. Esta es una consideración importante porque las contradicciones que se dan al interior de los movimientos sociales y políticos conectados con las luchas por el agua a menudo expresan la existencia de intereses materiales, creencias, valores, principios y fines de carácter frecuentemente antagónico y, a veces, incluso irreconciliables. Aunque dichas contradicciones no sean necesariamente inevitables o irresolubles, sí es importante reconocer que las mismas son el resultado de procesos históricos específicos que caracterizan el desarrollo del movimiento ambientalista en general (véase, por ejemplo, Martínez Alier, 2002: 1-15), y que también se expresan en las contradicciones que pueden observarse entre los actores involucrados en las luchas por el agua en América Latina y en otros lugares.

Por ejemplo, muy frecuentemente los actores que están involucrados en luchas orientadas a la protección de ecosistemas acuáticos frágiles y de la vida silvestre acuática (por ejemplo, véase WWFLA, 2011) han mantenido silencio con respecto a la rápida expansión de la privatización del agua en esos mismos territorios, a pesar de las enormes consecuencias que dichas políticas tienen en relación a la gobernabilidad democrática y la justicia social. Lo opuesto también es cierto con frecuencia, ya que como tendencia los actores que han estado al frente de la lucha contra la privatización del agua han puesto menos énfasis sobre los problemas específicos vinculados a la necesidad de proteger y recuperar fuentes de agua que han sido históricamente objeto de una gestión ecológicamente deficiente por parte de agentes públicos y privados. Más aún, con frecuencia los actores que luchan por la defensa del acceso universal a los beneficios derivados de la gestión social del agua han tenido grandes dificultades para adoptar una posición crítica con respecto a las políticas gubernamentales fundadas en la construcción de infraestructuras hidráulicas de gran escala, como son las represas, las hidrovías o los transvases de cuencas, entre otros ejemplos, muchas de los cuales tienen impactos negativos tanto sobre los ecosistemas acuáticos como sobre las poblaciones humanas.

Esta última contradicción es un elemento crucial en los conflictos por el agua que afectan a muchos de los proyectos de desarrollo implementados 
en América Latina, en los cuales la construcción de grandes infraestructuras, con demasiada frecuencia, ha causado el desplazamiento forzado de poblaciones indígenas y de color, la expropiación autoritaria de derechos de agua sin compensación adecuada y daños irreversibles a los ecosistemas. Estas políticas han dado lugar, recurrentemente, a casos de corrupción público-privada y a la reproducción de formas de injusticia socio-ambiental en el acceso a los beneficios derivados de la construcción de dichas obras, trátese de proyectos de agua para consumo humano, para irrigación o para la protección de las poblaciones contra eventos extremos como son las sequías o las inundaciones (por ejemplo, véase Valencio, 1995; Boelens y Hoogendam, 2002).

Actualmente existe un gran número de obras de infraestructura hídrica en América Latina enmarañadas en luchas sociales surgidas de los impactos sociales, políticos, económicos, culturales y ambientales de estos proyectos, -las hidrovías, represas y otras obras- que son parte del Plan Puebla-Panamá en México y Centroamérica, y de la Iniciativa para la Integración de la Infraestructura Regional (IIRSA) en Sudamérica (véase, entre otras fuentes, MAB, 2011; OLCA, 2011, REDLAR, 2011, TRAGUA, 2011).

Una distinción analítica más fundamental, siempre en la perspectiva de este trabajo, lleva a diferenciar las confrontaciones entre las fuerzas socio-económicas y políticas que impulsan la expansión y consolidación de relaciones capitalistas, en particular, mediante la aceleración y extensión del proceso de mercantilización del agua, y las diferentes formas de resistencia contra el avance de formas hegemónicas de gestión y gobernabilidad del agua. Estas luchas de resistencia adoptan un amplio rango de estrategias y "vocabularios de protesta" (Guha y Martínez-Alier, 1997: 11-16), que van desde la defensa de los derechos indígenas y la denuncia del "racismo hídrico" hasta la recuperación de los bienes comunes y públicos y la búsqueda del reconocimiento de un "derecho humano" al agua. El análisis de este aspecto de las luchas por el agua requiere tomar distancia con respecto a los discursos y a los objetivos declarados de los actores y una consideración cuidadosa de las tendencias estructurales tanto como de la dirección que toman dichos procesos en última instancia ya que las dinámicas son, en gran medida, autónomas de las preocupaciones más inmediatas de los 
participantes. La comprensión de la relación entre la dimensión subjetiva de las luchas y las tendencias estructurales y dirección general del proceso está frecuentemente más allá del alcance de los actores, en gran medida debido al carácter multi-dimensional y trans-temporal de dicha dinámica. Por ejemplo, en los debates contemporáneos sobre la privatización del agua en América Latina frecuentemente se reifica la tensión entre lo "público" y lo "privado", lo cual tiende a obscurecer el hecho de que a pesar de las aparentes contradicciones entre agentes públicos y privados, ambos "bandos" contribuyen al avance y consolidación de formas capitalistas de gestión del agua fundadas en modelos de gobernabilidad democrática y ciudadanía meramente formales, no substantivos. Esto puede verse en la práctica, y no solamente en América Latina, en las reformas introducidas desde la década de 1980 en las empresas de agua y saneamiento de propiedad y gestión públicos. A partir de dichas reformas se espera que estas empresas presten servicios esenciales para la vida como los de agua y saneamiento sobre la base de principios mercantiles y se les exige que abandonen la noción de que dichos servicios constituyen un derecho social o un bien público, no digamos ya un derecho humano. Este proceso de transformación de las empresas públicas en entes que se comportan como empresas privadas cuyo objetivo prioritario es la producción de ganancia antes que la satisfacción de las necesidades esenciales de las poblaciones ya se encuentra muy avanzado en América Latina, incluyendo el caso de algunos países cuyos gobiernos se ubican nominalmente a la izquierda del espectro político. Esta situación es un ejemplo de que el proceso de expansión de consolidación de formas capitalistas de gestión y gobernabilidad del agua es en gran medida autónomo del carácter público o privado de los agentes involucrados.

En relación a lo anterior, cabe aclarar que la identificación de esta ambigüedad en las confrontaciones entre lo "público" y lo "privado" no significa que debamos perder de vista la distinción entre privatización (en sus diferentes formas) y gestión pública del agua y sus servicios. En este sentido, existen lecciones muy importantes derivadas de ejemplos excelentes identificados en América Latina, particularmente en Brasil, Venezuela, México, Uruguay, Argentina, El Salvador, Bolivia y Perú, entre otros casos, donde los actores han desarrollado una comprensión muy clara de estas complejidades: 
como tendencia general sus luchas contra la mercantilización del agua son dirigidas indistintamente contra iniciativas privadas o públicas. Esto se expresa, por ejemplo, en el hecho de que sus luchas combinan blancos múltiples: la oposición a la mercantilización de servicios esenciales de agua-que incluye la resistencia contra formas abiertas o disimuladas de privatización, como por ejemplo las asociaciones o partenariados público-privados o la mercantilización de las empresas públicas- intentos de revitalizar la noción de que dichos servicios constituyen un derecho social de ciudadanía, un bien común, un derecho humano tanto como estrategias dirigidas a fortalecer a las autoridades locales y desarrollar asociaciones o partenariados público-públicos para la gestión eficiente y transparente de los servicios esenciales de agua y saneamiento (véase, por ejemplo, Balanyá et. al., 2005; RED VIDA, 2011). Las iniciativas y prácticas de estos actores están dando lugar a formas emergentes, potencialmente emancipatorias, de gestión y gobernabilidad del agua que requieren apoyo para su profundización. Mi argumento es que dichas iniciativas forman parte de la lucha más amplia por la democratización substantiva en América Latina.

A pesar de lo breve, esta reseña de algunos aspectos centrales de las luchas por el agua en América Latina no puede dejar de mencionar algunos de los desafíos emergentes que confrontan la gestión y la gobernabilidad democráticas del agua en la región. Además de las tendencias mencionadas anteriormente, que incluyen el deterioro y la contaminación de las fuentes de agua dulce, los impactos negativos de las grandes obras de infraestructura y la expansión penetrante y consolidación de la mercantilización del agua en diferentes formas, quiero resaltar la existencia de dos fuentes recurrentes y potencialmente crecientes de confrontación por el agua, que en alguna medida se encuentran interrelacionadas. La primera de ellas tiene que ver con el impacto negativo de la rápida expansión de procesos productivos basados en usos intensivos del agua, como por ejemplo la minería y los cultivos masivos como son los del eucaliptus destinado a la producción de celulosa, o de la soja, la caña de azúcar, el maíz y otros cultivos, que se encuentran en el centro de la revolución de los agro-combustibles que está teniendo lugar en la región. Aunque el impacto de la minería sobre las fuentes y servicios esenciales de agua sí ha dado lugar a un intenso debate, en el caso de los 
cultivos masivos y especialmente en el de los agrocombustibles se ha sobre enfatizado el impacto potencial de estos procesos sobre la seguridad alimentaria, mientras que las implicaciones que los mismos tienen en relación a los ecosistemas acuáticos y a los servicios de agua han recibido mucha menos atención, a pesar de que ya son significativas en muchos lugares.

La segunda tendencia que quiero resaltar tiene que ver con las posibilidades de confrontaciones militares conectadas con el control y gestión del agua y otros recursos naturales, que ya es objeto de importantes discusiones. Aunque dichas posibilidades de conflicto militar han sido probablemente exageradas en algunos trabajos, lo cierto es que este tema ha pasado a ser un objeto de preocupación en la región, y especialmente en Sudamérica. Este es el caso, por ejemplo, del Acuífero Guaraní, el reservatorio de agua dulce subterráneo más grande del mundo que es compartido por Argentina, Brasil, Paraguay y Uruguay. Algunos gobiernos han desarrollado incluso hipótesis de guerra basadas en la posibilidad de que fuerzas militares extranjeras puedan intentar tomar control del acuífero. Si bien es posible que, en forma similar a otras hipótesis de guerra por el agua que se han postulado en otras partes del mundo, las bases reales para que se produzcan confrontaciones militares por el agua son mínimas. De todas formas, estas conjeturas reflejan la preocupación regional por la amenaza potencial de que el futuro de la gestión y la gobernabilidad del agua en América Latina se vea fuertemente marcado por una conflictividad creciente entre países. Por otra parte, este debate tiene también un lado oscuro: la discusión entre los gobiernos de la región sobre la posibilidad de confrontaciones militares internacionales por el agua podría contribuir a obscurecer la persistencia de conflictos intra-nacionales causados por la desigualdad y la injusticia en relación al agua.

\section{Conclusión: las luchas por el agua y el proceso de democratización en América Latina}

Como tendencia general la gestión y la gobernabilidad del agua en América Latina han sido caracterizadas históricamente, con pocas excepciones, por prácticas paternalistas y en gran medida verticales y excluyentes. 
La gobernabilidad del agua, en la perspectiva de este artículo, es un proceso político que involucra el ejercicio del poder por parte de actores sociales que buscan influir en la elección de los fines que deben orientar el proceso social, incluyendo los medios para lograr el alcance de dichos fines, en este caso en relación al control y gestión del agua y sus servicios y a la distribución de los beneficios (y la protección contra los peligros) derivados de los mismos. Siempre como tendencia general, este proceso ha sido caracterizado por el déficit democrático, si rechazamos la reducción del proceso democrático a la formalidad de los eventos electorales o su limitación al espacio de la política partidaria y, más bien, defendemos una noción de la democracia que reclama como principio de partida el ejercicio substantivo de la ciudadanía. Dadas estas tendencias no sorprende, entonces, que en muchos de los países de América Latina la historia de la gestión y la gobernabilidad del agua haya estado marcada por conflictos sociales, algunos de los cuales fueron agravándose desde mediados del siglo veinte debido al rápido avance de los procesos de urbanización e industrialización. Las políticas de privatización del agua y sus servicios desde la década de 1980 y la expansión generalizada de actividades productivas basadas en consumos intensivos de agua -que frecuentemente dependen de la explotación de ecosistemas acuáticos ya fragilizados-, han tendido a exacerbar los conflictos relacionados con el agua preexistentes y a promover la emergencia de nuevos conflictos. Estos eventos y tendencias, sin embargo, se han venido dando en un contexto de creciente estado de alerta en América Latina sobre las consecuencias ambientales del orden capitalista prevaleciente, el cual tiende a caracterizarse por la falta de atención a los procesos ecológicos cuando no directamente por prácticas que conducen a la destrucción ambiental. Ese estado de alerta creciente de la población en parte se expresa en las numerosas luchas por el agua que continúan deflagrándose en la región.

Si bien debe hacerse un esfuerzo para evitar proyectar visiones románticas de las luchas por el agua en América Latina, estoy convencido de que, y con relativa autonomía con respecto al nivel de conciencia de los actores y de sus objetivos declarados, dichas luchas están íntimamente conectadas con la lucha por la democratización substantiva de las sociedades de la región. En este sentido, una de las dimensiones cruciales de la lucha es el de 
la producción de conocimiento científico sobre el tema. En el caso del agua no hay alternativa a la visión radical del rol de la ciencia: se trata no solamente de estudiar la realidad sino de transformarla.

\section{Bibliografía}

Balanyá, Belén, Brid Brennan, Olivier Hoedeman, Satoko Kishimoto, y Philipp Terhorst (eds.) (2005), Reclaiming Public Water. Achievements, Struggles and Visions from Around the World, Amsterdam: Transnational Institute and Corporate Europe Observatory.

Bennett, Vivianne, Sonia Dávila-Poblete y María Nieves Rico (eds.) (2005), Opposing Currents The Politics of Water and Gender in Latin America, Pittsburgh: University of Pittsburgh Press.

Boelens, Rutgerd y Paul Hoogendam (eds.) (2002), Water Rights and Empowerment, Assen: Van Gorcum.

Castro, José Esteban y Wagner Costa Ribeiro (eds.) (2010), La Tensión entre Justicia Ambiental y Justicia Social en América Latina: el Caso de la Gestión del Agua, Ponencias de la Conferencia Internacional de la Red WATERLAT (107 trabajos), San Pablo y Newcastle upon Tyne (Reino Unido): Instituto de Estudios Avanzados de la Universidad de San Pablo, y Escuela de Geografía, Ciencia Política y Sociología de la Universidad de Newcastle.

Castro, José Esteban (2009), "Systemic conditions and public policy in the water and sanitation sector", en José Esteban Castro y Léo Heller (eds.), Water and Sanitation Services: Public Policy and Management, Londres y Sterling, VA.: Earthscan, pp. 19-37.

Castro, José Esteban (2008), "Los bienes comunes y la ciudadanía: contradicciones de una relación en pleno desarrollo", en Silke Helfrich (Coord.), Genes, Bytes y Emisiones: Bienes Comunes y Ciudadanía, México DF: Ediciones Fundación Heinrich Böll, pp. 68-80. 
Castro, José Esteban (2007), "Poverty and citizenship: sociological perspectives on water services and public-private participation", Geoforum, 38(5), pp. 756-771.

Castro, José Esteban (2006), Water, Power, and Citizenship. Social Struggle in the Basin of Mexico, Houndmills, Basingstoke and New York: Palgrave-Macmillan.

Castro, José Esteban (2004), "Urban water and the politics of citizenship: the case of the Mexico City Metropolitan Area (1980s-1990s)", Environment and Planning A, 36(2), pp. 327-46.

Crespo Flores, Carlos O. (2009), "Privatización del agua y racismo ambiental en ciudades segregadas. La empresa Aguas del Illimani en las ciudades de La Paz y El Alto (1997-2005)",

Anuario de Estudios Americanos, Vol. 66, No 2, pp. 105-122.

Guha, Ramachandra y Joan Martínez-Alier (1997), Varieties of Environmentalism: Essays North and South, Londres: Earthscan.

Laurie, Nina, Sarah Radcliffe, y Robert Andolina (2002), “The new excluded 'indigenous'?: The implications of multi-ethnic policies for water reform in Bolivia", en Rachel Sieder (ed.): Multiculturalism in Latin America. Indigenous Rights, Diversity and Democracy, Houndmills, Basingstoke y Nueva York: Palgrave-Macmillan, pp. 252-276.

Martínez-Alier, Joan (2002), The Environmentalism of the Poor. A Study of Ecological Conflicts and Valuation, Cheltenham y Northampton: Edward Elgar.

MAB - Movimento dos Atingidos por Barragens Brasil, 2011 (http://www. mabnacional.org.br, consultado el 27 de mayo de 2011). 
OLCA - Observatorio Latinoamericano de Conflictos Ambientales, 2011 (http://www.olca.cl, consultado el 27 de mayo de 2011).

REDLAR - La Red Latinoamericana contra Represas y por los Ríos, sus Comunidades y el Agua, 2011 (http://www.redlar.org/, consultado el 27 de mayo de 2011).

RED VIDA - Red de Vigilancia Interamericana para la Defensa y el Derecho al Agua, 2011 (http://www.laredvida.org/, consultado el 27 de mayo de 2011).

TRAGUA - Tribunal Latinoamericano del Agua, 2009 (http://www.tragua. com, consultado el 27 de mayo de 2011).

Valencio, Norma Felicidade (1995), Grandes Projetos Hidricos no Nordeste. Suas Implicaciones Para a Agricultura do Semi-arido, Natal, Brasil: Universidad Federal de Rio Grande do Norte.

WWFLA - World Wildlife Fund Latin America, 2011 (http://www.worldwildlife.org/wildplaces/lac.cfm, consultado el 27 de mayo de 2011). 


\section{Capítulo 2}

\section{Incertezas manufacturadas, tecnociência e as políticas da desigualdade: o caso da gestão da água ${ }^{1}$}

\section{Introdução}

A gestão dos recursos hídricos tornou-se uma questão global nas duas últimas décadas. Iniciativas políticas de longo alcance têm sido implementadas, desde medidas para travar os crescentes fenómenos de desertificação e poluição que afectam os recursos hídricos mundiais a políticas destinadas a combater as ineficiências na colocação e distribuição da água para uso humano em áreas rurais e urbanas. Instituições multilaterais e governos uniram esforços para abrir a gestão da água ao sector privado, especialmente em zonas urbanas, na esperança de que as empresas privadas ajudassem na gigantesca tarefa de actualizar, manter e expandir os serviços hídricos, nomeadamente levar água e condições sanitárias salubres aos pobres e contribuir para o esbatimento das desigualdades sociais crescentes (Banco Mundial, 1998: 1; Savedoff et al., 1999; IDB, 1998: 120).

É, todavia, cada vez mais consensual que, apesar dos importantes esforços realizados a partir dos finais da década de 70, a batalha para implementar sistemas de gestão da água capazes de preencher o objectivo internacional de fornecerem a cada indivíduo no planeta água suficiente ${ }^{2}$ e de

1 Originalmente publicado em: Hermínio Martins e José Luis García (eds.), Dilemas da Civilização Tecnologica, Lisboa: Imprensa de Ciencias Sociais, 2003, pp. 199-223. Tradução de Maria Inês Amaro.

2 A Conferência da Água das Nações Unidas, em 1977, em Mar del Plata, Argentina, que conduziu à Década Internacional do Fornecimento de Água Potável e Condições Sanitárias (1980-1990), declarou que todos têm "direito a ter acesso a água potável em quantidade e de qualidade iguais às suas necessidades básicas”. A Década foi oficialmente encerrada pela Consulta Global realizada em 
serem, simultaneamente, ecologicamente sustentáveis, ${ }^{3}$ economicamente viáveis e politicamente legítimos, está a ser perdida em muitos países. De acordo com relatórios recentes realizados pela UNICEF, mais de 600 milhões de pessoas em áreas urbanas do mundo em desenvolvimento continuam a estar permanentemente expostas a riscos mortais devidos às precárias condições de vida, especialmente à falta de água e condições sanitárias salubres. Como consequência, as doenças relacionadas com a água continuam a estar entre as principais causas de morte, sendo a razão da morte de cerca de 2 milhões de crianças todos os anos. Para além disso, cerca de 900 milhões de pessoas todos os anos sofrem de doenças relacionadas com a água. Neste processo, o ciclo da água é fortemente pressionado, devido à sobre-exploração dos recursos hídricos e à degradação em larga escala causada pelo "abandono" de água inutilizada (menos de $5 \%$ da água inutilizada nos países menos desenvolvidos é tratada). No entanto, melhorar o acesso à água e a condições sanitárias salubres não é apenas crucial devido aos seus impactos ambientais e na saúde, mas também devido aos seus efeitos socio-económicos mais alargados, por exemplo, através do "aumento da produtividade do agregado" contribuindo assim para o fechamento do grande hiato de desigualdades no mundo em desenvolvimento (IDB, 1998:120-121).

Compreensivelmente, a gestão sustentada e eficiente dos recursos hídricos, seja para a irrigação agrícola, a produção de energia hidráulica ou para o fornecimento de serviços hídricos, tornou-se numa "das mais importantes questões globais” do século XXI (IDB, 1998b: 1). Em particular, tal

Nova Deli em 1990, que produziu a Declaração de Nova Deli que apela para "alguma [água] para todos, em vez de demais para alguns".

3 A Conferência sobre Água e Ambiente realizada em Dublin em Janeiro de 1992, como reunião de preparação para a Conferência sobre o Ambiente e o Desenvolvimento das Nações Unidas (UNCED) (A Cimeira da Terra), Rio de Janeiro, em 1992, produziu um conjunto de Princípios Orientadores, os "Princípios de Dublin", e uma Agenda de Acção de 40 páginas, que forneceu as linhas orientadoras para o desenvolvimento, gestão e conservação dos recursos hídricos. A UNCED aprovou a Agenda 21, que incorporou os Princípios de Dublin como parte do seu Capítulo 18, "Protecção da Qualidade e Fornecimento dos Recursos Hídricos", e acabou por se constituir na base do desenvolvimento sustentado, incluindo os recursos hídricos. 
como sublinhado pela Comissão Mundial da Água no Século XXI ${ }^{4}$ a melhoria dos serviços de fornecimento e tratamento de água continua a ser crucial para o desenvolvimento das condições de vida de biliões de pessoas, não apenas nos países menos desenvolvidos. Estes problemas são de longa duração e, apesar dos enormes esforços empreendidos, o objectivo de melhorar o acesso das pessoas à água potável e, particularmente, às condições sanitárias, estabelecido pela comunidade internacional em 1980, não foi alcançado, ao passo que as necessidades continuaram a crescer rapidamente em resultado da expansão demográfica e urbana sustentadas.

Apesar de se terem vindo a atingir elevados níveis de sofisticação nos campos da hidrologia, da engenharia hidráulica e, mais recentemente, da biotecnologia aplicada à gestão da água, continuamos longe de um pleno entendimento dos processos históricos, socio-económicos, culturais e políticos que operam neste campo. Por um lado, estes são processos a longo prazo, muitas vezes impenetráveis por esforços políticos bem-intencionados dirigidos à promoção de uma gestão sustentável dos recursos hídricos em áreas de actividade específicas. Por outro lado, e apesar das crescentes preocupações globais com a transferência transtemporal dos riscos ambientais de diferentes tipos, na prática as políticas hidrológicas implementadas para evitar ou minimizar estes riscos tiveram, até ao momento, um impacto muito limitado. Este hiato entre os campos de saber tecnocientífico e socio-político, defendemos, pode contribuir para explicar porque é que o enorme progresso tecnológico verificado no sector da água nas décadas recentes não se reflectiu em práticas mais sustentáveis de gestão dos recursos hídricos ou num acesso mais justo e mais abrangente à água e ao saneamento pela população, particularmente nos países menos desenvolvidos. Nesta conjunção, é cada vez mais reconhecida a necessidade de encontrar um equilíbrio entre as vertentes técnica, socio-económica e política da gestão dos recursos hídricos, que permanecem artificialmente separadas na prática e, também, em grande parte da literatura especializada. Da mesma forma, o estabelecimento de sistemas de gestão da água

4 A Comissão é assessorada por um grupo de consultores de alto nível e tem o patrocínio de entidades globais como o Banco Mundial, a UNESCO, a UNEP e a UNDP. 
social e ambientalmente sustentáveis, que também sejam economicamente viáveis e democraticamente justificáveis é um dos mais urgentes desafios que encaramos.

\section{Incertezas da água}

Relacionar os recursos hídricos com a incerteza tornou-se cada vez mais comum. Por exemplo, a maior parte dos casos com que se ilustram os actuais debates sobre o risco e a incerteza prendem-se com diferentes tipos de perigos ambientais, entre os quais se destacam os desastres relacionados com a água. Alguns autores burilaram o conceito de "incerteza manufacturada", querendo com ele significar que a geração de novos riscos dá-se no decurso de processos conduzidos pelo Homem, que se supõe manterem o risco sob controlo (Beck, 1992, 1995). Talvez a maior expressão deste desenvolvimento seja o consenso político a que se chegou desde os anos 80 no que concerne à necessidade de redução significativa das emissões de gás do efeito de estufa para parar o processo de aquecimento global, a que se atribuiu a responsabilidade por grande parte das ameaças ambientais, desde os cada vez mais frequentes e destrutivos tufões, cheias, furacões e processos de desertificação provocados pelo Homem até à re-emergência de velhas (que se julgavam erradicadas) e novas doenças epidémicas relacionadas com a água, incluindo a malária, o dengue e a cólera. A preocupação internacional com estes assuntos levou a uma grande variedade de esforços destinados a avaliar a dimensão e a escala destes riscos e ao seu controlo.

Obviamente, a última incerteza ligada à água é a de que - para pedir de empréstimo o título de um relatório recente da UNESCO - se há suficiente água doce no mundo para todos. Particularmente a água para fins agrícolas, que conta actualmente com cerca de $70 \%$ do consumo mundial de água doce, coloca um desafio crucial: enquanto que a manutenção dos níveis de segurança dos alimentos necessita de um aumento de $15 \%$ a $20 \%$ do gasto de água até ao ano de 2025, os ambientalistas advogam que, para parar a desertificação e preservar os recursos hídricos já sobreutilizados, o gasto de água deverá ser reduzido em pelo menos $10 \%$ no mesmo período. É difícil, com o actual nível de conhecimento e tecnologia, prever como poderemos 
alcançar a segurança nos alimentos e a sustentabilidade ambiental simultaneamente. A este propósito, as atenções estão agora viradas para a aplicação da biotecnologia à gestão da água, o que inclui um leque diverso de opções, desde o desenvolvimento de tecnologias moleculares para a detecção e identificação de micro-organismos patogénicos nos sistemas de tratamento de água (bio-monitorização) (OECD, 1996; OECD-WPB, 1999) à transferência de traços genéticos para as colheitas com o objectivo de aumentar a sua tolerância à escassez de água e assim fomentar a segurança da água na agricultura (OECD, 1996; MSSRF, 1999; WCW, 1999). Esta é uma audaz tentativa de utilizar a biotecnologia como um instrumento de gestão da procura de água e está a ser desenvolvida por companhias multinacionais, como a Monsanto, com o apoio da comunidade científica. Tal como o coloca o "pai da revolução verde" e laureado com o Nobel Norman Borlaug:

Os cientistas estão a adquirir capacidade para inserir genes (em plantas) que criam defesas biológicas contra as doenças e os insectos... e transmitem traços genéticos que permitem às colheitas tolerar melhor condições de seca. Com este poderoso novo conhecimento genético, os cientistas têm a possibilidade de armazenar grandes quantidades de tecnologia numa única semente (cit. in CBI, 2000).

Nitidamente nem toda a comunidade científica partilha da perspectiva optimista de Borlaug mesmo os investigadores pró-biotecnologia mais avançados alertaram para o facto de que, dado o limitado conhecimento sobre os determinantes fisiológicos, bioquímicos e genéticos da tolerância das plantas e dos microorganismos à falta de água, é necessária mais investigação antes que esta tecnologia possa ser utilizada na manipulação da resistência à escassez de água (WCW, 1999). Estas preocupações generalizaram-se em resultado das discussões científicas, políticas, económicas e éticas convocadas pelos recentes desenvolvimentos no campo da biotecnologia - ou engenharia genética como alguns críticos preferem designá-lo. O debate tem vindo a acompanhar, não só a transferência transtemporal do risco associado à nova tecnologia, mas também outras consequências 
transdimensionais das acções actuais e prospectivas, como as que emergem da produção de novas tecno-espécies, através de combinações diversas de materiais orgânicos e inorgânicos, desde os animais transgénicos aos sistemas de computador baseados no ADN (Martins, 1996).

Apesar da totalidade da água doce ser certamente uma consideração legítima e crucial, uma análise mais minuciosa do problema demonstra que a disponibilidade enquanto tal não é (e poderá não vir a ser num futuro próximo) o problema mais importante. Diversos trabalhos de investigação recentemente realizados sugerem que, pelo menos em termos dos volumes da água, existe água doce suficiente para satisfazer as necessidades de todos os seres humanos. Nesta base, alguns autores sublinharam correctamente que a última verdadeira incerteza da água é a de se somos capazes de assegurar o acesso à água com qualidade adequada a todas as pessoas do planeta (Samson e Charrier, 1997). Este é um problema crucial, dada a crescente certeza de que num futuro próximo a ocorrência de conflitos violentos em torno do acesso e controlo dos recursos hídricos entre e dentro dos países poderá ser inevitável. Concentraremos agora a atenção neste tópico específico.

\section{Conflitos em torno da água}

A perspectiva de que os conflitos sociais em torno da distribuição e localização da água serão cada vez mais "uma parte chave do panorama do séc. XXI" é actualmente uma das maiores preocupações da comunidade internacional. ${ }^{5}$ Consequentemente, ao longo das últimas décadas peritos em segurança internacional têm vindo a alertar para o facto de que a água se está a tornar mais importante que o petróleo como potencial fonte de conflitos mundiais (Gleick, 1993). E existem boas razões para este alerta, uma vez que os recursos de água doce têm uma distribuição irregular e desnivelada, que algumas regiões do mundo têm reservas de água extremamente escassas

5 Hans van Ginkel, subsecretário-geral das Nações Unidas, no Simpósio da Água em Estocolmo, 13 de Agosto 2001 (Financial Times, 14 Agosto 2001, p. 6). 
e que esses recursos são muitas vezes partilhados por dois ou mais países. Estima-se que menos de 10 países controlam cerca de $60 \%$ dos recursos mundiais de água doce, enquanto que a bacia de cerca de 300 rios e lagos e um número significativo dos lençóis friáticos são partilhados por dois ou mais países (Ohlsson, 1992; Samson e Charrier, 1997). Compreensivelmente, há um florescente corpo de literatura sobre os "conflitos em torno da água", que enfatizam os, assim designados, aspectos não militares da segurança internacional (por exemplo, elementos que se podem tornar em alvo para acções militares), entre os quais a água e os sistemas hídricos estão em posição de destaque. Da mesma forma, o papel da mudança ambiental, quer seja de origem antropogénica ou não, como causa de conflitos agudos foi explorado e a água ocupa um lugar central nesta literatura (Homer-Dixon, 1991).

Apesar de talvez a maior parte desta produção de conhecimento estar focalizada nos confrontos internacionais advindos do controlo e gestão da água, há também uma consciência emergente da dimensão intra-nacional do problema. Tal como foi recentemente apontado por Mikhail Gorbachev, actualmente o Presidente da Cruz Verde Internacional, "mais pessoas têm falta de água potável hoje do que há duas décadas atrás” (Gorbachev, 2000). Uma vez que a água é um factor essencial para assegurar o direito humano universal a "um padrão de vida adequado para [...] a saúde e o bem-estar", ${ }^{6}$ é evidente que cada vez mais os governos enfrentam o desafio de se desenrolarem conflitos sociais e políticos originados pela elevação das exigências dos cidadãos de quantidades adequadas e regulares de água potável.

Este segundo aspecto do problema - conflitos intra-nacionais em torno da água -, julgamos que até agora tem recebido menor atenção. Existem, contudo, contribuições importantes para esta questão crucial, entre as quais se destaca o estudo provocatório de Donald Worster sobre a construção o "império" hidráulico dos EUA (Worster, 1985; Hundley, 1992). Mais recentemente, tem surgido um corpo de literatura sobre a "segurança hidráulica", que se esboça a partir da base teórica e metodológica desenvolvida pela investigação em segurança alimentar e enfatiza as interligações e

6 Artigo 25, Declaração Universal dos Direitos Humanos. 
contradições entre a água como recurso natural, como uma comodidade e como um direito (Webb et al., 1998). Estes autores estão mais preocupados com a correlação entre "pobreza", "género" e, entre outros, "etnicidade" e a incapacidade de assegurar o acesso à água, afectando largos segmentos da população mundial. Desta forma, o seu trabalho tem alguns pontos em comum com a designada "abordagem dos direitos ambientais", que se baseia no trabalho de Amartya Sen no que se refere à ligação entre a pobreza e as fomes (Sen, 1981; Mearns, 1995; Gasper, 1993; Gore, 1993).

No contexto desta área temática, o meu trabalho focou-se precisamente no aspecto intra-nacional dos conflitos em torno da água. Em particular, gostaria de sublinhar o facto de que, não obstante os avanços formidáveis na tecnologia hidráulica, mesmo nos locais onde há disponibilidade de água em quantidades razoáveis, o acesso a este recurso vital continua a ser negado a um número elevado de pessoas. Neste caso, as incertezas da água podem ser claramente denunciadas como sendo o resultado de um sistema de desigualdade social que foi e continua a ser confrontado em diversos contextos. Em última análise, a gestão dos recursos hídricos não é apenas um desempenho técnico, mas é antes uma empresa social multi-escalonada que requer sempre sistemas mais sofisticados para assegurar a eficiência e a justiça. Neste sentido particular, os conflitos intra-nacionais em torno da água que procuram assegurar o direito universal à água são uma expressão da luta social mais alargada pela expansão e consolidação dos direitos de cidadania. Isto leva-nos à intersecção entre risco, governança e cidadania, que é o próximo assunto da nossa atenção.

\section{0 debate da governança}

A actual discussão sobre o risco, e particularmente o risco ambiental, está intimamente relacionada com a questão da governança, um conceito que foi pela primeira vez desenvolvido na análise económica para o estudo das corporações e mais tarde adoptado pela ciência política em relação a novas formas de governo e regulação para além das tradicionais hierarquias de estado e sistemas de mercado (Hirst, 1994; Held, 1995; Amin, 1997). Neste domínio, uma extensa literatura foi recentemente desenvolvida 
reflectindo o debate em curso sobre as transformações ocorridas no campo da "gestão dos recursos naturais", especialmente desde 1980, quando as "políticas de desenvolvimento sustentável" foram oficialmente adoptadas a nível internacional. Alguns autores descreveram estas transformações como a passagem de um modelo baseado no "monopólio estatal" para um novo modelo baseado no que alguns chamam de "pluralismo pragmático" (Esman, 1991).

Talvez um dos elementos chave deste corpo de literatura - largamente inspirado pela perspectiva neoliberal sobre a reforma do estado, apesar de não redutível ao quadro de pensamento neoliberal - tenha sido o reconhecimento do carácter multi-nivelado e multi-sectorial dos regimes de gestão. Assim, os sistemas de "governança" incluem as formas clássicas de autoridade incorporadas nos regimes de gestão do estado (hierarquia), mas também compreendem os da gestão privada (competição de mercado) e do sector do voluntariado (participação) (UNDP, 1997; Picciotto, 1997)7. Em consonância, o modelo da governança multi-escalonada seria caracterizado por uma combinação de estruturas hierárquicas, dinâmicas participativas, acções associativas e mecanismos de mercado e seria fundamentalmente baseado numa cultura de diálogo, negociação, cidadania activa, subsidariedade e fortalecimento institucional (Comissão Europeia, 2001).

A este propósito, um aspecto crucial do debate da governança é a relação entre as "incertezas manufacturadas", que caracterizam a cidadania e sociedade de risco Beck (1992a, 1992b, 1998) contemporâneas e que provocaram uma inflação das formas de cidadania, incluindo a "tecnológica", "ecológica" e "ambiental" (Frankenfeld, 1992; Steenbergen, 1994; Newby, 1996; Mehta, 1998). O debate contribuiu para especificar mais e até expandir as tradicionais categorias da cidadania, tal como foram estabelecidas

7 Ver também o conceito de "governança de interesses" proposto por Streeck e Schmitter (1985) em relação ao qual estes autores consideram um quarto modelo de ordem social, o modelo associativo, que funciona ao lado das ordens tradicionais incorporadas no estado (hierarquia), na comunidade (dinâmicas participativas) e no mercado (livre competição). Ver também o conceito de "acordos institucionais policêntricos" aplicado por Elinor Ostrom (1993) e outros autores à gestão dos recursos naturais. 
pelo sociólogo britânico T.H. Marshall, ${ }^{8}$ no sentido de incluir o direito à informação e ao consentimento informado, acrescendo ao direito de participação, tendo em conta a inovação tecnológica e as suas potenciais ou efectivas aplicações.

Neste sentido, há questões importantes relativas ao debate da sociedade de risco que permanecem obscuras, sem resposta ou não exploradas pela literatura. Por exemplo, quem são (seriam) os sujeitos políticos e sociais (os cidadãos) da sociedade de risco? Se o risco se prende com a tomada de consciência de perigos e riscos cada vez mais sofisticados e multifacetados e se os sujeitos da sociedade de risco são definidos em termos da sua consciência do risco, não quererá isto dizer que a sociedade de risco também acarreta formas mais sofisticadas e multifacetadas de produzir e reproduzir a desigualdade social? Como é que um acesso justo à participação em processos vitais de informação, exigido para garantir um nível "seguro" de consciência do risco, poderá ser alcançado no presente (e, presumivelmente, no futuro) contexto de crescimento em quantidade e complexidade das unidades de informação? E, não quererá isto também dizer, que nos cenários previstos, tanto o impacto real dos riscos e perigos como o espectro alargado de escolhas possíveis, as trajectórias seguirão um (previsível) padrão de distribuição muito titubeante, tal como é já sugerido pelo impacto real da maior parte dos desastres em larga escala tais como cheias, secas e surtos epidémicos causados por super-vírus resistentes às drogas? Não será a emergência da sociedade de risco semelhante ao que outros chamam um novo modo de desenvolvimento, informacionalismo, onde "as redes globais de riqueza e poder interligam pontos nodais e indivíduos valorizados por todo o planeta, ao mesmo tempo que desligam e excluem extensos segmentos das sociedades, regiões e mesmo países inteiros"? (Castells, 1996: 24-25). Não serão as sociedades de risco e em rede (informacionais) duas faces da mesma moeda? E quanto aos excluídos e "desligados"? Como é que o processo de exclusão se desenvolve através da emergência da sociedade de risco? E como é que estes reagem (será que reagem?)?

8 Marshall (1992) concebeu o referencial clássico para o estudo sociológico da cidadania e sugeriu três grandes tipos de direitos de cidadania: cívicos, políticos e sociais. 


\subsection{Governança, conflito e cidadania}

A este respeito, a contribuição feita pela abordagem da governança à análise dos conflitos intra-nacionais - muitas vezes o resultado das reacções dos cidadãos contra a exclusão e a desigualdade social - tem sido muito modesta. Em particular, se se permanecer no âmbito desta literatura é muito difícil aprofundar a análise dos conflitos para além das suas dimensões tecno-burocráticas. Mesmo no caso daqueles autores que são sensíveis aos processos de longo prazo e que examinam as formas institucionais não capitalistas, tais como, por exemplo, Elinor Ostrom (1990), em última análise, é a estabilidade dos sistemas políticos e socio-económicos existentes que continua a ser a sua preocupação central. Por esta razão, talvez se pudesse afirmar que a principal contribuição dada por esta literatura foi o empréstimo de um referencial teórico - talvez mesmo ideológico - à expansão sem precedentes dos mecanismos de mercado a quase todas as esferas da interacção humana, incluindo a gestão de recursos naturais como a água.

Assim, apesar do facto de que a abordagem da governança reconhece formalmente o carácter crescentemente multi-escalonado e multipolar da estrutura de governança dos sistemas complexos, em última análise, privilegia os mecanismos de mercado e os seus agentes, a que foi atribuído um papel de liderança entre outras componentes do complexo da governança. Em larga medida, pode defender-se que o consenso emergente desta literatura contribuiu para legitimar os processos políticos e socio-económicos particulares que promoveram a proeminência da competição capitalista sobre outros domínios da governança como o Estado ou a sociedade civil, no contexto de um modelo tecnocrático de desenvolvimento. Talvez o melhor exemplo deste processo possa ser encontrado no consenso gerado por esta literatura em favor da privatização (isto é, o sancionamento dos direitos de propriedade privada) e a adequação da natureza como instrumentos chave para controlar riscos como o de esgotamento dos recursos naturais (água, florestas, ar, pesca, etc.). Na verdade, o ímpeto para o mercado foi muito além o seu papel controverso de estratégia defensiva contra 
a, assim designada, "tragédia dos comuns" e já se estendeu aos próprios fundamentos da vida humana: mesmo os territórios do mapa genético, a ser decifrado pela indústria biotécnica, já estão a ser objecto de privatização e mercantilização com uma rapidez que alguns descreveram como "a conjugação da posição do mercado com a posição da tecnologia" (Martins, 1998a: 104-105).

Este processo foi diversas vezes causa de que os papéis do Estado e dos cidadãos comuns na definição, protecção e promoção do interesse público se tenham gradualmente desgastado pelo movimento mundial claramente em favor da privatização e da comercialização do sector público. Em muitos casos, e contrariamente à retórica predominante, na prática estas políticas não trouxeram nem serviços melhorados nem maior controlo das pessoas comuns sobre o antigo sector público. Em vez disso, permitiram que interesses corporativos aumentassem o seu domínio sobre as principais alavancas do poder económico (Martin, 1996). Contudo, a expansão e aprofundamento dos processos de privatização e mercantilização à custa do interesse público não acontece num vácuo social. Historicamente, estes processos sempre suscitaram a resistência social e política de importantes sectores sociais que pretendem proteger os seus interesses dos efeitos dos mecanismos de mercado (Schmidt, 1993) e não é surpreendente que as actuais tentativas encontrem resistência de sectores alargados da população mundial. Voltando ao caso da gestão da água, em muitos países a privatização dos serviços hídricos tornou-se num assunto político e social quente. $\mathrm{Na}$ América Latina e na África, por exemplo, a oposição aberta às políticas de privatização e o não cumprimento (por exemplo, recusa ao pagamento das contas da água) generalizou-se, dificultando os processos de privatização e resultando mesmo no cancelamento de concessões e consequente reversão de responsabilidades por este serviço para o sector público (Tamayo et al., 1999; Hardoy et al., 1999; Bond, 1997). Isto não está, porém, a acontecer apenas nos países menos desenvolvidos. No Reino Unido, os serviços hídricos que foram privatizados durante o período Thatcher estão a encontrar dificuldades crescentes em sobreviver como entidades privadas lucrativas e alguns deles já adoptaram formas de gestão alternativas, que incluem a 
total ou parcial colectivização das companhias. ${ }^{9}$ O caso do Reino Unido oferece um exemplo claro das dificuldades que envolvem a governança dos sistemas de gestão da água orientados para a consecução dos objectivos contraditórios de protecção ambiental, de resposta à crescente procura de água, de gestão como um negócio privado e de serem democraticamente responsáveis perante os cidadãos.

\subsubsection{Será suficiente? Manufacturação das desigualdades sociais e da escassez de água}

Voltemos atrás, à questão do conflito intra-nacional em torno da água. Tal como acima mencionado, apesar de formalmente a última incerteza da água ser a de se existe no mundo água doce suficiente para satisfazer as necessidades de todos os seres humanos, de facto, a questão mais crucial reporta à justiça no acesso e distribuição do recurso. É um facto bem documentado que mesmo onde existe água "suficiente", muitos seres humanos não têm acesso à sua parte..$^{10}$ Pedindo de empréstimo as conclusões de Amartya Sen sobre o análogo problema da fome, "escassez é a característica das pessoas não terem o suficiente [...], não é a característica de não haver suficiente. Enquanto os últimos podem ser a causa dos primeiros, essa é apenas uma de várias causas." (Sen, 1981: 1). Na perspectiva da "abordagem dos direitos" de Sen, a chave para compreender porque é que as pessoas morrem de fome não pode ser procurada em termos de disponibilização de comida por cabeça, uma vez que as fomes podem ocorrer mesmo sem

9 A Água de Yorkshire, por exemplo, pretende transferir a responsabilidade pela rede de fornecimento de água para uma espécie de organização comunitária, mantendo a parte de gestão em mãos privadas. Em Gales, os serviços hídricos já mudaram de propriedade e gestão privada para uma mistura de propriedade e gestão privada e pública (OFWAT, 2000a, 2000b, 2000c).

10 Aprendemos que a escassez e o conflito em torno da água pode acontecer mesmo onde os recursos hídricos são abundantes. Por exemplo, Guayaquil, a maior cidade do Equador, é atravessada pela água do rio Guayas, no entanto $35 \%$ da população não tem acesso a água potável e a cidade está sujeita a faltas de água crónicas. Uma duradoura estrutura de desigualdade social, clientelismo político e de conluio entre as autoridades e os empresários privados da água contam-se entre os principais factores que explicam as deficiências dos sistemas hídricos da cidade, que estão na base de muita insatisfação política e social. A descrição pode ser facilmente generalizada a várias cidades nos países em desenvolvimento (Swyngedouw, 1995; Swyngedouw et al., 2001; Castro, 2001). 
haver um declínio na produção alimentar ou na disponibilização por cabeça (Sen, 1990: 37). Pelo contrário, o autor defende que independentemente das suas causas particulares (por exemplo, secas, cheias, pressão inflaccionária geral, perda de emprego francamente recessiva, entre outras) uma fome reflecte uma falha generalizada de uso dos direitos de secções substanciais da população, uma situação que também pode ser resultado de diversas causas (idem: 36 ). Em suma, o principal problema não é tanto a disponibilidade de comida, mas antes a capacidade que os indivíduos e as famílias têm de estabelecer um comando sobre esta, uma situação que o autor designou de "problema de apropriação".

A discussão de Sen sobre a independência entre a produção per capita de alimentos e os segmentos que passam fome, traz luz sobre o análogo problema da disponibilidade de água per capita (na verdade, consumo de água per capita) e da generalização das doenças relacionadas com a água e da morte provocada pela falta de água potável. Avançando nesta discussão, a questão é que uma elevada produção de água por cabeça num determinado país ou região não assegura que os indivíduos e famílias terão um acesso justo e adequado aos serviços hídricos. ${ }^{11}$ A distinção entre direitos e concessão efectiva de direitos feita por Sen é certamente crucial para um entendimento mais claro de como os recursos são socialmente controlados e acedidos. De uma forma geral, a água tornou-se numa das comodidades essenciais de que os indivíduos e as famílias necessitam para assegurar a sua sobrevivência. Infelizmente, o reconhecimento formal do direito à água, ou mesmo a concessão formal de direitos de propriedade sobre ela, não assegura o acesso a este recurso vital de uma forma regular. Direitos formais podem ser conferidos às pessoas, por exemplo, o direito ao trabalho, à habitação, à saúde ou, como alguns académicos sugeriram, à água (Gleick,1999;

11 Por exemplo, o volume de fornecimento de água na Área Metropolitana da Cidade do México (MCMA) é em média de 300 litros per capita por dia (pcpd), bastante acima do padrão mínimo internacionalmente aceite de 100 litros pcpd. No entanto, enquanto que nalgumas zonas o consumo de água pcpd é superior a 1000 litros, em extensas áreas da metrópole milhões de pessoas têm em média 5-10 litros pcpd durante longos períodos e a água muitas vezes não é potável para consumo pessoal (Castro, 2001). 100 litros pcpd é a quantidade necessária para satisfazer necessidades básicas, tais como beber, lavar e cozinhar; só um litro é necessário para beber todos os dias (Clarke, 1991: 19). 
Petrella, 2001). Estes direitos podem ser formalizados numa carta nacional, mas esta concessão de direitos não garante às pessoas o direito efectivo e sustentado a ter um bom emprego ou uma casa ou serviços hídricos durante toda a sua vida. A passagem das concessões aos factos é afectada por uma quantidade de factores variáveis que podem até incluir a perda temporária ou permanente dos meios básicos e, assim, privar o indivíduo dos seus direitos. Tal como foi sarcasticamente expresso por um protagonista dos conflitos urbanos em torno da água que estudámos, "em alguns lugares a estação das secas já se prolongou por 15 anos". ${ }^{12}$ Assim, a escassez de água não é apenas o resultado natural do ciclo hidrológico, mas é também resultado das interacções entre os factores físico-naturais e socio-políticos. Apesar dos enormes progressos tecnológicos realizados no campo da gestão hidráulica, a produção e reprodução de desigualdades sociais duradouras continua a ser um factor determinante subjacente à incerteza da água.

\section{Produzir conhecimento sobre os conflitos em torno da água}

Contribuir para esclarecer os problemas de investigação acima expostos requer a exploração das interligações entre os processos físico-naturais e socio-políticos de uma forma interdisciplinar. O debate em desenvolvimento sobre o risco fornece provas fortes do facto de que normalmente as acções racionalmente planeadas e direccionadas para o controlo da natureza pelos seres humanos produzem efeitos não intencionais, tanto no sistema social como no natural. Um bom exemplo disto é a tomada de controlo sobre o fogo pelos seres humanos, que foi examinada pelo sociólogo holandês Johan Goudsblom (1992) no seu estudo intelectualmente provocatório sobre Fire and Civilization. Seguindo os contributos de Norbert Elias (1994) sobre os aspectos ecológicos, psicológicos e sociológicos do "processo civilizacional", Goudsblom salientou o da interligação do controlo humano sobre questões não humanas, interhumanas e intrahumanas por relação

12 Metrópoli, Cidade do México, 30 de Maio 1989, p. 2. 
ao controlo do fogo. Cada inovação conducente ao domínio da utilização do fogo trouxe novos perigos e riscos, ao mesmo tempo que também abriu um amplo leque de novas trajectórias para o desenvolvimento societal e individual: aumentou a produtividade humana e as capacidades físicas melhorando as possibilidades de vida das pessoas ao mesmo tempo que tornou os seres humanos vulneráveis a meios de destruição mais poderosos. Porém, um dos resultados-chave imprevistos do processo de longa duração de controlo do fogo tem sido a distribuição desigual do conhecimento, que a longo prazo transformou questões tais como a análise dos riscos envolvidos no controlo do (as cada vez mais sofisticadas formas e usos do) fogo em matéria para peritos.

Este desequilíbrio é ainda mais acutilante noutros campos do desenvolvimento tecnológico, como nos casos das alterações climáticas induzidas pelo homem e da inovação bioindustrial, em que a vasta maioria das pessoas, mesmo entre a classe média mais letrada, não detém uma compreensão básica destes processos, enquanto que as trajectórias de risco destes acontecimentos são imprevisíveis mesmo para os peritos envolvidos. O caso dos recursos hídricos, transformados para sempre em H2O, não é uma excepção. Mas, centremo-nos agora neste tópico de um ângulo diferente e olhemos os conflitos emergentes em torno do controlo, da gestão e da distribuição dos recursos hídricos sob a perspectiva do conflito em torno da água como um objecto de conhecimento.

\subsection{0 conflito em torno da água como um objecto de conhecimento}

Apesar de existirem cada vez mais provas demonstrativas de que os processos envolvendo os "conflitos da água" são largamente autónomos das condições físico-naturais e tecnológicas, tem sido muito difícil alcançar um modelo interdisciplinar que possa avançar com uma descrição e explanação integrais do problema. Uma razão essencial para isto, defende-se aqui, é a de que as condições para a observação científica do carácter social da ordem físico-natural se desenvolveu de uma forma muito lenta e fragmentada 
e sofreu de estagnação, inércia e até mesmo esquecimento em muitos aspectos. ${ }^{13}$

No que se refere à política da água, pode defender-se que o conhecimento da dimensão social dos processos envolvidos é quase negligenciável comparado com a acumulação alcançada noutras áreas como a hidrologia, a engenharia hidráulica e, mais recentemente, a biotecnologia aplicada à gestão da água. Para além disto, a fragmentação do conhecimento acumulado, que é reproduzido ao longo das linhas das "culturas epistémicas" que - tal como noutros campos - se desenvolveram de uma forma muito desligada (Knorr Cetina, 1999), continua a ser um obstáculo crucial para a compreensão dos processos que reforçam os "conflitos da água". Desta forma, os corpos de conhecimento que poderão um dia ser catalizadores de níveis mais elevados de restruturação cognitiva na área, permanecem hoje estranhos e esquecidos uns em relação aos outros, entrincheirados nas suas auto-perpetuadoras "maquinarias de conhecimento" (idem) e estruturas de poder. Todavia, a nossa tarefa não é analisar a importância relativa do peso político das diferentes disciplinas e profissões envolvidas na gestão da água, uma vez que estaria para além do âmbito deste documento. Em vez disso, o nosso objectivo é salientar alguns dos obstáculos epistemológicos que continuam a impedir a compreensão dessas inter-relações entre os processos físico-naturais, técnicos e socio-políticos que reforçam os "conflitos da água".

\subsection{Sujeitos epistémicos}

Nesta relação, propomos examinar certos actores no seu papel de sujeitos epistémicos, ${ }^{14}$ ou seja, como possuidores e produtores de corpos distintivos de conhecimento em relação à "água" como objecto de pesquisa científica, que podem estar incorporados em instituições, em equipas de

13 Para uma revisão recente das descontinuidades históricas no tratamento das questões ecológicas nas ciências sociais, ver Foster, 1999.

14 Pedimos o conceito de empréstimo a Jean Piaget. Ver, por exemplo, Piaget, 1971, pp. 138-140. 
trabalho, bem como serem indivíduos. No nosso trabalho anterior, ${ }^{15}$ identificámos três sujeitos epistémicos. Os dois primeiros, a quem chamámos o perito e o funcionário, ${ }^{16}$ adquiriram um elevado grau de poder e autoridade social no campo da gestão da água. O terceiro, o cientista social, está longe de ser um elemento novo neste campo mas, na nossa perspectiva, teve um grau de influência limitado no sector até ao presente.

o engenheiro hidráulico será talvez o principal exemplo do perito neste contexto. Este sujeito representa uma acumulação de conhecimento altamente sofisticada sobre os aspectos físico-naturais e técnicos da gestão da água e historicamente ocupou uma posição central no campo. Mais recentemente, os peritos económicos e financeiros também se juntaram aos engenheiros hídricos no desenvolvimento de peritagem técnica e no comando do poder no campo da gestão da água.

O funcionário político ${ }^{17}$ tem de lidar com processos que caem fora do domínio técnico do perito. Estamos aqui a pensar em funcionários políticos que ocupam posições no sector hidráulico, que têm de lidar com questões como o "descontentamento popular" em relação à distribuição dos serviços hídricos, "as características sociais e económicas da população" que podem afectar o seu acesso aos serviços hídricos ou "os valores económico, social, psicológico e ambiental da água” (SARH, 1981: 14). Enquanto o perito considera estes aspectos como externalidades,$^{18}$ na perspectiva do funcionário eles são factores cruciais que podem atingir uma posição muito proeminente na agenda política, por exemplo tornarem-se questões chave nos programas eleitorais e projectos de desenvolvimento.

15 A maior parte dos exemplos utilizados neste documento são retirados da minha pesquisa na Área Metropolitana da Cidade do México (Castro, 2001).

16 Não estamos aqui interessados no processo de implementação, onde os papéis dos peritos e dos funcionários se misturam, tal como demonstrado há muito tempo por Grindle (1977). O nosso enfoque é nas interacções entre estruturas cognitivas distintas organizadas em torno de "domínios artificialmente circunscritos" e as possibilidades de "coordenações interdisciplinares" entre elas (Piaget, 1971: 137).

17 Gostaria de salientar o carácter político do funcionário em contraste com a abordagem tecnocrática referente ao perito.

18 Para uma aplicação do conceito económico de "externalidade" das políticas de gestão da água ver, por exemplo, Roth, 1988, pp. 238-239. 
o facto de que muitos funcionários políticos no gabinete são engenheiros hídricos ou economistas por formação não deve obscurecer o ponto em discussão. A abordagem quantitativamente orientada dos peritos é largamente o produto da racionalidade técnica que crescentemente penetra as actividades de gestão da água e também, em sentido lato, a gestão pública. Em contraste, o funcionário incorpora as muitas vezes perspectivas contraditórias baseadas na racionalidade política (por exemplo político-partidária) presente nas burocracias hidráulicas.

Finalmente, o corpo de conhecimentos com o qual identificamos o nosso terceiro sujeito epistémico, o cientista social, tem vindo a preocupar-se com o entrelaçar entre as regularidades sociais e os processos físico-naturais, uma tradição que inclui figuras do séc. XIX anteriores à profissionalização das ciências sociais. 0 nosso trabalho resulta da perspectiva deste sujeito e faz uma tentativa para contribuir para o estabelecimento de coordenações interdisciplinares com os outros dois.

A análise dos "conflitos da água" dá uma boa ilustração das diferentes trajectórias intelectuais representadas pelos nossos sujeitos epistémicos. Por exemplo, quando os peritos da água falam sobre os "conflitos em torno da água" habitualmente referem-se a observações quantitativas. ${ }^{19}$ Os seus conceitos (disponibilidade da água, procura, oferta, consumo, custo) aponta para volumes de água por unidades de tempo, para séries numéricas correlacionando o crescimento populacional esperado com quantidades de metros cúbicos de água, metros de reservatórios, horas kilowatt, e por aí fora, num certo período de tempo. Nesta perspectiva, o conflito é o resultado da falta da correspondência esperada entre variáveis quantitativas.

No entanto, quando os funcionários falam sobre os conflitos em relação à água, usualmente fazem derivar a sua noção de "conflito" de um conjunto muito diferenciado de unidades observáveis. Assim, podem estar a referir-se aos acontecimentos recorrentes de protesto social que acontecem

19 O conceito de "unidade observável" encerra uma posição epistemológica: o objecto de conhecimento não é dado, mas é antes o resultado da acção de conhecer levada a cabo por um sujeito particular. Tanto a acção como o seu resultado, a unidade observável, são determinados pelas estruturas de conhecimento já existentes. Ver Piaget, 1978, pp. 43-46; e 1977, pp. 342-346. 
em determinada cidade devido à pobre qualidade dos serviços hídricos ou à desobediência civil dos consumidores de água que decidiram não pagar as suas contas. Tal como ficou demonstrado no nosso trabalho, estas acções constituem um tecido intricado quando observadas à escala da interacção diária entre cidadãos, autoridades municipais e serviços hídricos.

Apesar destas diferenças no entendimento do que é que "conflito da água" quer exactamente dizer, em última análise recorre-se aos factores físico-naturais e técnicos para explicar estes acontecimentos, passando por cima do carácter social do processo. É aqui que a perspectiva do cientista social pode dar um contributo positivo aclarando os processos sociais que sustentam a emergência destes "conflitos". Consideremos o seguinte exemplo.

\subsubsection{Tornando as regularidades sociais observáveis}

No jargão hidráulico, a população é classificada com nomes genéricos, tais como utilizadores ou consumidores. Em países menos desenvolvidos, é necessária uma categoria adicional de pessoas para reflectir o facto de amplos sectores da população não terem acesso às redes formais de fornecimento de água: no México, por exemplo, são chamados de "requerentes" [demandantes], literalmente, "aqueles que procuram" ser ligados às redes de fornecimento. O hiato entre estas diferentes categorias de cidadãos é, de facto, muito grande, tal como é explicitamente reconhecido pelas autoridades: "os mexicanos que têm acesso à água potável, à drenagem ou à irrigação estão numa posição privilegiada" ${ }^{20}$ Em suma, nem todos os mexicanos têm acesso aos serviços hídricos (ou seja, são reais utilizadores) e, de facto, uma grande parte da população tem falta deste serviço essencial. A explicação clássica dada a esta situação de desigualdade é a falta ou o

20 O engenheiro Fernando Gonzalez Villarreal, no seu discurso durante a campanha presidencial de 1982 pelo Partido Institucional Revolucionário (PRI) (PRI-IEPES, 1982b: 21). Em finais do anos 80 Gonzalez Villarreal tornou-se no número um da Comissão Nacional da Água (CNA). Actualmente, lidera uma das equipas da água do Banco Mundial. 
atraso no desenvolvimento devido a uma diversidade de causas $^{21}$ e, claro, a constrangimentos técnicos e físico-naturais, tais como a "escassez de água natural”, que parece apresentar uma justificação evidente para este estado de coisas.

No entanto, existem fortes razões para defender que esta explicação para o acesso diferenciado aos serviços hídricos não toma em consideração uma série de factores cruciais. Tal como já foi referido, é sobejamente conhecido que em muitos contextos onde água e peritagem hidráulica estão perfeitamente disponíveis, um elevado número de pessoas continua a não ter acesso aos serviços hídricos. Muito frequentemente, isto pode ser explicado por factores socio-políticos, tais como a operação de redes de poder que exercem controlo sobre o recurso. Não obstante, gostaria de debruçar a atenção noutros factores estruturais que estão na origem da desigualdade social no acesso aos serviços hídricos no México. Em particular, gostaria de realçar duas exigências básicas estabelecidas pelos serviços hídricos no México: a posse legal de terra e a exequibilidade técnica para o fornecimento dos serviços.

Pelo menos formalmente, para terem acesso aos serviços da rede hidráulica os utentes têm de ter um direito legal à sua terra, estarem "regularizados", pedindo de empréstimo o jargão da política. Em termos práticos, a regularização também se refere à exequibilidade técnica para trazer os serviços para o bairro. Apesar destas duas exigências parecerem extremamente claras no papel, quando observadas em profundidade ambas envolvem processos altamente problemáticos. Acresce a isto, o facto de serem largamente sujeitas a arbitrariedades das autoridades e de outros focos de poder nas comunidades. O facto é que a população é categorizada em dois grupos essenciais de acordo com estas características: regularizados

21 O diagnóstico oficial inclui: “conservação e manutenção deficientes das redes e das instalações electromecânicas; reduzida eficiência na utilização da água devido a furos na rede e desperdício dos utentes; falta de auto-suficiência financeira nos municípios; baixo rendimento nas agências hidráulicas operacionais devido à sub-taxação, e problemas políticos e sociais devidos a transferências de água entre regiões e estados e às mudanças de padrão na utilização do recurso" (SARH, 1981: 49). 
e não-regularizados. Examinemos estas questão em maior profundidade. Apesar da regularização da posse de terra se referir em princípio a aspectos legais formais, de facto, também implica outros factores, tais como as circunstâncias socio-económicas das pessoas envolvidas. No que concerne a exequibilidade, esta exigência refere-se a constrangimentos físico-naturais e técnicos implicados na introdução dos serviços hídricos de rede. Neste sentido, cerca de dez milhões de pessoas na MCMA, especialmente no Estado do México, vive em áreas urbanas ilegalmente desenvolvidas. Para além disso, a maior parte desses centros estão localizados em terras consideradas impróprias para o fornecimento de serviços públicos, tais como os declives rochosos a sudeste da cidade ou os terrenos a este agora ocupados em resultado da secagem de lagos, que estão expostos a cheias, na estação das chuvas, ou a tempestades de areia no período da seca (Rowland et al., 1996: 191).

Na perspectiva dos peritos e dos funcionários, o hiato entre os requerentes regularizados e não-regularizados é extremamente significativo, o que dá um exemplo pertinente dos pontos de vista frequentemente divergentes destes sujeitos epistémicos. No entanto, ser-se regularizado é apenas uma condição necessária, mas de forma nenhuma suficiente, para se ter acesso a esses serviços. De facto, existem casos de zonas urbanas não regularizadas que foram capazes de ultrapassar a exigência formal de regularização para obter os serviços públicos. Assim, o que inicialmente parecia ser uma identidade abstracta e universal, a de um requerente ou utilizador, torna-se muito mais complexa e diferenciada na base das características sociais e económicas das pessoas. Por sua vez, estas regularidades socio-económicas e a sua fachada legal e formal determinam quem tem ou não tem direito ao acesso formal aos serviços de água. Em última análise, uma densa trança de interacções sociais, entre as quais as relações de propriedade são paradigmáticas, opera como um mecanismo que governa a inclusão ou a exclusão de indivíduos e famílias no acesso à água. No entanto, esta divisão fundamental é enovoada pela aparente identidade universal do "procurador", o sujeito interpelado pelas autoridades hidráulicas. Se continuarmos no quadro de referência dado pelas estruturas cognitivas desenvolvidas pelos sujeitos 
epistémicos, o carácter social da gestão da água permanece inobservável e os factores cruciais que sustentam a emergência dos "conflitos da água" são negligenciados ou, na melhor das hipóteses, reduzidos a determinações físico-naturais ou técnicas.

\section{Conclusão}

A nossa conclusão recai sobre a perspectiva do terceiro sujeito epistémico, o cientista social tal como foi anteriormente definido. Pode argumentar-se que este sujeito representa uma longa tradição que desenvolveu as estruturas cognitivas apropriadas para tornar observáveis tais regularidades como conflitos sociais cíclicos - seja em relação à água ou não. Apesar disto, o progresso no estabelecimento de coordenação interdisciplinar entre os domínios intelectuais, por exemplo, dos engenheiros hídricos e dos sociólogos, tem sido lento e relativamente infrutífero. 0 hiato é ainda maior quando consideramos os domínios intelectuais desenvolvidos pelos tecno-cientistas e pelos indivíduos envolvidos no estudo das desigualdades sociais estruturais. Isto tem efeitos importantes no efectivo entendimento dos "conflitos da água" e, consequentemente, nas possibilidades que podemos ter de evitar as suas consequências negativas, que afectam quase sistematicamente os sectores mais vulneráveis da sociedade.

Neste sentido, a perspectiva do cientista social é céptica quanto ao carácter indiferenciado atribuído pelo jargão da água à população como requerentes, utentes ou consumidores, o que pressupõe a existência de um campo de nível em termos do acesso aos serviços hídricos. De facto, as estruturas cognitivas deste sujeito permitem-lhe tornar observáveis os processos que criam e reproduzem desigualdades socio-económicas estruturais, tais como os que provocam a falta de acesso a água segura e condições sanitárias que afecta milhões de pessoas no México e noutros locais. Assim, nesta perspectiva, os "conflitos da água" não podem ser reduzidos às suas determinações físico-naturais e técnicas, devem antes ser analisados como parte integrante de processos mais alargados que estruturam a vida social.

Não obstante o facto de que a crua materialização destes problemas na forma de pobreza da água e a constelação de problemas sociais que lhe estão 
associados ter vindo cada vez mais a tornar-se no objecto de esforçados programas e declarações de política em todo o mundo nas últimas décadas, os processos políticos e socio-económicos que lhe subjazem são, em larga medida, deixados sem resposta. Assim, aqueles aspectos que para nós constituem as unidades observáveis chave para compreender e eventualmente evitar a incerteza da água e os conflitos da água, permanecem largamente não observadas como objecto de conhecimento.

O nosso trabalho pretende contribuir para o estabelecimento de coordenações entre as diferentes estruturas cognitivas e culturas epistémicas envolvidas na produção de conhecimento sobre a água e particularmente sobre a gestão social deste recurso. Desta forma, a nossa proposição central será a de que a maior parte dos "conflitos da água" intra-nacionais deveriam ser considerados como parte e parcela da dinâmica que caracteriza um sistema social fundado na reprodução da desigualdade social estrutural e da exclusão social. Em consequência, defendemos que estes conflitos fazem parte de uma luta social para um maior e mais justo acesso às condições sociais de existência. Neste sentido, a sua importância não pode ser reduzida às determinações nem técnico-burocráticas nem físico-naturais da gestão da água.

\section{Referências Bibliográficas}

Amin, A. (1997), Beyond Market and Hierarchy: Interactive Governance and Social Complexity, Cheltenham, Elgar.

Banco Mundial (1992), Governance and Development, Washington DC, Banco Mundial.

(1998), Facilitating Private Involvement in Infrastructure: an Action

Programme, Washington DC, Banco Mundial.

Beck, Ulrich (1992a), Risk Society, Londres, Sage. 
(1992b), "From industrial society to risk society", Theory, Culture and Society, Vol. 9, n.․ 1, pp. 97-123.

(1995), Ecological Enlightenment, Atlantic Highlands, N.J., Humanities Press.

(1998), "Politics of risk society", in J. Franklin (ed.) The Politics of Risk Society, Cambridge e Oxford, Polity Press, pp. 9-22.

Bond, P. (1997), "Privatization, protest and participation: citizen opposition to the World bank in Haiti and South Africa", documento apresentado ao Banco Mundial/NGO Dialogue on Privatization, Washington DC, Friends of the Earth/World Bank.

Castells, M. (1996), The Rise of the Network Society. The Information Age: Economy, Society and Culture, Vol. I, Cambridge e Oxford, Blackwell.

Castro, J. E. (1992), El conflicto por el agua en México. Los casos de Tuxtla Gutiérrez, Chiapas y Ciudad Juárez, Chihuahua, 1986-1991, M. Phil. Thesis não publicada (Mexico City, Facultad Latinoamericana de Ciencias Sociales [FLACSO].

(1995), "Decentralization and modernization in Mexico: the management of water services", Natural Resources Journal, Vol. 35, n.ํ 3, pp.1-27.

(Coord.) (consultar o web-site para a lista completa dos co-participantes) (2001-2004), Barriers to and conditions for the involvement of private capital and enterprise in water supply and sanitation in Latin America and Africa: seeking economic, social, and environmental sustainability, Comissão Europeia - 5 Programa Quadro (INCO-DEV), Contrato: PL ICA4-2001-10041, (University of Oxford - School of Geography and the Environment, Oxford) (disponível em http://www.geog.ox.ac.uk/ prinwass/). 
e E. Swyngedouw (2000), Metropolitan Cities and Sustainable Use of Water (METRON), Estudo de Caso: Londres, Environment and Climate Programme, projecto do $4^{\circ}$ Programa Quadro, DGXII, Bruxelas, Comissão Europeia (disponível em http://www.feweb.vu.nl/re/regional/Metron/ metrondocs/london1.pdf).

(2002), Water, Power and Citizenship. Contemporary Social struggles in Valley of Mexico: a Long-term Perspective, Oxford, St. Antony's - Macmillan (no prelo).

E. Swyngedouw, e M. Kaika (2002), "London: structural continuities and institutional change in water management", European Planning Studies, Special Issue on "Water for the City: Policy Issues and the Challenge of Sustainability" (no prelo).

Centre for Interdisciplinary Research (ZIF) (2001), “Theoretical background. State of the art: citizenship, participation and social positioning in different legal contexts", International and Interdisciplinary Workshop: Communicating Citizenship in Decision Making Procedures. Towards an Interdisciplinary and Cross-Cultural Perspective, 27-30 Junho, Bielefeld, Universidade de Bielefeld.

Clarke, R. (1991), Water. The International Crisis, Londres, Earthscan Publications.

Comissão Europeia, Forward Studies Unit (FSU) (1996), “Governance”, Relatório de Progresso, Bruxelas, FSU.

Comissão Europeia (2001), “Achieving sustainable and innovative policies through participatory governance in a multi-level context”, Relatório de Progresso, Framework V - Programme Project, Bruxelas, Comissão Europeia. 
Council for Biotech Information (CBI) (2000), "Biotechnology Can Help Protect The Environment", Reference n. ${ }^{\circ}$ 3229, 24 Abril, Council For Biotech Information (disponível em http://www.biotechknowledge.com/ showlib.php3?uid=3229\&country=us).

Elias, N. (1994), The Civilising Process, Oxford e Cambridge, Blackwell.

Esman, M. J. (1991), Management Dimensions of Development: Perspectives and Strategies, West Hartford: Kumarian Press.

Foster, J. B. (1999), "Marx's theory of metabolic rift: classical foundations for environmental sociology", American Journal of Sociology, Vol. 105, n.․ 2, pp. 366-405.

Frankenfeld, Ph. (1992), Technological Citizenship: a Normative Framework for Risk Studies, Science, Technology and Human Values, Vol. 17, pp. 459-484.

Gasper, D. (1993), "Entitlements analysis: relating concepts and contexts," Development and Change, Vol. 24: pp. 679-718.

Gleick, P. H. (1993), "Water and conflict: fresh water resources and international security", International Security, Vol. 18, n. 1, pp. 79-112.

(1999), “The human right to water", Water Policy, Vol. 1, n. 5, pp. 487-503.

(2000a), “Water conflict chronology”, Development, Environment and Security, Oakland, Pacific Institute for Studies.

(2000b), "The changing water paradigm. A look at twenty-first century water resources development", Water International, Vol. 25, n.ำ 1, pp. 127-38. 
Gorbachev, M. (2000), "The Global Water Crisis", Artigo Introdutório in Civilization, the Magazine of the US Library of Congress, Outubro-Novembro, (disponível em http://www.gci.ch/GreenCrossPrograms/waterres/waterresource.html).

Gore, C. (1993), “Entitlement relations and 'unruly' social practices: a comment on the work of Amartya Sen", Journal of Development Studies, Vol. 29, n. .3 , pp. $429-460$.

Goudsblom, J. (1992), Fire and Civilization, Londres, Allen Lane.

Grindle, M. S. (1977), "Power, expertise and the 'tecnico': suggestions from a Mexican case study", The Journal of Politics, Vol. 39, n.2, pp. 399-426.

Hardoy, A. e R. Schusterman (1999), "Las privatizaciones de los servicios de agua potable y saneamiento y los pobres urbanos", Medio Ambiente y Urbanización, Vol. 15, n.ํ5, pp. 63-76.

Held, D. (1995), Democracy and the Global Order: from the Modern State to Cosmopolitan Governance, Cambridge, Polity Press.

Hirst, P. (1994), Associative Democracy: New Forms of Economic and Social Governance, Cambridge, Polity Press.

Homer-Dixon, Th. F. (1991), "On the threshold: environmental changes as causes of acute conflict", International Security, Vol. 16, n..2, pp. 76-116.

Homer-Dixon, Th. F., J. H. Boutwell, e G. W. Rathjens (1993), "Environmental change and violent conflict", Scientific American, Fevereiro, pp. 16-23.

Hundley, N. (Jr.) (1992), The Great Thirst. Californians and Water, 1770s-1990s, Berkeley, Los Angeles e Oxford, University of California Press. 
Interamerican Development Bank (IDB) (1998a), Facing up to Inequality in Latin America. Economic and Social Progress in Latin America, Washington DC: IDB.

(1998b), "Strategy for integrated water resources management", Documento ENV-125 (Dezembro), Washington DC, IDB.

Johnson, B.B. e V. T. Covello (eds.) (1987), The Social and Cultural Construction of Risk. Essays on Risk Selection and Perception, Dordrecht, Reidel.

Kasperson, J. X., R. E. Kasperson, e B. L. Turner II (eds.), Regions at Risk. Comparison of Threatened Environments, Tóquio, Nova Iorque, Paris, United Nations University Press.

Knorr Cetina, K. (1999), Epistemic Cultures. How the Sciences Make Knowledge, Cambridge, Mass., e Londres, Harvard University Press.

Krimsky, S. e A. Plough (1988), Environmental Hazards. Communicating Risks as a Social Process, Dover, MA, Auburn House.

Latour, B. (1991), We have Never been Modern, Hemel Hempstead, Prentice Hall - Harvester Wheatsheaf.

Marshall, T.H. (1992 [1950]), "Citizenship and social class”, in T.H. Marshall e T. Bottomore, Citizenship and Social Class, Londres e Concord, Mass., Pluto Perspectives, pp. 3-51.

Martin, B. (1996), "From the many to the few. Privatization and globalization”, The Ecologist, Vol. 26, n.․ 4, Jul/Ago., pp. 145-155.

Martins, H. (1996), Hegel, Texas e Outros Ensaios de Teoria Social, Lisboa, Século XXI. 
(1997), “Tecnologia, modernidade e política”, Lua Nova, n.․․ 40-41, pp. 289-322.

(1998a), "Risco, incerteza e escatologia. Reflexões sobre o experimentum mundi tecnológico em curso", Episteme, Vol. 1, n.1, pp. 99-121.

(1998b), "O deus dos artefatos: sua vida, sua morte", Tecnociência e Cultura. Ensaios sobre o Tempo Presente, São Paulo, Estação Libertade.

Mearns, R. (1995), "Environmental entitlements: towards empowerment for sustainable development," in N. Singh, e V. Titi (eds.), Empowerment: Towards Sustainable Development, Londres, Zed Books.

Mehta, M. (1998), "Risk and decision making: a theoretical approach to public participation in techno-scientific conflict situations", Technology and Society, Vol. 20, n.ำ 1, pp. 87-98.

M.S. Swaminathan Research Foundation (MSSRF) (1999), "Biotechnology and water security”, Chennai, Madras, Índia (disponível em http://www. mssrf.org.sg/d99-biotech-water.html).

Newby, H. (1996), “Citizenship in a green world: global commons and human stewardship”, in M. Bulmer e A. Rees (eds.), Citizenship Today. The Contemporary relevance of T. H. Marshall, Londres, UCL Press, pp. 209-221.

Organization for Economic Co-operation and Development (OECD) Working Party on Biotechnology (WPB) (1999), Health Policy Brief. Molecular Technologies for Safe Drinking Water, Paris, OECD (disponível em http://www. eawag.ch/publications_e/proceedings/oecd/Proceedings.html). (1996), Biotechnology for Water Use and Conservation. The Mexico '96 Workshop, Paris, OECD. 
Office of Water Services (2000a) The Current State of Market Competition, Birmingham, OFWAT.

Office of Water Services (2000b) The Changing Structure of the Water and Sewerage Industry in England and Wales, Birmingham, OFWAT.

Office of Water Services (2000c) New Ownership Structures in the Water Industry. A Consultation Paper by the Director General of Water Services, Birmingham, OFWAT.

Ohlsson, L. (ed.) (1992), Regional Case Studies of Water Conflicts, Göteborg, Peace and Development Research Institute (PADRIGU), Universidade de Göteborg.

Ostrom, E. (1990), Governing the Commons. The Evolution of Institutions for Collective Action, Cambridge, Nova Iorque e Melbourne, Cambridge University Press.

, L. Schroeder, e S. Wynne (1993), Institutional Incentives and Sustainable Development: Infrastructure Policies in Perspective, Boulder, Westview Press.

Petrella, R. (2001), The Water Manifesto. Arguments for a World Water Contract, Londres e Nova Iorque, Zed Books.

Piaget, J. (1971), Structuralism, Londres, Routledge e Kegan Paul.

Picciotto, Robert (1997), "Putting institutional economics to work: from participation to governance", in Christopher K. Clague (Ed.) Institutions and economic development: growth and governance in less-developed and post-socialist countries, Baltimore and Londres, John Hopkins University Press, pp. 343-367. 
Prigogine, I., e I. Stengers (1979), La Nouvelle Alliance: Metamorphose de la Science, Paris, Gallimard.

Redclift, M., e T. Benton (1994), Social Theory and the Global Environment, Nova Iorque, Routledge.

Roth, G. (1988), The Private Provision of Public Services in Developing Countries, Washington, DC, The World Bank e Oxford University Press.

Rowland, A., e P. Gordon (1996), "Mexico City: no longer a leviathan?", in A. Gilbert (ed.) The Mega-City in Latin America, Tóquio e Nova Iorque, United Nations University Press, pp. 173-202.

Samson, P., e B. Charrier (1997), "International freshwater conflict. Issues and prevention strategies", Geneva, Green Cross International.

Savedoff, W., e P. Spiller (1999), Spilled Water. Institutional Commitment in the Provision of Water Services, Washington DC, Interamerican Development Bank (IDB).

Schmidt, C. (1993), "On economization and ecologization as civilizing processes," Environmental Values, n.. 2, pp. 33-46.

Secretaría de Agricultura y Recursos Hídricos (SARH) (1981), Comisión del Plan Nacional Hidráulico, Plan Nacional Hidráulico, Cidade do México, SARH.

Sen, A. (1981), Poverty and Famines. An Essay on Entitlement and Deprivation, Oxford, Clarendon Press.

(1990), "Food, economics, and entitlements", in J. Drèze e A. Sen

(eds.), The Political Economy of Hunger, Oxford, Clarendon Press, pp. 34-52. 
Steenbergen, B. (1994), "Towards a global ecological citizen”, in B. Van Steenbergen (ed.), The Condition of Citizenship, Londres, Sage, pp. 141-152.

Stockholm Environment Institute (SEI) (1995), International Environmental Bulletin, Vol. 2, n. 2, Setembro, (disponível em http://www.sei.se/bulletin/ sb9509a.html).

Streeck, W. e Ph. Schmitter (1985), Private Interest Government, Londres, Sage.

Swyngedouw, E. A. (1995), "The contradictions of urban water provision", Third World P Review, Vol. 17, n. 4, pp. 387-405.

(1999), Flows of Power: Nature, Society and the City, Oxford, Oxford University Press.

(2000), "Authoritarian governance, power and the politics of rescaling", Environment and Planning D "Society and Space" (no prelo).

, J. E. Castro, e B. Page (eds.) (2001), Sustainability, Risk and Nature: the Political Ecology of Water in Advanced Societies, Londres (no prelo).

Tamayo, G., R. Barrientos, E. Conterno, e A. Bustamante (1999), "Reform efforts and low-level equilibrium in the Peruvian water sector", in W. Savedoff e P. Spiller, Spilled Water. Institutional Commitment in the Provision of Water Services, Washington DC, Interamerican Development Bank (IDB), pp. 89-134.

United Nations (1948), Universal Declaration of Human Rights, adopted and proclaimed by General Assembly resolution 217 A (III) of 10 December 1948 (http://www.un.org/Overview/rights.html). 
United Nations Development Programme (UNDP) (1997) Governance for Sustainable Growth and Equity, New York: UNDP.

Ward, C. (1997), Reflected in Water. A Crisis of Social Responsibility, Londres e Washington, Cassell.

Webb, P., e M. Iskandarani (1998), "Water insecurity and the poor", Discussion Papers on Development Policy, Bona, Center for Development Research.

World Commission on Water for the 21st Century (WCW) (1999), The Biotechnology Panel, "Inter-disciplinary Dialogue on 'Climate, Biotechnology and Food and Water Security", Chennai, Madras, Índia, 4-5 Fevereiro.

Worster, D. (1985), Rivers of Empire. Water, Aridity, and the Growth of the American West, Nova Iorque-Oxford, Oxford University Press.

\section{Outros web sites consultados}

Analytical technology (ATI), http://www.analyticaltechnology.com/.

Consumer Federation of America, http://www.consumerfed.org.

Friends of the earth (FoE), http://www.foe.co.uk/campaigns/real_food/ index.html.

Green Cross International, http://www.gci.ch/.

Greenpeace, http://www.greenpeace.org/\%7Egeneng/reports/food/ food001.htm.

Monsanto, Biotech Basics, http://www.biotechbasics.com. 
N-Viro International Corp, http://www.nviro.com/.

Pacific Institute for Studies in Development, Environment and Security, http://www.pacinst.org.

Siemens, Fresh Solutions for Waste Water \& Drinking Water, http://www. is.siemens.de/water/index_en.html.

U. S. Food e Drug Administration, http://vm.cfsan.fda.gov/ /rd/biotechm. $\underline{h t m l}$.

The Institute of Food Science \& Technology, http://www.ifst.org/.

Water Technology, The Web Site for the Water Industry, http://www. water-technology.net/contact.html.

World Resources Institute, http://www.wri.org/.

World Water Institute, http://www.wri.org/wri/wr-98-99/freshwat.htm. 


\title{
Capítulo 3
}

\section{Proposiciones para el examen teórico y empírico de la privatización: el caso de los servicios de agua y saneamiento en América Latina ${ }^{1}$}

\begin{abstract}
"Siempre la mayor parte de las inversiones en materia de agua debe ser del sector público', declaró a La Jornada Katherine Sierra, vicepresidenta de infraestructura y desarrollo del BM [Banco Mundial], quien encabeza la delegación del organismo en el cuarto Foro Mundial [del Agua] que inició ayer [en la Ciudad de México]. [...]

Katherine Sierra indicó que el BM 'ha tenido una evolución muy interesante' en la forma en que plantea el tema de las inversiones en el sector. 'En los años 90, debido a la cantidad muy fuerte de recursos que se necesitan, creímos que el sector privado podía hacer inversiones importantes que podrían salvar al sector del agua. Pero no había mucha inversión del sector privado; 90 por ciento de los recursos siguen siendo del sector público, aun en las épocas más fuertes de participación privada'"
\end{abstract}

La Jornada, Ciudad de México, 17 de marzo de 2006

\section{Introducción}

Los argumentos presentados en este artículo se basan en los resultados de una serie de trabajos de investigación recientes, en particular el Proyecto PRINWASS (CASTRO, 2004a). Este proyecto examinó en perspectiva

1 Una versión previa de este texto fue publicada en: Nueva Sociedad, No 207, 2007, pp. 93-112. 
comparativa una serie de casos de privatización ${ }^{2}$ de servicios de agua y saneamiento en África, América Latina, y Europa, incluyendo ejemplos de Argentina, Bolivia, Brasil, y México (el Cuadro A-1 en el Apéndice ofrece una descripción sintética de los casos de estudio). ${ }^{3}$ El artículo está estructurado en función de cuatro proposiciones elaboradas a partir de los resultados de investigación:

Proposición No. 1: Las políticas de privatización implementadas desde la década de 1990 para reorganizar los servicios de agua y saneamiento en América Latina han tenido poca relación con los problemas específicos de dichos servicios. En los argumentos utilizados para promover estas políticas frecuentemente se presentó la privatización como solución a la crisis de dichos servicios, caracterizados entre otros problemas por la falta de cobertura a amplios

2 Utilizaremos en este artículo el concepto de "privatización" en forma genérica para denominar ciertas formas de participación privada que caracterizan a las políticas impulsadas por los organismos financieros internacionales y los gobiernos de los países desarrollados desde la década de 1980. En términos rigurosos, preferimos utilizar el término "privatización" para referirnos a una de las formas que asume la participación privada: la transferencia completa de la propiedad y la gestión de empresas públicas al sector privado (comúnmente referida en inglés como full divestiture), pero a los fines de este artículo utilizaremos el término en forma genérica. Véase el Cuadro A-2 en el Apéndice para una síntesis de las formas principales que puede adoptar la participación privada en la prestación de servicios de agua y saneamiento. También, utilizaremos en forma intercambiable los términos "privatización", "política privatista", "política neoliberal” y formas similares.

3 El Proyecto PRINWASS empleó una metodología combinada (métodos cuantitativos y cualitativos) para el análisis comparativo de los casos en seis dimensiones analíticas: económico-financiera, ambiental, político-institucional, socio-política y cultural, tecno-infraestructural, y socio-demográfica. Los informes del proyecto están disponibles en forma gratuita y pueden solicitarse en: http://www.prinwass.org. Los documentos incluyen los informes de los casos de estudio (AZPIAZU et al., 2003; CASTRO, 2003; CRENZEL, 2003; KALLIS; COCCISSIS, 2003; CRESPO et al., 2003; MASHAURI, 2003; NYANGERI, 2003; ROZE, 2003; SEPPALA et al., 2003; TORREGROSA et al., 2003; VARGAS, 2003), los informes comparativos de las seis dimensiones analíticas (AZPIAZU; SCHORR, 2004; CASTRO; LAURIE, 2004; CRENZEL; FORTE, 2004; KALLIS; COCCOSSIS, 2004a; TORREGROSA et al., 2004; VARGAS; SEPPALA, 2004), los informes estratégicos por país (AZPIAZU et al., 2004; CASTRO, 2004b; LAURIE et al., 2004; KALLIS; COCCOSSIS, 2004b; MASHAURI, 2004; NYANGERI, 2004; SEPPALA, 2004; TORREGROSA; KLOSTER, 2004; VARGAS, 2004), y los informes que contienen la revisión bibliográfica y las síntesis de resultados (CASTRO, 2002; 2004c; SEPPALA; HUKKA, 2002). 
sectores de la población, la calidad inadecuada de la prestación, la corrupción o la falta de inversión pública en la expansión y renovación de la infraestructura. Sin embargo, nuestro argumento es que la razón principal para la implementación de dichas políticas no fue la búsqueda de soluciones a dichos problemas, sino más bien la aceptación acrítica de una política fundada en los principios y argumentos característicos de la ideología privatista, que resurgió durante la década de 1980 y pasó a influir el diseño y la implementación de políticas públicas a nivel global, incluyendo las políticas para los servicios de agua y saneamiento. En nuestra perspectiva, la crisis real de los servicios fue utilizada -y en algunos casos provocada- para promover la política privatista en este sector de actividad.

Proposición No. 2: Los argumentos utilizados para promover las políticas de privatización de los servicios de agua y saneamiento ignoran la evidencia histórica existente sobre la interrelación entre los sectores público y privado en la organización de los servicios de agua y saneamiento. En particular, dichas políticas han desconocido el registro histórico que demuestra que la universalización del acceso a estos servicios esenciales en los países desarrollados requirió la desprivatización de las empresas que gestionaban estos servicios y la creación de empresas públicas, con inversión pública. Los argumentos privatistas han reemplazado estas lecciones provenientes de la evidencia histórica con prescripciones derivadas del marco ideológico neoliberal que no tiene fundamento empírico.

Proposición No. 3: Las políticas de privatización implementadas para reorganizar los servicios de agua y saneamiento en América Latina han fracasado en el logro de sus objetivos explícitos, entre los cuales se destacaba la atracción de capitales privados para financiar la expansión y la renovación de infraestructura, 
la extensión de los servicios a la población no atendida, el incremento de la eficiencia en la gestión de los servicios, el alivio de la responsabilidad financiera del sector público y la reducción de la pobreza y la desigualdad, entre los más importantes.

Proposición No. 4: Aunque las políticas de privatización de los servicios de agua y saneamiento en América Latina han fracasado en sus objetivos declarados, la implementación de dichas políticas puso en marcha una serie de procesos cuya fuerza inercial continuará ejerciendo influencia en la organización y gestión de estos servicios por un largo tiempo. No solamente las reformas privatizadoras han dejado irresueltos a la mayor parte de los problemas pre-existentes, agudizándolos con frecuencia, sino que además han generado la emergencia de nuevos problemas y obstáculos para la gestión sustentable y democrática de dichos servicios.

\section{Ideología privatista y políticas públicas}

Las políticas de privatización implementadas en los servicios de agua y saneamiento en América Latina desde la década de 1990 han sido presentadas frecuentemente como una solución técnica, desprovista de contenido político, a los problemas crónicos que caracterizan a estos servicios en muchas ciudades y regiones del continente. Por ejemplo, Terence Lee y Andrei Jouravlev de la Comisión Económica para América Latina y el Caribe de las Naciones Unidas (CEPAL) afirman que existe amplio apoyo para el argumento de que la transferencia de empresas de agua y saneamiento públicas a manos de "monopolios de propiedad y administración privada podría incrementar la eficiencia económica” (LEE; JOURAVLEV, 1997, p.8-9). Ellos enumeran una lista de ventajas que podrían resultar de la privatización de los servicios, incluyendo reducción de la "interferencia política", restauración de los "incentivos para minimizar los costos", cancelación de la "captura regulatoria" -que ocurre cuando el estado es a la vez prestador y regulador del servicio-, "administración financiera más efectiva" y 
capacidad de planeamiento a largo plazo que supuestamente no existe en las empresas públicas (LEE; JOURAVLEV, 1997).Otro ejemplo es el de Paulina Beato, Economista en Jefe de la División de Infraestructura y Mercados Financieros del Banco Interamericano de Desarrollo, quien presenta argumentos muy similares a los de Lee y Jouravlev citados anteriormente y añade que:

la experiencia demuestra que los sistemas administrados en forma privada alcanzan más alta calidad con menor inversión [...] al incorporarse al sector privado la administración de la empresa se vuelve independiente de las decisiones políticas. [...] la participación privada aumenta la capacidad financiera de los servicios. Por un lado, la participación privada mejora el cobro de tarifas y reduce los costos, aumentando de esta forma el flujo de fondos internos a través del capital o de deuda [...] De este modo, la participación del sector privado permite romper con el círculo de ineficiencia creciente (BEATO, 1997, p. 11-2).

Estos ejemplos podrían multiplicarse fácilmente ya que desde fines de la década de 1980 la promoción de las políticas de privatización se constituyó en una actividad floreciente a nivel global y, particularmente, en América Latina, la cual quedó reflejada en la literatura relevante. Ahora bien, a pesar del esfuerzo consistente de estos autores por presentar la privatización como un instrumento técnico neutral, apolítico, no logran ocultar el carácter esencialmente político e ideológico del modelo. En este sentido, el análisis de esta literatura permite destilar lo que podemos denominar los principios clave de la política neoliberal para la gestión del agua y sus servicios, que se ilustran en el cuadro 1. 
Cuadro 1. Principios clave de la política neoliberal para la gestión del agua y de los servicios de de agua y saneamiento

a) Los recursos hídricos deben ser asignados a través del mercado; para esto deben crearse derechos privados de agua para reemplazar las formas de derechos colectivos o públicos que puedan preexistir. Los derechos privados deber ser libremente comercializables;

b) Los servicios de agua deben ser considerados un bien económico, en el sentido de ser un bien privado que debe ser adquirido en el mercado; por definición, una vez que los servicios del agua pasan a ser considerados bienes privados es posible excluir de su uso a quienes no pagan; la noción de que los servicios del agua son un bien público o social debe ser abandonada;

c) Los servicios del agua deben ser provistos por operadores privados, que son inherentemente más eficientes que los públicos; de ser posible, los servicios del agua deben ser autoregulados mediante mecanismos de mercado y la intervención estatal deber ser minimizada y, de ser posible, totalmente anulada;

d) Los servicios del agua no son un monopolio natural, como argumentan quienes defienden la intervención estatal; la mayor parte de las operaciones pueden abrirse a la competencia, quizás con la excepción de algunas operaciones básicas; sin embargo, la existencia de altos costos de transacción pueden dificultar la competencia, en cuyo caso es preferible tener un monopolio privado antes que un monopolio público; en este caso también es mejor mantener la regulación al mínimo o de ser posible, anularla por completo;

e) Los usuarios del agua deber ser convertidos en consumidores, y los tenedores de derechos en clientes.

Estos principios han sido derivados de la literatura especializada que promueve la privatización de las empresas públicas y en particular los servicios de agua y saneamiento. Entre otros ejemplos hemos consultado:

ROTH, 1988; NELLIS; KIKERI, 1989; SÁNCHEZ; CORONA, 1993; ROGOZINSKI, 1993; RICHARD; TRICHE, 1994; WINPENNY, 1994; RIVERA, 1996; BEATO, 1997; BROOK COWEN, 1997a, 1997b; FARLEY, 1997; LEE: JOURAVLEV, 1997; NICKSON, 1997; PIERCY, 1997; ROEMER, 1997; Banco Mundial, 1998; BROOK COWEN; COWEN, 1998; LEE; JOURAVLEV, 1998; ROGOZINSKI, 1998; LEE, 1999; NEWBERY, 1999; WSPPPIAF, 2002; NELLIS, 2003; BALEN, 2006; Banco Mundial, 2006 b.

Fuente: CASTRO, 2006, p. 176-7. 
Desde otro ángulo, la promoción de la privatización de los servicios de agua y saneamiento estructurada sobre la base de estos principios está articulada con las directivas provenientes de los organismos financieros internacionales y otros agentes como las agencias de cooperación de algunos países europeos y los Estados Unidos. Por ejemplo, el Banco Mundial a través de su Grupo para la Participación del Sector Privado en Infraestructura se abocó a la tarea de promover la "participación privada en infraestructura dentro del contexto de sus objetivos generales de apoyar la reducción de la pobreza y el desarrollo sustentable" (Banco Mundial, 1998, p. 1). El Programa de Acción del Grupo declaraba que:

La participación privada ofrece un enorme potencial para mejorar la eficiencia de los servicios de infraestructura, extender su distribución hacia los pobres, y aliviar la presión sobre los presupuestos públicos que, por mucho tiempo, fueron la única fuente de financiamiento. Incentivar un mayor involucramiento privado requiere que los gobiernos cambien su papel donde ya no proveen servicios de infraestructura en forma directa sino que más bien se encargan de fomentar la competencia entre proveedores privados, regulando en aquellos lugares donde la competencia es débil, y apoyando al sector privado en general (Id., p. 1).

En la misma dirección, pero abogando por un curso de acción radical para privatizar los servicios de agua y saneamiento en los países menos desarrollados, la especialista en Sector Privado del Banco Mundial Penelope Brook Cowen argumentaba a favor de la "privatización desregulada", "monopolios privados desregulados", y "laissez faire" donde "la provisión de servicios sea regulada por las fuerzas del mercado y por incentivos económicos" para resolver la crisis de estos servicios (BROOK COWEN; COWEN, 1998, p. 22, 28). La prescripción era:

La completa privatización de los activos del agua y un monopolio natural desregulado [...] La razón principal de la privatización desregulada es clara. Un monopolio privado desregulado 
podría tener un incentivo para atraer al sistema tantos compradores potenciales como resulte posible, para maximizar la ganancia. De este modo, los monopolios privados desregulados aumentarían en forma significativa el número de conexiones de agua en los países en desarrollo. Si la privatización desregulada pudiera producir conexiones para los consumidores de bajos ingresos, ahora abandonados, los pobres terminarían con mayores ingresos, mejor servicio sanitario, mayor tiempo para otros emprendimientos y una mayor probabilidad de una larga expectativa de vida (Id., 1998, p. 22-3).

Sin bien los argumentos de Brook Cowen representan en alguna medida la versión más extrema del argumento privatista, ya que pocos autores proponen tan abiertamente la idea de crear monopolios privados no regulados, el hecho de que la autora ocupara un puesto de importancia estratégica en el Banco Mundial muestra que este modelo privatista radical cuenta con el apoyo de sectores importantes dentro de las instituciones financieras internacionales, como lo sugiere la notable crítica de Stiglitz, Premio Nobel de Economía y ex Economista en Jefe del Banco Mundial:

Al establecer las reglas del juego, los intereses y modos de pensar comerciales y financieros parecen haber prevalecido al interior de las instituciones económicas internacionales. Lo que ahora prevalece es una visión particular del rol del gobierno y de los mercados -una visión que no es compartida universalmente en los países desarrollados, pero que está siendo forzada sobre los países en vías de desarrollo y las economías en transición (STIGLITZ, 2002, p. 224-225).

Esta expansión de las reglas de juego privatistas a escala global se convirtió en una cuestión de militancia, particularmente debido a las resistencias encontradas a las políticas de privatización en muchos países. Como lo señalara un analista favorable a la privatización:

Es un hecho que la privatización de empresas del estado en la región del Africa sub-Sahariana, en Asia y en América Latina no tendrá éxito a menos que los países occidentales 
industrializados y desarrollados, las instituciones financieras internacionales tales como el Banco Mundial y el FMI, y otros donantes continúen ejerciendo presión sobre estos gobiernos para privatizar el sector público [...]. Una vez que el espíritu de libre empresa reine en estos países en desarrollo a través de la privatización, emergerán la economía de libre mercado y la democracia (DINAVO, 1995, p. 133).

En este sentido, "el Consenso de Washington" -entendido como el conjunto de iniciativas políticas orientadas a transformar el régimen de política económica de los países en desarrollo a través de la desregulación, la liberalización del comercio, la disciplina fiscal y la privatización- se constituyó en una cultura compartida ampliamente en el espectro político, siendo adoptado en Europa tanto por gobiernos social demócratas como conservadores y en América Latina hasta por ex defensores del estructuralismo económico como la CEPAL. Esta amplia aceptación de las reglas de juego prevalecientes ha sido explicada como el resultado de un complejo conjunto de factores, entre los que se incluyen presiones externas, emulación de políticas, la expansión de las ideologías neoconservadoras, pragmatismo político en tiempos de profunda crisis económica, estrategias políticas dirigidas a cambiar el equilibrio de poder entre actores socioeconómicos nacionales (MANZETTI, 1999) y también, muy notoriamente, "briberization" ("bribe" puede traducirse como "coima”), el término inglés utilizado sarcásticamente por Stiglitz para denunciar la corrupción asociada con la promoción de la privatización por parte del Banco Mundial y el Fondo Monetario Internacional durante la década de 1990 (STIGLITZ, 2002, p. 58).

En este marco, la influencia del gobierno de los Estados Unidos parece haber ejercido un rol fundamental, ya sea a través de la acción directa de los departamentos del gobierno, a través de las políticas de préstamo de la Agencia Norteamericana para el Desarrollo Internacional (USAID) o a través de programas diseñados e implementados por instituciones bilaterales y multilaterales (COMMANDER; KILLICK, 1988, p. 314). Las formas en que se ejerce esta influencia fueron descritas por un simpatizante de las políticas privatizadoras: 
Se ha ejercido presión "sobre los países en desarrollo por parte de organizaciones internacionales tales como el Banco Mundial, el Fondo Monetario Internacional (FMI), y la Agencia Norteamericana para el Desarrollo Internacional, para seguir la política de privatización como parte de un paquete de reformas económicas [cita]". Para que los líderes de los países en desarrollo vean a la privatización como la mejor alternativa, ellos tienen que ser entrenados y educados en este campo a través de seminarios dictados por académicos y profesionales activos que tienen el conocimiento (know-how) en este campo [la cursiva es nuestra] (DINAVO, 1995, p. 51).

Ostensiblemente, esta agenda privatizadora encontró fuerte oposición por parte de diferentes sectores, una reacción que a menudo ha sido explicada por los promotores de dichas políticas como el resultado del prejuicio ideológico y de la ignorancia que existiría en los países en desarrollo en relación a los beneficios que podrían esperarse de la política privatista. Tal como lo declaró un representante de USAID comentando acerca del papel preponderante que la agencia trata de asumir en la promoción de la privatización en el Siglo XXI:

La Agencia Norteamericana para el Desarrollo Internacional está definiendo direcciones futuras para la asistencia a las privatizaciones basada en la experiencia de los últimos 15 años desde un comienzo modesto en Latinoamérica hasta el reciente aumento dominado por la asistencia a estados previamente comunistas. En los países del centro y este de Europa y en la ex Unión Soviética, la privatización de empresas administradas por el estado y el desmantelamiento de los monopolios estatales son críticos para la transición de estas naciones a mercados libres [...] los países más pobres y los gobiernos ideológicamente opuestos a la apertura de los mercados -en gran parte de la región del Africa SubSahariana, el Cercano Oriente, y el sur de Asia-necesitarán un continuo soporte técnico y de políticas, así como también de intervenciones nuevas y creativas [nuestra cursiva] (FARLEY, 1997, p. 10). 
No cabe duda de que esta cruzada a favor de la privatización ha ejercido una influencia significativa en las últimas dos décadas, y es en el contexto de dicha política global que debemos examinar la situación de América Latina. En este sentido, afirmamos que las políticas privatistas en los servicios de agua y saneamiento han sido la consecuencia de una determinación política a escala internacional, que constituyó uno de sus campos experimentales en la América Latina durante la década de 1990 (Tabla 1).

Tabla 1 - Proyectos de Privatización de Servicios de Agua y Saneamiento por Región (1990-2005)

\begin{tabular}{lcccc}
\multicolumn{1}{c}{ Región } & Número de contratos & \% & Valor (US\$ en millones) & \% \\
\hline Asia Oriental y Área Pacífico & 139 & 36,5 & 19,207 & 42,6 \\
América Latina y el Caribe & 147 & 38,6 & 20,971 & 46,5 \\
Resto del Mundo & 95 & 24,8 & 4,956 & 10,9 \\
Total & 381 & 100 & 45,134 & 100 \\
\hline
\end{tabular}

Fuente: Resumen elaborado por el Banco Mundial (2006a). Según el Banco Mundial, estos datos cubren proyectos en países con bajos y medios ingresos. Es importante tomar nota del hecho que estos datos incluyen diferentes fuentes de inversión y que las fuentes privadas no tienen un rol significativo en este contexto.

Dichas políticas no tuvieron como objetivo principal la resolución de la crisis real que afecta a estos servicios básicos. Por lo contrario, en su diseño e implementación se ha ignorado consistentemente un hecho fundamental: la evidencia histórica disponible muestra que la organización socialmente eficaz y la universalización de los servicios básicos de agua y saneamiento en aquellos países que lograron alcanzar estos objetivos requirió la desprivatización de dichos servicios y la implementación de una política pública centrada en el principio de que los mismos constituyen un bien público y un derecho ciudadano. Este es el objeto de la Proposición No 2 que desarrollamos en la siguiente sección. 


\section{El carácter ahistórico de la política privatista}

Los argumentos utilizados para promover las políticas de privatización de los servicios de agua y saneamiento son de carácter ahistórico ya que ignoran las experiencias previas sobre la interrelación entre los sectores público y privado en la organización de los servicios de agua y saneamiento. Dichas políticas han desconocido el registro histórico de la participación privada en los servicios de agua y saneamiento y han reemplazado las lecciones provenientes de la evidencia histórica con prescripciones derivadas del marco ideológico neoliberal, que no tienen fundamento empírico. En particular, en la literatura privatista se excluye sistemáticamente la referencia al proceso histórico por el cual los países desarrollados lograron universalizar sus servicios esenciales de agua y saneamiento. Este proceso, que tuvo lugar desde fines del Siglo XIX, aproximadamente, en Europa y en los Estados Unidos, envolvió la creciente regulación de las empresas privadas de servicios de agua, y posteriormente, la desprivatización de las empresas y su reemplazo por empresas públicas, primero a nivel municipal $\mathrm{y}$, posteriormente, como tendencia, a nivel regional y nacional.

Entre otras razones, para estas reformas se encontraba el hecho de que las empresas privadas no eran eficientes, tendían a servir solamente ciertas áreas de las ciudades más importantes porque no tenían incentivos para extender los servicios a los sectores más pobres y, además, no estaban interesadas en desarrollar los servicios de recolección y tratamiento de aguas sucias (se concentraban en los servicios de agua limpia). Existe una amplia literatura que documenta este proceso histórico en Europa y en los Estados Unidos (LASKI et al., 1935; MUKHOPADHYAY, 1975; SCHULTZ; MCSHANE, 1978; GOUBERT, 1986; LUCKIN, 1986; WARNER, 1987; MILLWARD, 1991; FINER, 1997; WARD, 1997; HASSAN, 1998; OGLE, 1999; MELOSI, 2000; PEZON, 2000; NRC, 2002; HUKKA; KATKO, 2003).

El proceso fue similar en América Latina, como lo demuestra una serie de trabajos recientes y en vía de expansión, véase, por citar algunos ejemplos, Catenazzi y Kullock (1997) para Argentina; Connolly (1970) y Aboites Aguilar (19980) para México; Pérez-Rincón (2002) para Colombia; Swyngedouw $(1999,2004)$ para Ecuador; Rezende y Heller (2008) para Brasil. En resumen, 
la evidencia histórica es concluyente: la organización socialmente eficaz de los servicios esenciales de agua y saneamiento y la consecuente universalización de los mismos durante el Siglo XX en Europa y en los Estados Unidos requirió: a) primero la regulación y, posteriormente, la desprivatización de los monopolios privados que gestionaban los servicios de agua corriente desde los Siglos XVIII (en Inglaterra) y XIX (en el resto de Europa, Estados Unidos, y América Latina); b) el abandono de la noción de que estos servicios eran solamente para quienes podían pagar por ellos, y la aceptación de que los mismos constituyen un bien público y un derecho social de ciudadanía, cuya provisión y satisfacción universal, respectivamente, debe recaer en manos del Estado; y c) como consecuencia de lo anterior, la aceptación de que estos servicios deben estar a cargo de empresas públicas o bajo control público, ser de propiedad pública, y que la mayor parte del financiamiento requerido debe estar a cargo del Estado. ${ }^{4}$

Volviendo a nuestro punto principal, la literatura privatista consistentemente ignora o incluso tergiversa la evidencia histórica sobre el desarrollo de los servicios de agua y saneamiento. Por ejemplo, el Informe del Desarrollo Mundial 2004 del Banco Mundial tiene un recuadro sobre "la participación privada en la historia" de los servicios de agua y saneamiento en el cual se alega que los monopolios privados no regulados que servían la ciudad de Londres en el Siglo XIX habrían sido exitosos y que los mismos habrían contribuido a la universalización de los servicios en esa ciudad (Banco Mundial, 2003, p.167). Aparte de cometer varios errores históricos, el texto de ese recuadro omite información crucial para entender el proceso de universalización de estos servicios en Londres y en Inglaterra, en general. En particular, el texto no dice nada de las batallas políticas que tuvieron lugar desde mediados del Siglo XIX para obligar a los ocho monopolios

4 Esto no significa desconocer el rol de formas alternativas de organización y provisión de servicios de agua (y en menor medida, también de saneamiento), que en algunos países, particularmente en los menos desarrollados pero también en ciertos países europeos (por ejemplo en los países nórdicos como Finlandia), han jugado un rol muy importante en la expansión de estos servicios, como son las cooperativas en zonas rurales o las organizaciones comunitarias. Sin embargo, históricamente la tendencia mayoritaria en la universalización de estos servicios se ha fundado centralmente en el rol del Estado dada la magnitud y la escala del esfuerzo requerido. 
privados que proveían agua a la ciudad de Londres a adoptar estándares de calidad, extender los servicios a las zonas periféricas y proveer el servicio a precios accesibles, un largo y difícil proceso que culminó en 1902 con la desprivatización de los monopolios privados y la creación de una empresa única controlada por las autoridades de la ciudad, para el caso de Londres y de Inglaterra en general como lo sugieren los trabajos de Laski et al. (1935); Mukhopadhyay (1975); Millward (19910; Finer (1997); Ward (1997); Hassan (1998). Un dato fundamental en este proceso fue el hecho de que la desprivatización de las empresas monopólicas contó con el apoyo mayoritario de representantes de todo el espectro político, ya que incluso los defensores del liberalismo económico admitían que servicios esenciales como el agua y el saneamiento no podían organizarse sobre la base de principios mercantilistas y debían ser provistos y controlados por el Estado. Todavía pasarían varias décadas más hasta que, finalmente, se aceptó que la universalización de estos servicios requería la acción del Estado a través del financiamiento de la infraestructura y el control general del proceso, un objetivo que sólo se logró después de la Segunda Guerra Mundial.

Pero el texto del Banco Mundial (Banco Mundial, 2003, p.167). va más allá y, además de presentar una versión distorsionada que ignora la evidencia histórica hace referencia a la re-privatización de los servicios de agua y saneamiento en Inglaterra y Gales que llevó a cabo la Primera Ministra Margaret Thatcher en 1989 sugiriendo que con dicha decisión el orden de cosas habría retornado a la normalidad, presumiblemente la normalidad del orden privatista Cabe decir adicionalmente que el informe del Banco Mundial O BM hace extensivo el argumento "histórico" al caso de otros países, incluyendo a los Estados Unidos, con lo cual extiende también la distorsión histórica a otros casos.

El anterior es un breve ejemplo, pero un análisis de la literatura privatista en general demuestra que la evidencia histórica acerca de cómo se logró efectivamente la universalización de los servicios de agua y saneamiento en los países desarrollados es sistemáticamente ignorada o en el mejor de los casos distorsionada para fortalecer el caso de la privatización. La historia suele ser convocada para señalar el fracaso del Estado en la mayoría de los países de América Latina en desarrollar servicios públicos 
eficientes y de acceso universal pero el debate crucial acerca de cómo se logró la universalización en los países que alcanzaron dicho objetivo es simplemente ignorado o manipulado. De este modo, el debate necesario sobre cómo deben organizarse los servicios esenciales de agua y saneamiento en los países menos desarrollados ha sido reemplazado por prescripciones simplistas, derivadas de la ideología privatista disfrazada de teoría económica rigurosa e ignorando la evidencia histórica.

En este sentido, y en perspectiva histórica, los resultados de la reforma privatista de los servicios de agua y saneamiento en América Latina podrían haberse anticipado con cierta certeza: dichas políticas han fracasado en el logro de sus objetivos declarados. Este es el tema de la Proposición No. 3 que discutimos a continuación.

\section{El fracaso de la privatización}

A pesar de que los expertos privatistas se resisten a reconocer el fracaso de la privatización (LEE, 1999; NELLIS, 2003) el caso de los servicios de agua y saneamiento deja poco lugar a dudas acerca de los resultados negativos de las políticas privatistas en América Latina. No podemos analizar este tema en detalle dada la brevedad de este artículo, pero hemos examinado algunos aspectos en mayor profundidad en otros trabajos que pueden consultarse (CASTRO, 2004c, 2005, 2007, 2008; CASTRO; LAURIE, 2004). Aquí nos concentraremos principalmente en el fracaso de la política privatista en dos temas cruciales: la promesa de la inversión privada y la promesa de reducir la pobreza y la desigualdad.

Uno de los argumentos centrales que se utilizan para promover la reforma privatista en los servicios de agua y saneamiento es que la privatización contribuiría en "aliviar la presión sobre los presupuestos públicos mediante la provisión de inversión privada fresca" (Banco Mundial, 1998, p.1) y la atracción de "nuevas fuentes [privadas] de capital" (WSP-PPIAF, 2002, p.8-10). La evidencia obtenida por nuestro equipo de investigación, la cual resulta congruente con resultados similares obtenidos por otros equipos, revela que las políticas privatistas han fallado en el logro de dicho objetivo. No solamente el volumen de la inversión privada asociada con 
la privatización de servicios de agua y saneamiento ha sido muy modesta, sino que el grueso de los recursos financieros captados por las empresas privatizadas han provenido de la recaudación, de subsidios públicos o del endeudamiento (AZPIAZU; SCHORR, 2004).

Por ejemplo, la Tabla 2 presenta el caso de la empresa Aguas Argentinas en Buenos Aires, que ha sido recomendada con frecuencia por el Banco Mundial como un modelo de privatización exitosa (véase por ejemplo, Banco Mundial, 2003, p.168). Como muestra la Tabla, el capital privado solamente aportó el 2.6 por ciento de los capitales invertidos en la empresa entre el período 1993 -2001. Por otra parte, la empresa adoptó una estructura financiera basada fuertemente en el endeudamiento, que en algunos momentos de la década de 1990 superó el 15 por ciento del total de recursos financieros disponibles. La mayor parte de esta deuda se tomó en mercados internacionales y llegó a representar cerca de un tercio de las ganancias de la empresa calculadas sobre el patrimonio neto (ASPIAZU et al., 2003).

\begin{tabular}{lcc}
$\begin{array}{c}\text { Tabla } 2 \text { - Fuentes de Financiamiento - Aguas Argentinas (mayo de } \\
\text { 1993-diciembre de 2001) }\end{array}$ & (en US\$ y porcentajes) \\
Fuente & US\$ (millones) & Porcentaje \\
\hline Recaudación & $3.640,2$ & 78,1 \\
Incremento neto de la deuda & 706,1 & 15,2 \\
Capital privado (socios) & 120,0 & 2,6 \\
Otros ingresos financieros & 140,0 & 3,0 \\
Otras & 54,0 & 1,1 \\
Total & $4.660,3$ & 100,0 \\
\hline
\end{tabular}

Fuente: AZPIAZU y SCHORR (2004, p. 9).

El caso de Aguas Argentinas no es un caso aislado y más bien es consistente con el patrón observado en otros casos de nuestro estudio (AZPIAZU; SCHORR, 2004) y con los resultados de investigación de otros equipos (HALL, 2002, 2004, 2006; HUKKA; KATKO, 2003). En perspectiva, inclusive el informe Camdessus sobre formas de financiamiento de los servicios de agua y saneamiento presentado durante el Tercer Foro Mundial del Agua en Japón en 
2003, un documento claramente enmarcado dentro de la agenda privatista, reconoció que existen ciertos factores que "limitan la contribución de los operadores privados en términos estrictamente financieros" (CAMDESSUS, 2003, p.2). De todas formas, como lo ilustra la cita de Katherine Sierra que encabeza este artículo (La Jornada, 2006), existe un creciente reconocimiento incluso por parte del Banco Mundial de que este objetivo de la privatización ha fracasado y que el mismo se fundaba en la presuposición errónea de que el sector privado se convertiría en el principal proveedor de los recursos financieros necesarios para expandir y renovar la infraestructura de estos servicios (Banco Mundial, 2003, p.10-11; KLEIN, 2003; HALL et al., 2003, p. 5-7).

El segundo aspecto que consideraremos brevemente aquí es el del fracaso de la reforma privatista de los servicios de agua y saneamiento en reducir la pobreza y la desigualdad (para una elaboración más detallada de este argumento consultar Laurie, 2006). Este objetivo fue explicitado claramente en los documentos privatistas a partir de mediados de la década de 1990. Por ejemplo, el Banco Mundial afirmaba que "la participación privada ofrece un enorme potencial para mejorar la eficiencia de los servicios de infraestructura [y] extender su distribución hacia los pobres" (Banco Mundial, 1998, p.1; SAVEDOFF; SPILLER, 1999; BID, 1998). Igualmente, como ya señalamos, oficiales de alta jerarquía en el sector de agua y saneamiento del Banco Mundial propusieron formas radicales de privatización como la creación de monopolios privados sin regulación (autorregulados) como la mejor solución para extender el acceso a los servicios a los sectores pobres y mejorar sus condiciones de vida en general (BROOK COWEN; COWEN, 1998).

La evidencia empírica también demuestra que la privatización fracasó en lograr estos objetivos. Por ejemplo, examinemos brevemente el caso de Cochabamba en Bolivia, donde los servicios de agua y saneamiento de la ciudad fueron privatizados en 1999 mediante una concesión a la empresa Aguas del Tunari. Una de las primeras decisiones de la empresa fue elevar las tarifas del servicio en un promedio de $35 \%$, y a pesar de que el incremento estaba orientado teóricamente a los usuarios de mayores ingresos, en la práctica, los más afectados fueron los sectores pobres ya que la tarifa básica pasó a representar el 22\% del salario mínimo (CRESPO et al., 2003, 
p.140). Este fue uno de los elementos detonantes de la movilización y protesta social que en marzo del año 2000 resultaría en la renuncia del gabinete entero del gobierno federal y en la cancelación del contrato de privatización. La empresa ha demandado una indemnización al Estado boliviano y el caso se sigue discutiendo en un tribunal internacional al momento de escribirse este artículo.

Los casos de estudio en Argentina también ejemplifican el fracaso de este objetivo de la política privatista. En Buenos Aires, la empresa Aguas Argentinas incrementó las tarifas en un $88,2 \%$ entre 1993 y 2002, un período durante el cual el índice general de precios al consumidor aumentó solamente el 7,3\%. El impacto del incremento en la tarifa del servicio de agua y saneamiento afectó particularmente a los sectores más pobres: en el Gran Buenos Aires la tarifa pasó a representar el 9\% del ingreso familiar para el decil de menores ingresos, mientras que para el usuario promedio constituía solamente el 1,9\% (AZPIAZU et al., 2004, p.14). El otro caso estudiado en Argentina fue Tucumán, provincia donde se privatizaron los servicios de agua y saneamiento en 1993 mediante una concesión a la empresa Aguas del Aconquija. Aquí también una de las primeras medidas de la empresa privada fue aumentar la tarifa, la cual si se suma un nuevo cargo introducido para financiar al organismo regulador representó un aumento inmediato del 106\%. Además, la empresa introdujo un "cargo de infraestructura", que efectivamente trasladaba a los usuarios la responsabilidad de financiar la expansión de la red. El impacto de dichas medidas no se hizo esperar y desencadenó un movimiento de desobediencia civil que incluyó una campaña de no pago de las facturas del servicio a la cual adhirió el 86\% de los usuarios, incluyendo a las pequeñas empresas locales y a los organismos públicos. Finalmente, tras varios meses de conflicto, la concesión fue cancelada en 1997 pero, al igual que la situación de Cochabamba, el caso continúa siendo debatido en un foro internacional ya que la empresa privada demanda una indemnización de 300 millones de dólares al Estado argentino (CRENZEL, 2003).

Finalmente, el caso de estudio en México fue el Estado de Aguascalientes, donde los servicios de agua y saneamiento fueron privatizados en 1993 con la concesión otorgada a la Concesionaria de Aguas de Aguascalientes. A pesar 
de que este estado mexicano experimentó un boom económico durante la década de 1990- de acuerdo a la propia empresa privada cerca del 70\% de sus usuarios domésticos estaban catalogados como "de bajos ingresos" (período 2001-2004)-, lo cual resulta significativo ya que estos usuarios representan el 91\% del total de usuarios de la empresa. Según el plan financiero de la concesión la viabilidad de la empresa requería un aumento en la tarifa del 170\%, el cual comenzó a aplicarse en 1993 mediante incrementos parciales bimensuales. Sin embargo, la crisis financiera que afectó a México en 1994 interrumpió la aplicación del plan, lo que condujo a la empresa al borde del colapso financiero, del cual fue rescatada por el gobierno mexicano mediante un paquete de medidas que incluyeron la renegociación del contrato para transferir de vuelta al Estado toda responsabilidad por inversión en infraestructura. El paquete de medidas también incluyó un Fondo de Subsidio para los usuarios pobres y fue complementado por una Ley de Aguas aprobada en el año 2002 que prohibió la desconexión de los usuarios por falta de pago debido a su negativo impacto social (TORREGROSA et al., 2003).

Como ejemplo complementario es aleccionador referirse al caso de Inglaterra y Gales, que como dijimos suele ser mencionado como un caso de privatización exitosa digno de réplica. En este caso, el impacto de la privatización de los servicios de agua y saneamiento sobre las condiciones de pobreza y desigualdad es también significativo, lo cual provee un excelente punto de referencia para el análisis de estas políticas en América Latina. Entre el comienzo de la privatización en 1989 y 1999 las empresas aumentaron las tarifas de agua y saneamiento en un 95\%, y en los primeros 5 años el número de intimaciones de pago enviadas a los usuarios morosos aumentó en un 900\%, mientras que casi 2 millones de usuarios (alrededor de 9\% del total) dejaron de pagar su factura en 1994 (HERBERT; KEMPSON, 1995; BAKKER, 2001; DRAKEFORD, 2002). La situación continuó empeorando y, según estimaciones recientes, entre el 15 y el 20\% de los usuarios no paga actualmente su factura de agua y saneamiento en el país, mientras que según datos del gobierno entre 2 y 4 millones de familias están viviendo en situación de "pobreza del agua" dado que la factura de agua y saneamiento excede el 3\% de su ingreso familiar (KLEIN [G], 2003; FITCH; PRICE, 2002; GREENE, 2002; UKP, 2003; OFWAT, 2004; NCC, 2005). 
Volviendo al caso de América Latina, el análisis del impacto de la privatización sobre la pobreza y la desigualdad debe ponerse en el contexto de las condiciones generalizadas de aumento de las desigualdades socio-económicas que han afectado a la región durante la década de 1990, precisamente cuando la reforma privatista comenzaba a implementarse. En particular nos referimos a los patrones regresivos de distribución del ingreso, el incremento del desempleo y el subempleo, la profundización de la segregación espacial en las ciudades y el empeoramiento de lis indicadores de pobreza (BAYLISS; KESSLER, 2006; CRENZEL; FORTE, 2004; PNUD, 2004; UN-HABITAT, 2003; PERRY et al., 2003; BID, 1998). Fue en este contexto que se implementó la política privatista, fundada en el principio de que los servicios de agua y saneamiento deben convertirse en bienes privados cuya provisión debe estar en manos de empresas privadas orientadas a la obtención de ganancias. No sorprende que la evidencia empírica indique que dichas políticas han fracasado en su objetivo de reducir la desigualdad y la pobreza (UN-HABITAT, 2003). Tampoco sorprende que recientemente instituciones como el propio Banco Mundial hayan comenzado a reconocer que las empresas privatizadas "no carecen de problemas, especialmente cuando se trata de servir a los más pobres" (Banco Mundial, 2003, p.10-11). Por otra parte, tras la serie de conflictos que derivaron en la cancelación de contratos de concesión en diversos países y, particularmente, después de la debacle de la economía argentina en 2001 y la subsiguiente crisis de la empresa Aguas Argentinas que constituía el caso modelo empleado por los promotores privatistas, las empresas transnacionales que han sido el actor principal de la privatización de los servicios de agua y saneamiento anunciaron su retirada de América Latina y de otras regiones menos desarrolladas para concentrar su actividad en expandir su influencia en Europa y en los Estados Unidos, regiones que consideran más favorables en términos de estabilidad política y económica (HALL, 2002, 2006; HALL et al., 2003). Como lo sintetizó un comentarista ligado a estas empresas: "quién puede seguir imaginándose invertir divisas fuertes en proyectos de agua en países como las Filipinas, Argentina o Bolivia?" (GWI, 2004, p. 5).

En perspectiva, hay algo de verdad en el argumento de algunos autores según los cuales cuando se observa lo limitado de la experiencia concreta 
de la privatización y lo modesto de su alcance en términos de logros concretos, los debates y las controversias surgidos sobre este tema parecen estar un tanto sobredimensionados (BUDDS; MCGRANAHAN, 2003). De hecho, a pesar de la campaña privatizadora lanzada a escala global durante la década de 1990 hoy menos del 10\% de la población mundial recibe sus servicios de agua y saneamiento de empresas privadas (HALL et al., 2004; UN-Habitat, $2003^{5}$ ). Por lo tanto, teniendo en cuenta estos resultados y dado el creciente reconocimiento del fracaso de la reforma privatista por parte de sus propios promotores, sería de esperar que se introdujeran cambios profundos en las políticas del sector. Sin embargo, la evidencia indica que las reformas introducidas han puesto en marcha mecanismos y procesos cuyas fuerzas inerciales continuarán determinando y restringiendo la capacidad de acción de los países en relación a los servicios de agua y saneamiento. Este es el tema de la cuarta y última proposición que discutimos a continuación.

\section{Conclusión: las fuerzas inerciales de las reformas privatistas}

Aunque las políticas de privatización de los servicios de agua y saneamiento en América Latina han fracasado en sus objetivos declarados, la implementación de dichas políticas puso en marcha una serie de procesos cuya fuerza inercial continuará ejerciendo influencia en la organización y gestión de estos servicios por un largo tiempo. No solamente las reformas privatizadoras han dejado irresueltos la mayor parte de los problemas pre-existentes - con frecuencia los ha agudizado-, sino que además han generado la emergencia de nuevos problemas y obstáculos para la gestión sustentable y democrática de dichos servicios.

5 En mayor detalle, la expansión de la privatización en el sector presenta fuertes variaciones entre países y regiones. Por ejemplo, la Argentina pasó de 0 a 70\% de la población servida por empresas privadas de agua y saneamiento entre 1993 y 1999 (el dato incluye un 10\% atendido por cooperativas; hay que agregar también que desde 2001 se ha reducido significativamente el peso del sector privado debido a los procesos de desprivatización y devolución de empresas al sector público) (AZPIAZU et al., 2004), mientras en Brasil las empresas privadas atienden cerca de 7 millones de personas (ABCON, 2006), menos del 4\% de la población. 
En primer lugar, cabe señalar que a pesar del reconocimiento del fracaso de los objetivos de la privatización por parte de funcionarios del Banco Mundial y de otras instituciones, la campaña privatizadora sigue vigente, como lo demuestran documentos recientes del propio Banco (Banco Mundial, 2006b), de otras entidades con influencia global como la UNESCO ${ }^{6}$ y las agencias de desarrollo de los países desarrollados (HALL, 2004) así como también de consultores y académicos afines al modelo (BALEN, 2006). En segundo lugar, el adoctrinamiento realizado desde fines de la década de 1980 ha dado resultado y, por lo tanto, los argumentos privatistas están muy enraizados en ciertos sectores académicos y políticos de los países menos desarrollados, ciertamente en América Latina. Por ejemplo, aunque el propio Banco Mundial ha reconocido el error del argumento de que la solución para resolver la crisis de los servicios de agua y saneamiento reside en la inversión privada, el mismo tiene gran vitalidad en los debates actuales de la región, no solamente en países que continúan aplicando el modelo neoliberal ${ }^{7}$ sino también en países con gobiernos de centroizquierda. ${ }^{8}$

En relación con lo anterior debe enfatizarse el hecho que incluso en aquellos casos en los cuales las concesiones privadas fueron canceladas o abandonadas - como ocurrió en Buenos Aires, Tucumán y Cochabamba, entre los casos mencionados aquí-,, los problemas causados a los países por las políticas privatistas no han terminado sino que por el contrario han empeorado ya que por una parte queda la promesa incumplida de

6 Es sorprendente ver que el último informe de la UNESCO sobre el agua a nivel mundial clasifica a los servicios de agua y saneamiento domésticos como "bienes privados o mercancías" (UNESCO, 2006, p.409), ignorando por completo el hecho de que existe un debate a nivel internacional del cual forma parte la propia Organización de las Naciones Unidas sobre si el agua y sus servicios deben ser considerados un bien público, común, y un derecho humano o un bien económico privado y una mercancía. Para un debate más a fondo de esta controversia actual, véase por ejemplo: ESCH et al., 2006 y Castro, 2010.

7 En México, por ejemplo, el Banco Nacional de Obras Públicas (BANOBRAS) tiene como requisito para otorgar apoyo financiero a las empresas públicas de agua y saneamiento que las mismas se asocien con una empresa privada.

8 Por ejemplo, véase el debate sobre el rol del sector privado en los servicios de agua y saneamiento que tiene lugar en Brasil. Puede consultarse los sitios de Internet de ABCON (2006), la organización que representa los intereses de las empresas privadas del sector en Brasil, y de ASSEMAE (2006), la Asociación Nacional de Servicios Municipales de Agua y Saneamiento. 
renovación y expansión de la infraestructura que debe ser asumida por el sector público, pero al mismo tiempo los países confrontan nuevos desafíos en la forma de demandas judiciales emprendidas por las empresas privadas que buscan una indemnización por el lucro cesante no obtenidos debido a la cancelación de contratos que se extendían por 20 o 30 años. Argentina solamente enfrenta en este momento unos 30 juicios de empresas transnacionales, incluyendo juicios por centenares de millones de dólares por parte de Aguas del Aconquija en Tucumán y de Aguas Argentinas en Buenos Aires. En este sentido, es posible que países como Argentina, Brasil o México sean capaces de diseñar sus propias estrategias financieras y políticas para resolver la crisis de los servicios de agua y saneamiento, pero países más pobres como Bolivia, que son extremadamente dependientes de la ayuda externa, tienen mucho menos margen de maniobra para decidir e implementar políticas autónomas. Bolivia también enfrenta en este momento varios juicios millonarios en dólares emprendidos por multinacionales que buscan indemnizaciones por las cancelaciones de los contratos de privatización, incluyendo los casos de Cochabamba y, más recientemente, La Paz-El Alto. Este también es uno de los resultados de la privatización de los servicios de agua y saneamiento, cuyo costo real para los países de América Latina todavía espera ser estimado en su real magnitud.

Sin embargo, probablemente la dimensión más importante de lo que llamamos aquí las fuerzas inerciales de la reforma privatista reside en las transformaciones introducidas mediante las reformas legales e institucionales que se introdujeron en los distintos países con el objetivo de promover la privatización, en particular las medidas dirigidas a convertir a los servicios esenciales de agua y saneamiento en bienes privados, mercancías, cancelando la noción de que estos servicios constituyen un bien público y que existe un derecho ciudadano al acceso universal a los mismos que debe ser independiente de la capacidad de pago de los usuarios. Este último punto es crucial, pues implica la reducción del ciudadano a la dimensión de un consumidor de mercancías lo cual entra en confrontación con el consenso creciente a nivel internacional en defensa del derecho humano a los servicios esenciales de agua y saneamiento. Esta transformación ocurre con independencia del carácter público o privado de las empresas que prestan 
los servicios, de tal modo que en muchos países las empresas públicas ya están operando sobre principios mercantilistas, con el peligro de que servicios esenciales para la reproducción vital de las personas como los servicios de agua y saneamiento sean reorganizados sobre el principio de exclusión dictado por la mera eficiencia económica (sólo recibe el servicio quien lo puede pagar) y no sobre el principio de inclusión social que permitió la universalización de estos servicios en Europa y en los Estados Unidos.

Desde otra perspectiva, este es un proceso muy dinámico, con cambios frecuentes de dirección y con un futuro incierto. Un desarrollo muy importante, desde el punto de vista socio-político, ha sido la creciente insatisfacción pública y la oposición abierta hacia las políticas privatistas que se han venido registrando en muchos países de la región latinoamericana en el período bajo estudio. Es un error intentar explicar esta oposición meramente como un rechazo de las políticas de libre mercado o un ataque al sector privado, como algunos autores suelen sugerir, ya que de hecho existió bastante apoyo -o al menos tolerancia- a la reforma privatista en algunos países a comienzos de la década de 1990, como ser en Argentina. Sin embargo, la combinación de procesos autoritarios en la toma de decisión e implementación de dichas políticas (como las privatizaciones por decreto introducidas sistemáticamente por el Presidente Menem en Argentina), la ausencia de participación ciudadana que las ha caracterizado, la amplia percepción (y frecuente confirmación) de la existencia de corrupción pública y privada asociada con las privatizaciones y la creciente evidencia de que tales políticas han favorecido los intereses de las empresas privadas, particularmente transnacionales, antes que los intereses de las comunidades locales, han contribuido a la proliferación de acciones de protesta, desobediencia civil, e incluso violencia abierta contra el modelo privatista y sus representantes.

La evidencia sugiere que la reforma privatista de los servicios de agua y saneamiento pasó por alto los desafíos que presenta la transformación de relaciones y estructuras sociales requerida para su implementación. Dichas políticas presuponen la existencia de ciertas identidades y relaciones sociales, tales como el consumidor con estatus de sujeto de crédito y solvente que puede comprar bienes y servicios a precios que permiten la viabilidad 
de la ganancia privada y, en general, la generalización de relaciones sociales mercantiles en la organización de los servicios públicos esenciales. Sin embargo, dichas identidades y relaciones sociales sólo tienen un desarrollo parcial y fragmentario en los países menos desarrollados, y con frecuencia ni siquiera existen en amplias áreas del planeta donde se concentra la población pobre e indigente, incluyendo ciertamente América Latina. Por otra parte, el desarrollo de las identidades y relaciones sociales mercantiles entra en contradicción con identidades y relaciones sociales alternativas, algunas pre-existentes, otras en plena emergencia, las cuales constituyen primeramente un obstáculo para las políticas privatistas y al mismo tiempo prefiguran la posibilidad de formas de sociabilidad más avanzadas en el desarrollo histórico. De este modo, puede argumentarse que el intento neoliberal de impulsar el proceso de mercantilización de los servicios públicos de agua y saneamiento confronta simultáneamente la resistencia de una amplio abanico de formas sociales que parecen converger, desde espacios muy diferentes, en una oposición común al modelo privatista. Por otro lado, la iniciativa neoliberal confronta también una trama de relaciones y estructuras sociales bien atrincheradas, como aquellas enraizadas en las tradiciones de propiedad y gestión del agua indígenas que pueden identificarse, por ejemplo, en Cochabamba o aquellas representadas en los movimientos muy bien organizados que defienden la tradición de un sector público eficiente en la gestión del agua y el saneamiento, que puede observarse por ejemplo en América Latina y en Europa, como lo revelan los resultados de nuestro trabajo de investigación. También, el avance neoliberal confronta el desafío de nuevas identidades y relaciones sociales que rechazan el reduccionismo mercantilista y el dominio capitalista en su busca de formas superiores de organización social. Una de las expresiones que asumen estas formas sociales en pleno desarrollo puede identificarse en las luchas sociales que tienen lugar a nivel global por la democratización de la gobernabilidad y la gestión del agua y de sus servicios, como por ejemplo aquellas que buscan el reconocimiento del derecho humano al agua para usos esenciales.

Finalmente, cabe enfatizar que el desarrollo de alternativas factibles a la reforma privatista de los servicios de agua y saneamiento en América Latina requiere la comprensión de los factores que permitieron el logro de 
los objetivos de universalización de estos servicios en los países más desarrollados. La evidencia histórica demuestra que ese logro fue posible porque como resultado de largas confrontaciones sociales y políticas que tuvieron lugar desde el Siglo XIX las políticas del sector pasaron a fundarse en el principio de que el acceso a dichos servicios debe ser considerado un derecho social universal, un bien común que debe recibir prioridad sobre los intereses particulares y los principios y mecanismos de la eficiencia mercantil. Los principios y políticas que inspiraron la universalización de estos servicios en Europa y Estados Unidos fueron aceptados y apoyados por un amplio rango de fuerzas sociales y políticas, que incluyó a sectores que en otros respectos defendían los principios del libre mercado pero que llegaron a aceptar que la organización de los servicios públicos esenciales requería arreglos diferentes a los del mercado. En nuestra perspectiva, el éxito en el diseño e implementación de políticas de agua y saneamiento orientadas a la universalización de estos servicios sólo será posible si logra articular una combinación similar de fuerzas sociales amplias y de carácter universalista. El aspecto positivo es que estos procesos están ya en marcha, a pesar de que siguen siendo todavía incompletos y fragmentarios. El apoyo crítico a dichos procesos con el objeto de contribuir a su multiplicación y expansión debe constituirse en una prioridad para las fuerzas progresistas en América Latina.

\title{
Referencias
}

ABCON - Asociación Brasilera de Concesionarios Privados de Agua y Servicios Públicos, 2006. Páginas de Internet (http://www.abcon.com.br).

\author{
ABOITES AgUilaR, Luis. El Agua de la Nación. Una Historia Política de \\ México (1888-1946), México D. F.: Centro de Investigaciones y Estudios \\ Superiores en Antropología Social (CIESAS), 1998.
}

ASSEMAE - Asociación Nacional de Empresas Municipales de Agua y Saneamiento (Brasil), 2006. Páginas de Internet (http://www.assemae. org.br/ibam.htm). 
AZPIAZU, Daniel; SCHORR, Martín. 2004. Informe Comparativo de la Dimensión Económico-Financiera. In: CASTRO, José Esteban (Coord.), Proyecto PRINWASS. Oxford: Universidad de Oxford, 2004.

AZPIAZU, Daniel; CATENAZZI, Andrea; CRENZEL, Emilio; DA REPRESENTAÇAO, Natalia; FORTE, Gustavo; FORCINITO, Karina; MARÍN, Juan Carlos. 2003. Buenos Aires - Informe del Caso de Estudio de Argentina. In: CASTRO, José Esteban (Coord.), Proyecto PRINWASS. Oxford: Universidad de Oxford, 2003

AZPIAZU, Daniel; CRENZEL, Emilio; FORTE, Gustavo; MARÍN, Juan Carlos; ROZE, Jorge; Schorr, Martín. Argentina Country Strategic Report. Buenos Aires - Informe del Caso de Estudio de Argentina. In: CASTRO, José Esteban (Coord.), Proyecto PRINWASS. Oxford: Universidad de Oxford, 2004.

BAKKER, Karen. Paying for water: water pricing and equity in England and Wales. Transactions of the Institute of British Geographers, v. 26, n. 2, p. 143-164, 2001.

BALEN, Mischa. Water for life. The case for private investment and management in developing country water systems, Londres: The Globalization Institute, 2006.

BID - BANCO INTERAMERICANO DE DESARROLLO. Facing up to Inequality in Latin America. Economic and Social Progress in Latin America. Washington D.C.: BID, 1998.

BANCO MUNDIAL. Private Participation in Infrastructure Database. Washington D.C.: Banco Mundial, 2006a

BANCO MUNDIAL. Privatizing Water and Sanitation Services. Páginas de internet (consultadas en 2006) (http://rru.worldbank.org/PapersLinks/ Privatizing-Water-Sanitation-Services), $2006 \mathrm{~b}$. 
BANCO MUNDIAL. World Development Report 2004. Making Services Work for Poor People. Washington D.C.: Banco Mundial y Oxford University Press, 2003.

BANCO MUNDIAL. Facilitating Private Involvement in Infrastructure: an Action Programme. Washington D. C.: Banco Mundial, 1998.

BAYLISS, Kate; KESSLER, Tim. Can privatization and commercialisation of public services help achieve the MDGs? An assessment. Brasilia: United Nations Development Programme, International Poverty Centre, 2006.

BEATO, Paulina. Participación del sector privado en los sistemas de agua potable y saneamiento. Ventajas, riesgos y obstáculos. Washington: Infrastructure and Financial Markets Division, Sustainable Development Department, Banco Interamericano de Desarrollo, 1997.

BROOK COWEN, Penelope. J. The private sector in water and sanitation - How to get started. In TILMES, Klaus (Coord.) The Private Sector in Infrastructure. Strategy, Regulation and Risk, Washington D.C.: The World Bank, The International Forum for Utility Regulation, p. 89-92, 1997a.

BROOK COWEN, Penelope. J. Getting the private sector involved in water What to do in the poorest of countries. In K. TILMES (Coord.) The Private Sector in Infrastructure. Strategy, Regulation and Risk, Washington D.C.: The World Bank, The International Forum for Utility Regulation, p. 93-96, 1997b.

BROOK COWEN, Penelope. J.; COWEN, Tyler. Deregulated private water supply: a policy option for developing countries. Cato Journal, v. 18, n. 1, p. 21-41, 1998. 
BUDDS, Jessica; MCGRANAHAN, Gordon. Are the debates on water privatization missing the point? Experiences from Africa, Asia and Latin America. Environment and Urbanization, v. 15, n. 2, p. 87-113, 2003.

CAMDESSUS, Michel (Chair). Financing Water for All. Report of the World Panel on Financing Water Infrastructure. Kyoto: World Water Council, Global Water Partnership, 2003.

CASTRO, José Esteban. The interdisciplinary challenge in water policy: the case of "water governance". In CABRERA, Enrique; ARREGUI, Francisco (eds.), Water Engineering and Management Throughout the Times (Learning from History), Londres: Taylor \& Francis, p. 259-276, 2010.

CASTRO, José Esteban. Neoliberal water and sanitation policies as a failed development strategy: lessons from developing countries. Progress in Development Studies, v. 8, n. 1, p. 63-83, 2008.

CASTRO, José Esteban. Poverty and citizenship: sociological perspectives on water services and public-private participation, Geoforum, v. 38, n. 5, p. 756-771, 2007.

CASTRO, José Esteban. Water, Power and Citizenship. Social Struggle in the Basin of Mexico. Houndmills, Basingstoke and New York: Palgrave Macmillan, 2006.

CASTRO, José Esteban. Agua y gobernabilidad: entre la ideología neoliberal y la memoria histórica. Cuadernos del CENDES, n. 59, p. 1-22, 2005.

CASTRO, José Esteban (Coord.). Barriers to and conditions for the involvement of private capital and enterprise in water supply and sanitation in Latin America and Africa: seeking economic, social, and environmental sustainability (PRINWASS), Proyecto de Investigación, 
Comisión Europea, Quinto Programa Marco, INCO-DEV, Contrato PL ICA42001-10041. Oxford: Universidad de Oxford, 2004a.

CASTRO, José Esteban. Informe Estratégico de Inglaterra y Gales. In:

CASTRO, José Esteban (Coord.), PRINWASS Project. Oxford, University of Oxford, 2004b.

CASTRO, José Esteban. Informe Final. In: CASTRO, José Esteban (Coord.), Proyecto PRINWASS. Oxford: Universidad de Oxford, 2004c.

CASTRO, José Esteban. Informe del Caso de Estudio de Inglaterra y Gales. In: CASTRO, José Esteban (Coord.), Proyecto PRINWASS. Oxford: Universidad de Oxford, 2003.

CASTRO, José Esteban. Argumentos utilizados para promover la participación privada en los servicios de agua y saneamiento. In: CASTRO, José Esteban (Coord.), Proyecto PRINWASS. Oxford: Universidad de Oxford, 2002.

CASTRO, José Esteban; LAURIE, Nina. Informe Comparativo de la Dimensión Socio-Política y Cultural. In: CASTRO, José Esteban (Coord.), Proyecto PRINWASS. Oxford: Universidad de Oxford, 2004.

CATENAZZI, Andrea; KULLOCK, David. Política de agua y saneamiento en el Area Metropolitana de Buenos Aires. Estrategias de acceso de los sectores de bajos recursos, antes y después de la privatización. Buenos Aires: Secretaría de Ciencia y Técnica, Universidad de Buenos Aires (UBACyT), 1997.

COMMANDER, Simon; KILLICK, Tony. Privatization in developing countries: a survey of the issues. In: P. COOK, Paul; KIRKPATRICK, Colin (eds.). Privatization in Less Developed Countries. Hemel Hempstead: Harvester Wheatsheaf, p. 91-124, 1998. 
CONNOLLY, Priscilla. El Contratista de Don Porfirio. Obras Públicas, Deuda y Desarrollo Desigual, México D.F.: El Colegio de Michoacán, Universidad Autónoma Metropolitana Azcapotzalco, y Fondo de Cultura Económica, 1997.

CRENZEL, Emilio. Tucumán - Informe del Caso de Estudio de Argentina. In: CASTRO, José Esteban (Coord.), Proyecto PRINWASS. Oxford: Universidad de Oxford, 2003.

CRENZEL, Emilio; FORTE, Gustavo. Informe Comparativo de la Dimensión Socio-económica y Demo-geográfica. In: CASTRO, José Esteban (Coord.), Proyecto PRINWASS. Oxford: Universidad de Oxford, 2004.

CRESPO, Carlos; LAURIE, Nina; LEDO, Carmen. Cochabamba - Informe del Caso de Estudio de Bolivia. In: CASTRO, José Esteban (Coord.), Proyecto PRINWASS. Oxford: Universidad de Oxford, 2003.

DINAVO, Jacques Vangu. Privatization in Developing Countries. Its Impact on Economic Development and Democracy. Westport, Conn., y Londres: Praeger, 1995.

DRAKEFORD, Mark. Providing Water in Wales: is there a Third Way? The Welsh experience with public and private utilities and the emergence of the not-for-profit model. Second Research Workshop, Oxford, 28 de febrero de 2002. In: CASTRO, José Esteban (Coord.), Proyecto PRINWASS. Oxford: Universidad de Oxford, 2002.

ESCH, S. M. DELGADO, S. HELFRICH, H. SALAZAR RAMÍREZ, M. L. TORREGROSA, e I. ZÚÑIGA PÉREZ-TEJADA. La Gota de la Vida: Hacia una Gestión Sustentable y Democrática del Agua, México D.F.: Fundación Heinrich Böll Ediciones (disponible en: http://www.boell-latinoamerica. org/download_es/Libro_La_Gota.pdf), 2006. 
FARLEY, P. USAID: setting directions for the next decade of privatization. Economic Perspectives. An International Journal of the U.S. Information Agency, v. 2, n. 1, p. 10-2, 1997.

FINER, Samuel. E. (reimpresión). The Life and Times of Sir Edwin Chadwick. Londres, Routledge \& Thoemmes Press, 1997.

FITCH, Martin; PRICE, Howard. Water poverty in England and Wales. Londres: Centre for Utility Consumer Law and Chartered Institute of Environmental Health, 2002.

GLOBAL WATER INTELLIGENCE - GWI. 2004. Goodbye International Water, Global Water Intelligence, v. 5, n. 7, p. 5.

GOUBERT, Jean Pierre. The Conquest of Water. The Advent of Health in the Industrial Age. Cambridge y Oxford, Polity Press and Basil Blackwell, 1986.

GREEN, Joanne. The England and Wales Water Industry Privatisation. A Desk Study. Londres: WaterAid, 2002.

HALL, David. Corporate actors. A global review of multinational corporations in the water and electricity sectors. Greenwich: Public Services International Research Unit (PSIRU), University of Greenwich, 2006.

HALL, David. Privatising other people's water. The contradictory policies of Netherlands, Norway and Sweden, Greenwich: Public Services International Research Unit (PSIRU), University of Greenwich, 2004.

HALL, David. The water multinationals 2002. Financial and other problems. Greenwich: Public Services International Research Unit (PSIRU), University of Greenwich, 2002. 
HALL, David; LANZ, Klaus; LOBINA, Emanuele; DE LA MOTTE, Robin. International context, Watertime Informe de Proyecto, Greenwich: Public Services International Research Unit (PSIRU), University of Greenwich, 2004.

HALL, David; LOBINA, Emanuele; DE LA MOTTE, Robin. Public solutions for private problems? Responding to the shortfall in water infrastructure investment. Greenwich: Public Services International Research Unit (PSIRU), University of Greenwich, 2003.

HASSAN, John. A History of Water in Modern England and Wales. Manchester: Manchester University Press, 1998.

HERBERT, Alice ; KEMPSON, Elaine. Water Debt \& Disconnection. Londres: Policy Studies Institute (PSI), 1995.

HUKKA, Jarmo J.; KATKO, Tapio S. Water privatisation revisited: panacea or pancake? IRC Occasional Paper Series 33. Delft: International Water and Sanitation Centre (IRC), 2003.

KALLIS, Giorgos; COCCOSSIS, Harry. Informe Comparativo de la Dimensión Ambiental. In: CASTRO, José Esteban (Coord.), Proyecto PRINWASS. Oxford: Universidad de Oxford, 2004a.

KALLIS, Giorgos; COCCOSSIS, Harry. Informe Estratégico de Grecia. In: CASTRO, José Esteban (Coord.), Proyecto PRINWASS. Oxford: Universidad de Oxford, 2004b.

KALLIS, Giorgos; COCCOSSIS, Harry. Atenas - Informe del Caso de Estudio de Grecia. In: CASTRO, José Esteban (Coord.), Proyecto PRINWASS. Oxford: Universidad de Oxford, 2003. 
KLEIN, Georgia. Life lines: the NCC's agenda for affordable energy, water, and telephone services. Londres: National Consumer Council, 2003.

KLEIN, M. Entrevistado por M. Phillips en "The World Bank wonders about utility privatizations", The Wall Street Journal, 21 July 2003.

LA JORNADA. 2006. Inversión mixta en los sistemas, plantea el BM. 17 de marzo de 2006, (http://www.jornada.unam.mx/2006/03/17/046n1soc. php).

LASKI, H. J.; JENNINGS, W. I.; ROBSON, W. A. (eds.). A Century of Municipal Progress 1835-1935. London, George Allen \& Unwin, 1935.

LAURIE, N. (ed.) 2006. Número Especial sobre “"Pro-poor' water: past present and future scenarios", Geoforum, v. 38, n. 5, 2007.

LAURIE, Nina; CRESPO, Carlos; LEDO, Carmen. 2004. Informe Estratégico de Bolivia. In: CASTRO, José Esteban (Coord.), Proyecto PRINWASS. Oxford: Universidad de Oxford, 2004.

LEE, Terence R. Water Management in the 21st Century. The Allocation Imperative, Cheltenham: Edward Elgar, 1999.

LEE, Terence R. ; JOURAVLEV, Andrei. Private participation in the provision of water services. Alternative means for private participation in the provision of water services. In: Medio Ambiente y Desarrollo, Santiago de Chile: United Nations Economic Commission for Latin America and the Caribbean (ECLAC), n. 2, 1997.

LEE, Terence; JOURAVLEV, Andrei. Prices, property and markets in water allocation, (LC/L 1097), Santiago de Chile: UN Economic Commission for Latin America and the Caribbean (ECLAC), 1988. 
LUCKIN, B., 1986. Pollution and Control: a Social History of the Thames in the Nineteenth Century. Londres, Adam Hilger, 1986.

MANZETTI, L. Privatization South American Style. Oxford: Oxford University Press, 1999.

MASHAURI, A. 2004. Informe Estratégico de Tanzania. In: J. E. Castro (Coord.), Proyecto PRINWASS. Oxford: Universidad de Oxford.

MASHAURI, Alfred. Dar es Salaam - Informe del Caso de Estudio de Tanzania. In: CASTRO, José Esteban (Coord.), Proyecto PRINWASS. Oxford: Universidad de Oxford, 2003.

MELOSI, Martin V. 2000. The Sanitary City: Urban Infrastructure in America from Colonial Times to the Present (Creating the North American Landscape), Baltimore: John Hopkins University Press, 2000.

MILLWARD, B. Emergence of gas and water monopolies in nineteenth century Britain: contested markets and public control. In: FOREMANPECK, J. (ed.), New Perspectives in Late Victorian Economy: Essays in Quantitative Economic History 1860-1914. Londres, Cambridge University Press, 1991.

MUKHOPADHYAY, A. K. The politics of London water. The London Journal, vol. 1, n. 2, p. 207-226, 1975.

NCC - NATIONAL CONSUMER COUNCIL. Web page on affordability problems in the privatised WSS sector in England and Wales (Consultada en 2005, http://www.ncc.org.uk/fuelandwater/index.htm\#water). Londres, NCC, 2005.

NELLIS, John, Privatization in Latin America. Working Paper 31, Washington, DC: Center for Global Development, 2003. 
NELLIS, John; KIKERI, Sunita. Public enterprise reform: privatization and the World Bank. World Development, v. 17, n. 5, p. 659-672, 1989.

NEWBERY, David M. Privatization, Restructuring, and Regulation of Network Utilities. The Walras-Pareto Lectures, Cambridge, Mass. y Londres: The MIT Press, 1999.

NICKSON, Andrew. The public-private mix in urban water supply, In: International Review of Administrative Sciences, v. 63, p. 165-186, 1997.

NRC - NATIONAL RESEARCH COUNCIL - Committee on Privatization of Water Services in the United States. Privatization of Water Services in the United States. An Assessment of Issues and Experience. Washington DC, National Academy of Sciences, 2002.

NYANGERI NYANCHAGA, Ezekiel. Informe Estratégico de Kenia. In: CASTRO, J. E. (Coord.), Proyecto PRINWASS. Oxford: Universidad de Oxford, 2004.

NYANGERI NYANCHAGA, Ezekiel. Nyeri and Tala - Informe del Caso de Estudio de Kenia. In: CASTRO, José Esteban (Coord.), Proyecto PRINWASS. Oxford: Universidad de Oxford, 2003.

OFWAT - OFFICE OF WATER SERVICES. Water companies' final plans seek average bill rise of $\mathbf{2 9 \%}$. Birmingham: OFWAT, 2004.

OGLE, Maureen. Water supply, waste disposal, and the culture of privatism in the mid-nineteenth-century American city. Journal of Urban History, v. 25, n. 3, p. 321-347, 1999.

PÉREZ-RINCÓN, Mario Alejandro. Public-private partnerships in provision of water and sanitation services: the case of Palmira City, Colombia. In: Hukka, Jarmo, y Tapio Katko, Water privatization revisited - Panacea 
or pancake?, Working Paper, Tampere, Finland: Tampere University of Technology, 2002.

PERRY, Guillermo E.; FERREIRA, Francisco H. G.; WALTON, Michael. Inequality in Latin America and the Caribbean: Breaking with History? Washington D.C.: Banco Mundial, 2003.

PEZON Christelle. Le Service d'Eau Potable en France de 1850 à 1995. Paris: CNAM, Presses du CEREM, 2000.

PIERCY, Jan (entrevistado). 1997. The challenge of privatization: meshing social policy and development goals. Economic Perspectives. An International Journal of the U.S. Information Agency, v. 2, n. 1, p. 6-9 (consultado en 2012 http://www.usembassy.it/pdf/ej/ijee0197.pdf).

PNUD- PROGRAMA DE LAS NACIONES UNIDAS PARA EL DESARROLLO. Democracy in Latin America. Towards a Citizens' Democracy. Nueva York y Buenos Aires: PNUD y Aguilar, Altea, Taurus, Alfaguara, 2004.

REZENDE, Sonaly Cristina; HELLER, Léo. O Saneamento no Brasil. Políticas e Interfaces, 2.ed., Belo Horizonte, Minas Gerais: Editora de La Universidade Federal de Minas Gerais, 2008.

RICHARD, Barbara; TRICHE, Thelma A. Reducing Regulatory Barriers to Private-Sector Participation in Latin America's Water and Sanitation Services, Policy Research Working Papers, n. 1322, Water, and Urban Development Department, The World Bank, Washington DC: Banco Mundial, 1994.

RIVERA, Daniel. Private Sector Participation in the Water Supply and Wastewater Sector: Lessons from Six Developing Countries. A Directions in Development Book, Washington, DC.: Banco Mundial, 1996. 
ROEMER, Andrés. Derecho y Economía: Políticas Públicas del Agua, México D.F.: Centro de Investigación y Docencia Económicas (CIDE), Sociedad Mexicana de Geografía y Estadística (SMGE), y Miguel Angel Porrúa, 1997.

ROGOZINSKI, Jacques. La Privatización de Empresas Paraestatales. Una Visión de la Modernización de México, México D.F.: Fondo de Cultura Económica, 1993.

ROGOZINSKI, Jacques. High Price for Change: Privatization in Mexico, Washington, DC.: Banco Interamericano de Desarrollo.

ROTH, Gabriel. The Private Provision of Public Services in Developing Countries. Washington, DC., The World Bank and Oxford University Press, 1988.

ROZE, Jorge. Chaco and Corrientes - Informe del Caso de Estudio de Argentina. In: CASTRO, José Esteban (Coord.), Proyecto PRINWASS. Oxford: Universidad de Oxford, 2003.

SÁNCHEZ, Manuel; CORONA, Rossana (eds.). Privatization in Latin America, Mexico City: Inter-American Development Bank e Instituto Tecnológico Autónomo de México (ITAM), 1993.

SAVEDOFF, William ; SPILLER, Pablo. Spilled Water. Institutional Commitment in the Provision of Water Services, Washington DC.: Banco Interamericano de Desarrollo, 1999.

SCHULTZ, Stanely K.; MCSHANE, Clay. To engineer the metropolis: sewers, sanitation, and city planning in late-nineteenth century America. The Journal of American History, v. 65, n. 2, p. 389-411, 1978. 
SEPPÄLÄ, Osmo. Informe Estratégico de Finlandia. In: CASTRO, José Esteban (Coord.), Proyecto PRINWASS. Oxford: Universidad de Oxford, 2004.

SEPPÄLÄ, Osmo; HUKKA, Jarmo. International and national policies that facilitate or hinder private participation especially in developing countries Informe del Caso de Estudio de Argentina. In: CASTRO, José Esteban (Coord.), Proyecto PRINWASS. Oxford: Universidad de Oxford, 2002.

SEPPÄLÄ, Osmo; KATKO, Tapio; HUKKA, Jarmo; PIETILÄ, Pekka. Lahti, Kangasala, and Lappavesi - Informe del Caso de Estudio de Finlandia. In: CASTRO, José Esteban (Coord.), Proyecto PRINWASS. Oxford: Universidad de Oxford, 2003.

STIGLITZ, Joseph. E. Globalization and its Discontents. Londres: Penguin, 2002.

SWYNGEDOUW, Erik. Social Power and the Urbanization of Water. Flows of Power. Oxford: Oxford University Press, 2004.

SWYNGEDOUW, Erik. Flows of Power: Nature, Society and the City. Oxford, Oxford University Press, 1999.

TORREGROSA, María Luisa; SAAVEDRA, Fernando; PADILLA, Esther; QUIÑONES, Alice; KLOSTER, Karina; COSÍO, Gabriel; LENIN, Christian. Aguascalientes - Informe del Caso de Estudio de México. In: CASTRO, José Esteban (Coord.), Proyecto PRINWASS. Oxford: Universidad de Oxford, 2003.

TORREGROSA, María Luisa, KLOSTER, Karina; TORREGROSA, Luis; MEZA, Medardo. Informe Comparativo de la Dimensión Infraestructural. In: CASTRO, José Esteban (Coord.), Proyecto PRINWASS. Oxford: Universidad de Oxford, 2004. 
TORREGROSA, María Luisa; KLOSTER, Karina. Informe Estratégico de México. In: CASTRO, José Esteban (Coord.), Proyecto PRINWASS. Oxford: Universidad de Oxford, 2004.

UNESCO - UNITED NATIONS EDUCATIONAL, SCIENTIFIC AND CULTURAL ORGANIZATION, WORLD WATER ASSESSMENT PROGRAMME. Water, a Shared Responsibility. The United Nations World Water Report 2, Paris y Nueva York: UNESCO y Berghahn Books, 2006.

UKP - UNITED KINGDOM PARLIAMENT, Select Committee on Environment, Food and Rural Affairs. Memorandum submitted by the Public Utilities Access Forum. Londres, UKP, 2003.

UN-UNITED NATIONS - HABITAT. Water and Sanitation in the World's Cities: Local Action for Global Goals. Londres: Earthscan Publications Ltd., 2003.

VARGAS, Marcelo. C. Informe Estratégico de Brasil. In: CASTRO, José Esteban (Coord.), Proyecto PRINWASS. Oxford: Universidad de Oxford, 2004.

VARGAS, M. C. y O. SEPPÄLÄ. 2003. Informe Comparativo de la Dimensión Político-Institucional y Regulatoria. In: CASTRO, José Esteban (Coord.), Proyecto PRINWASS. Oxford: Universidad de Oxford.

VARGAS, Marcelo. C. Limeira, Niterói, y la Región de los Lagos - Informe del Caso de Estudio de Brasil. In: CASTRO, José Esteban (Coord.), Proyecto PRINWASS. Oxford: Universidad de Oxford, 2003.

WARD, Colin. Reflected in Water. A Crisis of Social Responsibility. Londres, Cassell, 1997. 
WARNER, Bass. The Private City: Philadelphia in Three Periods of its Growth, (2nd ed.). Philadelphia, University of Pennsylvania Press, 1997.

WSP-PPIAF - WATER AND SANITATION PROGRAM Y PUBLIC PRIVATE INFRASTRUCTURE ADVISORY FACILITY. New Designs for Water and Sanitation Transactions. Making Private Sector Participation Work for the Poor. Washington DC: WSP-PPIAF, 2002.

WINPENNY, James. Managing Water as an Economic Resource, Londres y Nueva York: Routledge, 1994. 


\section{Apéndice}

Cuadro A-1 - Casos de Estudio del Proyecto PRINWASS

\begin{tabular}{|c|c|c|c|c|}
\hline $\begin{array}{l}\text { REGIÓN/ } \\
\text { PAIIS }\end{array}$ & CASO & POBLACIÓN & $\begin{array}{l}\text { OPERADOR DE LOS } \\
\text { SERVICIOS DE AGUA Y } \\
\text { SANEAMIENTO }^{9}\end{array}$ & $\begin{array}{l}\text { PERÍODO DE } \\
\text { OPERACIÓN }\end{array}$ \\
\hline \multicolumn{5}{|l|}{ ÁFRICA } \\
\hline \multirow[t]{2}{*}{ Kenia } & Nyeri & 120,540 & $\begin{array}{l}\text { NYEWASCO, empresa } \\
\text { municipal organizada sobre } \\
\text { principios comerciales }^{10}\end{array}$ & 1998 a la fecha \\
\hline & Tala & 22,375 & $\begin{array}{l}\text { Romane Agencies Ltd., } \\
\text { privada }\end{array}$ & 1999 a la fecha \\
\hline Tanzania & Dar es Salaam & $2,497,940$ & $\begin{array}{l}\text { City Water Services Ltd., } \\
\text { privada, (Biwater Plc / JBG } \\
\text { Gauff Ingenieure) }{ }^{11}\end{array}$ & $2003-2005$ \\
\hline \multicolumn{5}{|l|}{ EUROPA } \\
\hline Inglaterra & Cuenca del Río Támesis & $12,493,000$ & Thames Water, privada & 1989 a la fecha \\
\hline Grecia & Atenas & $3,187,734$ & $\begin{array}{l}\text { EYDAP, ente mixto } \\
\text { controlado por el estado }{ }^{12}\end{array}$ & $\begin{array}{c}\text { As a mixed } \\
\text { entity since } \\
1999 \text { a la fecha }\end{array}$ \\
\hline \multirow{3}{*}{ Finlandia } & Lahti & 98,000 & $\begin{array}{l}\text { LV Lahti Water Ltd., } \\
\text { municipal }\end{array}$ & Over 30 years \\
\hline & Lappavesi $^{13}$ & 36,000 & $\begin{array}{l}\text { Lappavesi Ltd. and Lapua } \\
\text { Sewerage Ltd., municipal }\end{array}$ & 1972 a la fecha \\
\hline & Kangasala & 23,000 & $\begin{array}{c}\text { Kangasala Municipality } \\
\text { Water and Sewerage Ltd., } \\
\text { municipal }\end{array}$ & 1950s a la fecha \\
\hline
\end{tabular}

Fuente: Castro, 2004c

9 Nombre del operador, tipo (público, privado o mixto), y socio principal (en el caso de consorcios multinacionales).

10 NYEWASCO es propiedad de la Municipalidad de Nyeri pero está dirigido por un Equipo Corporativo de Gestión sobre la base de modelos de operación y gestión privados. Es parte de un Proyecto Piloto para reorganizar los servicios de agua y saneamiento en Kenia en base a principios comerciales, en preparación para una posible privatización de dichos servicios en el país.

11 La concesión al operado privado fue cancelada en el año 2005.

12 La empresa ha colocado el 39 por ciento de sus acciones en la bolsa, de esa forma transfiriendo parcialmente la propiedad a inversores privados.

13 Atiende a las municipalidades de Lapua (población 13,000 habitantes), Nurmo (población 11,000 habitantes), Kauhava (población 8,000 habitantes), y Kuortane (población 4,000 habitantes). 
Cuadro A-1 - Casos de Estudio (sigue)

\begin{tabular}{|c|c|c|c|c|}
\hline $\begin{array}{l}\text { REGIÓN/ } \\
\text { PAÍS }\end{array}$ & CASO & POBLACIÓN & $\begin{array}{l}\text { OPERADOR DE LOS } \\
\text { SERVICIOS DE AGUA Y } \\
\text { SANEAMIENTO }\end{array}$ & $\begin{array}{l}\text { PERÍODO DE } \\
\text { OPERACIÓN }\end{array}$ \\
\hline \multicolumn{5}{|c|}{ AMÉRICA LATINA } \\
\hline \multirow{3}{*}{ Argentina } & Buenos Aires & $11,453,725$ & 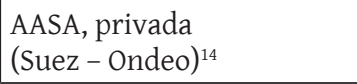 & $1993-2006$ \\
\hline & Tucumán & 697.936 & ENOHSA, provincial ${ }^{15}$ & 1998 a la fecha \\
\hline & Resistencia (Chaco) & 365,637 & SAMEEP, provincial & 1980 a la fecha \\
\hline Bolivia & Cochabamba & 517,024 & SEMAPA, municipal ${ }^{16}$ & 1967 a la fecha \\
\hline \multirow{3}{*}{ Brasil } & Niterói (Rio de Janeiro) & 459,451 & Águas de Niterói, privada & 1999 a la fecha \\
\hline & $\begin{array}{l}\text { Región de los Lagos }{ }^{17} \\
\text { (Rio de Janeiro) }\end{array}$ & 403,418 & PROLAGOS, privada (EPAL) & 1998 a la fecha \\
\hline & Limeira (Sao Paulo) & 249,046 & $\begin{array}{l}\text { Aguas de Limeira, privada } \\
{\text { (Suez, Ondeo) }{ }^{17}}\end{array}$ & 1995 a la fecha \\
\hline México & Aguascalientes & 643,419 & $\begin{array}{l}\text { CAASA, privada } \\
\text { (Vivendi - Veolia) }\end{array}$ & 1993 a la fecha \\
\hline
\end{tabular}

Fuente: Castro, 2004c

14 AASA fue desprivatizada por decisión del gobierno nacional en marzo de 2006 y reemplazada por una empresa pública

15 En 1995 los servicios de agua y saneamiento de Tucumán fueron concesionados a la empresa Aguas del Aconquija, un consorcio multinacional liderado por el grupo francés Vivendi, pero el contrato fue cancelado en 1997 y los servicios retomados por una empresa provincial.

16 En 1999 los servicios de agua y saneamiento de Cochabamba fueron concesionados a la empresa Aguas del Tunari, un consorcio multinacional liderado por International Water (controlada por la compañía norteamericana Bechtel), pero la concesión fue cancelada en abril del año 2000 y los servicios fueron retomados por una empresa municipal.

17 Incluye las municipalidades de Arauama, Saquarema, Silva Jardim, Armação dos Búzios, Arraial do Cabo, Cabo Frío, Iguaba Grande y S. Pedro da Aldeia.

18 El socio principal en el consorcio, Suez-Ondeo, decidió abandonar la concesión en agosto de 2006. La concesión quedó en manos de operador privado brasilero. 


\title{
Cuadro A-2 - Formas Principales de Participación Privada en los Servicios
}

\author{
de Agua y Saneamiento
}

\section{PRIVATIZACIÓN COMPLETA (FULL DIVESTITURE)}

Transferencia completa al sector privado, incluyendo la propiedad de la infraestructura. El sector privado pasa a ser responsable por la inversión de capitales, el mantenimiento, las operaciones y la cobranza.

\section{PRIVATIZACION PARCIAL (PARTIAL DIVESTITURE)}

El gobierno (u otra entidad pública relevante) vende una parte de las acciones a inversores privados y crea una nueva empresa con participación de los socios privados.

\section{CONCESIÓN}

El gobierno otorga los servicios a una empresa privada mediante un contrato de largo plazo, usualmente 25 años o más. El operador privado pasa a ser responsable por la inversión de capitales, el mantenimiento, las operaciones y la cobranza.

\section{LEASE}

Contrato de largo plazo (usualmente 10-20 años pero puede ser más largo). El operador privado pasa a ser responsable por las operaciones y el mantenimiento, incluyendo a veces la renovación de infraestructura. La infraestructura permanece en manos públicas y la mayor parte de la inversión de capitales sigue siendo responsabilidad del sector público.

\section{CONTRATOS BOT (Build-Operate-Transfer) / BOO (Build-Operate-Own)}

Estos son contratos realizados para la construcción de elementos de infraestructura específicos, como ser una planta de tratamiento de agua. Normalmente en este tipo de contratos el sector privado es responsable por la inversión de capitales y mantiene la propiedad de la infraestructura hasta que la misma es transferida al sector público. La excepción es en los contratos tipo BOO, en los cuales se mantiene la propiedad privada de la infraestructura.

\section{CONTRATOS DE GESTIÓN}

Son contratos de corto plazo, típicamente por cinco años. La empresa privada es responsable solamente por las operaciones y el mantenimiento.

\section{CONTRATOS DE SERVICIO [BUYING IN]}

Contratos para la prestación de servicios específicos (por ejemplo, para la instalación de medidores).

Fuente: Adaptado de SEPPALA; HUKKA (2002). 


\title{
Capítulo 4
}

\section{Agua, democracia, y la construcción de la ciudadanía ${ }^{1}$}

\author{
La barbarie [...] es más bien un subproducto de la vida \\ en un contexto social e histórico particular, [...] \\ los niveles de barbarie se incrementaron durante el siglo veinte y no \\ existen indicios de que dicha tendencia esté por terminar. [...] \\ Primero, la ruptura y el colapso de los sistemas de reglas \\ y conducta moral por los cuales todas las sociedades \\ tienden a regular las relaciones entre sus miembros \\ $\mathrm{y}$, en menor medida, entre sus miembros y los de otras sociedades. \\ Segundo [...] la reversión de lo que podemos denominar \\ el proyecto del Iluminismo del siglo dieciocho, \\ es decir el establecimiento de un sistema universal de dichas reglas \\ y estándares de conducta moral, \\ encarnados en instituciones estatales \\ dedicadas al progreso racional de la humanidad.
}

Eric Hobsbawm, La Barbarie: Una Guía para Usuarios

\section{El contexto del debate}

Una de nuestras premisas al investigar el agua como mirador privilegiado para examinar cuestiones fundamentales de la vida social y política contemporánea es que la situación de desigualdad extrema que impera a nivel planetario tanto en el acceso a los beneficios derivados del agua como

1 Uma versão prévia foi publicada em Esch, Delgado, Helfrich, Salazar Ramírez, Torregrosa, e PérezTejada, La Gota de la Vida: Hacia una Gestión Sustentable y Democrática del Agua, Cidade do México: Edições da Fundação Heinrich Böll, 2006, pp. 266-287. 
en el sufrimiento causado por la ineficiencia y la injusticia en la gestión de este elemento tiene raíces de carácter social, económico y político. El estudio de la relación entre agua y ciudadanía permite iluminar algunos de los aspectos más importantes de esta problemática y tiene la potencialidad de contribuir a la identificación de posibles soluciones prácticas. Ciertamente, la pobreza y la desigualdad social encuentran una expresión extrema en relación a la distribución de bienes y males vinculados a la gestión de ecosistemas y cuerpos acuáticos y, notablemente, en el acceso a los servicios esenciales de agua y saneamiento. Una gran proporción de las amenazas y peligros que acechan al ser humano se encuentran precisamente relacionados con la gestión del agua. ${ }^{2}$ Sin embargo, la gestión adecuada del agua a nivel de los ecosistemas y de los cuerpos acuáticos y en relación al acceso universal a los servicios esenciales de agua y saneamiento, son sólo condiciones necesarias ya que su impacto real en el bienestar de las personas está condicionado por otras consideraciones, entre las cuales se encuentran aspectos cruciales de la ciudadanía como son el acceso a la educación (por ejemplo la educación higiénica de los niños) ${ }^{3}$ y la participación de la población en la gobernabilidad del agua y de sus servicios derivados. ${ }^{4}$ Lamentablemente, el crecimiento de la desigualdad y la injusticia social experimentada por América Latina en las últimas dos décadas se encuentra correlacionado con los graves retrocesos experimentados en relación al desarrollo de la ciudadanía y al establecimiento de sistemas de gobernabilidad basados en los principios de la democracia sustantiva. ${ }^{5}$

2 SIMS, J., y BUTTER, M. E., "Gender, equity and environmental health." EnWorking Paper Series, Harvard Center for Population and Development Studies, Harvard University, 2000 (http://www. hsph.harvard.edu/organizations/healthnet/HUpapers/gender/simsbutter.html); SMITH, K. R., CORVALÁN, C. F. y KJELLSTRÖM, T. "How much global ill health is attributable to environmental factors." En Epidemiology, Vol. 10, \#5, 1999.

3 CAIRNCROSS, S., y KOCHAR, V. (eds.). Studying Hygiene Behaviour. Sage, Nueva Delhi,1994.

4 MCGRANAHAN, G., JACOBI, P., SONGSORE, J., SURJADI, Ch., y KJELLEN, M. The Citizens at Risk. From Urban Sanitation to Sustainable Cities.Stockholm Environment Institute y Earthscan, Londres y Sterling, VA., 2001.

5 Utilizamos la noción de "democracia sustantiva" para diferenciarla de la democracia formal, institucional, que constituye tan sólo una dimensión del proceso democrático. Similarmente hablamos en este capítulo de "ciudadanía sustantiva" para enfatizar la necesidad de profundizar el análisis y trascender la dimensión formal/institucional de la ciudadanía. 
En conexión con esto, antes de adentrarnos en el análisis es importante contextualizar el debate de la ciudadanía en relación a los procesos históricos recientes en la región latinoamericana. ${ }^{6}$ En este sentido, cabe decir que tras promediar ya más de dos décadas desde que comenzara la retirada de los regímenes militares en la región y se iniciara su reemplazo por gobiernos elegidos democráticamente en la mayor parte de los países, la implementación de las instituciones y principios formales de la democracia liberal, como precisamente lo es el ejercicio de los derechos ciudadanos, sigue constituyendo una promesa largamente incumplida. Aún si restringimos el concepto de "democracia" a su momento electoral y al respeto de sus principios elementales tales como la división de poderes -y aceptando que su recuperación, aún precaria, ha supuesto de por sí un enorme paso adelante respecto del período dominado por el autoritarismo militar- no podemos menos que reconocer que los avances logrados han sido opacados por graves retrocesos en áreas fundamentales. En realidad, si lo que nos interesa es medir la extensión alcanzada por los principios liberales y su encarnación en la identidad social que supone su plena realización, el ciudadano/la ciudadana, entonces cualquier evaluación objetiva de la situación nos conducirá a asumir una posición crítica y radical. ${ }^{7}$ No podría ser de otra manera dado que el retorno de gobiernos elegidos democráticamente en Sudamérica y Centroamérica desde mediados de la década de 1980 y los procesos de ampliación de la participación política ciudadana, como en el caso de México desde la década de 1990 se han correlacionado en

6 Por razones de espacio no podemos hacer justicia en este breve capítulo al amplio debate académico y político que tiene lugar en este momento en América Latina en torno a los problemas de la democracia y la ciudadanía. Entre otros influyentes trabajos recientes que pueden consultarse al respecto, pueden mencionarse: PROGRAMA DE LAS NACIONES UNIDAS PARA EL DESARROLLO, La Democracia en América Latina: Hacia una Democracia de Ciudadanas y Ciudadanos. (2da edición), Aguilar, Altea, Taurus, Alfaguara, Buenos Aires, 2004 (http://democracia.undp. org/Informe/); DE SOUSA SANTOS, BOAVENTURA (organizador), Democratizar a Democracia: Os Caminhos da Democracia Participativa, Vol. 1 de la Colección Reinventar a Emancipação Social: Para Novos Manifestos. Editora Civilização Brasileira,Río de Janeiro, 2002.

7 CASTRO, J. E. "El retorno del ciudadano. Los inestables territorios de la ciudadanía en América Latina." En Perfiles Latinoamericanos, Facultad Latinoamericana de Ciencias Sociales, México D. F., Num.14, 1999. 
forma perversa con el crecimiento desmesurado de la desigualdad social así como también con la persistencia de situaciones de pobreza extrema en la mayoría de los países. Un informe del Banco Interamericano de Desarrollo a fines de la década de 1990 anunciaba que América Latina tiene el triste privilegio de ser la región más desigual -no la más pobre ciertamente- del mundo, ${ }^{8}$ una situación que ha sido recientemente confirmada por expertos del Banco Mundial ${ }^{9} \mathrm{y}$ por investigaciones académicas que han ratificado las desigualdades existentes en el acceso a los servicios esenciales de agua y saneamiento en la región. ${ }^{10}$ Como veremos a continuación, el enfoque de este problema desde la perspectiva de la construcción de la ciudadanía permite hacer observables algunos de los factores fundamentales que subyacen a dichas condiciones de desigualdad.

\section{Ciudadanía y agua: un marco conceptual}

Es importante señalar que en este artículo se reconoce la relevancia de los derechos de ciudadanía como vehículo emancipatorio en el marco de las condiciones que caracterizan al sistema capitalista. En palabras de Marx, la ciudadanía representa "la forma final de emancipación humana en el contexto del orden mundial existente". ${ }^{11}$ Sin embargo, y continuando el razonamiento de Marx, buscamos evitar conceptualizar los sistemas de ciudadanía vigentes como si los mismos ofrecieran efectivamente el máximo grado de emancipación posible para los seres humanos. Por lo contrario, enfatizamos las limitaciones intrínsecas de los sistemas de ciudadanía, los cuales constituyen en nuestra perspectiva una etapa parcial en la búsqueda

8 BANCO INTERAMERICANO DE DESARROLLO. América Latina frente a la Desigualdad. Progreso Económico y Social en América Latina. Informe 1998-1999. Washington, D.C., 1998.

9 PERRY, G. E., FERREIRA, F. H. G., y WALTON, M. Desigualdad en América Latina y el Caribe: ¿Ruptura con la Historia? Washington, 2003 (http://wbln0018.worldbank.org/LAC/LAC.nsf/ ECADocByUnid2ndLanguage/4112F1114F594B4B85256DB3005DB262?. pendocument).

10 CRENZEL, E., y FORTE, G. “Cross-comparative Report on the demo-geographic and socio-economic dimension", en: CASTRO, J. E. (Coord.), Proyecto PRINWASS, Oxford: Universidad de Oxford, 2004 (http://users.ox.ac.uk/ prinwass/).

11 MARX, K “On the Jewish Question" En MARX, K. y ENGELS, F., Collected Works, Vol. 3, Lawrence and Wishart, Londres, 1975. 
y en la construcción de formas sociales emancipatorias. Sin embargo, no pasa inadvertido el hecho de que gran parte de las luchas sociales contemporáneas parecen estar orientadas hacia la apertura, ampliación y conquista (y reconquista) de los territorios sociales delineados por los sistemas de ciudadanía existentes. Aquí tomamos como punto de partida la noción de la ciudadanía como un territorio en disputa y nos proponemos analizar ciertos aspectos de dicha confrontación en el contexto de los procesos políticos, económicos y sociales relacionados con la gestión del agua.

Debo aclarar que inicialmente empleo el concepto de ciudadanía en su sentido más laxo de "membresía plena de una comunidad" siguiendo la clásica definición del sociólogo inglés T. H. Marshall, ${ }^{12}$ y luego avanzaré hacia una definición más precisa en relación con el tema del agua. En la definición laxa que uso para iniciar la discusión, "ciudadanía", se refiere al conjunto de derechos y obligaciones que determinan el carácter de las relaciones entre los individuos de una determinada comunidad política. Ahora bien, por una parte la ciudadanía tiene una dimensión formal, que da cuenta de cierta identidad que los individuos adquieren a partir de su pertenencia a la comunidad política relevante, como miembros de un estado nación o de una comunidad de naciones (ej. la Comunidad Europea o el Mercado Común del Cono Sur). Por otra parte, sin embargo, la ciudadanía incorpora fundamentalmente una dimensión substantiva, la cual no se encuentra necesariamente vinculada a la dimensión formal. ${ }^{13}$ La ciudadanía sustantiva hace referencia a un determinado conjunto de derechos y formas de participación en la vida política, económica y social que no se encuentran garantizados por la mera pertenencia formal a un estado-nación o a una comunidad de estados y cuyo ejercicio efectivo se encuentra sujeto a una serie de determinaciones ancladas en mecanismos de distancia social, en particular en las diferencias de clase, étnicas y de género.

12 MARSHALL, T. H.“Citizenship and social class.”En MARSHALL, T. H. y BOTTOMORE, T. Citizenship and Social Class, Pluto Perspectives, Londres y Concord, Mass.,, 1992.

13 BRUBAKER, W. R. (ed.). Immigration and the Politics of Citizenship in Europe and North America. University Press of America, Lanham, Nueva York y Londres, 1989. 
Se acepta generalmente que los elementos básicos para una conceptualización integral de los derechos de ciudadanía fueron enunciados en el trabajo clásico de Marshall originalmente presentado en $1949,{ }^{14}$ el cual se ha convertido en el punto de partida clásico del debate. En su estudio del caso inglés Marshall describió el desarrollo de los derechos ciudadanos como una evolución histórica en tres etapas, los derechos civiles o legales, representados principalmente por los derechos de propiedad cuyos antecedentes rastreó por lo menos hasta el siglo XII y encarnados en instituciones como las cortes, el habeas corpus y el derecho a un juicio justo; los derechos políticos, que comenzaron a desarrollarse en los siglos XVIII y XIX mediante la democracia parlamentaria y que incluyeron el derecho a votar, el de libre asociación así como también el de participar en las instituciones de gobierno; y finalmente, en el Siglo XX, los aspectos sociales como un conjunto complementario de derechos individuales a ser incorporados, principalmente, en relación al acceso universal a los servicios de salud y educación. ${ }^{15}$ Los escritos de Marshall reflejan el ambiente político de posguerra a finales de 1940 cuando la creación del estado de bienestar inglés buscaba consolidar la universalización de servicios esenciales, una política aceptada entonces por amplios sectores como derechos sociales de ciudadanía.

Ahora bien, aunque en su análisis Marshall dividió los derechos ciudadanos en tres conjuntos diferentes -los civiles, los políticos y los sociales- algunos críticos han señalado que en realidad dichos conjuntos no son excluyentes entre sí ya que existen derechos que pueden clasificarse dentro de varias de estas categorías. ${ }^{16}$ Además, con el transcurso del tiempo ha habido una expansión de los derechos de ciudadanía, a punto tal que distintos

14 MARSHALL, T. H. citado antes, 1992.

15 No avanzamos en este capítulo, por motivos de espacio, en el análisis de la relación entre la definición clásica de los derechos de ciudadanía (civiles, políticos y sociales) que forma parte del debate en las ciencias sociales que seguimos aquí, y las definiciones derivadas del debate sobre los derechos humanos y los derechos económicos, sociales y culturales (véase por ejemplo, en relación al agua, la documentación al respecto suministrada en el sitio de Internet del FORO INTERSECTORIAL POR EL DERECHO AL AGUA EN LA CIUDAD DE MÉXICO: http://www.derechoalagua.org/documentosdesca.html).

16 KING, D. S., y WALDRON, J. "Citizenship, social citizenship and the defence of welfare provision." En British Journal of Political Science ,18, 1988. 
autores hablan de ciudadanía "tecnológica", ${ }^{17}$ "ecológica", 18 "ambiental", 19 "cibernética", ${ }^{20}$ para mencionar solamente algunos ejemplos, lo cual ha contribuido a concretar y, ciertamente, a extender las categorías tradicionales sugeridas por Marshall para incluir, por ejemplo, el derecho a la información (ej. sobre cómo se gestionan y gobiernan los ecosistemas acuáticos y los servicios públicos esenciales) y al consenso informado (por ejemplo, el derecho a contar con información precisa antes de otorgar consentimiento a una cierta política pública, como la privatización de servicios esenciales), los cuales son especialmente importantes para nuestra discusión.

Uno de los aspectos más controvertidos del análisis sugerido por Marshall concierne a la categoría de los derechos sociales. Según él los derechos sociales, reestablecidos durante el Siglo XX en el curso de un largo proceso de lucha entre los movimientos por una ciudadanía inclusiva y las fuerzas propulsoras de un orden social fundado en los principios de libre mercado, habrían logrado equipararse en importancia con las otras dos categorías fundamentales de la ciudadanía (los derechos civiles y políticos) a través de la universalización del acceso a servicios esenciales como la salud y la educación. ${ }^{21}$ En su perspectiva, la institucionalización de los derechos sociales permitiría la abolición de las "desigualdades cualitativas", las cuales, en contraste con las "desigualdades cuantitativas", son concebidas como incompatibles con los principios de la democracia liberal. Mientras que en la democracia liberal las desigualdades cuantitativas (las desigualdades económicas que están determinadas por el lugar que ocupan los individuos en el mercado) son vistas como un factor de libertad en la

17 FRANKENFELD, Ph., “Technological citizenship: a normative framework for risk studies”, en Science, Technology and Human Values, Vol. 17, 1992.

18 STEENBERGEN, B. van, “Towards a global ecological citizen”, en The Condition of Citizenship, Londres: Sage, 1994.

19 NEWBY, H. “Citizenship in a green world: global commons and human stewardship." En BULMER M. y REES A. (eds.). Citizenship Today. The Contemporary relevance of T. H. Marshall. University College Press, Londres, 1996.

20 GRAY, Ch. H. Cyborg Citizen. Politics in the Posthuman Age. Routledge, Nueva York y Londres, 2001.

21 MARSHALL, T. H. citado antes, 1992. 
medida en que se trata de desigualdades en el acceso a la provisión de bienes y servicios determinadas por la capacidad adquisitiva de los individuos, las desigualdades cualitativas implican desigualdades de derechos, y son incompatibles con la democracia liberal porque se trata de desigualdades determinadas por la situación de clase, étnica o de género que caracterizan a los individuos. En la perspectiva de Marshall, el progreso de la ciudadanía a través de la institucionalización de los derechos sociales a mediados del Siglo XX habría contribuido a abatir las desigualdades cualitativas mediante el otorgamiento de un derecho de acceso universal a los bienes esenciales para la vida en comunidad (no solamente los bienes y servicios necesarios para la supervivencia sino también aquellos requeridos para el disfrute del estándar de vida mínimo disponible en la sociedad). Este proceso permitiría que las posibilidades que tienen los individuos para acceder a dichos bienes y servicios esenciales se independizaran de sus condiciones económicas inmediatas resultantes de las desigualdades cuantitativas determinadas por su posición en el mercado. En sus palabras, el otorgamiento de los derechos sociales de ciudadanía habría creado "un derecho universal a un ingreso real que no es proporcional al valor de mercado del demandante". ${ }^{22}$ Esta universalización del derecho de acceso a los satisfactores esenciales para el bienestar social tenía como objetivo potenciar la participación universal y sin discriminación de género, clase u origen étnico en el proceso económico, social y político. Puede decirse que, al argumentar que el derecho a las condiciones mínimas de bienestar social es un componente crucial de la ciudadanía en las sociedades modernas, Marshall reflejaba las condiciones existentes en una etapa central de la larga lucha por la construcción de la ciudadanía sustantiva y ofreció un marco interpretativo para la defensa de una concepción incluyente de la misma. ${ }^{23}$

Otro aspecto relevante para nuestra discusión es que Marshall reconocía la existencia de una tensión inherente entre el sistema de producción capitalista, fundado en la reproducción de las desigualdades cuantitativas asociadas con el valor de mercado de los individuos, y el proceso de la

22 MARSHALL, T. H. citado antes, 1992.

23 KING, D. S., y WALDRON, J.citados antes, 1988. 
ciudadanía, que se fundamenta en la eliminación de las desigualdades cualitativas y que, consecuentemente según hemos visto, conlleva también la reducción potencial de desigualdades cuantitativas. Por eso para Marshall el impacto del desarrollo de los derechos de ciudadanía sobre la desigualdad de clase característica del sistema capitalista tomaría la forma de un conflicto entre los principios opuestos de la democracia liberal y el capitalismo. Éstos y otros argumentos de Marshall son claramente discutibles y han sido criticados desde distintas posiciones del espectro político. Lo que sí nos interesa destacar aquí fundamentalmente es el reconocimiento de la contradicción que se da en el seno de la democracia liberal capitalista entre el proceso de ciudadanía en expansión, en el plano político, y el proceso de reproducción de desigualdades cuantitativas, en el plano socio-económico.

Marshall ha sido criticado entre otras cosas porque basó sus generalizaciones en la experiencia británica y dejó fuera de consideración otros procesos históricos que difieren notablemente de aquél. En este sentido, el concepto de ciudadanía es el resultado de procesos históricos específicos que llevaron a la formación de estados-nación modernos en los países occidentales desarrollados. La conceptualización de estos procesos en la literatura especializada refleja, principalmente, la experiencia concreta de los países de Europa Occidental y los Estados Unidos. Sin embargo, incluso en estos países la conceptualización y las prácticas asociadas con la ciudadanía han adoptado formas diversas, por ejemplo, entre las concepciones de la ciudadanía que corresponden a la tradición anglosajona de libre mercado y las que corresponden a las tradiciones social democrática, republicana, comunitaria, o radical..$^{24}$ De igual forma, mientras que en la cultura política europea, con excepción de la tradición de libre mercado, se ha desarrollado una noción -que aunque adopte formas diversas en cada país y cultura política tiende a aceptar que el acceso universal a ciertos bienes y servicios esenciales- constituye un derecho social de la ciudadanía, no

24 FRASER, N. y GORDON L. "Civil citizenship against social citizenship? On the ideology of contract-versus-charity", En STEENBERGEN, B. van, The Condition of Citizenship. Sage, Londres, 1994; COHEN, J. L. y ARATO A. Civil Society and Political Theory. The Massachusetts Institute of Technology (MIT) Press,Cambridge, Mass. y Londres, 1994. 
existe una noción equivalente en la cultura política de los Estados Unidos de Norteamérica. En este último país, con la excepción posiblemente única de las políticas del New Deal del Presidente Roosevelt en la década de 1930, la tradición dominante ha sido la de reservar la categoría de derechos ciudadanos para referirse exclusivamente a los derechos civiles y políticos. ${ }^{25}$ Esto también nos previene contra la generalización acrítica de conceptos como el de ciudadanía al examinar las experiencias de los países en América Latina y el Caribe ya que el establecimiento y desarrollo a través del tiempo de los derechos de ciudadanía en las diferentes formaciones sociales centroamericanas y caribeñas ha seguido procesos singulares que no pueden ser ignorados en el análisis, a los cuales nos referiremos más adelante.

Retomando brevemente el caso de Marshall cabe señalar que una de las críticas más severas que se han hecho a su enfoque es que el mismo coloca el énfasis en el impacto del proceso de la ciudadanía sobre el sistema capitalista de clases sociales sin explorar la relación inversa, es decir, el impacto de la estructura y la dinámica de clases sobre el acceso a y el ejercicio de estos derechos. En esta perspectiva, una radicalización del esquema de Marshall implicaría la superación del modelo del bienestar que se funda en la asignación de un porcentaje del producto nacional para el gasto en seguridad social pero deja intocadas las cuestiones cruciales de cómo se organiza el proceso productivo y cómo se distribuye el producto del trabajo, procesos que están, precisamente, determinados por la estructura y la dinámica de clases capitalistas. Por otra parte, desde la derecha del arco político-ideológico los teóricos neoliberales y neoconservadores (quienes han lanzado un ataque sostenido sobre las instituciones de bienestar desde fines de los años 1970) han argumentado que el modelo de Marshall ha servido para legitimar una cultura de la dependencia. Estos autores abogan por políticas orientadas a revertir el modelo de bienestar teorizado por Marshall y a subordinar el ejercicio de los derechos ciudadanos a las condiciones

25 Para una discusión reciente de la relación entre ciudadanía y desigualdad, incluyendo importantes referencias al caso de los Estados Unidos, véase TILLY, Ch. Durable Inequality.University of California Press, Berkeley, Los Angeles y Londres, 1999. 
demarcadas por la dinámica capitalista. ${ }^{26}$ En el sector del agua este movimiento que busca desmantelar la estructura de derechos sociales ha logrado ejercer una influencia relevante en el campo de las políticas públicas, como lo evidencian los argumentos defendidos por instituciones como el Banco Mundial, en el sentido de que debe abandonarse la noción de que servicios como los de agua y saneamiento son un "servicio público o un bien social". ${ }^{27}$

Visto desde otro ángulo, el proceso de la ciudadanía puede examinarse como un avance en la expansión de derechos y del acceso a los mismos en el largo plazo que, sin embargo, se encuentra sujeto a frecuentes obstáculos e incluso, retrocesos. Como lo ilustra la Figura 1, en el devenir histórico al conjunto original de derechos básicos de ciudadanía se han ido agregando nuevos derechos al mismo tiempo que se ha ido ampliando el acceso al conjunto de derechos existentes a un número tendencialmente mayor de seres humanos. Por ejemplo, en la mayoría de los países, las mujeres no lograron ganar acceso a los derechos políticos hasta entrado el Siglo XX $\mathrm{y}$, como acabamos de ver, los derechos sociales de ciudadanía sólo fueron consolidados como tales hacia mediados del Siglo XX, aunque en muchos países estos derechos nunca lograron suficiente reconocimiento. Producto de confrontaciones sociales y de otros procesos, como la creciente toma de conciencia a nivel global del impacto social y político de los problemas ambientales, nuevos derechos han ido aceptándose y formalizándose, como

26 Véase por ejemplo, MEAD, L. Beyond Entitlement: The Social Obligations of Citizenship. Free Press, NuevaYork, 1986; y SAUNDERS, P. “Citizenship in a liberal society” En B. S. Turner (ed.). Citizenship and Social TheorySage, Londres, 1993.

27 WATER AND SANITATION PROGRAM AND PUBLIC PRIVATE INFRASTRUCTURE ADVISORY FACILITY. New Designs for Water and Sanitation Transactions. Making Private Sector Participation Work for the Poor. Washington D. C., 2002. Para un argumento similar pero en relación a la gestión del agua en general, véase LEE, T. y JOURAVLEV A. Los precios, la propiedad y los mercados en la asignación del agua. (LC/L 1097), Comisión Económica para América Latina y el Caribe (CEPAL), Santiago de Chile1998. Es importante señalar aquí que algunos de estos autores parecen argumentar indiscriminadamente a favor de la mercantilización y privatización del agua, sin diferenciar entre los distintos usos y funciones de la misma. No es lo mismo aplicar el principio de racionalidad mercantil al uso del agua en, para dar un ejemplo, los servicios turísticos o la agricultura mercantilizada a gran escala, que hacerlo en relación a los usos esenciales domésticos, particularmente en zonas urbanas de países menos desarrollados (sobre esto, véase por ejemplo el debate formulado en la Declaración Europea por una Nueva Cultura del Agua (http://moncayo.unizar.es/fnca/europeandeclaration.nsf). 
precisamente el derecho a un medio ambiente limpio y, más recientemente, el derecho al agua. Sin embargo, la relación entre estos nuevos "derechos" y los derechos de ciudadanía es un tema controvertido, que abordamos en la siguiente sección en mayor detalle.

Figura 1. El proceso de la ciudadanía

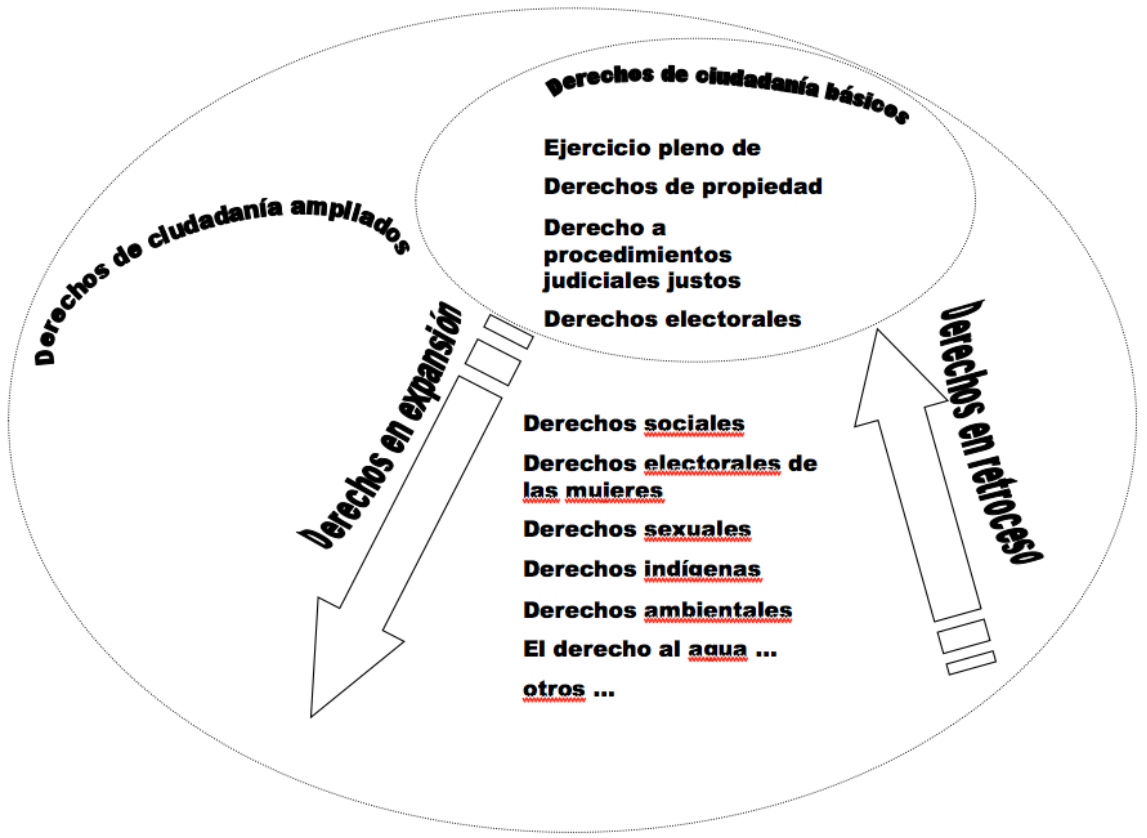

Fuente: CASTRO. ${ }^{28}$

Como ya se señaló, el proceso de la ciudadanía tiene también obstáculos y retrocesos, como lo indica la figura. Evidentemente, esto resulta claro en relación con los derechos civiles y políticos que, en América Latina, han sido recurrentemente amenazados, restringidos y suspendidos en el curso de dictaduras militares y otras circunstancias similares. Pero también es

28 CASTRO, J. E. Water, Power, and Citizenship. Social Struggles in the Basin of Mexico. Palgrave-Macmillan, Houndmills, Basingstoke y Nueva York, 2006. 
importante reflexionar en los aspectos sociales de la ciudadanía, que con frecuencia han sido también recortados o inclusive negados, muchas veces, en el nombre de la democracia y la libertad. Este es un elemento central del debate sobre la "crisis del estado", cuya expresión política dominante desde la década de 1980 han sido las políticas de ajuste estructural, la liberalización, la transferencia de empresas públicas al sector privado (como las de servicios de agua y saneamiento) y la des- y re-regulación en el ámbito económico. ${ }^{29}$ En relación al agua, estas políticas se han expresado en diversas formas, que van desde la creación de derechos privados y mercados de agua para la gestión de ecosistemas acuáticos, ${ }^{30}$ hasta ciertos modelos de descentralización, y expansión de la participación privada en la provisión de servicios esenciales de agua y saneamiento, incluyendo la privatización radical (full-divestiture) de las empresas siguiendo el modelo de Inglaterra y Gales implementado por Margaret Thatcher en la privatización de 1989 y, en Chile, durante la década de 1990. Tanto la creación de mercados de agua privados para reemplazar sistemas de derechos indígenas, comunales o públicos, ${ }^{31}$ como la transferencia de la gestión de servicios esenciales de agua al sector privado cobró gran fuerza en México, Centroamérica y el Caribe desde la década de 1980 y sus consecuencias para el desarrollo de la ciudadanía continúan siendo largamente inexploradas. ${ }^{32}$ Volvemos sobre este tema en las siguientes páginas.

29 LEYS, C.,Market-Driven Politics. Neoliberal Democracy and the Public Interest. Verso, Londres, 2001.

30 Véase por ejemplo BAUER, C. Canto de Sirenas: El Derecho de Aguas Chileno como Modelo para Reformas Internacionales. Bakeaz, Bilbao, 2004; y del mismo autor, Contra la Corriente: Privatización, Mercados de Agua y el Estado en Chile. LOM Ediciones / Fundación Terram / Resources for the Future,Santiago, Chile, 2002.

31 Véase, por ejemplo, BOELENS, R. y HOOGENDAM, P. (eds.). Water Rights and Empowerment.Van Gorcum.Boelens y Hoogendam, Assen, Holanda,2002.

32 Para una primera aproximación al tema, véase CASTRO, J. E. citado antes, 2006 (capítulo 6); CASTRO, J. E. y LAURIE, N., "Cross-comparative Report on the Socio-political and cultural dimension." En: CASTRO, J. E. (Coord.). PRINWASS Project, Oxford, University of Oxford, 2004 (http:// users.ox.ac.uk/ prinwass/). 


\section{Agua y ciudadanía: la especificidad del vínculo}

La relación entre agua y ciudadanía puede abordarse desde varios ángulos, como lo ilustra la Figura 2. Por una parte, el desarrollo de los derechos de propiedad y sus instituciones relacionadas constituyó un elemento central en la formación de los sistemas de ciudadanía modernos, en particular de los derechos civiles. ${ }^{33}$ Teniendo en cuenta dicha perspectiva, los derechos de propiedad sobre el agua o los derechos de agua pueden ser considerados como un componente de los derechos civiles de la ciudadanía. No es común realizar esta asociación. En particular, en los medios urbanos los individuos y las familias no se plantean con frecuencia el tema de quién tiene el derecho (en el sentido de tener el título de propiedad sobre) al agua y, en general, dichos derechos en áreas urbanas están en poder de instituciones (municipios, empresas, otros organismos de gobierno), no de personas privadas. La situación es diferente en zonas rurales donde los derechos de agua han sido históricamente más conspicuos, por así decir, y son frecuentemente detentados por personas privadas o por entidades conocidas (por ejemplo, por comunidades de regantes).

Figura 2 - Algunos vínculos entre el agua y los derechos de ciudadanía

\section{Derechos de ciudadanía}

Derechos civiles (derechos de propiedad, iusticia)

\section{Derechos políticos (ejercicio democrático del poder)} Derechos sociales (estándares
civilizados de bienestar)

\section{Vínculos con el agua}

\section{Derechos de agua, igualdad y} iusticia en el acceso

\section{Gobernabilidad democrática del} agua y de sus servicios derivados, participación

Acceso universal a volúmenes y servicios de agua esenciales para la vida

Fuente: CASTRO, J. E. citado antes, 2006

33 MARSHALL, T. H. citado antes, 1992. 
Por otra parte, puede argumentarse que el desarrollo de los derechos de agua ha estado estrechamente relacionado también con el desarrollo de los derechos políticos y sociales de la ciudadanía. Por ejemplo, en relación a los derechos políticos, los principios e instituciones asociados a la definición y el ejercicio de los derechos de agua están íntimamente ligados a la gobernabilidad del agua y de sus servicios derivados. Hablamos aquí de gobernabilidad-un concepto relativamente reciente acuñado en los países desarrollados y sujeto a permanente controversia- porque este tema ha venido a ocupar un lugar central en los debates internacionales actuales pero no podemos analizar aquí el concepto en gran detalle por razones de espacio. ${ }^{34}$ Sin embargo, queremos apuntar que en nuestra perspectiva el proceso de la gobernabilidad -pensado en relación al agua- es el resultado de la incesante confrontación social en torno a la definición de los principios, valores, e instituciones que intervienen en el gobierno, gestión y asignación del agua y sus servicios derivados así como también en las decisiones acerca de quién gobierna, gestiona y asigna el agua y sus servicios y para el beneficio de quiénes. ${ }^{35}$ Esta es un área crucial de decisión política de la cual

34 Una secuencia de obras recientes permite trazar los contornos de este debate. Véase por ejemplo HIRST, P. Associative Democracy: New Forms of Economic and Social Governance. Polity Press, Cambridge1994; HELD, D. Democracy and the Global Order: from the Modern State to Cosmopolitan Governance. Polity Press, Cambridge, 1995; AMIN, A., Beyond Market and Hierarchy: Interactive Governance and Social Complexity. Elgar, Cheltenham, 1997; KOOIMAN, J. "Societal governance: levels, modes, and orders of social-political interaction." En PIERRE, J. (ed.).Debating Governance. Authority, Steering and Democracy. Oxford University Press, Oxford,2000; y SWYNGEDOUW, E. A. "Authoritarian governance, power, and the politics of rescaling."En Environment and Planning D; Society and Space, Vol. 18, 2000. Para aplicaciones del concepto en áreas de política ambiental véase por ejemplo PROGRAMA DE LAS NACIONES UNIDAS PARA EL DESARROLLO, Governance for Sustainable Growth and Equity. Nueva York, 1997; GLOBAL WATER PARTNERSHIP. Effective Water Governance. Learning from the Dialogues. 2003 (http:// www.gwpforum.org/gwp/library/Effective\%20Water\%20Governance.pdf), y SWYNGEDOUW E., PAGE, B., y KAÏKA, M. Kaika. "Sustainability and policy innovation in a multi-level context: crosscutting issues in the water sector." En HEINALT, H., GETIMIS, P., KAFKALIS, G., SMITH, R., y SWYNGEDOUW, E. (eds). Participatory Governance in Multi-level Context. Leske y Budrich, Opladen,2002.

35 Para una definición de gobernabilidad que es congruente con esta interpretación, véase HANF, K. y JANSEN, A. (eds.). Governance and Environment in Western Europe, Addison Wesley Longman, Harlow,1998. 
la mayoría de las personas han sido históricamente excluidas o en la cual han visto su participación severamente limitada, en el mejor de los casos. ${ }^{36}$

Por otra parte, en relación a los derechos sociales puede decirse que el acceso a los servicios esenciales de agua ha sido una parte crucial de la expansión del "derecho a compartir la herencia social y a vivir la vida de un ser civilizado según los estándares prevalecientes en la sociedad", es decir, la característica de ser un miembro pleno de la sociedad si aceptamos una definición incluyente de la ciudadanía. ${ }^{37}$ En este sentido, por ejemplo, la universalización de los servicios de agua y saneamiento en Europa se convirtió en una prioridad no sólo por razones de higiene o salud sino también por ser un factor de crecimiento económico. ${ }^{38}$ Ahora bien, es importante señalar que la noción de que el acceso a una cantidad de agua esencial para la vida constituye un derecho inalienable de los seres humanos surgió mucho antes de que se desarrollaran los sistemas modernos de ciudadanía y puede encontrarse en las costumbres de las diversas sociedades. Es una noción que en verdad pertenece a la herencia de la civilización humana y que recientemente ha sido reformulada con la Declaración del Derecho Humano al Agua por parte del Comité de Derechos Económicos, Sociales y Culturales (CDESC) de las Naciones Unidas. ${ }^{39}$ Sin embargo, e ilustrando el argumento sobre el carácter agonístico del desarrollo de los derechos, la noción de que el acceso a volúmenes esenciales de agua sea un derecho humano sigue constituyendo un objeto de confrontación a nivel internacional a tal punto que la ONU no

36 Sobre la exclusión histórica de la participación ciudadana en los procesos de gestión pública, véase, por ejemplo, el estudio de DRYZEK, J.The Politics of the Earth. Environmental Discourses. Oxford University Press, Oxford 1993.

37 MARSHALL, T. H. citado antes, 1992.

38 GOUBERT, J. P. The Conquest of Water. The Advent of Health in the Industrial Age. Polity Press and Basil Blackwell, Cambridge y Oxford, 1986; HASSAN, J., A History of Water in Modern England and Wales, Manchester University Press, Manchester, 1998.

39 ORGANIZACIÓN DE LAS NACIONES UNIDAS,.The right to water. (articles 11 and 12 of the International Covenant on Economic, Social, and Cultural Rights), Nueva York, 2002; véase también ORGANIZACIÓN MUNDIAL DE LA SALUD, El derecho al agua. Ginebra, 2003 (http://www. who.int/water_sanitation_health/rightowater/es/). Vease también LANGFORD, Malcolm y KHALFAN, Ashfaq. Una introducción al Derecho Humano al Agua, en este mismo libro. 
ha refrendado todavía la declaración del CDESC debido a la fuerte oposición por parte de un número importante de gobiernos..$^{40}$

En resumen, los vínculos entre el agua y un concepto incluyente de la ciudadanía involucran varios aspectos que van desde el desarrollo de los derechos de propiedad sobre el agua y de las instituciones que gobiernan el manejo del agua y sus servicios derivados, la participación ciudadana en la gestión de lo público y las interconexiones entre el acceso al agua y sus servicios y la salud y el bienestar general. Ahora bien, vista en una perspectiva de largo plazo, la incorporación de individuos al territorio de la ciudadanía forma parte del proceso histórico de integración creciente de seres humanos en unidades de organización social cada vez más amplias, siguiendo la conceptualización sugerida por Norbert Elias en su análisis de los procesos de cambio social de largo plazo. ${ }^{41}$ Sin embargo, el hecho que una gran parte de la población humana, normalmente la más vulnerable, continúe sujeta a altas tasas de morbi-mortalidad debido a la gestión ineficiente del agua o a la desigualdad en el acceso a los servicios esenciales de agua y saneamiento demuestran que, cuando hablamos de una lucha sobre el territorio de la ciudadanía, no estamos meramente utilizando una imagen metafórica. Existen procesos que subyacen a las tendencias a largo plazo de ampliación de la ciudadanía y que continúan restringiendo el alcance de los derechos, impidiendo el acceso pleno a dicho territorio a grandes sectores de la población humana dificultando o negando el ejercicio efectivo de los derechos e, incluso, causando la pérdida de ciertos derechos que habían sido conquistados en batallas favorables. En la siguiente sección analizaremos brevemente algunos ejemplos basados en el caso histórico de México.

40 AMNESTY INTERNATIONAL, “Human right to water (public statement)", Londres, 2003 (http:// web.amnesty.org/library/index/engIOR100022003?open\&of=eng-398).

41 ELIAS, N. El Proceso de la Civilización. Investigaciones Sociogenéticas y Psicogenéticas. Fondo de Cultura Económica, México D. F., 1989. 


\section{Agua y ciudadanía en México}

Como discutimos en páginas previas, el proceso de formación de sistemas ciudadanos sigue siendo un proyecto incompleto a escala planetaria, una de las expresiones de la "desigualdad persistente" que caracteriza a los sistemas sociales contemporáneos..$^{42}$ Este es un proceso que adopta características extremas en el caso de los países llamados menos desarrollados incluyendo México y la mayoría de los países centroamericanos y caribeños. En este sentido, las advertencias hechas hace ya varias décadas acerca de los grandes atrasos en el proceso de ciudadanización en este país continúan teniendo gran validez, ${ }^{43}$ a pesar de la existencia de indudables avances en varias áreas. Ahora bien, las condiciones de desigualdad que enmarcaron la construcción histórica de la ciudadanía en México pueden rastrearse hasta el período colonial, lo cual en un cierto sentido permite establecer puntos de contacto y analogías con el estudio de Marshall sobre el caso inglés, aunque por razones de espacio sólo revisaremos brevemente aquí algunos procesos desde el Siglo XIX.44

Desde la primera mitad del Siglo XIX México se convirtió en un campo experimental de procesos de ingeniería social dirigidos a desmantelar los sistemas colectivos de propiedad, encarnados en las posesiones de la Iglesia y de los poblados indígenas con el objeto de impulsar los procesos de individualización y construcción de derechos de ciudadanía inspirados en las revoluciones democráticas de fines del Siglo XVIII. ${ }^{45}$ Este proceso tuvo una expresión concreta en la transformación de la estructura de la propiedad de la tierra y el agua. Las fracciones liberales de la sociedad lucharon desde

\footnotetext{
42 TILLY, Ch. citado antes, 1999.

43 Véase por ejemplo GONZÁLEZ CASANOVA, P. La Democracia en México.Era, México D. F., 1965.

44 Hemos desarrollado esto en mayor detalle, incluyendo una discusión sobre la aplicabilidad del concepto de ciudadanía en la Nueva España en CASTRO (citado antes, 2006). Algunos autores, como Brian Roberts, también han señalado que América Latina en general, México incluido, ha seguido un modelo de ciudadanización más cercano al caso del Segundo Imperio alemán de Bismarck que al modelo inglés estudiado por Marshall, aunque la referencia de Roberts es a un período histórico más breve (ROBERTS, B. R. The Making of Citizens. Cities of Peasants Revisited. Arnold, Londres, 1995).
}

45 ESCALANTE G., F. Ciudadanos Imaginarios. El Colegio de México, México D. F.,1992. 
temprano por erradicar las formas colectivas de propiedad en manos de las órdenes religiosas y de las comunidades indígenas, pero durante la primera mitad del siglo diecinueve sus esfuerzos fueron derrotados por las fuerzas conservadoras que resistían las reformas. No fue sino hasta mediados de la década de 1850 que las fuerzas liberales lograron una primera oportunidad para ejecutar su proyecto, consolidado con la abolición de las inmunidades del clero por parte del Ministro de Justicia Benito Juárez (1855), la Ley Lerdo que obligaba a las órdenes religiosas la venta de sus propiedades (1856) y la Constitución de 1857 en la que, por primera vez, se extendieron los derechos civiles y políticos de ciudadanía fuera de los límites de la élite oligárquica que gobernaba el país. ${ }^{46} \mathrm{~A}$ pesar de estos avances en la dirección de un proceso ampliado de ciudadanización existe un consenso amplio entre los historiadores y analistas del período en que la política de los sectores liberales tenía un doble carácter: por una parte, el programa liberal intentaba emular el modelo de la democracia norteamericana basada en una amplia clase pionera de pequeños propietarios pero, en la práctica, el proceso social real asumió la forma de un "colonialismo interno" ${ }^{47}$ reafirmando el patrón colonial de apropiación extensiva de las tierras y el agua por parte de grandes terratenientes. No causa sorpresa por lo tanto que muchos de estos terratenientes se encontraran entre los principales promotores de las reformas liberales. ${ }^{48}$ El proceso de expropiación y acumulación extensiva de la tierra avanzó rápidamente durante la modernización porfiriana (1884-1911), que exacerbó el proceso de exclusión social al favorecer la concentración de la propiedad de la tierra en manos de un reducido grupo de acumuladores

46 BAZANT, J.“From Independence to the Liberal Republic, 1821-1867." En BETHELL, L. (ed.). Mexico since Independence. 2nd rep., Cambridge University Press, Cambridge, 1994.

47 GONZÁLEZCASANOVA,P. “Internal colonialism and national development." En Studies in Comparative International Development, Vol. I, \#4, 1965.

48 BAZANT, J. citado antes, 1994; KATZ, F. “The Liberal Republic and the Porfiriato, 1867-1910.” En BETHELL, L. (ed.). Mexico since Independence. 2nd rep., Cambridge University Press, Cambridge, 1994; TUTINO, J. From Insurrection to Revolution in Mexico. Social Bases of Agrarian Violence 1750-1940. Princeton University Press, Princeton, NJ, 1986; y del mismo autor, "Agrarian social change and peasant rebellion in nineteenth-century Mexico: the example of Chalco."En KATZ, F. (ed.). Riot, Rebellion, and Revolution. Rural Social Conflict in Mexico. Princeton, Princeton University Press, NJ:1988. 
privados a punto tal que hacia fines del régimen cerca del 90 por ciento de los campesinos habían sido despojados de sus tierras. ${ }^{49}$

Sin embargo, es importante resaltar aquí que el caso del agua siguió un proceso diferente al de la tierra. Las mismas fuerzas sociales que formaban la base del régimen porfiriano y su política privatizadora de la tierra tendieron a favorecer, cuando no directamente impulsar, una política de aguas que otorgaba al estado nacional un rol primordial, particularmente en relación a los usos productivos del agua en la agricultura de irrigación y en la industria..$^{50}$ Esto en realidad no constituyó una excepcionalidad mexicana, ya que la tendencia a nivel internacional desde fines del siglo diecinueve crecientemente otorgaba al estado, en el nombre del interés público, la responsabilidad por la inversión masiva necesaria para la expansión de la infraestructura básica de la economía, incluyendo la infraestructura hidráulica. ${ }^{51}$ En el caso de México este proceso tomó la forma de una creciente monopolización del control del agua en manos estatales con el rápido desarrollo de un cuerpo de expertos al servicio del estado, la expansión masiva de información sobre los recursos hídricos en el país y el intento de consolidar el proceso a través de la legislación. ${ }^{52}$

En el caso de los servicios esenciales de agua y saneamiento, al menos en el plano formal-legal, durante el período porfiriano se consolida el reconocimiento del estatus de bien común y uso prioritario ligado a los usos esenciales del agua. También, en el período 1880-1910 la inversión en obras hidráulicas de agua, saneamiento y drenaje urbano en la Ciudad de México fue muy importante, representando más de un tercio del total invertido

49 KATZ, F. citado antes, 1994.

50 KROEBER, C. B. El Hombre, la Tierra y el Agua. Las Políticas en Torno a la Irrigación en la Agricultura de México, 1885-1911. Instituto Mexicano de Tecnología del Agua y Centro de Investigaciones y Estudios Superiores en Antropología Social, México D. F., 1994; ABOITES AGUILAR, L. El Agua de la Nación. Una Historia Política de México (1888-1946). Secretaría de Educación Pública (SEP) y Centro de Investigaciones y Estudios Superiores en Antropología Social (CIESAS), México D. F.,1998.

51 SWYNGEDOUW, E. A., KAÏKA, M, y CASTRO, J. E.“Urban water: a political-ecology perspective.” En Built Environment 28 (2), 2002.

52 KROEBER, C. B.citado antes, 1994; ABOITES AGUILAR. citado antes, 1998. 
en obras públicas en la metrópolis..$^{53}$ Sin embargo, el carácter real del proceso estaba marcado por una polarización y desigualdad social extrema y el acceso a los servicios estaba limitado a una reducida élite de habitantes mientras que la mayoría de la población estaba sujeta a condiciones de insalubridad y elevadas tasas de morbi-mortalidad, en gran medida, determinadas por la falta de servicios adecuados. ${ }^{54}$ Por ejemplo, el Ingeniero Alberto Pani, escribiendo en plena Revolución, decía que si bien la Ciudad de México era el lugar más avanzado en el país en relación a las condiciones materiales de vida, la metrópolis era también "la ciudad más insalubre del mundo". Pani fundamentaba este juicio en un análisis comparativo de las condiciones en más de treinta ciudades de Europa, América, Asia, y África, y llegaba a la conclusión de que "el agua que han consumido los habitantes metropolitanos, hasta hace muy poco tiempo, [... constituye] una de las causas determinantes de la mortalidad y, sobre todo, de la alta morbilidad de la ciudad de México". El libro de Pani está fundamentado, en el estilo de los ingenieros sanitaristas de la época, en datos estadísticos y en el conocimiento científico disponible acerca de las relaciones entre las condiciones materiales de vida y la salud individual y pública. Sin embargo, él añadía un elemento político y moral a su evaluación: "el país necesita, ante todo y sobre todo, organizar su Administración Pública sobre una base de absoluta moralidad". Sacadas de contexto, sus palabras pueden ser interpretadas en forma negativa como excesivamente moralizantes, pero al leer el texto completo uno percibe que Pani escribía motivado por un odio profundo por las condiciones de desigualdad imperantes ante la "indiferencia o abstención del estado -que es el único poder capaz de conjurarlos”, una indiferencia que él consideraba "monstruosamente criminal". ${ }^{55}$

53 MANSILLA, E. De cómo Porfirio Díaz dominó las aguas: historia de la construcción de la obra hidráulica. Concurso Nacional Sobre Historia y Etnohistoria de los Aprovechamientos Hidráulicos en México, Comisión Nacional del Agua y Centro de Investigaciones y Estudios Superiores en Antropología Social, México D. F.. 1994.

54 MÁRQUEZ MORFín. La Desigualdad ante la Muerte en la Ciudad de México. El Tifo y el Cólera. Siglo XXI, México D. F.,1994.

55 PANI, A. J. La Higiene en México. Imprenta de J. Ballesca, México D. F.,1916. 
Los pasajes de Pani citados más arriba reflejan el momento crítico previo al final de la Revolución Mexicana, en el cual se forjaron algunos de los principios que serían poco después formalizados en la Constitución Revolucionaria de 1917, particularmente en su Artículo 27, y que conducirían a la creación del Consejo de Salud Pública en el mismo año. Sin embargo, a pesar de los esfuerzos de Pani y otros, como Molina Enríquez, ${ }^{56}$ por otorgar a los servicios esenciales de agua y saneamiento prioridad máxima en las políticas públicas, en perspectiva histórica se puede ver que la inversión en estos servicios fue mínima durante las primeras décadas del período revolucionario. ${ }^{57}$ Escribiendo en 1927, el Ingeniero Miguel Ángel de Quevedo decía que la situación del país en relación a los servicios de agua y saneamiento era lamentable debido a la pobre infraestructura, la falta de mantenimiento, y la ausencia de educación sanitaria. ${ }^{58}$ No es de extrañar que las epidemias relacionadas con la falta de servicios adecuados de agua y saneamiento afectaran regularmente a la población durante la primera mitad del siglo XX y las enfermedades relacionadas con el agua siguieron siendo la primera causa de mortalidad hasta la década de $1970 . .^{59}$

De esta forma, y retomando el tema de la ciudadanía, puede decirse que aunque la Revolución Mexicana formalmente buscó revertir el proceso de exclusión y expandir el alcance y el ejercicio de los derechos ciudadanos, por ejemplo, en relación al acceso a la tierra y a los servicios esenciales básicos para "seres humanos que viven en una comunidad civilizada", ${ }^{60}$ en la práctica, la formalización de la ciudadanía revolucionaria no fue suficiente

56 MOLINA ENRÍQUEZ, A. Los Grandes Problemas Nacionales. Instituto Nacional de la Juventud Mexicana,México D. F., 1964.

57 WILKIE, J. W. The Mexican Revolution: Federal Expenditure and Social Change since 1910. University of California Press, Berkeley y Los Angeles,1967; PERLÓ COHEN, M.Historia de las obras, planes y problemas hidráulicos en el Distrito Federal: 1880-1987. Taller de Investigación Nro 6, Universidad Nacional Autónoma de México, Instituto de Investigaciones Sociales, Mexico D. F.,1989.

58 CENICEROS, J. A. El Problema Social de la Insalubridad. Ediciones Botas, México D. F.,1935.

59 FUGIGAKI, L., y GONZÁLEZ GALVÁN, A., "Epidemias conocidas en México durante el siglo XX." En FLORESCANO, E. y MALVIDO E. (eds.). Ensayos sobre la Historia de las Epidemias en México. Vol. 2, IMSS, México D. F.,1982.

60 PANI, citado antes, 1916. 
para revertir "la dinámica interna de la desigualdad" que caracterizaría al período posrevolucionario. ${ }^{61}$ En realidad, la implementación práctica de los principios constitucionales, como los contenidos en el Artículo 27, pasó a ser el objeto de luchas prolongadas durante el Siglo XX y hasta hoy, irresueltas. ${ }^{62}$ En relación a los servicios esenciales de agua y saneamiento el proyecto de algunos revolucionarios como el Ingeniero Pani no tomó fuerza en la práctica hasta la década de $1970,{ }^{63}$ a pesar de los notables esfuerzos realizados durante la presidencia de Lázaro Cárdenas en la década de $1930 .{ }^{64}$ En verdad, a comienzos del Siglo XXI, la deficiencia en el acceso a los servicios de agua y saneamiento continúa siendo uno de los factores cruciales que determinan los niveles de morbi-mortalidad por enfermedades prevenibles en México, incluso en el Área Metropolitana de la Ciudad de México. ${ }^{65}$ En perspectiva histórica, la promesa revolucionaria permanece incumplida y el acceso al territorio de la ciudadanía plena continúa cerrado para una proporción muy grande de mexicanos y mexicanas. Salvando las distancias históricas particulares, el proceso de ciudadanización visto desde el mirador del agua reviste características lamentablemente similares en los países centroamericanos y caribeños. ${ }^{66}$

61 GONZÁLEZ CASANOVA. citado antes, 1965.

62 BARTRA, A., Los Herederos de Zapata. Ediciones Era, México D. F., 1985; BARTRA, R. Estructura Agraria y Clases Sociales en México. Ediciones Era, México D. F.,, 1978; TUTINO, J. citado antes, 1986; GORDILLO, G. Campesinos al Asalto del Cielo. De la Expropiación Estatal a la Apropiación Campesina. Siglo XXI, México D. F., 1988; KNIGHT, A. The Mexican Revolution. 2 vols., University of Nebraska Press y Cambridge University Press, Lincoln y Londres, 1990.

63 PERLÓ COHEN. citado antes, 1989.

64 ABOITES AGUILAR. citado antes, 1998.

65 CIFUENTES GARCÍA, E., MAZARI-HIRIART, M., FERREIRA, F., BIANCHI, F., y GONZÁLEZ, D. "The risk of enteric diseases in young children and environmental indicators in sentinel areas of Mexico City." En International Journal of Environmental Health. 2003 (en español: http://www.insp.mx/cisp/ censa/agua/trada.php); CIFUENTES GARCÍA, E., HERNÁNDEZ-AVILA, J., VENCZEL, L., y HURTADO, M. "Panorama of acute diarrheal diseases in Mexico" En Health and Place. \#5, 1999.

66 Una excepción notable en este contexto, en relación al acceso a la salud, los servicios esenciales, y la educación sanitaria es Cuba, como ha sido reconocido recientemente por el Banco Mundial: "así como una democracia que funciona adecuadamente no garantiza que la gente pobre se beneficie de los servicios públicos, algunos estados de partido único muestran buenos resultados en salud y en educación incluso en relación a la población pobre. Cuba tiene algunos de los mejores indicadores de América Latina -aunque tiene un ingreso mucho más bajo que sus pares, por ejemplo Chile 
En vista de las condiciones arriba descritas, no es de extrañar que en las últimas décadas los problemas relacionados con el acceso al agua y a sus servicios esenciales se hayan constituido en un objeto privilegiado de la lucha social y política en México y otros países. En el caso de México, por ejemplo, cuando uno observa el proceso desde fines de la década de 1970 llama la atención el nivel de conflicto social en relación a la gobernabilidad y la gestión del agua y sus servicios y la consecuente politización de las cuestiones relacionadas con el agua, que es en gran medida una respuesta del sistema político a las demandas cada vez más extendidas por parte de la población por la democratización de la vida pública, incluyendo la gestión del agua y el acceso a sus servicios esenciales. ${ }^{67}$ En este período se registró una enorme cantidad de acciones por parte de la población mexicana por cuestiones que van desde la demanda por acceder a los servicios esenciales de agua y la mejora de la calidad de dichos servicios hasta la lucha contra la corrupción en la administración del agua, pasando por una extensa gama de problemas que incluyen la contaminación de fuentes, el impacto de enfermedades relacionadas, la disputa por el control de fuentes de agua entre distintos actores sociales y políticos y, a partir de comienzos de la década de 1990, la lucha contra la privatización de las empresas públicas. ${ }^{68}$ Esta creciente movilización social en torno al agua fue correspondida por una también creciente politización del tema que se ilustra, por ejemplo, en el rol central que los problemas del agua pasaron a tener en las campañas presidenciales de la década de 1980 y, posteriormente, en las reformas institucionales que se introducirían en el sector desde comienzos de la década de 1990. Por ejemplo, candidatos presidenciales como Miguel de la Madrid Hurtado

y Costa Rica" (BANCO MUNDIAL. World Development Report 2004. Making Services Work for Poor People. Banco Mundial y Oxford University Press, Washington D.C.,2003 (http://www-wds. worldbank.org/servlet/WDS_IBank_Servlet?pcont=details\&eid=000090341_20031007150121).

67 Hemos estudiado en más detalle este caso en CASTRO (2006), citado antes. Nuestro estudio tomó como punto de partida el material empírico producido por el Programa de Investigación "Agua y Sociedad" coordinado por la Dra. María Luisa Torregrosa Armentia en el marco de cooperación establecido entre la Facultad Latinoamericana de Ciencias Sociales (FLACSO), Sede México, y el Instituto Mexicano de Tecnología del Agua (IMTA) durante la década de 1990.

68 Véase también ÁVILA, Patricia: Movimiento urbano y conflictos por el agua. en este mismo libro. 
en 1982 y Carlos Salinas de Gortari en 1988 constituyeron la cuestión del agua en uno de sus temas de campaña centrales. Durante la campaña presidencial del Partido Revolucionario Institucional (PRI) de 1982, el Ingeniero Fernando González Villarreal, quien años más tarde presidiría la recién creada Comisión Nacional del Agua (1989), presentó un discurso en la ciudad de Tuxtla Gutiérrez, Chiapas, en el que dio centralidad a "la lucha por el agua" en la búsqueda por mejorar las condiciones de vida de la población de acuerdo a los principios constitucionales. Él agregó que para lograr dichos objetivos sería necesario trascender los factores técnicos y económicos para incorporar también las cuestiones de equilibrio ecológico y justicia social. ${ }^{69}$ Años después, en la siguiente campaña presidencial del PRI (1988), el candidato Carlos Salinas de Gortari volvió a colocar los problemas del agua en el centro de su discurso. En un encuentro celebrado en Acapulco, Guerrero, en 1987, titulado "Agua, un recurso vital”, Salinas presentó lo que en gran medida constituía una repetición de los temas discutidos en la Reunión de Tuxtla Gutiérrez. ${ }^{70}$ No obstante, la influencia de los cambios políticos acontecidos en el período presidencial que culminaba (1982-88) se reflejó en el énfasis especial dado por Salinas a dos temas originales: la necesidad de crear una autoridad del agua central a nivel nacional y la determinación de cambiar el estatus del agua de bien público a bien privado y re-centrar la gobernabilidad del agua en torno a los principios de mercado. En palabras de Salinas, sería necesario "erradicar la noción válida en otras épocas de que el aire y el agua son gratuitos porque hoy ni el aire ni el agua pueden considerarse gratuitos". ${ }^{71}$ Esta premisa dominaría en lo que, posteriormente, las autoridades del agua pasarían a denominar una "nueva cultura del agua" en México. Estos dos temas constituirían pilares centrales en la política del

69 PARTIDO REVOLUCIONARIO INSTITUCIONAL - INSTITUTO DE ESTUDIOS POLÍTICOS, ECONÓMICOS Y SOCIALES. "eunión Preparatoria de Consulta Popular. La Problemática de los Servicios Hidráulicos en el Distrito Federal (Agua Potable / Drenaje). México D. F., 1982.

70 PARTIDO REVOLUCIONARIO INSTITUCIONAL - INSTITUTO DE ESTUDIOS POLÍTICOS, ECONÓMICOS Y SOCIALES. "El agua: recurso vital." En Diálogo Nacional. Revista de la Consulta Popular. México D. F., 1987.

71 PARTIDO REVOLUCIONARIO INSTITUCIONAL - INSTITUTO DE ESTUDIOS POLÍTICOS, ECONÓMICOS Y SOCIALES. citado antes, 1987. 
agua mexicana en los años subsiguientes y, en verdad, formaban parte del avance a nivel internacional de las políticas neoliberales impulsadas desde los países centrales y las instituciones financieras internacionales. ${ }^{72}$

No es este el lugar para analizar el alcance, grado de concreción y estatus real de dichas políticas en México dado el espacio limitado de que disponemos. ${ }^{73}$ En realidad, a pesar de la retórica neoliberal, cuando se compara la experiencia mexicana en el sector del agua con otros países surgen serias dudas en cuanto al alcance efectivo logrado por dichas políticas neoliberales. Por ejemplo, mientras que en Argentina entre 1993 y 1998 la proporción de la población cuyos servicios de agua y saneamiento pasaron a ser provistos por empresas privadas creció de 0 por ciento a aproximadamente 70 por ciento, en el caso mexicano la proporción no llegaba al 5 por ciento al final de dicho período, lo cual deja serias dudas sobre el alcance de dichas políticas en México. En realidad, Argentina ha sido un caso extremo, sólo comparable con el de Inglaterra, donde la privatización de 1989 abarcó al 100 por ciento de la población, o el de Chile, que constituye un caso excepcional dada la radicalidad del proyecto neoliberal en ese país. A nivel global, a fines de la década de 1990 la población cuyos servicios eran provistos por empresas privadas fluctuaba entre 5-7 por ciento. De todas maneras, lo importante en esta discusión no es en sí el alcance de las políticas de agua nominalmente neoliberales, sino la relación entre las mismas y el proceso de la ciudadanía. Terminaremos este breve artículo con una reflexión al respecto.

\section{Conclusión: el momento neoliberal en el proceso de la ciudadanía}

Volvamos brevemente al problema de la promesa incumplida de la revolución, en el caso de México, o pensando más allá de México, en la promesa incumplida de la democracia en los países llamados menos desarrollados.

72 LEYS, C.citado antes, 2001; STIGLITZ, J. E. Globalization and its Discontents. Penguin, Londres, 2002.

73 Para un tratamiento más extenso del tema por parte del autor, véase CASTRO, J. E. (citado antes, 2006), especialmente el capítulo 6. 
Aunque 'funcione adecuadamente' en el sentido electoral, para parafrasear al Banco Mundial ${ }^{74}$ en garantizar el acceso de la población a las condiciones de vida dignas, en este caso a los servicios esenciales de agua y saneamiento $y$, en general, a un ambiente limpio y saludable. En este sentido, no se puede negar, por supuesto, la validez de la crítica a los sistemas públicos por sus niveles elevados de ineficiencia, corrupción y desatención de las necesidades de las fracciones sociales marginadas del sistema, una crítica ampliamente generalizada en todos los sectores del espectro político. Sin embargo, en nuestra perspectiva las preguntas fundamentales que surgen cuando reflexionamos sobre este tema en relación al proceso de la ciudadanía son: ¿sobre qué fundamento teórico o empírico se basa una política que parte de presuponer que las fallas del sector público pueden resolverse mediante la mercantilización y la privatización de la gestión -y en casos extremos como el de Chile también de la propiedad- del agua y de los servicios derivados, como los servicios esenciales de agua y saneamiento? ¿En qué momento histórico y en qué país o región del mundo se logró universalizar el acceso a estos servicios de forma ecológica, social, económica y políticamente sostenible, sin que el Estado haya tenido que jugar un rol central en el proceso?

En este sentido, corresponde señalar que en un país como los Estados Unidos, claramente uno de los abogados más notorios, activos y poderosos en la campaña neoliberal global, el porcentaje de la población que recibe sus servicios básicos de agua y saneamiento de empresas privadas es alrededor de 15 por ciento, y los expertos de ese país pronostican que no existen posibilidades de que ese porcentaje crezca significativamente en el futuro. ${ }^{75}$ Entonces, ¿sobre qué base se puede esperar que otros países puedan cumplir esa parte de la promesa implícita en los principios de la ciudadanía liberal democrática asociada con la universalización de sus servicios básicos

74 Citado antes, 2003.

75 NATIONAL RESEARCH COUNCIL - COMMITTEE ON PRIVATIZATION OF WATER SERVICES IN THE UNITED STATES. Privatization of Water Services in the United States. An Assessment of Issues and Experience. National Academy, Washington DC, 2002 (http://www.nap.edu/cata$\underline{\log / 10135 . h t m l)}$. 
mediante la mercantilización y la privatización de los mismos, cuando eso no ha ocurrido ni ocurre siquiera en los países centrales? ¿Cómo podrían hacerlo en cualquier caso, dadas las condiciones crecientes de desigualdad socio-económica registradas en la región desde la década de 1990, que en la práctica impiden la expansión de relaciones mercantiles en el sector de los servicios esenciales ya que amplios sectores de la población se ven imposibilitados de pagar por los mismos? ${ }^{76}$

Ahora bien, un elemento central en el debate sobre el proceso de la ciudadanía en relación al agua tiene que ver con el ejercicio efectivo de los derechos, por ejemplo, en el acceso a la información sobre las decisiones cruciales en relación a cómo se gobierna el agua, quién la gobierna, o sobre cómo se decide quién y cómo se gobiernan el agua y sus servicios esenciales. En resumen, el acceso a la información necesaria para la participación social en el control, en el monitoreo de las instituciones públicas a cargo de los servicios esenciales, que en las condiciones actuales constituye un requisito central para el desarrollo de una democracia sustantiva. En este sentido, puede decirse que las políticas de reforma estatal de corte neoliberal, especialmente el desmantelamiento del sector público y la mercantilización acelerada de los servicios esenciales de educación, salud, agua y saneamiento, entre otros, tienden a eliminar los derechos de ciudadanía. Se trata de transformar lo que en una época se había definido como "derecho" en una mercancía, en nombre de lo que un sociólogo neoliberal ha denominado "la soberanía del consumidor".77

En verdad, este intento de reducir al sujeto portador de derechos civiles, políticos, y sociales al común denominador de un sujeto mercantil, el consumidor o la consumidora de mercancías, forma parte de la utopía privatista característica de las vertientes extremas del liberalismo y guarda poca relación con los procesos y los actores y actoras concretos. Como lo demuestran

76 Para ejemplos del impacto socio-económico de la privatización de los servicios de agua y saneamiento sobre los sectores mas empobrecidos, incluyendo los casos de Aguascalientes (México), Cochabamba y Buenos Aires, véase el informe comparativo de diferentes estudios de caso compilados por CRENZEL y FORTE, 2004, antes citado.

77 SAUNDERS, P., citado antes, 1993. 
las luchas en expansión en México y América Latina por la defensa del derecho humano al agua y por la provisión de servicios públicos de calidad, con control y participación social, la confrontación va mucho más allá del aparente conflicto entre "público" y "privado". Si las "amenazas" neoliberales de privatización y mercantilización creciente de la vida social desaparecieran, las razones fundamentales de la confrontación persistirían debido a la recurrente producción de la desigualdad social que caracteriza al sistema social. La expansión, extensión y profundización de una concepción de la ciudadanía que busca la democratización sustantiva de la política y la gestión del agua es una de las expresiones de dicho proceso. 


\section{Capítulo 5}

\section{Agua y gobernabilidad: entre la ideología neoliberal y la memoria histórica ${ }^{1}$}

\section{Introducción: la historia se repite}

El espíritu de la época estaba dominado por la creencia en que la iniciativa privada solucionaría todos los problemas humanos y que la empresa pública era perversa y dispendiosa por naturaleza. El resultado fue la emergencia de un nuevo tipo de crimen: el robo de agua (Ward, 1997, pág. 5).

Las frases precedentes ${ }^{2}$ podrían ser escritas en cualquier momento del futuro no tan lejano con respecto a los años ochenta y noventa del Siglo $\mathrm{XX}$, caracterizados notoriamente por el renacimiento y expansión de la ideología neoliberal y de la dinámica mercantil a escala planetaria y por su tendencia a colonizar casi todos los espacios de la vida social, incluyendo el que nos ocupa en este artículo, el de la cultura del agua. Sin embargo no es así, y la historia a la que hace referencia la cita del comienzo nos retrotrae más a bien a la Inglaterra de mediados del Siglo XIX. Allá por el año 1844, en Preston, pleno corazón del noroeste industrial del país, un periódico publicaba el siguiente "Llamado de atención a los ladrones de agua":

Ayer, Elizabeth Stubbs se presentó ante los jueces acusada de tomar agua de una de las canillas provistas por la empresa Preston Waterworks Co., sin tener un contrato previamente firmado con la compañía que la autorizara. Con todas las pruebas en su contra, se le ordenó pagar una pequeña multa más los gastos de litigio.

1 Originalmente publicado en Cuadernos del CENDES, Vol. 22, \#59, 2005, pp. 1-22.

2 Las referencias a esta historia en este y los siguientes párrafos han sido tomadas de Ward, op. cit., pp. 5-6. 
Por cierto, el de Elizabeth Stubbs fue tan sólo un caso ejemplarizante elegido convenientemente para aleccionar al número creciente de "ladrones de agua" creado por la transformación de lo que previamente era considerado un recurso de uso común en propiedad privada. En verdad, esta política no se limitaba al tema del agua, como lo demuestra la crítica del joven Marx escribiendo en 1842 sobre las leyes alemanas "castigando los robos de leña", que estaban "convirtiendo un derecho consuetudinario de los pobres en un monopolio de los ricos" (Marx, 1842: 258). ${ }^{3}$ Podríamos decir que estos eventos formaban parte de un proceso más amplio, uno de cuyos correlatos en el plano de la cultura de los grupos dominantes se daba en la cristalización de la tradición "privatista", una de las formas más extremas de la cultura asociada al libre mercado y estructurada en torno a:

la suposición de que el sector privado es inherentemente dinámico, productivo y confiable; la creencia de que las instituciones privadas son intrínsecamente superiores a las instituciones públicas para el suministro de bienes y servicios $y$, la confianza en que la eficiencia de mercado es el criterio apropiado para evaluar el rendimiento social en prácticamente todas las esferas de actividad comunitaria (Barnekov et. al., 1989:1).

3 En realidad, esta noción de que el acceso a los elementos esenciales para la subsistencia tales como el agua, los alimentos o el abrigo, constituyen un patrimonio humano universal puede hallarse en las más diversas culturas. Por ejemplo en el Islam, aunque se permite la venta del agua existe un principio por el cual no puede negarse al sediento impedido de pagarla. Una expresión material de esta tradición cultural es el zir, una vasija de cerámica que se utiliza para ofrecer agua gratuita a los caminantes. Puede verse el uso del zir en las ciudades contemporáneas del mundo islámico. La noción del agua como bien "procomunal" en la cultura hispánica, heredera de las vertientes culturales germánica, cristiana y musulmana es otro ejemplo, que además en casos como México y otros países con una amplia base indígena al tiempo de la llegada de los conquistadores se "mestizó" con las culturas del agua indígenas en las que el estatus comunal del recurso era prioritario sobre los usos privados (ver, por ejemplo, Morse, 1984; Meyer, 1997; Glick, 1970; Musset, 1991; Hundley, 1992; Cano, 1991; Lanz Cárdenas, 1982). El carácter del agua como bien público y objeto de satisfacción de las necesidades humanas esenciales también halló su expresión material en diversas formas en la cultura iberoamericana, entre las cuales obviamente son ejemplos paradigmáticos las fuentes públicas y otros instrumentos de distribución comunitaria gratuita de volúmenes de agua esenciales. 
En este sentido, el desarrollo temprano de los servicios de suministro de agua en los países europeos industrializados y en Estados Unidos estuvo estrechamente correlacionado con el auge de los ideales privatistas, e Inglaterra se constituyó en proveedora del modelo típico de servicios de suministro de agua basado en los principios del libre mercado. Existe un amplio acuerdo en la literatura respecto a este carácter privatista asumido por el desarrollo de los sistemas de suministro de agua hasta mediados del Siglo XIX en Inglaterra, Francia, EE UU y que fue exportado a otros lugares, incluyendo América Latina, con diferentes grados de éxito. Este modelo dio lugar a una proliferación de compañías de agua relativamente pequeñas que, normalmente, operaban en los centros urbanos más grandes y ricos donde, con raras excepciones, abastecían principalmente a los barrios más prósperos, una cultura elitista en la que se entendía que la provisión de agua era solamente para aquellos que podían pagarla. ${ }^{4}$

En Europa y EE UU esta cultura privatista fue desafiada desde muy temprano por un movimiento de carácter más universalista que percibía en forma creciente los impactos sociales y ambientales negativos de una sociedad centrada exclusivamente sobre los principios del libre mercado. Esta oposición fue alimentada por un complejo grupo de fuerzas políticas y sociales que incluía a algunos defensores del libre mercado, portadoras de una cultura más sensible a los procesos sociales y políticos. Por ejemplo, en 1844, el mismo año en que Elizabeth Stubbs y otros "ladrones de agua" eran perseguidos en Preston y otros lugares de Inglaterra, en la ciudad de Liverpool, Samuel Holme -un acaudalado hombre de negocios que llegó a ser líder del Partido Conservador y alcalde de la ciudad-argumentaba que:

El agua es tan esencial para la salud y el bienestar de la humanidad como lo es el aire que respiramos, y cuando la humanidad se agrupa en masas de miles de personas como ocurre crecientemente en nuestras

4 Sobre la abundante evidencia histórica existente sobre el tema, véanse, entre otros autores: Hassan (1998), Luckin (1986), Mukhopadhyay (1975), MWB (1949), y Laski et. al. (1935) para el caso de Gran Bretaña; Goubert (1986) para Gran Bretaña, Francia y Alemania; Katko (2002) para el caso de Finlandia; Ogle (1999), Warner (1987) y Schultz y McShane (1978) para EE UU. 
ciudades es esencial para la salud pública que exista una mayor provisión de agua accesible mediante una tarifa pública que sea calculada para recuperar el costo neto, no para generar tasas de ganancia privada del 30 por ciento (citado en Ward, 1997: 5-6).

Otros miembros conspicuos de las sociedades británica y europea se amalgamaron en lo que se ha dado en llamar en un sentido amplio el movimiento higienista. ${ }^{5}$ En ese período se acuñaron nociones tales como "conciencia sanitaria" o "política social" en el mundo anglosajón, Francia, Alemania, EE UU, mientras que en América Latina se desarrollaban procesos similares. ${ }^{6}$ El creciente imperativo social con relación a la necesidad de garantizar el acceso universal a la higiene y al saneamiento debió confrontar la cultura prevaleciente entre las élites económica y política de que los servicios de agua eran sólo para aquellas personas que podían pagarlos. En gran medida, el avance de esta cultura más universalista y heterogénea fue ayudada por los horrores ocasionados por las epidemias del Siglo XIX, en particular, el cólera, que no respetaban límites de clase en sus estragos. Tal como lo plantea Goubert, "por encima de especialidades o nacionalidades, existía una toma de conciencia de que si los estados nacionales querían proteger a sus hijos, debían asumir el deber de mantener a la población sana y fuerte para prevenir la procesión de enfermedades evitables" (Goubert, 1986: 103-9). ${ }^{7}$

Pero retornemos ahora por un momento al escenario de la Inglaterra industrial durante los años cuarenta. La experiencia de la ciudad de Preston, con sus alarmantes tasas de mortalidad causadas por enfermedades relacionadas con la falta de agua y drenaje sanitario condujo finalmente a la

5 Ver Finer (1997) para el caso británico; también Goubert (1986) para Gran Bretaña y Europa en general; Schultz et. al. (1978), para el caso de EE UU, que revistió características muy diferentes al movimiento europeo.

6 Ciertamente, hacia fines del Siglo XIX y comienzos del XX América Latina también jugó un papel muy importante en este movimiento y tuvo figuras muy destacadas, como la del Ing. Alberto Pani en el caso de México. Para un tratamiento más extenso del caso de México, ver Castro (2005).

7 Ver también el trabajo clásico de Karl Polanyi sobre el consenso generalizado en torno a la necesidad de regulación y control público para resolver las crisis social y económica, incluyendo la de salud pública (Polanyi, 1957: 144-150). 
decisión por parte del gobierno municipal de comprar la empresa Preston Waterworks, ya que ésta se limitaba a atender solamente un sector pequeño de la ciudad. Este tipo de medida se generalizó en Inglaterra -y también en otros países europeos y en EE UU- desde la década de los años 1840 mediante un proceso, primero de regulación creciente por medio de contratos con las autoridades locales, y. luego, tras el fracaso de la regulación como método de inducir cambios en la conducta del sector privado, la directa municipalización de los servicios de suministro de agua (Foreman-Peck y Millward, 1994; Millward, 1991). También fue dentro de este contexto que los sistemas cloacales en red fueron desarrollados a través de iniciativas públicas, ya que los empresarios privados no se involucraban en resolver el creciente desafío de la recolección, tratamiento y disposición de volúmenes cada vez mayores de "agua sucia". En resumen, puede decirse que hacia fines del Siglo XIX se había conformado una cierta cultura de carácter más universalista, compartida por sectores procedentes de las más diversas afiliaciones políticas e ideológicas, según la cual la provisión de agua y drenaje sanitario -entre otros bienes y servicios esenciales- no podía dejarse librado a las fuerzas del libre mercado sino que constituía más bien un deber social y moral que recaía necesariamente en manos del poder público.

\section{Estado, mercado y gobernabilidad}

Como resultado de una convergencia de procesos complejos, incluyendo los desarrollos sumariamente descritos en la sección previa, hacia comienzos del Siglo XX se había instalado en el mundo occidental desarrollado y, de forma creciente, en los países de la periferia capitalista, un modelo de gobernabilidad centrado en la premisa de que el Estado debía asumir un rol ordenador y director del desarrollo social. Este modelo de gobernabilidad se profundizó como resultado de las crisis de entreguerras, aún más, desde la segunda posguerra y hasta fines de la década de los setenta. En el sector del agua este desarrollo tuvo su correlación, entre otros procesos, en la formación de burocracias estatales especializadas en la gestión del recurso y sus servicios, lo que -tomando prestadas las palabras de John Dryzek- ha dado en llamarse la tradición del "racionalismo administrativo", un matrimonio 
entre el conocimiento científico de los procesos físico-naturales involucrados en la gestión del agua y la profesionalización burocrática del Estado (Dryzek, 1997). Ahora bien, mientras que por muy diversas razones en los países más desarrollados de Europa y en EE UU el modelo de la gobernabilidad centrado en el Estado permitió alcanzar el objetivo de universalizar el acceso a los servicios esenciales de agua y saneamiento, en general, en algún momento de la década de los sesenta, en la mayoría de los países periféricos el Estado "falló" en alcanzar esos objetivos. Incluso países como México, cuya constitución revolucionaria a comienzos del Siglo XX había entronizado el carácter de bien común y prioritario del acceso al agua, el avance en la universalización de servicios esenciales fue muy lento hasta la década de los setenta y, a pesar del enorme progreso realizado desde entonces, la promesa sigue siendo largamente incumplida. En otros casos donde situaciones socio-económicas más favorables habían permitido mayores avances como en Argentina, donde para 1930 se había logrado otorgar cobertura total en la provisión de agua en la Capital Federal, en las últimas décadas se han experimentado grandes retrocesos caracterizados por una desestructuración y polarización social en términos de una creciente desigualdad y exclusión de los sectores más desfavorecidos (Azpiazu et. al., 2003).

Desde la década de los ochenta - también producto de una serie de procesos bastante conocidos que no podemos discutir en detalle aquí por razones de espacio- el rol tradicional del Estado en garantizar el acceso universal a los servicios y bienes esenciales, rol que había surgido de un amplio consenso social hacia fines del Siglo XIX, pasa a ser fuertemente cuestionado y eventualmente transformado mediante las políticas de liberalización, desregulación y privatización implementadas a través del globo. Dentro de este marco, nuestro interés particular en este artículo se centra específicamente en los cambios introducidos a partir de estas transformaciones en el campo de la gobernabilidad de los recursos hídricos y de los servicios de agua y saneamiento. En particular, nos referimos a las políticas de expansión de la participación privada en el sector que han privilegiado la acción de grandes monopolios del agua privados nacionales e internacionales y, por lo tanto, las reflexiones no aplican con el mismo rigor a otras formas privadas de gestión en el sector, como por ejemplo, los pequeños vendedores de agua que 
abastecen a gran parte de la población en las grandes ciudades de los países desarrollados. Hecha esta aclaración, antes de proseguir nos detendremos brevemente para revisar lo que entendemos por "gobernabilidad" en este contexto.

Desde una cierta perspectiva, se ha argumentado que el concepto de gobernabilidad se refiere a los procesos mediante los cuales se gestionan los asuntos colectivos e involucra la articulación de reglas de conducta y el acuerdo de principios para la asignación de recursos en el marco de una comunidad política (Healey, 1997: 206). Similarmente, se enfatiza que la gobernabilidad tiene que ver con la elección de los fines y valores que deben orientar a la sociedad, así como también de los medios por los cuales se deben perseguir estos fines y valores, lo cual implica "la formación y sustento de los arreglos de autoridad y poder dentro de los cuales se toman decisiones y se implementan políticas que involucran actores individuales y colectivos en diferentes niveles territoriales (estatal, regional, municipal)" (Hanf y Cansen, 1998: 3). En este sentido, puede decirse que las transformaciones introducidas en el campo de la gestión de los recursos naturales y de servicios públicos esenciales desde la década de los ochenta, especialmente mediante las políticas de desregulación, liberalización y privatización constituyen un intento por descentrar el sistema de gobernabilidad tradicionalmente fundado sobre la premisa del rol rector del Estado y recentrarlo sobre la base de los principios del libre mercado. Esto constituye a la vez una reformulación de los fines y valores que orientan el desarrollo social, así como también el de los arreglos institucionales y de poder involucrados en la prosecución de esos fines. Clara y explícitamente esa reformulación en el caso que nos ocupa ha conducido al abandono de las metas universalistas adoptadas desde fines del Siglo XIX y su reemplazo por valores de mercado donde se intenta redefinir el estatus del agua transformando su carácter de bien público y derecho social universal en bien privado sujeto a las reglas del libre mercado. Como lo plantea un documento recientemente publicado por una de las agencias del Banco Mundial a cargo de promover la participación privada en el sector del agua, "la mayoría de los Gobiernos ha creado monopolios para la provisión de servicios de saneamiento. [...] El público se ha acostumbrado a esto y percibe a dichos servicios como 'un bien público' 
o inclusive un "bien social"' (WSP \& PPIAF, 2002: 8). Una percepción que debe ser abandonada, en la visión predominante en las instituciones internacionales, mediante la transformación del agua y sus servicios en bien económico, privado, o más llanamente hablando, en una mercancía. ${ }^{8}$

Un punto de inflexión importante en estae revitalización de los principios privatistas tuvo lugar como resultado de la Declaración adoptada en la Conferencia de las Naciones Unidas para el Agua y el Medio Ambiente en Dublín (enero de 1992), cuyo Cuarto Principio estableció que "el agua tiene un valor económico en todos sus usos y debería ser reconocido como un bien económico" (ONU, 1992). El principio en sí contiene un alto grado de ambigüedad pero a partir de éste se han derivado conclusiones con consecuencias mucho más definitivas con relación a los cambios en el sistema de gobernabilidad del recurso y sus servicios. Por una parte, no se puede negar que la introducción de principios de racionalidad económica es una condición necesaria para resolver los graves problemas de gestión en el sector. Sin embargo, el reconocimiento de que el agua tiene un valor económico no implica que el recurso (y por derivación sus servicios) deba ser conceptualizado como un bien económico ${ }^{9}$, según la teoría económica que distingue entre bienes públicos y bienes económicos, donde los segundos son aquellos en los que resulta posible excluir de su consumo a quienes no pagan. Hay un implícito -pero no muy sutil- desplazamiento de significados en esta operación, como lo demuestra la siguiente interpretación del cuarto principio de Dublín:

finalmente, en la declaración de Dublín [...] la retórica de los encuentros internacionales sobre la gestión de recursos hídricos reconoció que el agua es esencialmente un bien económico.

8 En relación con el agua, y los bienes y servicios relacionados con el medio ambiente en general, la "mercantilización" puede definirse como el proceso por el cual las relaciones entre los seres humanos y el medio ambiente son crecientemente transformadas en transacciones mercantiles y los elementos de la naturaleza crecientemente convertidos en mercancías.

9 Esto plantea el problema de la inconmensurabilidad, que no podemos discutir aquí por la brevedad de este artículo. Para un debate reciente sobre inconmensurabilidad, teoría económica y conflicto social en torno a la distribución de bienes y "males" ecológicos, véase Martínez-Alier (2002). 
[...] Esta no es una propuesta muy nueva. Los economistas interesados en la gestión de recursos hídricos han insistido por largo tiempo en la necesidad de reconocer que el agua es un bien económico y que no debe ser considerada como un bien "de importancia singular" sino más bien como un bien más entre todos los demás. [...] Si el agua es un bien económico, entonces debería ser posible gobernar su distribución por medio del mercado (Lee y Jouravlev, 1998: 7). ${ }^{10}$

El desplazamiento de significados ha sido operado y del reconocimiento de una necesidad (la de introducir principios de racionalidad económica) se ha pasado al dictado de lo que no es más que una opción de política -recentrar la gobernabilidad del recurso y sus servicios en torno a los principios de libre mercado- como si fuera la única consecuencia lógica del primer movimiento. Para estos autores, que -conscientemente o no- reflejan en ese pasaje el renovado ímpetu de la cultura privatista, racionalidad económica es equivalente a mercantilización. Una expresión más extrema de este movimiento puede encontrarse en los escritos de la especialista en Sector Privado del Banco Mundial, Penelope Brook Cowen, quien ha argumentado en favor de la "privatización desregulada", la creación de monopolios privados desregulados para los servicios de agua y saneamiento, y "laissez faire" donde "la provisión de servicios sea regulada por las fuerzas del mercado y por incentivos económicos" para resolver la crisis de estos servicios y extender su cobertura a los pobres (Brook Cowen y Cowen, 1998: 22-3, 28.). Podríamos sumar otros ejemplos a la lista, pero el propósito de esta discusión es simplemente realzar algunos de los ejes más importantes de lo que hemos caracterizado como el intento de recentrar la gobernabilidad del agua y sus servicios en función de los principios privatistas.

10 Podría iniciarse aquí un útil debate sobre las implicaciones de este tipo de posicionamiento sobre los procesos culturales, pero no tenemos el espacio para eso. De todas, formas cabe señalar la arrogancia con que se suele asumir que es posible transformar la valoración social de un cierto bien o servicio mediante ciertas operaciones "técnicas" como un cambio en la legislación de los países o la inclusión de cláusulas de condicionamiento en los préstamos otorgados por los organismos financieros internacionales. Los procesos culturales y las formas sociales de valoración de bienes y servicios han sido largamente ignorados -o minimizados- en el debate dominante, lo cual ha conducido a numerosos fracasos en la implementación de esas políticas (para una discusión de estos problemas basada en estudios de casos recientes, véase Castro (2004b). 
En este sentido, detengámonos ahora por un momento para reflexionar sobre estos procesos. En primer lugar, cabe preguntarse cuál ha sido el fundamento histórico y/o empírico que suministra la base para este renacimiento del privatismo en el sector del agua. Por ejemplo, ¿en qué lugar del planeta y en qué período histórico se logró la universalización de servicios esenciales como el agua y el drenaje sanitario mediante la acción de monopolios privados?; ¿en qué espacio histórico-social se ha registrado un proceso de universalización de estos servicios que incluya a los sectores más desposeídos de la sociedad mediante su mercantilización?; ¿qué criterios permitieron llegar a la conclusión de que las fallas evidentes observadas en la mayoría de los países menos desarrollados por parte del sector público con relación a la universalización de servicios esenciales serían subsanadas mediante la mercantilización de dichos servicios en manos del sector privado? y, ¿cuáles son los resultados observados en este sentido a partir de la implementación de estas políticas alrededor del planeta desde la década de los ochenta?

Algunas de estas preguntas han sido largamente debatidas por muchos autores y este no es el espacio para reproducir esos debates. ${ }^{11}$ En breve, sí corresponde decir que es preocupante observar cómo la historia del privatismo ha sido "rescrita" en años recientes en un aparente esfuerzo por legitimar la política neoliberal predominante en el sector del agua desde los años ochenta. ${ }^{12}$ Por ejemplo, en el Informe del Desarrollo Mundial 2004 publicado por el Banco Mundial (Banco Mundial, 2004) se presenta un breve resumen de "la participación privada en la historia" de los servicios de agua en Europa y EE UU que pasa por alto la evidencia abrumadora que existe, entre otros temas, sobre cómo la decisión de municipalizar y luego estatizar el sector del agua durante la segunda mitad del Siglo XIX fue una respuesta al fracaso del modelo privatista. En particular, nada se dice de las epidemias de cólera de mediados de aquel siglo en la ciudad de Londres, que era servida por ocho monopolios privados no regulados, ni tampoco de la falta de interés del sector privado en el desarrollo de los sistemas de drenaje

11 Hemos revisado este debate con mayor profundidad en Castro (2003).

12 Véase "Principios de la política neoliberal en el sector del agua", en el Apéndice a este artículo. 
sanitario, que fueron exclusivamente desarrollados por el sector público. Se nos dice, a modo de advertencia, que en la década de 1980 Inglaterra finalmente retornó al modelo privatista, como si se tratara del regreso de un hijo descarriado al seno del hogar. Lamentablemente, el informe tampoco reflexiona sobre la experiencia de Inglaterra desde su retorno al buen sendero, un ejercicio que permitiría introducir un mayor grado de racionalidad en el análisis, como brevemente ilustramos a continuación con materiales tomados de nuestra investigación.

\section{La experiencia de Inglaterra y Gales}

Las diez empresas de aguas y saneamiento públicas regionales de Inglaterra y Gales fueron privatizadas por el gobierno de Margaret Thatcher en 1989. Tras la privatización, se autorizó a las empresas a incrementar los precios por encima de la inflación, lo cual generó un aumento promedio del 95 por ciento durante el período 1989-1999. En una reedición actualizada del escenario de mediados de Siglo XIX , descrito al comienzo, las empresas fueron autorizadas a desconectar a los usuarios que no pagaban la factura, con lo cual entre 1990 y 1995 el número de intimaciones por falta de pago creció en 900 por ciento, mientras que tan solo en 1994 alrededor de 2 millones de hogares ( 9 por ciento del total) dejaron de pagar su factura (Herbert y Kempson, 1995; Drakeford, 2002). ${ }^{13}$ Pero el año de 1995 fue también un parteaguas, en sentido literal y simbólico, y una prolongada sequía expuso los graves problemas que afectan a las empresas privadas en la gestión de estos servicios, incluyendo falta de cumplimiento con los programas de inversión comprometidos y carencia de alternativas para resolver crisis como la producida por la sequía mencionada (Bakker, 2000).

La sequía fue el amplificador de un debate que se venía sosteniendo con relación a varios aspectos de la privatización, que van desde el problema de la desconexión y su impacto sobre la salud pública, hasta la performance

13 Es importante notar que de acuerdo con entrevistas a personal que trabajó en las empresas inglesas antes de la privatización, el problema de la falta de pago habría sido muy limitado antes de pasar a manos privadas. 
y sustentabilidad financiera de las empresas y, de gran importancia para nuestra discusión, la transparencia en la gestión y el control público de las compañías privadas, en otras palabras, algunos de los presupuestos básicos de la gobernabilidad democrática. Con relación al primer punto, tras una larga lucha por parte de diversos sectores sociales y políticos, incluyendo organizaciones como la Asociación Médica Británica, la desconexión por falta de pago fue prohibida por el Gobierno en 1997. El mismo año, el regulador económico OFWAT exigió a las empresas que redujeran el precio del servicio en un promedio de 12 por ciento en todo el país, para compensar por la acumulación de ganancias extraordinarias desde la privatización. Esto, en parte, fue una respuesta del gobierno recientemente electo del primer ministro Tony Blair al creciente descontento entre la población por los incrementos de precios y por las ganancias extraordinarias distribuidas entre los accionistas y dirigentes de las empresas privadas de agua y saneamiento. ${ }^{14}$ Sin embargo, la situación empeoró sensiblemente desde fines de la década de 1990 a tal punto que en 2004 el 20 por ciento de los hogares de Inglaterra y Gales estaban en mora en el pago de sus cuentas de agua y saneamiento, mientras que según los propios criterios del Gobierno entre 2 y 4 millones de hogares se encontraban entonces en una situación de pobreza con relación al costo de estos servicios. ${ }^{15}$

Con relación al segundo punto solamente mencionaremos aquí que las propias empresas que en 1989 habían comenzado su nueva vida como entidades privadas sin deudas, ${ }^{16}$ para 2004 habían acumulado una deuda combinada de 19 mil millones de libras esterlinas (más de 34 mil millones de dólares), dando lugar a un intenso debate en el país sobre la viabilidad del sistema privatizado en el mediano y largo plazo. En realidad, son pocos los autores -incluso entre los que favorecen la privatización de las empresas de

14 Este descontento creciente de la población fue tema regular en la prensa británica durante los años noventa. Las empresas pagaron a sus accionistas un total de 17 mil millones de libras esterlinas (casi 31 mil millones de dólares) durante el período 1990-2002 (Shaoul, 2004).

15 Sobre el debate en Inglaterra y Gales acerca de la deuda creciente de los usuarios con las empresas de agua, véanse: Fitch y Price (2002), Taylor (2002), Klein (2003).

16 El Estado británico asumió las deudas de las empresas públicas al momento de la privatización (Greene, 2002). 
agua y saneamiento- que recomiendan la aplicación del modelo privatista inglés en otras partes pero este es tema de otro debate.

Finalmente, con relación al tercer punto, la transparencia en la gestión y el control público de las empresas, fundamentos básicos de la gobernabilidad, nos referiremos en la siguiente sección ${ }^{17}$.

\section{Gobernabilidad y democracia substantiva en el sector del agua}

Como ya se dijo, la gobernabilidad tiene que ver con la elección de los criterios centrales que orientan el funcionamiento social, la adopción de ciertas metas colectivas, de ciertos valores, y de ciertos medios mediante los cuales se espera poder alcanzar esas metas colectivas. En este sentido es de gran relevancia resaltar el hecho de que en el año 2002 el Comité de Derechos Económicos, Sociales y Culturales (CDESC) de las Naciones Unidas complementó el texto del Pacto Internacional de Derechos Económicos, Sociales y Culturales declarando que el "acceso a agua limpia potable y a condiciones sanitarias adecuadas [... y a] un medio ambiente sano" es "un derecho humano fundamental e indispensable para el ejercicio de los demás derechos humanos" (ONU-CDESC, 2002; ver también OMS, 2003). ${ }^{18}$ Desde una cierta perspectiva, podemos decir que este paso representa una reafirmación de vertientes culturales más universalistas, que rechazan las formas más extremas del mercantilismo y el neoliberalismo como principios ordenadores del sistema social. En este sentido, existe una tensión fuerte entre

17 La falta de espacio nos impide referirnos a otras experiencias aparte de la británica. Véase el resumen de resultados de investigación más importantes de nuestro proyecto más reciente, donde examinamos ejemplos de participación privada en los servicios de agua y saneamiento en varios países de África, Europa y América Latina desde la década de los ochenta. Estas son tendencias generales bien documentadas, que son coherentes con los resultados obtenidos por otros colegas, y que han sido en parte corroborados por algunas de las empresas privadas multinacionales con las cuales hemos mantenido un contacto profesional a lo largo del estudio (http://users.ox.ac. uk/ prinwass/PDFs/OW04Summary_es.pdf).

18 Es importante especificar que. al momento de escribirse este artículo (agosto de 2005) este reconocimiento del carácter de derecho humano asociado a los servicios esenciales de agua y saneamiento y a un ambiente sano no ha sido todavía aceptado al más alto nivel de Naciones Unidas. Esta declaración sólo ha sido hecha hasta el momento por el CDESC de la ONU. 
los valores y el ideal de sociedad expresados en esta declaración y aquellos encarnados en el modelo privatista que se ha venido impulsando globalmente desde la década de los ochenta. En el centro de esta tensión se colocan los temas cruciales de la gobernabilidad democrática y la democracia substantiva.

Ahora bien, en el debate más reciente, el sistema de gobernabilidad democrático ha sido representado incluyendo las formas clásicas de autoridad estatal (orden jerárquico), las formas de gestión privada (competencia mercantil), y la participación social solidaria y voluntaria propia de la "sociedad civil” (por ejemplo, ver Picciotto, 1997). Frecuentemente, esta forma de entender el proceso de gobernabilidad se representa como un sistema ideal, caracterizado por relaciones simétricas de poder entre los actores centrales, a saber el Estado, el mercado y la sociedad civil (Figura 1).

\section{Figura 1}

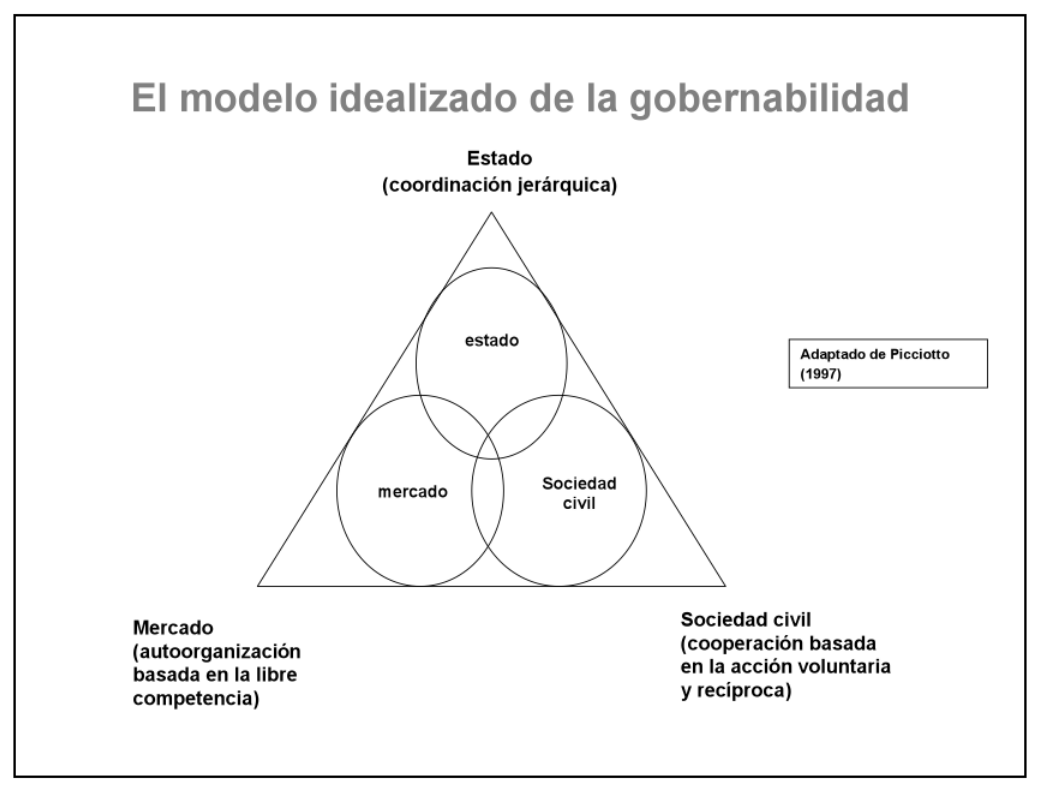

En realidad, cuando examinamos el proceso de reordenamiento del sistema de gobernabilidad que ha tenido lugar desde la década de 1980, no solamente en el sector del agua, nos encontramos que este modelo 
idealizado de la gobernabilidad oculta el hecho de que el mercado ha pasado a tener un rol dominante con relación al Estado y a la sociedad civil. En este sentido, el debate idealizado de la gobernabilidad provee un marco teórico e ideológico a la expansión del proceso de mercantilización que amenaza con abarcar todas las esferas de interacción humana (Martins, 1998), incluyendo la gestión del agua y sus servicios. Esta reificación del imperativo mercantil, que según algunos autores forma parte de un intento concertado para establecer hegemonía ideológica y política (Swyngedouw, 2000), ha tomado precedencia a tal punto que en muchos países menos desarrollados el Estado y la sociedad civil son incapaces de ejercer un rol que contrabalancee y ejerza un mínimo de control sobre las actividades privadas corporativas. Sistemáticamente hemos observado esto en nuestra investigación, especialmente con relación a la ausencia o debilidad extrema de los sistemas regulatorios en las experiencias de participación privada en los servicios de agua y saneamiento, uno de cuyos ejemplos máximos ha sido el de la concesión de la empresa municipal de agua y saneamiento en Cochabamba, Bolivia, en 1999. Sin embargo, situaciones muy similares han podido observarse en Argentina, Brasil, México, en los países de África que hemos considerado en nuestro estudio (Kenia y Tanzania), e incluso en varios países europeos.

Los acontecimientos registrados en el caso de Cochabamba en Bolivia, ${ }^{19}$ uno de los países más pobres de América Latina, nos sugieren que los planificadores de la reforma neoliberal en la gestión del agua parecen haber identificado a este país como un campo experimental ideal para sus políticas de desregulación, liberalización, y mercantilización/privatización. En septiembre de 1999 el Gobierno Boliviano otorgó una concesión de 40 años a la empresa Aguas del Tunari, un consorcio liderado por la compañía británica Internacional Water, subsidiaria de la estadounidense Bechtel, un miembro del grupo Enron, para prestar los servicios de agua y saneamiento en la Ciudad de Cochabamba. Este fue un caso único en varios aspectos: por una parte, la concesión incluyó no solamente los servicios de agua y saneamiento

19 Esta referencia al caso de Cochabamba está basada en Laurie et. al. (2003). 
sino también control sobre los recursos hídricos; por otra parte, la concesión incluía la construcción y explotación de una gran obra hidráulica, la represa Misicuni. El proceso de concesión se caracterizó desde el comienzo por la falta de transparencia y la ilegitimidad, como lo ilustra el hecho de que la propia empresa concesionaria, Aguas del Tunari, tenía base legal en las Islas Caimán, un paraíso fiscal y no en Bolivia. Aún más, la empresa fue creada con un capital simbólico de 2000 dólares mientras que recibió en concesión una empresa pública con un valor estimado en unos 110 millones de dólares. Finalmente, aunque la ley boliviana requiere la existencia de al menos tres ofertas para validar el proceso de concesión, Aguas del Tunari fue el único oferente, pese a lo cual el gobierno dio por válido el proceso. No sorprende, entonces, que protegiera estas acciones mediante una cláusula de confidencialidad que impedía el acceso a la información que la empresa consideraba crítica, lo cual incluía su modelo financiero. En cualquier caso, el hecho de que Aguas del Tunari fuera una empresa extraterritorial, sin existencia legal en Bolivia, la colocaba fuera del alcance de la legislación y de las instituciones regulatorias bolivianas.

Por estos y otros elementos que no podemos discutir aquí en detalle, Cochabamba constituye un ejemplo notable para reforzar nuestro argumento de que el modelo dominante de la gobernabilidad es principalmente un instrumento retórico para legitimar la implementación de políticas neoliberales radicales. En la práctica, la sociedad civil y los ciudadanos comunes son tratados con completo desinterés por sus preferencias y opiniones, lo cual fue particularmente cierto en Cochabamba, donde además de la falta de transparencia que caracterizó al proceso se incurrió también en un increíble grado de ignorancia con relación a los valores culturales y las instituciones de la población indígena. Sin embargo, ignorar a los actores sociales no les impidió a éstos ejercer la defensa de lo que consideraban sus derechos legítimos, y los usuarios del agua de Cochabamba tenían una larga tradición de organización y lucha en la protección de sus recursos hídricos y sus derechos de aguas. Su respuesta no se hizo esperar y en noviembre de 1999 lanzaron una serie de movilizaciones orientadas a rechazar la concesión y la acción ciudadana se generalizó después de enero de 2000 cuando la empresa privada decidió aplicar un aumento de tarifas del 35 por ciento. 
Finalmente, en marzo de 2000, y a pesar de una represión masiva lanzada por el Gobierno, la movilización social por el agua obligó a la renuncia del gabinete federal en pleno con la única excepción del Presidente de la República. La empresa Aguas del Tunari decidió dejar la concesión y, en una estrategia similar a la seguida por la empresa Aguas del Aconquija, subsidiaria del grupo francés Vivendi, en Tucumán, Argentina, decidió enjuiciar al Gobierno boliviano ante el Centro Internacional de Arreglo de Diferencias Relativas a Inversiones (CIADI) por una suma de 30 millones de dólares. El caso sigue en litigio al momento de escribirse este artículo (agosto de 2005).

El caso de Cochabamba, y otros como Tucumán y Buenos Aires en Argentina $^{20}$ son evidencia concreta de que más allá de la retórica de la gobernabilidad y la participación, la transformación de servicios públicos esenciales como los de agua y saneamiento en negocios privados se ha convertido en un fin en sí mismo y no en un medio para el alcance de objetivos de interés social más general. Por ejemplo, en el caso de Inglaterra y Gales, el principal rol del regulador económico (OFWAT) no es velar por el interés de los usuarios y garantizar que los mismos tengan acceso asegurado a los servicios esenciales sino más bien garantizar que se cumplan las condiciones para que las empresas privadas sean rentables y por lo tanto puedan continuar prestando el servicio. ${ }^{21} \mathrm{El}$ ordenamiento de los valores ha sido invertido: la viabilidad comercial de las empresas privadas se ha convertido en un objetivo social. Aunque en términos comparativos el ciudadano de Inglaterra y Gales, en principio, tiene muchos más dispositivos democráticos a su disposición para protegerse que su contraparte en la mayoría de los países menos desarrollados, su peso específico en el sistema de gobernabilidad del agua y de los servicios de agua y saneamiento es extremadamente limitado.

En cierto modo, los ciudadanos de algunas regiones de América Latina han logrado ejercer un nivel de control más importante que sus contrapartes en Gran Bretaña. Por ejemplo, cuando se tomó la decisión de privatizar las empresas en Inglaterra y Gales en 1989 las encuestas de opinión demostraban

20 Ver el artículo a cargo de Azpiazu et. al. en este mismo número.

21 Ver, por ejemplo, Schofield y Shaoul (1997). 
que alrededor del 80 por ciento de la población se oponía a la decisión, pero la decisión se tomó sin consultar ni tener en cuenta las preferencias de la ciudadanía. Como es notorio, este tipo de situación ha sido repetida numerosas veces en nuestros países, donde los procesos de privatización han sido normalmente implementados de espaldas a la ciudadanía y sin garantizar condiciones mínimas de control de la gestión de las empresas privadas. Sin embargo, cabe destacar que en el curso de nuestra investigación hemos identificado ciertos procesos de ejercicio democrático que tienden a brindar a los ciudadanos una mayor capacidad de control sobre este tipo de procesos. Por ejemplo, en la Provincia de Chaco en Argentina, en 1994 se realizó una consulta ciudadana vinculante para sondear si existía apoyo a la política de privatizaciones impulsada por el gobierno nacional del momento. Los votantes rechazaron masivamente la opción y la decisión se incorporó a la constitución provincial, que prohibió la privatización de servicios públicos en su territorio, un desarrollo de notable trascendencia dado que ocurrió en un momento en el que el gobierno federal implementaba una ola de privatizaciones aprovechando la virtual ausencia de oposición política y la gran apatía social que reinaba en el país (Roze, 2003). ${ }^{22}$

Otros ejemplos notables, quizás mejor conocidos, son los del proceso participativo en algunas municipalidades de Brasil, como Porto Alegre y Recife o la reciente reforma al marco regulatorio de los servicios de agua y saneamiento en Venezuela. ${ }^{23} \mathrm{El}$ caso de Porto Alegre es relativamente bien conocido por haber sido la cuna del modelo del presupuesto participativo que, desde la llegada del Partido de los Trabajadores al poder municipal en la década de 1980, permitió a los habitantes de esa ciudad disfrutar de un experimento de "democracia redistributiva" original y sustantivo (Sousa Santos, 1998). En el sector de los servicios de agua y saneamiento este proceso participativo permitió la virtual universalización de los servicios en la ciudad

22 Lamentablemente para la provincia de Chaco, el rechazo de la privatización por el voto negativo de sus ciudadanos llevó a la exclusión de la provincia de los beneficios del plan nacional de inversiones en agua y saneamiento, financiado parcialmente por el Banco Interamericano de Desarrollo, que incluía una cláusula condicional de préstamos a cambio de la privatización de empresas públicas.

23 Para una consideración en mayor detalle de la reforma, véase Lacabana et. al., (2004). 
en el curso de una década (Viero, 2003), lo que convirtió a la empresa municipal (Departamento Municipal de Aguas y Esgotos, DMAE) en un modelo internacionalmente reconocido de eficiencia en gestión pública. ${ }^{24}$ En el caso de la Ciudad de Recife, capital del Estado de Pernambuco, ésta tiene concesionados sus servicios de agua y saneamiento a una empresa pública estatal, la Companhia Pernambucana de Saneamento (COMPESA) desde la década de los setenta. Desde comienzos de los años 1990, particularmente a partir de 1995, Brasil impulsó una fuerte política de privatizaciones que, en el caso de las empresas de agua y saneamiento, se convirtió en una cláusula condicionante en el otorgamiento de préstamos para infraestructura. La empresa de Pernambuco pasó a ser una de las candidatas a la privatización y hacia 1999-2000 se había avanzado en el proceso preparatorio para el llamado a concurso, cuando ocurrió un hecho inesperado: el Partido de los Trabajadores (PT) ganó las elecciones municipales en Recife y en otros municipios metropolitanos con un programa de oposición a la privatización. En el año 2002, el nuevo gobierno municipal de Recife convocó a la Primera Conferencia Municipal de Saneamiento, en la cual se invitó a la población a expresar su opinión y preferencias en relación con la política de agua y saneamiento, entre muchos otros temas, y el resultado fue una decisión masiva a favor de retener los servicios de agua y saneamiento en el sector público. Ante este resultado, el gobernador estatal que favorecía la privatización decidió imponer un compás de espera y congelar el proyecto, que sigue en discusión al momento de escribirse este artículo (agosto de 2005). ${ }^{25}$

Estos y otros ejemplos nos permiten centrar el foco de atención en un aspecto central del problema de la gobernabilidad: la "participación de la sociedad civil". No podemos detenernos aquí a discutir el complejo concepto

24 El éxito del modelo de democracia participativa en Porto Alegre ha sido reconocido por el Banco Mundial (2003: 42), aunque el análisis de los expertos del banco tiende a sobreenfatizar los aspectos técnicos del modelo y presta mucho menos atención al carácter social y político del proceso. Para un análisis detallado del proceso en Porto Alegre, véanse Fedozzi (2001) y Sousa Santos (2002).

25 Entrevista del autor con el Ing. Antônio da Costa Miranda Neto, ex Secretario de Saneamiento de la Municipalidad de Recife (12-12-2003). Para una descripción de la promoción del proceso participativo en Recife véase Rocha Ferreira (2003). 
de sociedad civil aunque es necesario recalcar que ese rótulo oculta muchas veces una gran variedad de fenómenos mutuamente contradictorios. ${ }^{26}$. Tampoco podemos detenernos en el aún más controvertido concepto de "participación". Pero podemos afirmar a partir de la evidencia recabada en la investigación, que en el modelo de gobernabilidad centrado en el mercado que se ha venido instalando desde la década de 1980, la noción de participación de la sociedad civil tiende a entenderse como obediencia esperada a decisiones ya tomadas con antelación. Aspectos cruciales del ejercicio de los derechos ciudadanos esenciales, tales como el derecho a decidir quién, cómo y para quién se gobierna, quedan afuera de consideración. Por ejemplo, en el caso del agua y sus servicios derivados, el ejercicio de los derechos políticos de ciudadanía incluiría el derecho a decidir sobre quién debe gobernar esos bienes y servicios (ej.: cómo se elige a los que gobiernan el agua, quién los elige, etc.), cómo se los debe gobernar, y para quién, es decir, para el beneficio de quién. Estos son elementos cruciales y, en verdad, elementales, de la gobernabilidad del agua y sus servicios. Sin embargo, el modelo dominante tiende a agravar la indefensión ciudadana ya existente con relación al control y acceso a los bienes y servicios esenciales mediante el intento de convertirlos en bienes económicos, mercancías, que no requieren ciudadanos sino tan sólo proveedores y consumidores. Participación, en este modelo, es equivalente a obediencia y voluntad de pago.

\section{Conclusiones}

Ya no es posible, en cierto sentido y para retornar al tema del inicio, evitar la repetición de la historia y estamos observando los efectos predecibles de esta imposibilidad. El impulso de un modelo de gobernabilidad social centrado en la predominancia de los principios mercantiles ha contribuido a exacerbar las condiciones ya existentes de desigualdad y polarización social,

26 Por ejemplo, mientras que en la tradición anglosajona de libre mercado la sociedad civil es idéntica al mercado, una amalgama de individuos egoístas persiguiendo sus propios intereses, en las tradiciones republicana y comunitaria la sociedad civil tiende a representar el espacio de cooperación y solidaridad que existe entre el espacio de la competencia mercantil y el Estado. 
no solamente en los países menos desarrollados. La necesidad de introducir principios de racionalidad económica para mejorar la gestión del agua y sus servicios ha sido confundida con la introducción de la racionalidad mercantil que, a diferencia de la primera, invierte el orden de los valores y transforma en fin lo que debería ser el instrumento. En este modelo la sociedad debe garantizar las condiciones de la ganancia privada y no la iniciativa privada contribuir al alcance de las metas colectivas. A pesar de la retórica democrática y participativa que suele adornar los programas privatistas el análisis de las prácticas concretas derivadas de los mismos permite identificar los trazos de una cultura fundada en el principio de exclusión.

Sin embargo, tal como ocurriera en la Inglaterra de los "ladrones de agua”, las formas culturales de carácter más universalista suelen atravesar campos políticos e ideológicos en gran medida irreconciliables cuando lo que está en juego son elementos esenciales para el ser humano, como el acceso a los satisfactores vitales. En realidad, en otro cierto sentido, la historia nunca vuelve a repetirse. 


\section{Apéndice}

\section{Principios de la política neoliberal en el sector del agua}

a) Los recursos hídricos deberían ser asignados para su uso a través de mecanismos capitalistas de mercado; se deben crear y asignar derechos de agua privados que reemplazarán las formas colectivas y/o públicas de derechos de agua pre-existentes y que serán libremente comercializables;

b) los servicios de agua y saneamiento deben ser considerados como un bien económico, en el sentido de ser un bien privado que debe comprarse en condiciones de mercado; por definición, una vez que estos servicios sean considerados bienes privados será posible excluir de su uso a quienes no pagan por ellos; la noción de que estos servicios constituyen un bien público o un bien social debe ser abandonada;

c) los servicios de agua y saneamiento deben ser provistos por operadores privados, quienes son inherentemente más eficientes que los públicos; si es posible, estos servicios deben ser autorregulados mediante mecanismos de mercado y la regulación debe ser minimizada o, de ser posible, evitada;

d) los servicios de agua y saneamiento no constituyen un monopolio natural, tal como lo argumentan los defensores de la intervención estatal; la mayoría de las operaciones puede ser abierta a la competencia mercantil, con la única excepción, quizás, de algunas actividades centrales, aunque la introducción de mecanismos competitivos puede ser dificultada por los elevados costos de transacción; en estos casos, un monopolio privado es preferible a un monopolio público y en lo posible debe ser un monopolio no regulado;

e) los usuarios de los servicios de agua y saneamiento deben ser convertidos en consumidores y los derecho-habientes en clientes.

Fuente: Castro (2005), capítulo 6. 


\section{Referencias}

Azpiazu, Daniel, Andrea Catenazzi, Emilio A. Crenzel, Natalia Da Representaçao, Gustavo Forte, Karina Forcinito, and Juan C. Marín (2003). «Caso de Estudio Buenos Aires, Argentina», en J. E. Castro, coord. Barreras y condiciones para la participación de la empresa y el capital privados en los servicios de agua y saneamiento en Latinoamérica y África: A la búsqueda de la sustentabilidad económica, social, y ambiental (Prinwass) (http://users.ox.ac. uk/ prinwass/), Comisión Europea - 5to Programa Marco, INCO-DEV, Contrato PL ICA4-2001-10041. Oxford, Universidad de Oxford.

Bakker, Karen (2000). «Privatising water, producing scarcity: The Yorkshire drought of 1995», Economic Geography, año 76, nº 1, pp. 4 -27.

Banco Mundial (2003). World Development Report 2004: Making Services Work for Poor People (http://econ.worldbank.org/wdr/wdr2004/). Washington DC, World Bank.

Barnekov, Timothy, Robin Boyle, y Daniel Rich (1989). Privatism and Urban Policy in Britain and the United States. Oxford, Oxford University Press.

Brook Cowen, Penelope J., y Tyler Cowen (1998). «Deregulated private water supply: a policy option for developing countries». Cato Journal, año 18, no 1, pp. 21-41 (http://www.cato.org./research/natur-st.html).

Cano, G. J. (1991). «Legislación de aguas: relación entre países americanos y España», in Cehopu, Antiguas Obras Hidráulicas en América. Actas del Seminario (México, 1988), pp. 371-383. Madrid, Cehopu.

Castro, José Esteban (forthcoming 2005). Water, Power, and Citizenship. Social Struggle in the Basin of Mexico. Houndmills, Palgrave-Macmillan. 
Castro, José Esteban (2004a). «Urban water and the politics of citizenship: the case of the Mexico City Metropolitan Area (1980s-1990s)», Environment and Planning A, año 36, nº 2, pp. 327-46.

Castro, José Esteban (2004b). «Socio-political and Cultural Factors Affecting Private Participation Projects in Water and Sanitation Services», en J. E. Castro, coord. Barreras y condiciones para la participación de la empresa y el capital privados en los servicios de agua y saneamiento en Latinoamérica y África: A la búsqueda de la sustentabilidad económica, social, y ambiental (Prinwass) (http://users.ox.ac.uk/ prinwass/), Comisión Europea - 5to Programa Marco, INCO-DEV, Contrato PL ICA4-2001-10041. Oxford, Universidad de Oxford.

Castro, José Esteban (2003). «Argumentos utilizados en los programas actuales que promueven una mayor participación privada en los servicios de agua y saneamiento», en J. E. Castro, coord. Barreras y condiciones para la participación de la empresa y el capital privados en los servicios de agua y saneamiento en Latinoamérica y África: A la búsqueda de la sustentabilidad económica, social, y ambiental (Prinwass) (http://users.ox.ac.uk/ prinwass/), Comisión Europea - 5to Programa Marco, INCO-DEV, Contrato PL ICA4-2001-10041. Oxford, Universidad de Oxford.

Drakeford, Mark (2002). «Providing Water in Wales: is there a Third Way? The Welsh experience with public and private utilities and the emergence of the not-for-profit model» (http://users.ox.ac.uk/ prinwass/feb02_workshop.shtml), ponencia presentada en el Segundo Taller de Investigación - Prinwass, Private Sector Participation in Water and Sanitation: Institutional, Socio-political, and Cultural Dimensions. Oxford, St Antony's College, Universidad de Oxford. 28 de febrero de 2002.

Dryzek, J. (1997). The Politics of the Earth. Environmental Discourses. Oxford, Oxford University Press. 
Fedozzi, Luciano (2001). Orçamento Participativo. Reflexões sobre a Experiência de Porto Alegre. Porto Alegre, Tomo Editorial.

Finer, S. E. (1997). The Life and Times of Sir Edwin Chadwick. Londres, Routledge \& Thoemmes Press.

Fitch, Martin, and Howard Price (2002). Water poverty in England and Wales. Londres, Centre for Utility Consumer Law y Chartered Institute of Environmental Health.

Foreman-Peck, James, y B. Millward (1994) (Eds.). Public and Private Ownership of British Industry, 1820-1990. Oxford, Clarendon Press.

Glick, T. F. (1970). Irrigation and Society in Medieval Valencia. Cambridge, Mass., Harvard University Press.

Goubert, Jean-Pierre (1986). The Conquest of Water. The Advent of Health in the Industrial Age. Cambridge y Oxford. Polity Press y Basil Blackwell.

Greene, Joanne (2002). The England and Wales Water Industry Privatisation. A Desk Study. Londres, WaterAid.

Hanf, K. y A. Jansen (1998). (Eds.) Governance and Environment in Western Europe. Harlow, Addison Wesley Longman.

Hassan, J. (1998). A History of Water in Modern England and Wales. Manchester, Manchester University Press.

Healey, Patsy (1997). Collaborative Planning: Shaping Places in Fragmented Societies. Londres, Macmillan.

Herbert, A., y E. Kempson (1995). Water Debt \& Disconnection. Londres, Policy Studies Institute (PSI). 
Hundley, N. (Jr.) (1992). The Great Thirst. Californians and Water, 1770s-1990s. Berkeley, Los Angeles, y Oxford, University of California Press.

Katko, Tapio (2000). Water! Evolution of Water Supply and Sanitation in Finland from the mid-1800s to 2000. Tampere, Finlandia, Finnish Water and Waste Water Works Association.

Klein, Georgia (2003). Life lines: the NCC's agenda for affordable energy, water, and telephone services. Londres, National Consumer Council.

Lacabana, Miguel, Cecilia Cariola, y Verónica Carrodeguas (2004). «El Marco Regulatorio del SAPS. Oportunidades, Restricciones y Desafíos para mejorarlo. El caso de la Región Metropolitana de Caracas, Venezuela», en J. Dávila, coord. Service Provision Governance in the Peri-urban Interface of Metropolitan Areas Research Project. Londres, Development Planning Unit, University College London.

Lanz Cárdenas, J. T. (1982). Legislación de Aguas en México (Estudio histórico-legislativo de 1521 a 1981), 4 vols. Tabasco, México, Consejo Editorial del Gobierno del estado de Tabasco.

Laski, H. J., W. I. Jennings, y W. A. Robson (Eds.), (1935). A Century of Municipal Progress 1835-1935. Londres, George Allen \& Unwin.

Laurie, Nina, Carlos Crespo Flores, y Carmen Ledo (2003). «Caso de Estudio Cochabamba, Bolivia», en J. E. Castro, coord. Barreras y condiciones para la participación de la empresa y el capital privados en los servicios de agua y saneamiento en Latinoamérica y África: A la búsqueda de la sustentabilidad económica, social, y ambiental (Prinwass) (http://users.ox.ac.uk/ prinwass/), Comisión Europea - 5to Programa Marco, INCO-DEV, Contrato PL ICA42001-10041. Oxford, Newcastle y Cochabamba, Bolivia, Universidad de Oxford, Universidad de Newcastle, Reino Unido, y Universidad Mayor de San Simón, Cochabamba, Bolivia. 
Lee, Terence R., y Andrei Jouravlev (1998). Prices, property and markets in water allocation, (LC/L 1097). Santiago de Chile, Comisión Económica para América Latina y el Caribe (Cepal).

Luckin, B. (1986). Pollution and Control: a Social History of the Thames in the Nineteenth Century. Londres, Adam Hilger.

Martínez-Alier, Joan (2002). The Environmentalism of the Poor. A Study of Ecological Conflicts and Valuation. Cheltenham y Northampton, Edward Elgar.

Martins, Herminio (1998). «Risco, incerteza e escatologia -reflexões sobre o experimentum mundi tecnológico em curso», en Episteme, año 1, ํำ 1, pp. 99-121.

Marx, Karl (1842). «Debates sobre la ley castigando los robos de leña», en Carlos Marx y Federico Engels (1982), Obras Fundamentales. Vol. 1., Marx. Escritos de Juventud, pp. 248-83. México D. F., Fondo de Cultura Económica.

Metropolitan Water Board (MWB) (1949). The Water Supply of London. Londres, Staples Press.

Meyer, Michael C. (1997). El Agua en el Suroeste Hispánico. Una Historia Social y Legal-1550-1850, México D. F.: Instituto Mexicano de Tecnología del Agua y Centro de Investigaciones y Estudios Superiores en Antropología Social.

Millward, B. (1991). «Emergence of gas and water monopolies in nineteenth century Britain: contested markets and public control», in James Foreman-Peck (Ed.), New Perspectives in Late Victorian Economy: Essays in Quantitative Economic History 1860-1914. Londres, Cambridge University Press.

Morse, R. M. (1984). «The urban development of colonial Spanish America», in L. Bethell (ed.) The Cambridge History of Latin America, Vol. 2, pp. 67-104. Cambridge, Cambridge University Press. 
Mukhopadhyay, A. K. (1975). «The politics of London water», in The London Journal, año 1, nº 2, pp. 207-226.

Musset, A. (1991). De l'Eau Vive à l'Eau Morte. Enjeux Techniques et Culturels dans la Vallée de Mexico (XVIe-XIXe Siècles). París, Éditions Recherche sur les Civilisations (ERC).

Ogle, Maureen (1999). «Water supply, waste disposal, and the culture of privatism in the mid-nineteenth-century American city», in Journal of Urban History, año 25, n 3, pp. 321-347.

Organización Mundial de la Salud (OMS) (2003). El Derecho al Agua (http://www.who.int/water_sanitation_health/rightowater/es/). Ginebra, OMS.

Pani, Alberto. J. (1916). La Higiene en México. México D. F., Imprenta de J. Ballesca.

Picciotto, Robert (1997). «Putting institutional economics to work: from participation to governance» en Christopher K. Clague (Ed.), Institutions and Economic Development: Growth and Governance in Less-developed and Postsocialist Countries. Baltimore y Londres, John Hopkins University Press.

Polanyi, Karl (1957). The Great Transformation: the Political and Economic Origins of Our Time. Boston, Beacon Press.

Rocha Ferreira, Hermelinda Maria (2003), «La participación popular en la gestión de los servicios de saneamiento en Recife». Ponencia presentada en la Segunda Conferencia Internacional Prinwass Private Participation in Water and Sanitation: Tools for Exploring and Evaluating Current Policies in the Sector, México D.F, 2-3 de abril de 2003, http://users.ox.ac.uk/ prinwass/ PDFs/Rocha.PDF). 
Roze, Jorge (2003). «Estudio de Caso Chaco y Corrientes, Argentina», en J. E. Castro, coord. Barreras y condiciones para la participación de la empresa y el capital privados en los servicios de agua y saneamiento en Latinoamérica y África: A la búsqueda de la sustentabilidad económica, social, y ambiental (Prinwass) (http://users.ox.ac.uk/ prinwass/), Comisión Europea - 5to Programa Marco, INCO-DEV, Contrato PL ICA4-2001-10041. Oxford y Resistencia, Argentina, Universidad de Oxford y Universidad Nacional de Resistencia, Argentina.

Schultz, Stanley K., y Clay McShane (1978). «To engineer the metropolis: sewers, sanitation, and city planning in late-nineteenth century America», in The Journal of American History, año 65, nº 2, pp. 389-411.

Schofield, Richard, y Jean Shaoul (1997). «Regulating the water industry: by any standards?», in Utilities Law Review, año 8, nำ 2, pp. 56-70.

Shaoul, Jean (2004). «Privatization: does it hold water?». Ponencia presentada en la Escuela de Geografía y Medio Ambiente, Universidad de Oxford, 9 de junio de 2004. El Dr Shaoul tiene una lista de publicaciones caracterizadas por un análisis riguroso de la performance financiera de las empresas de agua y saneamiento privatizadas en Inglaterra y Gales que puede consultarse en: http://les1.man.ac.uk/accounting/staff/academic/J_shaoul.htm.

Sousa Santos, Boaventura de (1998). «Participatory budgeting in Porto Alegre: Toward a redistributive democracy», en Politics \& Society, año 26, no 4, pp. 461-510 (http://www.ssc.wisc.edu/ wright/santosweb.html).

Sousa Santos, Boaventura de (2002). Democracia e Participação. O Caso do Orçamento Participativo de Porto Alegre. Porto (Portugal), Edições Afrontamento. 
Swyngedouw, Erik A. (2000). «Authoritarian governance, power, and the politics of rescaling», Environment and Planning D; Society and Space, año 18, pp. 63-76.

Taylor, Pamela (2002). «Debt - a water industry issue», paper presented at the Water UK Information \& Learning Conference on "Debt Management", 16 de Julio de 2002, Londres.

Organización de las Naciones Unidas (1992). «Declaración de Dublín Sobre el Agua y el Desarrollo Sostenible», Conferencia Internacional sobre el Agua y el Medio Ambiente (http://www.wmo.ch/web/homs/documents/ espanol/icwedecs.html). Dublín, ONU.

Organización de las Naciones Unidas - Comité de Derechos Económicos, Sociales y Culturales (ONU-CDESC) (2002). Pacto Internacional de Derechos Económicos, Sociales y Culturales (http://www. unhchr.ch/spanish/html/menu3/b/a_cescr_sp.htm). Nueva York, ONU-CDESC.

Viero, Odete María (2003). «Water supply and sanitation in Porto Alegre, Brazil». Ponencia presentada en la Segunda Conferencia Internacional Prinwass Private Participation in Water and Sanitation: Tools for Exploring and Evaluating Current Policies in the Sector, México D.F, 2-3 de abril de 2003, (http://users.ox.ac.uk/ prinwass/PDFs/DMAE.PDF).

Ward, Colin (1997). Reflected in Water, A Crisis of Social Responsibility. Londres y Washington DC, Casell.

Warner, Bass (1987). The Private City: Philadelphia in Three Periods of its Growth, $2^{\text {nd }}$ ed., Filadelfia, University of Pennsylvania Press.

Water and Sanitation Program (WSP) and Public Private Infrastructure Advisory Facility (PPIAF) (2002). New Designs for Water and 
Sanitation Transactions. Making Private Sector Participation Work for the Poor (http://www.wsp.org/publications/global_newdesigns.pdf). Washington DC, WSP-PPIAF. 


\section{A normatização da prestação dos serviços de água e esgoto, a experiência de Inglaterra e Gales ${ }^{1}$}

\section{Introdução}

Este capítulo oferece uma breve introdução ao desenvolvimento da regulação no setor do saneamento ${ }^{2}$ na Inglaterra e Gales. ${ }^{3}$ A primeira seção explora os antecedentes históricos da regulação no país, com uma referência paralela a alguns aspectos da evolução dos princípios e instituições regulatórios nos Estados Unidos, já que os processos em ambos países têm importantes pontos em comum e se influenciaram mutuamente ao longo do tempo. A importância da visão histórica desses processos não deve ser excessivamente exagerada, mas um dos pressupostos principais do capítulo é que é necessário recuperar a memória histórica sobre o desenvolvimento dos serviços de saneamento especialmente nos países que tiveram sucesso para alcançar a sua universalização durante o século vinte. Os debates sobre políticas públicas e regulação com freqüência tendem a adotar uma

1 Originalmente publicado em: Alceu de Castro Galvão Junior e Marfisa Maria de Aguiar Ferreira Ximenes (eds.), Regulação: Normatização da Prestação dos Serviços de Água e Esgoto, Fortaleza, Brasil: Associação Brasileira das Agências de Regulação (ABAR) e Agência Reguladora de Serviços Públicos Delegados do Estado do Ceará (ARCE), 2008, pp. 161-201.

2 Em geral traduzi "water services" e "water and sanitation services" como "saneamento" ou "serviços de saneamento", mas, em alguns casos utilizei simplesmente "água e esgotos". Por exemplo, traduzi "Office for Water Services (OFWAT)" como "Escritório dos Serviços de Saneamento (OFWAT)", para facilitar a compreensão do leitor em português do Brasil.

3 Ainda que alguns aspectos genéricos da atividade regulatória correspondem ao Reino Unido da Grã-Bretanha (Inglaterra, Gales, Escócia, Irlanda do Norte e territórios de ultramar) em seu conjunto, a maior parte da reflexão neste capítulo baseia-se na experiência da Inglaterra e, no período mais recente (desde a privatização das empresas de saneamento em 1989) Inglaterra e Gales. Em muitos aspectos os casos de Escócia e Irlanda do Norte têm características diferentes (por exemplo, as empresas de saneamento não foram privatizadas). 
visão estritamente técnica que tende a excluir as lições históricas e não consideram adequadamente a relevância dos aspectos sócio-econômicos e políticos nesse desenvolvimento. A segunda seção examina mais em detalhe a estrutura e desenvolvimento da regulação do setor de saneamento desde a sua privatização, implementada em 1989, e oferece uma breve síntese do estado atual do debate e dos principais problemas que enfrenta o setor. As reflexões se baseiam principalmente nos resultados do projeto de pesquisa PRINWASS (www.prinwass.org), coordenado pelo autor, que entre outros casos considerou a experiência de reformas profundas introduzidas nos serviços de saneamento na Inglaterra e Gales particularmente a partir da privatização das empresas do setor em 1989.

\section{0 desenvolvimento da regulação na perspectiva histórica}

$\mathrm{Na}$ Inglaterra y nos Estados Unidos a regulação se desenvolveu a partir da necessidade de estabelecer controles sobre o fornecimento de bens e serviços como a distribuição de água e gás para uso doméstico por parte de empresas privadas durante a segunda metade do século dezenove (ForemanPeck e Millward, 1994; Newbery, 1999). Essas empresas eram pequenos monopólios que operavam sem regulação e que serviam em geral os bairros mais ricos nas cidades importantes. A necessidade de estabelecer controles rígidos sobre a atividade desses monopólios privados não regulados foi resultado em grande medida ao crescente mal-estar do público usuário pelo caráter insatisfatório (em qualidade, preços, cobertura, etc.) dos serviços prestados e pela necessidade de estendê-los ao conjunto da população, uma tarefa que não era assumida pelas empresas privadas e exigiu a ação decisiva do estado (uma breve análise da literatura existente sobre este tema pode ser consultada em Castro, 2005 e Castro et. al., 2003).

Mesmo que alguns setores liberais interpretaram o movimento a favor de uma maior regulação da vida econômica e social que começou no século dezenove como uma conspiração antiliberal e como um ataque à democracia, o fato é que as forças sociais e políticas que pugnavam pela introdução de uma regulação estrita eram muito heterogêneas e incorporavam a 
proeminentes representantes do pensamento liberal e, inclusive, a convencidos defensores do laissez faire que no entanto apoiavam uma maior regulação e intervenção estatal como meios para garantir a preservação do mercado e da propriedade privada. Naturalmente, as lutas dos trabalhadores por melhorar suas condições de trabalho e de vida e pela ampliação dos direitos de cidadania tiveram um papel decisivo nesse processo (Marshall, 1963). Não surpreende então que a introdução de uma política regulatória crescentemente estrita contasse com um amplo consenso e abrangesse praticamente todos os aspectos da vida social e econômica, com apelos à imposição de padrões mínimos de qualidade, o controle dos preços dos alimentos, a vacinação obrigatória das crianças, a cobrança de impostos para estender as redes de abastecimento de água e gás nas cidades, ou a proibição do trabalho infantil e da tortura dos trabalhadores por parte dos patrões, entre muitos outros temas (Polanyi, 1957: 144-150).

$\mathrm{Na}$ Inglaterra, o processo de crescente regulação dos serviços públicos se desenvolveu a partir de meados do século dezenove com a assinatura de contratos entre governos municipais e fornecedores privados que obtinham direitos de exploração de monopólios como a distribuição de gás e água com a condição do cumprimento de padrões de qualidade previamente estipulados e sujeitos a um controle de preços (Millward, 1991). No entanto, por volta do fim do século dezenove se havia chegado à conclusão de que a regulação de monopólios privados era insuficiente para garantir a qualidade dos serviços e, particularmente, para incentivar a expansão da cobertura em um contexto de rápido crescimento urbano e populacional e ameaças permanentes de epidemias. Eventualmente a solução adotada foi a municipalização dos serviços, e por exemplo a Cidade de Londres em 1902 decidiu reunir os oito monopólios privados de água que serviam a metrópole e substituí-los por uma empresa sob controle público, enquanto em outras regiões do país ocorriam processos similares (MWB, 1949; ver também Laski et. ao., 1935; Hassan, 1998). É bom frisar também que os monopólios privados se haviam concentrado na captação e distribuição de água "limpa", mas praticamente não participaram no desenvolvimento dos serviços de coleta e evacuação de esgotos e na proteção de bacias, atividades que foram desenvolvidas a partir da iniciativa do setor público às vezes secundada, como no 
caso da proteção ambiental, por organizações sem fins de lucro (Antonelli, 1992; Finer, 1952; Luckin, 1986).

Mas, as razões pelas quais os monopólios privados de água foram paulatinamente substituídos por empresas municipais não se limitavam à necessidade de elevar a qualidade dos serviços e estendê-los ao conjunto da população, já que além disso existiam o que podemos denominar fatores e condicionantes sistêmicos externos ao setor do saneamento, por exemplo considerações de caráter financeiro e político, que em grande medida determinavam o curso de ação que inexoravelmente conduzia a níveis crescentes de regulação e intervenção pública direta. Como indicou recentemente um analista do processo de municipalização de fins do século dezenove na Inglaterra, a propriedade municipal

fornecia apoio político local ao manter os preços em níveis razoáveis enquanto gerava ganhos para financiar os bens públicos locais e reduzir a carga dos impostos locais. Esse equilíbrio político-econômico outorgou voz política aos consumidores, e aos políticos poder econômico, enquanto os ganhos beneficiavam os dois. [...] Com o poder crescente da classe trabalhadora emergente, com ou sem democracia, chegaram demandas para aceder a esses serviços a preços "justos" - preços que a maioria da população pudesse pagar. As preocupações políticas se deslocaram da saúde e a segurança para a eqüidade e a eficiência [...]. o processo político, seja local ou central, estava inevitavelmente envolvido na regulação desses serviços públicos. Os verdadeiros problemas surgiram quando o processo político foi capturado por aqueles que viram que a necessidade de regular os serviços públicos em rede oferecia a oportunidade de redistribuir renda e adquirir poder de patronato (Newbery, 1999: 19-22).

Desse modo, podemos dizer que na Inglaterra o processo de desenvolvimento da regulação e, crescentemente, da intervenção estatal direta no fornecimento de serviços de água em rede e de coleta e evacuação de esgotos (assim como outros serviços públicos essenciais) desde fins do século dezenove foi o resultado da convergência de um número de fatores 
tanto internos como externos ao setor de saneamento propriamente dito. Como enfatizaremos novamente mais adiante, este é um elemento analítico importante para compreender o desenvolvimento da regulação, não só no passado mas também na conjuntura atual.

\subsection{0 caso dos Estados Unidos}

Paralelamente ao desenvolvimento da regulação dos serviços públicos essenciais na Inglaterra é importante considerar também o caso dos Estados Unidos, entre outras razões porque os processos em ambos países compartilham uma base jurídica comum e se influenciaram mutuamente ao longo do tempo. Convencionalmente se divide o desenvolvimento da regulação nos Estados Unidos em três períodos principais. A primeira etapa que teve lugar aproximadamente entre 1870 e 1930 e que inclui a criação da primeira instituição regulatória em 1887, a Comissão Interestatal de Comércio, que teve continuidade com uma série de entidades similares criadas nas décadas de 1910 e 1920. Uma segunda etapa se desenvolveu dentro do marco das políticas do New Deal implementadas pelo Presidente Franklin Roosevelt nos anos 1930 como resposta à Grande Depressão de 1929, um período durante o qual o setor privado apoiou consistentemente a aplicação de políticas regulatórias com o objetivo de proteger as condições do mercado e a propriedade privada em momentos de grande turbulência social e econômica. Uma terceira etapa, mais recente, estaria caracterizada por aquilo que alguns chamam de "regulação social", fazendo referência à extensão do braço regulatório para cobrir novas áreas tais como os padrões de saúde, de segurança e de qualidade ambiental, aspectos que foram ganhando importância desde a década de 1970 (Peters, 1998: 55-60). Mais amplamente, os processos desde a década de 1980, e em grande medida sob a influência dos Estados Unidos e a Grã-Bretanha, se caracterizaram por um agressivo retorno das políticas ultra-liberais que consideram a regulação como um obstáculo às liberdades privadas e ao espírito empresarial e defendem a desregulação e liberalização das atividades econômicas a partir do argumento de que a regulação é ineficiente e que o mercado pode ser auto-regulado efetivamente sem necessidade de intervenções burocráticas. 
Apesar da existência de pontos de contato fundamentais no desenvolvimento da regulação nos Estados Unidos e na Inglaterra, a evolução dos princípios e instituições regulatórias no primeiro seguiu um caminho bastante diferente do caso inglês, e em particular se destaca o papel central do poder judiciário nesse processo. Neste sentido, a Corte Suprema de Justiça estabeleceu uma série de princípios regulatórios fundamentais seguindo a Lei Comum anglo-saxona (Common Law), pela qual se afirmava que a regulação é necessária para proteger o interesse público e para corrigir problemas de concorrência imperfeita como os derivados da existência de monopólios naturais no fornecimento de serviços em rede como a água. Um desses princípios introduzidos para justificar a regulação estatal é que as companhias que fornecem serviços públicos estejam legalmente dentro do domínio público, desempenhando uma função pública, e portanto estão sujeitas a regulação. Por exemplo, uma regulamentação da Corte Suprema em 1877, relacionada com uma disputa sobre ferrovias, sentava este princípio da seguinte forma:

Quando o dono da propriedade a destina para um uso no qual o público tem certo interesse, ele de fato outorga ou cede ao público um interesse nesse uso, e debe até o ponto desse interesse, se submeter a ser controlado pelo público, para o bem comum, sempre e enquanto mantiver o uso (U. S. Supreme Court, 1877).

Outro exemplo tem a ver com o princípio de equilíbrio entre o respeito constitucional à propriedade privada e a proteção do interesse público, pelo qual se supõe que as companhias privadas não devem receber taxas de retorno desproporcionadas que beneficiem seus acionistas em prejuízo dos usuários. Por exemplo, em 1904 a Suprema Corte justificava a fixação de um limite à taxa de retorno de uma companhia de água privada na Califórnia da seguinte maneira:

O fato de fixar as tarifas de água de modo tal que dêem um ganho de seis por cento sobre o valor da propriedade que é usada com o propósito de fornecer água segundo prevê a lei, 
não é confisco, nem tomar a propriedade sem o devido processo legal, nem a negação da proteção equitativa das leis, ainda que, anteriormente a isto, se tenha permitido à companhia fixar tarifas que lhe assegurariam entre um, e um e meio por cento de retorno mensal sobre o capital investido no empreendimento. Se isso não é obstaculizado por um contrato inalterável, sempre e quando receber certa compensação, pensamos que uma lei que reduz a compensação até aqui permitida a seis por cento do presente valor da propriedade utilizada pelo público, não é inconstitucional. Não há nada de confiscatório nisso.

O custo original pode ter sido muito grande, podem ter sido cometidos erros de construção, mesmo que sem intencionalidade, aumentando o custo; pode ser que se tenha adquirido mais propriedade que a necessária para o propósito original. Outras circunstâncias podem existir que demonstrem que as tarifas originais são muito altas para uma compensação justa ou razoável no presente. Não obstante estes fatos, se pretende dizer que os acionistas da companhia vão ter direito a dezoito por cento sobre esse custo para sempre ou que a redução desse percentual, como está prevista na ata de 1885 , os destitui da propriedade, violando as previsões da Constituição Federal? Nós achamos que não (U.S. Supreme Court, 1904; veja também: U.S. Supreme Court, 1912).

Outro caso que envolveu à Knoxville Water Company em 1909 previa que haveria uma crescente necessidade de regulação nos próximos anos e discutia os problemas intrínsecos que enfrentam os reguladores que precisam preservar o equilíbrio entre os interesses privados e públicos. Ao mesmo tempo em que defendia a "santidade da propriedade privada" como fundamento do sistema social, a sentença da Corte Suprema neste caso confirmava o direito dos cidadãos a ter acesso aberto à informação sobre as operações das companhias privadas concessionárias de serviços públicos:

O regulamento das corporações de serviço público que desempenham suas tarefas sob condições de monopólio necessário, se exercerá com maior freqüência com o correr do tempo. É uma função delicada e perigosa, e deveria ser exercida com 
um agudo sentido de justiça por parte do corpo regulatório, em conjunto com uma abertura por parte da companhia a ser regulada. [...] Nosso sistema social descansa em grande parte na santidade da propriedade privada, e aquele estado ou comunidade que busque invadi-la rapidamente descobrirá o erro no desastre provocado. O mais leve ganho que o consumidor obteria pela redução das tarifas cobradas pelas corporações de serviços públicos não é nada comparado com sua parte na ruína que se suscitará ao negar-lhe à propriedade privada sua justa recompensa, desestabilizando valores e destruindo a confiança. Por outra parte, as companhias a serem reguladas encontrarão útil para seu interesse perdurável facilitar livremente a informação que sirva como fundamento para uma regulação justa (U. S. Supreme Court, 1909).

À margem das implicações políticas e ideológicas que podem identificar-se nesta e em outras sentenças da Corte Suprema, elas contribuíram no longo prazo ao estabelecimento de uma sólida tradição regulatória nos Estados Unidos, muitos de cujos princípios seguem tendo clara relevância contemporânea e influenciaram o desenvolvimento da regulação em muitos outros países. Um aspecto importante que cabe destacar é que a regulação era claramente percebida como um instrumento necessário para preservar o funcionamento do sistema capitalista e, em particular, a propriedade privada, apesar de que alguns setores empresariais e intelectuais liberais tendiam a criticar o avanço da regulação das atividades privadas como um ataque às liberdades individuais e, em última instância, ao sistema democrático. Este é um aspecto importante porque as tensões geradas ao interior do sistema capitalista em relação à regulação persistem até os nossos dias e permeiam em grande medida os debates contemporâneos, incluindo o debate atual no Brasil sobre a nova Lei de Saneamento (Lei ${ }^{\circ}$ 11.445/2007) e sobre as formas institucionais e alcance que deve adotar a atividade regulatória.

Finalmente, outro ponto que convém enfatizar novamente é que mesmo que os processos de desenvolvimento da regulação de serviços públicos básicos na Inglaterra y nos Estados Unidos se influenciaram mutuamente ao longo da história, ao mesmo tempo existem diferenças significativas 
entre ambos. Em particular, o poder judiciário não tem jogado um papel tão preponderante na Inglaterra como nos Estados Unidos e alguns autores argumentaram que na Inglaterra a negociação e o entendimento mútuo entre o governo e o setor privado sustentaram o desenvolvimento de um modelo regulatório "negociado", que contrasta com o caráter litigioso que caracteriza o caso dos Estados Unidos (Wilks, 1998). Esse é um aspecto importante para alcançar uma melhor compreensão do desenho e funcionamento do sistema regulatório existente no setor de saneamento na Inglaterra contemporânea.

\section{2 Racionalismo administrativo vs. Racionalismo econômico-mercantil}

O desenvolvimento da regulação e a crescente intervenção estatal direta na economia se acentuaram depois da primeira Guerra Mundial e, particularmente, depois da Grande Depressão de 1929, quando se expandiu o consenso a respeito de que o estado devia desempenhar um papel crucial para assegurar o crescimento econômico e a eqüidade social. No setor da água, o processo tomou a forma de uma crescente centralização dos serviços em mãos dos estados nacionais, com a criação de burocracias públicas organizadas hierarquicamente sobre a base da união entre conhecimento científico e excelência administrativa, no caso de instituições como o Bureau of Reclamation e o Corps of Engineers nos Estados Unidos (Lee 1999: 44). Esse processo forma parte do desenvolvimento da tradição que John Dryzek chamou o "racionalismo administrativo" (Dryzek, 1997) caracterizado por um papel central do estado na regulação e/ou intervenção direta dos serviços públicos essenciais - funções que os críticos da intervenção estatal tendem a denominar de "comando e controle"-, uma tradição que no setor da água foi em grande parte dominada por expertos em engenharia, em ciências do meio ambiente, e outras disciplinas relacionadas, que jogaram um papel-chave no desenvolvimento das estruturas e mecanismos regulatórios assim como nos padrões de monitoramento dos serviços.

Este modelo de regulação estatal, baseado na noção de que a intervenção governamental é necessária para assegurar o interesse público 
frente aos interesses privados, esteve fortemente associado às teorias da economia do bem-estar (Welfare Economics) e deu lugar ao desenvolvimento de um corpo de teoria regulatória que se conhece geralmente como a teoria normativa da regulação. A teoria normativa considera que é possível chegar em um resultado ótimo em um determinado problema, por exemplo o problema do acesso equitativo a serviços públicos essenciais, a partir de decisões baseadas em um julgamento justo e ético sobre quais são as melhores soluções disponíveis para alcançar o bem-estar social independentemente das preferências individuais dos atores. As noções de bem-estar social e interesse público, e a pressuposição de que as instituições públicas constituem o instrumento fundamental para garantir que os objetivos serão atingidos, ocupam um lugar central na teoria normativa da regulação, que jogou um papel crucial no desenvolvimento dos princípios e instituições regulatórias (Newbery, 1999).

Mas, os pressupostos e princípios da teoria normativa foram criticados desde o começo por uma tradição de autores que, genericamente, representam o que se deu em chamar teoria regulatória positiva, que rejeita a validade de conceitos como "bem-estar social" e "interesse público" que são o ponto de partida das teorias normativas (Newbery, 1999: 136-7). Essa tradição tem fortes pontos de contato com o que Dryzek denominou o "racionalismo econômico" (Dryzek, 1997), especialmente na sua versão extrema que favorece o desmantelamento das funções de controle e regulação públicas e o retorno ao modelo ultraliberal do laissez faire/laissez passer que preconiza a capacidade auto-reguladora do mercado. Esses autores rejeitam a noção de que o setor público seja inerentemente um maximizador benevolente do bem-estar social, e apóiam seu argumento na evidência empírica que sugere que pelo contrário com freqüência o setor público é mais um obstáculo que uma ajuda. Por exemplo, esses críticos argumentam que no setor da água após várias décadas de intervenção o estado fracassou na obtenção de suas metas, especialmente no que se refere à regulação econômica (Lee, 1999: 41-2). Esses autores desenvolveram uma série de argumentos fundados nas noções de falhas "de governo", "burocráticas" ou "regulatórias", onde a presunção principal é que longe de ser o guardião do bem público, o estado se encontra sujeito a princípios similares àqueles prevalecentes 
no setor privado. Por exemplo, o economista William Niskanen, um estudioso do comportamento burocrático que exerceu uma grande influência nos recentes debates acadêmicos e políticos a favor da desregulação, liberalização e privatização dos serviços públicos, aplica os fundamentos da economia neoclássica sobre os agentes econômicos à análise da burocracia: os burocratas segundo esse modelo são atores racionais que atuam em princípio por interesse próprio e buscam maximizar seus objetivos particulares (Niskanen, 1968; 1971; ver também Jackson, 1982; 1985). No caso das burocracias da água, críticos dentro desta linha de argumentação assinalaram que enquanto as teorias normativas do interesse público rara vez levam em conta que os funcionários públicos podem estar perseguindo seus próprios objetivos e não necessariamente procurem maximizar o bem-estar social através de suas ações, a teoria positiva parte do pressuposto de que os funcionários públicos têm objetivos alternativos, genericamente definidos como a busca de rendas individuais, o que costuma ter um impacto negativo nos processos de administração da água e seus serviços (Lee, 1999: 43).

Se bem indubitavelmente a teoria positiva da regulação conta no seu favor com uma abundante base empírica para fundar sua crítica à burocracia e, correspondentemente, à teoria normativa, as conseqüências que se derivam dela em termos de políticas concretas são o objeto de um debate inacabado e provavelmente inacabável. Em particular, essa abordagem que parte da consideração de que a regulação é desnecessária no melhor dos casos e no pior um obstáculo ao crescimento e ao desenvolvimento econômico inspirou reformas radicais no setor da água em nível mundial desde a década de 1980, momento em que nos Estados Unidos e na Grã-Bretanha começa a se promover uma política radical de desregulação, liberalização e privatização dos serviços públicos, que em teoria se propunha substituir a racionalidade administrativa por uma racionalidade fundada na assim chamada livre concorrência das forças do mercado autoregulado. ${ }^{4} \mathrm{O}$ argumento que prevaleceu neste novo contexto foi resumido por Newbery:

4 Este debate não é meramente uma divagação acadêmica e pelo contrário é de grande relevância para compreender os processos contemporâneos que têm lugar no setor do saneamento no Brasil e na América Latina em geral. Por uma parte, argumentamos em outros trabalhos (ver por 
A introdução da concorrência dentro dos serviços públicos em rede anteriormente monopolizados e regulados é o chave para alcançar os benefícios plenos da privatização. A privatização parece ser necessária, mas não é suficiente. A regulação é inevitavelmente ineficiente, o que sugere que seja confinada ao núcleo do monopólio natural da rede. Sempre que a concorrência for efetiva, pode substituir à regulação dos serviços em rede e assim aumentar sua eficiência (Newbery, 1999: 386). ${ }^{5}$

Mas, na prática, e em perspectiva histórica, esse processo não produziu a transformação radical no âmbito regulatório tal como se preconizava no papel e, de fato, em alguns casos os serviços públicos privatizados foram sujeitos a uma regulação pública ainda mais estrita, ou ré-regulaçao (Swyngedouw, 2009), como é o caso dos serviços de saneamento na Inglaterra e Gales desde sua privatização em 1989 (Hogwood, 1998; mas veja também Taylor, 1999, 2002; também Schofield e Shaoul, 1997 e Shaoul, 1998), que consideramos a continuação.

exemplo Castro, 2005, 2007a,b,c,, 2008) que a crescente influência do racionalismo econômico extremo, estreitamente vinculado com algumas posições derivadas da teoria positiva da regulação, influenciaram as políticas de reforma no setor do saneamento na América Latina e outras regiões desde a década de 1980 com chamados ao desmantelamento da intervenção pública e do regulamento e, como recomendara uma especialista em saneamento do Banco Mundial, a transferência dos serviços a "monopólios privados não regulados" (Brook Cowen e Cowen, 1998; Brook Cowen, 1997; ver também Richard e Triche, 1994; Foster, 1998, 1999; Zerbe e McCurdy, 2000). Sobre as conseqüências dessa política que têm grande relevância para o caso de Brasil, ver entre outros Solanes $(1999,2002)$.

5 Dado o breve espaço deste artigo não podemos estender-nos neste ponto, mas cabe assinalar que a partir desse tipo de argumentos se desenvolveu um extenso debate sobre as diferentes formas de "competitividade" que podem ser introduzidas na gestão dos serviços de saneamento e seu alcance relativo. Ver, entre outros, Lee (1999), Beato e Laffont (2002). Para o caso da Inglaterra e Gales ver por exemplo: OFWAT $(2000,2007,2008)$, Vass (2002) e, para uma avaliação crítica recente ver Yarrow et. al. (2008). 


\section{A regulação das empresas de saneamento privatizadas na Inglaterra e Gales ${ }^{6}$}

A estrutura atual do setor do saneamento na Inglaterra e Gales se estabeleceu em 1989 com a privatização das dez empresas regionais de água e esgoto nesse ano, sancionada pelo Ata da Água de 19897, que foi revisada logo depois e eventualmente substituída pela legislação subseqüente (Tabela 1). O sistema implementado então contemplava a propriedade e operação privadas das empresas (full divestiture), e mesmo que tenham ocorrido mudanças significativas que consideramos nas seguintes páginas em termos gerais, o modelo se manteve até o momento de redigir este capítulo. Um dos aspectos destacáveis é a expansão da atividade e instituições regulatorias a partir da privatização, que derivou em um complexo sistema composto por entidades do governo de diferentes níveis e a criação de um novo tipo de organismos híbridos curiosamente denominados "quasi non governamentais" (que passaram a conhecer-se como QUANGOS, sigla em inglês para "quasi ímpar governmental organizations") ou também “entidades públicas não departamentais”.

6 Como foi antecipado no início, nos concentramos principalmente no caso da Inglaterra e Gales porque Escócia e Irlanda do Norte seguiram um caminho diferente (entre outras questões, as empresas de saneamento só foram privatizadas na Inglaterra e Gales), mesmo que em diversos aspectos o sistema regulatório se aplica em general ao Reino Unido no seu conjunto.

7 Adicionalmente a estas dez empresas públicas regionais existiam na Inglaterra 29 pequenas empresas privadas que forneciam água somente (não coleta de esgotos) para cerca de 25 por cento da população, algumas das quais tinham subsistido desde o século dezenove. Essas empresas não foram incluídas na reorganização de 1989 mas com o tempo foram sendo fusionadas através de aquisições por parte de investidores nacionais e estrangeiros. 


\section{Tabela 1. Peças de legislação chave que governam a gestão dos serviços de saneamento na Inglaterra e Gales desde a privatização de 1989}

\begin{tabular}{|c|c|c|c|}
\hline Ano & Lei & Assunto & Medidas Relevantes \\
\hline 1989 & Ata da Água & Privatização & $\begin{array}{l}\text { Transferência das funções relativas aos serviços de água } \\
\text { e esgotos aos operadores privados; criação da NRA e } \\
\text { OFWAT }\end{array}$ \\
\hline 1991 & $\begin{array}{l}\text { Ata da Indústria da } \\
\text { Água }\end{array}$ & Organização e regulação & $\begin{array}{l}\text { Substituiu a Ata da Água de } 1989 \text {. Atribuiu poderes e } \\
\text { responsabilidades para a regulação da qualidade da } \\
\text { água para consumo humano na Inglaterra a Secretaria } \\
\text { de Estado de Ambiente, Transportes e as Regiões, e em } \\
\text { Gales a Secretaria de Estado para Gales }\end{array}$ \\
\hline 1991 & $\begin{array}{l}\text { Ata de Recursos } \\
\text { Hídricos }\end{array}$ & $\begin{array}{l}\text { Proteção dos recursos } \\
\text { hídricos }\end{array}$ & $\begin{array}{l}\text { Outorga de poderes e definição clara das } \\
\text { responsabilidades da NRA }\end{array}$ \\
\hline 1991 & $\begin{array}{l}\text { Ata que institui as } \\
\text { Obrigações } \\
\text { das Companhias }\end{array}$ & Organização e regulação & $\begin{array}{l}\text { Estabelece os direitos e obrigações estatutárias dos } \\
\text { operadores privados }\end{array}$ \\
\hline 1992 & $\begin{array}{l}\text { Ata de } \\
\text { Competitividade nos } \\
\text { Serviços Públicos }\end{array}$ & $\begin{array}{l}\text { Marco regulatório } \\
\text { para a competitividade } \\
\text { comparativa e de } \\
\text { mercado }\end{array}$ & $\begin{array}{l}\text { Estabelece o rol do regulador econômico e as obrigações } \\
\text { dos operadores privados em relação a competitividade } \\
\text { orientada a melhoria da eficiência do sector }\end{array}$ \\
\hline 1995 & Ata do Ambiente & $\begin{array}{l}\text { Proteção de recursos } \\
\text { hídricos }\end{array}$ & Criação da Agência do Ambiente (Environment Agency) \\
\hline 1998 & Ata de Pesticidas & $\begin{array}{l}\text { Proteção de fontes de } \\
\text { água para consumo } \\
\text { humano }\end{array}$ & $\begin{array}{l}\text { Revisão da Ata de Alimentos e Proteção Ambiental de } \\
1985\end{array}$ \\
\hline 1998 & $\begin{array}{l}\text { Ata de } \\
\text { Competitividade }\end{array}$ & $\begin{array}{l}\text { Marco regulatório } \\
\text { para a competitividade } \\
\text { comparativa e de } \\
\text { mercado }\end{array}$ & $\begin{array}{l}\text { Introdução de políticas anti-monopólio; outorga } \\
\text { maiores poderes ao regulador econômico (OFWAT) } \\
\text { para aplicar políticas antimonopólio; dá incentivos para } \\
\text { melhorar a competitividade comparativa e de mercado }\end{array}$ \\
\hline 1999 & $\begin{array}{l}\text { Ata de Prevenção } \\
\text { e Controle da } \\
\text { Contaminação }\end{array}$ & $\begin{array}{l}\text { Proteção contra a } \\
\text { contaminação ambiental }\end{array}$ & $\begin{array}{l}\text { Implementação da norma 96/61/EC da União } \\
\text { Européia relativa à prevenção e controle integrais da } \\
\text { contaminação }\end{array}$ \\
\hline 1999 & $\begin{array}{l}\text { Ata da Indústria da } \\
\text { Água }\end{array}$ & $\begin{array}{l}\text { Organização e regulação } \\
\text { do sector }\end{array}$ & $\begin{array}{l}\text { Proibição de corte por falta de pagamento; revisão } \\
\text { dos métodos de faturamento (impulso à instalação de } \\
\text { medidores) }\end{array}$ \\
\hline 1999 & $\begin{array}{l}\text { Regulações para } \\
\text { o Planejamento } \\
\text { Regional (Town and } \\
\text { Country Planning na } \\
\text { Inglaterra e Gales) }\end{array}$ & Proteção ambiental & $\begin{array}{l}\text { Implementação da Norma Européia introdutória de } \\
\text { Estudos de Impacto Ambiental para projetos que } \\
\text { envolvem recursos hídricos }\end{array}$ \\
\hline 2003 & Ata da Água & Organização e Regulação & Modifica a Ata da Água de 1991 \\
\hline
\end{tabular}

Existem, também, três códigos estatutários de conduta que regulam a) obrigações em relação a atividades ambientais e recreativas, b) boas práticas na agricultura, e c) o exercício dos poderes das empresas de saneamento no caso de terras privadas. Também, a Licença de Atribuição outorgada às empresas de saneamento em 1989 requeria que elas criassem seus próprios códigos de conduta em relação a a) as relações com os consumidores, b) os procedimentos para suspender o serviço por falta de pagamento e ouras ofensas, e c) a gestão de perdas na rede.

Fonte: adaptado de Castro (2002), basado en fontes do governo británico 
Na época da privatização em 1989 a responsabilidade pelo desenho de políticas e legislação no setor do saneamento e pela nomeação ${ }^{8}$ das companhias privadas para atuar como fornecedores dos serviços de água e esgoto passou a ser responsabilidade da Secretaria de Estado para o Ambiente e da Secretaria de Estado para Gales (a que foi substituída posteriormente pela Assembléia Nacional de Gales ${ }^{9}$ ). Por outra parte, o Ministério de Agricultura, Pesca e Alimentação (MAFF) manteve suas responsabilidades com relação às defesas contra inundações e pescas, assim como também sobre licenciamento, monitoramento e controle de efluentes e outras descargas ao mar. As Secretarias tinham também a seu cargo a elaboração e atualização do marco regulatório que estabelece entre outras coisas os padrões de desempenho de serviços, parâmetros de qualidade da água, critérios para monitorar o estado dos rios ou medidas para prevenir a contaminação das fontes de água. As Secretarias também tinham poderes para a aprovação de códigos de prática para as empresas e para impor sanções em caso de descumprimento de seus deveres estatuídos no contrato de sua nomeação. Desde 1998, com a chegada do governo trabalhista ao poder o ano anterior, esses poderes foram transferidos no caso da Inglaterra à Secretaria de Ambiente, Alimentação e Assuntos Rurais (DEFRA), e em caso de Gales, como já se disse, à Assembléia Nacional de Gales.

8 Este é um conceito importante, já que na Inglaterra e Gales a privatização não se implementou mediante uma concorrência aberta entre empresas, como ocorreu normalmente em nível internacional. Pelo contrário, o governo inglês criou 10 empresas privadas para substituir às 10 empresas públicas regionais que existiam, e as nomeou para prestar serviços (em muitos casos, como o da empresa Thames Water que serve a Londres e a bacia do Tâmisa, uma boa parte dos diretores da empresa privada criada em 1989 tinham sido diretores na empresa pública que existia anteriormente). A possibilidade de adquirir as empresas criadas em 1989 estava vetada por lei, o que foi modificado em 1994, momento a partir do qual começou uma etapa de aquisições das empresas especialmente por parte de investidores estrangeiros (ver Apêndice A2 para uma síntese da evolução do processo). Adicionalmente, a nomeação das empresas privadas para atuar como prestadoras do serviço foi protegida por uma cláusula que obrigava ao governo a dar 15 anos de aviso antecipado no caso de querer-se modificar o status das mesmas (ex. em caso de houver intenção de devolve-las ao setor público), cláusula modificada posteriormente pelo PrimeiroMinistro Tony Blair para estender o período obrigatório de aviso a 25 anos.

9 Gales recuperou um certo grau de autonomia com relação ao governo central a partir das eleições gerais de 1997 que ganhou o Partido Trabalhista com uma plataforma que incluía a devolução de certos poderes à Escócia, Gales e as regiões da Inglaterra. Entre outros poderes "devolvidos" a Gales se incluiu a gestão dos serviços públicos como os de saneamento. Sobre o caso específico dos serviços de saneamento em Gales vér Drakeford (2002). 
Mas a maior inovação foi a criação de um ente regulador específico para o setor: o Escritório de Serviços da Água (OFWAT), complementado com outras agências governamentais ou quasi governamentais, tais como a Inspetoria da Água Potável (Drinking Water Inspectorate, DWI) e a Autoridade Nacional de Rios (National Rivers Authority, NRA), substituída em 1995 pela Agência do Meio Ambiente (Environment Agency). Adicionalmente, outras entidades exercem um papel regulatório sobre aspectos específicos do funcionamento das empresas, como a Comissão de Monopólios e Fusões (Monopolies and Mergers Commission MCC, substituída posteriormente pela Comissão de Competitividade), a Inspetoria de Poluição (HM Inspectorate of Pollution, depois absorvido pela Agência do Ambiente), as Autoridades Distritais de Saúde (District Health Authorities) e as autoridades locais que mantiveram papel de controle sobre alguns aspectos particulares (ver sínteses na Figura 1). Por outra parte, existem outros entes reguladores que têm também uma ingerência importante no setor do saneamento, em particular o Departamento de Assuntos Constitucionais, a cargo de implementar a legislação sobre Liberdade no Acesso à Informação (Freedom of Information), e o Escritório de Comércio Justo (Office of Fair Trading, OFT), que tem a seu cargo diferentes aspectos relativos à proteção dos usuários.

Figura 1 - Instituições chave no sistema regulatório dos serviços de saneamento na Inglaterra e Gales

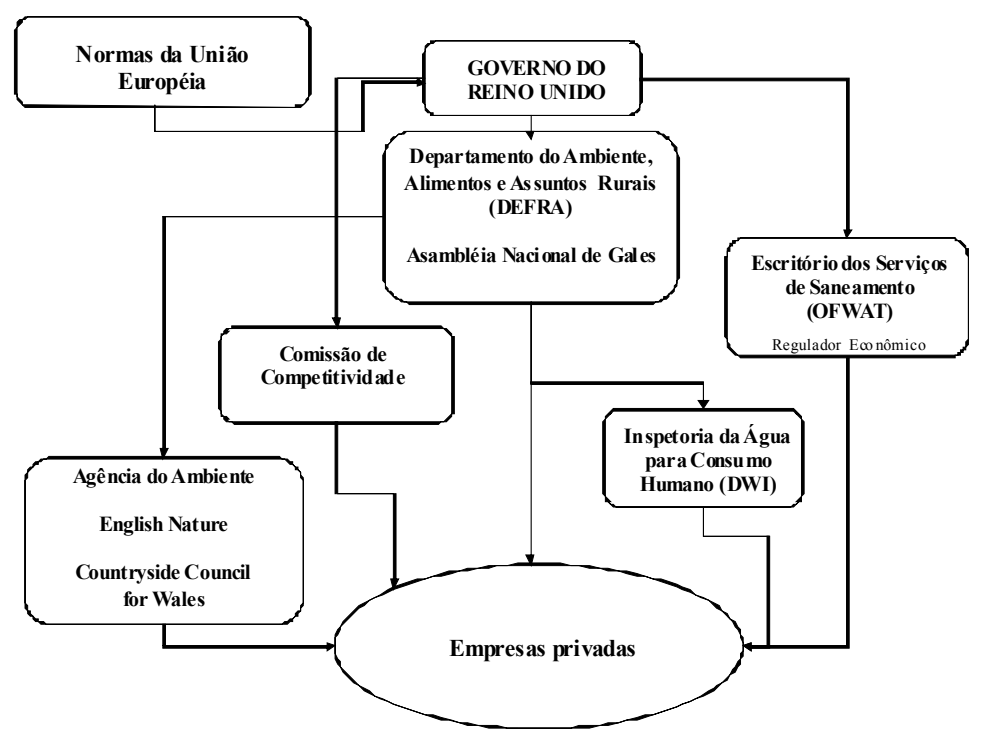


O regulador econômico OFWAT, criado em 1989, tem como obrigação primária assegurar o funcionamento adequado dos serviços, incluindo a de garantir a viabilidade financeira das empresas privadas. Adicionalmente a essa obrigação primária, OFWAT tem também responsabilidade pela proteção dos interesses dos usuários em relação à eqüidade no custo dos serviços, promover a eficiência econômica das empresas, e facilitar a competitividade entre elas. O sistema de regulação econômica de OFWAT está orientado ao controle de preços (price cap) mais que ao controle de ganhos (return rate regulation) como ocorre nos Estados Unidos. O princípio do sistema é que a regulação de preços da incentivos mais potentes para as melhoras em eficiência e inovação. OFWAT utiliza a denominada fórmula "RPI - X" que leva em conta um complexo conjunto de variáveis incluindo os requerimentos de investimento individuais para cada uma das dez empresas e o índice de preços de varejo para proteger o faturamento das companhias da inflação mais ou menos um valor $(\mathrm{X})$ determinado pelo próprio regulador a partir da análise das condições específicas de cada empresa. Os preços são fixados por períodos qüinqüenais com o objetivo de outorgar incentivos às companhias para melhorar a eficiência.

Adicionalmente, uma das responsabilidades de OFWAT é a de dirimir as disputas entre as companhias e os usuários. Em relação a isso, originalmente OFWAT designou dez Comitês de Serviço aos Clientes (CSCs) para cada região atendida por cada uma das dez empresas regionais, e os presidentes de cada comitê formavam juntamente com o Diretor de OFWAT o Conselho Nacional de Clientes. O sistema de representação dos consumidores foi reestruturado em 2002, entre outras razões em resposta às críticas recebidas pelo grau de extrema dependência dos CSCs com relação ao Diretor de OFWAT, que de fato nomeava pessoalmente seus membros, com a criação de WaterVoice, uma entidade também organizada com dez comitês regionais e um Conselho Nacional de WaterVoice. Em 2005, por sua vez, WaterVoice foi substituída pelo Conselho de Consumidores da Água (Consumer Council for Water), com uma estrutura similar. 


\subsection{Regulação do impacto ambiental dos serviços de saneamento}

Como já se mencionou, na época da privatização em 1989 a regulação ambiental das empresas de saneamento se confiou à Autoridade Nacional de Rios (NRA), que foi substituída em 1995 pela Agência do Meio Ambiente. A Agência do Meio Ambiente criou-se a partir da fusão da NRA, da Inspetoria de Poluição, de 83 Autoridades de Regulação dos Resíduos Sólidos (Waste Regulation Authorities), e de alguns escritórios do Departamento do Meio Ambiente. A Agência operou dentro do marco legal outorgado pela Ata de Recursos Hídricos de 1991 e a Ata do Meio Ambiente de 1995 (ver Tabela 1). As funções principais atribuídas à Agência foram a prevenção e controle da contaminação mediante a fixação de limites às descargas de substâncias perigosas ao ambiente, o estabelecimento de permissões para o despejo de efluentes por parte de estações de tratamento de esgoto, o controle do uso do lodo de águas residuais (sewage sludge) na agricultura, a fixação de fluxos mínimos para a corrente dos rios, a outorga de formas de abstração de água, o controle da pesca, espaços de recriação aquática, e a conservação e navegação de alguns rios. A Agência também desenvolveu uma série de atividades para promover iniciativas orientadas à gestão da demanda através de seu Centro Nacional para a Gestão da Demanda da Água, incluindo entre outras questões a promoção da conservação da água e medidas relacionadas como o desenho e difusão de mecanismos para a economia da água nos usos domésticos, industriais e públicos, programas de redução de perdas e expansão do uso de medidores de consumo de água ${ }^{10}$. A partir da chegada do governo trabalhista ao poder em 1997 os poderes e obrigações da Agência foram estendidos para cobrir também o planejamento da gestão de recursos hídricos a longo prazo e a prevenção e controle de secas, incluindo a

10 Apesar disso, entre o momento da privatização em 1989 e 2008 a porcentagem de usuários domésticos que têm um medidor de consumo de água na Inglaterra e Gales cresceu somente de 14 a 30 por cento. 
capacidade de monitorar regularmente os planos das empresas privadas de saneamento em relação a esses aspectos ${ }^{11}$.

\subsection{Regulação da qualidade da água para consumo humano}

Em 1990 criou-se um regulador específico para controlar a qualidade da água para consumo humano fornecida pelas empresas de saneamento, a Inspetoria de Qualidade da Água para Consumo Humano (Drinking Water Inspectorate, DWI). A Inspetoria tem a responsabilidade de monitorar o cumprimento das empresas como as normas do Governo Britânico e da Comissão Européia ${ }^{12}$ em relação aos parâmetros físico-químicos e biológicos da água distribuída para consumo humano (ingestão, higiene e preparação de alimentos). A Inspetoria realiza auditorias técnicas e inspeções regulares das empresas de saneamento, busca informações sobre os incidentes que afetam a qualidade da água para consumo humano, fornece apoio técnico na preparação da legislação correspondente e representa ao governo britânico no processo de padronização de critérios em relação à incorporação das normas da água européias na legislação do país. A Inspetoria também possui poderes para iniciar ações em nome da Secretaria de Estado e da Agência Nacional de Gales em casos extremos de violação dos regulamentos de qualidade da água (DWI, 2001; ver a informação atualizada anualmente no sítio de Internet da Inspetoria: www.dwi.gov.uk).

11 Essa ampliação dos poderes e obrigações da Agência do Meio Ambiente foi o resultado direto da ação do governo do Primeiro-Ministro Tony Blair fundada nas promessas da campanha eleitoral assumidas na Cúpula da Água (Water Summit) em 1997 de revisar radicalmente a gestão do setor da água e dos serviços de saneamento diante da insatisfação crescente da população com o desempenho das empresas privatizadas. Essa insatisfação se havia acentuado durante uma seca que teve lugar em 1995 e que expôs a falta de planejamento estratégico das empresas privadas em relação à gestão dos recursos hídricos em condições de crescente insegurança climática (sobre esse debate, ver por exemplo: OFWAT, 1998; Haughton, 1998; Bakker, 2000; Environment Agency, 2000; Walker e Smithers, 2007).

12 A Comissão Européia estabelece "normas" sobre a gestão da água e seus serviços que depois devem ser incorporadas na legislação dos estados-membros (ver figuras 1 e 2 e Apêndice A1). 


\section{4. Regulação da conduta empresarial e outros aspectos}

Finalmente existem outras entidades regulatórias que também têm poderes e obrigações em relação aos serviços de saneamento, em particular a Comissão de Monopólios e Fusões, depois substituída pela Comissão de Competitividade, e o Escritório de Comércio Justo. A primeira desempenha um papel similar a uma corte de apelação à que podem acudir tanto OFWAT como as empresas privadas em relação, por exemplo, a disputas sobre os controles de preços estabelecidos pelo regulador econômico. Este regulador também tem sob sua responsabilidade o monitoramento das propostas de fusões entre empresas. Por sua vez, o Escritório de Comércio Justo tem o papel de supervisar as atividades das empresas que possam afetar aos usuários.

Mesmo que significativamente menor em importância, as autoridades de planejamento e municipais também têm certo papel regulatório em relação à gestão da água e seus serviços, e a tendência recente foi para uma intencionalidade crescente à devolução de algumas funções regulatórias aos poderes locais e regionais, mesmo que não é claro o grau de progresso conseguido nessa direção (Environment Agency, 2001).

\subsection{Resumo e perspectivas futuras do sistema regulatório na Inglaterra y Gales}

Como sugerem os parágrafos anteriores, apesar da imagem que pode se obter a partir de alguns debates ideológicos que se suscitaram em torno da privatização de 1989, especialmente a noção de que era parte de um processo de encolhimento do setor público, se corrobora uma expansão substancial das atividades de controle e regulamento do setor de saneamento. Esse desenvolvimento obedece a uma série de fatores internos e externos ao setor do saneamento, em parte é um resultado não planejado já que certamente um dos objetivos declarados da privatização implementada pelo governo de Margaret Thatcher tinha sido precisamente o de liberar às empresas dos controles estatais e reduzir o setor público. No entanto, na prática o desenvolvimento do processo foi para uma multiplicação dos organismos 
reguladores e uma ampliação das áreas sujeitas ao controle regulatório (Hoogwood, 1998). Acrescentaram-se novas instâncias regulatórias para controlar as empresas privatizadas, ao mesmo tempo em que a influência das normas européias sobre os estados-membros foi aumentando a tal ponto que é necessário considerá-las como parte constitutiva do processo e institucionalização regulatória do país. A Figura 2 apresenta uma síntese da estrutura da regulação do setor de saneamento na Inglaterra e Gales que permite distinguir a existência de diferentes níveis e inter-relações entre as diferentes instâncias da regulação, particularmente as escalas internacional, nacional, horizontal (transetorial) e setorial (específica do setor de saneamento).

Figura 2. Estrutura da regulação do setor de saneamento na Inglaterra e Gales

Setorial Horizontal
\begin{tabular}{|l|l|l|l|}
\hline $\begin{array}{l}\text { OFWAT (regulador } \\
\text { econômico) }\end{array}$ & $\begin{array}{l}\text { Agência do Meio } \\
\text { Ambiente }\end{array}$ & $\begin{array}{l}\text { Departamento do Meio } \\
\text { Ambiente, Alimentos, e } \\
\text { Assuntos Rurais }\end{array}$ & $\begin{array}{l}\text { UNIÃO EUROPÉIA } \\
\text { Normas }\end{array}$ \\
\hline $\begin{array}{l}\text { Inspectoria de } \\
\text { Qualidade da Agua } \\
\text { para Consumo } \\
\text { Humano (DWI) }\end{array}$ & $\begin{array}{l}\text { Comisisão de } \\
\text { Competitividade }\end{array}$ & $\begin{array}{l}\text { Asambléia Nacional de } \\
\text { Gales }\end{array}$ & \\
\hline & $\begin{array}{l}\text { Escritório de } \\
\text { Comércio Justo }\end{array}$ & & \\
\hline & & & \\
\hline
\end{tabular}

Fonte: Adaptado de Doern e Wilks (1998).

Continua existindo um profundo debate sobre as razões que levaram à privatização das empresas de saneamento assim como dos resultados conseguidos pelo sistema regulatório nesta nova etapa, que não podemos refletir com justiça neste trabalho por razões de espaço (ver, entre outros, Green, 1997, 1999; Greene, 2002; DEFRA-OFWAT, 2003; Bakker, 2004; Hall e Lobina, 2007). Em particular, o esquema regulatório do setor de saneamento na Inglaterra e Gales é objeto de um debate contínuo, principalmente em 
referência a sua efetividade e possibilidade de ser implementado en otros países. Adicionalmente, se construíram certos mitos em torno ao sistema, que costumam aceitar-se sem críticas em outros países que se encontram desenvolvendo seus próprios sistemas de regulação do saneamento, em particular o que chamo o mito do regulador independente e neutro. É fundamental efetuar uma crítica objetiva que permita acabar com esse mito.

Nesse sentido, os críticos da privatização indicaram reiteradamente a existência de falhas severas no sistema e o fato de que os organismos reguladores, e em particular o regulador econômico OFWAT, tenderam a favorecer os interesses das empresas privadas antes que defender os direitos dos cidadãos e usuários das empresas (entre outros ver Schofield e Shaoul, 1997 e Shaoul, 1998; Taylor, 1999, 2002; Bakker, 2004; Hall e Lobina, 2007; Castro, 2007). Durante a década de 1990 o debate sobre o papel do regulador OFWAT se fez cada vez mais agudo por uma série de razões que incluíram a percepção que as empresas privadas gozaram de uma extrema flexibilidade na aplicação da lei e dos regulamentos, o que lhes permitiu acumular ganhos extraordinários e pagar salários milionários a seus diretores ao mesmo tempo em que se fazia evidente a falta de investimento na renovação da infra-estrutura (uma das razões esgrimidas para justificar a privatização) e de planejamento estratégico (ver nota de rodapé número 11), em um contexto de elevado aumento das tarifas para os usuários acompanhado de um grave processo de exclusão do acesso aos serviços através do corte por falta de pagamento que alcançou percentuais elevados no começo da década de $1990^{13}$. Esses problemas constituíram um dos temas importantes da campanha do Partido Trabalhista, que finalmente chegou ao poder em 1997, e como conseqüência a partir da sua chegada ao governo o ambiente regulatório sofreu mudanças significativas, que demonstram o mito da

13 Entre 1990 e 1995 o número de notificações de corte por falta de pagamento enviadas pelas empresas privadas às famílias aumentou em 900\%, e em 1994 quase 2 milhões de famílias (cerca de $9 \%$ do total) deixaram de pagar suas faturas de serviços de saneamento (Herbert e Kempson, 1995; Ward, 1997). Segundo informação obtida em entrevistas realizadas pelo autor com pessoas que tinham ocupado postos de direção nas empresas de saneamento antes da privatização historicamente a taxa de não pagamento dos usuários sempre se mantinha em um nível muito baixo, de $2-3 \%$ do total de usuários. 
suposta independência do regulador. Entre outras decisões fundamentais, o governo proibiu o corte do serviço por falta de pagamento a partir de 1997 e na definição de níveis de tarifas para o período 1999-2004 o regulador OFWAT obrigou às empresas a reduzi-las $12 \%$ em média para compensar pelos ganhos excessivos acumulados no período prévio e pelo descumprimento com os planos de investimento, o que constituiu uma mudança radical na conduta do regulador e que sugere uma adaptação de OFWAT ao novo ambiente político derivado da chegada da Partido Trabalhista ao poder. Adicionalmente, também em 1997 o governo trabalhista aplicou um imposto extraordinário às empresas (windfall tax) de cerca de 1,65 bilhão de libras esterlinas também em compensação pelos ganhos excessivos do período anterior.

Essas transformações no ambiente regulatório a partir da substituição do Partido Conservador, que tinha levado a cabo as privatizações, pelo Partido Trabalhista são evidência suficiente para indicar a fragilidade do conceito de "independência" ou "neutralidade" do sistema regulatório, que evidentemente se encontra fortemente determinado pelo processo político. No entanto, desde outra perspectiva as mudanças introduzidas não foram suficientes para restabelecer mais um equilíbrio favorável aos usuários das empresas privadas. Como resultado, a proporção de famílias com dívidas não pagas acumuladas com as empresas de saneamento continuou crescendo até alcançar cifras que em 2008 beiravam entre 15 e $20 \%$ do total de usuários, enquanto segundo dados do próprio governo entre 2 e 4 milhões de famílias vivem atualmente em "pobreza da água" (que ocorre segundo o governo, quando o custo da fatura dos serviços de saneamento supera $3 \%$ da renda familiar). ${ }^{14}$

Por outra parte, um dos objetivos declarados da privatização tinha sido o de introduzir competitividade no sistema mediante a exposição das empresas de saneamento às forças do mercado, um aspecto que o regulador OFWAT consistentemente tende a defender como uma conquista do

14 Ver por exemplo, Klein, 2003; Fitch e Price, 2002; Greene, 2002; UKP, 2003; OFWAT, 2004, pp. 14-19; NCC, 2005. A situação piorou nos últimos anos e é uma das preocupações atuais do governo em relação ao futuro do setor do saneamento no país. 
modelo regulatório introduzido em 1989. Um exemplo típico da postura do regulador econômico se encontra em um relatório sobre o "estado da competitividade" no setor saneamento, no qual pode ler-se que "a competitividade comparativa teve sucesso em estimular eficiência nas companhias. A competitividade do mercado está estimulando maior eficiência" (OFWAT, 2000: 1). No entanto, as empresas de saneamento foram o objeto de críticas permanentes pela sua falta de eficiência e, inclusive, a piora de sua performance, por exemplo, em relação ao impacto ambiental ${ }^{15}$. Esse é um aspecto claramente controvertido e os ferventes defensores da privatização e de seu sistema de regulação defendem o que consideram um exemplo bem-sucedido de políticas públicas e gestão no setor do saneamento em nível internacional (Rouse, 2009).

No entanto, apesar de que os defensores do sistema, incluindo o regulador econômico OFWAT, assinalam diversos elementos para fundamentar sua posição otimista sobre os resultados da privatização, as vozes discordantes com essa postura oficial são cada vez mais numerosas e audíveis, e não somente entre que são céticos da privatização dos serviços essenciais. Por exemplo, em claro reconhecimento da inexistência de uma competitividade real no setor do saneamento, um informe recente publicado por um jornal britânico que claramente apóia o setor privado desde uma perspectiva favorável à liberdade de mercado anunciava:

Ofwat, o regulador da água, deu os primeiros passos tentativos para a liberalização da indústria dos [serviços de] água na Inglaterra e Gales, e publicou um cardápio de opções que poderia dirigir à divisão dos monopólios regionais que se têm feito infames pelo seu abuso do mercado e seu deficiente serviço (Fortson, 2008).

15 Enquanto o regulador econômico OFWAT consistentemente informa melhoras constantes na infra-estrutura dos serviços por parte das empresas privadas nos seus relatórios anuais, o regulador ambiental (Agência do Ambiente) publica anualmente a lista das dez empresas mais poluentes do país entre as quais figuram várias das empresas de saneamento privatizadas e uma delas, Thames Water, consistentemente encabeça a lista dos "piores culpados". Ver, por exemplo, Beard, 2002; BBC, 2006. 
0 artigo não requer de maiores explicações dada sua eloqüência: do ponto de vista dos defensores da liberdade do mercado e da competitividade empresarial o sistema regulatório do setor de saneamento na Inglaterra e Gales fracassou e contribuiu para manter os privilégios de um mercado de monopólio controlado por um grupo reduzido de empresas privadas (o artigo sugere que o regulador OFWAT demorou 20 anos em dar os "primeiros passos tentativos" para introduzir competitividade no setor). Essa reportagem jornalística é somente um indicador do debate profundo que está ocorrendo no país neste momento. Em um relatório também recente baseado em um estudo detalhado do setor, os autores concluem que existem enormes dificuldades para avaliar a performance das empresas de saneamento e do processo regulatório na Inglaterra e Gales porque "a informação relevante [para efetuar uma avaliação] é limitada, em grande medida pelo papel restrito da competitividade no setor [do saneamento] até o momento" (Yarrow et. al., 2008: 4). O relatório é claramente cético sobre os resultados do modelo implementado desde a privatização:

\begin{abstract}
"as perspectivas para o desenvolvimento da competitividade na indústria de [os serviços de] de água deveriam ser boas, mas a realidade é que muito provavelmente não o sejam. Existiram um bom número de falsos avanços neste tema durante o período desde a privatização dos serviços de água na Inglaterra e Gales há já vinte anos, e a última tentativa de avançar, que se deu na forma da Ata da Água de 2003 que tratava o tema da abertura do mercado e do acesso às redes de serviço, é amplamente considerado um fracasso. [...] Aqueles que são céticos sobre as contribuições dos mercados competitivos podem certamente assinalar o fato de que a evidência de sucessos conseguidos é limitada" (Yarrow et. al. 2008: 86)
\end{abstract}

Esses e outros balanços críticos da privatização dos serviços de saneamento na Inglaterra e Gales e do sistema regulatório implementado de monitoramento somam-se à uma consistente série de críticas que foram sendo formuladas nas últimas duas décadas por uma série de autores que mencionamos ao longo do trabalho. Após duas décadas de funcionamento, 
o sistema de regulamento dos serviços de saneamento na Inglaterra e Gales será provavelmente sujeito a um severo julgamento e muito provavelmente deve esperar-se mudanças substantivos nele nos próximos anos, e não se deve descartar inclusive a desprivatização (estatização) das empresas (ver, por exemplo, Hall e Lobina, 2007). ${ }^{16}$

\section{Conclusões}

Certamente, o exame do modelo da Inglaterra e Gales encerra lições substantivas para o Brasil e outros países que se encontram desenvolvendo seus próprios modelos de organização e regulação do serviços de saneamento. Podemos sintetizar algumas destas lições em uma série de temas cada um dos quais mereceria provavelmente um estudo separadamente: a) o papel histórico do setor público na organização, regulação e universalização dos serviços, b) a existência de fatores internos e externos ao setor de saneamento, verdadeiros condicionantes sistêmicos, estruturais, que constituem elementos chaves no desenvolvimento desses processos e que são em grande medida independentes da ação racional dos atores envolvidos (governos, empresários, grupos sociais organizados, usuários individuais, etc.), c) a necessidade de promover estudos críticos, não contemporizadores, sobre os processos de regulação e de organização dos serviços de saneamento em geral, e especialmente desnudar os mitos criados em torno de diferentes questões, como por exemplo o mito do regulador "independente" ou "tecnicamente neutro" que pode ser muito atrativo por um número compreensível de razões mas que não sobrevive à análise rigorosa da evidência empírica sobre o funcionamento concreto da regulação na prática.

Com relação ao primeiro aspecto, cabe dizer que em grande parte do debate contemporâneo na América Latina, incluindo o Brasil, e também em outros países, se deixou de lado consistentemente a análise histórica de

16 Em 2001, logo depois da devolução de poderes a Gales, a empresa privada que servia o país foi desprivatizada, o que constituiu o primeiro caso de modificação radical do sistema privatizado em 1989 (Drakeford, 2002). 
como se conseguiram organizar efetivamente os serviços de saneamento nos países que alcançaram universalizar o acesso durante o século vinte. Esse "esquecimento" não é casual, em nossa opinião, e responde principalmente à predominância de enfoques analíticos que tendem a excluir a consideração dos processos de longo prazo que permitem explicar a gênese de um determinado fenômeno. No caso do saneamento, por exemplo, na literatura contemporânea especializada poucas vezes se pergunta "como se alcançou o sucesso na universalização dos serviços nos países que o alcançaram, como a Inglaterra y Estados Unidos?" A resposta é muito clara quando se examina o registro histórico, como argumentamos brevemente neste capítulo: a universalização e efetividade conseguidas nesses países, com todos seus problemas e limitações, só foi possível a partir de um papel decisivo do estado desde o fim do século dezenove e foi uma tarefa que demandou várias décadas de esforços. O retorno de uma participação direta do setor privado no setor, como é o caso na Inglaterra desde 1989, só foi possível pelas condições criadas por décadas de investimento e controle públicos no setor, e como vimos a política de privatizações está longe de ser um sucesso inclusive desde a perspectiva de que defendem uma política de mercado livre no Reino Unido. Considero que estas lições fundamentais da história do saneamento na Inglaterra y os Estados Unidos são lamentavelmente ignoradas sistematicamente em grande parte do debate que é realizado em nossos países, incluindo o Brasil, uma tendência que deveria ser revertida urgentemente para evitar repetir erros que outros cometeram e para beneficiar nossos países das experiências realmente positivas que podem se extrair desses exemplos.

Em relação ao segundo ponto, é também muito importante recuperar um equilíbrio entre o papel que lhes cabe aos agentes e às condições sistêmicas, estruturais, na análise dos processos que têm lugar em relação ao desenvolvimento da regulação e outros aspectos dos serviços de saneamento. Nesse sentido, uma lição fundamental que pode ser extraída do caso da Inglaterra é que a crítica aguda que pode ser feita ao sistema de privatização e seu modelo regulatório só é possível devido à existência de condições comparativamente abertas e muito transparentes de informação sobre o funcionamento das empresas, do governo e do sistema regulatório. 
Digo "comparativamente" porque como vimos no capítulo, os críticos do sistema na Inglaterra, desde diferentes âmbitos do leque político, isto é, desde os céticos do mercado e da privatização até ardentes defensores do mercado autoregulado sem controles burocráticos, têm severas reservas sobre a qualidade da informação disponível e sobre os mecanismos de produção e acesso à ela. No entanto, em comparação com a situação em muitos países do Sul Global, incluindo o Brasil, a disponibilidade de informação sobre o funcionamento dos sistemas tal como existe, por exemplo, na Inglaterra continua sendo pouco menos que ilusório. Este é na verdade um excelente exemplo de condições sistêmicas, estruturais, já que a possibilidade de contar com informação e mecanismos de acesso que permitem aos diferentes agentes sociais a análise e a tomada de posições com relação a um determinado fenômeno ou processo, como é o caso do funcionamento dos serviços de saneamento, faz parte do contexto sócio-político e cultural do país, que se expressa também nas suas instituições. Não é necessário fazer o papel de acordo com esse modelo nem pretender reproduzi-lo, que não é o que estou sugerindo, mas o ponto principal aqui é que a consideração das condições sistêmicas são um fator fundamental para entender e explicar o funcionamento concreto de, por exemplo, o sistema regulatório dos serviços de saneamento, algo que com freqüência se deixa de lado na literatura especializada no assunto e nos debates correspondentes. Certamente este é só um exemplo, já que existem diversos condicionantes sistêmicos, majoritariamente externos ao setor saneamento, que devem incorporar-se à análise, desde o impacto das condições do sistema financeiro internacional até os desafios à gestão dos recursos hídricos causados pelo processo de mudança climática, para dar só dois exemplos.

Em estreita relação com o anterior, o terceiro ponto que queríamos enfatizar na conclusão é a necessidade de promover estudos críticos, não contemporizadores, e especialmente a desmistificação de certos pressupostos como a muito celebrada "independência" ou "neutralidade" do regulador, que freqüentemente nos debates que têm lugar na América Latina e no Brasil costuma ser ilustrada precisamente com o caso do regulador econômico do serviços de saneamento na Inglaterra, OFWAT. Acho que o capítulo deu suficientes elementos para que o leitor quando menos questione sua posição 
com relação a esta noção de independência ou neutralidade, que na prática não resiste à análise crítica baseada na evidência empírica. O problema não é a intencionalidade ou posição moral dos atores envolvidos (mesmo que obviamente não deve descartar-se este aspecto, como nos lembram os teóricos positivos da regulação), um esclarecimento necessário para evitar confusões, já que precisamente consideramos que a independência e a neutralidade são com efeito impedidas pelas condições sistêmicas, estruturais, que determinam em grande medida a configuração e funcionamento dos sistemas regulatórios e suas relações com outras esferas da atividade como a economia ou os sistemas político e legal. Provavelmente a distinção chave que deveria explorar-se em maior profundidade é entre autonomia e independência, assumindo que enquanto um grau de autonomia do regulador é certamente possível a partir da criação de condições adequadas (financeiras, institucionais, etc.), a independência em termos restritos implicaria um status do regulador acima das próprias autoridades nacionais do país, uma situação que certamente não existe na Inglaterra ou em outros lugares com uma tradição regulatória sólida. Finalmente, o segundo mito que deve ser examinado em detalhe e exposto como tal é o da "neutralidade" do regulador, que supostamente exerce um rol técnico completamente libertado de implicações políticas, ideológicas, valorativas, etc. Este é obviamente um velho debate e continuará sendo um tema controvertido, mas desde nossa posição e em função dos exemplos considerados previamente, é claro que quienes tentam defender o argumento da neutralidade do regulador se colocam em uma posição de extrema fragilidade. Quando a Corte Suprema de Justiça dos Estados Unidos emitia suas sentenças históricas, bases dos princípios regulatórios hoje aceitos universalmente, o fazia inequivocamente a partir de claros supostos ideológicos e de uma posição política específica: a defesa da propriedade privada e do mercado capitalista. Quando o regulador OFWAT, ou qualquer um dos reguladores do sistema de saneamento inglês, exerce suas funções com autonomia e profissionalismo, o faz dentro de um determinado marco institucional, seguindo certas regras e diretrizes, que pressupõem um determinado entendimento de como deve organizar-se o sistema (por exemplo, com empresas privadas emprestando os serviços e onde o acesso não constitui um direito social nem um bem público, e portanto 
não está sujeito a nenhum tipo de subsídios para cobrir à população que não pode pagar o seu custo), que não é necessariamente compartilhado por todos os cidadãos (as pesquisas de opinião e outros estudos na Inglaterra consistentemente assinalaram que uma proporção importante da cidadania não está de acordo com o modelo existente). Nesse e outros sentidos que não podemos desenvolver em profundidade aqui, a suposta neutralidade do regulador é indefensível, o que certamente não implica que o regulador não possa exercer seu papel eficientemente.

\section{Referências bibliográficas}

Antonelli, C. F. (1992), “Acque sporche. Londra e il 'Metropolitan Board of Works', 1855-1865”, in: Storia Urbana, no. 61, pp. 61-81.

Bakker, Karen J. (2004), An Uncooperative Commodity Privatizing Water in England and Wales,

Oxford: Oxford University Press.

Bakker, Karen (2000), "Privatising water, producing scarcity: The Yorkshire drought of 1995”, Economic Geography, Vol. 76, no. 1, pp. 4 -27.

BBC Online News (2006), “Thames Water heads pollution list”, Londres, 26 de julio de 2006 (http://news.bbc.co.uk/2/hi/uk_news/5215504.stm).

Beard, Matthew (2002), "Water companies and farms singled out as Britain's worst polluters”,

The Independent, Londres, 25 de julio de 2002 (http://findarticles.com/p/ articles/mi_qn4158/is_20020725/ai_n12636045?tag=artBody;col1).

Beato, Paulina and Jean-Jacques Laffont (2002), "Competition in public utilities in developing countries", Washington DC: Sustainable Development 
Department, Inter American Development Bank (http://www.iadb.org/ sds/doc/IFM-127Competition-in-Public-Utilities-E.pdf).

Brook Cowen, Penelope J. (1997), "Getting the private sector involved in water What to do in the poorest of countries", in Klaus Tilmes (Coord.) The Private Sector in Infrastructure. Strategy, Regulation and Risk, The International Forum for Utility Regulation, Washington D.C.: The World Bank (http://www-wds.worldbank.org/servlet/WDSContentServer/ WDSP/IB/1997/09/01/000009265_3980804143615/Rendered/PDF/multiOpage.pdf), pp. 93-96.

Brook Cowen, Penelope J., and Tyler Cowen (1998), "Deregulated private water supply: a policy option for developing countries", Cato Journal, Vol. 18, \#1, pp. 21-41 (http://www.cato.org./research/natur-st.html).

Castro, José Esteban (2008), "Neoliberal water and sanitation policies as a failed development strategy: lessons from developing countries", Progress in Development Studies, Vol. 8, no. 1, pp. 63-83.

Castro, José Esteban (2007a), "Systemic conditions affecting the universalisation of water and sanitation services: a sociological exploration", Journal of Comparative Social Welfare, Vol. 23, no. 2, pp. 105-119.

Castro, José Esteban (2007b), "Poverty and citizenship: sociological perspectives on water services and public-private participation", Geoforum, Vol. 38, No. 5, pp. 756-771.

Castro, José Esteban (2007c), “La privatización de los servicios de agua y saneamiento en América Latina", in: Nueva Sociedad, no. 207, Buenos Aires: Friedrich Ebert Foundation, pp. 93-112.

Castro, José Esteban (2005), “Agua y gobernabilidad: entre la ideología neoliberal y la memoria histórica", in: Cuadernos del CENDES n. 59, Caracas: 
Centro de Estudios del Desarrollo, Universidad Central de Venezuela, pp. 1-22 (http://www.cendes-ucv.edu.ve/pdfs/59\%201-22.pdf).

Castro, José Esteban, Erik Swyngedouw e María Kaika (2003), "London: structural continuities and institutional change in water management", in: European Planning Studies, Special issue on "Water for the city: trends, policy issues and the challenge of sustainability", Vol. 11, \#3, pp. 283-298.

Castro, José Esteban (2002), "England and Wales (London) Case Study Report", PRINWASS Project, Oxford: University of Oxford, School of Geography and the Environment (www.prinwass.org).

Department for Environment, Food and Rural Affairs (DEFRA) (2008) Future Water, Londres: DEFRA (http://www.defra.gov.uk/environment/water/ strategy/pdf/future-water.pdf).

Department for Environment, Food and Rural Affairs (DEFRA) (2002), Directing the Flow. Priorities for Future Water Policy, Londres: DEFRA.

Department for Environment, Food and Rural Affairs (DEFRA) and the Office of Water Services (OFWAT) (2003), "Structure of the Water Industry in England: does it Remain fit for Purpose?", report prepared by John Smith and Duncan Hannan (http://www.defra.gov.uk/environment/ water/industry/structure-report/finalreport.pdf).

Doern, G. Bruce, and Stephen Wilks (eds.) (1998), Changing Regulatory Institutions in Britain and North America, Toronto, Buffalo, e Londres: Toronto University Press.

Drakeford, Mark (2002), "Providing Water in Wales: is there a Third Way? The Welsh experience with public and private utilities and the emergence of the not-for-profit model", in J E Castro (Coord.), PRINWASS Project, 
Oxford: University of Oxford, (http://prinwass.ncl.ac.uk/PDFs/Drakeford. PDF).

Drinking Water Inspectorate (DWI) (2001), Drinking Water 2001. A Report by the Chief Inspector, Londres: DWI (http://www.dwi.gov.uk/pdf/ index01.htm).

Dryzek, J. (1997), The Politics of the Earth. Environmental Discourses, oxford: Oxford University Press.

Environment Agency (2000), “The Environment Agency's review of water company drought plans. A submission to Central Government and the National Assembly for Wales", Bristol: Environment Agency (http:// www.environment-agency.gov.uk/commondata/acrobat/drought__00. pdf?lang=e).

Environment Agency (2001), "Water resources for the future. A strategy for England and Wales", Bristol: Environment Agency.

Fitch, M., e H. Price (2002), "Water poverty in England and Wales", Londres: Centre for Utility Consumer Law and Chartered Institute of Environmental Health.

Finer, Samuel E. (1952), The Life and Times of Sir Edwin Chadwick, Londres: Methuen.

Foreman-Peck, James, and B. Millward (1994) (Eds.), Public and Private Ownership of British Industry, 1820-1990, Oxford: Clarendon Press.

Fortson, Danny (2008), "Ofwat calls for water industry to be opened up to competition", in: The Independent, 17 May 2008 (http://www. independent.co.uk/news/business/news/ofwat-calls-for-water-industryto-be-opened-up-to-competition-830001.html). 
Foster, Vivien (1999) "Ten years of water service reform in Latin America: towards an Anglo-French model”, Washington D.C.: World Bank, Information and Communications Technology Division (http://go.worldbank.org/78WEEF91K1).

Foster, Vivien (1998), “Considerations for regulating water services while reinforcing social interests”, UNDP-World Bank Water and Sanitation Programme Working Papers, (http://go.worldbank.org/E62R3OC0E2).

Green, Richard (1999), "Checks and balances in utility regulation: The UK experience", the World Bank Public Policy for the Private Sector, Viewpoint Note No. 185, Washington, D.C.: World Bank (http://go.worldbank.org/I8DC1ZBSD1).

Green, Richard (1997), "Has price cap regulation of UK utilities been a success?", the World Bank Public Policy for the Private Sector, Viewpoint Note No. 132, Washington, D.C.: World Bank (http://go.worldbank. org/90U9(8D0G0).

Greene, Joanne (2002), “The England and Wales water industry privatisation. A desk study", Londres: WaterAid.

Guash, J. Luis and Robert W. Hahn (1997), "The costs and benefits of regulation: Some implications for developing countries", World Bank Infrastructure Working Paper No. 1773, Washington, D.C.: World Bank. (http://www-wds.worldbank.org/servlet/WDSContentServer/WDSP/IB/1 997/06/01/000009265_3971126124256/Rendered/PDF/multi_page.pdf).

Hall, David, e Emanuele Lobina (2007), "From a private past to a public future? The problems of water in England and Wales", Greenwich: Public Services International Research Unit (PSIRU), University of Greenwich (http://www.psiru.org/reports/2008-02-W-UK.doc). 
Hassan, John (1998), A History of Water in Modern England and Wales, Manchester: Manchester University Press.

Haughton, Graham (1998), "Private profits - public drought: the creation of a crisis in water management for West Yorkshire", Transactions of the Institute of British Geographers, Vol. 23, No. 4, pp. 419-433.

Herbert, A., Kempson, E. (1995), “Water debt and disconnection”, Londres: Policy Studies Institute.

Hogwood, B.W. (1998), "Regulatory institutions in the United Kingdom: increasing regulation in the 'shrinking state", in: Bruce Doern, G., Wilks, S. (Eds.), Changing Regulatory Institutions in Britain and North America, Toronto, Buffalo, e Londres: University of Toronto Press.

Jackson, Peter M. (1982), The Political Economy of Bureaucracy, Oxford: Phillip Allan.

Jackson, Peter M. (1985), “Economy, democracy, bureaucracy”, in R. Matthews (ed.), Economy and Democracy, Londres, Macmillan, pp. 168-203.

Klein, Michael (1996), “Economic regulation of water companies”, World Bank Policy Research Working Paper No. 1649, Washington, D.C.: World Bank (http://www-wds.worldbank.org/servlet/WDSContentServer/ WDSP/IB/1996/09/01/000009265_3961214162451/Rendered/PDF/multi_ page.pdf).

Klein, Michael and Timothy Irwin (1996), "Regulating water companies", World Bank Public Policy for the Private Sector, Viewpoint Note No. 30, Washington, D.C.: World Bank (http://go.worldbank.org/3IQM34D800). 
Klein, Georgia (2003), "Life Lines: the NCC's agenda for affordable energy, water, and telephone services', Londres: National Consumer Council.

Laski, Harold J;; Jennings, William I.; Robson, William A. (eds.) (1935), A Century of Municipal Progress 1835-1935, Londres: George Allen \& Unwin.

Lee, Terence R. (1999), Water Management in the 21st Century. The Allocation Imperative, Cheltenham: Edward Elgar.

Luckin, Bill (1986). Pollution and Control: a Social History of the Thames in the Nineteenth Century. Bristol: Adam Hilger.

Marshall, Thomas H. (1963), "Citizenship and social class", in: Sociology at the Crossroads and other Essays, Londres, Heinemann, pp. 67-127.

Metropolitan Water Board - MWB (1949), The Water Supply of London, Londres: Staples Press.

Millward, B. (1991), "Emergence of gas and water monopolies in nineteenth century Britain: contested markets and public control", in James Foreman-Peck (Ed.), New Perspectives in Late Victorian Economy: Essays in Quantitative Economic History 1860-1914, London: Cambridge University Press.

National Consumer Council - NCC (2005), "Affordability problems in the privatised WSS sector in England and Wales", Londres, NCC.

Newbery, David M. (1999), Privatization, Restructuring, and Regulation of Network Utilities. The Walras-Pareto Lectures, Cambridge, Mass. and London: The MIT Press.

Niskanen, William A. (1968), "The peculiar economics of bureaucracy", American Economic Review, Vol. 58, No. 2., pp. 293-305. 
Niskanen, William A. (1971), Bureaucracy and Representative Government, Chicago: Aldine.

OFWAT - Office of Water Services (2008), "Ofwat's review of competition in the water and sewerage industries: Part II", Birmingham: OFWAT

(http://www.ofwat.gov.uk/aptrix/ofwat/publish.nsf/Content/ pap_rsh_reviewmrktcomp).

OFWAT - Office of Water Services (2007), "Outcomes of Ofwat's internal review of market competition in the water sector", Birmingham: OFWAT (http://www.ofwat.gov.uk/aptrix/ofwat/publish.nsf/ AttachmentsByTitle/competitionreview_070404.pdf/\$FILE/competitionreview_070404.pdf).

OFWAT - Office of Water Services (2004), “Annual Report 2003-2004”, Birmingham: OFWAT:

OFWAT - Office of Water Services (2000), “The current state of market competition", Birmingham: OFWAT (http://www.ofwat.gov.uk/aptrix/ ofwat/publish.nsf/AttachmentsByTitle/currentstateofmarketcomp.pdf/\$FILE/currentstateofmarketcomp.pdf).

OFWAT - Office of Water Services (1998), “Ofwat Work Plan 1998-99. Protecting customers' interests”, Birmingham: OFWAT

(http://www.ofwat.gov.uk/aptrix/ofwat/publish.nsf/Content/ ofwatworkplan1998-1999).

Paredes, Ricardo M. (2001), "Redistributive impact of privatisation and the regulation of utilities in Chile", Discussion Paper No. 2001/19, World Institute for Development Economics Research (WIDER) (http://www. 
wider.unu.edu/publications/working-papers/discussion-papers/2001/ en GB/dp2001-19/).

Peters, B. Guy (1998), "Institutionalization and deinstitutionalization: regulatory institutions in American government", in: G. Bruce Doern and Stephen Wilks (eds.) (1998), Changing Regulatory Institutions in Britain and North America, Toronto, Buffalo, and London: Toronto University Press, pp. 51-79.

Rees Judith. A. (1998), "Regulation and private participation in the water and sanitation sector", TAC Background papers, No1, Sweden: Global Water Partnership, Technical Advisory Committee.

http://info.worldbank.org/etools/docs/library/80636/IWRM4_TEC01RegnAndPPInWatsan.pdf).

Richard, Barbara, and Thelma A. Triche (1994), "Reducing regulatory barriers to private-sector participation in Latin America's water and sanitation services", Policy Research Working Papers \#1322, Water, and Urban Development Department, The World Bank, Washington DC: World Bank (http://go.worldbank.org/8PM5GPDNJ2).

Rouse, Michael (2009), “The market-centred paradigm”, in: Castro, José Esteban e Léo Heller (eds.), Water and Sanitation Services: Public Policy and Management, Londres: Earthscan (no prelo).

Schofield, R., Shaoul, J. (1997), "Regulating the water industry: by any standards?", in Utilities Law Review 8 (2), pp. 56-70.

Shaoul, J. (1998), "Water clean up and transparency: the accountability of the regulatory processes in the water industry. A public interest report", Manchester: University of Manchester. 
Solanes, Miguel (1999), "Servicios públicos y regulación. Consecuencias legales de las fallas de mercado", Serie Recursos Naturales e Infraestructura \#2, Santiago de Chile: Comisión Económica para América Latina y el Caribe (CEPAL) (http://www.cepal.org/publicaciones/ xml/4/4464/LCL1252-E.pdf).

Solanes, Miguel (2002), “América Latina: ¿sin regulación ni competencia? Impactos sobre la gobernabilidad del agua y sus servicios", Comisión Económica para América Latina y el Caribe (CEPAL) (disponible en: http:// prinwass.ncl.ac.uk/PDFs/Solanes.PDF).

Swyngedouw, Erik (2009), "The political economy of essential public services", in: Castro, José Esteban, and Heller, Léo (eds.), Water and Sanitation Services: Public Policy and Management, Londres: Earthscan (no prelo).

Taylor, Graham (2002), "Regulating change in the water industry: The role of OFWAT in the redefinition of public service", in The Economics of Private Sector Participation in Water and Sanitation, First Research Workshop - PRINWASS Project. Oxford: University of Oxford (http://www. prinwass.org/jan02_workshop.shtml).

Taylor, Graham (1999), State Regulation \& the Politics of Public Service. The Case of the Water Industry, London and New York: Mansell.

UKP - United Kingdom Parliament, Select Committee on Environment, Food and Rural Affairs (2003), "Memorandum submitted by the Public Utilities Access Forum, Londres: UKP.

U. S. Supreme Court (1877), "Munn v. Illinois", 94 U.S. 113, (http://www. usscplus.com/online/index.asp?case=0940113).

(1904), "Sanislaus County v. San Joaquin and Kings River Canal and Irrigation Company", No. 80, Argued November 13, 30, December 1, 
1903, Decided January 18, 1904, 192 U.S. 201 (http://www.usscplus.com/ online/index.asp?case=1920201).

(1909), "City of Knoxville v. Knoxville Water Company", No. 17, Argued April 28, 1908, Decided January 4, 1909, 212 U.S. 1, (http://www. usscplus.com/online/index.asp?case=2120001).

(1912), "Cedar Rapids Gas Light Co. v. City of Cedar Rapids”, No. 163, Argued February 29, 1912, Decided March 11, 1912, 223 U.S. 655, (http://www.usscplus.com/online/index.asp?case=2230655).

Vass, Peter (2002), "Competition and restructuring in the UK water industry", in Journal for Network Industries, Vol. 3, \# 1, pp 77-98.

Walker, S, e H. A. Smithers (2007), "A review of the 1995-96 drought in the North West", in: Water and Environment Journal, Vol. 12, no. 4, pp. 273 -279 .

Ward, Colin (1997), Reflected in Water. A Crisis of Social Responsibility, Londres e Washington: Cassell.

Wilks, Stephen (1998), "Utility regulation, corporate governance, and the amoral corporation”, in G. Bruce Doern and Stephen Wilks (eds.) (1998), Changing Regulatory Institutions in Britain and North America, Toronto, Buffalo, and London: Toronto University Press, pp. 133-161.

Yarrow, George, Tony Appleyard, Christopher Decker, and Timothy Keyworth (2008), "Competition in the provision of water services", Oxford: Regulatory Policy Institute (http://www.rpieurope.org/Research/ Report\%20on\%20Competition\%20in\%20Water\%20Services.pdf).

Zerbe Jr., Richard O., and Howard McCurdy (2000), “The end of market failure", Regulation, Vol. 23, \#2, pp. 10-14 (http://www.cato.org/pubs/ regulation/regv23n2/zerbe.pdf). 


\section{Apéndice A1. Normas da União Européia que intervém no setor de saneamento}

\begin{tabular}{|c|c|}
\hline Norma & Objeto da Norma \\
\hline Norma de Nitratos & $\begin{array}{l}\text { reduzir a contaminação por nitratos na agricultura e preveni-la } \\
\text { no futuro }\end{array}$ \\
\hline Norma de Habitats & $\begin{array}{l}\text { proteger e restaurar habitats para a flora e fauna silvestres. } \\
\text { Revisão de licenças existentes de abstração de água e emissão de } \\
\text { efluentes. }\end{array}$ \\
\hline Norma de Peixes de Água Doce & $\begin{array}{l}\text { requer que os Estados Membros protejam as águas designadas } \\
\text { por a Norma de contaminação potencialmente perigosa para os } \\
\text { peixes }\end{array}$ \\
\hline Norma de Mariscos & $\begin{array}{l}\text { estipula níveis máximos de contaminação para substâncias que } \\
\text { podem ser tóxicas para os mariscos }\end{array}$ \\
\hline Norma de Substâncias & $\begin{array}{l}\text { proíbe jogar no meio ambiente certas substâncias perigosas } \\
\text { Perigosas sem autorização prévia }\end{array}$ \\
\hline Norma de Águas & $\begin{array}{l}\text { requer a prevenção de certas substâncias que não devem } \\
\text { Subterrâneas }\end{array}$ \\
\hline Norma de Tratamento de & $\begin{array}{l}\text { estabelece requisitos para a provisão de sistemas de Águas } \\
\text { Residuais Urbanas }\end{array}$ \\
\hline Norma de Água Potável & $\begin{array}{l}\text { proteção da saúde pública e manutenção da qualidade estética da } \\
\text { água para consumo humano }\end{array}$ \\
\hline Norma de Praias & $\begin{array}{l}\text { estabelece padrões para a proteção da saúde dos banhistas e } \\
\text { manter a qualidade estética das águas da costa utilizadas com } \\
\text { esse fim }\end{array}$ \\
\hline Norma de Abstração de & $\begin{array}{l}\text { estabelece parâmetros de qualidade para as fontes de água Águas } \\
\text { de Superfície }\end{array}$ \\
\hline Norma Marco da Água & $\begin{array}{l}\text { fornece um marco integral para a gestão da água na Europa (in- } \\
\text { corpora e substitui as normas anteriores) }\end{array}$ \\
\hline
\end{tabular}

Fonte: Adaptado de DEFRA (2002). 


\section{Apêndice A-2. Momentos chave na evolução recente da estrutura dos serviços de saneamento na Inglaterra y}

\section{Gales}

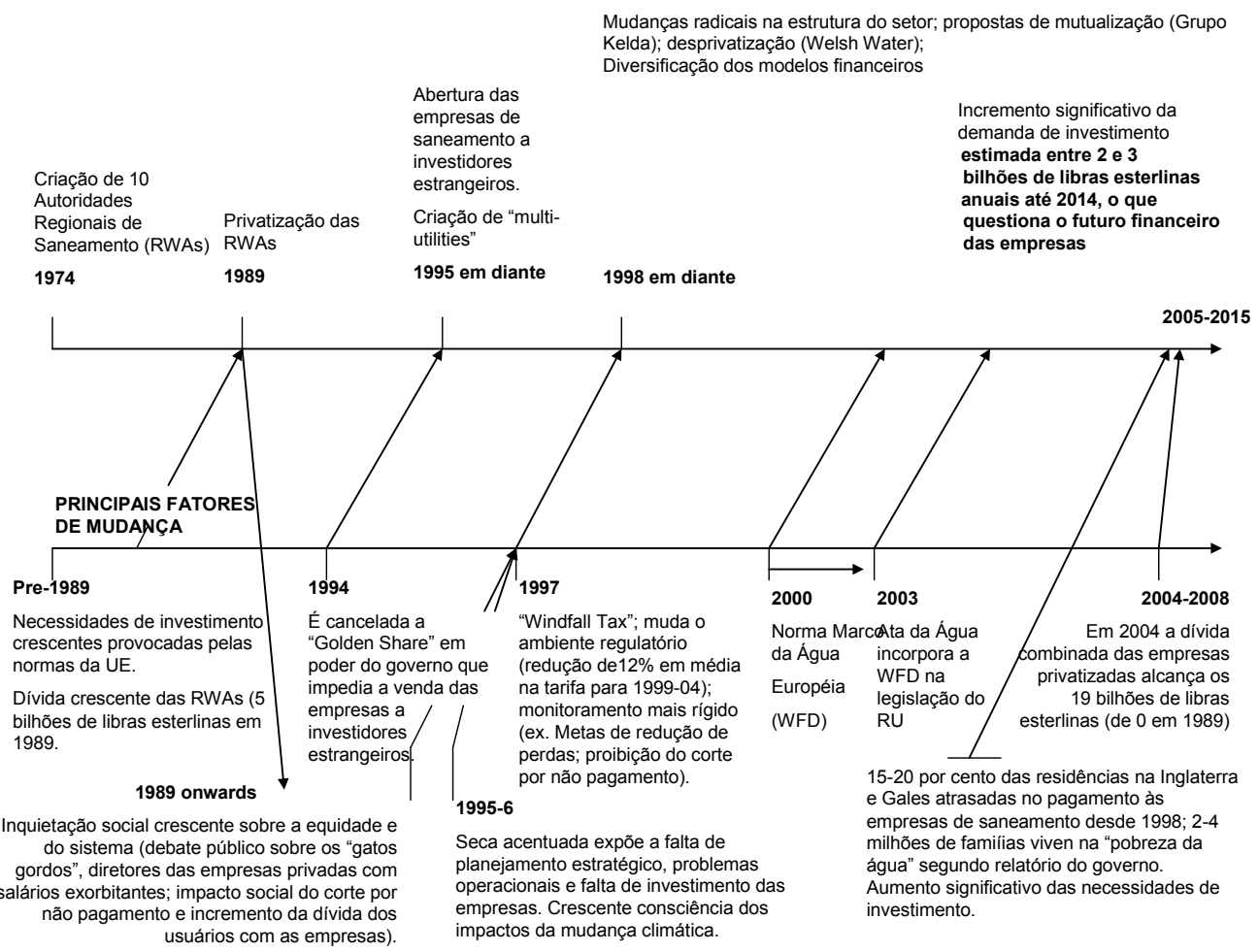




\section{A participação do setor privado nos serviços públicos de abastecimento de água e esgotamento sanitário: resposta aos fracassos do setor público? ${ }^{1}$}

\section{Introdução²}

Este artigo examina o que chamamos as "políticas dominantes de Abastecimento de Água e Esgotamento Sanitário” (AAES) 3 que foram implementadas desde os anos 80 para reorganizar a provisão desses serviços públicos em todo o mundo. Estas políticas são parte integrante do processo de gobalização econômica, que tem sido caracterizado pela expansão global de certas formas de participação do setor privado (PSP), ${ }^{4}$ incluindo

1 Uma versão prévia foi publicada em: Alceu de Castro Galvão Junior e Marfisa Maria de Aguiar Ferreira Ximenes (eds.), Regulação: Normatização da Prestação dos Serviços de Água e Esgoto, Fortaleza, Brasil: Associação Brasileira das Agências de Regulação (ABAR) e Agência Reguladora de Serviços Públicos Delegados do Estado do Ceará (ARCE), 2008, pp. 161-201

20 artigo traz os resultados de pesquisa do projeto PRINWASS (Programa da $5^{\mathrm{a}}$ Estrutura da Comissão Europeia, INCO-DEV, Contrato: PL ICA4-2001-10041, http//www.prinwass.org), que estudou a implementação de projetos PSP em AAES em nove países da África, Europa e América Latina, cuja metodologia e lista de casos podem ser consultados no website do projeto: http//www. prinwass.org/proreports.shtml. Versões previas de este material foram publicadas previamente em inglês.

3 Por "políticas dominantes de AAES" queremos nominar as políticas de desregulamentação e re-regulamentação, liberalização, comodificação e expansão do setor privado em AAES que têm sido a prioridade das instituições financeiras internacionais (IFIs) (ex: Banco Mundial), agências de ajuda (ex. USAID) e os governos dos países da OECD desde os anos 80. Sabemos que há diferentes abordagens dentro desta tendência política geral, e que não há posição monolítica mesmo dentro das instituições que têm estado à frente dessas políticas.

4 Evitou-se usar o conceito de "privatização" onde possível porque o seu uso na literatura e em debates públicos frequentemente obscurece o fato de que o setor privado têm sempre estado envolvido em diferentes formas na provisão de AAES e continuará a fazer assim. Portanto, escolheu-se o conceito mais amplo de "participação do setor privado" (PSP) para referir ao processo em 
a de monopólios multinacionais privados de água. Dois indicadores de globalização em AAES são o significante incremento de fluxos internacionais de investimentos, que subiram de estimados 300 milhões de euros entre 1984 e 1990 para 25.000 milhões de euros durante o período 1990-1997, e o número de contratos envolvendo várias premissas PSP, incluindo que: 1) utilidades de AAES dirigidas por instituições públicas são inerentemente ineficientes e subfinanciadas; 2) a PSP seria inerentemente mais eficiente na provisão de AAES; 3) a PSP contribuiria para reduzir o déficit do setor público proporcionando novos investimentos privados; 4) a PSP reduziria a interferência política e aumentaria a transparência; 5) a PSP ajudaria a ampliar a cobertura dos serviços para a população pauperizada; e 6) a PSP melhoraria a equidade social. Concluímos porém, que a evidência empírica emergindo de pesquisa recente e atual não dá apoio a estas constatações ${ }^{5}$.

Além do mais, o artigo indica que as reformas de política de AAES não foram dirigidas primariamente pela necessidade de resolver os problemas específicos que afetam esses serviços. Da nossa perspectiva, estas políticas são partes integrantes das "politicas dirigidas ao mercado" características do projeto político de globalização neoliberal (LEYS, 2001) que é dirigido para recentrar a organização da vida social ao redor de principios de mercado. $\mathrm{O}$ artigo também previne que apesar do crescente reconhecimento retórico pelas instituições financeiras internacionais (IFIs) e outros atores de que políticas de AAES falharam em conseguir seus objetivos declarados, na prática a continuação dessas iniciativas sob diferentes nomes e por diferentes meios, e as forças inerciais desatadas por estas políticas desde os anos 80 , vão continuar a influenciar e dar forma negativamente a reais desenvolvimentos no assunto (CASTRO, 2013). Portanto, em face ao desafio posto

geral e restringir o uso de "privatização" para aqueles casos específicos envolvendo a transferência de direitos de propriedade sobre fontes de água ou infraestrutura de água para o setor privado (ex: o completo modelo de venda de patrimônio (full divestiture), conforme implementado na Inglaterra desde 1989 até a data).

5 Fornecemos aqui um sumário de pareceres, e portanto o leitor pode achar útil também checar os relatos do projeto original listados nas Referências, como também nossas análises complementares do processo que foram publicadas em outras partes (CASTRO, 2007a, 2007b, 2008). 
pelos Objetivos de Desenvolvimento do Milênio (ODMs) ${ }^{6}$, o artigo conclui que há uma urgente necessidade de mudança radical nas opções de política distante da promoção explícita ou implícita da PSP como a solução para os graves problemas afetando o AAES em termos mundiais. Esforços deviam ser dirigidos para o fortalecimento do serviço público, particularmente no nível regional e local, criando oportunidades para a colaboração Norte-Sul e Sul-Sul, incluindo o apoio do desenvolvimento de parcerias público-público e público-comunitário, e promovendo governabilidade democrática e cidadania substantiva no gerenciamento da água e dos serviços públicos de abastecimento de água.

\section{As reivindicações de políticas dominantes de AAES}

As reivindicações apresentadas por promotores da PSP como solução chave para a crise no AAES são de amplo espectro e não é possível dar um tratamento abrangente da matéria num simples artigo. Por esta razão nos concentraremos aqui em alguns aspectos do que identificamos serem as principais justificativas usadas para promover estas políticas, como sumarizado por um documento do Banco Mundial:

A participação privada oferece enorme potencial para melhorar a eficiência dos serviços de infraestrutura, estender seu fornecimento aos pobres, e aliviar a pressão sobre orçamentos públicos que tem sido por muito tempo a única fonte de financiamento. O encorajamento de mais envolvimento privado requer que os governos mudem seu papel - não mais fornecendo diretamente serviços de infraestrutura, mas conduzindo o novo negócio de fomentar a competição entre fornecedores privados, regulando onde a competição é fraca, e apoiando o

6 A meta do ODM é de reduzir pela metade a proporção de população global que carece de acesso a AAES até 2015. No momento de se estabelecer os ODM, estimava-se em $17 \%$ a população mundial que não tinha acesso a água segura, e 40\% não tinha provisão de saneamento básico (UN 2000, 2002). A evidência recente sugere que o progresso em atingir essas metas tem sido realmente decepcionante. 
setor privado em geral (BANCO MUNDIAL, 1998, p.I; ver também SAVEDOFF; SPILLER, 1999).

Em acréscimo, tem também sido discutido que a expansão do PSP seria a mais adequada ferramenta "tanto para preencher os Objetivos de Desenvolvimento do Milênio (ODMs) e para contribuir ativamente para a justiça social no mundo inteiro" (BALEN, 2006, p. 4; IDB, 1998, p. 120; BANCO MUNDIAL, 2006). De outro ângulo, autores que promovem as políticas dominantes de AAES argumentam que não há particular razão pela qual AAES deveria ser categorizada como bem público ${ }^{7}$ que têm que ser excluído do mercado (ROTH, 1988; TRICHE, 1999), e alguns tem afirmado que "o argumento em favor da provisão de [suprimento urbano de água] têm sido tradicionalmente baseado na falsa premissa de que é um bem público" (NICKSON, 1966, p. 25), que teria levado as pessoas a acreditar erroneamente que AAES é um "serviço público" ou mesmo um "bem social” (WSP-PPIAF, 2002, p. 8-10). A campanha neoliberal para apagar a noção de que AAES são bens públicos ou sociais e reorganizar a provisão destes serviços como mercadorias foi incluso aderida pelo Programa de Assessoria da Água no Mundo da UNESCO, que reserva o status de bem público para atividades tais como a proteção do ambiente aquático e da biodiversidade mas define o suprimento de água e o esgotamento sanitário residenciais como "mercadorias privadas" (UNESCO, 2006, p.409).

Também, a literatura de tendência dominante fica repetindo que a "transferência de instituições e empresas públicas [AAES] para a propriedade privada pode trazer substanciais melhorias na eficiência produtiva” (LEE,

7 A noção de que serviços essenciais tais como AAES são "bens públicos" foi desenvolvida no processo que desde o fim do Século IX levou primeiro à crescente regulamentação de serviços prestados por empresas privadas, tais como o suprimento de água, e depois à municipalização e então o Estado absorveu estes serviços. Economistas do "Welfare State" argumentaram que existem "falhas de mercado" isto é situações onde o mercado não fornece uma eficiente alocação de recursos, que desafiou os clássicos princípios da economia do laisez-faire, tais como, que os mercados são auto-reguláveis e proporcionam uma racionalidade para a intervenção do setor público. A literatura da economia do "welfare" costumeiramente discute típicos exemplos de falhas de mercado como "monopólios naturais", "grandes economias de escala levando a custos decrescentes", "externalidades", "bens públicos puros" e "bens de mérito". A "falha de mercado" surge porque nessas situações particulares os mercados privados são improváveis para fornecer o padrão mais eficiente de bens e serviços preferidos pelos consumidores (ROTH, 1987, p.6-7; LEE, 1999). 
1999, p. 101), e que "a provisão privada competitiva pode ser a mais eficiente forma de organização para a entrega de serviços de água” (ROTH, 1988, p. 7). Como citado antes, o Banco Mundial assegurou oficialmente a superioridade da provisão de AAES privada sobre a pública (BANCO MUNDIAL, 1998). Além do mais, experts de proa no Banco abertamente adotaram uma posição extrema pró-mercado livre e pediram "completa privatização dos recursos de água" e a criação de "monopólios privados não regulados" para resolver a crise do AAES nos países em desenvolvimento (BROOK COWEN; COWEN, 1998, p. 22-23). Esta chamada para a provisão desregulamentada de AAES foi também defendida por autores que argumentam que "a privatização parece ser necessária, porém não suficiente," ela deve ser complementada com a competição, a qual se "efetiva, [...] pode substituir a regulação para serviços em rede e daí aumentar a eficiência” (NEWBERRY, 1999, p. 386).

Estas e outras justificativas para a expansão de PSP em AAES que podem ser encontradas na literatura de tendência dominante nos levou a formular um número de questões de pesquisa: Qual é a evidência histórica ou empírica para apoiar estes argumentos? Qual foi o real resultado da implementação destas políticas desde os últimos anos da década dos 80 ? Que lições podemos aprender deste processo?

\section{Background histórico}

Considerando a evidência histórica, políticas de AAES dominantes tendem a ignorar, se não mesmo deturpar o registro histórico da mudança de provisão de AAES privada para pública que teve lugar primeiro na Europa e nos EUA e depois em todas as partes desde o fim do Século XIX. Um caso em questão é a referência enganosa para a Inglaterra no Século XIX no Relato do Desenvolvimento Mundial do Banco Mundial de 2004. O relato dedica um box para a "Participação privada na história" onde os autores louvam os monopólios privados que serviram Londres no século dezenove como bem sucedidos e até mesmo sugerem que essas companhias privadas teriam contribuido para a universalização de AAES na referida cidade (BANCO MUNDIAL, 2003). Não somente é este um grosseiro erro histórico, mas o relato falha em mencionar o fato de que a performance abaixo do padrão 
de AAES privado na Inglaterra do Século XIX levou à municipalização dos serviços (HASSAN, 1998; LASKI et al., 1935; MILWARD, 1991), e no caso de Londres, a assumir a direção dos oito monopólios de água privada não regulados que serviam a metrópole por um joint board de autoridades locais em 1902 (MWB, 1949). Na Inglaterra, no fim do Século XIX havia aceitação geral de que a realização de justiça social na provisão de AAES não poderia ser deixada para o desregulado trabalho das forças de mercado e que assegurar o acesso universal à água limpa e a disposição segura de excretas eram um dever moral da comunidade (LUCKIN,1986; WARD, 1997; MUKHOPDHYAY, 1975; GOUBERT, 1986). Em consequência, serviços essenciais como os de AAES, que no passado haviam sido entregues como mercadorias privadas (disponível somente para pessoas que podiam pagar por elas), foram reconceitualizadas como bens públicos cuja provisão tornou-se uma responsabilidade do Estado e seu acesso universal se tornou um direito social da cidadania. Por fim, a conquista de tal amplo consenso, que era apoiada até mesmo por alguns defensores do mercado livre daquele tempo, levou à universalização dos serviços públicos de AAES no País. Similares processos tiveram lugar em outros lugares da Europa, incluindo a França, país que produziu as empresas privadas que hoje dominam o mercado global de AAES (JUUTI et al., 2006; GOUBERT, 1986; PEZON, 2000).

O processo foi similar nas Américas. Enquanto em 1806 ao redor de 94\% dos serviços públicos de abastecimento de água nos EUA eram privados, até $1896,53 \%$ tinham já sido incorporadas ou diretamente construídas pelo setor público, uma tendência que era especialmente significante nos maiores centros urbanos. Sistemas de esgotamento sanitário, como na Inglaterra, eram quase exclusivamente um empreendimento do setor público e seu desenvolvimento não começou até a segunda metade do Século XIX (HUKKA; KATKO, 2003; MELOSI, 2000; OGLE, 1999; WARNER, 1987; SCHULTZ; MCSHANE, 1978). A situação da América Latina se assemelhava às experiências da Europa e dos EUA - monopólios privados de água que serviam bairros ricos nas mais importantes cidades falharam ao expandir os serviços para cobrir a crescente população e foram progressivamente incorporados pelo setor público desde o fim do Século XIX (ver CATENAZZI; KULLOCK, 
1997, para a Argentina, CONOLLY, 1997 e ABOITES AGUILAR, 1998, para o México; PÉREZ-RINCÓN, 2002, para a Colômbia; SWYNGEDOUW, 1999, 2004, para o Equador; REZENDE; HELLER, 2002, para o Brasil).

Embora haja uma literatura muito rica sobre a história do AAES, documentos da política dominante ou falham consistentemente ao fazer alguma referência para isso ou tendem a representar mal o real desenvolvimento. O fato de que a universalização do AAES em países desenvolvidos foi conseguida somente porque o setor público interveio num campo previamente dirigido como negócio privado para lucro é completamente ignorada e substituída pelas prescrições da política dominante. Esta situação foi recentemente reconhecida, relutantemente, pelo Banco Mundial, que admitiu que seria errado

concluir que o governo deveria desistir e deixar tudo para o setor privado. [...] Se indivíduos são deixados à propria sorte, eles não darão níveis de educação e saúde que eles coletivamente desejam $[. .$.

Isto não só é verdade na teoria, mas na prática nenhum país conseguiu melhorias significativas na mortalidade infantil e educação primária sem o envolvimento governamental. Além do mais, como mencionado antes, o setor privado ou a participação de ONG na saúde, educação e infraestrutura não ocorre sem problemas - especialmente em atingir os pobres. A posição extrema é claramente não desejável (BANCO MUNDIAL, 2003, p.10-11). ${ }^{8}$

Resumindo, o registro histórico não dá suporte à reivindicação de que PSP pode dar a solução nos casos em que o setor público fracassa em fornecer acesso universal para o AAES nos países em desenvolvimento.

8 Nesta passagem o Banco Mundial implicitamente reconheceu que outra reivindicação para justificar a PSP, de que ajuda a expandir a cobertura de AAES para os pobres, é também imperfeita. Nós discutimos esta reivindicação em mais detalhe em outra parte (CASTRO, 2007a; LAURIE, 2007). 


\section{Evidências de pesquisa recente e em curso}

Uma das principais reivindicações para se promover a expansão PSP em AAES têm sido a necessidade de trazer fundos privados novos para "aliviar a pressão sobre os orçamentos públicos que tem sido por longo tempo a única fonte de financiamento" (BANCO MUNDIAL, 1998).

No entanto, depois de crescente evidência de que investimentos privados esperados da implementação de políticas dominantes de AAES não se materializaram, o Banco Mundial e outros atores, incluindo as próprias empresas privadas, reconheceram que esta reivindicação era imperfeita desde o princípio. Conforme afirmado por Katherine Sierra, a vice-presidente de Infraestrutura e Desenvolvimento do Banco Mundial durante o Quarto Fórum Mundial da Água no México:

Sempre o peso do investimento em água tem que ser fornecido pelo setor público [...] dada a magnitude dos recursos necessários, nos anos 90 nós acreditamos que o setor privado poderia fazer importantes investimentos para salvar o setor da água. No entanto, não tem havido muito investimento privado e $90 \%$ dos recursos vieram do setor público mesmo quando a participação privada estava no seu pico (LA JORNADA, 2006; ver também BANCO MUNDIAL, 2003, p.10-11; KLEIN, 2003; HALL et al., 2003, p.5-7).

Efetivamente, nossa pesquisa encontrou um padrão consistente nos casos estudados, de onde o real investimento por companhias privadas era muito modesto ou mesmo negligenciável (Quadro 1). 
Quadro 1. Aspectos econômicos financeiros de PSP: sumário de pareceres

- Rendimentos de taxas de AAES - com algumas variações de caso para caso são as mais importantes fontes de fundos para operadores de AAES, se públicos, privados ou mistos.

- Subsídios diretos do Estado e empréstimos são as próximas mais importantes fontes de financiamento; estas fontes estão crescentemente se tornando um componente estrutural no financiamento de AAES.

- "Recursos novos" (capital privado genuíno) têm um papel significantemente menor.

- Como tendência geral, a formação de capital bem abaixo do esperado com um padrão de:

- recorrente não conformidade de compromissos de investimento de acordo com o contrato;

- renegociação de contratos para reduzir os compromissos de investimento original da empresa privada ou imediata transferência do ônus do investimento de volta para o setor público.

Fonte: Azpiazu; Schorr (2004).

Um exemplo proeminente é o caso de Águas Argentinas em Buenos Aires, concessão privada concedida em 1993 para um consórcio liderado pela empresa privada francesa Suez, que foi finalmente cancelada pelo governo argentino em março de 2006. Conforme mostrado na Tabela 1, o real investimento privado neste projeto representava apenas justos 2,6\% do total de fontes de recursos da empresa entre 1993 e 2001. Este caso é significante porque naquele momento foi louvado pelo Banco Mundial como uma história de sucesso e um modelo a seguir (BANCO MUNDIAL, 2003, p.168). No entanto, este exemplo mostra que a reivindicação de que a PSP traria investimento privado novo e contribuiria para aliviar a pressão sobre orçamentos públicos não é sustentada pela evidência empírica. 
Tabela 1. Fontes de financiamento - Águas Argentinas (maio 1993-dez. 2001)

$(\mathrm{em} € \mathrm{e} \%)$

\begin{tabular}{lcc}
\multicolumn{1}{c}{ Fonte } & $\boldsymbol{\epsilon}$ (milhões)* & Percentagem \\
\hline Receita & $2,976,5$ & 78,1 \\
Aumento líquido do débito & 577,4 & 15,2 \\
Aporte de Capital de sócios & 98,1 & 2,6 \\
Outros rendimentos financeiros & 114,5 & 3,0 \\
Outros & 44,2 & 1,1 \\
Total & 3810,6 & 100,0 \\
\hline
\end{tabular}

Fonte: Azpiazu; Schorr (2004).

$*_{1}$ US\$ $=€ 0,8171$

Este padrão de baixo ou negligenciável investimento privado é constante por meio dos diferentes casos de estudo, embora com variações, e os pareceres são também consistentes com outros resultados de pesquisa (HALL, 2002, 2004, 2006; HUKKA; KATKO, 2003). Assim, representantes dos IFIs e empresas privadas globais de água reconheceram abertamente que a reivindicação sobre novos investimentos privados não se mostrava à altura das expectativas (AYLARD, 2004; LABRE, 2004; PRINWASS, 2004).

Outra reivindicação usada para justificar a política dominante de AAES é que os serviços públicos seriam irremediavelmente envolvidos num círculo vicioso de ineficiência e somente poderiam ser salvos por meio de reformas de PSP. Como outro documento relacionado com o Banco Mundial argumenta:

serviços públicos dirigidos em países em desenvolvimento têm sido singularmente mal sucedidos no fornecimento de um suprimento de água confiável e serviços de esgotamento sanitário. A maioria encontra-se trancado em uma espiral de incentivos de fraca performance, baixa vontade de pagar dos clientes, insuficiência de fundos para manutenção levando à deterioração de ativos, e interferência política. Uma medida 
comum de reforma está trazendo para seu interior o setor privado para fornecer expertise especializado, gerenciamento eficiente e novas fontes de capital (WSP; PPIAF, 2002, p.8-10).

Não obstante, a evidência colhida na pesquisa sugere que quando consideramos o processo de AAES como um todo, da captação de água à disposição final dos esgotos sanitários, os serviços privados tendem a funcionar tão mal quanto as tão criticadas entidades públicas (TORREGROSA et al., 2004). Inversamente, os serviços de AAES que funcionam melhor nos países estudados tendem a ser empresas públicas e não privadas, tal como nos casos do Brasil e México.9 A este respeito, a evidência mostra que embora as operadoras de água privadas tendam a introduzir significantes melhoramentos na eficiência comercial e aumentar os lucros, elas também tendem a subinvestir na renovação da infraestrutura, até mesmo falhando no cumprimento de acordos de investimento realizados por contrato. O que pode ser detectado é que as empresas privadas tendem a introduzir significantes melhoramentos nas tecnologias de gerenciamento dos usuários tais como sistemas de faturamento e coleta de taxas, e também expandindo a cobertura do suprimento de água para incluir novos clientes em setores comercialmente viáveis. Por exemplo, em Buenos Aires e Cochabamba a expansão das redes e o investimento na renovação de ativos, manutenção, e melhoria da qualidade do serviço foram principalmente dirigidos para as áreas que ofereciam a maior lucratividade (AZPIAZU et al., 2003; CRESPO et al., 2003). Também, no caso do Brasil (Limeira, Niterói e a Região dos Lagos), Buenos Aires e Aguascalientes, empresas privadas fizeram substancial

9 O fato bem estabelecido de que muitos operadores tanto em países em desenvolvimento como nos desenvolvidos têm níveis máximos de eficiência global têm sido largamente ignorado ou negligenciado também na literatura dominante. Por exemplo, no Brasil e no México depois de aproximadamente duas décadas de experiência de PSP na área de AAES, segundo o estudo as empresas de melhor desempenho eram públicas: SABESP (empresa estatal estadual de abastecimento de água e esgotamento sanitário de São Paulo) e DMAE (o departamento municipal de água e esgoto de Porto Alegre, no Rio Grande do Sul), entre muitas outras no Brasil, e a empresa estatal de água de Nuevo León SADM no caso do México. Na Colômbia, os multiserviços públicos como Empresas Públicas de Medellín criados em 1955, pertencente à municipalidade de Medellín, é outro proeminente exemplo de eficiência sustentada do setor público que raramente (talvez nunca) é mencionada na literatura dominante. Ver também Balanyá et al. (2005). 
progresso no melhoramento da data base do usuário, medida de consumo e faturamento de AAES (VARGAS, 2003; AZPIAZU et al., 2003; TORREGROSA et al., 2003). As operações privadas nos casos quenianos de Nyeri e Tala também reportaram significantes melhoras no gerenciamento global do usuario, do registro à medição e cobrança (NYANGERI NYANCHAGA, 2003). Não obstante, tem havido um claro desequilíbrio entre os esforços feitos para melhorar a eficiência comercial das empresas e aumentar a eficiência global dos sistemas. Isto tem levado a ampla insatisfação do usuário porque a crescente eficiência na cobrança e coleta de taxas e tarifas - acompanhada por elevados aumentos em tarifas de água - é raramente comparada com mais alta qualidade de serviço. Por exemplo, em Buenos Aires, o ente regulador, a Entidade Tripartite do Mecanismo de Serviços de Saneamento (ETOSS), e o Ouvidor tiveram que intervir muito frequentemente devido ao movimento de protestos dos usuários contra irregularidades na implantação das novas tecnologias de gerenciamento dos usuários pelas empresas privadas (e.g. erros no registro e na cobrança de faturas, supertaxação, ordens de pagamento injustificadas, etc.), o que levou à repetida aplicação de multas e outras sanções tendo alguns casos, chegado à Suprema Corte de Justiça (AZPIAZU et al., 2003). Outro exemplo é o caso de Aguascalientes, México, onde dada a pobre condição da rede de distribuição que transporta uma mistura de água e ar, a melhoria da leitura da água levou a um injusto aumento no volume de água/ar cobrados que afetou, em particular, os setores mais carentes da população. Compreensivelmente, de acôrdo com uma pesquisa levada a cabo pela municipalidade um terço dos usuários se queixou que a empresa privada continuava cobrando e pressionando a coleta de taxas sem considerar o fato de que seu suprimento de água potável era intermitente e não confiável (TORREGROSA et al., 2003).

Analistas do Banco Mundial reconheceram que a PSP têm tido resultados "mistos" no suprimento de AAES urbano (RICHARD; TRICHE, 1994, p.4), e que "o setor privado ou participação de ONG na saúde, educação e infraestrutura não é isenta de problemas - especialmente em alcançar os pobres" (BANCO MUNDIAL, 2003, p.11). Estas conclusões coincidem com os achados das nossas pesquisas, que mostram que as desigualdades sociais 
estruturais no acesso ao AAES que existiram por décadas nos países desenvolvidos, sob monopólio do setor público, não foram revertidas e foram bastante exacerbadas por essas políticas dominantes de AAES. Os operadores privados precisam focar seus investimentos para assegurar um retôrno de capital para os seus acionistas, que é sua principal prioridade, e, portanto, expandir a rede para os pobres claramente não têm sido parte de sua estratégia, com raras excessões que tendem a confirmar a regra (LAURIE, 2007; UN-HABITAT, 2003). Eles, confessadamente, somente expandiriam os serviços para os pobres se isto for um termo do contrato original. Não obstante as empresas não têm cumprido ao pé da letra nem os contratos originais, particularmente com respeito à expansão da infraestrutura para cobrir as populações mais carentes. Mesmo quando os requisitos de investimento são estipulados no contrato, na ausência de regulamentação apropriada e controle público, a não conformidade por provedores privados têm sido o padrão na maioria dos casos estudados.

\section{De cidadãos a consumidores?}

Outro aspecto crucial da política dominante de AAES é a tentativa de apagar a noção de que estes serviços são bens comuns ou sociais que deven ser fornecidos independentemente da situação financeira dos usuários, isto é, independente de sua capacidade de pagar por eles. ${ }^{10} \mathrm{~A}$ política visa remarcar estes serviços (e podemos acrescentar todos os outros serviços essenciais, tais como, a saúde pública ou a educação básica) classicamente conceitualizados como bens sociais desde o fim do Século XIX e considerados como direitos sociais da cidadania desde a Segunda Guerra Mundial, como bens privados, como mercadorias. Consequentemente, os próprios usuários tiveram que ser recategorizados: não haveria direito social para AAES como tal, mas somente o direito que pode ser ganho comprando-os no mercado, isto é, direitos de consumidor.

10 É importante notar aqui que a noção de bem público ou social não implica que estes serviços devam ser gratuitos, embora as duas noções são frequentemente confundidas em debates atuais. 
Como uma nota de cuidado, está claro que o processo de transformação de serviços essenciais tal como água potável em mercadorias têm estado em progresso por décadas a despeito de seu status sancionado de direitos sociais e bens públicos, como demostrado pelo fato bem conhecido de que milhões de pessoas que compõem a população pauperizada urbana em países em desenvolvimento têm que comprar água insegura de vendedores privados não regulamentados a preços várias vezes mais elevados do que aqueles cobrados pelo serviço público na mesma cidade. Naturalmente, o crescimento exponencial da indústria de água engarrafada, tanto em países desenvolvidos como nos em desenvolvimento, é outro exemplo. Não obstante, o processo de transformação de serviços essenciais em mercadorias têm sido bem mais lento no caso de AAES por rede, e, como já discutido, um dos objetivos explícitos das políticas dominantes de AAES têm sido mover este processo para diante acelerando a marketização destes serviços e eliminando a noção de que eles constituem um bem público ou um direito social universal.

Fazendo assim, os principais esforços da política dominante de AAES foram focados em transformar a identidade do fornecedor do serviço por meio do processo de reforma do setor público e expansão PSP. Uma importante implicação da transição para uma maior PSP recebeu muito menos atenção: aquilo de transformar a identidade do cidadão de titular do direito social de acessar o AAES como um bem público em um consumidor de AAES e cliente de um provedor privado. Talvez as políticas dominantes assumiram que a transição seria mecânica e que as pessoas simplesmente aceitariam as mudanças uma vez que o sistema baseado em PSP de provisão fosse colocado no lugar. No entanto, partidários da PSP deram pouca ou nenhuma importância à resposta potencial que essas políticas obteriam entre a população. Assim, a introdução de PSP nos serviços de AAES durante a década de 90 tomou a forma de uma experiência de engenharia social que assumiu que os valores, práticas, normas culturais, interesses materiais e relações sociais associadas com a água e com os serviços de água poderiam ser transformados por meio de mudanças legal-institucionais.

Por exemplo, o governo mexicano anunciou em 1993 que "a água tem cessado de ser um bem grátis e a partir de agora ela é um recurso que tem 
um valor econômico, e a sociedade deve pagar por ela" (CNA, 1993, p. 11; ROGOZINSKY, 1993, 1998). A suposição de que a água no México era grátis antes dessas reformas é uma inverdade, porque na prática para a maioria dos mexicanos a água potável segura tinha já se tornado um bem caro havia muito tempo. Mais importante, a suposição de que a transformação de "grátis" para bem econômico pode ser operada por meio de mecanismos legais e institucionais somente está no coração do fracasso experimentado por essas políticas no México e outras partes. A tentativa da engenharia social associada com políticas dominantes de AAES enfrenta não somente os problemas específicos envolvidos na transformação da água de bem "público" ou "social" em mercadoria, mas também um amplo espectro de problemas proporcionados pela tentativa de reduzir os valores conflitantes e interesses materiais representados por diferentes atores que operam no AAES a valores e interesses de mercado.

De qualquer maneira, este exercício de engenharia social não foi bem sucedido e a tentativa de acelerar essa transformação de AAES em mercadorias encontrou significantes desafios incluindo forte oposição dos cidadãos, que em casos extremos levou ao cancelamento de contratos de PSP (ex. Tucumán na Argentina em 1997, Cochabamba na Bolívia em 2000, Grenoble na França também em 2000, Gales no Reino Unido em 2001, Atlanta nos EUA em 2003, Buenos Aires na Argentina [Azurix] em 1999, Dar Es Salaam na Tanzânia em 2005, Buenos Aires na Argentina [Aguas Argentinas] em 2006, La Paz-El Alto na Bolívia em 2006, etc.), e até mesmo a proibição de introduzir a PSP em AAES (e.g. Chaco, Argentina em 1994, e Uruguai em 2004). Mais recentemente, a cidade de Paris, berço das multinacionais Suez e Vivendi que foram atores centrais em muitos dos casos estudados, também cancelou os contratos de PSP existentes com essas empresas e voltou a colocar a gestão dos AAES em mãos públicas em 2010 (PIGEON et al., 2012;). Conhecimento ou real experiência da inquietação dos usuários causada pela introdução de políticas de PSP levaram ao reconhecimento da necessidade de "envolvimento do usuário" ou "participação" para induzir a aceitação pública destas políticas. Assim, na maioria dos casos examinados em nosso estudo, havia uma explícita referência para a crucial importância do envolvimento do cidadão e sua participação para assegurar o sucesso da 
implementação da PSP. Infelizmente, na maioria dos casos, isto foi meramente um dispositivo retórico e o significante envolvimento da cidadania, mesmo em seu papel de clientes individuais, foi largamente negligenciado no processo. Por exemplo, no México reformas de grande alcance foram introduzidas em 1992 na área da água, buscando substituir as tradicionais práticas clientelistas que caracterizavam as políticas de AAES do setor público, por uma "nova cultura da água" baseada no envolvimento cidadão, responsabilidade da comunidade, e provisão dos serviços pelo setor privado (CASTRO, 2006). Na Bolívia foi promulgada uma Lei de Participação Popular em 1994, visando promover mais envolvimento cidadão em negócios do governo local, que foi complementada pela criação de uma estrutura regulatória inter-setorial que levava em conta a participação na regulação dos operadores de AAES (CRESPO et al., 2003). Na União Europeia, a Diretiva Quadro Europeia da Água que passou no ano 2000, e que está sendo transposta para cada legislação nacional dos países, declara que o seu sucesso "repousa em cooperação íntima e ação coerente nos níveis da comunidade, do estado e das autoridades locais, como também sobre o fornecimento de informação, a consulta e o envolvimento do público, incluindo os usuários" (EU, 2000). Não seria difícil estender o número de exemplos deste formal reconhecimento da crucial importância de se envolver os cidadãos e os usuários dos serviços públicos de AAES. No entanto, há uma esmagadora evidência de que na prática, o envolvimento dos cidadãos, mesmo quando seus papéis são reduzidos ao de consumidores, têm sido altamente restrito em muitos casos, e, particularmente, em processos envolvendo reformas pró-PSP em AAES. A seguir é apresentada uma seleção de exemplos.

Por exemplo, o caso de Cochabamba é o único entre os casos estudados onde os direitos sobre os recursos de água estavam em jogo, quando a nova lei da água passou em 1999 e a concessão outorgada a um consórcio privado no mesmo ano ameaçou expropiar os direitos de água existentes dos fazendeiros indígenas do Vale de Cochabamba. De fato, direitos de água indígenas, baseados no que é localmente conhecido como "usos e costumes", foram negligenciados nas relevantes reformas de política levadas a cabo na Bolívia durante os anos 1990 tal como o Plano Básico de Saneamento (1992-2000). Além do mais, ao transferir todos os direitos da água para a 
companhia privada, incluindo os direitos de extração de água previamente nas mãos do operador municipal SEMAPA, a expropriação se estendia para a comunidade inteira, que possui os direitos de água por meio do ente municipal. Esta foi uma das razões-chave para a mobilização de massa que levou ao cancelamento da concessão privada em março de 2000, menos de um ano desde a assinatura do contrato (CRESPO et al., 2003).

$\mathrm{Na}$ Bolívia, a estrutura institucional para a participação do usuário foi limitada à criação de canais formais para a apresentação de queixas e apelos sobre deficiências do serviço. Há também uma previsão pela qual o ente regulador têm o poder de convocar audiências públicas para consultar os usuários sobre items particulares. Em geral, esses instrumentos não ajudaram a promover um envolvimento significante dos cidadãos, como demostrado pelo fato de que uma audiência pública levada a cabo em Cochabamba, em dezembro de 1999, para consultar os usuários sobre o aumento de tarifas a ser implementada pela concessionária privada atraiu somente 14 participantes. Embora o regulador devesse agir em defesa dos interesses dos usuários, a percepção prevalescente entre a população era de que o interesse do operador privado de água estava recebendo prioridade sobre o da comunidade (CRESPO et al., 2003). Estes sentimentos foram mais acentuados porque a municipalidade foi também deixada de fora da discussão sobre os aumentos de tarifas, efetivamente cancelando o único outro mecanismo disponível para os cidadãos exercerem controle sobre o processo. Além do mais, as pessoas tinham sido alienadas desde o começo, porque o processo que levava à concessão tinha sido conduzido com completa desconsideração pelas preferências e opiniões dos cidadãos, em condições de segredo pelas quais informações essenciais tais como as obrigações contratuais e os planos financeiros do operador privado eram escondidos do escrutínio público por meio de uma cláusula de confidencialidade inclusa no contrato (CRESPO et al., 2003).

$\mathrm{Na}$ Argentina, a maioria das concessões para empresas privadas feitas durante os anos 90 foi levada a cabo contornando o Congresso (por meio do item especial "Decretos de Necessidade e Urgência") e evitando a consulta pública ou envolvimento do cidadão, tal como o caso de 1993 das Águas Argentinas, em Buenos Aires. Além do mais, concessões foram oferecidas 
na ausência de qualquer legislação anti-monopólio, entes de regulação específicos ou representação dos consumidores. No caso de Buenos Aires, sucessivas renegociações do contrato de concessão original seguiram o mesmo modelo favorecendo os interesses da empresa privada sobre o público. No extremo, o ente regulador ETOSS foi excluído de negociações cruciais em 1997 quando o ente tentou exercer algum grau de controle dada a clara falta de conformidade pela empresa privada com suas obrigações contratuais em relação a compromissos de investimento (AZPIAZU et al., 2003; AZPIAZU; CASTRO, 2012).

Outro aspecto crucial afetando a participação dos cidadãos em Buenos Aires foi a monopolização da produção, acesso e uso de informação vital sobre o funcionamento do operador privado, que resultou em que tanto os reguladores como as organizações de usuários ficaram dependentes da informação liberada pela empresa, o que deixou pouco espaço para a avaliação independente e monitorização da gestão. O papel das organizações de usuários foi somente definido depois que a concessão foi aprovada e era limitada a apresentar reclamações legais e administrativas. Após uma revisão do papel dos usuários, em face à crescente inquietação no fim da década de 90, o envolvimento do usuário permaneceu severamente restrito e era principalmente limitado ao engajamento das pessoas como fornecedoras de trabalho e materiais para a expansão da rede em bairros pobres, um programa que foi conjuntamente desenvolvido pela empresa privada e o escritório local de uma ONG internacional (UN-HABITAT, 2003). Embora essas formas de engajamento da "sociedade civil" fossem um passo adiante da alienação que os usuários sofreram no contrato de concessão original, eles ainda tinham pouco a dizer sobre cruciais aspectos da governança de AAES, especialmente no tocante a decisões sobre quem governa o sistema, como, a que custo e para quem. Finalmente, a concessão privada foi encerrada pelo governo Argentino em 2006, com base no alegado fracasso do operador privado cumprir com os compromissos contratuais (AZPIAZU; CASTRO, 2012).

No caso de Tucumán, o processo que conduziu à concessão da utilidade pública em 1995 foi anulado por falta de transparência e ampla suspeita de corrupção de funcionários públicos e políticos. As negociações foram 
levadas a cabo na ausência de debate público ou mesmo consulta, e os cidadãos foram também excluídos das atividades de controle e regulamentação previstas na estrutura regulatória e no contrato de licença. No entanto, em agudo contraste com o caso de Buenos Aires, o autoritário caráter do processo no fim resultou no prematuro colapso da concessão. O aumento de $106 \%$ aplicado às contas de água pouco depois de o operador tomar controle do serviço provocou ampla inquietação entre os usuários de água e acelerou a organização de uma ampla frente de oposição por meio de uma campanha "recusa a pagar" que teve a adesão das autoridades municipais, legisladores provinciais e trabalhadores que tinham sido suspensos do trabalho pela empresa privada. Em acréscimo, problemas com a qualidade da água fornecida e as extremas altas temperaturas do verão de 1995-96 pioraram a situação e o movimento de protesto cresceu rapidamente ao ponto de que $86 \%$ dos usuários, incluindo o comércio e departamentos governamentais se juntaram à desobediencia civil ao recusarem-se a pagar as contas de água (CRENZEL, 2003).

Em três casos estudo levados a cabo no Brasil, Limeira, Niterói e a Região dos Lagos, o padrão era bem semelhante: os processos que levavam à concessão foram envolvidos de controvérsia política, alegações de corrupção, e longos litígios no sistema judicial. Contra este pano de fundo, é possível talvez entender porque o antigo Diretor do escritório do Banco Mundial no Brasil, Sr. Vinod Thomas, declarou no fim de 2003 que "quando há o risco de que a privatização possa criar um monopólio, é melhor deixar os serviços nas mãos do Estado. ...[Ele se referiu] ao caso da Rússia, um país que nos últimos anos têm tido uma das piores performances em termos sociais, como um exemplo de processos de privatização que não deviam ter nunca acontecido" (Folha de São Paulo, 2003). Problemas similares estavam já afetando o processo de expansão de PSP no Brasil. Um traço comum nos casos brasileiros é o segredo envolvendo os contratos, especialmente a falta de informação sobre itens, tais como, as taxas autorizadas de retorno do investimento ou os detalhes do investimento comprometido e planos financeiros, o que tornava a monitorização regulatória e o escrutínio público impraticáveis (VARGAS, 2003). 
Inversamente, tem havido importantes exemplos do que pode acontecer quando os cidadãos são significativamente envolvidos no processo de tomada de decisão ou as autoridades locais têm algum grau de autonomia para decidir entre possibilidades alternativas, livres da pressão para introduzir a PSP vindo de condicionalidades de empréstimo ou a imposição de políticas dominantes de AAES pelo governo federal. Um de tais exemplos teve lugar na província de Chaco, na Argentina, quando em 1994, o governo provincial convocou uma consulta pública sobre a aceitabilidade de introduzir PSP no funcionamento dos serviços públicos, incluído o AAES. Os votantes maciçamente rejeitaram a opção de PSP e decidiram manter os serviços essenciais em mãos públicas. Este resultado da consulta, que era legalmente vinculante, tomou o establisment político de surpresa já que os mais importantes partidos políticos apoiavam, ou pelo menos não contestavam, o programa de longo alcance de expansão de PSP naquele tempo. Esta decisão foi inscrita na Constituição Provincial, a qual como resultado proibiu a introdução de PSP em seu território. Infelizmente para o Chaco, a democrática decisão tomada pelos cidadãos foi punida pelo governo federal, que excluiu a provincia do esquema de fundos para infraestrutura de AAES, parcialmente financiada pelo Banco Interamericano de Desenvolvimento (BID), porque o acesso aos fundos era condicionada pela introdução de PSP em AAES (ROZE, 2003).

Outros exemplos do que pode acontecer quando os cidadãos têm a oportunidade de expressar suas opiniões são fornecidas pelos processos participatórios implementados em várias cidades brasileiras, tais como Porto Alegre e Recife. O caso de Porto Alegre é muito melhor conhecido como um bem sucedido exemplo da participação cidadã na organização de serviços públicos (BANCO MUNDIAL, 2003). O Departamento Municipal de Água e Esgotos de Porto Alegre (DMAE), um serviço público municipal autônomo criado em 1961, é um dos melhores prestadores de serviços públicos de AAES no Brasil. Desde os anos 90, o DMAE se tornou repetidamente o alvo para a introdução de PSP. As razões para esta pressão não eram a necessidade de melhorar a eficiência da infraestrutura, aliviar orçamentos do setor público ou expandir o serviço para os pobres, porque o DMAE era auto-suficiente e já tinha conseguido altos padrões de eficiência 
e cobertura. As principais razões eram políticas, porque o governo federal estava empurrando uma agressiva política de expansão PSP com o apoio de IFIs como o Banco Mundial, o Fundo Monetário Internacional (FMI) e o Banco Interamericano de Desenvolvimento (BID). Os principais instrumentos desta política eram a nova Lei de Concessões (Lei $n^{\circ}$ 8.987) promulgada em 1995 pelo governo do então Presidente Fernando Henrique Cardoso, e o Programa de Modernização do Setor de Saneamento (PMSS) implementado pelo governo federal com financiamento do Banco Mundial. Neste contexto, o DMAE foi pressionado sistematicamente por representantes das IFIs com ofertas de empréstimos para financiar a renovação e expansão da infraestrutura sempre com a condição de que o serviço publíco deveria ser aberto à PSP. Estas ofertas, que, às vezes, alegadamente tomaram a forma de tentativas de suborno, foram consistentemente rejeitadas pelas autoridades do DMAE que almejavam manter a instituição em mãos públicas, graças ao alto nível de apoio público e político que eles tinham localmente. ${ }^{11}$

Em Recife, desde 1995, a Companhia Pernambucana de Saneamento (COMPESA) se tornou um alvo para o programa de PSP fomentado pelo governo federal. Em 1999/2000 os preparativos para a oferta de um lance estavam já bem adiantados com a concordância dos governos federal, estadual e municipal e com o apoio do Banco Mundial por meio do PMSS. Somado a isso, um empréstimo negociado com o Banco Mundial para investimento em infraestrutura básica foi amarrado à condição de que a COMPESA se tornasse aberta à PSP. Contudo, o inesperado sucesso eleitoral de uma aliança liderada pelo Partido dos Trabalhadores (PT) em Recife e outras importantes municipalidades da metrópole mudaram a dinâmica do processo, porque o PT venceu a eleição com um programa oposto às políticas dominantes de PSP nos serviços públicos. Em 2002, o governo municipal

11 Entrevista com o Eng. Atílio Todeschini, ex-diretor geral do DMAE e posteriormente vereador municipal, Câmara de Vereadores de Porto Alegre, Porto Alegre, janeiro de 2005. As "tentativas de suborno" se referem a situações onde se diz que funcionários das IFIs estavam tentando negociar empréstimos em troca de contratos de consultoria para companhias privadas dirigidas por eles mesmos, seus parentes ou amigos. Isto nos recorda da afirmação de Joseph Stiglitz de que a privatização conforme promovida pelas IFIs antes deveria chamar-se "subornação" (STIGLITZ, 2002, p.58). 
da Capital organizou a 1ª Conferência Municipal de Saneamento do Recife, abrindo o debate sobre o futuro dos serviços públicos na Cidade - junto com outros tópicos cruciais - num processo altamente participatório que levou a uma maciça votação a favor de se manter os serviços públicos, incluindo o AAES, em mãos públicas. Confrontado com o resultado da Conferência, e com a determinação das autoridades municipais em manter suas promessas de campanha, o governador do Estado concordou em congelar o processo de leilão. No entanto, mais pressão foi posta sobre o governo municipal para aceitar a introdução da PSP nos serviços públicos prestados pela COMPESA por meio das condições incluídas no empréstimo negociado com o Banco Mundial para a recuperação de áreas degradadas da Cidade. Foi somente após difíceis negociações levadas a cabo no Brasil e em Washington, e após a intervenção do governo federal do Brasil, que os negociadores do Banco concordaram em retirar a condicionalidade da PSP do contrato de empréstimo, como requerido pelas autoridades municipais de Recife na época.12

Estes são exemplos muito relevantes do que pode acontecer quando se dá a população uma significante oportunidade para participar e expressar suas preferências e isto é combinado com um minímo grau de autonomia para as autoridades locais e governos regionais. Infelizmente, como já foi mencionado, isto têm sido raramente o caso nas políticas dominantes promovendo PSP na área de AAES. Pode-se argumentar que embora retoricamente a participação social tenha sido reconhecida como um fator crucial para assegurar-se o sucesso de reformas de política de AAES (EC, 2002, 2003; GWP, 2002, 2003; UNDP, 2003), as práticas prevalentes continuam a alienar e excluir mais que incluir cidadãos no governo e no gerenciamento desses serviços.

12 Entrevista com o Eng. Antônio da Costa Miranda Neto, ex-Secretário de Saneamento da Prefeitura Municipal do Recife e Representante Internacional da Associação Nacional dos Serviços Municipais de Saneamento (ASSEMAE), Recife, 12 de dezembro de 2003. Nós omitimos os detalhes das negociações por razões de espaço, mas a entrevista forneceu boa evidência da força que as IFIs usaram condicionalidades de empréstimo para fomentar políticas de PSP nos países em desenvolvimento. As negociações finais para este projeto, chamado Prometrópole, teve lugar em Washington, em novembro de 2002, e o contrato foi finalmente assinado em 23 de junho de 2003. 
É importante, no entanto, situar esta crítica em perspectiva histórica. Deve ser reconhecido que a participação cidadã não têm sido uma característica das maneiras pelas quais os serviços de AAES têm sido governado e gerenciado no passado. Como apontado por John Dryzek, na tradição do racionalismo administrativo, o modelo altamente tecnocrático da entrega do serviço público que prevaleceu durante grande parte do Século XX e que têm sido o alvo das reformas do setor público desde os anos 80 , o princípio organizador era "deixe isso para os experts": esperava-se dos cidadãos que fossem passivos e obedientes beneficiários (DRYZEK, 1997).

Não obstante, deve ser também reconhecido que nas políticas dominantes desde os anos 80 , as oportunidades para uma participação cidadã substantiva são limitadas. A "participação" cidadã frequentemente e entendida como boa vontade por parte das pessoas para aceitar decisões já tomadas com pouca ou nenhuma consulta. Este não é um problema novo, e na maioria dos casos pode ser observado que lutas sociais para a democratização da governança da água são de longa data, como vividamente ilustrado pelas experiências analisadas dos países da América Latina. A despeito de um limitado grau de sucesso obtido durante os anos 80 por meio da experiência de descentralização em alguns países, a persistencia de arranjos políticos paternalistas e autoritários continuam a atrapalhar as possibilidades de aprofundar-se o exercicio da cidadania substantiva e a governança democrática. Infelizmente, a expansão de PSP promovida pela política dominante de AAES têm tendido a exacerbar problemas existentes e mesmo a criar novos, elevando o nível de contestação e inquietação cidadã, como refletido na aceitação declinante de políticas de PSP achado pela pesquisa de opinião do Latinobarômetro durante o período do estudo (Tabela 2). 
Tabela 2. Evolução do apoio público (\%) para PSP na América Latina*

(1998-2003)

$\begin{array}{cccc} & 1998 & 2002 & 2003 \\ \text { Costa Rica } & 60 & 32 & -- \\ \text { Brasil } & 51 & 38 & 33 \\ \text { Venezuela } & 51 & 38 & 32 \\ \text { México } & 49 & 28 & 31 \\ \text { Chile } & 51 & 22 & 29 \\ \text { Honduras } & 47 & 34 & 25 \\ \text { Colombia } & 39 & 23 & 24 \\ \text { Paraguai } & 46 & 19 & 23 \\ \text { Peru } & 44 & 32 & 22 \\ \text { Equador } & 52 & 40 & 20 \\ \text { Nicarágua } & 46 & 30 & 20 \\ \text { Bolívia } & 49 & 23 & 19 \\ \text { Guatemala } & 62 & 29 & 16 \\ \text { Uruguay } & 29 & 16 & 16 \\ \text { El Salvador } & 54 & 35 & 15 \\ \text { Argentina } & 32 & 14 & 12 \\ \text { Panamá } & 20 & 31 & 10 \\ \text { América Latina } & 46 & 28 & 22\end{array}$

Fonte: Lagos (2004)

* Percentagem de respostas positivas à questão: "Você concorda fortemente, concorda algo, discorda algo, ou fortemente discorda com cada das seguintes frases que eu vou ler: A privatização de empresas públicas/estatais foi benéfica para o país." A tabela só mostra resultados para as respostas "Concordo fortemente" e "Alguma concordância".

Os resultados da expansão do PSP têm sido catastróficos para os países em desenvolvimento e pobres, particularmente, se pensarmos em termos de oportunidades para conseguir atingir os ODMs em casos como o da Bolívia. ${ }^{13}$ A experiência têm sido também catastrófica para alguns

13 Um importante cálculo que está a miúdo faltando nos debates é o custo de introduzir a PSP nos países em desenvolvimento: o custo em termos de preparação de serviços públicos para a privatização. Somado a isto, em casos como a Bolívia: os contratos de PSP que fracassaram em Cochabamba (2000) e mais recentemente en La Paz-El Alto (2006) puseram uma pesada carga sobre o País, dado que os operadores privados processaram o governo boliviano, reclamando 
operadores privados que se aventuraram no programa de expansão de PSP com muito limitado conhecimento e entendimento das condições sócio-políticas e culturais locais. Como disse uma avaliação do então Vice-Presidente Executivo da Suez:

Eu gostaria de ter uma rápida visão para trás em 2002 e 2003, cujos desastrosos resultados balançaram nossas convicções até o íntimo: a exageradamente apressada expansão da água internacionalmente terminou em fracassos que foram dolorosos para todos nós; as aquisições pela ONDEO e SITA de empresas que deveriam ter sido fontes de crescimento em vez disso geraram perdas ou foram uma causa de preocupação. Nós fomos forçados a cair fora de projetos não lucrativos (Porto Rico, Atlanta, etc.) e a vender parte ou todas as companhias, tais como, Northumbrian e Cespa, cujo desenvolvimento nós não eramos capazes de financiar. Isto dolorosamente pôs à prova, no entanto, nossos comprovados modelos de negócios e nossas certezas (CHAUSSADE, 2004).

Esta experiência de fracasso de negócio é compartilhada por outros, ao ponto de que operadores globais de água anunciaram suas retiradas dos países em desenvolvimento. Nas palavras de um analista, "Pode alguém imaginar a inversão de moeda forte em projetos de água em países como as Filipinas, Argentina e Bolívia agora? (GWI, 2004). Esta questão fornece um insight da avaliação que empresas privadas globais de água fizeram a respeito do papel que elas podem desempenhar ajudando os países em desenvolvimento a conseguir os ODMs. Ela também dá mutatis mutandi, uma contribuição para a nossa própria avaliação das reclamações feitas nas políticas dominantes a respeito do papel do setor privado em resolver falhas públicas nos países em desenvolvimento.

compensação pela perda de futuros lucros da vida restante dos contratos. Uma similar situação é enfrentada pela Argentina em relação a numerosos contratos de PSP que falharam (AZPIAZU; CASTRO, 2012). 


\section{Conclusão}

Este artigo apresentou alguns dos achados chave e conclusões da pesquisa sobre políticas dominantes de AAES implementadas ao redor do mundo desde a década de 90. A evidência empírica derivada de nosso estudo não apoia as pretensões de que a PSP pode ser a solução para os fracassos prolongados do setor público, especialmente em países em desenvolvimento. Estes exemplos sugerem que a maioria dos argumentos usados para justificar a expansão de PSP ou são imperfeitos, como as pretensões de que a PSP pode fornecer o necessário investimento pela exploração de fontes de financiamento privadas ou que ele pode ser a melhor estratégia para expandir os serviços para a população pauperizada não servida, ou grandemente exagerado, porque a PSP não necessariamente produz níveis mais altos de eficiência global na provisão de serviços públicos de AAES. Quando observamos o ciclo inteiro do AAES desde a captação da água até a adequada disposição dos esgotos sanitários, os operadores privados tendem a evidenciar um pobre desempenho enquanto há excelentes exemplos de instituições/empresas públicas altamente eficientes e bem gerenciadas. Enquanto os operadores privados tendem a concentrar seus investimentos em ampliar os aspectos comerciais do negócio (e.g. medir e expandir a cobertura para água potável), eles tendem a negligenciar o investimento muito necessário em renovação da estrutura e no gerenciamento dos esgotos sanitários. Não há evidência nos casos estudados que operadores privados deem adequada atenção ao gerenciamento e planejamento ambiental ou de recursos naturais - que são componentes vitais das estratégias de sustentabilidade - mesmo quando essas atividades são estipuladas em contrato ou, de outra forma, sujeitas à estrita regulamentação.

Numa perspectiva histórica, mais do que ser conduzido por uma genuína procura por melhoramentos de eficiência e universalização do acesso ao serviço, as políticas de PSP dominantes formam parte de um ciclo pendular entre a expansão do setor público e privado que têm sido interligados com transformações nas estruturas sócio-econômicas dos países capitalistas líderes. Enquanto durante a maior parte do Século XX, e especialmente depois do período após Segunda Guerra Mundial, ao Estado foi 
dado um papel central como ator econômico-chave; no início dos anos 70, significantes mudanças na economia global transformaram completamente o peso relativo do Estado vis a vis outros atores, em particular o setor privado transnacionalizado. Uma das mais significantes consequências das políticas de AAES inspiradas pelo liberalismo de livre-mercado foi a tentativa de radicalmente transformar a estrutura de governança em AAES, que tinha sido tradicionalmente desenvolvida ao redor do princípio de que esses eram serviços essenciais que deveriam ser universalmente disponíveis e, portanto, fornecidos sob estrito controle do setor público ou diretamente pelo setor público. Sob as condições prevalentes internacionalmente desde os anos 80, tentativas têm sido feitas para reorganizar a governança em AAES ao redor de princípios de mercado, reduzindo o controle estatal sobre os operadores privados a um mínimo e transformando o status de AAES de serviços públicos essenciais em mercadorias.

No entanto, este não tem sido um processo linear e não produziu um modelo uniforme. A despeito de algumas "megatendências" (e.g. a monopolização do mercado privado de água por uma porção de operadores multinacionais, principalmente europeus) encontramos diferenças e diversidade em políticas e estratégias entre e no interior de países e regiões. Mesmo entre as instituições- chave que promoveram o modelo desde os anos 80, como o Banco Mundial, existem tensões internas e debate que produziram uma diversidade de resultados. Enquanto durante os anos 90 os críticos do modelo (por exemplo, dentro do Banco) eram pouco e suas vozes muito moderadas, mas desde 2002 a dissenção têm sido mais aberta e pronunciada. Finalmente, em seu Relatório do Desenvolvimento Mundial 2004 e posteriores afirmações, o Banco Mundial abertamente admitiu que a política dominante de AAES, face aos desafios assumidos pela comunidade internacional em relação aos ODMs, não podem ser baseados numa estrutura de governança centrada no mercado e o setor privado não pode ser considerado como o principal ator para universalizar os serviços públicos de AAES nos países em desenvolvimento.

Em retrospecto, é claro que essas mudanças no posicionamento das IFIs podem ser relacionadas com os fracassos recorrentes experimentados por projetos envolvendo a PSP durante os anos 90, e à crescente relutância de 
empresas privadas de água de se engajarem na provisão de AAES em países em desenvolvimento devido aos riscos políticos e financeiros envolvidos. Embora operadores privados possam estar dispostos a empreender a provisão destes serviços em condições que garantam um sustentável retorno para os seus acionistas, os países não podem confiar na PSP para a expansão e manutenção dos serviços públicos de AAES para a parcela da população em países em desenvolvimento que tem limitado ou nenhum acesso a estes serviços. Estes são normalmente os setores mais pobres da sociedade, nos quais uma larga proporção da população vive em extrema pobreza e mal podem pagar pelos serviços públicos de AAES ao verdadeiro preço do mercado internacional (e nem mesmo ao preço do seu custo-recuperação), e cuja situação foi piorada sistematicamente nos anos 90 devido à crescente desigualdade e privação (CRENZEL; FORTE, 2004; PERRY et al., 2003; IDB, 1998).

Além do mais, a tradição de longa data de limitar-se ou excluir-se o envolvimento cidadão na provisão de serviços públicos de AAES (seja público ou privado) continua, a despeito de recente retórica de que a participação civil se tornou um elemento-chave nos programas de AAES atuais. Isto é particularmente verdadeiro nos países em desenvolvimento, mas pode ser também detectado em países desenvolvidos. No extremo, a ausência de canais para o adequado envolvimento cidadão (ou a real violação do direito de significante participação e monitorização dos cidadãos) levou a amargos confrontos em muitos casos envolvendo a PSP, ampliado desde os anos 80. Tais confrontos levaram ao colapso das concessões, violência, crise política, destruição de propriedade e muito lamentavelmente, a perda de vidas humanas, como em Cochabamba (2000) e La Paz El Alto (2006), na Bolívia.

Como resultado dos fracassos e das situações contenciosas criadas, promotores de projetos PSP que dão prioridade ao lucro privado crescentemente reconhecem a necessidade de se levar em conta condições culturais e sócio-políticas ao projetarem-se políticas de abastecimento de água e esgotamento sanitário. Esta mudança foi refletida em novos programas para desenvolver "parcerias" e "parcerias tri-partites" (entre o público e os setores privado e voluntário), popularizadas recentemente no Brasil como PPPs. No entanto, o desconhecimento ou até mesmo a desconsideração com 
os processos culturais e sócio-políticos continua a ser um fator crucial em grande número de experiências e fracassos altamente controversos registrados. Em muitos casos, isto tem levado a amargos conflitos e ao colapso ou aborto prematuro de programas envolvendo a PSP (especialmente com operadores privados estrangeiros) na provisão de AAES. Na dimensão institucional, a fraqueza ou ausência de legislação adequada e estruturas regulatórias têm sido um problema recorrente nos casos estudados, o que é confirmado pela pesquisa levada a cabo por outros autores (e.g. HALL, 2002, 2006; HALL et al., 2003, 2004; HUKKA; KATKO, 2003). Alguns países reformaram a legislação (e.g. leis da água) para facilitar a expansão de PSP em AAES em formas que mostraram pouco caso para importantes considerações, tais como, a sustentabilidade ecológica (e.g. conservação dos recursos de água) e responsabilidade político-social (e.g. mecanismos para proteger os direitos dos cidadãos em seu papel como usuários de AAES). Na maioria dos países em desenvolvimento a PSP foi introduzida na ausência de quaisquer estruturas e entes regulatórios, enquanto pouca atenção foi dada à necessidade de fortalecer a capacidade local do setor público e de regulamentação e controle da PSP. Como regra, contratos de PSP para AAES têm sido mantidos longe do escrutínio público, e informação crucial necessária para a efetiva monitorização da conformidade por operadores privados não é disponível no domínio público (ela é normalmente considerada propriedade privada das empresas).

No coração do problema, há uma confrontação entre modelos alternativos de governabilidade, estruturados ao redor de princípios em mútua contradição, os quais no atual estágio histórico tomaram a forma de uma confrontação entre a ressureição de governança centrada no mercado contra o pré-existente modelo de governança centrada no Estado que prevaleceu na área de AAES pela maior parte do Século XX. Uma das questões cruciais que dirigiu este estudo é se a evidência teórica, histórica e empírica apoia a noção de que o fracasso de governança centrada no Estado em AAES de países em desenvolvimento poderia ser resolvida por transferir radicalmente o papel do Estado para monopólios privados. Este estudo encontrou escasso suporte histórico para este argumento. Novas evidências produzidas pela mais recente onda de PSP na área de abastecimento de água e esgotamento sanitário fortemente 
desaprovam reivindicações de que problemas crônicos em AAES enfrentados por países em desenvolvimento podem ser resolvidos confiando-se no setor privado, o que é aceito até mesmo pelas empresas privadas globais de água que tem acumulado uma longa experiência desde os anos 90.

No entanto, este tem sido um processo altamente dinâmico, com frequentes mudanças de direção e um horizonte muito pouco claro em termos de para onde o sistema vai se mover. Por um lado, a despeito da arrogante negligência com as preferências e opiniões do cidadão, especialmente, mas não somente nos países pobres em desenvolvimento, têm havido crescente insatisfação e aberto desafio para com as políticas de PSP em muitos países. Seria um erro caracterizar esta oposição como uma mera rejeição de políticas de mercado ou PSP; de fato, havia algum grau de apoio entre importantes setores no princípio da década de 90, em países como a Argentina. No entanto, a falta de participação na tomada de decisões e implementação, ampla percepção do público e corrupção privada na negociação da concessão de contratos, e crescente evidência de que o modelo PSP privilegia os interesses dos operadores privados mais do que as necessidades das comunidades, contribuiram para o observado marcante declínio na aceitação ou pelo menos tolerância de PSP e à explosão de protesto público, desobediência civil e até mesmo violencia contra estas políticas.

Por outro ângulo, a despeito da promoção de PSP em AAES durante os anos 90, o real impacto destas políticas tem sido bastante modesto e as empresas privadas de água ainda atendem a uma parcela restrita da população mundial (HALL et al., 2004; UN-Habitat, 2003). Mesmo no EUA, cujo governo é um dos campeões mundiais na promoção de PSP, somente $15 \%$ da população é atendida por empresas privadas e esta proporção não crescerá no futuro de acordo com um relato comissionado pelo governo (NRC, 2002). Países em desenvolvimento que nos anos 90 se tornaram o campo experimental líder para políticas de AAES neoliberais, como a Argentina onde entre 1991 e 1999 a proporção da população atendida por serviços privados de AAES subiu para cerca de $70 \%,{ }^{14}$ começou um acelerado processo para

14 Este número inclui 10\% atendidos por cooperativas (AZPIAZU et al., 2004, p.3-4) 
colocar os serviços públicos de AAES de volta nas mãos públicas como consequência de PSP ter falhado em entregar o prometido em contrato (PIGEON et al., 2012). Tendências similares podem ser identificadas em outros lugares, tanto nos países desenvolvidos como nos países em desenvolvimento, onde vários deles baniram a privatização de AAES em nível nacional (e.g. Uruguai, Suécia, Holanda). Não é surpreendente, portanto, que alguns analistas tenham argumentado que o debate de PSP foi exagerado de proporções (BUDDS; MCGRANAHAN, 2003). Embora isto seja verdade, há o perigo de minimizar-se a significância das forças desatadas por políticas dominantes desde os anos 80 , porque seu impacto pode ter consequências negativas de longo alcance nos anos vindouros, independentemente, do grau de real expansão de PSP. Em particular, o processo de transformar-se o status de serviços públicos de AAES (e outros serviços essenciais tais como a saúde e a educação) de bens públicos ou sociais em mercadorias e cancelar os direitos dos cidadãos, reduzindo-lhes o papel para o de meros consumidores está tomando lugar, independentemente, da expansão de PSP. Isto é porque a política de reforma é tambem implementada em serviços públicos, que são pressionadas a reorganizar o AAES nas bases de princípios comerciais e adotar critérios de eficiência de mercado, abandonando a noção de que estes serviços são bens públicos que devem ser universalmente disponíveis independentemente do status de mercado dos usuários. Além do mais, a despeito de uma retórica de mudança, as IFIs e outros atores dominantes continuam a empurrar a expansão de PSP sob diferentes formas e nomes, desconsiderando lições aprendidas em recentes experiências (CASTRO, 2013).

Algumas lições-chave podem ser tiradas da recente experiência com PSP em AAES a fim de pensar à frente e contribuir para a construção de alternativas factíveis. Tais alternativas deveriam priorizar direitos sociais e o bem comum sobre os interesses do mercado. Como no pasado, políticas abraçando estes princípios seriam aceitas e apoiadas por um amplo espectro de forças políticas e sociais, mesmo por setores que em outros aspectos defendem o liberalismo de livre mercado, mas reconhecem que a provisão universal de AAES requer diferentes arranjos. Conseguir sucesso no desenho e implementação de atuais e futuras políticas de AAES e alcançar os Objetivos de Desenvolvimento do Milênio (ODMs) da ONU pode somente 
acontecer por meio da fusão de uma ampla e universalista aliança de forças sociais para fomentar uma nova visão para defender o bem comum. Este processo já está tendo lugar, e deveria ser sustentado fortalecendo-se a capacidade local, fomentando a cooperação e as parcerias público-público e público-comunitárias e consolidando a democratização da governança e gerenciamento da água e serviços públicos de abastecimento de água e esgotamento sanitário.

\section{Referências}

ABOITES AGUILAR, L. El Agua de la Nación. Una Historia Política de México (1888-1946). Mexico DF: Centro de Investigaciones y Estudios Superiores en Antropología Social (CIESAS), 1998.

AYLARD, R. Apresentação no Painel "Achieving the UN goals for water and sanitation: what role can the private sector play? Under what circumstances?", PRINWASS 2004 Open Workshop. Oxford: Queen Elizabeth House, University of Oxford, 2004 (disponível em: http://www.prinwass.org/ OpenWorkshop_June04.shtml).

AZPIAZU, D.; CATENAZZI, E. A.; CRENZEL, N. Da Representação. FORTE, G.; FORCINITO, K.; MARÍN, J.C. Buenos Aires - Argentina Case Study Report (D5.1), PRINWASS, Research Project, Oxford: University of Oxford, 2003.

AZPIAZU, D.; SCHORR, M. Cross-comparative Report on the Economic-financial Dimension (D20), PRINWASS, Research Project, Oxford: University of Oxford, 2004.

AZPIAZU, D.; CASTRO, J. E. Aguas Públicas: Buenos Aires in Muddled Waters. In: PIGEON, M; MCDONALD, D. A.; HOEDEMAN, O.; KISHIMOTO, S. Remunicipalisation: Putting Water Back into Public Hands. Amsterdao: Transnational Institute, p. 58-73, 2012 (disponivel em: http://www.tni. org/tnibook/remunicipalisation). 
BALANYÁ, B.; BRENNAN, B.; HOEDEMAN, O.; KISHIMOTO, S.; TERHORST, P. (eds.). Reclaiming Public Water. Achievements, Struggles, and Visions from Around the World, Amsterdam: Transnational Institute e Corporate Europe Observatory, 2005.

BALEN, M. Water for life. The case for private investment and management in developing country water systems. Londres: The Globalization Institute, 2006.

BROOK COWEN, Penelope J.; COWEN, Tyler. Deregulated private water supply: a policy option for developing countries. Cato Journal, v. 18, n.1, p. 21-41, 1998 (disponível em: http://www.cato.org./research/natur-st.html).

BUDDS, J.; MCGRANAHAN, G. Are the debates on water privatization missing the point? Experiences from Africa, Asia and Latin America. Environment and Urbanization, v. 15, n.2, p. 87-113, 2003.

CASTRO, J. E. Water, Power, and Citizenship. Social Struggle in the Basin of Mexico, Houndmills, Basingstoke e Nova York: Palgrave-Macmillan, 2006.

CASTRO, J. E. Poverty and citizenship: sociological perspectives on water services and public-private participation. Geoforum, v. 38, n.5, p. 756-771, 2007a.

CASTRO, J. E. Systemic conditions affecting the universalisation of water and sanitation services: a sociological exploration. Journal of Comparative Social Welfare, v. 23, n.2, p. 105-119, 2007 b.

CASTRO, J. E. Neoliberal water and sanitation policies as a failed development strategy: lessons from developing countries. Progress in Development Studies, v. 8, n. 1, p. 63-83, 2008.

CASTRO, J. E. Políticas públicas de saneamento e condicionantes sistêmicos. In: HELLER, Léo; CASTRO, J. E. (Orgs.) Política Pública e Gestão de Serviços 
de Saneamento, Belo Horizonte e Rio de Janeiro: Editora UFMG e Editora Fiocruz, 2013. p. 52-75.

CATENAZZI, A.; KULLOCK, D. Política de agua y saneamiento en el Area Metropolitana de Buenos Aires. Estrategias de acceso de los sectores de bajos recursos, antes y después de la privatización. Relatório Final. Buenos Aires: Secretaría de Ciencia y Técnica, Universidad de Buenos Aires (UBACyT), 1997.

CHAUSSADE, J. L. Address to the staff of Suez Environnement. W2 News. The Power of Waste and Water, Suez Environnement Newsletter, Special Issue, 10 de março de 2004.

CNA-Comisión Nacional del Agua. Política Hidráulica 1989-1994. Mexico DF: CNA, 1993.

CONOLLY, P. El Contratista de Don Porfirio. Obras Públicas, Deuda y Desarrollo Desigual, Mexico DF: El Colegio de Michoacán, Universidad Autónoma Metropolitana Azcapotzalco, e Fondo de Cultura Económica, 1997.

CRENZEL, E. A. Tucumán - Argentina Case Study Report (D5.2), PRINWASS, Research Project, Oxford: University of Oxford, 2003.

CRENZEL, E.; FORTE, G. Cross-comparative Report on the Socio-economic and Demo-geographic Dimension (D17), PRINWASS, Research Project, Oxford: University of Oxford, 2004.

CRESPO, C.; LAURIE, N.; LEDO, C. Cochabamba - Bolivia Case Study Report (D6), PRINWASS, Oxford: University of Oxford, 2003.

DFID - Department for International Development. Strategies for Achieving the International Development Targets. Addressing the Water Crisis 
- Healthier and More Productive Lives for Poor People (Consultation Document), Londres: DFID, 2000.

DRYZEK, J. The Politics of the Earth. Environmental Discourses, Oxford: Oxford University Press, 1997.

EC - European Commission. EU Water Initiative: Water for Life. Health, Livelihoods, Economic Development, Peace, and Security, Bruxelas, 2002 (disponível em: http://europa.eu.int/comm/research/water-initiative/ index_en.html).

EC - European Commission. Water for Life. Luxemburgo: EU Initiative, International Cooperation: from Knowledge to Action, 2003.

EU - European Union. Directive of the European Parliament and of the Council 2000/60/EC Establishing a Framework for Community Action in the Field of Water Policy. Luxemburgo: Parlamento e Conselho Europeu, 2000 (http://europa. eu.int/comm/environment/water/water-framework/index_en.html).

Folha de São Paulo, 21/09/2003, p. B3.

GWI - Global Water Intelligence. Goodbye International Water, v. 5, n.7, p. 5, 2004.

GWP - Global Water Partnership. Effective Water Governance. Learning from the Dialogues, 2003 (http://www.gwpforum.org/gwp/library/Effective\%20 Water\%20 Governance.pdf).

GWP - Global Water Partnership. Dialogue on Effective Water Governance. 2002 (http://www.gwpforum.org/gwp/library/Governance.pdf).

GOUBERT, J. P. The Conquest of Water. The Advent of Health in the Industrial Age, Cambridge e Oxford: Polity Press e Basil Blackwell, 1986. 
HALL, D. Corporate actors. A global review of multinational corporations in the water and electricity sectors. Greenwich: Public Services International Research Unit (PSIRU), University of Greenwich, 2006.

HALL, D.; LANZ, K.; LOBINA, E.; MOTTE, R. de la. International context. Watertime Project Report. Greenwich: Public Services International Research Unit (PSIRU), University of Greenwich, 2004.

HALL, D.; LOBINA, E.; MOTTE, R. de la. Public solutions for private problems? Responding to the shortfall in water infrastructure investment. Greenwich: Public Services International Research Unit (PSIRU), University of Greenwich, 2003.

HALL, D. The water multinationals 2002. Financial and other problems", Greenwich: Public Services International Research Unit (PSIRU), University of Greenwich, 2002 (http://www.psiru.org/reportsindex.asp).

HASSAN, J. A History of Water in Modern England and Wales. Manchester: Manchester University Press, 1998.

HUKKA, J. J.; KATKO, T. S. Water privatisation revisited: panacea or pancake?. IRC Occasional Paper Series 33, Delft, International Water and Sanitation Centre (IRC), 2003 (disponível em: http://www.irc.nl/pdf/publ/op_priv. pdf).

IDB - Inter American Development Bank. Facing up to Inequality in Latin America. Economic and Social Progress in Latin America, Washington D.C.: IDB, 1998.

JUUTI, P.; KATKO, T. Katko; VUORINEN, H. (eds.). Environmental History of Water - Global Views on Community Water Supply and Sanitation, Londres: International Water Association (IWA) Publishing, 2006. 
KLEIN, M. Interviewed by M. Phillips in "The World Bank wonders about utility privatizations", The Wall Street Journal, 21 de julho de 2003.

LABRE, J. Achieving the UN goals for water and sanitation: What the private sector can do (and cannot do). Trabalho apresentado em PRINWASS 2004 Open Workshop Main Trends and Prospects Characterizing Private Sector Participation in Water and Sanitation: a Discussion of Project Findings, Queen Elizabeth House, University of Oxford, 2004.

La Jornada. Inversión mixta en los sistemas, plantea el BM. 17 de março de 2006, (http://www.jornada.unam.mx/2006/03/17/046n1soc.php).

LAGOS, M. Latinobarômetro 1996-2003. Focus Eurolatino (European Commission Directorate General for Foreign Relations), Canning House, Londres, 28 de junho de 2004 (http://www.canninghouse.com/ Presentation\%20Canning\%20House\%20June\%2028th\%202004.ppt).

LASKI, H.J.; JENNINGS, W. I.; ROBSON, W.A. (Eds.). A Century of Municipal Progress 1835-1935. Londres: George Allen \& Unwin, 1935.

LAURIE, N. (ed.). Pro-Poor Water? The Privatisation and Global Poverty Debate. Special Issue in Geoforum, v. 38, n. 5, 2007.

LEE, Terence R. Water Management in the 21st Century. The Allocation Imperative, Cheltenham: Edward Elgar, 1999.

LEYS, C. Market-Driven Politics. Neoliberal Democracy and the Public Interest, Londres: Verso, 2001.

LUCKIN, B. Pollution and Control: a Social History of the Thames in the Nineteenth Century, Londres: Adam Hilger, 1986. 
MELOSI, M. V. The Sanitary City: Urban Infrastructure in America from Colonial Times to the Present (Creating the North American Landscape), Baltimore: John Hopkins University Press, 2000.

MWB - Metropolitan Water Board. The Water Supply of London. Londres: Staples Press, 1949.

MILLWARD, B. Emergence of gas and water monopolies in nineteenth century Britain: contested markets and public control. In: FOREMANPECK, James (Ed.). New Perspectives in Late Victorian Economy: Essays in Quantitative Economic History 1860-1914, Cambridge: Cambridge University Press, 1991.

MUKHOPADHYAY, A. K. The politics of London water. The London Journal, v.1, n.2, p. 207-226, 1975.

NRC - National Research Council - Committee on Privatization of Water Services in the United States. Privatization of Water Services in the United States. An Assessment of Issues and Experience, Washington DC: National Academy Press, 2002 (disponível em: http://books.nap.edu/catalog/10135. html).

NEWBERY, D. M. Privatization, Restructuring, and Regulation of Network Utilities. The Walras-Pareto Lectures, Cambridge, Mass. e Londres: The MIT Press, 1999.

NICKSON, A. Urban water supply: sector review. School of Public Policy, University of Birmingham, Papers in the Role of Government in Adjusting Economies, n. 7, Birmingham: University of Birmingham, 1996.

NYANGERI NYANCHAGA, E. Nyeri and Tala - Kenya Case Study Report (D11), PRINWASS. Oxford: University of Oxford, 2003. 
OGLE, M. Water supply, waste disposal, and the culture of privatism in the mid-nineteenth-century American city. Journal of Urban History, v. 25, n. 3, p. 321-347, 1999.

PÉREZ-RINCÓN, M. A. Public-private partnerships in provision of water and sanitation services: the case of Palmira City, Colombia. In: HUKKA, J.; KATKO, T. Water privatization revisited - Panacea or pancake?, unpublished Working Paper, Tampere: Tampere University of Technology, 2002.

PERRY, G. E.; FERREIRA, F. H.G.; WALTON, M. Inequality in Latin America and the Caribbean: Breaking with History?, Washington: World Bank, 2003.

PEZON, C. Le Service d'Eau Potable en France de 1850 à 1995. Paris: CNAM, Presses du CEREM, 2000.

PIGEON, M; MCDONALD, D. A.; HOEDEMAN, O.; KISHIMOTO, S. Remunicipalisation: Putting Water Back into Public Hands. Amsterdam: Transnational Institute, 2012 (disponível em: http://www.tni.org/ tnibook/remunicipalisation).

PRINWASS. Report from the Open Workshop "Main Trends and Prospects Characterizing Private Sector Participation in Water and Sanitation: a Discussion of Project Findings". Oxford: University of Oxford, 2004 (disponível em: http://www.prinwass.org/PDFs/OW04Summary.PDF).

REZENDE, S. C.; HELLER, L. O Saneamento no Brasil. Políticas e Interfaces. Belo Horizonte: Editora da Universidade Federal de Minas Gerais, 2002.

RICHARD, B.; TRICHE, T. A. Triche. Reducing Regulatory Barriers to Private-Sector Participation in Latin America's Water and Sanitation Services. Policy Research Working Papers n.1322, Water, and Urban Development Department, The World Bank, Washington DC: World Bank, 1994. 
ROGOZINSKI, J. La Privatización de Empresas Paraestatales. Una Visión de la Modernización de México. Mexico DF: Fondo de Cultura Económica, 1993.

ROGOZINSKI, J. High Price for Change: Privatization in Mexico, Washington, D.C.: Inter-American Development Bank, 1998.

ROTH, G. The Private Provision of Public Services in Developing Countries. Washington, D.C.: The World Bank and Oxford University Press, 1988.

ROZE, J. Chaco y Corrientes - Argentina Case Study Report (casos complementares D5 -), PRINWASS, Research Project. Oxford: University of Oxford, 2003.

SAVEDOFF, W.; SPILLER, P. Spilled Water. Institutional Commitment in the Provision of Water Services, Washington D. C.: Inter American Development Bank (IDB), 1999.

SSCHULTZ, S. K.; MCSHANE, C. To engineer the metropolis: sewers, sanitation, and city planning in late-nineteenth century America. The Journal of American History, v.65, n.2, p. 389-411, 1978.

STIGLITZ, Joseph E. Globalization and its Discontents. Londres: Penguin, 2002.

SWYNGEDOUW, E. Social Power and the Urbanization of Water. Flows of Power. Oxford: Oxford University Press, 2004.

SWYNGEDOUW, E. A. Flows of Power: Nature, Society and the City, Oxford: Oxford University Press, 1999.

TORREGROSA, M. L.; SAAVEDRA, F.; PADILLA, E.; QUIÑONES, A.; KLOSTER, K.; COSÍO, G.; LENIN, C. Aguascalientes - Mexico Case Study Report (D12), PRINWASS, Research Project, Oxford: University of Oxford, 2003. 
TORREGROSA, M. L.; KLOSTER, K.; TORREGROSA, L.; MEZA, M. Crosscomparative report on the Techno-infrastructural Dimension (D18), PRINWASS, Research Project. Oxford: University of Oxford, 2004.

TRICHE, T. A. Private participation in the delivery of Guinea's water supply services. Working Papers n.47, Infrastructure and Urban development Programme, World Bank, Washington DC: World Bank, 1990 (disponível em: http://www-wds.worldbank.org/servlet/WDSContentServer/WDSP/ IB/1990/08/01/000009265_3960929174622/Rendered/PDF/multi_page. pdf).

UKP - United Kingdom Parliament, Select Committee on Environment, Food and Rural Affairs. Memorandum submitted by the Public Utilities Access Forum. Londres, 2003a.

UKP - United Kingdom Parliament. Memorandum by WaterVoice. $2003 \mathrm{~b}$.

UN - United Nations. Key Commitments, Targets and Timetables from the Johannesburg Plan of Implementation. Johannesburg: World Summit on Sustainable Development, 2002.

UN - United Nations. United Nations Millennium Declaration. Nova York, UN, 2000.

UNDP - United Nations Development Programme (UNDP). Mainstreaming Gender in Water Management. A Practical Journey to Sustainability: A Resource Guide. Nova York: UNDP, 2003 (disponível em: http://www.undp. org/water/docs/resource_guide.pdf).

UN-United Nations - Habitat. Water and Sanitation in the World's Cities: Local Action for Global Goals, Londres: Earthscan Publications Ltd., 2003. 
UNESCO - United Nations Educational, Scientific and Cultural Organization, World Water Assessment Programme. Water, a Shared Responsibility. The United Nations World Water Report 2. Paris e Nova York: UNESCO e Berghahn Books, 2006.

VARGAS, M. C. Limeira, Niterói, and Lakes Region - Brazil Case Study Report (D7), PRINWASS, Research Project, Oxford: University of Oxford, 2003.

WADE, R. H. Is globalization reducing poverty and inequality? World Development, v. 32, n.4, p. 567-589, 2004.

WARD, C. Reflected in Water, A Crisis of Social Responsibility. Londres e Washington: Casell, 1997.

WARNER, B. The Private City: Philadelphia in Three Periods of its Growth. 2nd ed. Philadelphia: University of Pennsylvania Press, 1987.

WSP-PPIAF - Water and Sanitation Program and Public Private Infrastructure Advisory Facility. New Designs for Water and Sanitation Transactions. Making Private Sector Participation Work for the Poor, Washington DC: WSP-PPIAF, 2002 (disponível em: http://www.wsp.org/ publications/global_newdesigns.pdf).

World Bank. Privatizing water and sanitation services, 2006 (disponível em: http://rru.worldbank.org/PapersLinks/ Privatizing-Water-Sanitation-Services).

World Bank. World Development Report 2004. Making Services Work for Poor People, Washington D.C.: World Bank and Oxford University Press, 2003.

World Bank. Facilitating Private Involvement in Infrastructure: an Action Programme, Washington D. C.: World Bank, 1998. 


\section{CAPítulo 8}

\section{Gestão democrática nos serviços de saneamento ${ }^{1}$}

\section{Introdução}

Este capítulo aborda o problema da democratização da gestão no setor de saneamento, a partir de uma perspectiva interdisciplinar baseada nas ciências sociais. Como será citado posteriormente, a necessidade de avançar no desenvolvimento de articulações interdisciplinares, de complexidade cada vez maior, principalmente entre as tecno-ciências e as ciências sociais, constitui um dos desafios mais importantes enfrentados pela democratização da gestão do saneamento. Este trabalho tenta fazer uma contribuição a este avanço.

O principal argumento do presente capítulo é que o desenvolvimento dos serviços modernos de saneamento nos países ocidentais, relativamente recente, datando do fim do século dezoito, está estreitamente relacionado ao desenvolvimento das formas modernas da democracia capitalista, em particular às instituições da cidadania. Por esta razão, analisamos detalhadamente as relações entre a evolução dos direitos de cidadania e o desenvolvimento dos serviços de saneamento, enfatizando os processos que contribuíram para a universalização do acesso a tais serviços, nas democracias capitalistas centrais, durante o século vinte. Este capítulo também analisa as principais etapas que podem ser distinguidas nas formas de governabilidade, que preponderaram no setor de saneamento urbano nos países ocidentais, desde suas origens, centradas nos princípios do privativismo econômico e político, predominantes no final do século dezoito, a institucionalização e profissionalização desses

1 Originalmente publicado em formato eletrónico em: Léo Heller (ed.), Panorama do Saneamento Básico no Brasil, Vol. 7, Brasilia: Ministério das Cidades, pp. 420-452. 
serviços e a ampliação do acesso, a partir da adoção dos princípios do racionalismo administrativo, desde o final do século dezenove, até as reformas neo-privatistas surgidas na década de 80.

O objetivo central do trabalho é esclarecer as relações entra a gestão do saneamento, tradicionalmente considerada uma atividade fundamentalmente técnica, e o processo de democratização da sociedade, que tem um caráter eminentemente social e político. 0 capítulo parte da premissa de que a democratização da gestão do saneamento é, consequentemente, um processo de caráter social e político, que enfrenta uma série de desafios cuja superação requer uma compreensão cada vez mais precisa das complexas relações entre a gestão desses serviços e o processo de democratização em nível sistêmico. Neste sentido, o trabalho também adota uma visão crítica das formas dominantes da democracia capitalista, que ditam o contexto e a estrutura aos desenhos particulares de gestão no setor de saneamento, já que as mesmas apresentam limitações severas ao processo de democratização substantiva da sociedade, ou seja, a democratização efetiva, não meramente formal ou retórica das relações sociais. No entanto, este capítulo examina objetivamente os avanços alcançados no interior da democracia capitalista, como a expansão do acesso aos serviços essenciais para uma vida digna, como os de saneamento, que foram o produto de lutas sociais de longo prazo, na busca pela emancipação humana e pela democratização substantiva. $O$ fato de que em décadas recentes alguns desses avanços foram revertidos, por exemplo, através da introdução de reformas neo-privativistas no governo e na gestão de serviços públicos, alerta para uma fragilidade dos sistemas atuais dos direitos do cidadão e para a necessidade de aprofundamento do processo de democratização, que requer, em primeiro lugar, a defesa dos direitos básicos que haviam sido obtidos em etapas passadas.

\section{As Dimensões Conceituais da Gestão Democrática}

A gestão dos serviços de saneamento modernos no mundo ocidental tem uma história relativamente recente, que remonta de fins do século dezoito. Não é por acaso que este seja o mesmo período que caracteriza a 
história da democracia moderna ocidental capitalista, fortemente ligada à herança das revoluções norte-americana e francesa, no final do mesmo século. Na realidade, o desenvolvimento dos serviços de saneamento está estreitamente ligado ao processo de democratização e esteve fortemente marcado pelas lutas sociais que caracterizam este último. Neste contexto, as dimensões conceituais que proponho abordar para discutir o processo de democratização, em relação aos serviços de saneamento são a) o processo de cidadanização e b) os modelos de governabilidade dos serviços de saneamento.

É importante esclarecer que a análise da inter-relação entre o desenvolvimento dos sistemas modernos de saneamento e o processo de democratização nos países ocidentais tem como propósito principal oferecer elementos para o estudo objetivo das condições e mecanismos que podem facilitar a democratização substantiva, não meramente formal, da gestão destes serviços. Neste sentido, o trabalho explora as contradições intrínsecas do processo de democratização ocidental a partir da perspectiva de suas implicações na gestão do saneamento. Cabe destacar que este capítulo não considera que as formas concretas assumidas pelo processo de democratização prevalecente nos países ocidentais, ou seja, as distintas versões da democracia liberal representativa que de um modo ou de outro, dão forma ao modelo dominante em nível internacional, constituem a forma máxima de democratização que se pode aspirar e muito menos que constituam a forma máxima de emancipação humana. Muito ao contrário, e em particular pensando nas experiências latino-americanas, as formas concretas assumidas pelos regimes democráticos dominantes levam a questionar profundamente o próprio sentido do conceito de democracia e, consequentemente, a adotar uma visão crítica a respeito das formas concretas assumidas no terreno que aqui denomino como o processo de democratização. Existe um debate profundo sobre este tema na América Latina, onde os regimes democráticos existentes foram conceituados, entre outros exemplos, como "tutelados" (Walksman, 1989; Portales, 2000), "de baixa intensidade” (Torres Rivas, 1989), “delegáveis” (O’Donnell, 1994), e onde, inclusive a própria democracia foi considerada conceitualmente, nas 
ácidas palavras de Jorge Luis Borges, como uma "superstição" (citado em Marín, 1996, p. 42). Não é de se estranhar que, neste contexto, até mesmo o aprofundamento dos princípios da própria democracia liberal e, particularmente os princípios da cidadania, possam assumir na prática o caráter de uma proposta que é vista como muito radical, até extrema, pelos setores dominantes. Como tento demonstrar neste capítulo, esse debate tem uma importância central para a gestão dos serviços de saneamento, um setor de atividade que tradicionalmente se restringe à dimensão técnico-administrativa, artificialmente isolando-se dos processos sócio-econômicos e políticos que, no entanto, estruturam, dão contexto e até mesmo determinam a forma em que estes serviços são organizados e geridos. Neste sentido, examinar as inter-relações entre o desenvolvimento dos serviços de saneamento e o processo de democratização nos permite atingir uma compreensão mais completa e profunda das condições sistêmicas, os obstáculos e as oportunidades que a democratização da gestão desses serviços essenciais enfrenta.

\subsection{O Processo de Cidadanização}

O desenvolvimento da cidadania no contexto da democracia liberal pode ser analisado enfocando-se dois aspectos fundamentais: a cidadania como identidade política e a cidadania como relação social. Ainda que ambos os aspectos se encontrem estreitamente relacionados, neste contexto enfatizaremos o segundo, que está fortemente vinculado ao desenvolvimento histórico dos serviços de saneamento e que constitui um elemento fundamental em sua gestão democrática. Entretanto, cabe explicar que a cidadania característica da democracia liberal constitui assim um fenômeno historicamente determinado, que, por sua vez, assume uma diversidade de formas em distintos territórios, o que é conseqüência do desenvolvimento específico de culturas nacionais, regionais e locais que refletem princípios, valores e interesses materiais também distintos. Entre outros autores que trataram deste problema em detalhe, podemos mencionar Rogers Brubaker, em seus estudos sobre as diferentes formas históricas de desenvolvimento da cidadania nos casos da Alemanha, Grã Bretanha e França, e também 
Benedict Anderson, em sua reflexão sobre o caráter artificial, "imaginário", das comunidades políticas (Brubaker, 1992; Anderson, 1983). Ou seja, apesar de serem um componente central da democracia capitalista ocidental, as formas específicas que a cidadania assume em diferentes territórios reflete grandes diferenças e contradições, que discutiremos mais detalhadamente na sequência.

Em relação ao primeiro aspecto, cumpre aqui dizer que a cidadania na democracia capitalista moderna é fundamentalmente a identidade política que os membros de um Estado nação assumem, o que constitui uma herança da Revolução Francesa (Delanty, 2000). Porém, o aspecto que é de interesse analisar neste trabalho é o da cidadania como relação social, ou como preferi denominar nesta seção, o processo de cidadanização, ou seja, o processo histórico do desenvolvimento da cidadania como relação social. Nesta perspectiva, esse segundo aspecto da cidadania tanto antecede como também pressupõe o primeiro: por um lado, a gênese histórica dos elementos característicos da cidadania como relação social antecederam a formação dos modernos Estados-nação, no entanto, por outro lado, desde finais do século dezoito o exercício da cidadania pressupôs que as pessoas pertencessem a uma comunidade política que garante os direitos e deveres sobre os quais definem tais relações. Esta tensão entre os dois aspectos do processo de cidadanização tente a se aprofundar e mudar a natureza no contexto das transformações vividas pelo Estado nação desde meados do século vinte, com a expansão de comunidades políticas sub e supranacionais. Entre outros exemplos destas transformações, pode ser mencionado o reconhecimento de comunidades políticas regionais no interior dos Estados, como o caso das autonomias étnicas dentro do Estado "pluri-nacional" da Bolívia, reconhecidas pela nova Constituição desse país, aprovada em 2009, ou a consolidação de certos direitos e deveres de cidadania em nível transnacional como o caso da Comunidade Européia de nações ou, de uma forma mais limitada, no caso dos países do MERCOSUL (ver, por exemplo, Dávalos, 2005; Garcés et. al., 2006; Giraudo, 2007; Lister e Pia, 2008). Neste processo, existem certos direitos e deveres que os cidadãos podem exercer com relativa independência de sua relação de identidade nacional, por exemplo, dentro 
da Comunidade Européia, os cidadãos de qualquer país membro podem exercer os direitos de propriedade, de residência, de emprego ou de justiça em qualquer dos outros países, e podem, inclusive, recorrer os vereditos de seus tribunais nacionais nos tribunais supranacionais da Comunidade (ver, por exemplo, Goldhaber, 2009). Este é um processo muito dinâmico e complexo, que necessariamente implica em profundas transformações nos conteúdos e na extensão da cidadania (ver, por exemplo, Theory and Society, 1997).

É claro que este não é um processo idílico e a cidadania, tanto no seu caráter de identidade política como no de relação social, apresenta contradições fundamentais. Neste sentido, nas democracias ocidentais capitalistas, a cidadania é uma relação entre sujeitos formalmente iguais e está circunscrita a um conjunto de direitos e obrigações que regula a propriedade, o acesso à justiça, a participação política e, em algumas sociedades, a distribuição de certos bens e serviços considerados essenciais como a educação, a saúde ou a habitação e os serviços de saneamento. Esta forma clássica da cidadania inspirada na tradição liberal democrática incorpora uma contradição fundamental entre a igualdade formal e a desigualdade real, entre a igualdade uniforme pressuposta nos direitos de cidadão e a gama de expressão concreta que assume a desigualdade no exercício real dos mesmos. Esta tensão entre igualdade formal e desigualdade concreta caracteriza o desenvolvimento histórico do processo de cidadanização, que viveu um movimento de expansão e extensão nos últimos séculos, mas que também sofreu retrocessos recorrentes, por exemplo, mediante a suspensão ou até mesmo revogamento de certos direitos do cidadão durante períodos autoritários ou de retrocesso democrático. Por exemplo, a suspensão do habeas corpus, um dos direitos civis fundamentais da democracia liberal, foi um fato recorrente tanto no âmbito das ditaduras cívico-militares, que suspenderam a democracia eleitoral na maioria dos países da América Latina durante décadas, como crescentemente também como conseqüência do avanço de setores autoritários dentro da própria democracia formal, como no caso do seqüestro e prisão sem direito a julgamento implementado sistematicamente pelo governo dos Estados Unidos 
e seus aliados no contexto da "guerra contra o terror", impulsionada por esses países desde 2001 (ver, por exemplo, Marín, 1996; Glenn, 200; Fallon Jr. e Meltzer, 2007; Morrison, 2007). Outro exemplo, que explicitaremos em seguida com mais detalhes dada sua relevância para os serviços de saneamento, foram as políticas neoliberais no setor de bens e serviços básicos, como a educação, a saúde e o saneamento básico. Essas políticas, implementadas globalmente desde a década de 1980, tentam cancelar a noção de que existem direitos sociais de acesso a tais bens e serviços básicos, um princípio que as democracias capitalistas ocidentais, pelo menos da Europa, haviam consagrado durante o período de pós-guerra, a partir de fins da década de 1940 (ver, por exemplo, Leys, 2001; Harvey, 2005). Retomaremos este ponto numa seção posterior.

É importante lembrar que fora da Europa e dos Estados Unidos, o processo de cidadanização foi transplantado, adotado, adaptado ou até mesmo imposto por diferentes mecanismos desde o século dezenove, o que acrescenta outro nível de complexidade à análise. Em geral, ocorreu um processo de implantação dos princípios e instituições da democracia liberal na maioria dos países da América Latina, um processo que em grande escala tomou a forma de confrontos armados e guerra civil. Em geral, o processo de cidadanização na América Latina esteve limitado a comunidades políticas restringidas, excludentes, frequentemente compostas pelas elites governantes emergentes da colonização européia e fechado às grandes maiorias. Apesar dos avanços significativos vividos pela maioria dos países da região desde o século dezenove, o exercício dos direitos de cidadania continua sendo negado a amplos setores da população em nossos países (Dagnino, 1994; Carvalho, 1995; Roberts, 1995; Fleury, 1997; Svampa, 2005; Sousa, 2006; Yamin, 2006). Na realidade, pode-se dizer que esta dinâmica de inclusão e exclusão é uma característica central do processo de cidadanização em geral, embora tenha tendido a adotar formas extremas nos países da América Latina. 
Quadro 1. A Cidadania como Processo de Inclusão e Exclusão

A cidadania como relação social característica da democracia capitalista implica em um duplo processo: por um lado a igualização formal dos indivíduos e, pelo outro, a reprodução de formas de diferenciação social e mecanismos de inclusãoexclusão entre os cidadãos e não-cidadãos, cujas raízes estruturais se encontram nas desigualdades de classe, de gênero, étnicas, entre outras. Este é um processo dinâmico e em constante mudança, que ao longo da história tendeu à contínua extensão do número de seres humanos que acessam a categoria de cidadãos em cada território, mas que também está sujeito a retrocessos freqüentes. Por exemplo, como tendência geral, as mulheres só adquiriram o direito de possuir propriedade muito tempo depois dos homens, e ainda existem territórios nos quais este direito lhes é severamente limitado. Ocorreu igualmente com o direito à justiça ou com os direitos políticos, aos quais as mulheres só tiveram acesso muito depois, durante o século vinte. As populações não-brancas (negros, índios, etc.) e as grandes maiorias não-proprietárias, trabalhadoras, ou marginalizadas dos mercados de trabalho também foram historicamente excluídas do exercício dos direitos de cidadania. Originalmente, os cidadãos eram os que tinham propriedade, e, apesar desta limitação ter sido superada no plano da legalidade formal, na prática das desigualdades estruturais, continuam constituindo a barreira fundamental que determina a exclusão de amplos setores da população do exercício da cidadania.

Por um lado, o processo de cidadanização na democracia capitalistas é parte fundamental do processo que garante a reprodução ampliada do sistema, já que os princípios fundantes da cidadania neste contexto são o direito à propriedade privada e à liberdade individual para o intercâmbio mercantil desta propriedade. Por outro lado, no entanto, a cidadania e o sistema capitalista entram também em contradição, "estão em guerra" como citou T. H. Marshall, já que a expansão e o aprofundamento do conteúdo, alcance e exercício da cidadania são constitutivos das lutas emancipatórias que caracterizam o sistema (Marshall, 1963). Desta maneira, a cidadania fornece a base da igualdade formal que legitima o sistema de desigualdade real, mas ao mesmo tempo fornece as condições que potencialmente podem dar lugar a um processo de equalização crescente dos desiguais. Como alguns exemplos que datam do século passado, o caso da extensão às mulheres dos direitos à propriedade e ao voto, que antes só estavam disponíveis para os homens, o reconhecimento dos direitos dos trabalhadores a uma jornada de 8 horas e a um salário mínimo, ou, mais recentemente, os direitos 
linguísticos das comunidades indígenas da América Latina, que alguns países começaram a formalizar. Sem dúvidas, a extensão do conteúdo dos direitos, a expansão da comunidade beneficiária dos mesmos e o aprofundamento do seu exercício real e não meramente formal constituem avanços no processo de democratização da sociedade, resultantes de lutas sociais recorrentes.

A partir de outro ângulo, o desenvolvimento da cidadania está intimamente relacionado com o processo de mercantilização, ou seja, com o processo mediante o qual as relações sociais tendem a se transformar em relações mercantis. A mercantilização crescente dos elementos da natureza, incluindo a água e os serviços baseados nos derivados da água, é parte constituinte deste processo. Este é outro aspecto importante das contradições que caracterizam o desenvolvimento do governo e a gestão democrática dos serviços de saneamento. Como discutiremos em seguida mais detalhadamente, o desenvolvimento dos primeiros sistemas urbanos de água nos países capitalistas centrais, principalmente na Inglaterra e na França, teve como princípio fundante a noção de que o serviço de água corrente nas habitações era uma mercadoria que deveria estar disponível a quem pudesse pagar por ela. Ou seja, o ponto de partida do desenvolvimento do que hoje consideramos um serviço essencial para a vida não foi o de satisfazer uma necessidade comum a todos os habitantes, mas o de produzir uma mercadoria, quer dizer, um objeto de apropriação privada, orientado a produzir um lucro e dirigida só a quem tinha a capacidade econômica de comprar essa mercadoria, o cliente privado adimplente ou consumidor. Necessariamente, nesta etapa inicial da história do saneamento, essa categoria social emergente, o cliente privado da água-mercadoria, correspondia a um setor muito reduzido da população, o mesmo que também constituía a cidadania propriamente dita, ou seja, aquela parte da população que tinha acesso ao exercício pleno dos direitos do cidadão. Evidentemente, esta relação íntima entre os processos de cidadanização e mercantilização não é exclusiva do ramo dos serviços de saneamento, mas caracteriza o desenvolvimento da democracia capitalista nos seus diversos aspectos, incluindo a esfera do acesso aos serviços de consumo coletivo (ver, por exemplo, Kroen, 2004; Soper and Trentmann, 2008). 


\subsubsection{Os Direitos de Cidadania, a Água e o Saneamento Básico}

A existência ou não de um direito ao acesso à água limpa para consumo humano e aos serviços básicos de esgotamento sanitário, coleta de lixo e outras necessidades essenciais para a vida digna é objeto de um debate inacabado (vê-se, por exemplo, Esch et. al., 2006). Este trabalho aborda esse tema a partir de dois ângulos: por um lado, examinamos brevemente a emergência dos direitos e deveres da cidadania e sua relação com esses serviços essenciais e, por outro lado, assume-se a posição de que de fato o acesso a esses serviços constitui um direito fundamental. Os direitos de cidadania clássicos desenvolvidos nos países ocidentais foram categorizados em "civis", "políticos" e "sociais", aos quais foram incorporando outras dimensões no curso do processo de cidadanização, como, por exemplo, os direitos trans-específicos (o reconhecimento de outras espécies, da própria natureza e inclusive de entes artificiais como sujeitos de direitos) e trans-geracionais (o reconhecimento das gerações futuras como sujeitos de direitos).

Os direitos civis de cidadania são basicamente o direito à propriedade e à justiça, quer dizer, os direitos individuais fundamentais no contexto da democracia capitalista. Os direitos políticos, que surgem a partir do século dezoito, têm a ver com o direito também individual de eleger quem governa e de ser eleito para participar do governo. Os direitos sociais, que consistem no reconhecimento de certos bens e serviços essenciais à vida digna, devem ser disponíveis a todos os membros da comunidade política independente de sua posição no mercado, ou seja, com independência de sua capacidade monetária. Existe uma grande controvérsia em torno dos direitos sociais: para a tradição liberal individualista, tais direitos não existem, já que a mesma restringe os direitos de cidadania somente aos direitos civis e políticos. Quer dizer, nesta tradição político-intelectual, bens e serviços essenciais, como os serviços de saneamento básico, não têm o status de direitos do cidadão, já que são considerados como bens econômicos privados que devem ser adquiridos individualmente no mercado como qualquer outro tipo de bem ou serviço, ou seja, como uma mercadoria. Como veremos mais detalhadamente nas seções seguintes, este foi e continua sendo um debate de importância central para a gestão democrática do setor de saneamento. 
Nas últimas décadas, o debate sobre os direitos e deveres da cidadania avançou incorporando novas dimensões, particularmente a partir da crescente tomada de consciência em nível internacional sobre a insustentabilidade do modelo de desenvolvimento dominante, especialmente em relação ao seu impacto sobre o meio ambiente e os processos ecológicos. O aprofundamento deste debate tem levado à ampliação do conteúdo dos direitos e deveres do cidadão, de modo que, adicionalmente aos direitos civis, políticos e sociais, incorporou-se uma série de direitos do cidadão ampliados que incluem o direito a viver em um ambiente limpo (livre de contaminação dos ecossistemas aquáticos, do solo ou do ar), mas também o direito do resto dos seres vivos e da própria natureza à preservação das condições que possibilitam a vida no planeta e o direito das futuras gerações a desfrutar de tais condições.

Figura 1. Evolução do Processo de Cidadanização Liberal Democrático

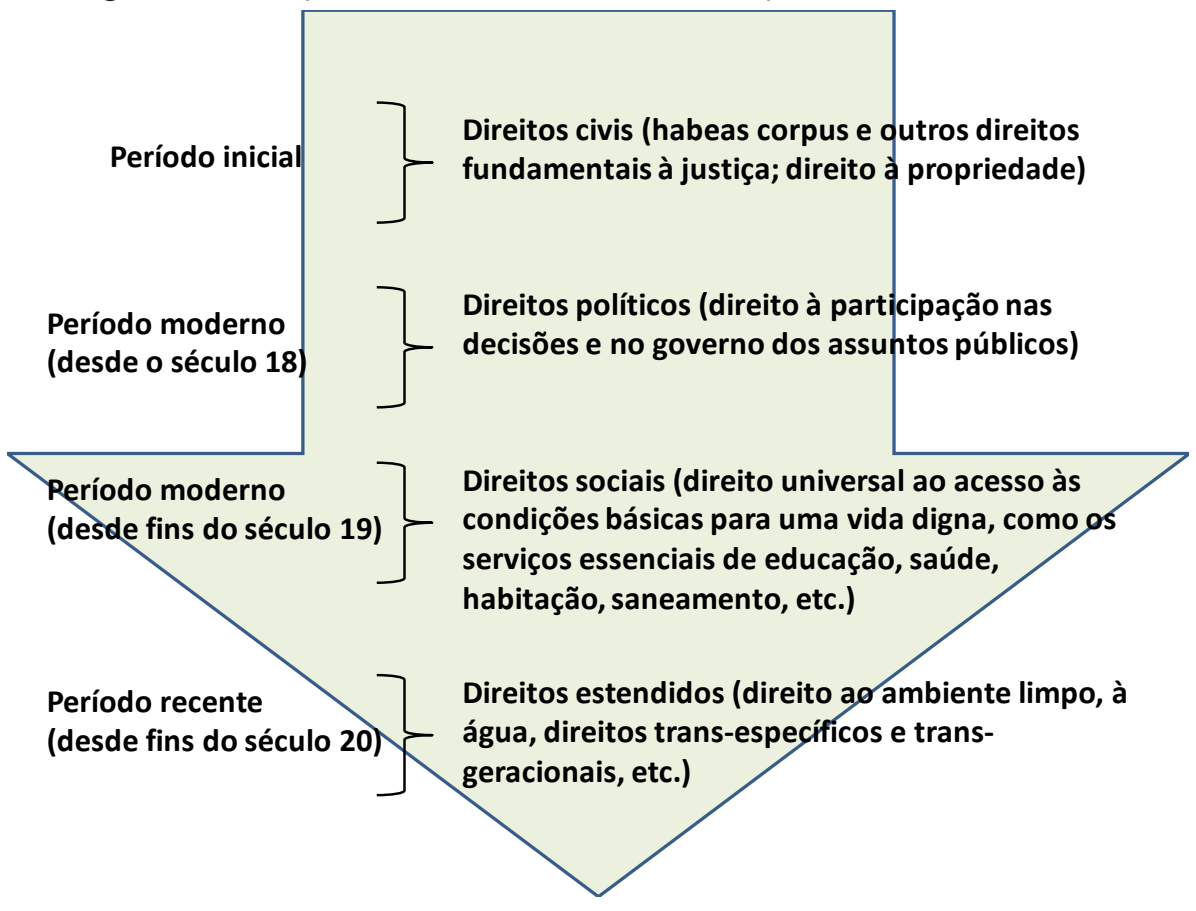


Não existe acordo referente a esses direitos estendidos ou ampliados da cidadania, e a partir de diferentes âmbitos do espectro político, discute-se a validade e utilidade de tais direitos. Por exemplo, para alguns atores envolvidos diretamente com o desenvolvimento da infra-estrutura de serviços, o debate dos "direitos" é uma discussão artificial, de pouca utilidade, que não contribui para as tarefas imediatas como são, por exemplo, a extensão de sistemas de saneamento às populações não atendidas. Num debate recente, ocorrido na Universidade de Sussex na Inglaterra ${ }^{1}$, por exemplo, atores envolvidos com a tarefa técnica de estender a infra-estrutura de serviços em países pobres argumentaram que o debate acerca do direito à água carece de sentido e tem pouca relação com a realidade que eles devem encontrar em campo. Os técnicos que expressavam esta opinião consideravam que a tarefa que eles realizavam como engenheiros civis encarregados da construção de obras de saneamento era "neutra" em termos políticos e viam com desconfiança e ceticismo a politização do debate sobre o

"Simpósio sobre a Água" conduzido pelo Institute of Development Studies (IDS) da Universidade de Sussex, 2 e 3 de novembro de 2009.

acesso a esses serviços, um debate que se dá precisamente em torno da noção de que existe um direito aos mesmos. Por outro lado, atores como as grandes empresas transnacionais que controlam o mercado privado dos serviços de saneamento em escala global começaram a utilizar a noção de "direito humano à água" abertamente declarando que eles apóiam a existência deste direito (vê-se, por exemplo, Labre, 2007; Veolia, 2007). Lamentavelmente, esses atores não aprofundaram as contradições existentes entre as noções de direito humano à água e o processo de mercantilização dos serviços básicos de saneamento que suas empresas incorporam na prática. De qualquer maneira, esses são apenas alguns exemplos das diversas posições que existem sobre a noção de "direitos" em relação aos serviços de saneamento básico, um debate cujas conseqüências analisaremos com mais detalhes na sequência. Apesar de alguns atores ativos no setor dos serviços de saneamento não visualizarem a relação entre a noção de direitos e a prática concreta, a inter-relação entre o processo de cidadanização, incluindo o desenvolvimento dos direitos de cidadania, e a evolução do 
setor de saneamento são muito claras, como veremos na seção histórica posterior. Porém nos deteremos brevemente aqui para considerar algumas vinculações conceituais entre ambos os processos.

\subsubsection{Direitos Civis}

Em primeiro lugar, quando consideramos os direitos civis de cidadania, quer dizer, fundamentalmente o direito à propriedade e à justiça, podem se estabelecer conexões importantes com o setor do saneamento. Sem dúvidas, o elemento chave no funcionamento deste setor é a água, ou melhor, os ecossistemas aquáticos, mesmo que com freqüência a linguagem técnica tenda a reduzir a água à sua dimensão econômica, a água como "recurso". Mas, mesmo numa concepção limitada do que é a água que a reduza a sua dimensão como "recurso" econômico, é possível tornar observável sua relação com os direitos do cidadão, o que nos leva a desenvolver uma série de perguntas. Se o direito básico da cidadania na democracia capitalista é a propriedade, quem tem a propriedade sobre a água? Esta pergunta tem uma resposta mais simples no caso da água nos setores rurais, onde em geral a propriedade da água costuma estar vinculada à propriedade da terra. Mas em relação aos serviços de saneamento básico em meios urbanos, a pergunta assume outro caráter, dado que a propriedade à água no caso dos aglomerados humanos implica num problema diferente. Formalmente, os direitos de propriedade sobre a água, com algumas exceções, como é o caso do Chile, estão nas mãos do Estado, que por sua vez estende os direitos de extração de água limpa e de disposição de águas residuais às empresas que se encarregam do fornecimento destes serviços. Deixando de lado por um momento a dimensão legal, que considerando sua fundamental importância, só representa um aspecto do problema, vale à pena repetir a pergunta: quem tem a propriedade da água, no sentido de direito fundamental da cidadania, numa democracia capitalista, em relação aos serviços de saneamento básico? Os indivíduos têm um direito de propriedade sobre a água no que se baseiam estes serviços? Se o têm, de que forma exercem tal direito? $\mathrm{Na}$ prática, a resposta genérica a esta pergunta seria que o Estado exerce 
esse direito em nome dos indivíduos, já que o Estado detém os direitos de propriedade sobre a água em última instância. Ou, em outras palavras, os cidadãos exercem seu direito indiretamente, por mediação do Estado. Deste modo, quando o Estado outorga direitos de extração de água limpa ou direitos de disposição de águas residuárias a uma empresa de saneamento, o está fazendo em representação dos cidadãos, que são os que detêm o direito de cidadão sobre os ecossistemas aquáticos em questão. É provável que este argumento possa resultar esotérico a alguns leitores, porque, na prática, a relação entre os cidadãos e os ecossistemas aquáticos e com o território em termos gerais, costuma ser invisível, inobservável, já que a cidadania foi historicamente separada do controle efetivo da propriedade, governo e gestão de bens como a água.

Um problema importante que surge desta aplicação do conceito de direito civil de cidadania em relação à água, e em particular o direito à água como propriedade privada, é que na prática pode-se dizer que a formação de direitos privados desta natureza é um processo de muito longo prazo, que assumiu uma diversidade de formas nos diferentes territórios, e é um processo fundamentalmente parcial, incompleto, inacabado, já que uma grande parte da água utilizada em nível internacional não foi convertida em propriedade privada. Como discutiremos mais adiante, as políticas neoliberais implantadas desde a década de 1980 tentaram acelerar este processo de privatização da propriedade da água, mas encontraram enormes obstáculos e retrocessos e pode-se dizer que existam poucos exemplos em nível internacional onde este objetivo foi alcançado. Entre outras razões para esta contradição, pode-se dizer que a água, e especialmente a água em zonas urbanas, apresenta obstáculos formidáveis ao processo de privatização, entendido neste caso como o processo de transferência dos direitos de propriedade sobre a água a atores privados. Examinaremos com mais detalhes as implicações deste argumento posteriormente.

Outro importante problema que surge deste tratamento da relação entre os direitos civis da cidadania e a água é a contradição que se produz a partir da introdução das instituições e princípios da democracia liberal, como é a cidadania, em contextos nos quais pré-existem formas de propriedade 
e gestão da água, fundamentados em princípios e instituições diferentes, frequentemente antagônicos ao modelo liberal capitalista. Neste caso, a introdução de direitos do cidadão, como o da propriedade privada na gestão da água e seus serviços associados, conduz frequentemente a profundos confrontos, muitas vezes não solucionados ou possivelmente não solucionáveis. Por exemplo, este é um dos eixos no debate atual sobre a gestão da água na Bolívia, onde alguns atores advertem que a introdução de direitos do cidadão liberal democráticos na gestão da água representa a expropriação dos direitos da água pré-existentes, fundamentados em princípios e instituições indígenas caracterizados por uma diversidade de formas de direitos de propriedade coletivos. A mesma noção de um Estado que garante os direitos de propriedade da água privados é vista por esses atores como uma ameaça à gestão democrática efetiva da água e seus serviços, no âmbito de sociedades altamente segregadas, como a boliviana (vê-se, por exemplo, Crespo, 2010; também Boelens, 2008, sobre as sociedades andinas em geral). Este exemplo ilustra uma questão que retomaremos em breve: a evidência sugere que a interação entre o processo de cidadanização liberal democrático dominante e as formas pré e co-existentes de direitos e obrigações pode potencialmente contribuir à emergência de novas relações sociais em torno da propriedade, gestão e governo da água e de seus serviços essenciais.

\subsubsection{Direitos Políticos}

A segunda dimensão dos direitos básicos de cidadania é representada pelos direitos políticos. Neste caso, em relação à água e aos serviços básicos de saneamento, pode-se gerar uma série de questões que vão ao coração do problema da gestão democrática. Os direitos políticos têm a ver com a participação dos cidadãos no exercício do poder, no governo dos assuntos comuns, seja mediante a eleição de quem governa ou sendo eleitos para participarem diretamente do governo. Na prática corrente dos sistemas democráticos vigentes, o exercício dos direitos políticos tende a se limitar pela participação eleitoral, na qual os cidadãos elegem seus governantes e, portanto, o exercício dos direitos políticos além do momento eleitoral é 
excepcional. No caso da gestão do meio ambiente, incluindo a água, e dos serviços de infra-estrutura básica, os exemplos da ausência do exercício dos direitos políticos são abundantes. Por exemplo, na Cúpula da Terra das Nações Unidas, ocorrida no Rio de Janeiro em 1992, a maioria dos governos se comprometeu a estabelecer mecanismos jurídicos e administrativos que possibilitassem aos cidadãos o exercício de seus direitos ambientais. 0 Princípio 10 adotado na cúpula estipula que:

"A melhor forma de tratar as questões ambientais é assegurar a participação de todos os cidadãos interessados ao nível conveniente. Ao nível nacional, cada pessoa terá acesso adequado às informações relativas ao ambiente detidas pelas autoridades, incluindo informações sobre produtos e atividades perigosas nas suas comunidades e a oportunidade de participar em processos de tomada de decisão. Os Estados deverão facilitar e incentivar a sensibilização e participação do público, disponibilizando amplamente as informações. $O$ acesso efetivo aos processos judiciais e administrativos, incluindo os de recuperação e de reparação, deve ser garantido" (ONU, 1992).

Entretanto, apesar das louváveis intenções da Declaração do Rio e dos avanços significativos que foram obtidos no plano legal-formal em muitos países, na prática, os cidadãos comuns, a maioria da população nos diferentes países segue assistindo mais como espectadores do que como participantes com direitos a gestão ambiental, incluindo a gestão da água e seus serviços. Um exemplo notório na América Latina foi o aprofundamento e a aceleração da implantação das políticas neoliberais durante a década de 1990, precisamente a mesma década na qual se aprovou a declaração do Rio. Na grande maioria dos países, a implementação destas políticas, que incluíram não somente a privatização da água e seus serviços, como também uma ampla classe de iniciativas com conseqüências diretas sobre o direito a um ambiente limpo e seguro, como o são a introdução de cultivos geneticamente modificados, o incentivo direto ou indireto ao desflorestamento, o enraizamento de indústrias contaminantes que emigram dos países centrais onde a 
regulação é mais severa, a expansão de monoculturas que estão destruindo as terras mais férteis da região, o uso incontrolado de defensivos agrícolas que envenenaram as terras e as águas e estão afetando a saúde de milhões de pessoas, a continuidade de obras enormes de infra-estrutura com impactos sociais e ambientais altamente negativos, a expansão sem precedentes da mineração a céu aberto, inclusive em regiões de alta fragilidade ecológica, entre outras várias políticas que vem sendo implementadas em grande escala, dando costas à opinião e interesses das comunidades afetadas e da maioria dos cidadãos. Nos poucos casos que os governos deram a seus cidadãos a oportunidade de participar de forma decisiva nas decisões, manifestou-se uma rejeição contundente a estas iniciativas, mas na maioria dos casos optou-se pela implantação de tais políticas ignorando, ou até mesmo violando os direitos políticos do cidadão. As privatizações massivas realizadas pelos governos de Carlos Menem na Argentina (1989-1999), Gonzalo Sánchez de Losada (1993-1997) e Hugo Banzer (1997-2001) na Bolívia e Fernando Henrique Cardoso (1995-2002) no Brasil são exemplos notáveis desta situação, mas, lamentavelmente, o exercício dos direitos políticos em relação ao ambiente e aos serviços essenciais continua sendo postergado e até negado, mesmo no âmbito dos governos que nominalmente se consideram progressistas ou de esquerda.

Um determinante fundamental na manutenção das situações que impedem a maioria da população de exercer seus direitos políticos de maneira extensiva, ou ao menos que limita severamente este exercício, é a reprodução de desigualdades sociais estruturais, notoriamente extremas na América Latina. Historicamente, o exercício substantivo dos direitos políticos na região foi restringido a certas frações de classes dominantes e a rápida ampliação da participação da população no exercício destes direitos desde meados do século vinte foi violentamente restringida mediante a instauração de ditaduras cívico-militares que deixaram uma marca profunda nas sociedades do referido continente. Na realidade, como demonstram os acontecimentos recentes na Bolívia (2008), Honduras (2009) e Paraguai (2009), mas também, em menor quantidade, em outros países, o cancelamento mediante o recurso a golpes de Estado dos ainda muito limitados 
direitos políticos em vigor na América Latina é um mecanismo latente e que conta com o apoio de importantes setores da sociedade. Porém, inclusive no marco institucional vigente, os direitos políticos dos cidadãos vêem-se limitados, em grande escala, ao exercício do voto nos períodos eleitorais, e qualquer tentativa de ampliação deste exercício deve enfrentar a oposição férrea dos setores que tradicionalmente detiveram o poder. Estas severas limitações da cidadania política na América Latina estão estreitamente relacionadas com o caráter restrito, tutelado, de baixa intensidade, da democracia em nossos países, como analisamos anteriormente. Não é de se estranhar que, num contexto social no qual os direitos políticos em geral encontram-se altamente restringidos, seu exercício em relação à gestão da água e os serviços de saneamento também se encontre severamente afetado, o que abordaremos com mais detalhes e com referência a exemplos concretos numa seção posterior.

\subsubsection{Direitos Sociais}

A terceira dimensão da cidadania em sua forma liberal democrática é a dos direitos sociais. A noção de direitos sociais de cidadania, incorporada nas instituições do "Estado de Bem Estar" desenvolvidas na Europa do segundo pós-guerra e adotadas em diferentes formas em outros países, parte do reconhecimento de que o acesso a certos bens e serviços essenciais à sobrevivência e à vida digna deve ter caráter universal e deve ser independente da posição dos indivíduos e das famílias no mercado, ou em termos mais simples, deve ser independente da capacidade monetária das pessoas. Como expressou T. H. Marshall (1963), a noção de direitos sociais assume que todos os membros de uma comunidade política devem ter acesso irrestrito ao "patrimônio comum" que foi desenvolvido pela sociedade em questão, especificamente em termos de certas questões fundamentais como a educação básica, o cuidado com a saúde e as condições materiais de vida essenciais, como a habitação e os serviços de saneamento. No entanto, esta noção de direitos sociais foi sempre rejeitada por algumas tradições intelectuais, particularmente pelas tradições liberais individualistas e algumas 
facções neoconservadoras, para as quais a noção de direito social constitui senão um obstáculo ao exercício da cidadania. Para estes atores, os direitos de cidadania se reduzem aos direitos civis e políticos, enquanto que os assim chamados direitos sociais constituem um atentado à liberdade individual e um obstáculo ao cumprimento dos deveres da cidadania, já que o fornecimento público de bens e serviços seria uma fonte de corrupção do sentido de responsabilidade dos indivíduos (ver, por exemplo, Murray, 1984; Mead, 1986; vê-se também a crítica de King, 1988). Outras tradições localizadas mais à esquerda no espectro político também dirigiram severas críticas aos direitos sociais de cidadania, ou mais precisamente a suas instituições como o "Estado de Bem Estar", já que as mesmas foram utilizadas para legitimar o sistema capitalista de exploração mediante políticas redistributivas, que apenas servem para amortecer o impacto das desigualdades estruturais do sistema sem questionar seus fundamentos. Deste modo, nesta perspectiva, as políticas associadas aos direitos sociais de cidadania representam mais uma contribuição à manutenção da exploração de classes, do que uma possibilidade emancipatória para as maiorias trabalhadoras (ver, por exemplo, os trabalhos já clássicos de Preteceille, 1974, Decaillot et al., 1977; Lojkine, 1979, entre outros; mais recentemente, Kouvélakis, 2005).

Em relação à experiência da América Latina, o debate sobre os direitos sociais de cidadania ilumina uma série de contradições que caracterizam o desenvolvimento de nossas comunidades políticas. Por um lado, em sentido restrito e com poucas exceções, os direitos sociais na América Latina não chegaram a se consolidar no tipo de instituições que se desenvolveram na Europa como parte do "Estado de Bem Estar". Embora alguns países tenham desenvolvido sistemas eficientes e de caráter universal para a provisão de certos serviços, como a educação básica ou a atenção à saúde, na grande maioria dos casos estes desenvolvimentos foram muito limitados em seu alcance, com a exceção clássica da Cuba revolucionária e, em algumas áreas e durante certos períodos históricos, de países como a Argentina, o Chile, a Costa Rica ou o Uruguai. Por outro lado, como frisou Roberts, em alguns aspectos, o desenvolvimento dos direitos sociais de cidadania na América Latina precedeu o desenvolvimento dos direitos civis e políticos, o que 
constitui um processo inverso ao que ocorreu nas democracias capitalistas centrais, nas quais os direitos sociais foram os últimos a se consolidar (Roberts, 1995).

\section{Quadro 2. Os Direitos Clássicos de Cidadania e o Saneamento}

A discussão da relação entre os direitos de cidadania e a água leva a uma série de questionamentos onde é necessário se aprofundar.

Em relação aos direitos civis de cidadania, quem tem a propriedade da água em uma cidade, em uma região? Como os cidadãos exercem esse direito de propriedade? Que mecanismos os cidadãos têm para exercer seu direito à justiça, em relação aos serviços de saneamento?

Em relação aos direitos políticos: quem governa a água e os serviços básicos baseados na água? Como se exercem os direitos políticos de cidadania em relação à água, ao saneamento e, em geral, à gestão ambiental? Quem elege os que governam a água e o saneamento? Como os elegem? Pode qualquer cidadão participar no governo da água e seus serviços? Ou esse é um tema reservado somente aos especialistas técnicos e aos políticos profissionais? Como os cidadãos controlam quem governa a água e seus serviços?

Em relação aos direitos sociais: qual é o status dos serviços de saneamento básico, tanto em termos formal-legais, como em termos práticos? $\mathrm{O}$ acesso a estes serviços constitui um direito do cidadão independente da capacidade monetária dos indivíduos e famílias? Ou tal acesso está determinado pela capacidade monetária e, portanto, mediado por uma relação mercantil? Em outras palavras, o acesso aos serviços básicos de saneamento é um direito ou uma mercadoria? A diferença importa?

No caso do fornecimento de serviços de saneamento básico, como discutiremos com mais detalhes em seções posteriores, a América Latina apresenta um quadro de grande desigualdade e iniquidade, que, também com poucas exceções, caracterizou a história inteira de nossos países. $\mathrm{Na}$ realidade, a desigualdade no acesso aos serviços essenciais de saneamento é um indicador muito eloqüente na dinâmica excludente que caracteriza as democracias predominantes em nossa região. 


\subsubsection{Os Direitos Estendidos ou Ampliados}

Os direitos estendidos da cidadania são o resultado de processos que ocorreram principalmente desde a década de 1960. Tanto por seu caráter recente, como por sua natureza e conteúdo, estes direitos também acabam sendo altamente controversos, tendo sido sujeitados a fortes críticas. Em primeiro lugar, podemos indicar a extensão dos direitos e deveres da cidadania a uma série de âmbitos não contemplados anteriormente de forma direta ou explícita, como, por exemplo, os direitos sexuais, o direito ao meio ambiente, os direitos das crianças, os direitos étnicos, ou mais recentemente, o "direito à água", que desencadeou um amplo debate (ver, por exemplo, Esch. et al., 2006). Em geral, estes direitos e deveres foram incluídos em declarações internacionais, muitos deles foram sancionados nas constituições dos países e foram inclusive incorporados na legislação, levando em conta que as evidências sugerem que o progresso foi mais retórico que real, na maioria dos casos. Esta é a base das críticas mais severas, que, a partir de diferentes âmbitos do espectro político, apontam a falta de concretização destes direitos ampliados e, principalmente, as dificuldades inerentes à sua implantação prática. Em segundo lugar, deu-se um processo de extensão espaço-temporal do sujeito da noção de cidadania. Por um lado, alguns direitos foram atribuídos a entes e seres não humanos, os quais, segundo algumas opiniões, deveriam ser aceitos como sujeitos de direitos do cidadão. Diferentes tentativas em estender os direitos de cidadania além da espécie humana procuram converter os animais, a natureza e até entes artificiais, como os robôs, em sujeitos de direitos do cidadão (ver, por exemplo, Goodin et. al., 1997; Gray, 2001; IPSOS-MORI, 2006). Por outro lado, em debates como o da sustentabilidade ambiental, deu-se uma convergência dos argumentos a favor de formas trans-específicas de cidadania com aqueles que propõem a extensão trans-geracional dos direitos. De fato, na perspectiva da sustentabilidade, é implícito o reconhecimento do direito das gerações ainda não nascidas às condições básicas de vida, que requerem a preservação da base natural da vida e do meio ambiente (ver, entre outros, Steenbergen, 1994; Newby, 1996). 
Quadro 3. Os Direitos Estendidos de Cidadania e o Saneamento

Os direitos estendidos da cidadania são de origem mais recente e altamente controversos.

Em relação aos direitos trans-específicos de cidadania, é possível e desejável reconhecer direitos a entes e seres não humanos? Que significado tem reconhecer um direito à água para os animais e as plantas? É possível e desejável reconhecer que a natureza também é sujeito de tais direitos? Como os seres e entes não humanos podem exercer tais direitos?

Em relação aos direitos trans-geracionais: é possível e desejável reconhecer estes direitos às gerações humanas futuras?

Em perspectiva histórica, o processo de extensão e aprofundamento dos direitos e deveres do cidadão resultante de diversas lutas emancipatórias foi transformando o significado da cidadania muito particularmente em seu caráter de relação social. Simultaneamente, é necessário evitar que os avanços que este processo representa no plano legal-formal obstaculizem nossa compreensão da complexidade do mesmo, já que tais avanços vêm frequentemente acompanhados pelo aprofundamento de certas formas tradicionais de exclusão e desigualdade social e pela emergência de novas formas (Tilly, 2003). Por outro lado, o processo de cidadanização carece de potencial para transformar o caráter da cidadania e dar lugar a novas formas de relação social que eventualmente superem as contradições dos sistemas de cidadania prevalecentes, que estão fundamentados, em última instância, nos princípios da democracia liberal capitalista.

\subsubsection{A Participação Social e a Esfera Pública}

A participação é um componente central dos conceitos de cidadania e de gestão democrática. No desenvolvimento histórico da cidadania como relação social, pode-se dizer que aquilo que nos debates contemporâneos denomina-se como a "participação cidadã" tem sua origem nas lutas sociais pela expansão dos direitos do cidadão a setores cada vez mais amplos da população, e em particular pela expansão dos direitos políticos que começa a se consolidar na Europa durante o século dezenove. Neste sentido, a participação cidadã está estreitamente vinculada ao desenvolvimento da esfera 
pública, um processo que também esteve sujeito às particularidades históricas dos distintos territórios e que tomou dimensões diferentes em função da diversidade de tradições e culturas políticas. Por exemplo, enquanto a tradição liberal da democracia representativa convencionalmente restringe a participação nas decisões da esfera pública aos políticos profissionais e aos especialistas, outras tradições recusam esta definição restrita e elitista e propõem diversas alternativas, incluindo a participação direta dos cidadãos nas decisões (vê-se, por exemplo, Robbins, 1995; Ferree et al., 2002). Isto ilustra o fato de que conceitos como "democracia", "cidadania" ou "participação" são vagos e de alta generalidade, que requerem incorporar a dimensão histórico-social e o contexto, para dar maior precisão a seu significado. Este ponto tem grande relevância para o debate sobre a participação e o controle social na gestão democrática dos serviços de saneamento no Brasil.

Quadro 4. Esfera Pública e Participação Social em Tradições Políticas Rivais

\begin{tabular}{|c|c|c|c|}
\hline \multirow{2}{*}{$\begin{array}{l}\text { Tradições } \\
\text { políticas }\end{array}$} & \multicolumn{3}{|c|}{ Critérios de participação social } \\
\hline & Quem participa? & Em que tipo de processo? & Resultado \\
\hline Liberal representativa & $\begin{array}{l}\text { A elite política profissional; } \\
\text { os especialistas }\end{array}$ & Livre mercado de idéias & $\begin{array}{l}\text { Restrição (sistêmica) da } \\
\text { participação }\end{array}$ \\
\hline Liberal participativa & $\begin{array}{l}\text { Possibilidade de participação } \\
\text { popular restrita }\end{array}$ & Empoderamento & $\begin{array}{l}\text { Evitar a restrição (sistêmica) } \\
\text { da participação }\end{array}$ \\
\hline Discursiva & Inclusão popular & Deliberativo & $\begin{array}{l}\text { Evitar a restrição prematura, } \\
\text { não consensuada }\end{array}$ \\
\hline Construcionista & Inclusão popular & $\begin{array}{l}\text { Empoderamento } \\
+ \\
\text { Reconhecimento }\end{array}$ & $\begin{array}{l}\text { Evitar a restrição excludente } \\
\text { Expande a comunidade } \\
\text { política }\end{array}$ \\
\hline
\end{tabular}

Fonte: Adaptado de Ferree et. al., 2002. 
Aproximadamente desde a década de 1980, o conceito de participação passou a ganhar grande importância na América Latina, incluindo os debates sobre as políticas públicas nos setores de serviços essenciais como a atenção à saúde ou o acesso à habitação, a educação ou o saneamento básico. Por um lado, a retirada das ditaduras cívico-militares e o retorno da democracia eleitoral aos países da região permitiram a abertura de espaços mais amplos para a participação efetiva da população na vida política. Por outro lado, desde a década de 1970, em muitos países da região, se registrou uma crescente mobilização social em torno da busca por melhorias das condições materiais de vida, especialmente nas zonas urbanas e peri-urbanas, um processo no qual a luta pelo acesso aos serviços de água e esgotamento sanitário passou a ter um papel muito importante (Castro, 2006). Neste sentido, pode-se dizer que, neste contexto de recuperação dos espaços da democracia formal e de crescente mobilização social pela melhoria das condições vitais, o conceito de participação social foi tomando conteúdos concretos surgidos de tais experiências. Em alguns casos, notoriamente no Brasil, o processo chegou inclusive a promover iniciativas de políticas públicas fundamentadas no princípio da participação cidadã efetiva e na democracia direta, como é o caso do modelo do orçamento participativo (Dutra e Benevides, 2001; Fedozzi, 2001).

No entanto, como em todo processo social e político, as experiências tendem a seguir desenvolvimentos que são determinados por múltiplas circunstâncias e dinâmicas, cujos resultados são imprevisíveis e incontroláveis para os atores envolvidos. Neste sentido, "participação" se converteu com o tempo num vocábulo de grande utilidade instrumental empregado não somente por acadêmicos nos seus estudos do processo de re-democratização, mas também por movimentos sociais, organizações não governamentais, grupos políticos, governos, instituições financeiras internacionais e, inclusive, quando já iniciada a década de 1990, por empresas privadas de saneamento. Deste modo, em muitos casos o conceito foi transmutado e ainda esvaziado de seu sentido através dos usos instrumentais de que foram objeto para diferentes atores. Como mostra uma literatura crescentemente abundante, devido ao abuso, o conceito "participação" social da cidadania foi assumindo diversos significados e foi, inclusive, convertido 
num instrumento de cooptação, manipulação e desmobilização dos atores sociais. Em algumas opiniões, a participação é entendida na prática como obediência antecipada por parte da população em relação às decisões tomadas por especialistas e políticos profissionais. Em outros casos, em nome da participação, implementam-se políticas que procuram liberar o Estado de suas responsabilidades pela prestação de serviços essenciais e transferir tais responsabilidades aos cidadãos, incluindo a responsabilidade do financiamento e do fornecimento de força de trabalho voluntária para a construção de obras de infra-estrutura básica. Não é de se surpreender então que alguns autores definiram essas formas instrumentais de participação como "a nova tirania" (Cooke e Khotari, 2001).

Neste sentido, o tema da participação social é um aspecto central no setor de saneamento básico na América Latina, onde tradicionalmente o desenvolvimento destes serviços se caracterizou por um alto nível de desigualdade de acesso por parte da população e pela ausência de mecanismos de controle democrático efetivo sobre o funcionamento dos organismos e empresas envolvidos. Retomaremos este assunto posteriormente para apresentar alguns exemplos destes usos e abusos do conceito de participação social no caso dos serviços de saneamento.

\subsection{A Governabilidade na Gestão do Saneamento}

O conceito de governabilidade é de desenvolvimento relativamente recente e, de maneira similar aos conceitos modernos de cidadania, democracia ou sociedade civil, o mesmo surge das experiências específicas das democracias capitalistas ocidentais. O conceito também esta sujeito a um amplo debate e deu espaço a um grande número de definições, muitas delas contraditórias entre si. Assim, como no caso dos direitos de cidadania que abordamos anteriormente, os confrontos entre diferentes tradições intelectuais e políticas determinam que o conceito de "governabilidade" assuma significados diversos e até mesmo antagônicos. Por exemplo, uma das definições mais convencionais da governabilidade tende a apresentá-la como a articulação de três regimes de gestão: de forma sintetizada, a gestão pública estatal, a gestão privada mercantil e a gestão voluntária e solidária 
característica da "sociedade civil" (ver, por exemplo: Piccioto, 1997). Mesmo que esta concepção de governabilidade tenha se convertido em dominante, a mesma tem uma grande fragilidade porque, para dar um exemplo, o significado de "sociedade civil" é muito diferente para as diversas tradições intelectuais e políticas. Por exemplo, para a tradição liberal individualista e, muito particularmente em sua versão neoliberal privativista contemporânea, a "sociedade civil" é sinônimo de "mercado", ou seja, uma constelação de indivíduos, cada um destes perseguindo seus próprios interesses. Quer dizer, os campos de ação real para esta tradição são o Estado e o mercado e a meta central para um neoliberal privativista é a redução do papel do Estado à sua mínima expressão possível e a ampliação máxima da esfera de influência dos atores privados. Podemos dizer que o ideal neoliberal da governabilidade é a ação privada livre de regulação e controle, incluindo o controle democrático por parte dos cidadãos, tema que retomaremos em breve com alguns exemplos. Dado que esta tradição intelectual e política dominou, em nível internacional, o campo das políticas públicas, incluindo as políticas públicas de saneamento, desde a década de 1980, fica claro que o emprego do conceito de governabilidade em relação à gestão democrática dos serviços básicos deve ser examinado em profundidade e com ceticismo intelectual. Por exemplo, quando atores e instituições fortemente inspirados pela ideologia neoliberal privativista falam de governabilidade nos serviços públicos, é importante se perguntar o que estes atores e instituições entendem por governabilidade. Não podemos assumir que existe um conceito de governabilidade universalmente aceito, ainda que às vezes seja apresentado assim na literatura de políticas públicas oficial.

Um dos maiores problemas que se detecta no uso do conceito de governabilidade em relação à gestão de serviços públicos essenciais, como os de saneamento, é a redução do conceito ao plano técnico-administrativo, instrumental, e sua virtual despolitização (Castro, 2007a). Por exemplo, segundo alguns atores mais influentes no setor da gestão da água em nível global, governabilidade refere-se ao conjunto de instrumentos técnico-administrativos disponíveis para a administração da água e os bens e serviços relacionados (GWP, 2003; UNESCO, 2006). Em outros casos, e em relação ao que mencionamos anteriormente, a governabilidade tende a se identificar 
com o conceito de parcerias tripartites entre os governos, a iniciativa privada e a "sociedade civil", este último conceito sujeito a uma ampla discussão, mas que, no contexto destes debates, costuma ser utilizado como sinônimo de organizações não governamentais (ONGs). Em geral, estas maneiras de conceituar a governabilidade reduzindo-a em suas dimensões técnico-administrativas cumprem uma função instrumental de esvaziar o conceito de um de seus componentes centrais: o exercício do poder. De fato, a governabilidade tem a ver principalmente com o exercício do poder na tomada de decisões, por exemplo, em relação à distribuição dos benefícios provenientes dos investimentos que a sociedade faz no desenvolvimento dos bens e serviços básicos e no controle democrático da sua gestão por parte dos cidadãos, mas estes aspectos ficam postergados a um segundo plano, quando não diretamente excluídos, nas conceitualizações instrumentais da governabilidade.

Em relação ao ponto anterior, cabe ressaltar que a relação entre democracia e governabilidade não é necessária nem mecânica, já que frequentemente o exercício do poder, que caracteriza a governabilidade, toma formas autoritárias e até mesmo anti-democráticas, como é obviamente o caso das ditaduras cívico-militares, mas também recorrentemente no contexto das democracias restringidas ou de baixa intensidade. Como citaram Hanf e Jansen em seu trabalho sobre governabilidade ambiental na Europa, a governabilidade tem a ver com o exercício do poder em relação aos fins e valores que articulam a visão da sociedade desejada, assim como sobre os meios mediante os quais os atores de determinada sociedade procuram alcançar estes fins e defender estes valores (Hanf e Jansen, 1998). Na prática, o exercício do poder neste sentido tem a ver com o confronto entre fins e valores alternativos, às vezes antagônicos e incompatíveis, que correspondem às preferências e interesses materiais de diferentes atores sociais. Por esta razão, é fundamental extrapolar as visões idealizadas e ideológicas da governabilidade que a reduzem a um conjunto de técnicas de governo, supostamente apolíticas, e restabelecer uma compreensão da governabilidade que dê centralidade aos processos políticos e ao exercício do poder. Como veremos mais detalhadamente na seção seguinte, este debate tem uma importância crucial para a gestão democrática dos serviços de saneamento. 


\section{Quadro 5. A Governabilidade dos Serviços de Saneamento e o Poder}

Em relação à gestão democrática dos serviços de saneamento, a governabilidade, entendida como exercício do poder, implica em confrontos sociais em torno de questões, tais como:

Quem deve ser responsável pelo financiamento dos bens e serviços básicos? Quem devem ser os beneficiários de tais bens e serviços e em que ordem de prioridade? Quais devem ser os critérios e mecanismos para decidir como os beneficiários terão acesso aos mesmos?

Quais devem ser os valores e fins que orientam a gestão do saneamento? Estes devem ser considerados um bem público, um direito social, ou uma mercadoria? Que tipo de meios devem ser empregados para obter tais fins e defender tais valores?

Como se decide quem deve tomar e implementar as decisões no setor do saneamento? Como se decide qual deve ser o papel do Estado, do setor privado e da "sociedade civil" na gestão destes bens e serviços? Quais mecanismos existem para impedir, ou pelo menos limitar, o autoritarismo e as formas anti-democráticas de gestão no setor de saneamento?

Outro aspecto importante que cabe destacar é que, de forma analógica ao tema da participação social que foi discutido previamente, a governabilidade num ramo determinado de atividade, como pode ser o setor de saneamento, está enquadrada no processo de governabilidade no nível do sistema social e imbricada com os processos de governabilidade de outros setores inter-relacionados, como, por exemplo, a governabilidade ambiental, que inclui a governabilidade da água, das bacias, etc., ou a governabilidade do sistema básico de saúde (ver figura 2).

Figura 2. Governabilidade inter-setorial e multi-nível

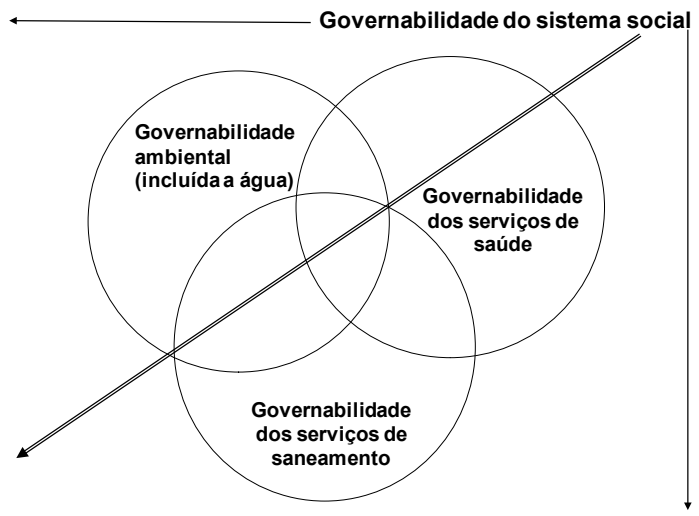


Neste sentido, por exemplo, seria possível que uma determinada sociedade introduzisse mudanças no sistema de governabilidade do setor de saneamento orientadas à democratização da gestão, por exemplo, impulsionando uma legislação que promovesse a participação efetiva dos usuários no controle da gestão, e, no entanto, o impacto potencial de tais reformas se visse diminuído ou mesmo neutralizado porque a estrutura de governabilidade em nível sistêmico é altamente refratária ao processo de democratização e tende a se estabilizar em torno da manutenção das relações de poder tradicionais que podem ter um caráter tecnocrático, com participação altamente restrita, quando não francamente autoritário. Da mesma forma, é possível que sejam introduzidas reformas na governabilidade do setor de saneamento orientadas a aprofundar o caráter democrático de sua gestão, mas que simultaneamente outros setores estreitamente vinculados ao saneamento, como são a gestão das bacias ou da saúde pública, tendam a reproduzir formas de governabilidade que obstaculizem o processo democratizador. Claramente, também podem ocorrer contradições e desajustes entre os processos de governabilidade em escalas territoriais diferentes (por exemplo, entre os níveis nacional, regional e local) ou entre domínios territoriais de nível similar (por exemplo, entre diferentes estados e municípios). As implicações deste caráter inter-setorial e multi-nível da governabilidade são efetivamente um aspecto fundamental que deve ser incorporado à análise da gestão democrática do saneamento, o que discutiremos novamente com referência aos exemplos citados na seção seguinte.

\section{A Gestão Democrática dos Serviços de Saneamento em Perspectiva Histórica}

A origem dos serviços de saneamento em sua forma moderna, principalmente nos setores urbanos dos países ocidentais, está estreitamente ligada aos processos de cidadanização e de mercantilização. Para efeito de síntese, podemos, em termos gerais, analisar este processo histórico em três etapas: 1) o privatismo, que engloba desde fins do século dezoito até a segunda metade do século dezenove, 2) o racionalismo administrativo, 
que se estabelece desde finais do século dezenove, e 3) o neo-privatismo, que tenta se reinstalar a partir da década de 1980. Necessariamente, esta divisão em etapas com fins analíticos não pretende ser exaustiva, nem tampoco significa que as etapas sejam mutuamente excludentes entre si, o que explicaremos em seguida. No entanto, estas etapas surgem da análise das tendências centrais observáveis no desenvolvimento dos serviços de saneamento nos países capitalistas ocidentais, o que, certamente, não significa que não existam variações ou até mesmo casos que se afastem de tais tendências (para uma breve revisão da literatura sobre este assunto, ver Castro, 2005; um tratamento mais ampliado do assunto pode ser consultado em Castro, 2011).

\subsection{O Saneamento Privatista}

O surgimento dos primeiros sistemas de abastecimento domiciliar de água encanada em áreas urbanas a partir de fins do século dezoito na Inglaterra e na França, os países pioneiros neste desenvolvimento, se dá no âmbito das condições particulares que caracterizam o desenvolvimento da democracia capitalista nestes países. Neste contexto, o fornecimento do serviço de água aos domicílios particulares começa pela forma de empreendimentos privados pautados pelo lucro, frequentemente financiados por recursos públicos. Nesta etapa inicial, entendia-se que o acesso domiciliar a água encanada era uma decisão individual, uma escolha, e o caráter de tal fornecimento era o de uma relação mercantil, privada, entre um fornecedor e um cliente. O caso típico deste modelo foi a cidade de Londres, onde até meados do século dezenove, o fornecimento de água às habitações estava nas mãos de pequenas empresas privadas que detinham monopólios territoriais, um modelo que logo se estendeu ao resto do país. Processos similares ocorreram na França e nos Estados Unidos e o modelo se estendeu posteriormente em nível internacional, inclusive à maioria dos países da América Latina.

O modelo privatista de saneamento enfrentou desde o começo numerosos obstáculos. Por um lado, o fornecimento domiciliar de água encanada 
pautada no lucro privado requeria a expansão ampliada de uma identidade social que até então só tinha uma existência limitada: o cliente privado e adimplente de água domiciliar. o disciplinamento social requerido para a reprodução ampliada do cliente privado de água como identidade social foi percebida por historiadores como Colin Ward, quem registra em seu trabalho tanto o caráter excludente do processo, como as limitações do modelo. De fato, a expansão dos serviços de água privados e pautados no lucro deu lugar à criminalização dos que, por um motivo ou outro, resistiam ao modelo, ou simplesmente ficavam excluídos do mesmo, convertendo em "ladrões de água" os que ousaram utilizar a água para satisfazer suas necessidades básicas sem firmar primeiro um contrato com as empresas (Ward, 1997: 5). Este processo de disciplinamento é inteiramente compreensível desde a perspectiva do modelo privatista, já que o mesmo se fundamentava no princípio de exclusão: o acesso à água domiciliar era fundamentalmente um bem privado, disponível somente aos que pudessem pagar por ele. É interessante, como exemplo deste princípio fundante do modelo privatista, que um artigo do The Economist, o porta-voz histórico e por excelência do capitalismo liberal britânico, escrito apenas dois anos depois das epidemias de cólera que afetaram Londres em 1847-48 e no meio de um forte debate político com setores pleiteando a estatização das empresas de água privadas, defendia o modelo privatista dizendo que a cidade já contava com a tecnologia para dotar de água a qualquer moradia, inclusive aquelas localizadas nos pontos mais altos das redondezas, sempre e quando os proprietários estivessem dispostos a pagar o preço respectivo. Como para eliminar qualquer dúvida a respeito do caráter político-ideológico que assumia a gestão da água urbana, o editor acrescentava:

"a grande distinção entre a Inglaterra e as nações do continente, a principal fonte de nossa superioridade, foi o grande espaço outorgado à empresa privada e à muito limitada esfera de operações do governo. Eventos recentes reforçaram nossa crença e não podemos permitir que a influência do terror momentâneo, ocasionado por uma epidemia, suprima todas as 
convicções morais que foram tangíveis à experiência dos séculos" (The Economist, 1850:62).

De maneira semelhante, o historiador Jean-Pierre Goubert registra o caso de um Comitê Consultivo do governo francês que, em 1819, examinava um pedido de instalação de sistemas purificadores de água para consumo humano das populações, ao qual os oficiais promulgam que, ainda que o fornecimento de água limpa seja certamente algo desejável, este não é um assunto do governo e deve ser resolvido de maneira privada (Goubert, 1860: 40). Estes exemplos ilustram a visão dominante neste período: a noção de que o acesso à água potável devia ser garantido ao conjunto da população não fazia parte do modelo de gestão privatista prevalecente nessa fase, para o qual o acesso a este serviço, inclusive em situações de ameaças epidêmicas como as que afetavam as cidades européias do século dezenove, constituía estritamente uma relação mercantil entre atores privados. A partir do ponto de vista da gestão democrática, este modelo incorporava a visão liberal privatista clássica da cidadania, na qual os direitos se circunscrevem às dimensões civil e política e, muito particularmente, ao direito à propriedade, cujo intercâmbio deveria ocorrer de acordo com as regras do mercado e sem interferência do Estado. Nesta visão, a identidade do cidadão tende a se confundir quase totalmente com a do proprietário privado.

Uma das implicações deste caráter excludente do modelo privatista, mercantilizado, dos serviços de água domésticos, foi a limitação da expansão dos serviços às áreas que as empresas consideravam rentáveis. Este enfoque de serviços de água orientados aos setores urbanos que podiam oferecer uma demanda efetiva levou ao desenvolvimento de um padrão de alta desigualdade no acesso ao serviço que caracterizou a situação na Europa, Estados Unidos e, posteriormente, também na América Latina. Quanto a isto, cabe acrescentar que o desenvolvimento dos sistemas de esgotamento sanitário foi praticamente uma tarefa exclusiva do setor público, já que as empresas privadas a cargo da distribuição de água não se interessavam pelo problema da "água suja", entre outras razões, pela escala dos investimentos necessários, que excediam a capacidade financeira das empresas vista a sua escassa potencialidade que apresentavam estes serviços para sua efetiva 
comercialização. Por outro lado, durante a etapa privatista e praticamente até a segunda metade do século dezenove, as empresas privadas a cargo dos serviços estavam sujeitas a poucos controles, quando não diretamente livres de toda regulação, em termos de qualidade e regulação do serviço, preços, etc. A necessidade de regular estas empresas começa a surgir a partir de meados do século dezenove, quando os problemas e limitações do modelo privatista se tornam cada vez mais evidentes num contexto de rápido crescimento urbano e populacional nas cidades da Europa e dos Estados Unidos, ainda que não seja até fins do século dezenove que os princípios e as instituições reguladoras do setor de saneamento começam a se estabelecer firmemente (para uma análise mais detalhada do desenvolvimento da regulação no setor de saneamento, ver Castro, 2008a).

\section{Quadro 6. Aspectos do modelo privatista de gestão do saneamento}

A origem dos sistemas modernos de saneamento nos países capitalistas centrais, especialmente na Inglaterra, França e Estados Unidos, desde fins do século dezoito, foi orientada pela ideologia liberal privatista. Os princípios fundamentais deste modelo de gestão eram:

- o fornecimento de serviços de água nas mãos de empresas privadas monopolistas, desreguladas;

- a concepção de que o acesso à água nos domicílios era uma escolha individual, sujeita a um acordo contratual entre atores privados, sem mediação do Estado;

- a consolidação da identidade do cidadão-proprietário privado típica da versão liberal individualista da cidadania;

- a formação de novas identidades sociais, como o cliente privado da água e o ladrão de água;

- a concentração dos serviços nos bairros abastados das cidades mais ricas;

- a incapacidade (financeira, técnica) ou falta de interesse dos prestadores privados em estender as redes ao conjunto da população ou ampliar os serviços para incluir o esgotamento sanitário.

Como conseqüência, desde fins do século dezenove, vem ocorrendo um processo de crescente controle e regulação dos serviços de água prestados por empresas privadas, e uma crescente participação do Estado, especialmente através de autoridade locais, na prestação direta destes serviços, incluindo o esgotamento sanitário. Um caso notável foi o da 
cidade de Londres onde, depois de várias décadas de confrontos políticos, um governo conservador, liderado pelo partido que representava os interesses empresariais, decide colocar as empresas de água privada em mãos públicas com a criação, em 1902, da Junta Metropolitana de Águas. Casos semelhantes ocorreram no resto da Inglaterra, Europa e Estados Unidos e, posteriormente também nos países da América Latina (ver, entre outros autores, Mukhopadhyay, 1975; Ogle, 1999; Melosi, 2000; Pezon, 2000; Castro e Heller, 2006; Rezende e Heller, 2008). Um dos motores deste processo foi o movimento sanitarista, ainda que os atores que participaram nestes confrontos pela ampliação do acesso aos serviços essenciais compusessem uma ampla gama de alianças que incluíam defensores do livre mercado e da empresa privada. Como tendência geral, até inícios do século vinte, havia se estabelecido certo consenso sobre a necessidade de concentrar a responsabilidade pelo controle e gestão dos serviços essenciais no setor público, o que refletiu na progressiva retirada do modelo de gestão privatista e na consolidação de um novo modelo que, utilizando a definição de John Dryzek, podemos denominar como o "racionalismo administrativo" (Dryzek, 1997).

\subsection{O Racionalismo Administrativo no Setor do Saneamento}

O conceito de racionalismo administrativo, derivado dos trabalhos de Max Weber sobre os processos de racionalização e burocratização, faz referência ao modelo de gestão que se instalaria crescentemente nos países ocidentais, a partir de fins do século dezenove e, em particular, inícios do século vinte. O racionalismo administrativo se constituiu a partir da articulação da crescente aplicação do conhecimento científico e da organização burocrática governamental no âmbito da gestão de recursos, bens e serviços. A regulação crescente das atividades privadas que, como foi mencionado antes em referência aos serviços privados de água, começa a se ampliar a partir do final do século dezenove, fazendo parte constitutiva do processo que crescentemente conduziu ao estabelecimento de uma forma de gestão centrada em grande escala no controle e intervenção 
direta do Estado em praticamente todas as esferas de atividade. Este processo consolidou-se a partir do desastre do modelo de livre mercado no período de entre-guerras que, por fim, resultou no colapso financeiro mundial de 1929 (ver, entre outros autores que analisam este processo: Polanyi, 1957; Aglietta, 1976; Hobsbawm, 1994). Como resultado, durante a primeira metade do século vinte, o racionalismo administrativo retira a idéia por completo, praticamente, do privatismo como modelo dominante de gestão dos serviços públicos essenciais no mundo ocidental e, a partir do segundo pós-guerra, pode-se dizer que existe um consenso dominante, até mesmo entre os defensores do livre mercado, sobre o papel fundamental do Estado no fornecimento direto de tais serviços (Swyngedouw et. al., 2002).

Um dos resultados indiscutíveis do avanço e consolidação do racionalismo administrativo no âmbito dos serviços essenciais, e do saneamento em particular, foi a expansão e, finalmente, a universalização do acesso a estes serviços. Na maioria dos países industrializados, por exemplo, o acesso aos serviços urbanos de água para consumo humano consegue se universalizar aproximadamente na década de 1960. Em países como a Inglaterra, que foi o berço do modelo de gestão privatista, a adoção e avanço do racionalismo administrativo na gestão do saneamento em muitos aspectos representou uma guinada de 180 graus com relação ao passado. Na América Latina, o avanço do racionalismo administrativo refletiu, por exemplo, na criação de poderosas instituições públicas dedicadas à gestão do saneamento urbano na maioria dos países e também na estatização das empresas privadas de água que, como seus semelhantes na Europa e Estados Unidos, não podiam encarar as requisições de expansão e aprimoramento dos serviços no contexto de um rápido crescimento urbano e populacional. 


\section{Quadro 7. Aspectos do modelo racional-administrativo na gestão do}

saneamento

o modelo racional-administrativo de gestão do saneamento começou a se consolidar desde fins do século dezenove e progressivamente substituiu o modelo liberal privatista durante a primeira metade do século vinte. Os princípios fundamentais deste modelo de gestão são:

- a noção de que o fornecimento dos serviços de saneamento é afetado por "falhas do mercado" (constituem um monopólio natural e um bem público a cujo acesso ninguém pode ser excluído; em geral, requerem economias de escala; geram externalidades positivas e negativas que não podem ser adequadamente capturadas pelos mecanismos do mercado; são bens de mérito ao nível da sociedade, mas não podem não ser valorizados como tais pelos consumidores individuais, etc.);

- a regulação das empresas privadas de água domiciliar em nome do interesse público;

- a substituição da empresa privada pela empresa pública como ator central na gestão da água domiciliar; o desenvolvimento dos sistemas de esgotamento sanitário por parte das empresas públicas;

- a extensão do controle centralizado dos serviços de saneamento a cargo de entidades públicas (nacionais e internacionais) dotadas de pessoal técnico-administrativo especificamente capacitado (conformação de hidroburocracias). A formulação de padrões gerais de qualidade do serviço sob o controle destas entidades;

- a expansão das redes de água e esgotamento sanitário para universalizar o acesso aos serviços, com financiamento público;

- $\quad$ a substituição das identidades sociais geradas pelo modelo privatista (o cliente privado da água e o ladrão de água) pela identidade do cidadão formalmente dotado do direito ao acesso aos bens e serviços básicos considerados parte dos padrões socialmente aceitos da vida civilizada.

A partir de outro ângulo, e retomando o debate anterior, é importante analisar as contradições do modelo de gestão do racionalismo administrativo desde o ponto de vista do exercício da cidadania. Por um lado, este modelo fundamentado na ação decisiva do Estado para a resolução de problemas sociais básicos, como o acesso aos serviços essenciais, constituiu um passo fundamental na direção de uma ampliação dos benefícios derivados do investimento social no conjunto da população. Este processo de ampliação concreta do acesso aos serviços básicos essenciais se encontrava estreitamente vinculado à ampliação das dimensões da cidadania, que passavam a incorporar, pelo menos no campo das tradições intelectuais 
e políticas dominantes na Europa, a noção de direitos sociais, que sancionava o princípio de que o acesso aos bens e serviços essenciais deve ser universal, independente da capacidade monetária dos indivíduos e famílias. Nas palavras de T. H. Marshall, em sua análise clássica dos direitos sociais de cidadania, o reconhecimento destes direitos na Inglaterra do segundo pós-guerra era uma resposta à reivindicação do conjunto da população que procurava acessar o gozo do padrão da vida civilizada alcançado por sua sociedade, ou seja, a reivindicação da maioria de conseguir "a admissão ao [direito de] compartilhar o patrimônio comum da sociedade, o que, por sua vez, significa uma reivindicação de serem aceitos como membros plenos da comunidade, quer dizer, como cidadãos" (Marshall, 1963: 72).

Este enfoque representava uma inversão do princípio privatista de exclusão. Na visão liberal-social da cidadania defendida por Marshall, o acesso a serviços essenciais que já faziam parte do padrão de vida civilizada alcançado pela sociedade inglesa, como acesso à água limpa ou o esgotamento sanitário, já que não podiam continuar sendo conceituados como uma escolha individual, um assunto que devia ser resolvido entre atores privados, uma mercadoria disponível somente aos que podiam pagar por ela. 0 acesso a estes serviços devia ser garantido pelo Estado a todos os membros da sociedade, independente de sua posição no mercado. Os direitos sociais, nesta perspectiva, não eram somente um elemento que compunha a cidadania, mas, além disso, constituíam as condições necessárias para o exercício pleno dos outros direitos do cidadão, sempre no contexto da democracia capitalista. Seguramente, como já foi citado anteriormente, a noção de direitos sociais da cidadania foi fortemente criticada por diferentes âmbitos do espectro político. Apesar de não repetirmos aqui essa discussão, retomaremos esse tema na seção final.

Entretanto, e atrelado ao exercício dos direitos de cidadania, uma característica medular do racionalismo administrativo foi a verticalidade do modelo, fundada no pressuposto que o papel central nos processos de gestão corresponde aos políticos profissionais e aos especialistas científicos. De fato, tradicionalmente o modelo racional-administrativo deixou pouco espaço para a participação efetiva dos cidadãos, tanto na tomada de decisões, como no monitoramento e controle democrático da gestão dos 
serviços. Enquanto nos países capitalistas centrais este problema teve provavelmente menos repercussão devido à grande efetividade do modelo em alcançar a expansão e universalização do acesso ao saneamento, a tendência do resto dos países foi a de um grande conflito social e político em relação à gestão destes serviços (Castro, 2006). Lamentavelmente, e com poucas exceções, o racionalismo administrativo na América Latina não obteve o mesmo nível de êxito em alcançar as metas de qualidade e universalização dos serviços de saneamento. No Brasil, um exemplo eloqüente dos êxitos e fracassos do modelo do racionalismo administrativo foi o Plano Nacional de Saneamento (PLANASA), cujos avanços e limitações foram analisados detalhadamente por Rezende e Heller (2008).

Por outro lado, as implicações complexas do avanço do modelo racional-administrativo para a gestão democrática de bens e serviços essenciais no meio urbano foram estudadas e discutidas profundamente por diversos autores há tempos (ver, entre outros, Preteceille, 1974; Decaillot et. al., 1977; Lojkine, 1979; Topalov, 1979). Entre outros aspectos desta discussão, que são dignos de serem destacados brevemente, encontram-se o caráter instrumental deste avanço e a consolidação do racionalismo administrativo para a superação da crise que o sistema capitalista enfrentava, sobretudo a partir da grande crise de 1929. Neste sentido, ainda que em debates contemporâneos, algumas correntes de opinião tendem a opor "Estado" e "mercado" como se estes tratassem de campos antagônicos, mesmo em relação ao tema da gestão dos serviços de saneamento, durante a maior parte do século vinte, a necessidade de uma ação decisiva do Estado para garantir a acumulação privada de capital e a própria reprodução do sistema era um princípio aceito nas políticas públicas dominantes. Inclusive a nova etapa que analisaremos na seqüência, a tentativa de reintroduzir o modelo de gestão privatista, caracterizou-se pelo papel ativo do Estado na promoção de tal modelo, mesmo que, no debate atual, continue se contrapondo o estatal e o mercantil, como se fossem duas esferas naturalmente antagônicas.

Finalmente, é importante destacar que o racionalismo administrativo como modelo de gestão conciliou-se, na prática, com formas de organização política muito diversas, que vão desde a democracia liberal representativa 
até as ditaduras cívico-militares, que teve como exemplo precisamente a implementação do PLANASA, no Brasil, a partir de 1968. Em relação a este ponto, como discutimos na seção anterior, o processo da governabilidade não se reduz meramente ao campo da gestão técnico-administrativa, como entendem alguns atores. Pelo contrário, a governabilidade tem a ver, sobretudo, com o exercício do poder na tomada de decisões a respeito dos fins que devem seguir uma sociedade, os valores e os interesses materiais que se deseja defender, e os meios pelos quais se tentará alcançar essas metas. Neste sentido, como tendência geral, no contexto do racionalismo administrativo, existiu pouco espaço para o exercício dos direitos políticos da cidadania na tomada de decisões sobre tais questões, como as relacionadas à gestão dos bens e serviços públicos, o que é um aspecto fundamental do processo de governabilidade. Como diz John Dryzek em relação ao racionalismo administrativo no campo da gestão ambiental, o princípio operador deste modelo pode se resumir na frase "deixe estas questões para os especialistas" (Dryzek, 1997). Quer dizer, a participação efetiva dos cidadãos se viu severamente restringida no contexto do racionalismo administrativo, inclusive no contexto dos governos democráticos, dado que um pressuposto central deste modelo foi a outorga de exclusividade virtual na gestão aos especialistas científicos, aos administradores e aos políticos profissionais.

Este enfoque dominante do modelo racional-administrativo de gestão conduz à abordagem de uma série de interrogações em relação ao exercício dos direitos políticos, que constituem um componente chave do processo de governabilidade democrática. Por exemplo: quais são os mecanismos para a designação dos funcionários e especialistas a cargo da gestão dos serviços de saneamento no contexto do racionalismo administrativo? Quem os designa e com quais critérios? Como se definem as metas que a sociedade deve fixar em relação à gestão dos serviços essenciais? Quais valores e interesses materiais são refletidos em tais metas? São levados em conta os valores e os interesses materiais de quem na fixação destas metas? Como se chega nessa definição? Quais mecanismos têm os cidadãos para exercer um controle sobre os atores e instituições que estão a cargo destas decisões e de sua implementação? As respostas a estas e outras perguntas de ordem 
semelhante, em geral, conduzem à conclusão de que o racionalismo administrativo, inclusive quando teve êxito em seus objetivos concretos como a universalização do acesso aos serviços essenciais, se caracterizou por combinar-se com formas de gestão democrática restrita, verticais, pouco participativas, quando não com formas de gestão diretamente autoritárias ou inclusive ditatoriais. Este fato foi utilizado precisamente com grande êxito por parte dos defensores do retorno do modelo privatista de gestão a partir da década de 1980, os quais utilizaram o caráter pouco participativo do modelo racional-administrativo de gestão como uma desculpa para promover a desregulação, a liberação e a privatização destes serviços. Como veremos na seção seguinte, este desenvolvimento recente tem conseqüências importantes para a gestão democrática do saneamento.

\subsection{O Neo-Privatismo na Gestão dos Serviços de Saneamento}

Esta etapa cobre o período mais recente da evolução dos serviços de saneamento, particularmente a partir da década de 1980. É marcada pela introdução de reformas que objetivavam substituir o modelo de gestão baseado no racionalismo administrativo por uma versão atualizada do modelo privatista, que havia imperado no setor de saneamento até fins do século dezenove. Por falta de espaço, não me deterei a discutir aqui os detalhes deste processo, que foram desenvolvidos por numerosos autores (incluindo, por exemplo, Castro, 2005, 2007b, 2008b, 2009, 2010). O que é importante destacar aqui são as principais tendências desta etapa, incluindo as possíveis trajetórias futuras, ressaltando as relações e implicações deste modelo para a gestão democrática do saneamento.

Atrelado ao que foi dito antes, cabe destacar que, ainda que a promoção das políticas que procuram instalar um modelo de gestão neo-privatista no setor do saneamento tenha tentado frequentemente justificar como uma resposta à crise interna destes serviços, na prática, a origem destas políticas teve muito pouco ou nada a ver com os problemas próprios do saneamento. Em geral, a aplicação de políticas neo-privatistas fez parte do assim chamado Consenso de Washington, que representou um marco ideológico e político para estas reformas em praticamente todos os campos de atividade, 
incluindo a gestão dos serviços básicos (ver, entre outros, Leys, 2001; Harvey, 2005). Ainda que desde o início desta década o processo político em nível internacional, e notoriamente na América Latina, tenha tendido a cancelar ou, pelo menos, limitar o alcance de certos aspectos importantes do Consenso de Washington, estas reformas instalaram mecanismos e desencadearam forças cuja dinâmica inercial continua e provavelmente continuará influenciando e até determinando as formas de governabilidade e gestão em quase todos os setores, incluindo o dos serviços de saneamento. Retomaremos este ponto na última seção deste trabalho.

Neste sentido, as políticas neo-privatistas no setor de saneamento se caracterizam fundamentalmente pela tentativa de transferir o controle, e nos casos mais radicais, inclusive a propriedade, da gestão do saneamento para a iniciativa privada por diferentes meios. Por exemplo, o Banco Mundial, uma das instituições que motivaram com mais força as reformas neo-privatistas em décadas recentes, escalou um Grupo para a Participação do Setor Privado em Infra-estrutura, para o qual foi encomendada a tarefa de aumentar a "participação privada em infra-estrutura dentro do contexto dos objetivos gerais [do Banco] de apoiar a redução da pobreza e o desenvolvimento sustentável" (Banco Mundial, 1998). O Plano de Ação do Grupo declara que:

"A participação privada oferece um enorme potencial para melhorar a eficiência dos serviços de infra-estrutura, estender sua distribuição até os pobres e aliviar a pressão sobre os pressupostos públicos que, por muito tempo, foram a única fonte de financiamento. Incentivar um maior envolvimento privado requer que os governos mudem seus papéis onde já não fornecem serviços de infra-estrutura de maneira direta, mas se encarregam de fomentar a competição entre fornecedores privados, regulando naqueles casos onde a concorrência é fraca, e apoiando o setor privado em geral" (Banco Mundial, 1998, p.1).

Ou seja, a estratégia central destas reformas foi a de tirar o Estado da função de prestação direta dos serviços, que deveriam ser transferidos a empresas privadas, e limitar a função de controle e regulação estatal das 
empresas privadas ao mínimo possível, efetivamente transformando o papel do Estado no de suporte e fiador da gestão privada dos serviços essenciais. Em outras palavras, na visão neo-privatista, trata-se de restabelecer a noção do Estado mínimo característica do liberalismo individualista, que em sua versão contemporânea determina que o Estado já não deva fazer o papel de provedor e responsável pelo acesso universal da população aos serviços básicos, como foi durante a maior parte do século vinte, seguindo o modelo de gestão do racionalismo administrativo. Nas novas condições promovidas pelo neo-privatismo, os serviços básicos devem voltar a ter o status de mercadoria, de bens privados que devem ser adquiridos no mercado, sem mediação do Estado. Por exemplo, num documento do Banco Mundial, que promove o modelo neo-privatista de gestão como solução para estender o acesso aos serviços de saneamento aos pobres, os autores sugerem que um dos obstáculos mais importantes na introdução deste modelo é que "o público se acostumou [à prestação dos serviços de saneamento por empresas públicas] e define estes serviços como um 'serviço público' ou inclusive como um 'bem social'” (WSP-PPIAF, 2002: 8). Em outras palavras, segundo o documento, é necessário banir a noção de que o acesso aos serviços essenciais de saneamento é uma responsabilidade do Estado e um direito de todas as pessoas e, além disso, deve ser instaurada a noção de que as pessoas são responsáveis por comprar estes serviços de maneira privada. Este princípio central da iniciativa neo-privatista também está sendo proposto por alguns setores dentro das instituições especializadas das Nações Unidas, como mostra o Segundo Informe Mundial da Água da UNESCO, no qual são classificados os serviços de água e esgotamento sanitário domiciliar como "bens mercantis ou privados” (UNESCO, 2006: 409). É importante ressaltar aqui novamente que este assunto não deve se confundir com o clássico debate "público x privado" na gestão do saneamento, que ocorreu em anos recentes. O ponto principal aqui é que a reforma neo-privatista busca reformular completamente o papel do Estado e o status dos serviços básicos, independente do tipo de prestador do serviço, ou seja, mesmo se este for uma empresa pública, um assunto que retomaremos mais adiante. 
Na prática, como se sabe, as formas predominantes assumidas por esta política no setor do saneamento foram as concessões e os contratos parciais a empresas privadas e, mais recentemente, as assim chamadas parcerias público-privadas. Mesmo que estas políticas tenham sido implementadas, em nível global, desde a década de 1980 (ainda que algumas experiências já houvessem sido realizadas anteriormente no Chile durante época passada), esta implementação avançou em velocidades e em seqüências diferentes nos diversos territórios. Por exemplo, na Inglaterra e em Gales, o governo de Margaret Tatcher procedeu com a privatização completa (full divestiture) das empresas de saneamento, em 1989, um modelo que, com algumas modificações, continua vigente ainda hoje. Por outro lado, nos Estados Unidos, por exemplo, a maior parte da população (em torno de 85\%) continua sendo atendida por empresas públicas já que, em geral, não se optou pela possibilidade de transferir estes serviços ao setor privado, apesar de que o governo desse país foi um dos principais defensores das políticas neo-privatistas no resto do mundo. Na América do Sul, o Chile e a Argentina foram os dois países que mais avançaram na implementação das políticas neo-privatistas. No caso da Argentina, o governo do presidente Carlos Menem realizou uma transferência maciça das empresas públicas ao setor privado, o que, no caso do saneamento, fez com que, em entre 1993 e 1999, passou-se de 0\% a 70\% a população atendida por fornecedores privados. Já no Brasil, apesar dos esforços do presidente Fernando Henrique Cardoso em aprofundar as reformas neo-privatistas, durante a década de 1990, a proporção da população atendida por empresas privadas de saneamento não passou de $10 \%$ durante essa década, uma proporçãoque é ainda menor em outros países, como o México.

Entretanto, enquanto as experiências negativas com as reformas neo-privatistas levaram a um número importante de governos à decisão de cancelar as reformas neo-privatistas e recuperar as empresas públicas, incluindo casos na Argentina, Bolívia, China, Estados Unidos, França, Tanzânia e Uruguai, entre muitos outros, em outros casos, como no Brasil e no México, a aceleração e aprofundamento do processo começou mais tarde. 


\section{Quadro 8. Aspectos do modelo neo-privatista de gestão do saneamento}

A re-introdução de muitos dos princípios do privatismo do século dezenove mediante a reforma da gestão dos sistemas de saneamento a partir da década de 1980 surge como resultado da implementação em nível internacional das políticas neo-liberais motivadas pelo assim denominado Consenso de Washington. $\mathrm{Na}$ prática, muitas das reformas introduzidas no setor de saneamento tiveram pouco a ver com os problemas intrínsecos do setor, e foram, senão, o resultado da dinâmica imposta pelos governos centrais e as agências internacionais de financiamento, com a aceitação voluntária ou obrigada das administrações nacionais. Os princípios fundamentais deste modelo de gestão são:

- o fornecimento de serviços de saneamento deveria ser transferido às empresas privadas monopolistas, com o menor grau possível de regulação. O Estado deve retirar-se da função de provedor destes serviços e exercer o papel de facilitador da gestão privada;

- a concepção de que o acesso aos serviços de saneamento constitui um direito social ou é um bem público deve ser abandonada e deve-se retomar o princípio de que estes serviços são, não realidade, uma mercadoria, um bem privado que os indivíduos e famílias devem adquirir mediante um contrato com as empresas privadas e sem mediação do Estado;

- a promoção da identidade social do cliente privado da água (e do ladrão de água), o que constitui uma redenção do processo iniciado no começo do século dezenove durante a época privatista, tentando deslocar a identidade do cidadão portador de direitos típico da versão liberal da cidadania, que havia predominado nas democracias capitalistas durante boa parte do século vinte;

- a redução dos direitos do cidadão à dimensão civil e, em particular, a um aspecto dos direitos de propriedade privada: o direito do consumidor.

As conseqüências das reformas neo-privatistas no setor de saneamento a partir da perspectiva da gestão democrática destes serviços são múltiplas e, em sua maior parte, regressivas. Não me detenho aqui a examinar as conseqüências dos processos concretos de expansão da participação privada, incluindo a privatização total ou parcial dos serviços, que foram objetos de numerosos trabalhos, alguns dos quais citei nesta seção. Senão que me concentrarei aqui nos aspectos conceituais e nas tendências discerníveis neste processo. Um ponto central que deve ser ressaltado, antecipado anteriormente, é que os mecanismos e as forças surgidos através das reformas neo-privatistas transcendem as dicotomias retóricas de "Estado x mercado" ou "público x privado", já que estas reformas conseguiram instalar os 
princípios e os valores do privatismo no funcionamento do próprio Estado e das instituições públicas, inclusive as empresas públicas de saneamento. Um exemplo recente procedente de Uganda permite ilustrar este ponto:

"Ainda não faz um ano desde que a água limpatratada começou a chegar ao centro de saúde Tiriri, em Katine, no nordeste de Uganda, e o serviço foi cortado já faz dois meses porque o centro não tem dinheiro para pagar a conta de água. A Corporação Nacional de Saneamento (NWSC) desconectou o fornecimento há dois meses, dado que as autoridades de saúde não pagaram a conta de mais de 600.000 chelines ugandenses (uns 560 reais). As autoridades dizem que não têm dinheiro para pagar a dívida. A decisão despertou a preocupação entre os pacientes e os trabalhadores do hospital de que a falta de água limpa poderia gerar a proliferação de infecção. A sala mais afetada é a sala da maternidade. [...] 0 ano passado, o governo de Uganda construiu $7 \mathrm{~km}$ de extensão da rede de água que abastece o distrito vizinho de Kaberamaido até Katine, beneficiando particularmente o centro de saúde [...] Mas o governo não planejou com detalhes a forma que os serviços de saúde deveriam pagar suas contas de serviços e muitas autoridades em Uganda estão tendo dificuldades para pagar a água e a eletricidade. Além disso, como a assistência médica é gratuita nas instalações do governo, o centro de saúde não tem fontes alternativas de financiamento. A desconexão agora significa que o centro de saúde deve depender da água de chuva, poços de qualidade questionável e água insalubre procedente de pântanos" (Malinga, 2009)

Uganda é um dos principais exemplos na África da implementação das reformas neo-privatistas no setor de saneamento, em particular a reforma do setor público mediante a introdução das políticas de recuperação total de custos (eliminação completa de subsídios) como ante-sala para a posterior privatização dos serviços básicos, um caso que o Banco Mundial e outros atores que promovem as reformas neo-privatistas apresentam com um exemplo do êxito de tais políticas (ver, por exemplo, Jones et al., 2008). Este não é um exemplo isolado, mas é um caso recente que ilustra a continuidade de uma política cujos resultados regressivos já foram convincentemente demonstrados em muitos países. O principal ponto que desejo 
ilustrar com este exemplo é a extinção da noção de direito universal a um serviço essencial para a vida digna, como a água potável, e sua substituição pelo princípio de exclusão: a água é somente para quem pode pagar por ela, uma regra que se aplica inclusive às próprias instituições públicas responsáveis por serviços essenciais para a vida, como o cuidado com a saúde.

Neste sentido, por um lado, e em relação aos direitos de cidadania, as políticas neo-privatistas constituem um ataque à visão social liberal de cidadania que havia predominado desde meados do século vinte. Se é aceito o nosso argumento inicial de que inclusive os direitos sociais de cidadania são apenas um reconhecimento formal das desigualdades estruturais da democracia capitalista, que são só um paliativo frágil para confrontar o impacto real de tais desigualdades, e que, na prática, em muitos países, muito notavelmente na América Latina, a institucionalização de tais direitos foi fragmentária e inconsistente, com poucas exceções, então sua abolição e substituição pelos princípios do privativismo do século dezenove constituem um retrocesso injustificável. Pegando emprestadas as palavras de Eric Hobsbawn, a revogação dos direitos sociais e o retorno ao princípio privatista de exclusão constituem outro passo no processo de "barbarização", que é expresso na inversão "das regras e padrões de conduta moral que haviam sido incorporadas nas instituições dos Estados dedicadas ao progresso racional da humanidade" (Hobsbawm, 1997: 253-254).

No entanto, mesmo se limitarmos os direitos do cidadão às dimensões civil e política, como é o caso da versão liberal individualista da democracia capitalista, ainda é possível realizar uma crítica às políticas neo-privatistas no setor do saneamento, já que a aplicação lógica dos princípios de cidadania civil e política podem ter consequências de alcance potencialmente radical. Por exemplo, consideremos brevemente as conseqüências das reformas neo-privatistas na gestão democrática dos serviços de saneamento:

- o modelo e implementação destas reformas, com poucas exceções, foram realizados contra a vontade da maior parte das cidades. $\mathrm{Na}$ maioria dos casos, reformas como a privatização dos serviços de saneamento foram implementadas por decreto ou sem debate público, até mesmo sem debate legislativo. Este foi o caso, por 
exemplo, na Inglaterra, quando Margaret Tatcher privatizou os serviços de saneamento em 1989, ainda que a opinião pública, em sua maioria, se opusesse a esta política. Este foi também o caso em praticamente todos os países da América Latina;

- nos poucos casos onde se chamou à consulta pública, através de plebiscitos ou outras formas de participação aberta da população, como ocorreu, por exemplo, na província de Chaco, Argentina, em 1994, ou no Uruguai em 2004, a população maciçamente rejeitou a implementação das reformas privatistas (Roze, 2003; Santos e Villarreal, 2005);

- em geral, a implementação destas reformas, particularmente as diversas versões da privatização, se realizou sem o provimento de mecanismos de controle e regulação mínimos do cidadão. 0 estabelecimento de controle e regulação foi historicamente o resultado das demandas populacionais por causa de problemas com a qualidade dos serviços ou por abuso dos Estados. Mas, ainda nesses casos, a cidadania teve pouca capacidade de monitorar a gestão destes serviços básicos, inclusive em países com ampla tradição de instituições de regulação e controle, como a Inglaterra (ver, por exemplo, o crítico relatório de Yarrow e outros sobre as falhas da regulação dos serviços de saneamento na Inglaterra: Yarrow et al., 2008; para o caso da América Latina, vê-se, por exemplo, Solanes, 2002).

\section{Conclusões: os desafios que enfrenta a democratização substantiva da gestão do saneamento}

Com foi dito no começo deste trabalho, ao falar de gestão democrática dos serviços de saneamento, nos referimos ao processo de democratização substantiva, não meramente às versões da democracia formal, retórica. Esta abordagem me levou a analisar em certo detalhe alguns elementos fundamentais do processo de democratização assim entendido, em particular a relação entre o desenvolvimento dos serviços de saneamento e o processo de cidadanização, assim como os modelos sucessivos de governabilidade do 
setor de saneamento. Para concluir, desejo insistir em alguns dos desafios mais importantes que podem ser identificados em relação às possibilidades de aprofundar o processo de democratização na gestão destes serviços básicos.

Um aspecto importante do processo de democratização substantiva da gestão de saneamento tem a ver com a produção do conhecimento. Historicamente, a produção do conhecimento sobre a água, o meio ambiente e os serviços essenciais foi fundamentalmente uma tarefa reservada às disciplinas tecno-científicas. Crescentemente é reconhecido, pelo menos retoricamente, que os complexos problemas apresentados pela gestão dos bens e recursos naturais, incluindo a gestão de serviços como os de saneamento, num contexto de profundas transformações sócio-ecológicas, são de caráter multidimensional e requerem a adoção de enfoques inter e trans-disciplinares, que permitam aproximar-se com maior precisão e efetividade da compreensão de tal complexidade. Entretanto, existem obstáculos significativos para o desenvolvimento de enfoques que transcendam os limites mono-disciplinares e, mais além, de enfoques que outorguem um papel aos atores não acadêmicos na produção e utilização do conhecimento.

Por um lado, apesar do reconhecimento retórico da necessidade de maior interdisciplinaridade, a institucionalização da produção de conhecimentos segue, em grande escala, o modelo centrado em torno de disciplinas especializadas em aspectos específicos. Apesar dos esforços importantes realizados neste campo, o avanço na busca de níveis de coordenação interdisciplinar cada vez mais elevados foi lento e fragmentário. No caso dos serviços de infra-estrutura básica como o saneamento, houve importantes avanços, especialmente com a crescente participação de estudiosos das ciências sociais e campos afins falando amplamente para incluir a economia, as ciências de administração, o direito e os estudos históricos, levando em conta que persistem abismos importantes, especialmente entre os campos das disciplinas técno-científicas e as demais: em muitos sentidos, continua predominando a noção de que a gestão dos serviços como o saneamento é uma questão fundamentalmente técnica. Como conseqüência, as contribuições a este tema advindas das ciências sociais, tendem também, frequentemente, a concentrar-se nos aspectos mais técnicos, como a 
formulação e implementação de políticas públicas, as reformas legais e institucionais ou modelos e aplicações de sistemas de administração e gestão de empresas. o problema da democratização da gestão dos serviços, que é um problema fundamentalmente político, costuma ficar marginalizado como objeto de conhecimento legítimo neste campo. Este é um só exemplo, ainda que muito importante, da necessidade de promover maiores oportunidades de articulação entre as diversas disciplinas envolvidas com o setor de saneamento.

Por outro lado, existe um crescente reconhecimento de que a produção e utilização do conhecimento não se restringem ao âmbito acadêmico e profissional, e sim que existe uma gama mais ampla de atores sociais que participam do processo, independente de que este seja ou não reconhecido formalmente. As noções de trans-disciplinaridade e de ciência pós-normal tentam capturar este aspecto do processo de produção do conhecimento, o que apresenta grande relevância para a democratização da gestão do saneamento. Este ponto está estreitamente conectado ao processo de cidadanização em relação, neste caso, à gestão dos serviços básicos. De fato, como já foi discutido em seções anteriores, a consolidação das formas de gestão destes serviços nos países ocidentais, especialmente nas áreas urbanas, foi possível no âmbito da adoção dos princípios do racionalismo administrativo, que outorgaram primazia aos especialistas técno-científicos e aos políticos profissionais em tal gestão. Sem dúvida, o êxito obtido no avanço da universalização destes serviços nas democracias capitalistas centrais até meados do século vinte foi, em grande parte, devido à capacidade do modelo de gestão do racionalismo administrativo fundado num poderoso compromisso entre o conhecimento científico aplicado na gestão destes serviços e à perícia administrativa de um setor público profissionalizado. Entretanto, como foi também dito anteriormente, um dos aspectos mais frágeis do racionalismo administrativo, como modelo de gestão do saneamento foi o escasso espaço outorgado à participação social democrática, ao exercício dos direitos do cidadão de acesso ao conhecimento sobre como estes serviços de interesse público são governados e geridos e, sobretudo, ao controle social democrático da gestão. Lamentavelmente, as reformas neo-privatistas implementadas desde a década de 1980, em geral, tenderam 
a reproduzir e até piorar estas condições, tornando ainda mais difícil o acesso à informação sobre a gestão destes serviços e o controle social democrático. Por exemplo, alguém pode perguntar, a título de ilustração, quando o Segundo Informe Mundial da Água da UNESCO, citado anteriormente, nos disse que os serviços de água e esgotamento sanitário domiciliar são "mercadorias, bens privados", ou quando o Banco Mundial, em seus documentos de promoção das reformas neo-privatistas argumenta que a população incorretamente crê que estes serviços são "um bem público ou, até mesmo, um bem social", já que os mesmo são efetivamente uma mercadoria na visão destas instituições, como chegaram a estas conclusões? Que tipo de processo de desenvolvimento do conhecimento aconteceu? Quem pode se autodesignar o direito de decidir em nome de todos que estes serviços são uma mercadoria, um bem privado, e não mais um serviço público ou direito social? Com quem discutiram estas questões? Qual foi o processo de elaboração conceitual que os leva a defender essas afirmações? Os interesses de quem estão defendendo? Certamente, como esclarecemos anteriormente, estas perguntas não têm a ver com o debate "público x privado" ou "Estado x mercado", já que as reformas neo-privatistas também estão transformando o contexto e as formas de operação dos organismos públicos, incluindo as empresas públicas de saneamento. As respostas a essas e outras perguntas são bem conhecidas, já que uma longa lista de estudos recentes abertamente disponíveis, muitos dos quais foram citados neste capítulo, demonstram que, com poucas exceções, a população encontra-se em uma situação de desamparo, incapacitada de exercer seu direito de cidadão no controle democrático efetivo do processo político, incluindo a gestão de serviços essenciais para a vida, como os de saneamento. Este é também um dos desafios cruciais que a democratização da gestão destes serviços enfrenta.

Finalmente, e em relação a este último ponto, é muito importante reafirmar o fato de que o processo de democratização ocorre na escala do sistema social, não é possível pensar no "setor" do saneamento como um compartimento estanque, mas o mesmo se encontra envolvido numa grande complexidade sistêmica de ordem crescente, em particular em relação às rápidas transformações sócio-ecológicas que estão ocorrendo aceleradamente. Como já foi antecipado anteriormente, no contexto histórico recente 
e, particularmente nos países da América Latina, a defesa das, em grande quantidade, tímidas conquistas da democracia social liberal, como são os direitos sociais da cidadania, que formalmente tentam estabelecer o reconhecimento do direito das maiorias a compartilhar os benefícios dos padrões de vida social alcançados por uma determinada comunidade política, parece se converter numa empresa radical, muito difícil de levar a cabo e sob permanente ameaça devido ao avanço generalizado das formas neo-privatistas da democracia. Além disso, obter êxito em defender essas tímidas conquistas, como o direito a uns poucos litros de água limpa por pessoa e a sistemas de esgotamento sanitário que permitam o gozo de condições de vida minimamente dignas, independente da capacidade econômica das pessoas, se trataria de um passo a mais na longa caminhada em busca da democratização substantiva da sociedade. Isto não desmerece a validade da empresa que busca democratizar a gestão do saneamento, mas nos alerta para o fato de que a mesma forma parte de um processo de grande complexidade histórica que devemos tentar compreender cada vez mais com o objetivo de tentar transformá-lo na direção desejada.

\section{Referências}

AGLIETTA, M. A theory of capitalist regulation. The US experience. Londres: Calmann-Lévy, 1976.

ANDERSON, B. Imagined communities. Londres e Nova York: Verso, 1983.

BANCO MUNDIAL. Facilitating private involvement in infrastructure: an action programme. Washington D. C.: Banco Mundial, Grupo de Trabajo sobre Infraestructura, 1998.

BOELENS, R. The rules of the game and the game of the rules. Normalization and resistance in Andean water control. Wageningen: Wageningen University Press, 2008. 
BRUBAKER, R. Citizenship and nationhood in France and Germany. Cambridge, Mass. e Londres: Harvard University Press, 1992.

CARVALHO, J. M. Desenvolvimiento de la ciudadanía en Brasil. México DF: El Colegio de México e Fondo de Cultura Económica, 1995.

CASTRO, J. E. Against water privatization. Houndmills, Basingstoke e Nova York: Palgrave-Macmillan (en preparación, previsto para 2011).

CASTRO, J. E. Private sector participation in water and sanitation services in the context of globalization: is it the right answer to public sector failures? En: RINGER, C., BISWAS, A. K., e CLINE, S. A. (Eds.), Globalization, trade, and global change: implications for water and food security. New York: Springer, 2009 (no prelo).

CASTRO, J. E. A normatização da prestação dos serviços de água e esgoto, a experiência de Inglaterra e Gales. En: GALVÃO JUNIOR, A., FERREIRA XIMENES, M. M. (eds.), Regulação: normatização da prestação dos serviços de água e esgoto. Fortaleza: Associação Brasileira das Agências de Regulação (ABAR) e Agência Reguladora de Serviços Públicos Delegados do Estado do Ceará (ARCE), 2008a, p. 161-201.

CASTRO, J. E. Neoliberal water and sanitation policies as a failed development strategy: lessons from developing countries. En: Progress in Development Studies, 2008b, Vol. 8, No. 1, p. 63-83.

CASTRO, J. E. Water governance in the twentieth-first century. En Ambiente e Sociedade, 2007a, Vol. 10, \#2, p. 97-118.

CASTRO, J. E. La privatización de los servicios de agua y saneamiento en América Latina. En Nueva Sociedad, 2007b, No 207, p. 93-112.

CASTRO, J. E. Water, power, and citizenship. Social struggle in the Basin of Mexico. Houndmills, Basingstoke e Nova York: Palgrave-Macmillan, 2006. 
CASTRO, J. E. Agua y gobernabilidad: entre la ideología neoliberal y la memoria histórica. Cuadernos del Cendes, 2005, Vol. 22, No. 59, p. 1-22.

CASTRO, J. E, HELLER, L. The development of water and sanitation services in Argentina and Brazil. En JUUTI, P. S., KATKO, T. S., VUORINEN, H. (eds.), Environmental history of water - global views on community water supply and sanitation. Londres: International Water Association (IWA) Publishing, 2006, p. 429-445

COOKE, B., KOTHARI, U. Participation: the new tyranny? Londres: Zed Books, 2001.

CRESPO, C. Privatización del agua y racismo ambiental en ciudades segregadas. En SIMÓN RUIZ, I., CASTRO, J. E. (eds.), "Número Interdisciplinario Especial sobre Agua, Ambiente, y Territorios en América Latina", Anuario de Estudios Americanos (no prelo), 2010.

DAGNINO, E. (ed.). Os anos 90: política e sociedade no Brasil. Sao Paulo: Brasiliense, 1994.

DÁVALOS, P. (ed.). Pueblos indígenas, Estado y democracia. Buenos Aires: Consejo Latinoamericano de Ciencias Sociales (CLACSO), 2005.

DECAILLOT, M., PRETECEILLE, E., TERRAIL, J.P. (eds.). Besoins et mode de production. Paris: Editions Sociales, 1977.

DELANTY, G. Citizenship in a global age: society, culture, politics. Philadelphia, PA.: Open University Press, 2000.

DRYZEK, J. S. The politics of the earth. environmental discourses. Oxford: Oxford University Press, 1997.

DUTRA, O., BENEVIDES, M. V. Orçamento participativo e socialismo. Sao Paulo: Perseu Abramo, 2001. 
ESCH, S., DELGADO, M., HELFRICH, S., SALAZAR RAMÍREZ, H., TORREGROSA, M. L., e ZÚÑIGA PÉREZ-TEJADA, I. La gota de la vida: hacia una gestión sustentable y democrática del agua. México DF: Fundación Heinrich Böll Editions, 2006.

FALLON Jr., R. H. e MELTZER, D. J. Habeas Corpus jurisdiction, substantive rights, and the war on terror. Harvard Law Review, 2007, 120(8), p. 2029-2112.

FEDOZZI, L. Orçamento participativo. Reflexões sobre a experiência de Porto Alegre. Porto Alegre: Tomo Editorial e FASE, 2001.

FERREE, M. M., GAMSON, W. A., GERHARDS, J., RUCHT, D. Four models of the public sphere in modern democracies. Theory and Society 31(3), 2002, p. 289-324.

FLEURY, S. Estados sin ciudadanos. Seguridad social en América Latina. Buenos Aires: Lugar Editorial, 1997.

GARCÉS, M., GIRALDEZ, S., GOLDAR, M. R., DO CARMO ALBUQUERQUE, M., RIQUELME, Q., e BURONI, T. Democracia y ciudadanía en el MERCOSUR. Santiago de Chile: LOM Ediciones 2006.

GIRAUDO, L., (ed). Ciudadanía y derechos indígenas en América Latina: Poblaciones, Estados y orden internacional. Madrid: Centro de Estudios Políticos y Constitucionales, 2007.

GLENN, E. Citizenship and inequality: historical and global perspectives. Social Problems 47(1), 2000, p. 1-20.

GLOBAL WATER PARTNERSHIP (GWP). Effective water governance. Learning from the dialogues, 2003. Disponível em: http://www.gwpforum. org/gwp/library/Effective_Water_Governance.pdf . Acesso em: nov. 2009. 
GOLDHABER, M. D. A people's history of the European Court of Human Rights. Nueva Jersey: Rutgers University Press, 2009.

GOODIN, R. E., PATEMAN, C. e PATERMAN, R. Simian Sovereignty. Political Theory 25(6), 1997, p. 821-849.

GOUBERT, J. P. The conquest of water. The advent of health in the industrial age. Cambridge e Oxford: Polity Press e Basil Blackwell, 1986.

GRAY, Ch. H. Cyborg citizen : politics in the posthuman age. Nueva York e Londres: Routledge, 2001.

HANF, K., JANSEN, A-I. (eds.). Governance and environmental quality: environmental politics, policy and administration in Western Europe. Harlow: Addison Wesley Longman, 1998.

HARVEY, D. A brief history of neoliberalism. Oxford: Oxford University Press, 2005.

HOBSBAWM, E. On History. New York: The New Press, 1997.

HOBSBAWM, E. Age of extremes. The short twentieth century 1914-1991. London, Michael Joseph, 1994.

IPSOS-MORI. Robo-rights: Utopian dream or rise of the machines? Londres: office of Science and Innovation's Horizon Scanning Centre, United Kingdom Government, 2006.

JONES, L., JAMMAL, J., GÖKGÜR, N., e KIKERI, S. Doing privatization right. Public policy for the private sector, No. 319, Washington DC.: Banco Mundial, 2008 (http://rru.worldbank.org/documents/publicpolicyjournal/ 319Doing_privatization_right.pdf, consultado en noviembre de 2009). 
KING, D. S. New Right ideology, welfare state form, and citizenship: a comment on Conservative capitalism. Comparative Studies in Society and History, Vol. 30, No. 4, 1988, p. 792-799.

KOUVÉLAKIS, The Marxian critique of citizenship: for a rereading of 'On the Jewish question'. South Atlantic Quarterly, 2005 104(4), p. 707-721.

KROEN, S. A political history of the consumer. The Historical Journal, 47(3), 2004, p. 709-736.

LABRE, J. Human rights and access to drinking water and sanitation. (Contribución a la consulta de la Oficina del Alto Comisionado de las Naciones Unidas para los Derechos Humanos (ACNUDH). París: Suez Environment, 2007 (disponible en http://www2.ohchr.org/english/issues/ water/contributions/PrivateSector/Suez.pdf - consultado en noviembre de 2009).

LEYS, C. Market-driven politics: neoliberal democracy and the public interest. Londres: Verso, 2001.

LISTER, M., e PIA, E. Citizenship in contemporary Europe. Edimburgo: Edinburgh University Press, 2008.

LOJKINE, J. El marxismo, el Estado y la cuestión urbana. México: Siglo XXI, 1979.

MALINGA, J. Water supply at Katine health centre turned off. The Guardian, 23 de noviembre de 2009 (http://www.guardian.co.uk/katine/2009/ nov/23/health-centre-water-disconnected, consultado en noviembre de 2009).

MARÍN, J. C. Los hechos armados. Argentina 1973-1976. La acumulación primitiva del genocidio. Buenos Aires: Ediciones PICASO-La Rosa Blindada, 1996. 
MARSHALL, T. H. Citizenship and social class.En Sociology at the crossroads and other essays. Londres: Heinemann, 1963, p. 67-127.

MEAD, L. M. Beyond entitlement: the social obligations of citizenship. Nueva York: Free Press, 1986.

MELOSI, M. V. The sanitary city: urban infrastructure in America from colonial times to the present (creating the North American landscape). Baltimore: John Hopkins University Press, 2000.

MORRISON, T. W. Suspensions and the extrajudicial constitution. Columbia Law Review. 107(7), 2007, p. 1533-1616.

MUKHOPADHYAY, A. K. The politics of London water. En The London Journal, 1975, Vol. 1, No 2, p. 207-226.

MURRAY, C. Loosing ground. Nueva York: Basic Books, 1984.

NEWBY, H. Citizenship in a green world: global commons and human stewardship. En BULMER, M. e REES, A. M. Citizenship Today. The Contemporary relevance of T. H. Marshall. Londres: University College Press, 1996, p. 209-221.

O’DONNELL, G. A. Delegative democracy. Journal of Democracy. 1994, Vol. 5, No 1, p. 55-69

OGLE, M. Water supply, waste disposal, and the culture of privatism in the mid-nineteenth-century American city. En Journal of Urban History, 1999, Vol. 25, No. 3, p. 321-347.

ONU - ORGANIZACIÓN DE LAS NACIONES UNIDAS. "Declaración", Conferencia de las Naciones Unidas sobre el Medio Ambiente y el Desarrollo. Río de Janeiro: ONU, 1992. 
PEZON, C. Le Service d'eau potable en France de 1850 à 1995. Paris: CNAM, Presses du CEREM, 2000.

PICCIOTTO, R. Putting institutional economics to work: from participation to governance. En: CLAGUE, Ch. K. (ed.), Institutions and economic development: Growth and governance in less-developed and post-socialist countries. Baltimore e Londres: John Hopkins University Press, 1997, p. 343-367.

POLANYI, K. The Great Transformation: the political and economic origins of our time. Boston: Beacon Press, 1957.

PORTALES, F. Chile: una democracia tutelada. Santiago de Chile: Editorial Sudamericana Chilena, 2000.

PRETECEILLE, E. La planification urbaine. Les contradictions de l'urbanisation capitaliste. En: Economie et Politique, 1974, Vol. 236, p. 94-114.

REZENDE, S. C.,HELLER, L. O saneamento no Brasil. Políticas e interfaces. 2a edição. Belo Horizonte, Editora UFMG, 2008.

ROBBINS, B. (ed.). The phantom public sphere. Minneapolis: University of Minnesota Press, 1995.

ROBERTS, B. R. The making of citizens. Cities of peasants revisited. Londres: Arnold, 1995.

ROZE, J. Chaco e Corrientes - Informe del Estudio de Caso de Argentina, Proyecto PRINWASS. Oxford: Universidade de Oxford, 2003 (www.prinwass. org). 2003.

SANTOS, C.; VILLARREAL, A. (2005). Uruguay: direct democracy in defence of the right to water. En: BALANYÁ, B., BRENNAN, B., HOEDEMAN, O. KISHIMOTO, S., TERHORST, P. Reclaiming public water. Achievements, struggles 
and visions from around the world. Londres: Transnational Institute and Corporate Europe Observatory, 2005, p. 173-179.

SOLANES, M. América Latina: ¿sin regulación ni competencia? Impactos sobre la gobernabilidad del agua y sus servicios. Santiago de Chile: Comisión Económica para América Latina y el Caribe (CEPAL), 2002 (disponible en: http://prinwass.ncl.ac.uk/PDFs/Solanes.PDF).

SOPER, K., TRENTMANN, F. (eds.) Citizenship and consumption. Houndmills, Basingstoke, e Nova York: Palgrave-Macmillan, 2008.

SOUSA, J. A construção social da subcidadanía. Para uma sociologia política da modernidade periférica. Belo Horizonte e Río de Janeiro: Editora UFMG e IUPERJ, 2006.

STEENBERGEN, B. von. Towards a global ecological citizen. En The condition of citizenship. Londres: Thousand Oaks, 1994, p. 141-152.

SVAMPA, M. La sociedad excluyente. La Argentina bajo el signo del neoliberalismo. Buenos Aires: Taurus, 2005.

SWYNGEDOUW, E., KAÏKA, M., CASTRO, J. E. Urban water: a political-ecology perspective. En: Built Environment, 2002, Vol. 28, No. 2, p. 124-137.

THE ECONOMIST. Regulation of the supply of water. 1850, No. 334, p. 62.

THEORY AND SOCIETY, Special issue on recasting citizenship. Theory and Society 26(4), 1997.

TILLY, Ch. Changing forms of inequality. En Sociological Theory, 2003, Vol. 21, No. 1., p. 31-36.

TOPALOV, C. La urbanización capitalista. México: Edicol, 1979. 
TORREGROSA, M. L., SAAVEDRA, F., PADILLA, E., Quiñones, A., KLOSTER, K., Cosío, G. e Lenin, C. Aguascalientes - Informe del Estudio de Caso México, Proyecto PRINWASS. Oxford: Universidade de Oxford, 2003 (www.prinwass. org).

TORRES RIVAS, E. Democracias de baja intensidad. En Pensamiento Iberoamericano, 1989, No. 14, p. 221-230.

VEOLIA. The right to water: from concept to effective implementation. (Respuesta a la consulta de la Oficina del Alto Comisionado de las Naciones Unidas para los Derechos Humanos (ACNUDH). Paris: Veolia, 2007 (disponible en http://www2.ohchr.org/english/issues/water/contributions/ PrivateSector/Veolia.pdf - consultado en noviembre de 2009).

UNITED NATIONS EDUCATIONAL, SCIENTIFIC AND CULTURAL ORGANIZATION -

UNESCO, WORLD WATER ASSESSMENT PROGRAMME. Water, a Shared Responsibility. The United Nations world water report 2. París e Nova York: UNESCO e Berghahn Books, 2006.

WAKSMAN, G. Uruguay: Consagración de la democracia tutelada. En Nueva Sociedad, No. 102, 1989, p. 13-19.

WARD, C. Reflected in water. A crisis of social responsibility. Londres: Cassell.

WATER AND SANITATION PROGRAM (WSP) e PUBLIC PRIVATE INFRASTRUCTURE ADVISORY FACILITY (PPIAF). New designs for water and sanitation transactions. Making private sector participation work for the poor. Washington, DC, World Bank, 2002.

YAMIN, A. E. Derechos económicos, sociales y culturales en América Latina. Del invento a la herramienta. México DF: Asociación pro Derechos Humanos 
(APRODEH), Centro Internacional de Investigaciones para el Desarrollo (IDRC), y Plaza y Valdés, 2006.

YARROW, G., APPLEYARD, T., DECKER, Ch., e KEYWORTH, T. (2008), Competition in the provision of water services. Oxford: Regulatory Policy Institute, 2008 (http://www.rpieurope.org/Research/Report\%200n\%20 Competition\%20in\%20Water\%20Services.pdf consultado en noviembre de 2009). 


\section{Capítulo 9}

\section{Participación y control social en los servicios de agua y saneamiento ${ }^{1}$}

\section{Participación y gestión de los asuntos públicos}

El concepto de participación ha pasado a formar parte del vocabulario estándar de la gestión de servicios públicos en general y de los servicios de saneamiento básico en particular. Las muchas razones que explican esta creciente popularidad del concepto ocupan un amplio rango de posibilidades que van desde la genuina presión ejercida por los actores sociales que procuran mejorar sus condiciones de vida y exigen mayor transparencia y rendición de cuentas por parte de las autoridades y los prestadores de servicios hasta el oportunismo manipulador de quienes ven en la "participación" social un mecanismo ideal de cooptación y de disciplinamiento social. Por otra parte, la participación social es un proceso constitutivo de los conceptos centrales de la tradición democrática occidental moderna, tales como "ciudadanía”, “esfera pública”, y "sociedad civil”, para mencionar sólo algunos de los más importantes dada la brevedad de este capítulo. Sin embargo, tanto el contenido y extensión del concepto así como también su significado en la práctica presentan una gran variación e inclusive, en el extremo, pueden ser completamente incompatibles entre sí.

Una de las contradicciones fundamentales que determinan esas variaciones es la que existe en relación al concepto de libertad que, a su vez, determina la conceptualización de los distintos derechos asociados con el proceso democrático y muy particularmente con los derechos de la

1 Una versión previa fue publicada en Léo Heller (Ed.), Agua y Saneamiento: en la Búsqueda de Nuevos Paradigmas para las Américas, (ISBN: 978-92-75-11669-2), Washington, D.C.: Organización Panamericana de la Salud, pp. 137-155. 
ciudadanía. Mientras que la tradición política del liberalismo individualista pone énfasis en el carácter negativo de la libertad, entendiendo a ésta como la ausencia de límites o barreras a la búsqueda de la satisfacción de deseos y metas individuales, en las tradiciones asociadas con la democracia radical el énfasis se enfoca más bien en el carácter positivo de la libertad. Para estas tradiciones tiene que ver con las condiciones estructurales que garantizan que todos los individuos puedan desarrollar sus potencialidades lo cual, por definición, requiere la existencia de reglas y límites que impidan que los individuos y grupos de poder monopolicen el control de dichas condiciones. Entre ambas posiciones existe toda una gama de posibilidades que permiten dar cuenta de las distintas variaciones que pueden identificarse en la práctica y que ejercen una influencia determinante en el desarrollo de las instituciones, incluyendo aquellas involucradas en la gestión de los servicios esenciales. En particular, las distintas concepciones de la libertad en un sistema democrático que surgen de dichas tradiciones políticas conducen a interpretaciones divergentes, muchas veces incompatibles, del significado de la participación social en su carácter de derecho ciudadano.

En conexión con lo anterior, la noción de participación como un derecho ciudadano está estrechamente vinculada con el desarrollo de la esfera pública, que a su vez asume formas diversas en distintos territorios y momentos históricos (Ferree, Gamson et al. 2002). Mientras que en las tradiciones políticas predominantes, fundadas en los principios de la democracia liberal representativa, se tiende a restringir la participación en la gestión de los asuntos públicos a los políticos profesionales y a los expertos, las tradiciones que alientan la profundización y ampliación del proceso democrático proponen una ruptura del monopolio elitista de la gestión y la incorporación de sectores cada vez más amplios de la población en el proceso. Estas profundas contradicciones entre la concepción elitista, restringida de la participación social, y las concepciones que ven en la ampliación de la participación social uno de los instrumentos claves del proceso de profundización de la democracia substantiva han ejercido y continúan ejerciendo una influencia determinante en la gestión de los asuntos públicos en general, incluyendo los servicios públicos esenciales. 
En este sentido, la evidencia histórica sugiere que la gestión de los servicios públicos en general, ${ }^{2}$ con pocas excepciones que han tendido a confirmar la regla, se ha caracterizado por sus formas tecnocráticas, jerárquicas, fundadas en la noción de que dichas actividades son un monopolio de los expertos tecno-científicos y de los políticos profesionales, no del ciudadano común. Parafraseando a John Dryzek, en los enfoques tradicionales de gestión de estos servicios el lema ha sido "déjelo a los expertos" (Dryzek 1997). Este modelo jerárquico, no participativo, muy frecuentemente paternalista, normalmente opaco al escrutinio de los ciudadanos, de sus representantes, de los usuarios directos y de la población en general, acompañó el gran éxito de la sociedad contemporánea, al menos la de los países capitalistas centrales, que condujo a la universalización de dichos servicios $\mathrm{y}$, consecuentemente, a la expansión de los beneficios concomitantes con dicho proceso, desde la drástica reducción de la morbi-mortalidad hasta la mejora sustantiva de la calidad de vida. Es conveniente aclarar que nos referimos aquí a las tendencias dominantes, ya que existen diversos ejemplos históricos de gestión de los servicios básicos que han asumido formas más democráticas y han estado sujetas en distintos grados a formas de control democrático, como es el caso por ejemplo de los servicios básicos de saneamiento en los países de la Europa nórdica donde existe una fuerte tradición de democracia local (Pietilä, Gunnarsdóttir, et al., 2009). Del mismo modo, debe recordarse que los logros mencionados son relativamente recientes incluso en los países más avanzados, en los cuales la universalización de los servicios públicos esenciales tuvo lugar generalmente a partir del fin de la Segunda Guerra Mundial y, en muchos casos, a partir de la década de 1960, mientras que en la gran mayoría de los países capitalistas periféricos la promesa de la universalización nunca logró materializarse.

Desde luego, una pregunta incómoda que nos surge a partir de este panorama histórico es por qué, si la tendencia histórica dominante sugiere

2 Esta característica aplica muy particularmente a los servicios públicos principalmente en áreas urbanas, aunque frecuentemente también puede extenderse al caso de las áreas rurales, y muy específicamente a partir de la creciente intervención directa del estado en la provisión de estos servicios esenciales que se dio a partir de fines del Siglo XIX. 
que el logro de los grandes avances en la universalización de servicios públicos básicos tuvo lugar en el marco de formas de gestión de carácter elitista-no participativo, paternalista, y muy frecuentemente autoritario, por qué, repetimos, insistir en la necesidad de una gestión participativa, de la profundización de formas democrático-participativas de gestión de estos servicios. Esta es una cuestión que no podemos resolver en este breve artículo y que en realidad tiene que ver con un problema más amplio: la democratización mediante la profundización de la participación social en la gestión de los servicios públicos es parte del proceso de democratización de la sociedad en su conjunto, en sus distintos niveles y esferas de actividad y responsabilidad. En última instancia, la decisión de apoyar la profundización del proceso de democratización de la sociedad, incluyendo la democratización de la gestión de servicios públicos básicos, es una preferencia normativa, fundada en la defensa del principio de la igualdad y la equidad.

En este sentido, las formas dominantes de gestión tecnocrática y jerárquica que excluyen, $\mathrm{o}$, en el mejor de los casos, limitan severamente las posibilidades de participación en el monitoreamiento y control social democrático por parte de los ciudadanos, han sido históricamente criticadas y confrontadas desde diversos espacios, particularmente, por parte de los actores que luchan por la profundización del proceso de democratización. En América Latina, en las últimas dos décadas, esta confrontación entre las concepciones elitistas y democratizantes de la participación social ha sido frecuentemente exacerbada por el impulso de las reformas neoliberales del sistema político que han preconizado la privatización de la gestión de los asuntos públicos en nombre de una mayor participación de la sociedad. A través de estas reformas la gestión de estos servicios, que históricamente había tendido a ser un monopolio de la acción estatal, ha sido frecuentemente convertida en un monopolio de las empresas privadas garantizado por el estado y, por lo general, blindado contra el escrutinio democrático por parte de los ciudadanos y lo usuarios. No es de extrañar entonces que las reformas recientemente implementadas en la gestión de los servicios públicos esenciales hayan provocado en muchos países de la región una 
multiplicación de los conflictos sociales en torno a la democratización de dicha gestión, a veces, mediante el reavivamiento de conflictos pre-existentes pero muchas veces, también, mediante la emergencia de nuevas confrontaciones.

\section{Tendencias en la gestión participativa del saneamiento en América Latina y el Caribe}

En función de la discusión previa sobre las formas que asume la "participación" de la población en distintos contextos, particularmente, en diferentes marcos socio-económicos, culturales y político-institucionales, esta sección examina algunos ejemplos provenientes de la investigación reciente sobre la gestión de los servicios básicos de saneamiento en América Latina. Podemos identificar ciertas tendencias en las formas de participación, las cuales no son mutuamente excluyentes sino que más bien están frecuentemente asociadas entre sí:

1. formas de gestión tecnocráticas que excluyen la participación de la población tanto en su carácter ciudadano como también en su carácter de usuario-cliente-consumidor de los servicios públicos;

2. formas de gestión tecnocrática que permiten (o inducen) espacios de participación altamente restringidos que tienden a circunscribir la misma, por ejemplo, a las actividades de auto-ayuda o al ejercicio de derechos de consumidor;

3. la participación social desde abajo, promovida por organizaciones sociales de distinto tipo (trabajadores, usuarios, comunidades, ONGs ambientales, etc.);

Cabe aclarar que estas tendencias no son puras, en el sentido de que en el terreno se pueden identificar distintas combinaciones de estas formas de gestión que, a su vez, se van transformando en el tiempo, lo cual es el resultado de la dinámica de los procesos socio-económicos, políticos y culturales. Por ejemplo, las formas de gestión tecnocráticas que inducen formas restringidas y controladas de participación suelen iniciar procesos con resultados 
no esperados, que pueden producir el desarrollo de formas emergentes de participación genuinamente autónomas. En contraste, muchas veces, los procesos de participación que surgen como experiencias autónomas en el seno de la sociedad terminan siendo cooptados y eventualmente desmovilizados y/o neutralizados. A continuación consideramos algunos ejemplos surgidos de la investigación reciente en distintos países de América Latina, que nos permiten ilustrar estas tendencias predominantes.

\section{La gestión tecnocrática no participativa}

Como se vio en la sección previa, el modelo tecnocrático no participativo ha sido la forma dominante de gestión en los servicios públicos esenciales. Durante el período de expansión y consolidación de estos servicios que tuvo lugar durante la mayor parte del siglo XX la gestión de los mismos fue, fundamentalmente, una actividad monopolizada o, cuando menos, controlada por el Estado en sus distintos niveles. Este fue claramente el caso del desarrollo de los servicios de agua y saneamiento en la mayoría de los países de América Latina (ver por ejemplo: Castro 2006; Castro and Heller 2006; Rezende and Heller 2008, para los casos de Argentina, Brasil y México, entre otros). En el caso de Brasil, por ejemplo, ha sido notorio el rol del Plano Nacional de Saneamento (PLANASA) que introdujo la dictadura militar iniciada en 1964, cuyos rasgos principales continúan demarcando en buena medida el funcionamiento de estos servicios en el país (Heller 2009). De esta forma aunque, como discutimos en una sección posterior en años recientes Brasil, ha visto el desarrollo de mecanismos altamente participativos en ciertos aspectos de la gestión de servicios esenciales, el modelo tecnocrático no participativo sigue teniendo fuerte presencia. Valga como ejemplo el caso de los Comités de Cuencas creados a fines de la década de 1990 que formalmente están compuestos principalmente por los distintos usuarios del agua en cada cuenca, pero en los cuales los usuarios domésticos no tienen participación como tales ya que son representados por las empresas prestadoras del servicio, que para la ley constituyen el "usuario" con derecho a participar en los comités. De esta forma millones de usuarios domésticos de las áreas metropolitanas del país son representados en los 
comités por las respectivas empresas de agua y cloacas, sin que los usuarios, como tales, tengan participación en el monitoreo de la gestión. ${ }^{3}$ Situaciones similares pueden identificarse en la mayoría de los países de la región (ver, por ejemplo, Castro, Kloster et al. 2004a; Castro, Kloster et al. 2004b para el caso de México).

En diversas formas, la introducción de políticas agresivas de privatización de los servicios esenciales a partir de la década de 1990, muchas veces, justificadas como una forma de promover una mayor participación y monitoreo del funcionamiento de los servicios por parte de la sociedad, ha tendido a consolidar o inclusive profundizar el carácter no participativo, frecuentemente, autoritario de esta forma de gestión tecnocrática. ${ }^{4}$ En este sentido, puede tomarse como ejemplo la experiencia de Argentina en la década de 1990, cuando el país se convirtió en uno de los campos experimentales más importantes a nivel internacional para la implementación de las políticas de liberalización, desregulación ${ }^{5}$ y privatización de los servicios públicos, incluyendo los servicios de saneamiento básico. Argentina llevó a cabo una transferencia masiva de la gestión de sus servicios de saneamiento básico

3 Por ejemplo, en entrevistas realizadas por el autor con representantes de varios comités de cuenca en Pernambuco durante 2009 se pudo confirmar que los usuarios domésticos no tienen representación directa en los comités y son representados por la Companhia Pernambucana de Saneamento (COMPESA). Por su parte, al menos hasta el momento de realizarse las entrevistas, la COMPESA no contaba con organismos internos de participación para sus usuarios domésticos. Del intercambio de información con investigadores en distintas regiones del país se pudo confirmar que el caso de Pernambuco no es una excepción y en general los usuarios domésticos de servicios de saneamiento en Brasil no cuentan con mecanismos de participación en el monitoreamiento de la gestión.

4 Los críticos de la gestión y la regulación centralizadas y verticalistas (no participativas) adoptaron el concepto militar de "comando y control" para describir el carácter centralizador y monopolizador de la toma de decisiones en estas formas de gestión. Sin embargo, esa crítica frecuentemente ha sido convenientemente utilizada no para promover mayor participación y control ciudadano sino más bien para transferir el rol de "comando y control" de monopolios de poder público a monopolios privados. Ver por ejemplo: Castro (2010); Malloy (2010).

5 Mientras que en los países más desarrollados las políticas neoliberales incluyeron un proceso de re-regulación que en algunos casos, como en Inglaterra y Gales, condujeron a una expansión de las instancias y mecanismos regulatorios (Hogwood, 1998); Bakker, 2004); Swyngedouw, 2005), la tendencia general en los países del Sur Global fue la del desmantelamiento y neutralización de las instituciones regulatorias y fiscalizadoras, cuya operación frecuentemente se subordinó a los intereses de los operadores (Azpiazu and Schorr, 2004; Castro, 2007, 2008; Solanes, 2002). 
al sector privado entre 1993 y 1999 al punto que para esta última fecha, aproximadamente, el 70 por ciento de la población llegó a estar atendida por empresas privadas. En su mayor parte, el proceso consistió en otorgar concesiones a largo plazo (25-30 años) a consorcios multinacionales, en la mayoría de los casos evitando el debate público con los ciudadanos o con sus representantes, ya que casi todas las concesiones se realizaron mediante Decretos Presidenciales de Necesidad y Urgencia, como por ejemplo ocurrió en el caso de la concesión de los servicios en el Área Metropolitana de la Ciudad de Buenos Aires a la empresa Aguas Argentinas en 1993. En este caso, no sólo la concesión se otorgó sin participación de los usuarios, ni de los ciudadanos o sus representantes políticos sino que, además, la capacidad de ejercer control democrático sobre la gestión de la empresa privatizada quedó severamente limitada dado que el único derecho otorgado a los usuarios fue el de presentar quejas mediante procedimientos administrativos y legales pero sin posibilidad de ejercer ningún tipo de control democrático de la gestión. Aún más, la posibilidad de que el organismo regulador ETOSS (Ente Tripartito de Obras y Servicios Sanitarios) pudiera ejercer efectivamente su función de contralor de la gestión privada quedó neutralizada porque ETOSS carecía de acceso independiente a los datos necesarios para auditar a la empresa, ya que esa información había pasado a ser propiedad privada del concesionario (Azpiazu, Catenazzi et al. 2003). Eventualmente, el creciente descontento de la población llevó a la reforma del sistema y más tarde a la cancelación del contrato de concesión en el año 2006.

A pesar de ser un caso conspicuo por sus características particulares, de ninguna manera Argentina constituye un caso aislado, sino que más bien el modelo de gestión tecnocrático no participativo sigue teniendo una influencia substancial en la mayoría de los países de América Latina, incluyendo aquellos que han experimentado avances notables en el proceso de democratización de la gestión en épocas recientes (Castro 2005; Castro 2005). Sin embargo, en la mayoría de los casos lo que puede registrarse es una flexibilización de las formas rígidas, estrictamente autoritarias o no participativas, en donde la gestión tecnocrática permite grados limitados de "participación”, altamente controlados y frecuentemente inducidos desde 
el poder. Este tipo de gestión con participación restringida es probablemente el más recurrente.

\section{La gestión tecnocrática con participación restringida}

Por diversas circunstancias el modelo tecnocrático, a veces, introduce elementos de participación restringida o inducida y dirigida desde el poder. En algunos casos, el proceso asume formas paternalistas, clientelares, relativamente "benignas" en las que la participación inducida cumple una función de inclusión política de la población, mientras que en otros casos se trata de formas más directas de manipulación y control. Frecuentemente, también, la apertura de canales restringidos de participación es meramente una concesión, muchas veces provisional, resultante de la presión social por una mayor democratización de la gestión. Por ejemplo, en relación a este último comentario, en el caso de Buenos Aires el creciente descontento de los usuarios, especialmente hacia fines de la década de 1990, obligó a la ampliación de los mecanismos de participación en la gestión de los servicios. Sin embargo, estos mecanismos se limitaron al involucramiento de los usuarios como proveedores de insumos y de mano de obra para la expansión de las redes a los barrios pobres, un programa desarrollado por la empresa privada y un grupo de ONGs locales e internacionales (Azpiazu, Catenazzi et al. 2003; Almansi and Urquiza 2005). Si bien esta ampliación de la "participación" ciudadana representó un cierto avance respecto a la situación anterior en los temas cruciales de control y seguimiento democrático del funcionamiento de los servicios los usuarios y ciudadanos continuaron excluidos. La investigación sugiere que este tipo de participación restringida, dirigida desde arriba, es probablemente el más recurrente en el caso de los servicios esenciales.

Por ejemplo, a comienzos de la década de 1990 el gobierno de México introdujo una serie de reformas importantes en el sector del agua en general, y de los servicios de agua y saneamiento, en particular. En el lenguaje empleado por las autoridades de la época dichas reformas estaban orientadas a reemplazar las prácticas clientelares que caracterizaron a la gestión del agua y sus servicios durante décadas por una "nueva cultura del agua" 
que debía estar fundada en el involucramiento de la ciudadanía, la responsabilidad de los usuarios, y la creciente transferencia de la gestión de los servicios públicos de agua y saneamiento al sector privado. En realidad, las autoridades mexicanas habían comenzado a enfatizar la necesidad de una mayor participación de los usuarios en la gestión del agua en general al menos desde comienzos de la década de 1980, cuando el Plan Nacional Hidráulico de 1981 propuso la promoción de "una participación más amplia de los usuarios en la resolución de los problemas comunes" (SARH 1981). Ya en la década de 1990, el gobierno intentó institucionalizar ciertos aspectos de la participación de los usuarios, por ejemplo, creando una Coordinación de Participación dentro de la Comisión Nacional del Agua (CNA), una Subcoordinación de Participación Social en el Instituto Mexicano de Tecnología del Agua (IMTA) e incluso un Movimiento Ciudadano del Agua a nivel nacional. Sin embargo, este intento de formalizar e instituir desde arriba la participación de los usuarios en la gestión del agua no condujo a una mayor participación efectiva ni tampoco al desarrollo de la "nueva cultura del agua" que se buscaba promover. A pesar de que sucesivos gobiernos han continuado con la implementación de reformas institucionales similares, la noción de "participación" prevaleciente en dichas reformas tiende a reducir el proceso a su dimensión técnica y administrativa, en desmedro de los aspectos socio-políticos de la participación, y a entender la participación como acatamiento, obediencia por parte de los usuarios a las decisiones tomadas por las autoridades y los expertos (Torregrosa, Saavedra et al. 2003; Castro, Kloster et al. 2004; Castro 2006). En este modelo, la participación no incluye, por ejemplo, el debate público, ciudadano, sobre los principios que deben guiar la gestión de los servicios públicos esenciales o las modalidades de dicha gestión (pública, privada, comunitaria, etc.), entre otros temas cruciales que no se abren a la consulta pública ni al control democrático. Más aún, el gobierno decide quién puede participar en los organismos creados, lo cual restringe severamente las posibilidades de participación autónoma de los usuarios y ciudadanos (Jiménez Cisneros and Torregrosa 2009). Con demasiada frecuencia, la "participación" que este modelo promueve se limita al aumento de las responsabilidades por parte de los usuarios, muy particularmente, en lo referente a aceptar incrementos de tarifas ("la 
voluntad de pago") pero también en relación a inversiones directas por parte de los usuarios conectadas, por ejemplo, con la expansión de las redes de servicios, ya sea en forma pecuniaria o mediante la provisión de materiales y trabajo voluntario.

En el caso de Bolivia, ${ }^{6}$ en 1994 se aprobó una nueva Ley de Participación Popular para promover el involucramiento de la ciudadanía en los asuntos de gobierno local. También una serie de reformas introducidas durante el período 1993-1997, a partir de la creación de un nuevo marco regulatorio para las empresas de servicios públicos, incorporaron algunos mecanismos de participación ciudadana. Por ejemplo, el nuevo marco regulatorio contemplaba la posibilidad de convocar audiencias públicas para consultar a los usuarios sobre temas específicos. Sin embargo, en general, en este modelo la "participación" se veía restringida a la provisión de canales administrativos para la presentación formal de quejas y apelaciones por parte de los usuarios con respecto a falencias y otros problemas con la prestación de los servicios, mientras que la función del organismo regulador se vio afectada desde el comienzo por una severa crisis de legitimidad. Por ejemplo, en la Ciudad de Cochabamba donde los servicios de agua y saneamiento fueron entregados en concesión a un consorcio privado en 1999, el ente regulador convocó a una audiencia pública en diciembre de ese año para consultar a los usuarios sobre un incremento de precios a punto de ser aplicado por la empresa privada, pero solamente 14 personas respondieron a la convocatoria. La investigación realizada sobre este caso demostró que una gran mayoría de la población percibía al regulador como un defensor de los intereses de la empresa privada más bien que de los de la población, una percepción que se acentuó cuando el propio gobierno municipal fue excluido de las negociaciones relacionadas con dicho incremento de las tarifas lo cual, efectivamente, cerró el único canal que restaba a la ciudadanía para ejercer algún tipo de contralor sobre el proceso. Como es bien sabido, el proceso de privatización de los servicios de agua y saneamiento en Cochabamba tuvo un final violento con la así denominada "Guerra del

6 Para esta descripción del caso de Bolivia nos hemos basado en el trabajo de Crespo Flores, Laurie, et al. (2004). 
Agua", una movilización popular que condujo a la cancelación del contrato con el consorcio privado en marzo del año 2000. Volvemos a este caso en la próxima sección.

La tensa interrelación entre las formas tecnocrático-no participativa y tecnocrática con participación restringida se puso de manifiesto con notoria claridad en las confrontaciones políticas libradas en Brasil en relación al proyecto de una nueva Ley Nacional de Saneamiento Ambiental propuesta por el gobierno del Presidente Lula a partir del año 2003. Dicho proyecto de ley, concebido en el contexto de una amplia movilización popular que buscaba una mayor democratización en la gestión de los servicios públicos, contenía importantes elementos de democracia directa dando un amplio rol a las organizaciones sociales y a los movimientos ciudadanos tanto a nivel local y estatal como nacional. Estas iniciativas, lideradas por movimientos de base como el Frente Nacional de Saneamento Ambiental (FNSA) y la Associação Nacional dos Serviços Municipais de Saneamento (ASSEMAE) y asumidas por los cuadros sociales y sindicales que habían logrado acceder al poder político y actuaban desde la Secretaría Nacional de Saneamiento Ambiental del Ministerio de las Ciudades, enfrentaron una poderosa oposición articulada por la oposición política y por los lobbies empresariales (públicos y privados) con fuertes intereses en el sector de los servicios de agua y saneamiento. Eventualmente, los mecanismos de democracia directa fueron severamente restringidos o directamente excluidos de la Lei Nacional de Saneamento Básico que finalmente se logró aprobar en 2007, un recordatorio tanto de la influencia persistente del modelo tecnocrático que excluye, o en el mejor de los casos severamente restringe, la participación, así como también del carácter fundamentalmente político de los modelos de gestión de los servicios públicos esenciales.

\section{La participación social "desde abajo"}

Ahora bien, en décadas recientes se ha producido una amplia movilización social dirigida a profundizar la democratización de la gestión de y el acceso a los servicios públicos esenciales, notablemente los de agua y saneamiento y recolección y reciclaje de residuos, en la mayoría de los países de América Latina (Grosse, Thimmel et al. 2004; Medina 2005; Grosse, 
Santos et al. 2006; Bell, Conant et al. 2009; Castro 2009; Red Latinoamericana de Recicladores 2010). Esta movilización ha tomado diversas formas desde denuncias y demostraciones pacíficas hasta confrontaciones violentas, muchas veces, resultantes en pérdidas humanas y materiales. Muy frecuentemente, también la población ha decidido tomar responsabilidad por el desarrollo de los servicios ante la inacción del estado mediante formas diversas de autoorganización que van desde la formación de empresas comunitarias hasta cooperativas de servicios. En ciertos casos, estos movimientos de base han tenido una gran capacidad de acción y de articulación política, lo cual les ha permitido acceder a instancias importantes de poder y consolidar su capacidad de intervención directa en la gestión de estos servicios lo cual ha sido el caso, entre otros ejemplos, en Argentina, Bolivia, Brasil, Ecuador, Nicaragua, Uruguay y Venezuela. ${ }^{7}$ Por razones de espacio no podemos cubrir estos ejemplos en su totalidad ni tampoco con la profundidad requerida para un análisis riguroso pero, al menos, presentamos aquí una breve referencia dada su importancia y también por sus implicaciones para el estudio de la desmovilización y la cooptación de la participación social, tema de la siguiente sección. En efecto, los casos que describimos abajo representan al mismo tiempo formas muy exitosas de participación social desde la base así como también, en algunos casos, de su posterior desmovilización y cooptación en el marco de procesos en los cuales los movimientos sociales participantes formaron parte de la base de apoyo que condujo a la toma del poder político.

7 Los casos de Bolivia y Ecuador resaltan dado el rol central de los movimientos populares, particularmente indígenas y campesinos pero también urbanos, en los procesos políticos que llevaron al poder a los presidentes Juan Evo Morales Ayma en 2006 y Rafael Correa en 2007, respectivamente. En el caso de Bolivia, el movimiento social conectado con las "guerras del agua" pasó a formar parte del equipo de gobierno del Presidente Morales, notoriamente mediante la creación del Ministerio del Agua encabezado por Abel Mamani, líder del movimiento popular de la ciudad de El Alto. En el caso de Ecuador, cabe notar la creación a nivel nacional de una Secretaría de Pueblos, Movimientos Sociales y Participación Ciudadana, que desde 2010 es encabezada por la ministra Alexandra Ocles Padilla, dirigente de los derechos civiles de las poblaciones indígenas y afro-descendientes del país. En el marco de dichos procesos políticos recientes, ambos países tomaron la delantera a nivel internacional en declarar que el agua es un bien común, y que el acceso al agua constituye un derecho humano, declaraciones que pasaron a formar parte de las respectivas constituciones nacionales. 
Bolivia. El caso de la Guerra del Agua en Bolivia, primero en Cochabamba en 1999-2000 y, posteriormente, en La Paz-El Alto en 2005-2006 se convirtió en un emblema global de la lucha popular contra la privatización de los servicios públicos esenciales. En particular, el caso de Cochabamba tuvo amplias repercusiones a nivel nacional, donde el gabinete entero del gobierno renunció en marzo del año 2000 como consecuencia de la confrontación, e internacional, donde se convirtió en un símbolo de la participación popular que busca profundizar la democratización de la gestión de los servicios públicos esenciales (ver entre otros: Assies 2003; Crespo Flores, Laurie et al. 2004; Laurie and Crespo 2007; Spronk and Webber 2007; Pérez Barriga 2010). En este caso, muchas de las organizaciones sociales que lideraron la movilización contra la privatización constituyeron un componente fundamental de la base social que llevó al Presidente Evo Morales al poder en 2006 y que posteriormente pasaron a tener un rol significativo en el intento de reorganización de las empresas públicas.

Argentina. En el caso de Argentina, cabe mencionar en primer lugar la sucesión de luchas ciudadanas contra la privatización de los servicios de agua y saneamiento y la defensa de carácter público de los mismos en la provincia de Tucumán, en la década de 1990. El gobierno provincial otorgó una concesión para la prestación de estos servicios a un consorcio multinacional en 1995, en un proceso que se vio afectado desde el comienzo por denuncias de corrupción, falta de transparencia, y ausencia de debate o consulta públicos, lo cual atizó una fuerte resistencia. Un aumento del $105 \%$ en las tarifas e impuestos de estos servicios, agravado por serios problemas en calidad del agua distribuida, desencadenó una masiva protesta ciudadana que incluyó entre sus participantes a autoridades municipales, legisladores provinciales, trabajadores despedidos por la empresa pública privatizada, y representantes del empresariado local. Alrededor del 86 por ciento de los usuarios 
participó en una campaña de desobediencia civil mediante el "no pago" de la factura del servicio y demostraciones públicas de protesta que incluyó una "Sesión Popular de la Legislatura" para denunciar el carácter corrupto del proceso de privatización. Finalmente el contrato fue cancelado en 1997 (Crenzel 2004; Luna and Cecconi 2004: 234).

Otro caso notable fue el de la provincia del Chaco. En 1994 el Gobierno Provincial convocó a una Consulta Popular sobre la posibilidad de viabilizar en el Chaco la política de privatizaciones impulsada desde el Gobierno Nacional por el Presidente Carlos Menem. Este llamado a consulta tuvo un carácter inusual ya que en el resto del país los procesos de privatización se venían realizando mediante decretos presidenciales especiales y en ausencia de debate público, pero en el Chaco la Consulta era un requisito de la Constitución Provincial. Lo que torna interesante este caso es que a) los partidos políticos más importantes apoyaban la privatización de los servicios y b) el resultado de la Consulta Popular tenía carácter vinculante y debía ser incorporado a la Constitución Provincial. El resultado de la Consulta tomó por sorpresa al establishment político provincial, que no anticipó la posibilidad de un voto negativo a la propuesta. Sin embargo, una mayoría de los votantes rechazó la enmienda a la Constitución Provincial y de esa manera quedó decretado el rechazo a la privatización y la decisión de mantener los servicios esenciales en el ámbito público. Lamentablemente, la elección soberana de los ciudadanos del Chaco fue severamente penalizada por el gobierno central, el cual excluyó a la provincia del programa de inversiones para infraestructura de servicios públicos, un programa parcialmente financiado por el Banco Interamericano de Desarrollo (BID) y que exigía la privatización de las empresas públicas como condición para recibir el financiamiento (Roze 2002).

Otro ejemplos importantes de participación social en la forma de movilización popular son los casos de Buenos Aires, donde la población fue progresivamente pasando de una cierta apatía a comienzos de la década de 1990 a formas muy activas de presión sobre las autoridades y las empresas privatizadas, que finalmente condujo a la cancelación de los contratos de 
privatización vigentes (Azpiazu, Catenazzi et al. 2003; Amorebieta 2005). Del mismo modo, en las provincias de Santa Fe y Córdoba organizaciones sociales de distinto tipo, incluyendo grupos ambientalistas, trabajadores y movimientos de vecinos, con el apoyo de académicos y representantes políticos locales, llevaron a cabo campañas muy efectivas. En el caso de Santa Fe, la movilización popular, ayudada por el ascenso al poder de una alianza de partidos de centroizquierda, contribuyó a la decisión de cancelar los contratos de privatización de los servicios de agua y saneamiento en el año 2006 y a la implementación de formas de control ciudadano de la gestión de los servicios (Rovere 2010). En Córdoba, al momento de escribir este trabajo los grupos sociales de base continúan una lucha de larga data por la cancelación del contrato de privatización, la recuperación de las empresas públicas, y la búsqueda de soluciones a los problemas de falta de acceso y mala calidad de los servicios mediante la autoorganización popular (Spedale 2009; Berger 2010). También, aparte del caso de los servicios de agua y saneamiento, existen ejemplos significativos de formas exitosas de autoorganización popular en otros servicios básicos, notablemente en la recolección y reciclado de residuos (ver, por ejemplo: Paiva 2004; Angélico and Maldovan 2008; Los Caminantes 2010).

Brasil. Quizás el ejemplo de participación social desde abajo más conocido y celebrado internacionalmente, conectada con la construcción de formas de democracia participativa y directa, es el de Brasil. Al igual que en Bolivia, los movimientos de base que participaron activamente en la lucha contra la privatización de los servicios y por la universalización del acceso fueron actores importantes del proceso político que llevó al Presidente Luiz Inácio Lula da Silva al poder en el año 2002 y pasaron a ocupar posiciones en las instituciones de gobierno responsables por estos servicios. Entre otras iniciativas de base popular introducidas en el marco de este proceso cabe destacar particularmente la bien conocida experiencia del presupuesto participativo, iniciada en la ciudad de Porto Alegre y luego replicada con éxito en muchas otras ciudades y regiones, que constituye un caso paradigmático de las 
políticas participativas (Dutra and Benevides 2001; Fedozzi 2001). De igual manera, pueden destacarse las experiencias participativas promovidas por organismos como los Consejos y Conferencias de las Ciudades para la discusión y establecimiento de prioridades de políticas públicas a nivel de los servicios urbanos. Incluso instituciones internacionales como el Banco Mundial han reconocido su capacidad movilizadora y efectividad en la generación de legitimidad para la implementación de políticas públicas, como por ejemplo en relación a las iniciativas para universalizar el acceso a los servicios esenciales con mecanismos de control social democrático de la gestión (ver, por ejemplo: World Bank 2003: 42). En el caso de los servicios de agua y saneamiento Brasil cuenta con numerosas experiencias exitosas de gestión pública, principalmente, a nivel local, con amplia participación ciudadana (Maltz 2005; Miranda Neto 2005; Costa, Heller et al. 2006). De igual manera, los movimientos de 'catadores de lixo', o 'agentes ambientais' como los denominan quienes buscan dignificar el rol de estos actores, constituyen otro ejemplo notable de las interacción entre formas de autoorganización social y procesos políticos de carácter progresista e inclusivo (Pimenta Velloso 2005; MNCR 2010).

Por falta de espacio haremos aquí sólo una breve referencia a otros procesos cuya relevancia para nuestro tema no puede resaltarse con justicia en este texto pero que permiten completar nuestra ejemplificación de las formas emergentes de autonomías participativas en la gestión de servicios públicos esenciales en América Latina. Sólo consideraremos aquí los casos de Nicaragua y Venezuela. ${ }^{8}$

8 Entre otros muchos ejemplos, ver: para Colombia, Vélez Galeano, Budds, et al. (2010), para Ecuador, CEDA, (2009), para Perú Cabel Noblecilla, Ortiz Sánchez, et al. (2004), Cordero (2005), para Uruguay, Santos y Villarreal (2005). 
Nicaragua. La experiencia reciente de Nicaragua ${ }^{9}$ añade algunas lecciones importantes. Por una parte, desde la década de 1990, en consonancia con el impulso a nivel regional de políticas de descentralización de la gestión del agua y sus servicios, el gobierno nicaragüense procedió a delegar la gestión de servicios de saneamiento a los gobiernos locales en algunas regiones. En algunos casos, el proceso respondía a la movilización de la población que luchaba por un mayor control sobre la gestión para mejorar los niveles de acceso y calidad de los servicios. El gobierno también ha estimulado algunos mecanismos formales de participación como son los Cabildos abiertos, las Asociaciones de Consumidores y los Comités de Desarrollo Municipal.

Sin embargo, investigaciones recientes sugieren que las formas de participación más efectivas tienen que ver principalmente con dos procesos: a) la gestión de los servicios básicos en áreas no servidas por el estado, principalmente, en zonas rurales y en las periferias urbanas y, b) en la lucha contra la privatización de las empresas públicas. En parte, estas formas participativas se inscriben en una tradición de organización popular en torno a los servicios básicos de saneamiento en Nicaragua que puede rastrearse hasta la décadas de 1960 y 1970, con la creación de "comités de agua" que buscaban resolver el problema de los asentamientos urbanos periféricos. Estas experiencias populares atravesaron diversos procesos de cambio como resultado de las transformaciones políticas experimentadas por el país desde entonces. En relación al primer punto, en las zonas rurales y de la periferia urbana se han creado Comités de Agua Potable y Saneamiento (CAPS), compuestos por miembros elegidos por las comunidades locales y que tienen a su cargo la cobranza y el mantenimiento de los servicios. Se estima que existen unos 6000 CAPS en todo el país que dan servicio a casi un cuarto de la población y que en muchos casos han logrado desarrollar mecanismos de participación

9 Para el caso de Nicaragua me he basado principalmente en: Kreimann Zambrana (2009); Barrios Jackman y Wheelock Díaz (2005). 
y control democrático efectivos. Los miembros de los CAPS son elegidos en Asambleas Comunitarias, mecanismo que, a su vez, convoca a la población a discutir las tarifas de los servicios, las prioridades de inversión y las formas de regulación de usos del agua incluyendo las sanciones a aplicarse a los infractores. Ahora bien, la relativa autonomía de operación de los CAPS con respecto al gobierno y a otros actores es el objeto de tensiones con las instancias gubernamentales, en parte, porque la autoorganización a nivel local frecuentemente entra en colisión con los procesos dirigidos desde el poder central, inclusive en el marco de la nueva administración sandinista que llegó al poder en el año 2006.

En relación al segundo aspecto, el proceso de participación desde abajo, al igual que en muchos otros países de la región, recibió un fuerte impulso a partir del rechazo popular a las políticas de privatización del gobierno, particularmente a partir del año 2001. Un momento clave en este desarrollo fue la creación en el año 2003 de una Alianza por la No Privatización y Acceso al Agua, que se vino a sumar a las acciones de la Red de Acción Conjunta de Iglesias y de ONGs que representan los derechos de los consumidores. Estos son movimientos de gran heterogeneidad en términos del origen social e identidades políticas de los actores, pero que han encontrado una base de entendimiento en la defensa del agua como bien común y de los servicios básicos de saneamiento como un bien público y un derecho humano.

Venezuela. ${ }^{10} \mathrm{Como}$ en la mayoría de los países de la región, las experiencias participativas en torno a la gestión de los servicios básicos en Venezuela pueden rastrearse hasta por lo menos la década de 1960. En tiempos recientes, una de las experiencias fundantes del proceso de movilización social en torno a estos servicios se dio en la década de 1990 en la zona periférica de Caracas donde se inició el desarrollo de un proceso de democracia directa a nivel de las parroquias locales en el cual la gestión de los servicios de saneamiento ocupó un papel central. Este proceso dio lugar a la creación

10 Esta sección sobre Venezuela se basa en Arconada Rodríguez (1996, 2005, 2006); Lacabana y Cariola (2005); Ramírez (2006); Arreaza (2008); López Maya (2008); Matos (2008). 
de Mesas Técnicas del Agua (MTAs) y Gobiernos Parroquiales, instancias de participación local efectiva que comenzaron en dos municipios de la metrópolis, Antímano y El Valle y que, posteriormente, se convertirían en un referente de la política nacional a partir de la llegada al poder del Presidente Hugo Chávez Frías en 1999. En efecto, a partir de las experiencias en estos dos municipios se introdujo en el debate público que condujo eventualmente a la elaboración de la nueva Constitución venezolana la propuesta de crear a nivel nacional MTAs y Consejos Comunitarios de Agua (a los que se sumaría luego las Organizaciones Comunitarias Autogestionarias, a partir del año 2004) con el objeto de promover la participación efectiva de la población en los asuntos de interés local inmediato, como son el estado de las cuencas y los servicios públicos esenciales. Entre otros mecanismos concretos, el funcionamiento de las MTAs involucra a la población conjuntamente con los funcionarios y técnicos del gobierno local y de la empresa pública a cargo de los servicios en el desarrollo de un "censo" de la situación local, incluyendo la elaboración de planos o croquis que representan gráficamente las redes de infraestructura y otros componentes del espacio en el que habitan las comunidades. Frecuentemente, la elaboración de estos planos condujo a la incorporación de situaciones desconocidas o ignoradas por las autoridades, incluyendo elementos de la infraestructura como redes, equipos, válvulas y otros componentes de los servicios de saneamiento cuya existencia era desconocida por las autoridades y las empresas a cargo de los mismos. Otra función de las MTAs es la de elaborar diagnósticos de situación y proyectos de intervención para solucionar los problemas identificados, monitorear el cumplimiento de las obras y la calidad de los servicios, así como también cogestionar el financiamiento recibido para la realización de obras, incluyendo la regularización del pago de las tarifas por parte de las comunidades. Por su parte, las MTAs, como instancias locales de participación en una determinada región administrativa o geográfica, se reúnen periódicamente en el marco de Consejos 
Comunitarios de Agua, que constituyen una instancia de nivel superior que permite coordinar las acciones de las MTAs en sus distintos territorios. Se estima que existen actualmente unas 2700 MTAs en todo el país.

\section{Obstáculos y posibilidades para la democratización substantiva de la gestión del saneamiento}

Los ejemplos considerados en la sección previa no solamente ilustran algunas de las tendencias más importantes en las formas de gestión de los servicios públicos esenciales sino que también contribuyen a identificar algunos de los obstáculos y oportunidades que se presentan en función del proceso de democratización de dicha gestión. Las luchas sociales orientadas a la ampliación del espacio democrático que se registran en toda la región han abierto oportunidades de transformación, permitiendo logros importantes en una serie de dimensiones que van desde la introducción de experiencias de democracia directa en distintos niveles de la gestión de los servicios públicos hasta la consolidación de formas autónomas de la misma , particularmente, en zonas rurales y periféricas. Existen numerosos ejemplos de experiencias exitosas que representan un enorme potencial para la expansión de formas de participación social conducentes a la profundización del proceso de democratización de la gestión. Sin embargo, no existen panaceas y los procesos participativos desde abajo, incluso cuando se trata de formas genuinamente emergentes a partir de la base social, están expuestos a todo tipo de distorsiones y amenazas, desde la corrupción y degradación interna del proceso de democratización, cuando los sectores sociales acceden a posiciones de poder político, hasta la cooptación y manipulación de los movimientos sociales por parte del Estado, los organismos de cooperación y de financiamiento internacionales e incluso las grandes corporaciones privadas que actúan en el sector (Cooke and Kothari 2001). Frecuentemente también, desde el estado se han promovido formas de participación social que encubren una política de abandono de la responsabilidad estatal por garantizar el acceso universal a los servicios esenciales, 
muchas veces transfiriendo a la población -generalmente a los sectores desatendidos, que suelen ser obviamente los más pobres y marginalizados- la carga de financiar los costos de provisión de la infraestructura de servicios.

Ahora bien, en una perspectiva más general, el predominio de las formas de la democracia representativa, basada en el principio de que la gestión de los asuntos públicos es una materia para políticos profesionales y expertos sigue constituyendo uno de los obstáculos centrales para la profundización del proceso democratizador. Estas formas de la democracia representativa continúan ocupando un lugar dominante en América Latina y El Caribe, incluyendo a los países que en la última década han experimentado la llegada al poder político de gobiernos impulsados por la movilización de amplios sectores sociales. Este situación se ve agravada por las tendencias regresivas de la propia democracia representativa, que han tendido a exacerbar aún más las condiciones de exclusión ciudadana que de por sí caracterizaban a las sociedades de la región. La tradición de lucha social que caracteriza a las sociedades de América y El Caribe en relación con la dignificación de las condiciones de vida y la profundización de la democracia substantiva, no meramente formal o retórica, permite explicar algunas de las transformaciones progresivas experimentadas por la democracia representativa en la región, particularmente la apertura a formas de participación social limitadas, vigiladas, circunscritas a esferas específicas de actividad, a territorios bien definidos y en el marco de temporalidades bien demarcadas. En el caso de los servicios públicos esenciales, los gobiernos frecuentemente han respondido a las presiones resultantes de las luchas sociales, por ejemplo, las luchas por la ampliación del acceso a los servicios de saneamiento básico, con la promoción de formas de participación que, normalmente, se limitan a la autoayuda y a la corresponsabilidad en la organización de ciertos aspectos como la inversión en materiales y mano de obra para la extensión de redes o la regularización de los sistemas de cobranza de las tarifas. Sin embargo, con pocas excepciones, cuestiones substantivas como son las decisiones en relación a los principios y valores que deben orientar a la gestión de dichos servicios son consistentemente excluidas del debate público y cerradas a la participación de las mayorías. 
Este tipo de participación limitada, restringida, vigilada y circunscrita a temas específicos pero que excluye del debate público los componentes políticamente substantivos es promocionada también por las agencias de cooperación y por los organismos financieros internacionales, para los cuales la "participación" en los servicios públicos se ha convertido incluso en un requisito para el otorgamiento de financiamiento para infraestructura de servicios. Lamentablemente, con demasiada frecuencia la noción de participación que se maneja en estas esferas podría traducirse mejor como "obediencia esperada" por parte de la población usuaria a las decisiones tomadas por los políticos profesionales y los expertos, y, de ninguna forma, como participación ciudadana substantiva en las decisiones fundamentales y sobre todo en el control democrático de la gestión. En décadas recientes esta situación se ha puesto de manifiesto muy particularmente en relación a las decisiones relacionadas con la mercantilización de los servicios esenciales, es decir, con el abandono de la noción de que los servicios esenciales constituyen un bien público y un derecho ciudadano y su transformación en bienes privados, mercantiles. Si bien las formas más extremas de dicho proceso se han dado mediante la introducción de diversas formas de participación privada en el gobierno y gestión de estos servicios, el proceso de mercantilización se viene dando con independencia del carácter público-estatal o privado de las empresas que prestan el servicio. Esto es así porque las empresas públicas se ven cada vez más presionadas a adoptar criterios mercantiles de operación, en los que los objetivos sociales de los servicios públicos esenciales quedan crecientemente subordinados a la lógica de la producción de un excedente a partir de la cobranza de las tarifas, tal como si se tratara de empresas privadas orientadas a la acumulación de ganancias. En gran medida, este es el resultado de un proceso que ha erosionado la ética del espacio público que mal o bien se había instalado desde fines del Siglo XIX en el sector de la provisión de servicios esenciales para la vida digna, como los servicios de saneamiento básico.

Esta erosión de la ética de lo público, sobre la que se sustentaba la noción de que el acceso a servicios esenciales para la vida debía ser independiente de la capacidad de pago de los individuos y las familias, y su reemplazo por 
una ética mercantilista constituye uno de los obstáculos más importantes que confronta la democratización substantiva de la gestión del saneamiento en la región. La defensa y recuperación de dicha ética y su ampliación y profundización mediante la consolidación de la noción de que el acceso a los servicios esenciales para la vida es un bien común cuya gestión debe estar excluida de la lógica mercantil orientada a la acumulación de la ganancia privada constituye uno de los desafíos fundamentales que confronta nuestra civilización.

\section{Referencias}

Almansi, F. and G. Urquiza, Eds. (2005). La Lucha por Acceder al Agua. La Tierra, la Expansión y Prestación de Servicios de Agua y Saneamiento en Barrios Informales de Buenos Aires. Buenos Aires, IIED-AL, Instituto Internacional de Medio Ambiente y Desarrollo - América Latina.

Amorebieta, G. (2005). Argentina: worker's co-operative takes over post-Enron. Reclaiming Public Water. Achievements, Struggles and Visions from Around the World. B. Balanyá, B. Brennan, O. Hoedeman, S. Kishimoto and P. Terhorst. London, Transnational Institute and Corporate Europe Observatory: 149-157.

Angélico, H. and J. Maldovan (2008). El reciclaje de residuos sólidos urbanos: las cooperativas como un actor diferenciado en el circuito productivo. V Encuentro de Investigadores Latinoamericanos de Cooperativismo. Movimiento Cooperativo, Transnacionalización e Identidad Cooperativa en América Latina. Ribeirão Preto, São Paulo, Brasil, Alianza Cooperativa Internacional.

Arconada Rodríguez, S. (1996). "La experiencia de Antimano. Reflexiones sobre algunos aspectos de la lucha por la constitución de los Gobiernos Parroquiales en el Municipio Libertador de la ciudad de Caracas." Revista Venezolana de Economía y Ciencias Sociales II(4): 155-165. 
Arconada Rodríguez, S. (2005). "Seis años después: mesas técnicas y consejos comunitarios de agua (aportes para un balance de la experiencia desarrollada)." Revista Venezolana de Economía y Ciencias Sociales 11(3): 187-203.

Arconada Rodríguez, S. (2006). "Mesas técnicas de agua y consejos comunitarios de agua." Revista Venezolana de Economía y Ciencias Sociales 12(2): $127-132$.

Arreaza, A. (2008). La regulación de los servicios sanitarios a través de la contraloría social en Venezuela. I Foro Interamericano sobre Servicios de Agua y Saneamiento. Santiago de Chile.

Assies, W. (2003). "David versus Goliath in Cochabamba: Water Rights, Neoliberalism, and the Revival of Social Protest in Bolivia." Latin American Perspectives 30(3): 14-36.

Azpiazu, D., A. Catenazzi, et al. (2003). Buenos Aires - Argentina Case Study Report. PRINWASS, Research Project (European Commission, Fifth Framework Programme, INCO-DEV, Contract PL ICA4-2001-10041. J. E. Castro. Oxford, University of Oxford.

Azpiazu, D. and M. Schorr (2004). Cross-comparative Report on the Economic-Financial Dimension. PRINWASS Project. J. E. Castro. Oxford, School of Geography and the Environment, University of Oxford.

Bakker, K. (2004). An uncooperative commodity privatizing water in England and Wales. Oxford, Oxford University Press.

Barrios Jackman, M. and S. I. Wheelock Díaz (2005). Movilización Social y Gestión del Agua en Nicaragua Managua, Universidad Centroamericana (UCA), Campus Nitlapan. 
Bell, B., J. Conant, et al. (2009). Changing the Flow: Water Movements in Latin America, Food and Water Watch, Other Worlds, Reclaiming Public Water, Red VIDA, Transnational Institute.

Berger, M. (2010). Cuerpo, experiencia y narración: las prácticas de autoorganización en la defensa de derechos. La lucha de las Madres de Barrio Ituzaingó Anexo de la Ciudad de Córdoba, 2001- 2009. Facultad de Ciencias Sociales. Buenos Aires, Universidad de Buenos Aires. Doctorado en Ciencias Sociales.

Cabel Noblecilla, W., I. Ortiz Sánchez, et al. (2004). Desafíos del Derecho Humano al Agua en el Perú. Lima, Centro de Investigación y Educación Popular - ALTERNATIVA and Centro de Asesoría Laboral del Perú (CEDAL).

Castro, J. E. (2005). “Agua y gobernabilidad: entre la ideología neoliberal y la memoria histórica." Cuadernos del Cendes 22(59): 1-22.

Castro, J. E. (2005). Águas disputadas: regimes conflitantes de gobernabilidade no setor dos serviços de saneamento. Administrando a Água como se Fosse Importante: Gestão ambiental e Sustentabilidade. L. Dowbor and R. A. Tagnin. Sao Paulo, SENAC: 47-59.

Castro, J. E. (2006). Water, Power, and Citizenship. Social Struggle in the Basin of Mexico. Houndmills, Basingstoke and New York, Palgrave-Macmillan.

Castro, J. E. (2007). “La privatización de los servicios de agua y saneamiento en América Latina." Nueva Sociedad(207): 93-112.

Castro, J. E. (2008). A normatização da prestação dos serviços de água e esgoto, a experiência de Inglaterra e Gales. Regulação: Normatização da Prestação dos Serviços de Água e Esgoto. A. d. C. Galvão Junior and M. M. d. Aguiar Ferreira Ximenes. Fortaleza, Ceará, Brazil, Associação Brasileira das 
Agências de Regulação (ABAR) e Agência Reguladora de Serviços Públicos Delegados do Estado do Ceará (ARCE): 161-201.

Castro, J. E. (2009). "Luchas sociales por el agua en América Latina." Anuario de Estudios Americanos 66(2): 15-22.

Castro, J. E. (2010). Private-sector participation in water and sanitation services: the answer to public sector failures? Global change: Impacts on Water and Food Security. C. Ringer, A. Biswas and S. A. Cline. Berlin and Heidelberg, Springer: 169-193.

Castro, J. E. and L. Heller (2006). The development of water and sanitation services in Argentina and Brazil. Environmental History of Water - Global Views on Community Water Supply and Sanitation. P. S. Juuti, T. S. Katko and H. Vuorinen. London, International Water Association (IWA) Publishing: 429-445

Castro, J. E., K. Kloster, et al. (2004a). Ciudadanía y gobernabilidad en la cuenca del Río Bravo-Grande. El Agua en México Vista desde la Academia (Water in Mexico: an Academic Perspective). B. Jiménez and L. Marín. ¿?Mexico City, Academica Mexicana de Ciencias: 199-232.

Castro, J. E., K. Kloster, et al. (2004b). Ciudadanía y gobernabilidad en México: el caso de la conflictividad y la participación social en torno a la gestión del agua. El Agua en México Vista desde la Academia (Water in Mexico: an Academic Perspective). B. Jiménez and L. Marín. Mexico City, Academia Mexicana de Ciencias: 339-370.

CEDA, C. E. d. D. A. (2009). Memorias del Foro "Los nuevos retos de la Participación Ciudadana en el Ecuador: una mirada desde lo socioambiental". Quito, Centro Ecuatoriano de Derecho Ambiental (CEDA).

Cooke, B. and U. Kothari, Eds. (2001). Participation: the New Tyranny? London, Zed Books. 
Cordero, N. C. P. M. E. R. L. V. R. V. M. (2005). Construyendo Ciudadanía: el Derecho Humano al Agua. Lima, Consorcio de Investigación Económica y Social (CIES), Observatorio del Derecho a la Salud, Centro de Estudios para el Desarrollo y la Participación (CEDEP).

Costa, S. S. d., L. Heller, et al. (2006). Successful Experiences in Municipal Public Sanitation Services from Brazil, Transnational Institute and National Association of Municipal Services of Water and Sanitation (ASSEMAE),

Crenzel, E. A. (2004). Tucumán, Argentina, Case Study, PRINWASS Project. J. E. Castro. Oxford, School of Geography and the Environment, University of Oxford.

Crespo Flores, C., N. Laurie, et al. (2004). Cochabamba, Bolivia. Case Study. PRINWASS Project. J. E. Castro. Oxford, School of Geography and the Environment, University of Oxford.

Dryzek, J. S. (1997). The Politics of the Earth. Environmental Discourses. Oxford, Oxford University Press.

Dutra, O. and M. V. Benevides (2001). Orçamento participativo e socialismo. Sao Paulo, Perseu Abramo.

Fedozzi, L. (2001). Orçamento Participativo. Reflexões sobre a Experiência de Porto Alegre. Porto Alegre, Tomo Editorial and Federação de Órgãos para Assistência Social e Educacional (FASE).

Ferree, M. M., W. A. Gamson, et al. (2002). "Four models of the public sphere in modern democracies.” Theory and Society 31(3): 289-324.

Grosse, R., C. Santos, et al., Eds. (2006). Las Canillas Abiertas de América Latina II. La Lucha contra la Privatización del Agua y los Desafíos de una 
Gestión Participativa y Sustentable de los Recursos Hídricos. Montevideo, Casa Bertolt Brecht.

Grosse, R., S. Thimmel, et al., Eds. (2004). Las Canillas Abiertas de América Latina II. La Lucha contra la Privatización del Agua y los Desafíos de una Gestión Participativa y Sustentable de los Recursos Hídricos. Montevideo, Casa Bertolt Brecht.

Heller, L. (2009). Water and sanitation policies in Brazil: historical inequalities and institutional change. Water and Sanitation Services. Public Policy and Managament. J. E. Castro and L. Heller. London and Sterling, VA, Earthscan: 321-337.

Hogwood, B. W. (1998). Regulatory institutions in the United Kingdom: increasing regulation in the 'shrinking state' Changing Regulatory Institutions in Britain and North America. G. B. Doern and S. Wilks. Toronto, Buffalo and London, University of Toronto Press: 80-107.

Jiménez Cisneros, B. and M. L. Torregrosa (2009). Challenges facing the universal access of water and sanitation in. Water and Sanitation Services. Public Policy and Management. J. E. Castro and L. Heller. London and Sterling, VA, Earthscan: 338-352.

Kreimann Zambrana, M. R. (2009). Gestión social de un bien común: Los Comités de Agua en Nicaragua. Contextos diferenciados periferia urbana y rural. Centro de Estudios Demográficos, Urbanos y Ambientales. México DF, El Colegio de México. Maestría en Estudios Urbanos: 103.

Lacabana, M. and C. Cariola (2005). "Construyendo la participación popular y una nueva cultura del agua en Venezuela." Cuadernos del Cendes 22(59): $111-133$. 
Laurie, N. and C. Crespo (2007). "Deconstructing the best case scenario: lessons from water politics in La Paz-El Alto, Bolivia." Geoforum 38(5): 841-854.

López Maya, M. (2008). "Innovaciones participativas en la Caracas bolivariana: La MTA de la pedrera y la OCA de barrio Unión-Carpintero.” Revista Venezolana de Economía y Ciencias Sociales 14(1): 65-93.

Los Caminantes. (2010). “Cooperativa de recolectores de basura." Retrieved 9 May 2010, 2010, from http://www.loscaminantescoop.com.ar/.

Luna, E. and E. Cecconi, Eds. (2004). Indice de Desarrollo Sociedad Civil de Argentina. Total País. Buenos Aires, Programa de las Naciones Unidas para el Desarrollo (PNUD), Banco Interamericano de Desarrollo (BID), Grupo de Análisis y Desarrollo Institucional y Social Argentina (GADIS).

Malloy, T. (2010). "The Social Construction of Regulation: Lessons from the War Against Command and Control.” Buffalo Law Review 58(2): 267-355.

Maltz, H. (2005). Porto Alegre's water: public and for all. Reclaiming Public Water. Achievements, Struggles and Visions from Around the World. B. Balanyá, B. Brennan, O. Hoedeman, S. Kishimoto and P. Terhorst. London, Transnational Institute and Corporate Europe Observatory: 29-36.

Matos, M. G. (2008). Gestión comunitaria de los servicios públicos en Venezuela: entre la nueva institucionalidad y el gobierno desde y para la ciudadanía. XIII Congreso Internacional del Centro Latinoamericano de Administración para el Desarrollo (CLAD) sobre la Reforma del Estado y de la Administración Pública. Buenos Aires.

Medina, M. (2005). Cooperativas de recicladores informales en América Latina. Mexico City, Asociación Interamericana de Ingenierìa Sanitaria y Ambiental (AIDIS), División Técnica de Residuos Sólidos (DIRSA). 
Miranda Neto, A. (2005). Recife, Brazil: building up water and sanitation services through citizenship. Reclaiming Public Water. Achievements, Struggles and Visions from Around the World. B. Balanyá, B. Brennan, O. Hoedeman, S. Kishimoto and P. Terhorst. London, Transnational Institute and Corporate Europe Observatory: 113-119.

MNCR, M. N. d. C. d. M. R. (2010). "Movimento Nacional dos Catadores de Materiais Recicláveis.” Retrieved 9-10-2010, 2010, from http://www.mncr. org.br/.

Paiva, V. (2004). "Las cooperativas de recuperadores y la gestión de residuos sólidos urbanos en el área metropolitana de Buenos Aires." Revista Theomai 2003(Número especial).

Pérez Barriga, J. (2010). Challenges and Opportunities for the Participatory Management of Water and Sanitation Services. The Case of La Paz-El Alto, Bolivia. School of Geography, Politics and Sociology. Newcastle upon Tyne, Newcastle University. M Phil in Geography

Pietilä, P. E., M. J. Gunnarsdóttir, et al. (2009). Decentralized services: the Nordic experience. Water and Sanitation Services. Public Policy and Managament. J. E. Castro and L. Heller. London, Earthscan: 218-233.

Pimenta Velloso, M. (2005). "Os catadores de lixo e o proceso de emancipação social." Ciência \& Saúde Coletiva 10(supp): 49-61.

Ramírez, L. A. (2006). Participación comunitaria y empresa: Un ejercicio de corresponsabilidad y contraloría social. VI Jornadas de Investigación del Decanato de Administración y Contaduría, Universidad Centroccidental Lisandro Alvarado. Barquisimeto, Venezuela, Universidad Centrooccidental Lisandro Alvarado. 
Red Latinoamericana de Recicladores. (2010). "Red Latinoamericana de Recicladores." Retrieved 9-5-2010, 2010, from http://www.redrecicladores. net/.

Rezende, S. and L. Heller (2008). O Saneamento no Brasil. Políticas e interfaces. Belo Horizonte, Minas Gerais, Universidade Federal de Minas Gerais.

Rovere, L. (2010). Historia de la Asamblea Provincial por el Derecho al Agua. Rosario, Argentina, Taller Ecologista.

Roze, J. P. (2002). Chaco, Argentina, Case Study, PRINWASS Project. J. E. Castro. Oxford, School of Geography and the Environment, University of Oxford.

Santos, C. and A. Villarreal (2005). Uruguay: direct democracy in defence of the right to water. Reclaiming Public Water. Achievements, Struggles and Visions from Around the World. B. Balanyá, B. Brennan, O. Hoedeman, S. Kishimoto and P. Terhorst. London, Transnational Institute and Corporate Europe Observatory: 173-179.

SARH, S. d. A. y. R. H.-C. d. P. N. H. (1981). Plan Nacional Hidráulico. Mexico City, Secretaría de Agricultura y Recursos Hidráulicos (SARH).

Solanes, M. (2002). América Latina: ¿sin regulación ni competencia? Impactos sobre gobernabilidad del agua y sus servicios. Santiago de Chile, Comisión Económica para América Latina y el Caribe (CEPAL).

Spedale, G. (2009). Córdoba: crisis hídrica y shock social. Córdoba, Argentina, Coordinadora Córdoba en Defensa del Agua y la Vida (CCODAV)

Spronk, S. and J. R. Webber (2007). "Struggles against Accumulation by Dispossession in Bolivia: The Political Economy of Natural Resource Contention." Latin American Perspectives 34(2): 31-47. 
Swyngedouw, E. (2005). "Dispossessing H2O: the contested terrain of water privatization." Capitalism Nature Socialism 16(1): 81 - 98.

Torregrosa, M. L., F. Saavedra, et al. (2003). Aguascalientes, Mexico. Case Study. PRINWASS Project. J. E. Castro. Oxford, School of Geography and the Environment, University of Oxford.

Vélez Galeano, H., J. Budds, et al., Eds. (2010). Justicia Hídrica. 7 Ensayos como Aportes para Articular las Luchas. Bogotá, CENSAT Agua Viva and Amigos de la Tierra Colombia.

World Bank (2003). World Development Report 2004: making services work for poor people. Washington, DC. 


\title{
Los bienes comunes y la ciudadanía: contradicciones de una relación en desarrollo ${ }^{1}$
}

\author{
General
}

\begin{abstract}
Dos tendencias que se sustentan sobre bases enteramente heterogéneas lucharán entre sí.

El viejo orden económico preguntaba, ¿cómo puedo darle trabajo y sustento al mayor número de hombres con esta porción de tierra? El capitalismo pregunta: ¿cómo puedo producir el mayor número posible de cosechas para el mercado usando al menor número posible de hombres? [...] El capitalismo extrae frutos de la tierra, de las minas, las fundiciones e industrias de máquinas. Los miles de años del pasado luchan contra la invasión del espíritu del capitalismo.
\end{abstract}

Max Weber, Ensayos de Sociología

Desde el punto de vista de una formación socio-económica más elevada, la propiedad privada de ciertos individuos en la tierra será igual de absurdo que la propiedad privada de un hombre dentro de otro. Incluso toda una sociedad, un país, o todas las sociedades en su conjunto que existen simultáneamente no son dueños de la tierra.

Karl Marx, Capital, Vol. 3.

Este artículo busca contribuir al debate continuo de los bienes comunes explorando el potencial emancipador de las luchas contemporáneas por su defensa y recuperación en conexión con el desarrollo de una ciudadanía

1 Uma versão prévia foi publicada em: S. Helfrich (Ed.), Genes, Bytes y Emisiones: Bienes Comunes y Ciudadanía, Cidade do México: Edições da Fundação Henrich Böll, 2008, pp. 68-80. 
sustantiva, y no meramente formal. En favor de la claridad, organicé el análisis en tres propuestas centrales:

Propuesta 1: los principios de la ciudadanía, conforme se han desarrollado en las democracias capitalistas, tienden a contradecir los principios relacionados con la existencia y sobrevivencia y persistencia de los bienes comunes.

Propuesta 2: a corto y mediano plazo el ejercicio sustantivo, y, no meramente formal de las formas existentes de ciudadanía, podría contribuir a la defensa y la recuperación de los bienes comunes.

Propuesta 3: la exitosa defensa y recuperación de los bienes comunes a escala global podría contribuir a la emergencia de nuevas formas sociales que transciendan los límites impuestos por los sistemas existentes de ciudadanía.

Primeramente, aunque estamos tratando con la noción un tanto abstracta de los "bienes comunes" nuestra reflexión se centra en la investigación empírica de una clase particular de los "commons": los arreglos sociales y políticos que caracterizan el control y la gestión del agua dulce como un bien común. Nuestro trabajo más reciente ha abordado sus distintos aspectos de gestión y gobernanza, incluyendo el desarrollo de ciudadanía con relación al control del agua. Este capítulo presenta una parte importante de los argumentos derivados de nuestra investigación. ${ }^{2}$ Es por ello que la mayoría de los ejemplos y referencias hechas tienen que ver con casos de Latinoamérica, aunque las lecciones extraídas también arrojan luz en procesos similares en otras partes.

2 CASTRO, José E.: Agua, Electricidad y Ciudadanía. La lucha social en la Cuenca de México. Houndmills, Basingstoke y New York, Palgrave-Macmillan. 2006.; CASTRO, José E. \& LACABANA, Miguel: "Agua y desarrollo en América Latina: por una democracia sustantiva en la gestión del agua y sus servicios." Cuadernos del Cendes 22(59), 2005. ix-Xv. 
En segundo lugar, aunque nos concentremos en defender y reclamar los bienes comunes como un proyecto contra hegemónico estamos conscientes de que no necesariamente todos los bienes comunes son conducentes a la democracia sustantiva y política emancipadora y de que ciertos proyectos desarrollados bajo la bandera de "gestión de bienes comunes" pueden, en realidad, ser vehículos primitivos de acumulación, mayor expropiación y encierre de los mismos logrando empeorar la exclusión social. ${ }^{3}$

En tercer lugar, nos aproximamos a la "ciudadanía" desde una perspectiva sociológica que enfatiza más el proceso que el estatus. Ante todo, la ciudadanía es un sistema de inclusión-exclusión que opera siguiendo criterios específicos para definir la membresía de las personas dentro de cierta comunidad política incluyendo la asignación de sus derechos y obligaciones. Dicho proceso es altamente dinámico porque la ciudadanía evoluciona con el paso del tiempo en términos cualitativos y cuantitativos va adoptando una diversidad de formas en los distintos territorios, y se caracteriza por las contradicciones en curso entre el estatus formal otorgado a las y los ciudadanos en lo individual y el ejercicio actual, sustantivo de los derechos y obligaciones que se les permite en términos prácticos.

En resumen, en este artículo la conexión entre ciudadanía y nacionalidad $\mathrm{u}$ otras formas de identidad política no nos concierne. Más bien, nos enfocaremos en la ciudadanía como el conjunto de relaciones sociales con reconocimiento de los derechos y obligaciones mutuas entre miembros de igualdad formal de la sociedad y las tensiones que surgen de las contradicciones entre esta igualdad abstracta del estatus formal y las asimetrías sociales y desigualdades reales que caracterizan a los verdaderos seres humanos.

Propuesta 1: los principios de la ciudadanía, conforme se han desarrollado en las democracias capitalistas, tienden a contradecir los principios relacionados con la existencia y persistencia de los bienes comunes.

3 GOLDMAN, Michael:"Customs in Common": The Epistemic World of the Commons Scholars." Theory and Society 26(1): 1-37. 1997. También McCARTHY, James: "Commons as counterhegemonic projects." Capitalism Nature Socialism 16(1), 2005. pp. 9-24. 
Los principios e instituciones que caracterizan los modelos prevalentes de ciudadanía son, a grandes rasgos, un producto histórico específico de las sociedades occidentales. Se puede decir, por analogía a la caracterización clásica de Herman Heller del estado- nación moderno, que el desarrollo de formas modernas de ciudadanía ha sido un proceso circunscrito por el "círculo occidental de países". ${ }^{4}$ Esto no significa que no existan componentes de los sistemas modernos de ciudadanía en otras sociedades pero el punto es que los principios e instituciones más importantes que son el sello distintivo de las formas de ciudadanía que hoy prevalece (particularmente los derechos y obligaciones civiles y políticos) son, en gran medida, el resultado del desarrollo de las sociedades occidentales y su adaptación, adopción o imposición en otras sociedades, particularmente, desde el Siglo XVIII. Pero sobre todo, significa que, al igual que con el caso de los conceptos occidentales, "ciudadanía” no deberá aplicarse mecánicamente a otras sociedades sin analizar cuidadosamente sus implicaciones.

En relación al punto anterior, la formación y expansión de los sistemas modernos de ciudadanía son parte integral del desarrollo de la democracia capitalista. Ante todo, la ciudadanía se encuentra en el centro de la contradicción crucial entre la igualdad formal y las condiciones reales de desigualdad que estructuran las democracias capitalistas. Hace mucho tiempo, T. H. Marshall afirmaba que la ciudadanía en una democracia capitalista proporciona el fundamento de la igualdad formal sobre el que se basan las desigualdades estructurales socio-económicas que caracterizan al capitalismo. ${ }^{5}$ En este sentido, en una sociedad contemporánea el sistema de ciudadanía es instrumental a la reproducción y expansión del capitalismo. Esto es altamente pertinente para nuestro análisis porque el proceso más formidable de intrusión a los bienes comunes ocurre por medio de la expansión de las formas capitalistas de organización social, particularmente, por medio del proceso de comodificación (commodification). No sólo no son incompatibles estos procesos con las formas prevalentes de ciudadanía sino

4 HELLER, Hermann: Teoría del Estado. México DF, Fondo de Cultura Económica. 1987. pp. 43, 78.

5 MARSHALL, Thomas H.: Citizenship and social class. Sociology at the Crossroads and other Essays. London, Heinemann. 1963. pp: 67-127. 
que de hecho las instituciones mismas de ciudadanía llegan a promover la colonización de los bienes comunes por medio de formas capitalistas de propiedad y gestión.

Desde otro ángulo, la evolución a largo plazo de la ciudadanía occidental se ha caracterizado, en términos generales, por una expansión cualitativa y cuantitativa que ha sido dispareja y ha estado sujeta a las tendencias de regresión. Hablando en términos generales, el ser ciudadano en épocas modernas evolucionó de ser burgués (jefe de familia masculino, dueño de propiedad) en ciudades europeas medievales, ${ }^{6}$ a convertirse en un individuo (todavía hombre, dueño de propiedad) miembro de un estado- nación hacia finales del Siglo XVIII con la Revolución Francesa. Posteriormente, se llegaron a desarrollar formas de ciudadanía más incluyentes (delimitadas por el estado- nación), particularmente, durante los Siglos XIX y XX, e incluyeron la expansión formal de ciudadanía a mujeres y a la mayoría de dueños que no tuvieran propiedad (todavía con importantes exclusiones de sectores de la población, a menudo, por motivos étnicos). En tiempos más recientes, hemos sido testigos de la reaparición de formas viejas de ciudadanía y del surgimiento de las nuevas cuya tendencia es trascender las fronteras de las naciones-estado, como el caso de ciudadanías "pos-nacionales", "trasnacionales", "cosmopolitas", "del mundo", o "globales". Por lo tanto, en una perspectiva a largo plazo, puede decirse que, como patrón general, la membresía formal de los sistemas de ciudadanía se ha expandido para incorporar - como dice Norbert Elias- a "números siempre crecientes" de seres humanos. ${ }^{8}$ Más aún, en tiempos recientes, los debates en torno a la

6 WEBER, Max: Economy and Society. Berkeley, Los Angeles, London, University of California Press. 1978. p. 1243.

7 Para ver el resumen de este debate, consultar: THEORY AND SOCIETY: "Special Issue on Recasting Citizenship “Theory and Society 26(4), 1997. También: DELANTY, Gerard: Citizenship in a global age: society, culture, politics. Philadelphia, PA, Open University Press. 2000.

8 ELIAS, Norbert: The Civilizing Process. The History of Manners, and State Formation and Civilization. Oxford, Basil Blackwell. 1994. p. 354. 
ciudadanía abarcan, cada vez más, la idea de ampliar la ciudadanía a no-humanos, así sean animales ${ }^{9} \mathrm{o}$ incluso a entes artificiales. ${ }^{10}$

Esta evolución también tiene una dimensión cualitativa dado que el contenido de ciudadanía - particularmente, los derechos y obligaciones de su ejercicio- ha avanzado en amplitud y profundidad. Por lo tanto, los componentes tradicionales básicos de ciudadanía -las dimensiones civiles y políticas- se ampliaron durante el Siglo XX al incorporarse la dimensión social consolidada tras la Segunda Guerra Mundial. Desde las últimas décadas del Siglo XX se ha venido dando una transformación rápida del contenido de ciudadanía sobre todo a través de una mayor especificación del significado y alcance de los derechos y obligaciones pero también, yendo más allá de las inquietudes clásicas antropocéntricas, pasando por la incorporación de áreas totalmente nuevas como son la ciudadanía ecológica, ${ }^{11}$ verde (los seres humanos como guardianes de los bienes comunes globales), ${ }^{12}$ o pos-humana, tecnológica (cyborg). ${ }^{13}$

Sin embargo, esto no ha sido un avance lineal ni uniforme y, el desarrollo histórico de la ciudadanía lo han puntualizado más bien las luchas sociales recurrentes, incluso quedando sujeto a retrocesos importantes cuando los derechos, adquiridos durante épocas favorables, se han suspendido o cancelado en su totalidad. Esto se puede ilustrar con la cancelación de derechos civiles básicos, como el habeas corpus, en dictaduras capitalistas ${ }^{14}$

9 GOODIN, Robert E., Carole PATEMAN, and Roy PATERMAN: "Simian Sovereignty." Political Theory 25(6), 1997. pp. 821-849.

10 IPSOS-MORI:"Robo-rights: Utopian dream or rise of the machines?", London, Office of Science and Innovation's Horizon Scanning Centre, United Kingdom Government. 2006.

11 STEENBERGEN, Bart v.: Towards a global ecological citizen. The Condition of citizenship. Bart. v. STEENBERGEN. London, Thousand Oaks, 1994. pp. 141-152.

12 NEWBY, Howard:. Citizenship in a green world: global commons and human stewardship. Citizenship Today. The Contemporary relevance of T. H. Marshall. Martin BULMER \& Anthony M. REES. London, UCL Press. 1996. pp. 209-221.

13 GRAY, Chris H.: Cyborg citizen : politics in the posthuman age. New York, London, Routledge. 2001.

14 MARÍN, Juan C.: Los Hechos Armados. Argentina 1973-1976. La Acumulación Primitiva del Genocidio. Buenos Aires, PICASO - La Rosa Blindada. 1996. 
y democracias ${ }^{15}$ o con la reducción o hasta anulación de derechos sociales por medio de reformas neoliberales instrumentadas mundialmente desde los ochentas. ${ }^{16}$ Además, queda bien establecido que hasta en democracias tradicionales y capitalistas el ejercicio real de la ciudadanía es altamente desparejo, lo cual obliga a puntualizar la diferencia entre ciudadanía formal y sustantiva, además de las asimetrías sociales expresadas en el desarrollo actual de las distintas jerarquías de ciudadanos (ciudadanos de primera, segunda y hasta de tercera clase, los no ciudadanos, etc.).. La desigualdad de clase, género y etnicidad son los que determinan que, para grandes sectores de la población en democracias capitalistas, la ciudadanía es, principalmente, una formalidad cuyo impacto en sus vidas diarias es limitada.

Además, dentro la experiencia occidental existen diferentes modelos de ciudadanos que se inspiran en las tradiciones rivales intelectuales y políticas, y las reproducen. ${ }^{17}$ Por otra parte, las instituciones particulares de ciudadanía derivadas de estos modelos tienden a divergir, a menudo y marcadamente, entre culturas políticas nacionales y regionales. Las instituciones de ciudadanía que prevalecen en la Europa nórdica han seguido un patrón muy diferente al del resto del continente, ${ }^{18}$ mientras que también son significativas las diferencias entre Oeste y Sur y, entre la Europa anglosajona y la continental. ${ }^{19}$ Así mismo existen variaciones fundamentales entre las instituciones europeas de ciudadanía y las que se desarrollaron en los Estados Unidos. ${ }^{20}$

15 MORRISON, Trevor W.: "Suspensions and the extrajudicial constitution." Columbia Law Review 107(7), 2007. 1533-1616.

16 LEYS, Colin: Market-driven politics: neoliberal democracy and the public interest. London, Verso. 2001.; HARVEY, David: A brief history of neoliberalism. Oxford, Oxford University Press. 2005.

17 DELANTY, op cit.

18 ESPING-ANDERSEN, Gøsta: The three worlds of welfare capitalism. Princeton, N.J., Princeton University Press. 1990. KAUTTO, Mikko, Johan FRITZELL, Bjørn HVINDEN, Jon KVIST \& Hannu UUSITALO, Eds.: Nordic Welfare States in the European Context. London, New York, Routledge.2001.

19 BRUBAKER, Rogers: Citizenship and Nationhood in France and Germany. Cambridge, Mass. y London, Harvard University Press. 1992. STEENBERGEN, op. cit.

20 GLENN, Evelyn: “Citizenship and Inequality: Historical and Global Perspectives." Social Problems 47(1), 2000. pp. 1-20. 
De manera comprensible, la aplicación mecánica del concepto de ciudadanía a las experiencias de países no europeos es aún más problemático. Por ejemplo, ¿qué quiere decir ser ciudadano en América Latina o, mejor dicho, en cada uno de sus países y regiones? Algunos autores dicen que el caso de los países latinoamericanos es el de "estados sin ciudadanos" en donde el desarrollo de las naciones- estado no tuvo correspondencia con la formación de una ciudadanía que pudiera dar base legítima al ejercicio del poder político. ${ }^{21}$ Incluso otros han escrito sobre "los ciudadanos imaginarios", refiriéndose así a los limitados intentos, a menudo artificiales, de trasplantar las instituciones liberales de ciudadanía (particularmente, los de propiedad privada) a países como México, nación que tenía tradiciones indígenas y españolas muy bien establecidas de propiedad colectiva de los activos naturales (tierra, agua, bosque). ${ }^{22}$ De hecho, ¿qué significa ser un ciudadano, en la práctica, por ejemplo, para la gran proporción de poblaciones indígenas en países como Bolivia, Ecuador, Guatemala, México y Perú (pero también para las proporciones menores de indígenas y gente no blanca que integran la población de la mayoría de los países en la región)? Por otra parte, aún en lugares en donde las condiciones para ejercer la ciudadanía, en principio, han experimentado cierto grado de desarrollo, como en los países del Cono Sur, las décadas de dictadura seguidas por reformas neoliberales implementadas desde los ochenta han empeorado marcadamente esas condiciones, como se observa claramente con el resurgimiento de una “sociedad excluyente" en países como Argentina ${ }^{23}$ y Chile. ${ }^{24}$

21 FLEURY, Sonia: Estados sin Ciudadanos. Seguridad Social en América Latina. Buenos Aires, Lugar Editorial. 1997.

22 ESCALANTE GONZALBO, Fernando: Ciudadanos Imaginarios. México DF, El Colegio de México. 1992. Ver también el artículo de Leticia Merino: "La propiedad colectiva en México y su papel en el resguardo de los bienes y servicios ambientales" y "Las comunidades forestales en México", en este mismo libro.

23 SVAMPA, Maristella:. La Sociedad Excluyente. La Argentina bajo el Signo del Neoliberalismo. Buenos Aires, Taurus. 2005.

24 LATIN AMERICAN PERSPECTIVES: “Chile since 1990: The Contradictions of Neoliberal Democratization (Special Issue, Part 1).” Latin American Perspectives 30(5), 2003. 


\section{Ciudadanía y los bienes comunes: las contradicciones}

Las formas de ciudadanía institucional que prevalecen son parte integral de la democracia capitalista. Se desarrollan en correspondencia íntima con los otros componentes clave estructurales del mismo sistema: la mercancía y el proceso correspondiente de mercantilización, en permanente expansión hacia nuevos territorios.

Dentro de esta conexión, la mercantilización es un proceso a largo plazo por el que se mediatizan y transforman cada vez más las relaciones entre los seres humanos en el marco de la producción y circulación de productos, procesos centrados en la apropiación privada -no común- de la naturaleza. El desarrollo de los sistemas de ciudadanía que actualmente prevalece y que está centrado en los derechos individuales, además de ser instrumental a tal proceso, ha sido parte inextricable del mismo. Dicha relación entre los principios de la ciudadanía y el capitalismo es más transparente en la tradición liberal-individualista de la ciudadanía, que se sustenta en el supuesto de que las personas son fundamentalmente racionales y siempre buscan maximizar su propio beneficio personal. En esta visión de la ciudadanía, las decisiones racionales individuales conducen a los mejores resultado posibles para el conjunto social, con la condición de que estén presentes las condiciones apropiadas (por ejemplo, la existencia generalizada de la propiedad privada). Tales suposiciones son conocidas en los debates sobre los bienes comunes, por ejemplo en los influyentes argumentos de Garret Hardin en "La Tragedia de los Bienes Comunes", 25 y de neoinstitucionalistas como North y Thomas quienes aseveraron que la propiedad común es un legado anacrónico de tiempos pasados cuando los recursos eran vastos ${ }^{26}$ hasta las posiciones extremas de corte neoliberal que tratan de sustituir a

25 HARDIN, Garret: “The Tragedy of the Commons." Science 162(3859), 1968. pp. 1243-1248.

26 NORTH, Douglass C. and Robert P. THOMAS (1973). The rise of the Western world: a new economic history. Cambridge, Cambridge University Press. 
los bienes comunes por la propiedad privada como solución a la crisis de los "recursos" 27 naturales.

En función de lo anterior, cabe afirmar que las formas prevalentes de ciudadanía son, en principio, antagónicas a la existencia misma de los comunes. Se puede argumentar que la lógica del progreso de la ciudadanía en democracias capitalistas tiende a la sustitución de los bienes comunes por la propiedad privada y sus instituciones. En el largo plazo, la lógica de la ciudadanía capitalista conduce a la extinción de las relaciones sociales fundadas en la noción de bienes comunes.

Propuesta 2: A corto y mediano plazo, el ejercicio sustantivo, no meramente formal, de las formas existentes de ciudadanía, podría contribuir a la defensa y la recuperación de los bienes comunes.

A pesar del aspecto instrumental de la ciudadanía en el contexto de democracia capitalista, como se planteó antes, su desarrollo histórico ni ha sido monolítico ni lineal. Más bien se ha caracterizado por la divergencia, la diversidad y por las contradicciones entre la lógica de la ciudadanía y la lógica de la acumulación privada característica del capitalismo. En palabras de T.H. Marshall, desde una cierta perspectiva, los principios de la ciudadanía y del capitalismo siempre han estado "en guerra", particularmente, porque mientras que el capitalismo se basa en la producción y reproducción de las desigualdades sociales, los principios de la ciudadanía se sustentan sobre la noción de igualdad universal, cuya extensión y profundización en la práctica puede contribuir a la disminución de las desigualdades estructurales cualitativas. ${ }^{28}$ Además, la expansión cuantitativa y cualitativa de la ciudadanía, con el tiempo también ha incorporado formas embrionarias de modos potencialmente emancipadores de organización social que, entre otras cosas, pueden promover la defensa y la recuperación de los bienes comunes. Como afirmó Marx, el ejercicio de ciudadanía representa "la forma

27 SMITH, Robert J. (1981. "Resolving the tragedy of the commons by creating private property rights in wildlife.” The CATO Journal 1(2): 439-468.

28 MARSHALL, op. cit. 
última de la emancipación humana dentro del orden del mundo actual". ${ }^{29}$ Exploremos algunos de los aspectos de dicho potencial emancipador a corto plazo de la ciudadanía.

Los componentes básicos de la ciudadanía en una democracia capitalista atañen las dimensiones civiles y políticas, básicamente, los derechos y obligaciones involucrados en tener propiedad, protección judicial y en participar en la vida política. Con el paso del tiempo, estos derechos se han ampliado para incorporar los derechos sociales (ciertamente un tema controvertido, ya que para los liberales individualistas la ciudadanía se limita a las dimensiones civil y política). Aunque tales derechos y obligaciones se asignan principalmente a las personas, las implicaciones reales del ejercicio sustantivo de tales derechos y obligaciones rebasan por mucho la esfera individual. Por ejemplo, mientras que la propiedad del agua dulce, en relación con ciertos usos se asigna a actores privados individuales, como en general acontece con los derechos del agua subterránea, los derechos de uso del agua en medios urbanos normalmente están en manos de actores colectivos como son los municipios o los gobiernos provinciales o nacionales. En muchos casos, estos derechos consisten en permisos de abstracción otorgados por el Estado pero, ocasionalmente, toman la apariencia de un derecho de propiedad de facto sobre el agua que pudo haberse adquirido junto con los derechos de propiedad de la tierra. Sea cual fuera el caso, el ejercicio real de los derechos y obligaciones derivados de los derechos de agua en manos de actores colectivos, como son las ciudades o las regiones metropolitanas, puede entenderse como una expresión del ejercicio de los derechos de ciudadanía por parte de la población de esos conglomerados urbanos.

En relación con esto y, quedándonos sólo dentro del ámbito de los derechos civiles y políticos, surge una serie de preguntas. ¿Qué clase de derechos y obligaciones ciudadanos intervienen en las actividades de control, gobierno y asignación de agua en áreas urbanas? ¿Está disponible la información sobre la existencia de estos derechos y obligaciones a los habitantes urbanos? Si cuentan con esa información, ¿cómo ejercen los habitantes urbanos tales

29 MARX, Karl (1975). On the Jewish Question. Collected Works. Karl MARX and Friedrich ENGELS. London, Lawrence and Wishart. 3: 146-74. 
derechos y obligaciones en la práctica? La cuestión de fondo en relación a los derechos civiles relacionados con el agua sería: ¿quién es el dueño del agua en una ciudad o una zona metropolitana? ¿Son sus habitantes (aunque la propiedad esté formalmente en manos de las instituciones gubernamentales)? Si lo son, ¿cómo ejercen sus derechos de propiedad sobre el agua? ¿Qué mecanismos e instituciones (jurídicas y administrativas) están disponibles para que los ciudadanos puedan ejercer esos derechos y obligaciones en relación al agua? Además, ya en relación a dimensión política de la ciudadanía, ¿cómo participan los ciudadanos en las decisiones políticas relacionadas con el control, el gobierno y $1 \backslash$ asignación del agua en sus ciudades? ¿Cómo se toman las decisiones (por ejemplo, al decidir si los servicios urbanos de agua deben proporcionarse como un bien público o como un servicio comercializado o directamente privatizado)? ¿Quién decide? ¿Eligen los ciudadanos a quienes deciden estos temas? ¿Qué mecanismos hay para impugnar las decisiones y prácticas de los diseñadores e implementadores de las políticas y las legislaciones relacionadas con el agua? ¿Qué instrumentos permiten a los ciudadanos tomar consciencia de sus propias responsabilidades como guardianes del agua y de otros bienes comunes?

La respuesta a estas y otras preguntas es que, en perspectiva histórica, a los ciudadanos se les ha excluido de ejercer sus derechos en relación al agua, porque las decisiones en torno al control, gobierno y asignación del agua en las ciudades ha sido históricamente un patrimonio de las burocracias hídricas. Esto no solo es aplicable a la política y la gestión del agua convencionalmente paternalista, cuando no autoritaria, que ha caracterizado históricamente a este sector de actividad, sino también a las formas de gobierno y gestión del agua implementadas en épocas recientes bajo la bandera de la "participación ciudadana" y el empoderamiento, que, en buena medida, continúan ignorando, si no es que de plano cancelando, los derechos de la población con relación al control del agua en sus ciudades y regiones, pues resultan instrumentales a la continuidad de formas verticales y tecnocráticas de gobierno y gestión.

En este sentido, al analizar las políticas prevalecientes desde la década de 1980 a nivel internacional en torno al agua puede observarse un patrón claro de exclusión sistemático de los usuarios del proceso de toma de 
decisiones e incluso de la posibilidad monitorear a los tomadores e implementadores de decisiones. En general, el gobierno y el control del agua se caracterizan por la negación, implícita o explícita, del ejercicio de los derechos ciudadanos, no solamente en los casos altamente publicitados de privatización de los servicios de agua y saneamiento sino también en todo el rango de decisiones políticas en el sector, desde las decisiones de crear "mercados" de agua hasta la construcción de grandes infraestructuras hidráulicas (como represas, trasvases de ríos, o hidrovías), o la implementación de actividades con gran impacto sobre la base material de la vida, la tierra, el agua, el aire (grandes proyectos extractivos, agricultura intensiva con uso masivo de agrotóxicos, etc.) que afectan no solamente los derechos ciudadanos de millones de seres humanos sino que ponen en riesgo su propia existencia. De hecho, las decisiones políticas relacionadas con el agua, generalmente, se adoptan desatendiendo completamente las opiniones, los valores y los intereses de la mayoría de los usuarios y de los ciudadanos, aún en los casos en los que dichas políticas están correctamente orientadas a solucionar problemas como la seguridad alimentaria, la protección contra desastres, o el subdesarrollo.

Este es el patrón general y no es alentador. Sin embargo, al mismo tiempo, como vemos en las crecientes luchas sociales relacionadas con la defensa del derecho al agua y de los bienes comunes en general, el intento por transformar los derechos de ciudadanía meramente formales en un ejercicio sustantivo, material de los derechos civiles, políticos y sociales tiene un potencial emancipador formidable. Ya sea mediante acciones directas, como sucedió en las famosas guerras bolivianas por el agua que condujeron a la cancelación de los proyectos de privatización de los servicios esenciales de agua y saneamiento en Cochabamba (2000) y en La Paz-El Alto (2006), o a través de confrontaciones políticas como el plebiscito uruguayo del año 2004 que culminó con la prohibición de la privatización del agua en la Constitución Nacional, los usuarios de agua no han sido víctimas pasivas de las prácticas de exclusión ciudadana y de la toma de decisiones autoritarias.

Las fuerzas sociales y políticas que han surgido de las luchas contra el autoritarismo y los gobiernos dictatoriales en América Latina han hecho progresos importantes en contribuir al desarrollo de formas innovadoras 
de ciudadanía sustantiva, que ya han demostrado su potencial de democratización en relación a la defensa y recuperación de los bienes comunes. Ello incluye el ejemplo mundialmente conocido de las políticas de presupuesto participativo implementadas en Porto Alegre y en otros municipios brasileños ${ }^{30}$ replicado exitosamente en otras ciudades latinoamericanas y europeas. Otro ejemplo lo dan las Mesas Técnicas y los Consejos Comunitarios de Agua en Venezuela, que enfatizan la promoción de participación ciudadana en la toma de decisiones a nivel local. ${ }^{31}$ Estos ejemplos pueden multiplicarse fácilmente en relación a las luchas contra la desigualdad y la injusticia ambiental emprendidas mundialmente para proteger o recuperar los bienes comunes de la apropiación privada promovida por el Estado y los actores dominantes en el mercado. ${ }^{32}$ Estos procesos dan excelentes ejemplos de cómo las formas existentes de ciudadanía pueden, a la larga, convertirse en vehículos de cambio radical en la lucha por la defensa y recuperación de los bienes comunes. De hecho, el potencial existente en estos procesos para profundizar el ejercicio de la ciudadanía es muy importante lo cual reviste consecuencias significativos ya que la tarea de cerrar la enorme brecha que existe entre la ciudadanía formal y el ejercicio substantivo de los derechos es uno de los desafíos más importantes que confronta el proceso de democratización.

Propuesta 3: la exitosa defensa y recuperación de los bienes comunes a escala global podría contribuir a la emergencia de nuevas formas sociales que transciendan los límites impuestos por los sistemas existentes de ciudadanía.

30 DUTRA, Olivio \& Maria V. Benevides: Orçamento participativo e socialismo, Perseu Abramo. 2001. MALTZ, Hélio: Porto Alegre's water: public and for all. In BALANYÁ, et. al., op. cit., 2005. pp. 29-36; MIRANDA NETO, Antonio: Recife, Brazil: building up water and sanitation services through citizenship. In BALANYÁ, et. al., op. cit., 2005. pp. 113-119.

31 ARCONADA, Santiago: "Seis años después: mesas técnicas y consejos comunitarios de agua (aportes para un balance de la experiencia desarrollada)." Revista Venezolana de Economía y Ciencias Sociales 11(3), 2005. pp. 187-203.

32 Por ejemplo, vea GOLDMAN, Michael, Ed.: Privatizing Nature: Political Struggles for the Global Commons. London, Pluto Press. 1998. MARTINEZ-ALIER, Joan: The Environmentalism of the Poor: A Study of Ecological Conflicts and Valuation. Cheltenham, UK y Northampton, MA., Edward Elgar. 2002. 
El desencadenar el potencial emancipador por medio de un ejercicio substantivo de los derechos de ciudadanía ciertamente puede ser un instrumento poderoso para preservar y recuperar los bienes comunes. Sin embargo, no podemos dar descontada la replicabilidad de las experiencias exitosas ni su sustentabilidad, dado que las condiciones para ejercer la ciudadanía son altamente desiguales para los individuos y los grupos sociales, se caracterizan por un equilibrio inestable y, son determinadas en gran medida por la lógica y las limitaciones que impone la democracia capitalista. La dinámica capitalista impulsa el proceso de mercantilización, que requiere la expansión de derechos privados de propiedad, lo cual conlleva la eliminación progresiva de los bienes comunes y su conversión en bienes privados. Sin embargo, este no es un proceso necesario ni teleológico y, a pesar del impulso dado por las políticas neoliberales a los procesos de mercantilización y privatización, los obstáculos que confronta la dinámica capitalista para profundizar el proceso de mercantilización de los bienes comunes siguen siendo enormes. ${ }^{33}$ Esto deja amplio espacio para los proyectos contra hegemónicos dirigidos a la preservación y la recuperación de los bienes comunes existentes y también para el desarrollo de nuevas formas de propiedad, gobierno y gestión fundadas en el principio de la igualdad, que promuevan la distribución social y no la acumulación privada de la riqueza.

Sin embargo, existen posibilidades y escenarios alternos, algunos de los cuales nos presentan dilemas difíciles en relación con el futuro tanto de los bienes comunes como de la propia ciudadanía. Por un lado, como ya se dijo, el avance de la apropiación capitalista de los bienes comunes no es incompatible con las formas prevalecientes de ciudadanía. Es más, las formas actuales dominantes de la democracia capitalista basadas en la representación formal dictaminan la exclusión de la mayoría de los ciudadanos de la esfera pública, ya que en esta forma prevaleciente de la democracia formal se considera que la esfera pública es una reserva exclusiva de los especialistas técnicos y de los políticos profesionales.

33 HEYNEN, Nik y ROBBINS, Paul: "The neoliberalization of nature: Governance, privatization, enclosure and valuation.” Capitalism Nature Socialism 16(1), 2005. pp.5 - 8. 
Este modelo imperante de ciudadanía restricta se ha visto fortalecido durante las últimas décadas, simultáneamente con el proceso de expansión acelerada de apropiación privada de los bienes comunes, un proceso que crecientemente se extiende a nivel planetario y tiende a abarcar las fuentes de agua dulce, los mares, los bosques, la propia atmósfera. Por otro lado, las luchas sociales por la defensa y recuperación de los bienes comunes tienden también a asumir una dimensión global y suelen estar asociadas con las formas de ciudadanía que mayor énfasis hacen en la participación directa de los ciudadanos en los debates y decisiones y en el mismo gobierno y gestión de lo público y lo comunitario. Un ejemplo de esto proviene de otro caso también conocido mundialmente, como ha sido la lucha de los zapatistas mexicanos que basaron su declaración de "guerra" de 1993 en el Artículo 39 de la Constitución de México, diciendo que uno de sus objetivos principales era el de "suspender el saqueo de nuestra riqueza natural". ${ }^{34}$ Puede decirse, y espero no malinterpretar a los zapatistas, que su lucha es tanto por lograr la ciudadanía sustantiva logrando el reconocimiento de la población indígena como ciudadanos plenos y la participación actual de los ciudadanos mexicanos en los asuntos públicos de su país y por proteger, defender y recuperar sus espacios y bienes comunes.

En perspectiva, y como sugiere la experiencia de los zapatistas y de muchos otros actores, la defensa exitosa de los bienes comunes tiene el potencial de promover el desarrollo de nuevas relaciones sociales que puedan trascender las limitaciones que imponen las formas e instituciones prevalecientes de la ciudadanía capitalista. Este tipo de procesos no puede ser planificado, no es necesario y puede no acontecer. Como anticipó Marx:

"Sólo cuando el hombre individual real recobra en sí al ciudadano abstracto y se convierte, como hombre individual, en ser genérico, en su trabajo individual y en sus relaciones

34 COMANDO GENERAL DEL EJÉRCITO ZAPATISTA DE LIBERACIÓN NACIONAL (EZLN) Declaración de la Selva Lacandona EZLN Documentos y Comunicados. 1994. en ? Antonio G. d. LEÓN, Elena PONIATOWSKA y Carlos MONSIVÁIS. Mexico City, Ediciones Era: 33-35. 
individuales; sólo cuando el hombre ha reconocido y organizado sus 'forces propres' como fuerzas sociales y cuando, por tanto, no desglosa ya de sí la fuerza social bajo la forma de fuerza política, sólo entonces se lleva a cabo la emancipación humana." ${ }^{35}$

No hay certeza de que la emancipación humana así definida así se alcance, por lo menos no en el corto plazo, a juzgar por la enajenación creciente de los ciudadanos comunes provocada por la globalización neoliberal hegemónica de las últimas décadas. Sin embargo, la lucha por la defensa y la recuperación de los bienes comunes forma una de las líneas de avanzada en la lucha más amplia por el territorio de la democracia y la ciudadanía substantivas. En el proceso es dable esperar que surjan nuevas formas sociales que contribuyan a reequilibrar el sistema en un nivel superior de organización humana que privilegie la cooperación y la solidaridad intra- e intergeneracional en lugar de la dinámica ciega de la competencia y de la supervivencia del más fuerte.

35 MARX, op. cit.: 168. 


\section{A água (ainda) não é uma mercadoria: aportes para o debate sobre a mercantilização da água ${ }^{1}$}

Em 2008, uma empresa comercial denominada Makhena divulgou na internet a seguinte propaganda: "venda de água doce em grandes volumes - comercializa-se água doce de rios” (MAKHENA, 2008). A propaganda oferecia a remessa de "água doce natural e não tratada de rios de planícies da Argentina, [...] entre 60.000 e 70.000 toneladas por embarque para consumo, irrigação e potabilização etc." (MAKHENA, 2008). O comercial despertou a atenção de pesquisadores e políticos da Argentina e deflagrou uma investigação pelas autoridades das atividades de exploração comercial da água nos rios da Prata e Paraná. Descobriram que tentativas semelhantes haviam sido realizadas na década de 1980, que este tipo de empreendimento não estava sujeito a regulação, e que, portanto, em princípio, não poderia ser considerado ilegal uma vez que havia uma lacuna na legislação a esse respeito. A maior preocupação na época parecia ser a necessidade de regulamentação daquilo que poderia se tornar um novo tipo de negócio e não o impacto ambiental que níveis potencialmente altos e não regulados de extração de água doce poderiam exercer sobre os ecossistemas fluviais. No entanto, a iniciativa desencadeou uma série de questões para as quais, em princípio, não haveria respostas claras. Quem deveria ser responsável pela regulação da extração comercial de água fluvial? A atividade seria sujeita a tributação ou a alguma taxa de extração? Quais os critérios a serem utilizados para estimar o valor desses encargos assim como para definir o que precisamente deveria ser objeto de encargo? Quem teria os direitos de propriedade para impor tais tributações ou taxas? Que tipo de instituição deveria assumir a responsabilidade? Por fim, Makhena afirmou que, embora compradores

1 Originalmente publicado em: Revista da Universidade Federal de Minas Gerais (UFMG), Vol. 20, No. 2, 2014, pp. 190-221. 
potenciais da Argélia, Israel, Espanha, Tanzânia e algumas ilhas caribenhas tivessem demonstrado interesse em encomendar volumes de água doce a granel, eles não puderam garantir qualquer transação devido aos custos proibitivos da remessa da carga (LATIN AMERICAN HERALD TRIBUNE, 2011). A essa altura, na província de Santa Fé rio acima, especialistas já haviam solicitado ao Congresso local que fosse iniciada uma investigação a respeito das alegações de que embarcações não controladas estariam retirando água do Rio Paraná para venda, mas o caso foi posteriormente rejeitado pelas autoridades (ORSOLINI, 2011).

Essas iniciativas não são originais nem excepcionais. Na verdade, a remessa comercial de água doce a granel (inclusive o transporte de icebergs por longas distâncias) já tem sido praticada por algum tempo e a viabilidade técnica e comercial de aumento dessas atividades continua em discussão (e.g. GLOBAL WATER INTELLIGENCE, 2006; SPANDONIDE, 2009). A importância do assunto não deveria ser subestimada como sugerido pelo fato de que, em maio de 2010, após uma longa década de debates políticos, a Câmara dos Comuns do Canadá finalmente aprovou o Projeto de Lei C-26, banindo as exportações de quantidade massiva de água doce a granel do país. Embora o principal argumento utilizado para justificar a proibição canadense de exportações de água doce a granel tenha sido tecnicamente baseado em questões de proteção ambiental, preocupações com as implicações da permissão de que volumes de água doce a granel se tornassem uma mercadoria no contexto do Acordo de Livre Mercado Norte-Americano com os Estados Unidos e México aparentemente foram a maior razão da decisão tomada (CANADA DEPARTMENT OF ENVIRONMENT, 2010; HOUSE OF COMMONS OF CANADA, 2010; QUINN, 2007). No entanto, o artigo versa não sobre empreendimentos de venda de água doce a granel, mais é uma tentativa de esclarecer alguns aspectos dos longos e históricos processos de valorização e mercantilização dos "recursos naturais", com ênfase no caso da água doce. ${ }^{2}$ Este é um tópico relevante como é já sugerido pela importância que os interesses financeiros globais parecem associar à água doce como a "nova commodity”, a "próxima

2 A água doce participa com aproximadamente $2,5 \%$ do total de águas do planeta, e somente uma pequena fração dela está disponível para consumo humano. 
commodity", a "commodity estratégica", ou simplesmente a "próxima fortuna” (DUGAN; FISHER, 2006; GEMAN; KANYINDA, 2007; HUDSON, 2007; LEWIS; SMITH, 2007; ROYAL BANK OF SCOTLAND, 2008).

Meu principal argumento é que a frequente noção de que a água já se haveria tornado uma mercadoria teria uma correspondência empírica relativamente fraca em termos globais. É essa a questão que sustento, pois o incessante processo de desdobramento da mercantilização capitalista da água é, ao mesmo tempo, incompleto, altamente fragmentado e em grande medida embrionário quando comparado aos avanços realizados, por exemplo, pela mercantilização de outros "recursos naturais", incluindo o próprio corpo humano (ver, entre outras discussões sobre o assunto: ALMELING, 2007; SEALE; CAVERS; DIXON-WOODS, 2006; MARTINS, 1996; 1998a, b). Assim, apesar das recorrentes referências na literatura à "mercantilização da água", eu gostaria de discutir que, se usamos um conceito teoricamente restrito de "mercantilização", então a maior parte da água do mundo, e não somente a água doce, permanece não mercantilizada. ${ }^{3}$ Se esse argumento é válido, pode-se dizer ainda que, entre outras razões, o fato de a maior parte da água no planeta permanecer não mercantilizada tem relação com os desafios ainda intransponíveis com que se depara o processo de racionalização nas interações entre os seres humanos e a hidrosfera. Para embasar este argumento, examino os atuais debates e evidências a respeito da valorização e da mercantilização capitalista da água. Discuto que esses processos ainda enfrentam grandes obstáculos, inclusive formas disseminadas e diversificadas de resistência social à invasão das relações sociais capitalistas nas atividades de controle e administração das águas, mesmo nos territórios capitalistas mais consolidados. As dificuldades encontradas por aqueles que tentam desenvolver um novo negócio exportando água doce a granel na Argentina e no Canadá discutidas anteriormente ilustram o tema.

3 A óbvia exceção à regra é a comercialização de água engarrafada, que agora está bem estabelecida no mundo inteiro e tem sido denominada por alguns a "commodity pura" (WILK, 2006; ver também OPEL, 1999). Por razões de espaço, não abordei em detalhe o caso da privatização de serviços de saneamento, que é objeto de uma literatura específica (e.g. BAKKER, 2004; 2010; CASTRO, 2008; 2010; GOLDMAN, 2007; LAURIE, 2007; SCHORR, 2006; SWYNGEDOUW, 2005). 
Divido este artigo em duas partes principais. A primeira parte discute o processo da mercantilização capitalista da água, enquanto a segunda se refere ao problema da valorização da água e analisa os paradigmas dominantes que reduzem as funções e valores multidimensionais da água ao papel de um mero fator no desenvolvimento humano.

\section{A água como mercadoria e a mercantilização da água}

A venda de água com fins lucrativos tem uma longa história demonstrada, por exemplo, pelo fato de que antigas sociedades do Oriente Médio implantavam regras para a justa alocação das fontes de água e proteção a segmentos vulneráveis da população expostos àqueles que exploravam os mananciais comercialmente. Estas regras incluíam a proibição de venda de água em casos de usos essenciais para as comunidades, o Direito à Sede para salvaguardar o acesso à água para consumo dos seres humanos e animais, e o princípio de que não se pode negar acesso à água para uso humano essencial a ninguém (CAPONERA, 1954; CIVIC, 1998; HIRSCH, 1959). Na prática, as relações sociais desenvolvidas em torno da circulação de água para uso humano essencial se substanciaram em diferentes formas, entre elas como mercadoria, como dádiva, e como direito coletivo desde tempos imemoriais (em debates mais recentes acerca da relação entre as noções de dádiva e de mercadoria, ver, por exemplo, CASTREE, 2003; GODDARD, 2000; LAPAVITSAS, 2004). Os princípios resultantes sobreviveram até hoje e, exemplarmente, pode-se verificar suas expressões concretas em cidades contemporâneas como o Cairo, onde as pessoas deixam seu zir, jarros de barro contendo água para beber, do lado de fora de suas casas para uso gratuito de transeuntes sedentos (para uma discussão sobre a relevância contemporânea desses princípios no Norte da África e Oriente Médio, ler SALZMAN, 2005; WOLF, 2000).

É interessante notar que empresas contemporâneas que comercializam produtos por meio de máquinas automáticas, inclusive água, têm argumentado como publicidade que a venda de água por meio de máquinas origina-se de uma invenção atribuída ao matemático e engenheiro grego Heron de Alexandria (ca. 10-70 d.c.): uma máquina vendedora de água benta 
operada por moedas no interior de templos (VENDING MACHINE BUSINESS, 2009). Embora pareça que a invenção de Heron tenha sido projetada para evitar o desperdício de água benta por fiéis mais incautos e não para vender água com fins lucrativos (HUMPHREYS apud JAFFE, 2006), ela parece haver atraído grande atenção entre os empreendedores contemporâneos interessados na mercantilização da água. Além disso, parece que a venda de água foi disseminada na maioria das sociedades como induzem comprovadamente a crer cenários tão díspares quanto o antigo Oriente Médio (CAPONERA, 1954), Tenochtitlan, a capital do império asteca pré-conquista (CORTÉS, 1520), cidades medievais europeias como a Londres do século XIV (SHEPPARD, 1998; SISLEY, 1899) ou a Lisboa do século XVI (RAMOS TINHORÃO, 1997), a Paris pré-revolucionária (GOUBERT, 1986), as cidades coloniais da IberoAmérica, como Buenos Aires (HERZ, 1979), a Cidade do México (LLAMAS FERNÁNDEZ, 1991), Rio de Janeiro (SOARES, 1988) e São Paulo (SANT'ANNA, 2007), ou os centros urbanos do mundo islâmico (GRAN, 1999). Em suma, o processo de mercantilização da água, compreendido como a venda privada de água com fins lucrativos, notadamente para o emprego básico humano, é pelo menos tão antigo quanto a história escrita.

No entanto, é preciso distinguir as commodities da água e a mercantilização capitalista da água. A esse respeito, os conceitos de commodity e mercantilização são frequentemente empregados tanto nos trabalhos acadêmicos quanto não acadêmicos sobre o tema, não raro com significados divergentes e potencialmente contraditórios (CASTREE, 2003). Exemplos incluem recentes obras acadêmicas que tecem uma crítica às políticas de mercantilização da água, como a de Karen Bakker, An Uncooperative Commodity (BAKKER, 2004), a de McDonald e Ruiters, The Age of Commodity (MCDONALD; RUITERS 2004), e referências à indústria de água engarrafada como um "puro" exemplo da mercantilização da natureza (OPEL, 1999; WILK, 2006). Além disso, há ainda o Segundo Relatório Mundial da Água da UNESCO, em que os serviços de água encanada e esgotamento sanitário são classificados como "mercadorias" (United Nations Educational Scientific and Cultural Organization, World Water Assessment Programme [UNESCO - WWAP], 2006, p. 409), artigos de consultores de investimento globais que alertam seus clientes a respeito do potencial das "futuras commodities de 
água" (LEWIS; SMITH 2007), e, evidentemente, o abundante trabalho dos movimentos sociais e outros atores sociais opositores da mercantilização da água em defesa dos direitos do cidadão, da comunidade, do ser humano e da Natureza (ver, por exemplo, BOND, 2004).

Todavia, mesmo num sentido mais amplo, o conceito de mercadoria originalmente definido por Marx como a articulação do valor de uso e do valor de troca na produção generalizada dos valores sociais de uso que caracteriza o modo capitalista de produção (MARX, 1974, p. 48) somente seria aplicável a um universo relativamente restrito de usos da água doce num sentido mais estrito. Sem dúvida alguma, a água tem uma diversidade de valores de uso para os seres humanos, e esse fato pode ser corroborado com relação ao desenvolvimento de relações sociais de produção e troca de mercadorias baseadas na água, inclusive as diferentes formas de venda de água nas ruas para satisfazer as necessidades humanas essenciais que se verificam na maioria das sociedades. No entanto, até que ponto essas formas tão diversificadas de uso da água podem ser analisadas como exemplos de mercantilização em seu sentido mais estrito é uma questão que precisa ser analisada cuidadosamente. Particularmente, o conceito de mercantilização capitalista pressupõe o conceito de propriedade privada, ou seja, o direito dos proprietários privados a trocar seus produtos no mercado. Há uma necessidade de se reter a distinção conceitual entre troca em geral e a forma particular de troca que caracteriza o modo mercantil de produção: a troca generalizada entre proprietários privados, com fins lucrativos, de produtos no mercado.

Nesse sentido, as formas de propriedade privada associadas à água, mesmo até hoje, foram, na maioria das vezes e com raras exceções, vinculadas ao direito de uso da água (para uso próprio ou para outros fins, inclusive de natureza produtiva), e não no sentido de trocar a água como uma mercadoria que é propriedade privada e que circula num mercado genuinamente capitalista. É verdade que há exemplos históricos e contemporâneos de "mercados de água" em todo o mundo, tais como os mercados de neve desenvolvidos na costa semiárida a leste da Espanha (MALLOL FERRÁNDIZ, 1989), os mercados de irrigação por água subterrânea nas Ilhas Canárias (AGUILERA KLINK, 2002; MACÍAS HERNÁNDEZ, 1990), Índia, Bangladesh ou 
Paquistão (MEINZEN-DICK, 2000; SADEQUE, 2000), ou os chamados mercados "maduros" ou "estabelecidos" de água na região sul da Austrália, Chile ou partes dos Estados Unidos como referido a seguir, embora devamos fazer uma advertência importante no que se refere ao verdadeiro significado de "mercados" neste contexto. Até que ponto as trocas realizadas nesses "mercados de água" são resultado de transações livres e espontâneas entre proprietários de direitos de propriedade sobre produtos da água em um processo de intercâmbio mercantil é uma questão que requer cuidadosa análise. Como sugerido pelas conclusões de um recente estudo que simpatiza com a implementação de políticas mercantis de administração da água que examinara exemplos contemporâneos de "mercados de água",

[...] Resultados eficientes de mercado só serão realizados em determinadas condições, tais como: um eficiente fluxo de informações de mercado, por exemplo, preço, demanda e fornecimento; direitos de propriedade seguros; facilitadores de mercado eficientes, e um esforço de pesquisa suficiente. Provavelmente o melhor exemplo de um mercado tão eficiente é o mercado de ações. Todavia, os mercados de água são desprovidos da maioria dessas características muito em função da natureza do recurso e do local do mercado, e, portanto, fadados a falhas de mercado. (BJORNLUND; MCKAY, 2002, p. 788)

De forma semelhante, Kaiser e Philips concluíram, no que se refere ao caso dos chamados mercados de transferência de água no Texas da atualidade, que, "na realidade, as transferências de água mais parecem negociações diplomáticas do que simples transações de mercadorias" (KAISER; PHILLIPS, 1998, p. 429-430). Estudos de mercados de água induzidos por políticas no Chile, que se transformaram num modelo de grande influência implementado em muitos outros países desde a década de 1990, também expuseram as falhas e mitos da pressuposição de que eles são realmente mercados capitalistas de água funcionais (DOUROJEANNI; JOURAVLEV, 1999; BAUER, 2004). Estes exemplos são muito relevantes porque os mercados de água australianos, chilenos e americanos acima mencionados são os principais casos recorrentemente discutidos na literatura dominante para apoiar a 
administração e alocação de água por meio de "mercados”. Entretanto, as evidências apontam que, em termos estritos, a troca generalizada de água como mercadoria em mercados genuinamente capitalistas é bastante rara. Por esta e outras razões a serem discutidas a seguir, é importante não se partir do pressuposto de que, uma vez que as atividades de controle, alocação e administração de água no mundo inteiro estão cada vez mais engolfadas de uma maneira ou de outra pela dinâmica do processo de mercantilização capitalista, então a água em si já se tornou uma mercadoria em seu sentido mais estrito.

\section{A água e o processo de racionalização: valorização e mercantilização}

Embora muitos elementos do processo de racionalização, dentre os quais se destacam a valorização e a mercantilização, não sejam exclusividade da experiência ocidental (e.g. GRAN, 1999; HOBSON, 2004; POMERANZ, 2000), foram as formas de desenvolvimento capitalista criadas no Ocidente as que vieram para dominar o sistema mundial nos últimos séculos. Neste contexto, o caso da água colocou imensos obstáculos ao avanço desses processos, que, segundo as percepções clássicas de Max Weber, são afirmados na crescente calculabilidade e previsibilidade da vida que tornam possível o controle humano do mundo (WEBER, 1946a, p. 139; 1946b, p. 215). De acordo com Weber, a calculabilidade e a previsibilidade são baseadas em conhecimento preciso e na subordinação e, afinal, no deslocamento de conhecimento e de sistemas de valores preexistentes (supersticioso, mítico, religioso etc.) pelas formas de organização e ação sociais características do capitalismo ocidental, em especial a produção e circulação capitalista de mercadorias. A esse respeito, pode-se discutir que, fundamentalmente, e a despeito dos avanços altamente sofisticados da ciência e tecnologia da água, em pleno século XXI a relação entre os humanos e a água se furta, em grande parte, ao processo de racionalização, até mesmo nos principais territórios da racionalidade capitalista (STRANG, 2004; 2005).

Isso pode ser ilustrado por uma recente declaração veiculada pelo Terceiro Relatório Mundial da Água da UNESCO com referência à natureza 
fragmentada, incompleta e até mesmo suspeita do conhecimento que a maioria dos países têm da água nos seus territórios:

Poucos países têm conhecimento de quanta água está sendo utilizada e para quais propósitos, a quantidade e qualidade da água disponível e o que pode ser retirado sem graves consequências ambientais, e quanto está sendo investido em administração e infraestrutura hídrica. A despeito da disponibilidade de sensoriamento remoto e tecnologias de sistemas de informação geográfica que podem simplificar o monitoramento e os relatórios, e apesar da crescente necessidade de tal informação num mundo cada vez mais complexo e que sofre rápidas alterações, sabe-se cada vez menos a cada década que passa. (UNESCO - WWAP, 2009, p. xi)

Acrescente-se a isso que o conhecimento fragmentado e incompleto a respeito da água estende-se ao tema crucial da propriedade da água, sua regulação e sua administração. A quase total falta de conhecimento de questões tais como quem possui qual água, ou quanta água é extraída quando, onde e por quem e para que fins em vastas extensões de território, quando não em países inteiros, expõe algumas das fragilidades do argumento de que a água já se tornou uma mercadoria. A calculabilidade e a previsibilidade são raramente estimadas na maioria das áreas de controle e administração da água, mesmo nos territórios das economias capitalistas avançadas. Este fato é especialmente fundamentado quando considerada a estreita relação entre o processo de mercantilização e de racionalização da propriedade incorporado no desenvolvimento dos direitos de propriedade privada claros e seguros que constituem a fundação dos mercados capitalistas de mercadorias. Com relação a isso, as sociedades humanas desenvolveram relações de propriedade baseadas na diversidade de formas da propriedade coletiva, sendo a água um exemplo fundamental. Não houve mudanças substanciais desde que North e Thomas discutiram que a lentíssima conversão de formas de propriedade coletivas do ar, florestas, água e outros recursos em formas privadas, comerciáveis - que, para eles, é principalmente devida ao subdesenvolvimento institucional e tecnológico - continua sendo o grande 
obstáculo para uma maior expansão do capitalismo ocidental (NORTH; THOMAS, 1973, p. 1-8, 91-101). Apesar dos grandes esforços mundiais desde o fim da década de 1980 no sentido de acelerar a racionalização capitalista das "águas comuns" do planeta por meio de massivos programas de privatização que incluíam a criação de direitos privados de água e "mercados de água", ${ }^{4}$ o progresso tem sido extremamente modesto devido, não em pequena medida, à oposição social e política à dita aceleração da invasão capitalista dos bens comuns (e.g. BAKKER, 2010; CASTRO, 2008; GOLDMAN, 1998; MCCARTHY, 2005; SWYNGEDOUW, 2005; URS; WHITELL, 2009).

A partir de outra perspectiva, o ritmo do processo de racionalização com relação às águas mundiais permanece incerto também em outros aspectos fundamentais, o que se reflete, entre outras questões, no fato de que, em pleno século XXI, ainda somos incapazes de responder a questões muito básicas como: Qual é o valor da água? Qual é a origem de seu valor? Qual é a natureza (econômica, social, política etc.) do valor ou valores que reconhecemos para a água e para bens e serviços baseados na água? De que forma são identificados e medidos ditos valores? É possível medi-los? o que deve ser incluído no "custo" da água e dos bens e serviços baseados na água? o "custo" é um custo para quem, especificamente? Por quê? As múltiplas funções da água como componente fundamental da biosfera impuseram grandes desafios aos processos de valorização e mercantilização a longo prazo em diferentes sociedades.

Nesse sentido, a abordagem de valores (e custos) da água na literatura especializada limita-se normalmente à dimensão econômica do problema que, por sua vez, é frequentemente reduzida à subdimensão do mercado. A despeito do crescente reconhecimento retórico da alta complexidade envolvida na estimativa do valor da água na literatura, na prática, os argumentos e instrumentos propostos seguem reproduzindo um número de pressupostos reducionistas e basicamente economicistas que informam as abordagens prevalecentes da administração e governo da água.

4 Nas palavras de um ex-funcionário das Nações Unidas e entusiasmado defensor da privatização da água: "o ato mais significativo da privatização pode ser a concessão de direitos de propriedade da água” (LEE, 1999, p. 93). 


\section{0 valor da água}

Recentemente, uma rica literatura que compreende uma grande variedade de áreas disciplinares tem sido publicada, discorrendo sobre os valores e a valorização da água havendo certo consenso de que os valores da água são multidimensionais, possuem vários níveis e até mesmo que esses valores são, muitas vezes, incomensuráveis. ${ }^{5}$ Por exemplo, um recente relatório sobre o estado mundial da água afirmou que:

$\mathrm{Na}$ qualidade de elemento vital físico, emocional e cultural, a água precisa ser considerada algo além de um mero recurso econômico. O compartilhamento da água é um imperativo ético e uma expressão da identidade e solidariedade humanas [...]. Valorar a água, incluindo a promoção da sustentabilidade hídrica e da diversidade cultural, o patrimônio, e o conhecimento relacionados com a água, é crítico para aprimorar nossa capacidade de adaptação a um mundo sempre mutável. A valorização econômica dos recursos hídricos precisa ser reconhecida dentro desse contexto mais amplo e mais complexo da valorização da água (UNESCO - WWAP, 2006, p. 403, 405).

5 Devido ao foco do artigo e o espaço limitado disponível, deixei de abordar uma série de questões importantes, que incluem as técnicas de valorização e de política de preços, tais como a análise de custo-benefício e outras alternativas como as técnicas de valorização baseadas em uma multiplicidade de critérios proposta por economistas ecológicos ou a economia hídrica dos economistas políticos evolucionários, que são assunto específico de uma vasta literatura (BLAMEY; COMMON, 1994; VAN DER BERGH; VAN DER STRAATEN, 1994; MERRETT, 1997; DINAR, 2000; VAN DER ZAAG; SAVENIJE, 2006; AGRAWALA; FANKHAUSER, 2008; ARNELL, 2009; entre outros). Tampouco discuti algumas das ferramentas conceituais mais importantes sendo desenvolvidas para a captação da água "oculta" que escapou historicamente - e que, em grande parte, continua escapando - da valorização econômica dos usos da água de uma maneira completa. Trata-se de conceitos como água "virtual" cunhado por Allan (1998; 2002) e elaborações mais recentes desta noção com relação ao conceito da "pegada hídrica" (CHAPAGAIN; HOEKSTRA, 2004; HOEKSTRA, 2006; 2007). Também deixei de lado outras ferramentas conceituais importantes, como "dívida ecológica" ou "trocas ecologicamente desiguais", colocadas por economistas ecológicos para lidar com as desigualdades intra e intertemporais envolvidas nas trocas entre o hemisfério norte desenvolvido e o resto do planeta (e.g. GUHA; MARTINEZ-ALIER, 1997; MARTINEZ-ALIER, 2002), que incluem desigualdades no uso da água, que continuam a ser desconsideradas nos debates dominantes sobre políticas da água. 
No entanto, apesar do reconhecimento formal cada vez maior dos valores multidimensionais da água ilustrados pela afirmativa, pode-se dizer com segurança que o entendimento prevalecente do valor da água nas culturas capitalistas ocidentais é baseado em três principais pressupostos reducionistas que refletem contradições e tensões fundamentais no que se refere ao processo de racionalização. O primeiro pressuposto é que a principal ou mesmo única fonte do valor da água é o trabalho humano. ${ }^{6}$ Em outras palavras, apesar das muitas discussões sobre a multidimensionalidade das funções e valores da água, na prática não há reconhecimento das dimensões pré-sociais (especialmente pré-econômicas) do valor da água, o que não ocorre somente no caso da água - prevalece também na abordagem do valor da Natureza em geral (sobre esse assunto, ver o debate de, entre outros: BENTON, 1989; BURKETT; FOSTER, 2006; GIRI, 2004; MARTINEZ-ALIER, 2002; MURPHY, 1997; O'CONNOR, 1998). Uma importante consequência desse pressuposto é que, independentemente dos variados tipos de fontes ou usos da água, da extração de água renovável de superfície ao bombeamento da água subterrânea fóssil (quase não renovável), do uso da água para suprir necessidades humanas essenciais em vilas pequenas à irrigação comercial em larga escala, a hidrocultura, a produção hidroenergética etc., o valor da água seria sempre estimado como uma combinação de capital (compreendido como trabalho passado ou morto) e o custo do trabalho. Ou seja, nas abordagens prevalecentes, a água em si é gratuita, uma dádiva da Natureza, como na clássica definição de Alfred Marshall: "o material e as forças que a Natureza despende gratuitamente para ajudar o homem, em terra ou água, em ar, em luz e calor" (MARSHALL, 2009, p. 115). ${ }^{7}$ Um segundo pressuposto é que o volume de água doce utilizável é ilimitado, eterno, que se

6 Ainda por falta de espaço, não foi possível desenvolver neste artigo a discussão da teoria do valor, central no conceito de mercantilização. Sobre este assunto, ver, entre outros: CASTREE, 2003; GIRI, 2004; LAPAVITSAS, 2004.

7 Todavia, os fundamentos que sustentam o pressuposto de que a Natureza é uma dádiva gratuita para os seres humanos estão presentes nas principais vertentes do legado intelectual ocidental, e alguns de seus aspectos centrais podem ser rastreados pelo filão da tradição grega e judaico-cristã. Uma recente crítica dos continuados debates a respeito das origens intelectuais desta noção da Natureza como uma dádiva gratuita para os seres humanos pode ser encontrada, por exemplo, em DUNLAP et al. 2002; REDCLIFT; BENTON, 1994. 
purifica automaticamente, ainda que a sua verdadeira disponibilidade seja sujeita a distribuições geográficas e temporais irregulares. As crenças profundamente arraigadas subjacentes a este pressuposto talvez tenham suas origens na Teogonia de Hesíodo, que registrou o antigo mito de Okeanus, um rio de infinitas águas doces circundando o planeta (BRYANT, 1986, p. 282). Embora hoje o pressuposto da água doce como um prêmio ilimitado seja cada vez mais difícil de se defender em discussões racionais, quanto mais à luz da preponderante evidência da redução ou mesmo exaustão das fontes de água doce limpa no planeta, ${ }^{8}$ ele se mantém estabelecido nas práticas diárias e na cultura da grande maioria dos seres humanos. ${ }^{9}$ Além disso, um terceiro pressuposto que dominou o pensamento e a prática no que se refere à água no Ocidente desde a Revolução Industrial é que a água é um "recurso", refletindo a redução das funções e valores multidimensionais da água a ser somente um fator de desenvolvimento humano.

Esses pressupostos estão subjacentes ao pensamento e prática dominantes com relação à água, inclusive quando a água desempenha o papel de sumidouro ambiental (por exemplo, a água como receptora direta ou indireta de fluxos poluentes), meio ou apoio (e.g., para recreação, navegação ou pescaria), ou fator de risco (como enchentes, transmissão de doenças etc.). o primeiro e o terceiro pressupostos, em boa parte, resultam do processo de

8 Embora o volume total de águas no planeta permaneça o mesmo, a quantidade relativa de água doce disponível de qualidade adequada para sustentar a biosfera vem sendo seriamente afetada em muitas regiões e a situação está piorando diante da crescente extração, poluição e deterioração generalizada das fontes de água doce. Conforme descrito no Terceiro Relatório da Água da UNESCO, "o padrão e a intensidade da atividade humana vêm impactando o papel da água como agente ambiental de primeira ordem quantitativa e qualitativamente. Em algumas áreas, a degradação e a poluição de bacias hidrográficas e aquíferos associados economicamente importantes ultrapassaram os limites e não têm retorno. Lidar com um futuro sem sistemas de recursos hídricos confiáveis é agora uma perspectiva real em algumas partes do mundo" (UNESCO - WWAP, 2009, p. xxiii).

9 Um indicador desta característica é o desperdício de água causado por infraestrutura ultrapassada ou defeituosa. Um recente relatório da situação dos 27 países da União Europeia mostrou que, no uso doméstico e público da água, que corresponde a 17\% do total de extrações de água, seria possível economizar até $50 \%$ da água que atualmente está sendo desperdiçada devido a tubulações com vazamento e outros problemas. Na agricultura, que emprega $24 \%$ das extrações totais, a economia seria de 15 a 60\%, dependendo das condições regionais e setoriais. A indústria usa cerca de $15 \%$ do total das extrações e estima-se que 15 a $90 \%$ dessa água poderiam ser economizados (DWORAK et al., 2007, p. 6-7). 
racionalização pelo qual a valorização da água é motorizada pela dinâmica da produção e acumulação capitalistas, deixando de lado ou ultrapassando sistemas de valores e racionalidades alternativos. No entanto, a displicência e o desperdício vinculados ao segundo pressuposto representam uma grande contradição - um elemento "irracional" - no processo de racionalização. Por um lado, a extração não controlada da água no planeta pode ser considerada uma permanente reapresentação da acumulação primitiva, também verificada com relação a outros "recursos naturais" (ver, por exemplo, MANSFIELD, 2004), que assegura acesso gratuito ou muito barato, muitas vezes por meio do intercâmbio ecológico desigual, a um fator de produção tão crucial como a água. Por outro lado, a ilusão da abundância ilimitada da água, de sua característica autolimpante e da eterna disponibilidade se opõe à calculabilidade e à previsibilidade necessárias ao funcionamento da mercantilização capitalista. No processo, a mercantilização de águas ainda não mercantilizadas emerge como uma nova fronteira nesse desenvolvimento a longo prazo e traz à tona a natureza contraditória da racionalização capitalista. ${ }^{10}$

O entendimento dominante da Natureza arraigado nesses pressupostos foi habilmente captado em recente livro da história do Niágara Falls, um verdadeiro exemplo de como as naturezas são socialmente construídas:

Na década de 1890, quando a cachoeira estava sendo aproveitada, uma torrente de artigos sobre a energia do Niágara chegou às bancas de revistas [...] promovendo a imagem do Niágara como um bônus interminável. O periódico Popular Science Magazine declarou em setembro de 1894 que "as pessoas de um modo geral têm a ideia de que a energia proveniente das águas do Niágara é inesgotável, e provavelmente é, em relação ao requerido pelas necessidades humanas". [...] Em 1903, o Harper's Weekly alardeava que o Niágara se revelava, como se esperava, ser "uma fonte ilimitada de energia barata". (STRAND, 2008, p. 163-164, 175)

10 No debate a respeito das contradições internas do processo de racionalização capitalista do meio ambiente, ver, entre outros: MURPHY, 1994; SCHNAIBERG; GOULD, 1994. 
Não foi talvez surpresa que a área do Niágara Falls tenha se tornado um dos locais que deram vazão a movimentos de justiça ambiental. Surgidos na década de 1970, esses movimentos, protestando contra o impacto da poluição sobre a saúde proveniente de atividades industriais atraídas pela promessa de energia hidráulica barata e ilimitada, significativamente contribuíram para a reavaliação radical das políticas ambientais em todo o mundo (GIBBS, 2002; LIVESEY, 2003). Evidentemente, com o tempo, a significância do Niágara Falls foi diminuída por outras infraestruturas hidráulicas gigantescas, como a Hidrelétrica de Itaipu na fronteira do Brasil com o Paraguai, considerada uma das "Sete Maravilhas do Mundo Moderno" pela American Association of Civil Engineering na década de 1990 (ASCE, 2011), ou a Hidrelétrica de Três Gargantas na China, concluída em 2003, hoje a maior do mundo. No entanto, foi sugerido, em recente artigo sobre a engenharia hidráulica chinesa, que "o combustível da hidrelétrica é 'essencialmente infinito", ou seja, o pressuposto da existência de uma fonte inesgotável e ilimitada de água se mantém mais forte que nunca (HUANG; YAN, 2009, p. 1653). Assim também as duradouras crenças humanas nas propriedades infinitamente autopurificadoras da água podem ser parte da explicação de por que uma grande proporção de água de esgoto no planeta ainda é descarregada sem tratamento, ou sem o tratamento adequado, no meio ambiente, o que não é uma exclusividade de países pobres que não podem se dar ao luxo de possuir caras tecnologias de tratamento. ${ }^{11} \mathrm{~A}$ esse respeito, há fortes evidências para se discutir que, a despeito do progresso observado nas últimas décadas no desenvolvimento de uma compreensão mais sofisticada do "valor" da água, e apesar do crescente reconhecimento retórico da complexidade desse valor, os pressupostos profundamente arraigados considerados acima

11 Por exemplo, cerca de $80 \%$ da água de esgoto urbana mundial, muitas vezes incluindo industriais perigosos, são descarregados sem qualquer tratamento (UNESCO - WWAP, 2009, p. 141). Entrevistas com especialistas e funcionários da área durante a nossa pesquisa não raro advogam que grandes corpos aquíferos como rios, lagos e mares têm propriedades quase ilimitadas de autopurificação, o que justificaria a descarga de água de esgoto não tratada na natureza. A descarga de esgoto no mar aberto vem sendo praticada até mesmo por países ricos até recentemente (e.g. WHILELAW; ANDREWS, 1988), e esta prática ainda prevalece no mundo inteiro. Um dos maiores impactos sobre os corpos aquíferos mundiais é a eutrofização resultante de imensas descargas de efluentes não tratados (e.g. KHAN; ANSARI, 2005). 
continuam sendo os princípios que fundamentam as formas predominantes de valorização da água no mundo inteiro. Isto se deve à expansão global e à consolidação das formas de gestão e uso de água baseadas nos pressupostos da gratuidade, infinidade, capacidade de autopurificação sem limites da água, e de que ela é meramente um recurso e um sumidouro para o crescimento econômico. Esta abordagem dominante provocou transformações quantitativas e qualitativas sem precedentes em nossa relação com a água e com a natureza de forma mais geral nas últimas décadas, como pondera John McNeill:

No século XX, a humanidade alterou a hidrosfera como nunca antes. Usamos e desviamos água numa escala nunca testemunhada em tempos idos. [...] As mudanças físicas impostas ao ciclo hidrológico tiveram vastas consequências para a vida selvagem, para as pessoas e para as sociedades, e, na medida em que coagimos o futuro para nos liberar do passado, as consequências se estenderam também para a posteridade. (MCNEILL, 2000, p. 190-191)

A crescente conscientização a respeito das reais ou potenciais consequências dessas transformações antropogênicas de longo alcance da hidrosfera provocou um debate cada vez mais expressivo a respeito da valorização da água e da própria Natureza em termos mais gerais. Embora apelos para a adoção de sistemas mais abrangentes de valorização da Natureza já sejam de longa data, ${ }^{12}$ provavelmente só na década de 1990 é que os debates sobre a valorização da água passaram por uma transformação qualitativamente significativa em termos globais. A reviravolta foi talvez marcada pela Declaração de Dublin sobre água e desenvolvimento sustentável de 1992 (UNITED NATIONS [UN], 1992). Particularmente, o Primeiro Princípio da Declaração de Dublin afirmava que "a água doce é um recurso finito e vulnerável, essencial para a manutenção da vida, do desenvolvimento e

12 Georgescu-Roegen sugeriu em seu debate a respeito da necessidade de se introduzir a consideração de fluxos materiais na análise da economia que talvez o primeiro a propor tal noção tenha sido o físico alemão em fins do século XIX G. Helm (GEORGESCU-ROEGEN, 1971, p. 283). 
do ambiente", ao passo que o Quarto Princípio sustentava que "a água tem um valor econômico em seus mais diversos usos, e deveria ser reconhecida como um bem econômico" (UN, 1992). No caso do Primeiro Princípio, o reconhecimento da finitude e vulnerabilidade da água refletiu a crescente influência das questões ecológicas nos círculos de políticas internacionais, que foi propulsionado pelo debate sobre o "desenvolvimento sustentável" desencadeado pela criação da Comissão Mundial sobre o Meio Ambiente e Desenvolvimento (WEDC) em 1984 e pela subsequente publicação do relatório da comissão intitulado Nosso Futuro Comum (WCED, 1987). Quanto ao Quarto Princípio, embora o reconhecimento do valor econômico da água tenha sido devidamente comemorado por muitos como um passo à frente no desenvolvimento de um entendimento mais exaustivo do valor da água, as reais aplicações do princípio muitas vezes contribuíram para a exacerbação do reducionismo prevalecente e do pensamento unidimensional. Primeiramente, a renovada ênfase na necessidade de se reconhecer o valor econômico da água muitas vezes levou, na prática, a uma abordagem reducionista pela qual: a) as funções e valores multidimensionais da água tendem a se transmutar em um equivalente econômico "amigável" para as políticas públicas dominantes, ou simplesmente são abandonados; e b) a complexidade econômica em si tende a ser diluída na prosaica instrumentalidade de considerações mercadológicas de curto prazo. Em segundo lugar e intimamente relacionados com os pontos anteriores, embora o ilusório pressuposto da abundância ilimitada da água tenha sido criticamente exposto no Primeiro Princípio, na prática esse pressuposto, não raro, foi substituído pela noção igualmente falaciosa de que a mercantilização do governo e da gestão da água não só solucionaria a maioria dos dilemas de alocação, como também os intricados problemas colocados pela valorização da água em diferentes contextos. É isso que se encontra no cerne dos debates contemporâneos sobre "valorização", "precificação" e "mercantilização" da água (ver, entre outros: WHITTINGTON et al., 1990; LEE; JOURAVLEV, 1998; MOSS et al., 2003; ADDAMS et al., 2009).

Com relação a isso, podemos ainda ponderar que, apesar das importantes iniciativas e de um inegável grau de progresso no debate a respeito da valorização da água, a preponderante abordagem reducionista se mantém em boa 
parte irredutível. Um claro indicador é o fato de que, embora referências à complexidade e multidimensionalidade estejam envolvidas na valorização da água, muito da literatura especializada continua a reproduzir os antigos pressupostos. Por exemplo, consideremos a discussão sobre os princípios e critérios de identificação do "valor total" e "custo total" da água desenvolvida por membros do Comitê Assessor da Parceria Global da Água (GWP em inglês), um think tank de política pública mundialmente influente sediado na Suécia. Os autores estão cientes de que, mesmo levando em consideração todos os "componentes de custos" que eles conseguem identificar nas atividades de gestão da água, o assim chamado "valor total" da água não é propriamente representado, que, em si, já supera o seu custo total (ROGERS; BHATIA; HUBER, 1998, p. 6-14). Eles defendem que o "valor total" é a soma do "valor econômico" mais o "valor intrínseco" da água. Todavia, enquanto eles fornecem indicadores para o "valor econômico", tais como o "valor para o usuário", "benefícios líquidos de fluxos de retorno", "benefícios líquidos de usos indiretos" e "ajustes para objetivos sociais", eles deixam a categoria "valor intrínseco" sem explicação (ROGERS; BHATIA; HUBER, 1998, p. 13). Assim, os autores falham na identificação de critérios para a avaliação da lacuna existente entre o custo total e o valor total, e, na verdade, eles nem mesmo conseguem explicar o que seria exatamente o seu conceito de valor da água. Este é um exemplo eloquente do reducionismo economicista dominante uma vez que, para os autores, o valor econômico da água é quase equivalente ao seu valor total, sendo que eles jogam todas as outras dimensões possíveis do valor da água na categoria residual do "valor intrínseco".

Vale notar que, como os autores reconhecem,

o conceito de valor econômico não atribui qualquer valor a questões como planejamento e gestão responsável de recursos, valores de legado e valores de pura existência. Embora sejam questões de difícil avaliação, elas representam conceitos válidos e realmente refletem o valor real associado ao uso (ou não uso) da água. (ROGERS; BHATIA; HUBER, 1998, p. 14)

Assim sendo, o reconhecimento dos valores da água fora do processo econômico permanece basicamente retórico. Além disso, em artigo 
publicado posteriormente pelos mesmos autores, os pressupostos subjacentes tornaram-se mais transparentes quando afirmam que "a água é um bem econômico" (ROGERS; SILVA; BATHIA, 2002). Portanto, a despeito da retórica em contrário, na prática, o entendimento comumente aceito da água como uma dádiva gratuita da natureza e como principalmente um recurso econômico permanece solidamente arraigado. A esse respeito, um estudo mais recente elaborado por um grupo de economistas para o Terceiro Relatório Mundial da Água da UNESCO em 2009 ilustra algo além. Seu trabalho também reconhece claramente que questões como "necessidades ecológicas" ou o "valor intrínseco da água" precisam ser levadas em consideração, mas, quando eles apresentam sua análise de "custos da água", essas categorias desaparecem e eles se concentram na discussão da convencional combinação dos custos trabalhistas e de capital:

Quase todas as atividades relativas à água, sejam elas estruturais (infraestrutura) ou não (planejamento, coleta de dados, regulamentação, educação pública etc.), exigem fundos para o desenvolvimento, implementação e execução [...] Embora a água seja muitas vezes descrita como "dádiva da natureza", o controle e gestão da água para as necessidades humanas e ecológicas implicam custos financeiros. Esses custos são frequentemente em muito ignorados, subestimados ou carecem de recursos suficientes, resultando em negligência e carência de importantes funções e ativos, enquanto os ativos e serviços existentes deterioram. [...] Os custos associados a essas funções são custos de capital (investimento) ou custos recorrentes anuais, tanto variáveis quanto fixos. Para operar adequadamente, o setor hídrico precisa cobrir todos os custos - e não somente aqueles das grandes infraestruturas físicas - de forma sustentável. Isso significa assegurar finanças confiáveis e previsíveis da arrecadação governamental (impostos), venda de serviços de água ou compromissos de auxílio de longo prazo. (CONNOR et al., 2009, p. 56-57)

Os exemplos acima mostram que, apesar do reconhecimento formal do que poderia ser chamado de fontes pré-sociais do valor da água, parece 
que há obstáculos intransponíveis para se vencer as prescrições tradicionais. Contudo, a valorização da água está subjacente ou mesmo subordinada a um conjunto de processos socioeconômicos e políticos mais amplo que determina como a água é realmente valorizada na prática. Nessa perspectiva, a continuada prevalência de formas de valorização fundamentadas em pressupostos convencionais referentes à fonte do valor da água reflete a configuração do poder entre sujeitos epistêmicos, interesses materiais, além dos valores e fins relativos à água e à natureza de forma mais generalizada, que são divergentes, rivais, e muitas vezes irreconciliáveis. Como sugerido por Funtowicz e Ravetz em seu artigo intitulado "Quanto vale o canto dos pássaros?":

O ameaçado canto dos pássaros representa um novo problema de valorização em que as medições não podem fingir ser independentes de metodologia e ética. [...] Uma nova linguagem enriquecida que não é dominada pela visão global de um tipo particular de interessados (expresso no padrão monetário) viria à tona quando negociadores reconhecerem a irredutível complexidade das questões que estão em jogo. Isso implica uma pluralidade de perspectivas e valores legítimos, inclusive a do insubstituível canto dos pássaros. (FUNTOWICZ; RAVETZ, 1994, p. 198-199) ${ }^{13}$

A transformação dos mecanismos por meio de quais valores são identificados e atribuídos para transcender os sistemas unidimensionais de valorização propostos por Funtowicz e Ravetz exige o reconhecimento da existência de uma pluralidade de racionalidades, interesses materiais, perspectivas, significados e conhecimento que não podem desaparecer como por capricho e encanto de truques metodológicos. Por exemplo, um ecologista científico pode levantar a discussão de que as estimativas do valor da água precisam abandonar o entendimento da água como um recurso econômico ilimitado e que considerações tais como limites ecológicos,

13 Para outras contribuições a este debate de uma perspectiva semelhante, ver também DALY, 1986; 1990; MARTINEZ-ALIER, 2002. 
insustentabilidade, direitos transespecíficos e transtemporais ou questões culturais precisam ser incorporadas ao processo de valorização. Segundo o hidrólogo espanhol e ecologista Javier Martínez Gil:

Até que ponto e em que circunstâncias concretas é moralmente admissível mudar essas funções do meio natural, dos rios, para transformá-las em um simples recurso? Como são estabelecidos os limites? Quem fará a distinção entre [água] como uma mercadoria temporária e o valor permanente que precisa ser preservado? (MARTÍNEZ GIL, 2003, p. 7) ${ }^{14}$

Por outro lado, especialistas a favor do livre mercado hídrico podem enfatizar considerações como eficácia econômica, custo-benefício, a existência de direitos a propriedade privada da água e a criação de mercados hídricos. Como alguns autores alinhados a essa linha de pensamento escreveram em defesa de sua própria interpretação do Quarto Princípio da Declaração de Dublin:

Finalmente, na Declaração de Dublin [...] a retórica dos encontros internacionais sobre a gestão de recursos hídricos reconheceu que a água é essencialmente um bem econômico. [...] Esta não é uma proposta muito nova. Os economistas interessados em gestão de recursos hídricos vêm debatendo há muito a necessidade de reconhecer que a água é um bem econômico e não tratá-la como detentora de uma importância única, mas como um bem em meio a tantos outros. [...] Se a água é um bem econômico, então deveria ser possível governar a sua alocação por meio do mercado. (LEE; JOURAVLEV, 1998, p. 7) ${ }^{15}$

14 É importante contextualizar a afirmação de Martínez Gil: a Espanha é o país com o maior número de represas por quilômetro quadrado e per capita do mundo, e ele escreve a partir de um contexto de acalorado debate político desencadeado por planos governamentais de construir centenas de novas represas e outras infraestruturas de grande porte, tais como transposições de rios. Ver também ARROJO AGUDO E MARTÍNEZ GIL, 1999; FUNDAÇÃO NOVA CULTURA DA ÁGUA, 2005.

15 Uma versão mais radical desta posição pode ser encontrada, por exemplo, em SEGERFELDT, 2005. 
As perspectivas do hidrólogo-ecologista e dos especialistas do mercado livre da água ilustram a natureza contraditória dos processos de valorização da água, que ainda poderia ser ilustrada pela incorporação das variadas perspectivas do valor da água fundamentadas não somente nas divisões disciplinares que caracterizam o conhecimento científico, mas ainda na cultura, classe, gênero e outros mecanismos de diferenciação e poder social (e.g. AKPABIO, 2011; BALL, 1999; BERRY, 1998; FARUQUI; BISWAS; BINO, 2001; BOELENS; DÁVILA, 1998; HUE, 2006; HUNDLEY, 1996; GHOSH, 2007; GYAWALI; DIXIT, 2001; MATSUI, 2005; MEYER, 1984; MORAES; PERKINS, 2007; MOSS et al., 2003; NEIBURG; NICAISE, 2009; PRITCHARD, 2004; TRENTMANN; TAYLOR, 2006; SEMENTELLI, 2008; WILLIAMS; FLOREZ, 2002). Portanto, embora dinâmica constante dos processos de expansão da mercantilização capitalista continue reduzindo a água à função de matéria-prima, fator produtivo, e bem privado que pode ser economicamente explorado, persistem as racionalidades alternativas que se expressam por meio de uma complexa gama, não raro incomensurável, de valores sociais, funções e interesses materiais que contribuem para a explanação do caráter incompleto e fragmentado dos processos de racionalização capitalista concernentes à água.

\section{Conclusões}

A mercantilização capitalista de naturezas é um processo histórico continuado que vem engolfando cada vez mais amplas áreas da atividade humana mas que, ao mesmo tempo, é incompleta e pontuada por enormes obstáculos, atrasos e muitas vezes até entraves significativos, resultantes, especialmente, da resistência de prolongadas lutas sociais contra maiores incursões da ordem capitalista. Enquanto teoricamente se pode dizer que a abrangente dinâmica de controle e gestão da água é motorizada pelo processo de mercantilização, empiricamente só podemos formular o problema por meio de perguntas de cunho investigativo, tais como: Até que ponto, onde e como a água se tornou uma mercadoria? Qual etapa do processo capitalista de mercantilização é refletida na produção de água engarrafada? É a mesma etapa refletida na extração da água fluvial de superfície ou na 
exploração comercial de icebergs árticos ou no bombeamento de aquíferos subterrâneos fósseis? Como discuti neste artigo, as respostas a essas e a muitas outras questões provenientes da análise da incompletude e do caráter fragmentário do processo de racionalização capitalista, e, em especial, dos processos de valorização e mercantilização, estão longe de serem respostas prontas e diretas.

De outra perspectiva, embora a maior parte das sociedades humanas tenha permitido vender água, formalmente o acesso à água tem sido amplamente regulado por princípios normativos que até hoje dão prioridade ao uso comum ou público mais do que ao privado, mesmo quando formas de direitos de propriedade privada relativos à água estão em pauta. Além disso, a maior parte das sociedades também formalizou, de uma forma ou de outra, o princípio de que a água para usos essenciais - tanto por humanos quanto por animais - não pode ser negada a quem quer que seja, mesmo a quem não possa pagar pelo acesso. ${ }^{16} \mathrm{Na}$ verdade, pode-se argumentar que as relações sociais envolvidas na circulação da água para uso essencial humano na maioria das sociedades, mesmo até hoje, tem tomado mais a forma de dádiva, ou de um bem comum, social ou público, e não a de uma propriedade privada que pode ser comercializada em mercados. ${ }^{17}$ Certamente não se pode negar que, em muitos casos, a água vem sendo tratada como uma mercadoria, mesmo em seu mais estrito sentido, como no caso da água comercializada em garrafas. Além disso, a água é parte integrante de qualquer processo de produção e comércio de mercadorias, embora ela seja sistematicamente incorporada como uma matéria-prima gratuita ou como um sumidouro ambiental, raramente como uma mercadoria de propriedade

16 Naturalmente, não houve congruência entre os princípios formais e a real universalização do acesso à água, que continua sendo uma das formas mais extremas de desigualdade e injustiça social no mundo inteiro. Faço referência a esse tópico em especial em outro trabalho (CASTRO, 2008, p. 2009).

17 Este princípio foi recentemente sancionado pela primeira vez, após longos e amargos debates, pela Assembleia Geral das Nações Unidas que declarou que "água potável limpa e segura e saneamento são um direito humano essencial à completa fruição da vida, entre outros direitos humanos" (UN, 2010). Vale mencionar que 41 países se abstiveram de votar, sendo que a maioria destes havia se oposto abertamente à proposta de declaração da água como um direito humano durante muitos anos de debate. Ver: AMNESTY INTERNATIONAL, 2003. 
privada comercializada no mercado. A noção de mercados capitalistas de água permanece amplamente como uma expressão de desejo e como um projeto político antes, que como um fato empiricamente demonstrável.

Há pouca dúvida ou nenhuma de que a mercantilização da produção é o modo dominante no sistema mundial, mas isso não significa que tudo o que é atualmente produzido e comercializado por seres humanos assumiu a forma de mercadoria. Nem tudo o que é "produzido" e comercializado de uma forma ou de outra corresponde às características-chave da forma "mercadoria", em particular a de se sujeitar ao regime de direitos de propriedade privada e de ser objeto de troca mercantil em mercados genuinamente capitalistas. O caso da água é um notável exemplo.

Não é surpresa que os promotores contemporâneos do capitalismo especulativo tendam a expressar claramente o fato de que a maior parte da água no planeta permanece não mercantilizada. Para eles, a hidrosfera, especialmente seu componente de água doce, configura um novo horizonte para o desenvolvimento capitalista: eles argumentam que a água está evoluindo para se tornar a "próxima commodity" (DUGAN; FISHER, 2006; GEMAN; KANYINDA, 2007; HUDSON, 2007; ROYAL BANK OF SCOTLAND, 2008). E eles estão falando sério.

\section{Referências}

ADDAMS, L. et al. Charting Our Water Future. Economic Frameworks to Inform Decision-Making. The 2030 Water Resources Group, McKinsey. 2009. Disponível em: <http://www.mckinsey.com/App_Media/Reports/Water/ Charting_Our_Water_Future_Full_Report_001.pdf_. Acesso em: novembro 2012.

AGRAWALA, S.; FANKHAUSER, S. (Ed.). Economic Aspects of Adaptation to Climate Change. Costs, Benefits and Policy Instruments. Paris: Organisation for Economic Co-Operation and Development (OECD), 2008.

AGUILERA KLINK, F. Los Mercados del Agua en Tenerife. Bilbao: Bakeaz, 2002. 
AKPABIO, E. M. Water and people: perception and management practices in Akwa Ibom State, Nigeria. Society and Natural Resources, 24, p. 584-596, 2011. doi: 10.1080/08941920903496945. Acesso em: novembro 2012.

ALLAN, J. A. Watersheds and problemsheds: Explaining the absence of armed conflict over water in the Middle East. Middle East Review of International Affairs, v. 2, n. 1, p. 49-51, 1998. Disponível em: <http://meria. idc.ac.il/æ. Acesso em: novembro 2012.

ALLAN, J. A. The Middle East Water Question. Hydropolitics and the Global Economy. London; New York: Tauris, 2002.

ALMELING, R. Selling genes, selling gender: egg agencies, sperm banks, and the medical market in genetic material. American Sociological Review, 72, p. 319-340, 2007.

AMNESTY INTERNATIONAL. Human Right to Water. Document IOR 10/002/2003. London: Amnesty International, 2003. Disponível em: <http://www.amnesty.org/en/library/info/IOR10/002/2003/en_. Acesso em: novembro 2012.

ARNELL, N. Costs of adaptation in the water sector. In: PARRY, M. et al. (Ed.). Assessing the Costs of Adaptation to Climate Change: A Review of the UNFCCC and Other Recent Estimates. London: International Institute for Environment and Development and Grantham Institute for Climate Change, Imperial College, 2009. p. 40-50.

ARROJO AGUDO, P.; MARTÍNEZ GIL, F. J. (Ed.). El Agua a Debate desde la Universidad. Hacia una Nueva Cultura del Agua. Zaragoza: Institución Fernando el Católico, Diputación de Zaragoza, 1999.

AMERICAN ASSOCIATION OF CIVIL ENGINEERS (ASCE). Seven Wonders. 2011. Disponível em: <http://www.asce.org/Content.aspx?id=2147487305>. Acesso em: novembro 2012. 
BAKKER, K. An Uncooperative Commodity Privatizing Water in England and Wales. Oxford: Oxford University Press, 2004.

BAKKER, K. Privatizing Water. Governance Failure and the World's Urban Water Crisis. Ithaca; London: Cornell University Press, 2010.

BALL, P. H2O. A Biography of Water. London: Phoenix, 1999.

BAUER, C. J. Siren Song: Chilean Water Law as a Model for International Reform. Washington DC: RFF Press, 2004.

BENTON, T. Marxism and natural limits - an ecological critique and reconstruction. New Left Review, 178, p. 51-86, 1989. Disponível em: <http://www. newleftreview.org>. Acesso em: novembro 2012.

BERRY, K. A. Race for water? Native Americans, eurocentrism, and western water policy. In: CAMACHO, D. E. (Ed.). Environmental Injustices, Political Struggles. Race, Class and the Environment. Durham, NC; London: Duke University Press, 1998. p. 101-124.

BJORNLUND, H.; McKAY, J. Aspects of water markets for developing countries: experiences from Australia, Chile, and the US. Environment and Development Economics, 7, p. 769-795, 2002. doi: 10.1017/ S1355770X02000463. Acesso em: novembro 2012.

BLAMEY, R. K.; COMMON, M. Sustainability and the limits to pseudo market valuation. In: VAN DER BERGH, J. C. J. M.; VAN DER STRAATEN, J. Toward Sustainable Development. Concepts, Methods, and Policy. Washington DC; Covelo, California: International Society for Ecological Economics and Island Press, 1994. p. 165-205.

BOELENS, R.; DÁVILA, G. (Ed.). Searching for Equity. Conceptions of Justice and Equity in Peasant Irrigation. Assen, The Netherlands: Van Gorcum, 1998. 
BOND, P. Water commodification and decommodification narratives: pricing and policy debates from Johannesburg to Kyoto to Cancun and back. Capitalism Nature Socialism, 15, p. 17-25, 2004. doi: 10.1080/1045575032000188957. Acesso em: novembro 2012.

BRYANT, J. M. Intellectuals and religion in ancient Greece: notes on a Weberian theme. The British Journal of Sociology, 37, p. 269-296, 1986.

BURKETT, P.; FOSTER, J. B. Metabolism, energy, and entropy in Marx's critique of political economy: beyond the Podolinsky myth. Theory and Society, 35, p. 109-156, 2006.

CANADA DEPARTMENT OF ENVIRONMENT. Prohibition of Bulk Water Removal. Quebec, 2010. Disponível em: <www.ec.gc.ca>. Acesso em: novembro 2012.

CAPONERA, D. A. Water Laws in Moslem Countries. Rome: Food and Agriculture Organization (FAO), 1954.

CASTREE, N. Commodifying what nature?. Progress in Human Geography, 27, p. 273-297, 2003. doi: 10.1191/0309132503ph428oa. Acesso em: novembro 2012.

CASTRO, J. E. Neoliberal water and sanitation policies as a failed development strategy: lessons from developing countries. Progress in Development Studies, 8, p. 63-83, 2008. doi: 10.1177/146499340700800107. Acesso em: novembro 2012.

CASTRO, J. E. Systemic conditions and public policy in the water and sanitation sector. In: CASTRO, J. E.; HELLER, L. (Ed.). Water and Sanitation Services. Public Policy and Management. London: Earthscan, 2009. p. 19-37. 
CASTRO, J. E. Private-sector participation in water and sanitation services: the answer to public sector failures?. In: RINGER, C.; BISWAS, A.; CLINE, S. A. (Ed.). Global Change: Impacts on Water and Food Security. Berlin; Heidelberg: Springer, 2010. p. 169-193.

CHAPAGAIN, A. K.; HOEKSTRA, A. Y. Water Footprints of Nations Vol. 1. The Value of Water Research Report Series, No 16. Delft: United Nations Educational Scientific and Cultural Organization (UNESCO) - Institute for Water Education, 2004. Disponível em: <http://www.unesco-ihe.org/ Value-of-Water-Research-Report-Series/Research-Papers>. Acesso em: novembro 2012.

CIVIC, M. A. A comparative analysis of the Israeli and Arab water law traditions and insights for modern water sharing agreement. Denver Journal of International Law and Policy, 26, p. 437-452, 1998. Disponível em: <http:// lawlib.wlu.edu/LJ/index.aspx?mainid=223>. Acesso em: novembro 2012.

CONNOR, R. et al. Financing - the missing link. In: UNITED NATIONS EDUCATIONAL SCIENTIFIC AND CULTURAL ORGANIZATION (UNESCO) World Water Assessment Programme. Water in a Changing World. The United Nations World Water Report 3. Paris; London: UNESCO; Earthscan, 2009. p. 56-67. Disponível em: <www.unesco.org/water/wwap/wwdr/wwdr3/>. Acesso em: novembro 2012.

CORTÉS, H. Second Letter to Charles V. Internet Modern History Sourcebook, 1520. Disponível em: <http://www.fordham.edu/halsall/mod/1520cortes. html>. Acesso em: novembro 2012.

DALY, H. E. Thermodynamic and economic concepts as related to resource-use policies: comment. Land Economics, 62, p. 319-322, 1986. Disponível em: <http://uwpress.wisc.edu/journals/journals/le.html>. Acesso em: novembro 2012. 
DALY, H. E. Sustainable development: from concept and theory to operational principles. Population and Development Review, 16, p. 25-43, 1990. Disponível em: <www.popcouncil.org/pdr/>. Acesso em: novembro 2012.

DINAR, A. The Political Economy of Water Pricing Reforms. Washington D.C.; New York: The World Bank and Oxford University Press, 2000.

DOUROJEANNI, A.; JOURAVLEV, A. El Código de Aguas de Chile: entre la Ideología y la Realidad. Documento LC/R. 1897. Santiago de Chile: United Nations Economic Commission for Latin America and the Caribbean (ECLAC), 1999.

DUGAN, G.; FISHER, A. Water - the new commodity?. Wealth Journal, London, Barclays Bank, 2006. Disponível em: <http://www.newsroom. barclays.com/imageLibrary/default.aspx?SubjectID=350>. Acesso em: novembro 2012.

DUNLAP, R. E. et al. (Ed.). Sociological Theory and the Environment. Classical Foundations, Contemporary Insights. Lanham; Boulder; New York; Oxford: Rowman and Littlefield, 2002.

Dworak, T., M. Berglund, C. Laaser, P. Strosser, J. Roussard, B. Grandmougin, M. Kossida, I. Kyriazopoulou, J. Berbel, S. Kolberg, J. A. Rodríguez-Díaz, and P. Montesinos. European Union Water Saving Potential (Part 1 - Final Report). Berlim: Ecologic - Institute for International and European Environmental Policy, 2007. Disponível em: http://ec.europa. eu/environment/water/quantity/pdf/water_saving_1.pdf. Acesso em: novembro 2012.

FARUQUI, N. I.; BISWAS, A. K.; BINO, M. J. (Ed.). Water Management in Islam. Tokyo; Ottawa: United Nations University Press and International Development Research Centre, 2001. 
FUNDAÇÃO NOVA CULTURA DA ÁGUA. Declaração Europeia por uma Nova Cultura da Água. Zaragoza: Fundação Nova Cultura da Agua, 2005. Disponível em: <http://www.unizar.es/fnca/euwater/docu/europeandeclaration.pdf>. Acesso em: novembro 2012.

FUNTOWICZ, S. O.; RAVETZ, J. R. The worth of a songbird: ecological economics as a post-normal science. Ecological Economics, v. 10, n. 3, p. 197-207, 1994. doi: 10.1016/0921-8009(94)90108-2. Acesso em: novembro 2012.

GEMAN, H.; KANYINDA, A. Water as the next commodity. The Journal of Alternative Investments, v. 10, n. 2, p. 23-30, 2007. doi: 10.3905/ jai.2007.695264. Acesso em: novembro 2012.

GEORGESCU-ROEGEN, N. The Entropy Law and the Economic Process. Cambridge, MA: Harvard University Press, 1971.

GHOSH, N. Women and the politics of water: an introduction. International Feminist Journal of Politics, 9, p. 443-454, 2007. doi: 10.1080/14616740701607929. Acesso em: novembro 2012.

GIBBS, L. Citizen activism for environmental health: the growth of a powerful new grassroots health movement. Annals of the American Academy of Political and Social Science, 584, p. 97-109, 2002.

GIRI, S. Nature, human labor and the limit of the social. Capitalism Nature Socialism, v. 15, n. 2, p. 65-78, 2004. doi: 10.1080/10455750410001691605. Acesso em: novembro 2012.

GLOBAL WATER INTELLIGENCE. Bulk water transport on the brink of breakthrough. Global Water Intelligence, v. 7, n. 3, 2006. Disponível em: <http://www.globalwaterintel.com/archive/7/3/>. Acesso em: novembro 2012. 
GODDARD, M. Of cabbages and kin: The value of an analytic distinction between gifts and commodities. Critique of Anthropology, v. 20, n. 2, p. 137151, 2000. doi: 10.1177/0308275x0002000203. Acesso em: novembro 2012.

GOLDMAN, M. (Ed.). Privatizing Nature: Political Struggles for the Global Commons. London: Pluto Press, 1998.

GOLDMAN, M. How "Water for All!" policy became hegemonic: The power of the World Bank and its transnational policy networks. Geoforum, v. 38, n. 5, p 786-800, 2007. doi: http://dx.doi.org/10.1016/j.geoforum.2005.10.008. Acesso em: novembro 2012.

GOUBERT, J. P. The Conquest of Water. The Advent of Health in the Industrial Age, Cambridge and Oxford: Polity Press and Basil Blackwell, 1986.

GRAN, P. Islamic Roots of Capitalism. Egypt, 1760-1840. Cairo: The American University of Cairo Press, 1999.

GUHA, R.; MARTINEZ-ALIER, J. Varieties of Environmentalism. Essays North and South. London: Earthscan, 1997.

GYAWALI, D.; DIXIT, A. Water and science: hydrological uncertainties, developmental aspirations and uningrained scientific culture. Futures, 33, p. 689-708, 2001.

HERZ, E. G. Historia del Agua en Buenos Aires. Buenos Aires: Municipality of Buenos Aires, 1979.

HIRSCH, A. M. Water legislation in the Middle East. American Journal of Comparative Law, 8, p. 168-186, 1959.

HOBSON, J. M. The Eastern Origins of Western Civilisation. Cambridge: Cambridge University Press, 2004. 
HOEKSTRA, A. Y. The global dimension of water governance: nine reasons for global arrangements in order to cope with local water problems. The Value of Water Research Report Series, n. 20, 2006. Delft: United Nations Educational Scientific and Cultural Organization (UNESCO) - Institute for Water Education. Disponível em: <http://www.unesco-ihe.org/Value-ofWater-Research-Report-Series/Research-Papers>. Acesso em: novembro 2012.

HOEKSTRA, A. Y. Human appropriation of natural capital: comparing ecological footprint and water footprint analysis. The Value of Water Research Report Series, n. 23. Delft: United Nations Educational Scientific and Cultural Organization (UNESCO) - Institute for Water Education, 2007. Disponível em: <http://www.unesco-ihe.org/Value-of-Water-ResearchReport-Series/Research-Papers>. Acesso em: novembro 2012.

HOUSE OF COMMONS OF CANADA. International Boundary Waters Treaty Act - Bill C-26. 2010. Disponível em: <http://www.parl.gc.ca/ HousePublications/Publication.aspx?Docid=4528706andFile=9>. Acesso em: novembro 2012.

HUANG, H.; YAN, Z. Present situation and future prospect of hydropower in China. Renewable and Sustainable Energy Reviews, 13, p. 1652-1656, 2009.

HUDSON, F. Water - the strategic commodity. Investment Adviser. Edinburgh: Standard Life Investments, 2007. Disponível em: <http:// us.standardlifeinvestments.com/press_office/published_articles/investment_adviser_8th_october.html>. Acesso em: novembro 2012.

HUE, L. T. V. Gender, Doi Moi and mangrove management in northern Vietnam. Gender Technology and Development, v. 10, n. 1, p. 37-59, 2006. doi: 10.1177/097185240501000103. Acesso em: novembro 2012. 
HUNDLEY JR., N. Water and the West in historical imagination. The Western Historical Quarterly, v. 27, n. 1, p. 5-31, 1996.

JAFFE, E. Old world, high tech. Smithsonian Magazine, Dec. 2006. Disponível em: <http://www.smithsonianmag.com/>. Acesso em: novembro 2012.

KAISER, R. A.; PHILLIPS, L. M. Dividing the waters: water marketing as a conflict resolution strategy in the Edwards Aquifer Region. Natural Resources Journal, 38, p. 411-444, 1998.

Khan, F. A., and A. A. Ansari. Eutrophication: an ecological vision. Botanical Review, vol. 71, n. 4, p. 449-482, 2005. doi: 10.1663/0006-8101(2005)071[0449:EAEV]2.0.CO;2. Acesso em: novembro 2012.

LAPAVITSAS, C. Commodities and gifts: why commodities represent more than market relations. Science and Society, v. 68, n. 1, p. 33-56, 2004.

LATIN AMERICAN HERALD TRIBUNE. Argentina investigates foreign water sales. Latin American Herald Tribune. Buenos Aires, 2011. Disponível em: <http://www.laht.com/article.asp?CategoryId=14093andArticleId=323287>. Acesso em: novembro 2012.

LAURIE, N. (Ed.). Special issue: the privatisation and global poverty debate. Geoforum, v. 38, n. 5, 2007. Disponível em: <http://www.journals.elsevier. com/geoforum/>. Acesso em: novembro 2012.

LEE, T. R. Water Management in the 21st Century. The Allocation Imperative. Cheltenham: Edward Elgar, 1999.

LEE, T. R.; JOURAVLEV, A. Prices, property and markets in water allocation. Document No LC/L 1097, Santiago de Chile: United Nations Economic 
Commission for Latin America and the Caribbean (ECLAC), Environment and Development Division, 1998.

LEWIS, L.; SMITH, L. Water whets the appetite of commodity traders with an eye to the next fortune. The Times, London, 19 Oct. 2007. Disponível em: <http://www.thetimes.co.uk/tto/business/industries/banking/article2155587.ece>. Acesso em: novembro 2012.

LIVESEY, S. M. Organizing and leading the grassroots: an interview with Lois Gibbs, Love Canal Homeowners' Association activist, founder of Citizens Clearinghouse for Hazardous Waste, and Executive Director of the Center for Health, Environment and Justice. Organization and Environment, 16, p. 470-473, 2003. doi: 10.1177/1086026603259099. Acesso em: novembro 2012.

LLAMAS FERNÁNDEZ, R. Abastecimiento de agua a la ciudad de México en el siglo XVI. In: CENTRO DE ESTUDIOS HISTÓRICOS DE OBRAS PÚBLICAS Y URBANISMO (CEHOPU) (Ed.). Antiguas Obras Hidráulicas en América [Ancient Hydraulic Works in America], Madrid: Centro de Estudios Históricos de Obras Públicas y Urbanismo (CEHOPU), 1991. p. 189-200.

MACÍAS HERNÁNDEZ, A. M. Aproximación al proceso de privatización del agua en Canarias c. 1500-1879. In: PÉREZ PICAZO, M. T.; LEMEUNIER, G. (Ed.). Agua y Modo de Producción [Water and Mode of Production]. Barcelona: Editorial Crítica, 1990. p. 121-149.

MAKHENA, S. A. Agua dulce a granel. Buenos Aires, 2008. Disponível em: <http://www.makhena.com/granel.html>. Acesso em: novembro 2012.

MALLOL FERRÁNDIZ, J. Alicante y el Comercio de la Nieve en la Edad Moderna . Alicante: Universidad de Alicante and Caja de Ahorros Provincial de Alicante, 1989. 
MANSFIELD, B. Neoliberalism in the oceans: "rationalization", property rights, and the commons question. Geoforum, v. 35, n. 3, p. 313-326, 2004. doi: 10.1016/j.geoforum.2003.05.002. Acesso em: novembro 2012.

MARSHALL, A. Principles of Economics. Unabridged Eight Edition. New York: Cosimo, 2009.

MARTINEZ-ALIER, J. The Environmentalism of the Poor. A Study of Ecological Conflicts and Valuation. Cheltelham, UK; Northampton, MA: Edward Elgar, 2002.

MARTínEZ GIL, F. J. Los Espejos del Agua. Homenajes y Reflexiones en Tiempos de Ayuno. Málaga: Ediciones del Genal, 2003.

MARTINS, H. Risco, incerteza e escatologia. Reflexões sobre o experimentum mundi tecnológico em curso (I). Episteme, v. 1, n. 1, p. 99-121, 1998 a.

MARTINS, H. Risco, incerteza e escatologia. Reflexões sobre o experimentum mundi tecnológico em curso (II). Episteme, v. 1, n. 2, p. 41-75, 1998 b.

MARTINS, H. Hegel, Texas e outros Ensaios de Teoria Social. Lisboa: Século XXI, 1996.

MARX, K. Capital. A Critical Analysis of Capitalist Production. London: Lawrence and Wishart, 1974. v. 1.

MATSUI, K. "White man has no right to take any of it": Secwepemc water-rights struggles in British Columbia. Wicazo Sa Review, v. 20, n. 2, p. 75-101, 2005.

McCARTHY, J. Commons as counterhegemonic projects. Capitalism Nature Socialism, v. 16, n. 1, pp. 9-24, 2005. doi: 10.1080/1045575052000335348. Acesso em: novembro 2012. 
McDONALD, D. A.; RUITERS, G. The Age of Commodity: Water Privatization in Southern Africa. London; Sterling, VA: Earthscan, 2004.

MCNEILL, J. Something new under the Sun. An Environmental History of the Twentieth Century. London: Penguin, 2000.

MEINZEN-DICK, R. S. Public, private and shared water: groundwater markets and access in Pakistan. In: BRUNS, B. R. (Ed.). Negotiating Water Rights. London: International Food Policy Research Institute, 2000. p. 245-268.

MERRETT, S. Introduction to the Economics of Water Resources. An International Perspective. London: University College London Press, 1997.

MEYER, M. C. Water in the Hispanic Southwest. A Social and Legal History, 1550-1850. Tucson: The University of Arizona Press, 1984.

MORAES, A.; PERKINS, P. E. Women, equity and participatory water management in Brazil. International Feminist Journal of Politics, 9, p. 485-493, 2007. doi: 10.1080/14616740701607986. Acesso em: novembro 2012.

MOSS, J. et al. Valuing Water for Better Governance. How to Promote Dialogue to Balance Social, Environmental, and Economic Values? Paris: Business and Industry CEO Panel for Water Suez, 2003. Disponível em: <http://www. pacinst.org/reports/valuing_water/>. Acesso em: novembro 2012.

MURPHY, R. Rationality and Nature. A Sociological Inquiry into a Changing Relationship. Boulder, CO.: Westview Press, 1994.

MURPHY, R. Sociology and Nature. Social Action in Context. Boulder, CO: Westview, 1997.

NEIBURG, F.; NICAISE, N. The Social Life of Water. Bel Air, Port-au-Prince, Haiti. Rio de Janeiro: Viva Rio, 2009. 
NORTH, D. C.; THOMAS, R. P. The Rise of the Western world: a New Economic History. Cambridge: Cambridge University Press, 1973.

O'CONNOR, J. Natural Causes. Essays in Ecological Marxism. New York: Guilford Press, 1998.

OPEL, A. Constructing purity: bottled water and the commodification of Nature. Journal of American Culture, v. 22, n. 4, p. 67-76, 1999. doi: 10.1111/j.1542-734X.1999.2204_67.x. Acesso em: novembro 2012.

ORSOLINI, H. Interview with the Head of the Water Secretariat, Province of Santa Fe, Argentina, by author [Tape recorded]. Sept. 22, 2011.

POMERANZ, K. The Great Divergence. China, Europe, and the Making of the Modern World Economy. Princeton; Oxford: Princeton University Press, 2000 .

PRITCHARD, S. B. Reconstructing the Rhône: the cultural politics of nature and nation in contemporary France, 1945-1997. French Historical Studies, v. 27, n. 4, p. 765-799, 2004. doi: 10.1215/00161071-27-4-765. Acesso em: novembro 2012.

QUINN, F. Canada's freshwater in a continental context. Journal of Contemporary Water Research and Education, 137, p. 55-61, 2007.

RAMOS TINHORÃO, J. Os Negros em Portugal - Uma presença silenciosa. Lisboa: Aminho, 1997.

REDCLIFT, M.; BENTON, T. (Ed.). Social Theory and the Global Environment. London; New York: Routledge, 1994. 
ROGERS, P.; BHATIA, R.; HUBER, A. Water as a Social and Economic Good: How to Put the Principle into Practice. Background Papers. Stockholm: Global Water Partnership (GWP), Technical Advisory Committee (TAC), 1998.

ROGERS, P.; SILVA, R.; BHATIA, R. Water is an economic good: How to use prices to promote equity, efficiency, and sustainability. Water Policy, 4, p. 1-17, 2002.

ROYAL BANK OF SCOTLAND. Water - the next commodity with a critical shortage? European Gazette, Sept. 2008. Edinburgh: Royal Bank of Scotland.

SADEQUE, S. Z. Nature's bounty or scarce commodity: competition and consensus over groundwater in rural Bangladesh. In: BRUNS, B. R. (Ed.). Negotiating Water Rights,. London: International Food Policy Research Institute, 2000. p. 269-291.

SALZMAN, J. Thirst: a Short History of Drinking Water. Duke Law School Legal Studies Research Paper Series, n. 92, 2005. Durham, NC, Duke University, Duke Law School. Disponível em: <http://ssrn.com/abstract=869970>. Acesso em: novembro 2012.

SANT'ANNA, D. B. Cidade das águas: usos de rios, córregos, bicas e chafarizes em São Paulo. São Paulo: SENAC, 2007.

SCHNAIBERG, A.; GOULD, K. A. Environment and Society. The Enduring Conflict. New York: St. Martin's Press, 1994.

Schorr, D. B. The first water-privatization debate: Colorado water corporations in the Gilded Age. Ecology Law Quarterly, v. 33, n. 2, p. 313-358, 2006. Disponível em: http://papers.ssrn.com/sol3/papers.cfm?abstract_ id=907431\#\#. Acesso em: novembro 2012. 
SEALE, C.; CAVERS, D.; DIXON-WOODS, M. Commodification of body parts: by medicine or by media? Body and Society, v. 12, n. 1, p. 25-42, 2006. doi: 10.1177/1357034x06061192. Acesso em: novembro 2012.

SEGERFELDT, F. Water for Sale. How Business and the Market can Resolve the World's Water Crisis. Washington, D.C.: The CATO Institute, 2005.

SEMENTELLI, A. J. Naming water: understanding how nomenclature influences rights and policy choices. Public Works Management Policy, v. 13, n. 1, p. 4-11, 2008. doi: 10.1177/1087724x08321165. Acesso em: novembro 2012.

SHEPPARD, F. London. A History. Oxford: Oxford University Press, 1998.

SISLEY, R. The London Water Supply. A Retrospect and a Survey. London: The Scientific Press, 1899.

SOARES, L. C. Os escravos de ganho no Rio de Janeiro do século XIX. Revista Brasileira de História, 16, p. 107-142, 1988. Disponível em: <http://www. scielo.br/scielo.php?script=sci_serial\&pid=0102-0188\&nrm=iso\&rep=\&ln$\mathrm{g}=\mathrm{pt}>$. Acesso em: novembro 2012.

SPANDONIDE, B. Iceberg freshwater sustainable transportation, a new approach. Paper presented at the Nineteenth International offshore and Polar Engineering Conference. The International Society of offshore and Polar Engineers (ISOPE), Osaka, 2009.

STRAND, G. Inventing Niagara. Beauty, Power, and Lies. New York: Simon and Schuster, 2008.

STRANG, V. The Meaning of Water. Oxford; New York: Berg, 2004. 
STRANG, V. Common senses: water, sensory experience and the generation of meaning. Journal of Material Culture, v. 10, n. 1, p. 92-120, 2005. doi: 10.1177/1359183505050096. Acesso em: novembro 2012.

SWYNGEDOUW, E. Dispossessing H2O: the contested terrain of water privatization. Capitalism Nature Socialism, v. 16, n. 1, p. 8-98, 2005. doi: 10.1080/1045575052000335384. Acesso em: novembro 2012.

TRENTMANN, F.; TAYLOR, V. From users to consumers: water politics in nineteenth-century London. In: TRENTMANN, F. (Ed.). The Making of the Consumer: Knowledge, Power and Identity in the Modern World. Oxford; New York: Berg, 2006. p. 53-73.

UNITED NATIONS (UN). The Dublin Statement on Water and Sustainable Development. Dublin: International Conference on Water and the Environment (ICWE), 1992. Disponível em: <www.un-documents.net/h2odub.htm>. Acesso em: novembro 2012.

UNITED NATIONS (UN). General Assembly declares access to clean water and sanitation is a human right. New York: United Nations, 2010. Disponível em: <http://www.un.org/apps/news/story.asp?NewsI$\mathrm{D}=35456 \& \mathrm{Cr}=$ SANITATION $>$. Acesso em: novembro 2012.

UNITED NATIONS EDUCATIONAL SCIENTIFIC AND CULTURAL ORGANIZATION (UNESCO) - World Water Assessment Programme (WWAP). Water, a Shared Responsibility. The United Nations World Water Report 2. Paris; New York: UNESCO; Berghahn Books, 2006. Disponível em: $<$ http://unesdoc.unesco.org/images/0014/001454/145405E.pdf>. Acesso em: novembro 2012.

UNITED NATIONS EDUCATIONAL SCIENTIFIC AND CULTURAL ORGANIZATION (UNESCO) - World Water Assessment Programme (WWAP). Water in a Changing World. The United Nations World Water 
Report 3. Paris; London: UNESCO; Earthscan, 2009. Disponível em: <www. unesco.org/water/wwap/wwdr/wwdr3/>. Acesso em: novembro 2012.

URS, K.; WHITELL, R. Resisting Reform? Water Profits and Democracy. New Delhi; Thousand Oaks CA; London; Singapore: Sage, 2009.

VAN DER BERGH, J. C. J. M.; VAN DER STRAATEN, J. (Ed.). Toward Sustainable Development. Concepts, Methods, and Policy. Washington DC; Covelo, CA: International Society for Ecological Economics and Island Press, 1994.

VAN DER ZAAG, P.; SAVENIJE, H. H. G. Water as an economic good: the value of pricing and the failure of markets. The Value of Water Research Report Series, n. 19, 2006. Delft: United Nations Educational Scientific and Cultural Organization (UNESCO) - Institute for Water Education. Disponível em: <http://www.unesco-ihe.org/Value-of-Water-ResearchReport-Series/Research-Papers>. Acesso em: novembro 2012.

VENDING MACHINE BUSINESS. History of vending machine. 2009.

Disponível em: <http://www.1st-vending-machine-business.com/history. html>. Acesso em: novembro 2012.

WEBER, M. Science as a vocation. In: GERTH, H. H.; MILLS, C. W. (Ed.). From Max Weber: Essays in Sociology. Oxford: Oxford University Press, 1946. p. 129-156.

WEBER, M. Structures of power. In: GERTH, H. H.; MILLS, C. W. (Ed.). From Max Weber: Essays in Sociology. Oxford: Oxford University Press, 1946. p. 159-244.

Whitelaw, K., and M. J. Andrews. Sludge disposal to sea: the Barrow Deep in the Thames estuary as a case study. Water and Environment Journal, vol. 2, n. 2, pp. 159-170, 1998. 
WHITTINGTON, D. et al. Estimating the willingness to pay for water services in developing countries: a case study of the use of contingent valuation surveys in Southern Haiti. Economic Development and Cultural Change, 38, p. 293-311, 1990.

WILK, R. Bottled water: The pure commodity in the age of branding. Journal of Consumer Culture, 6, p. 303-325, 2006. 10.1177/1469540506068681. Acesso em: novembro 2012.

WILLIAMS, B. L.; FLOREZ, Y. Do Mexican Americans perceive environmental issues differently than Caucasians: a study of cross-ethnic variation in perceptions related to water in Tucson. Environmental Health Perspectives, 110 (Supplement 2), p. 303-310, 2002.

WOLF, A. Indigenous approaches to water conflict negotiations and implications for international waters. International Negotiation, 5, p. 357-373, 2000.

WORLD COMMISSION ON ENVIRONMENT AND DEVELOPMENT (WCED). Our Common Future. Oxford: Oxford University Press, 1987. 


\section{Apuntes para una ecología política de la integración en América Latina y el Caribe ${ }^{1}$}

\section{Introducción}

América Latina y el Caribe pasan indudablemente por un momento excepcional en su historia en relación a las perspectivas de mayor integración de sus pueblos a través de la profundización de las relaciones económico-financieras, comerciales, culturales, de defensa, de infraestructura y, crucialmente, políticas. Es importante reconocer el carácter apasionante de la experiencia actual de los países de la región, especialmente, aunque no solamente en América del Sur. No es necesario excedernos en el romanticismo ni tampoco ignorar las contradicciones, errores, obstáculos y peligros, para partir de un hecho difícil de negar objetivamente: la región enfrenta el Siglo XXI en condiciones inéditamente favorables a la consolidación de procesos de integración con grados de autonomía potencialmente importantes. En el plano institucional no puedo dejar de mencionar como ejemplos los procesos de integración en América del Sur, con la consolidación del funcionamiento de algunas esferas de acción del Mercado Común del Sur (MERCOSUR), incluyendo sus subregiones, y la creación de la Unión de Naciones Suramericanas (UNASUR) y a nivel del continente el lanzamiento de la Comunidad de Estados Latinoamericanos y del Caribe (CELAC). Indudablemente incluso la persona más escéptica o crítica de estos procesos deberá admitir que los mismos representan avances incuestionables en

1 Una versión previa fue publicada en el Anuario de la Red de Investigadores sobre América Latina y el Caribe 2010, Guadalajara, Mexico: University of Guadalajara (UdG), 2014, pp.479-502. Otras versiones fueron publicadas en Bolivia, España y México. 
varias dimensiones del proceso de integración, notablemente en la coordinación de acciones entre países a nivel político institucional.

Ahora bien, en este breve trabajo me preocupa discutir fundamentalmente algunas cuestiones relativas a la relación entre los procesos de integración y de democratización substantiva de las sociedades de la región, colocando el énfasis en los conflictos derivados de las desigualdades e injusticias socio-ambientales, percibidas o demostradas, que emergen en la mayoría de los países en el marco de dichos procesos. Mi argumento central en este capítulo consiste en afirmar que uno de los obstáculos y amenazas más complejos que enfrenta la integración democrática de la región, y en realidad el futuro mismo de la democracia substantiva en nuestros países, es la destrucción de la base material de nuestras sociedades con la consecuente profundización de conflictos vinculados con la injusticia y la desigualdad socio-ambientales. Quiero aclarar que mi posicionamiento no parte del ambientalismo ni del ecologismo, sino que como sugiere el título del capítulo está anclado en los presupuestos de la ecología política. En esta perspectiva, la incorporación de la dimensión ambiental en el análisis y en la acción constituye un elemento fundamental en la lucha por la emancipación humana, particularmente la lucha contra la desigualdad y la injusticia en relación al acceso a los bienes y servicios y la protección contra las amenazas y peligros conectados con los procesos socio-naturales. El proceso de integración latinoamericano y caribeño, entendido como un proceso democrático en sentido substantivo y no meramente formal, confronta en la problemática socio-ambiental uno de sus obstáculos más importantes y difíciles de superar.

\section{Con el objeto de facilitar el análisis he ordenado el texto en la forma de cuatro proposiciones.}

Proposición No 1. Con independencia de la heterogeneidad de las tradiciones intelectuales y políticas y de las condiciones específicas que caracterizan a los distintos países y regiones, la dinámica central del proceso de integración yace en el avance y profundización de relaciones 
capitalistas de producción, distribución y consumo, y sus correspondientes expresiones socio-culturales y politicas. La evidencia sugiere que el proceso de integración está dinamizado fundamentalmente por la profundización de relaciones capitalistas, tanto sea mediante la constitución de algunas autonomías emergentes como por la consolidación y expansión de heteronomías prexistentes.

Proposición No 2. La consolidación y avance de relaciones capitalistas ha estado históricamente vinculada con la destrucción y la expoliación, con efectos muchas veces irreversibles, de la base material de las sociedades humanas. El pasado de América Latina y el Caribe ha sido marcado por el intercambio ecológico desigual con las grandes potencias imperialistas, que está en la base de la deuda ecológica acumulada desde el siglo dieciséis por dichos países y que incluye formas de depredación menos difundidas como el imperialismo tóxico y la biopiratería.

Proposición No 3. El proceso de integración en Sudamérica, con efectos potenciales en el resto de América Latina y el Caribe, está fundado en la consolidación y rápida expansión del crecimiento económico motorizado por un rol activo del estado en apoyar a los actores capitalistas nacionales y transnacionales en los países que lideran el proceso. La creciente autonomía de los estados de la región, reforzada en gran medida por el proceso de integración política, tiende a re-equilibrar en cierta medida la situación histórica de intercambio económico desigual que había sido profundizada por las políticas neoliberales desde la década de 1980. Sin embargo, las formas que asume el proceso de integración en el plano económico-productivo amenazan con profundizar las relaciones de intercambio ecológico desigual entre países y regiones y al interior de los propios países.

Proposición No 4. La destrucción de la base material que acompaña el proceso de intercambio ecológico desigual se presenta como una doble amenaza para el proceso de integración democrática en la región. Por una parte, la destrucción de la base material por definición constituye un 
obstáculo al propio modelo de integración fundado en la profundización de relaciones capitalistas, ya que erosiona los mismos fundamentos de la producción. Por otra parte, el proceso se ha constituido en uno de los motores de la producción y reproducción de desigualdades estructurales, en la forma de injusticia y desigualdad socio-ambientales, y como tal, en un obstáculo crucial al proceso de profundización de la democracia substantiva.

\section{Integración capitalista}

Proposición No 1. Con independencia de la heterogeneidad de las tradiciones intelectuales y políticas y de las condiciones específicas que caracterizan a los distintos países y regiones, la dinámica central del proceso de integración yace en el avance y profundización de relaciones capitalistas de producción, distribución y consumo, y sus correspondientes expresiones socio-culturales y políticas. La evidencia sugiere que el proceso de integración está dinamizado fundamentalmente por la profundización de relaciones capitalistas, tanto sea mediante la constitución de algunas autonomías emergentes como por la consolidación y expansión de heteronomías prexistentes.

El análisis del proceso de integración nos invita a plantear una serie de cuestiones básicas: ¿qué integración? ¿Integración de qué y de quiénes? ¿Integración para qué y para quiénes? ¿Integración a qué costo? El costo, ¿es un costo para quién? No pretendo dar respuesta plena a esas preguntas en un breve capítulo, pero las mismas apuntan a una serie de cuestiones centrales que no pueden ser soslayadas aun cuando se defienda una visión positiva, incluso optimista del proceso de integración. Al menos es importante plantearse estas y otras cuestiones similares en el marco del necesario debate racional que debe acompañar al proceso. En ese sentido, por ejemplo, a pesar de la retórica emitida desde el grupo de países que componen la Alianza Bolivariana para las Américas (ALBA), la dinámica de la integración regional es motorizada por el proceso de acumulación capitalista global, que impone determinaciones incluso a los países de dicha alianza, que defienden 
la construcción de un "socialismo del siglo XXI". Esto no implica negar los avances de la democracia directa en Venezuela ni desde luego los logros históricos de Cuba en una serie de áreas clave para la democratización substantiva de la sociedad como son la educación o la salud. Igualmente, no se trata de ignorar el avance significativo logrado por varios otros países de la región en la rápida reversión de las condiciones extremas de pobreza y la mejora del ingreso para amplios sectores de la población, hechos suficientemente documentados (CEPAL 2009; Cornia 2010; López-Calva y Lustig 2010). Sin embargo, es muy importante despejar equívocos y desmitificar discursos: los procesos de integración en marcha en América Latina y el Caribe están insertos en y son sobre determinados por las dinámicas del proceso de acumulación capitalista de escala global, que se encuentra en un momento de acelerada expansión y profundización en la región. Al mismo tiempo que deben reconocerse los avances democráticos concretos, logrados en un marco de gran heterogeneidad de formas culturales, institucionales, políticas y socio-económicas que caracterizan el proceso de integración en cada territorio nacional y regional, debe también señalarse que el carácter capitalista del proceso entraña consecuencias a distintos niveles, ciertamente en el plano socio-ambiental, que no pueden ignorarse. Vale la pena recordar aquí una conclusión de Norbert Elias sobre la tensión permanente entre la práctica y la estrategia, el corto y el largo plazo, y sobre todo en la relación entre conocimiento y acción en los procesos políticos:

"los gobiernos contemporáneos suelen afirmar -quizás en buena fe- que pueden superar los agudos problemas sociales de sus países 'racionalmente' o 'realísticamente'. Sin embargo, en la práctica lo que suelen hacer es llenar las lagunas de nuestro conocimiento empírico rudimentario sobre las dinámicas de las interrelaciones sociales con doctrinas dogmáticas, panaceas dictadas, o intereses partidarios de corto plazo. Tomando decisiones mayormente al azar, permanecen a la merced de los eventos, cuya secuencia los gobiernos entienden tan poco como su gobernados" (Elias 1978: 31). 
Sintonizando la reflexión de Elías con el proceso de integración que analizamos, no se trata de cuestionar el compromiso político o ideológico ni las intenciones de líderes políticos, gobiernos o alianzas de países, para mencionar solamente a algunos de los actores relevantes, sino de la necesidad de un análisis objetivo de los procesos estructurales que enmarcan el proceso de integración al margen de las voluntades y deseos humanos. En la perspectiva de este artículo, esto implica muy particularmente la necesidad de mayor conocimiento acerca de las interrelaciones entre el proceso de integración democrática y la dimensión socio-ambiental.

En relación con esto, la segunda pregunta, ¿integración de qué y de quiénes?, apunta precisamente a destacar la elevada heterogeneidad de regiones y actores, de tradiciones culturales y políticas, escalas, condiciones físico-naturales, procesos de formación estatal e institucional, y configuraciones de poder intra-, inter-, y trans estatal, entre otras cuestiones. Muy particularmente, entraña una consideración de las diversas tradiciones y prácticas históricas, incluyendo valores y expresiones culturales, de las relaciones que los distintos grupos humanos han establecido con la base material de sus sociedades en las regiones de América latina y el Caribe. Por ejemplo, en el proceso de integración tenemos a los países y regiones andinos, en algunos de los cuales se ha dado un proceso radical de democratización que al menos en el plano del discurso da centralidad a tradiciones y valores culturales (como los del "Buen Vivir" en Bolivia y Ecuador, ver por ejemplo: Farah y Vasapollo 2011; Gudynas 2011) que no tienen un correlato fuerte en las tradiciones prevalecientes en sus vecinos del Cono Sur. Al mismo tiempo, dichas tradiciones andinas también contrastan fuertemente con las dominantes en, solo por mencionar algunos casos, los diversos territorios del Brasil o de las áreas de México, Centroamérica y el Caribe. No se trata aquí de celebrar unas tradiciones sobre otras o establecer jerarquías entre ellas, sino simplemente de reconocer la extremadamente compleja diversidad de lo que se intenta integrar incluso si reducimos el análisis a la dimensión socio-ambiental del proceso.

Desde otro ángulo, en relación a la configuración del poder relativo de los distintos países en las relaciones inter y transnacionales, la integración 
tiene lugar en el marco de la constitución de autonomías capitalistas emergentes y en la consolidación simultánea de heteronomías prexistentes, procesos que se encuentran interconectados. La emergencia de Brasil como un poder económico global y su consolidación como "locomotora" del crecimiento en América del Sur es sin duda el ejemplo más destacado de una autonomía capitalista emergente en pleno proceso de constitución. Por otra parte, la consolidación de heteronomías prexistentes se da notoriamente en el caso de México y la región centroamericana, que desde la década de 1990 ha visto crecer su dependencia con los Estados Unidos, ya sea a través del Tratado de Libre Comercio entre México, Estados Unidos y Canadá iniciado en 1994 como también mediante otra serie de procesos que incluyen la dependencia de países enteros de las remesas enviadas por sus emigrantes y la militarización regional bajo control de los Estados Unidos en el marco de la "guerra contra las drogas", tomando en cuenta que esta última desde luego abarca también a países de América del Sur y particularmente Colombia (Delgado Wise y Ortega Breña 2006; Gammage 2006; Suárez Salazar y Ortega Breña 2007).

Por último, más allá de la retórica de la "integración de los pueblos", que compartimos como ideal y como proyecto político, el análisis desapasionado nos sugiere que en las dimensiones centrales del proceso de integración en marcha prevalece la integración de intereses particulares, no siempre representantes de las mayorías populares, y no en menor medida los intereses de agentes sociales externos a la propia región que se integra. Estos son fundamentalmente intereses capitalistas, es decir, intereses que privilegian la acumulación privada de la ganancia y no la distribución social de los beneficios del desarrollo. Retomaremos este punto con algunos ejemplos posteriormente. Si se acepta la primera proposición sobre el carácter esencialmente capitalista del proceso de integración, podemos examinar en mayor detalle los obstáculos y amenazas que enfrenta el proceso de integración, entendido como un proceso democrático en sentido substantivo, no meramente formal. 


\section{Las condiciones históricas}

Proposición $\mathrm{N}^{\circ}$ 2. La consolidación y avance de relaciones capitalistas ha estado históricamente vinculada con la destrucción y la expoliación, con efectos muchas veces irreversibles, de la base material de las sociedades humanas. El pasado de América Latina y el Caribe ha sido marcado por el intercambio ecológico desigual con las grandes potencias imperialistas, que está en la base de la deuda ecológica acumulada desde el siglo dieciséis por dichos países y que incluye formas de depredación menos difundidas como el imperialismo tóxico y la biopiratería.

Aunque sabemos que los seres humanos siempre han transformado el medio natural, con frecuencia con resultados negativos para el medio y para las propias sociedades humanas (De Vries y Goudsblom 2002), la relación entre la expansión global del sistema capitalista y el incremento cuantitativo y cualitativo de los procesos de destrucción de la base material de la vida, cuando no de la vida misma, está suficientemente documentado. Particularmente el Siglo XX constituyó una etapa de grandes transformaciones antropogénicas del medio ambiente con consecuencias para la vida en general y para la especie humana en particular que aún no alcanzamos a entender ni explicar cabalmente (McNeill 2000; Fischer-Kowalski y Haberl 2007). Desde luego, la relación entre la producción capitalista y la destrucción ambiental, particularmente en relación a sus consecuencias para la vida y las posibles formas de resolución de los problemas (ej. reducción de la biodiversidad, contaminación, calentamiento global, agotamiento de bienes no renovables, etc.), han sido y siguen siendo objeto de un intenso debate. Aunque dado lo breve de este trabajo no podemos desarrollar este punto en detalle, cabe al menos mencionar por su relevancia para nuestro tema que existe un amplio abanico de posiciones y argumentos, respaldados en tradiciones intelectuales y políticas de larga trayectoria, sobre dichas cuestiones.

Para simplificar, tenemos en un extremo a los representantes del determinismo tecnológico a ultranza, para quienes la destrucción de la base 
material por parte del sistema capitalista tiene solución dentro del marco del propio sistema: la solución es más desarrollo tecnológico. En esta posición coinciden tanto defensores del capitalismo así como también algunos de sus críticos más acérrimos, hecho sofisticadamente analizado por el sociólogo portugués Hermínio Martins (Martins 1996; Martins 1998; Martins 1998; Martins 1998). En este extremo del debate, no importa si los árboles desaparecen o si el agua dulce se torna inservible para la vida, pues la tecnología nos permitirá crear soluciones artificiales, en última instancia incluso árboles y agua sintéticos, para resolver esas molestias. En realidad el propio cuerpo humano ya es objeto de dicha transformación tecnológica, con la capacidad creciente de remplazar tejidos e incluso órganos humanos por sustitutos artificiales. En la perspectiva de esta tradición de pensamiento es cuestión de tiempo y de políticas adecuadas que dejen en libertad completa a los actores capitalistas para que puedan desarrollar su inventiva y recrear el universo. Como lo dice el Director de Estudios de los Recursos Naturales del ultra liberal Instituto CATO en Estados Unidos: "No solamente el mundo es hoy sustentable, sino que es más sustentable que nunca antes, en el sentido de que las generaciones futuras serán herederas de un volumen mayor de capital natural y artificial que les permitirá satisfacer sus necesidades mucho mejor que las generaciones precedentes" (Taylor 1994: 49). Para Taylor, el debate de la sustentabilidad es una solución en busca de un problema. En el otro extremo, varias tradiciones intelectuales y políticas han insistido al menos desde el siglo diecinueve en el proceso inherentemente destructor de la base material que caracteriza al capitalismo, hecho que fue conceptualizado por James O'Connor como la "segunda contradicción del capitalismo" (ver también los trabajos de Schnaiberg y colegas: Schnaiberg 1980; Schnaiberg and Gould 1994; O'Connor 1998). Si la primera contradicción enfrenta al capital con el proletariado, en la segunda contradicción el capital se enfrenta con la destrucción de su propia base material de la que depende su existencia.

Cabe aclarar que la toma de conciencia sobre este proceso de destrucción de la base material que caracteriza al sistema capitalista no ha sido, como algunos parecen pensar, un tema de socialistas y ambientalistas 
románticos que no entienden o no quieren entender las realidades económicas de la vida social. Desde la profundización del debate internacional sobre la existencia de "límites" ecológicos a la producción capitalista que se dio desde fines de la década de 1960, empresarios e intelectuales comprometidos con la democracia capitalista también han estado activamente involucrados en la tarea de investigar y demostrar no solamente la existencia de tales límites sino incluso que esos límites ya han sido superados y que la especie humana estaría viviendo "a crédito", en términos ambientales. Desde luego, uno de los casos más notables y mejor conocidos es el del Club de Roma, que en 1972 publicó el ya clásico informe de investigación sobre "Límites al Crecimiento", un informe que cumple 40 años en 2012 y está dando lugar a un debate renovado (Meadows, Meadows et al. 1972; Club de Roma 2012).

Ahora bien, históricamente América Latina y el Caribe formaron parte de los territorios de la acumulación originaria ampliada de los países capitalistas centrales, y estuvieron sujetos a relaciones de intercambio desigual en los diversos planos, incluso el ecológico. Este hecho ha pasado del plano de la mera retórica antimperialista y anticolonialista para formar parte de estudios rigurosos que inclusive han producido estimaciones de la deuda ecológica que los países industrializados han adquirido con el Sur Global, no solamente a través del saqueo colonial directo sino también a través de las formas más sutiles del intercambio ecológico desigual (ver entre otros autores: Bunker 1984; Guha y Martínez-Alier 1997; Hornborg 1998; Martinez-Alier 2002; Martínez-Alier y Olivares 2003; Rice 2007; Rice 2007; Roberts y Parks 2007; Nelson y Robertson 2008; Jorgenson y Clark 2009; Rice 2009; Simms 2009).

Más recientemente, otros mecanismos de injusticia y desigualdad socio-ambiental, algunos también de larga data, han adquirido mayor peso como resultado de los avances tecnológicos en el marco del proceso de globalización capitalista, como por ejemplo el imperialismo tóxico y la biopiratería. El imperialismo tóxico se refiere a la transferencia, impuesta o negociada, de residuos tóxicos originados en un país, normalmente un país industrializado, a países pobres cuyos gobiernos aceptan el trato a cambio 
de una compensación o simplemente no tienen las condiciones de control y regulación que les permitan evitar la descarga de substancias tóxicas en sus territorios. En julio de 2009 el Diario Clarín publicó una noticia que ejemplifica el problema: "Descubrieron en tres aduanas brasileñas 1.600 toneladas con bolsas de sangre, preservativos, pañales usados y jeringas. Llegaban desde Gran Bretaña como plástico. El gobierno dice estar 'furioso' y ordenó repatriar los desechos" (Gosman 2009). Este es un pequeño ejemplo de una práctica bien documentada y extendida a nivel mundial (Martinez-Alier 2002). Sin embargo, el imperialismo tóxico también asume formas más sutiles, como por ejemplo la transferencia a otros países de cargas contaminantes integradas en los productos mercantilizados (Muradian, O'Connor et al. 2002).

Por su parte, la biopiratería, que consiste en la apropiación de material y conocimiento biológico sin reconocimiento ni compensación, es una práctica antigua constituyente del "imperialismo ecológico", un proceso en el cual los países de América Latina y el Caribe fungieron como un escenario central (Crosby 1988; sobre el caso específico de Argentina, ver por ejemplo: Brailovsky y Foguelman 2007). En tiempos recientes, la práctica ha alcanzado niveles elevados de sofisticación a través de los avances de la biotecnología y la ingeniería genética, notablemente en el campo de la bioprospección relacionada por ejemplo con la producción industrial de drogas comerciales y semillas genéticamente modificadas (Shiva 2001). En este sentido, un artículo publicado en enero de 2007 en los Estados Unidos sobre el tema de la bioprospección, discutía “¿quién tiene el derecho a las curas naturales?" (Vecchio 2007). El artículo se refería al hecho que una empresa privada había logrado obtener una patente exclusiva para comercializar productos basados en las propiedades medicinales de la maca, un tubérculo que crece en las alturas andinas y que las comunidades quechuas han utilizado por siglos para aliviar el mal de altura y como afrodisíaco. El de la maca también es un ejemplo pequeño de un proceso global, en el cual los países de América Latina y el Caribe se han convertido en un territorio privilegiado en las disputas en torno a la bioprospección/biopiratería, en gran medida debido a la rica biodiversidad que caracteriza a la región (Peritore y Niles 1992; Falcon y Fowler 2002; Helfrich 2002; Brailovsky y Foguelman 2007). 


\section{Integración e intercambio ecológico desigual}

Proposición $\mathrm{N}^{\circ}$ 3. El proceso de integración en Sudamérica, con efectos potenciales en el resto de América Latina y el Caribe, está fundado en la consolidación y rápida expansión del crecimiento económico motorizado por un rol activo del estado en apoyar a los actores capitalistas nacionales y transnacionales en los países que lideran el proceso. La creciente autonomía de los estados de la región, reforzada en gran medida por el proceso de integración política, tiende a re-equilibrar en cierta medida la situación histórica de intercambio económico desigual que había sido profundizada por las políticas neoliberales desde la década de 1980. Sin embargo, las formas que asume el proceso de integración en el plano económico-productivo amenazan con profundizar las relaciones de intercambio ecológico desigual entre países y regiones y al interior de los propios países.

El desarrollo económico está innegablemente relacionado con la creciente autonomía de los países de la región, particularmente los sudamericanos, y con el proceso de integración en marcha. Los aspectos positivos del proceso ya han sido comentados previamente y son objeto de un amplio reconocimiento internacional, particularmente en el caso de Brasil (OCDE 2010). Ahora bien, hay tres aspectos interconectados que deseo destacar en relación a esta tercera proposición y que tienen que ver con la continuidad, y en algunos aspectos profundización, primero de las relaciones históricas de intercambio ecológico desigual Norte-Sur y la emergencia de dinámicas similares Sur-Sur y, segundo, de la dependencia extrema del extractivismo y la explotación de materias primas que siguen caracterizando a las economías latinoamericanas. En tercer lugar, debe mencionarse el productivismo desarrollista renuente a incorporar la dimensión socio-ambiental, que caracteriza al pensamiento dominante en las elites políticas e intelectuales de América Latina, más allá del nivel discursivo en el que se suele incorporar la temática de la sustentabilidad en sus distintas vertientes, incluyendo el de la concepción del "Buen Vivir" de las tradiciones andinas. 
En relación al primer punto, la continuidad e incluso profundización de las relaciones históricas de intercambio ecológico desigual Norte-Sur y la emergencia de dinámicas similares Sur-Sur constituyen una barrera al proceso democrático de integración. Un ejemplo lo constituye la transferencia de actividades industriales "sucias", prohibidas o extremadamente reguladas en los países centrales (lo que las vuelve económica o legalmente inviables en sus territorios), hacia los países de América Latina y el Caribe. El triste ejemplo de las "papeleras" que han estado en el centro de un conflicto con ribetes casi bélicos, al menos en el plano retórico, entre Argentina y Uruguay, es un caso en cuestión. El tema de los cultivos transgénicos, cuyo cultivo y consumo se encuentra prohibido en Europa por razones eminentemente democráticas (la mayoría de la población se opone a los mismos sobre la base de la información pública acerca de los peligros potenciales de dichos cultivos) pero que en América Latina se ha expandido prácticamente sin restricciones y frecuentemente sin siquiera controles de su impacto sobre la población. Otro caso es el de la minería a cielo abierto con uso de cianuro (y otras substancias peligrosas, como el mercurio), prohibido en mayo de 2010 por el Parlamento Europeo en todo el territorio de la Unión Europea sobre la base del Principio Precautorio y de la Convención sobre la Biodiversidad adoptadas en la Declaración de Río de Janeiro de 1992 (Parlamento Europeo 2010), que sin embargo es empleado por empresas mineras, en su mayoría con matrices en países del Norte pero también de capitales regionales, en toda América Latina y en otros países del Sur Global (Sibaud 2012).

Pero los problemas de intercambio ecológico desigual también se dan entre y al interior de países en el Sur, a veces como resultado de la aplicación irregular de las normas regulatorias que favorece la "migración" de actividades contaminantes a territorios con menos control y otras veces por una reproducción de la relación entre países industrializados y países proveedores de insumos productivos entre países y regiones de América Latina y el Caribe. Un ejemplo clásico ha sido la relación entre Brasil y Paraguay en torno a la energía eléctrica generada en la represa binacional de Itaipú, una situación de desigualdad que el Presidente Lula da Silva contribuyó a revisar en negociaciones recientes con el Presidente Lugo, precisamente 
en el marco del MERCOSUR. Sin embargo, acuerdos recientes entre Brasil y varios países limítrofes para la construcción de represas, por ejemplo, están siendo observados por algunos críticos como una forma de consolidación de relaciones ecológicamente desiguales entre los países. Informes procedentes del Centro de Información del Banco, una entidad basada en Washington que se dedica a monitorear las actividades del Banco Mundial incluyendo los impactos ambientales de los proyectos financiados, alertan sobre esta dimensión importante del proceso de integración. Por ejemplo, en relación a los acuerdos entre Brasil y Perú para la construcción de represas hidroeléctricas en la amazonia peruana los críticos señalan que a Perú le correspondería el rol de proveedor de energía eléctrica y sufriría la mayor parte de los impactos ambientales en su propio territorio (Bank Information Center 2011).

En lo que concierne al segundo punto, es ampliamente reconocido que la dependencia extrema del extractivismo, incluyendo el energético (gas y petróleo) y la explotación de materias primas siguen caracterizando a las economías latinoamericanas, incluso a las más industrializadas como Brasil. Un informe reciente nos recuerda que mientras que los países industrializados, incluyendo a China, exportan principalmente manufacturas, los países "menos desarrollados" siguen dependiendo en forma extrema de la exportación de materias primas: el 70\% de los ingresos de exportación de los países latinoamericanos procede de materias primas agrícolas y minerales (PNUMA 2011: 45-46). Este es un aspecto bien conocido que no tiene sentido repetir aquí, pero vale la pena destacar algunos aspectos que son menos conocidos y que están interrelacionados con el punto anterior, el intercambio ecológico desigual. Por ejemplo, estudios recientes a nivel internacional que buscan incorporar la dimensión ambiental y, particularmente las externalidades ambientales del proceso de producción, colocan el énfasis en factores previamente ignorados en el "costo" de los productos de exportación, por ejemplo los cereales o la carne, pero también los productos industrializados. Es el caso por ejemplo del "agua virtual”, término originalmente acuñado para conceptualizar el agua incorporada en los productos agrícolas de exportación en los países del Medio Oriente y África del Norte (Allan 1998; Allan 1999; Allan 2002). El concepto de agua virtual ha disparado 
un debate muy importante a nivel internacional en el que se demuestra que la mayor parte del agua incorporada en los flujos de intercambio comercial no es contabilizada, lo cual en muchos casos toma la forma de un intercambio ecológico desigual, una transferencia de recursos no remunerada ni compensada (Chapagain y Hoekstra 2004; Chapagain y Hoekstra 2004; Hoekstra 2006; Hoekstra 2007). Lo mismo ocurre, como ya comentamos, con los flujos de contaminación incorporados en los productos comerciales (Muradian, O'Connor et al. 2002), y desde luego con las transferencias en calidad del suelo (ej. consumo de la fertilidad del suelo) que tienen lugar en estos intercambios. Como ya lo anticipara Marx a mediados del sigo diecinueve, "todo progreso de la agricultura capitalista no es sólo un progreso en el arte de esquilmar al obrero, sino a la vez en el arte de esquilmar el suelo; todo avance en el acrecentamiento de la fertilidad de éste durante un lapso dado, un avance en el agotamiento de las fuentes duraderas de esa fertilidad" (itálicas en el original; Marx 1985: 612). Países cuyas economías dependen en gran medida de las exportaciones de productos primarios como carne, cereales y otros productos agrícolas o de materias primas como minerales, maderas, y bienes similares son particularmente afectados por este tipo de intercambio ecológico desigual. Prácticamente todos los países de la región se caracterizan por este tipo de dependencia, que tiene la edad del propio capitalismo. En su fase actual, aspectos centrales del proceso de integración, como es la integración de transportes multimodal que forma parte tanto de la Iniciativa para la Integración de la Infraestructura Regional Suramericana (IIRSA) como del Proyecto Integración y Desarrollo Mesoamérica (Proyecto Mesoamérica), están profundamente comprometidos con la expansión de dicho modelo primario-exportador.

El tercer punto, íntimamente ligado con los anteriores, es el del productivismo desarrollista renuente a incorporar la dimensión socio-ambiental, que caracteriza al pensamiento dominante en las elites políticas e intelectuales de América Latina. En este punto creo que es necesario distinguir entre el plano de la urgencia inmediata y el plano de la estrategia de largo plazo que presupone el proceso de integración. En el plano más inmediato, está claro que el resurgimiento de los países latinoamericanos de la profunda crisis social, económica y política de las últimas décadas es 
un logro extremadamente significativo que debe defenderse y consolidarse. Solamente pensar en que muchos de nuestros países emergieron de la larga noche de las dictaduras para entonces hundirse en la crisis promovida por las políticas neoliberales nos pone en una situación delicada, que a muchos quizás les impide adoptar una posición crítica en relación al proceso actual de recuperación, crecimiento económico e integración regional. Sin embargo, no puede soslayarse la necesidad de la crítica a las formas dominantes de desarrollo económico, que tienden a reproducir o incluso ampliar las tendencias históricas de intercambio ecológico desigual. Una forma concreta que asume el productivismo desarrollista se manifiesta en la división del trabajo, para llamarlo de alguna manera, que suele operarse entre los ministerios de los distintos países. Una tendencia importante es que el poder, materializado entre otras cosas en poder económico, se concentre en los ministerios a cargo de actividades "productivas", como la agricultura, las industrias extractivas, o las grandes obras de infraestructura, mientras que los ministerios a cargo de temas "sociales" y "ambientales" suelen quedar rezagados, cuando no directamente subordinados en la práctica. Un ejemplo relevante es el de Marina Silva, la ex Ministra de Medio Ambiente de Brasil desde el primer mandato del Presidente Lula da Silva, quien fue recriminada incluso públicamente por Lula como responsable por la demora en el proceso de desarrollo del país. En el centro de las tensiones, que finalmente condujeron a la renuncia de la ministra en el mes de mayo de 2008, estaban la insistencia del ministerio a su cargo en la necesidad de completar el procedimiento de licenciamiento ambiental antes de autorizar emprendimientos (ej. grandes obras de infraestructura) y, fundamentalmente, la política destinada a frenar la deforestación en el Amazonas. El caso de Marina Silva es emblemático por su repercusión internacional, habiendo sido además la mano derecha de Chico Mendes y por lo tanto un símbolo no meramente de la lucha ambiental pero también de la lucha por los derechos de los trabajadores rurales y las comunidades indígenas. Sería un error reducir el caso de Marina Silva a una mera anécdota y mucho menos a una confrontación entre individuos, una ruptura entre un presidente y una ministra, o a un problema circunscrito al caso de Brasil, sino que más bien debe analizarse como parte de un proceso que asume formas diferentes a lo largo y ancho 
de América Latina y El Caribe. El ejemplo ilustra un patrón preponderante en la región, en la que por una parte gobiernos y empresas privadas asumen oficialmente el discurso de la sustentabilidad y la responsabilidad ambiental pero en la práctica la dimensión socio-ambiental continúa siendo postergada o incluso ignorada, ante lo que se percibe como cuestiones siempre más urgentes, es decir el desarrollo económico y el progreso material. Sin renunciar a la necesidad evidente de mejora material de las condiciones de vida de las sociedades latinoamericanas, es fundamental no perder la perspectiva y examinar con criterio la direccionalidad del proceso: integración (y progreso material), ¿de quiénes (quiénes son integrados)? ¿para quién se integran las regiones (quién se beneficia)? ¿a qué costo (ambiental, económico, político y socio-cultural)? ¿quién paga ese costo? ¿cómo se paga? Estas y otras cuestiones apuntan a la relación fundamental que existe entre el proceso de integración y el proceso de democratización substantiva de la región, una relación que no podemos dar por sentada.

\section{La injusticia y la desigualdad ambientales}

Proposición $\mathrm{N}^{\circ}$ 4. La destrucción de la base material que acompaña el proceso de intercambio ecológico desigual se presenta como una doble amenaza para el proceso de integración democrática en la región. Por una parte, la destrucción de la base material por definición constituye un obstáculo al propio modelo de integración fundado en la profundización de relaciones capitalistas, ya que erosiona los mismos fundamentos de la producción. Por otra parte, el proceso se ha constituido en uno de los motores de la producción y reproducción de desigualdades estructurales, en la forma de injusticia y desigualdad socio-ambientales, y como tal, en un obstáculo crucial al proceso de profundización de la democracia substantiva.

Como se comentó anteriormente, la noción de "límites naturales" a la producción, es decir la toma de conciencia de que a pesar de la enorme capacidad científica y tecnológica desarrollada (y potencialmente alcanzable) 
por los seres humanos existen fronteras que impone la base material de las sociedades, no es meramente el producto de ambientalistas utópicos y profetas del apocalipsis ecológico sino que actores ilustrados, para llamarlos de alguna forma, entre los propios defensores de la democracia capitalista coinciden en el análisis, como en el caso ya mencionado del Club de Roma. En el mismo sentido, un informe reciente del Panel Internacional de Recursos de Programa de las Naciones Unidas para el Medio Ambiente (PNUMA) indica lo siguiente:

"al igual que en informes previos del Panel, la sobrexplotación de recursos, el cambio climático, los cambios en el uso del suelo, y la pérdida de biodiversidad se han elevado a la cima de las principales preocupaciones internacionales. Un resultado es que 'la sustentabilidad' se ha convertido en un imperativo social y económico entre los gobiernos, las organizaciones internacionales y las empresas. Líderes en estos sectores ahora comprenden que el progreso hacia una economía más sustentable requiere una reducción absoluta en el uso de recursos a nivel global, mientras que el bienestar de los seres humanos demanda simultáneamente una expansión de las actividades económicas y una disminución de los impactos ambientales. El dilema de expandir las actividades económicas y simultáneamente reducir la tasa de uso de recursos y el impacto ambiental que tales usos puedan tener presenta un desafío muy serio a la sociedad" (PNUMA 2011: 7-8).

En relación a nuestro tema, inmediatamente surgen algunas cuestiones relacionadas con las conclusiones de este informe. ¿Es posible plantearse esta noción de "límites" en el contexto de la integración regional de América Latina y el Caribe? ¿No sería la aceptación de la existencia de tales límites una tácita aceptación de la imposibilidad del desarrollo, es decir, de la "expansión de las actividades económicas" que el propio informe del PNUMA reconoce como un requisito para garantizar "el bienestar de los seres humanos" en nuestra región? En este sentido, un tema preocupante a plantearse es en qué medida los "líderes" políticos y empresariales, para usar el lenguaje del informe del PNUMA, del proceso de integración latinoamericano 
y caribeño también comprenden la necesidad de confrontar el dilema que presenta la necesidad de garantizar el bienestar de la población y simultáneamente proteger la base material de las sociedades de la región. El hecho de que una parte significativa de los conflictos sociales que tienen lugar en toda la región estén precisamente conectados en una forma u otra con la percepción y/o realidad efectiva de crecientes injusticias y desigualdades ambientales causadas entre otros factores por la minería a cielo abierto, las fumigaciones de cultivos transgénicos, la deforestación incontrolable, la biopiratería a veces negociada o por lo menos tolerada por los gobiernos, la imposición frecuentemente inconsulta e inclusive forzosa de la construcción de obras masivas de infraestructura que frecuentemente desplazan poblaciones enteras destruyendo sus lugares ancestrales y transformando irreversibles los ecosistemas, o la continua contaminación del aire, el suelo y el agua por actividades económicas no controladas o pobremente reguladas, sugiere que este dilema asume dimensiones aún más colosales en el contexto de nuestra región (Alimonda 2002; Jasanoff 2006; Brailovsky y Foguelman 2007; Kuecker 2007; van Dijck y den Haak 2007; Carruthers 2008; Newell 2009; Urkidi Azkarraga 2010; Zhouri y Laschefski 2010; Pieck 2011). Inclusive si asumimos que existen niveles de conciencia crecientes en los segmentos de liderazgo político y empresarial de América Latina y el Caribe sobre la naturaleza del desafío que se confronta, la evidencia sugiere que entre la toma de conciencia del dilema y la capacidad y/o voluntad de implementar acciones concretas al respecto existe un enorme vacío. Vaya como pequeño, aunque no por eso menos impresionante, ejemplo el caso del fallido intento de pasar una ley de protección de bosques en la provincia de Córdoba, Argentina en el año 2010. Se estima que Córdoba perdió en el curso del siglo veinte el 95 por ciento de su bosque serrano nativo, y el objetivo central de la ley propuesta por una alianza de sectores provinciales era impedir el avance de la deforestación promovido por la incursión acelerada de la agricultura sojera y otras actividades económicas (Barri y de Luca 2009). La ley para proteger ese 5 por ciento de bosque nativo sobreviviente no logró ser aprobada y en su lugar la legislatura provincial pasó otra ley que ha sido denunciada por una amplia gama de actores pues convalida la continua deforestación de la provincia, a punto tal que la propia Defensoría 
del Pueblo de la Nación acaba de expresarse al respecto (Redacción La Voz del Interior 2012). Desde ya, no se trata meramente de una confrontación entre ambientalistas preocupados con la preservación de la naturaleza en abstracto, por un lado, y de gobiernos y empresarios creadores de riqueza por el otro, como a veces se suelen plantear estas controversias en nuestras sociedades. Córdoba, una provincia semidesértica, ha visto seriamente agravada la situación ambiental en las últimas décadas y confronta entre otras cuestiones una crisis hídrica de gran magnitud, relacionada en gran medida con la deforestación extrema y el avance incontrolado de la agricultura intensiva. No solo está en juego la sustentabilidad del propio modelo productivo cordobés sino que la misma calidad de vida de las personas ya está siendo seriamente afectada lo cual sigue dinamizando recurrentes conflictos contra la injusticia y la desigualdad socio-ambientales derivadas de estos procesos. El ejemplo de Córdoba es un caso prominente, pero de ninguna manera constituye una excepción o rareza y más bien ejemplifica un patrón preocupante a nivel regional, ya que los conflictos socio-ambientales han pasado a ocupar un lugar central en nuestras sociedades y tienden a expresar la existencia de profundas contradicciones en el proceso de democratización regional.

\section{Conclusiones: democracia substantiva y lucha socio-ambiental}

En función de lo anterior cabe plantearse algunas cuestiones adicionales: ¿en qué medida el proceso de integración en marcha presupone la profundización de los procesos de injusticia y desigualdad socio-ambiental? ¿Es posible plantearse un modelo de integración democrático que tenga como eje central el abatimiento de la injusticia y la desigualdad simultáneamente en las dimensiones social y ambiental? Por momentos, la dirección que toma el proceso en algunos países de la región, donde la movilización de comunidades afectadas por la minería, las represas, las fumigaciones, y otros problemas similares ha sido respondida incluso con represiones violentas en los casos más extremos y con discursos de desaprobación (por ejemplo, "quienes se oponen a la minería, se oponen al progreso"), nos lleva 
a plantearnos una serie de cuestiones potencialmente importantes para el futuro de la integración regional.

¿Será que en América Latina y el Caribe implícitamente se acepta la hipótesis del politólogo norteamericano Ronald Inglehart según la cual la preocupación por cuestiones ambientales pertenecería a la etapa pos-material del desarrollo social, una característica avanzada que aún se encuentra en el futuro distante para la mayoría de las sociedades menos desarrolladas (Inglehart 1971)? Aunque la hipótesis de Inglehart ha sido consistentemente rechazada en el plano del conocimiento (Brechin y Kempton 1994; Brechin y Kempton 1997; Dunlap y Mertig 1997; Martinez-Alier 2002), la práctica política, incluyendo la de los gobiernos progresistas en relación a los ejemplos mencionados más arriba, frecuentemente parece asumir dicha hipótesis como presupuesto de su política ambiental y de desarrollo.

En relación con lo anterior, ¿será posible reconciliar la justicia y la igualdad sociales con la justicia y la igualdad ambientales? ¿Cuál es el "límite" o "umbral" aceptable de tolerancia a la injusticia y la desigualdad ambientales cuando estas parecen incompatibles con la justicia y la igualdad sociales? ¿En qué situaciones sería legítimo subordinar la justicia y la igualdad ambientales a la justicia y la igualdad sociales? ¿Es posible plantearse esta disyuntiva desde una posición de democracia substantiva, no meramente formal? Estas preguntas revisten gran relevancia, lo que queda de manifiesto particularmente en las grandes disyuntivas éticas y políticas que confrontan los gobiernos progresistas de la región en relación a las contradicciones entre sus políticas ambientales y de desarrollo económico. Valgan como ejemplos los conflictos generados por el proyecto de transvase del Río San Francisco en Brasil, el gasoducto trans-amazónico, la construcción de represas y la minería a cielo abierto en los diversos países de la región, la introducción de cultivos transgénicos, la continua deforestación, la destrucción de la biodiversidad y de la fertilidad de las mejores tierras del continente, la privatización y mercantilización del agua y sus servicios esenciales (aunque con otros nombres, como las "asociaciones público-privadas"), la gestión pública de los desastres "naturales", el tema nuclear (no 
debatido seriamente por los países de la región), o el impacto social de los procesos de cambio climático.

Con el afán de contribuir al debate crítico, en primer lugar, sería conveniente examinar la existencia de obstáculos epistemológicos e inobservables que frenan tanto el avance de la producción de conocimiento como la acción práctica sobre estos problemas. Específicamente es importante revisar los presupuestos de las tradiciones desarrollistas que predominan en la región, de gran vigencia en la actualidad, a la luz de los debates recientes a nivel internacional, incluyendo el debate latinoamericano, sobre la insustentabilidad del modelo de desarrollo prevaleciente. En segundo lugar, es importante discutir el repliegue del pensamiento y la acción políticos al "presente", con un predominio de las visiones hodiocéntricas, ahistóricas, características de la economía neoclásica y de las tecno-ciencias pero que en las últimas décadas han permeado también a las ciencias sociales y a las estrategias de los sectores progresistas comprometidos con la justicia social. ¿Cómo recuperar la capacidad de distanciamiento crítico con respecto a la realidad inmediata, la perspectiva histórica, el análisis de los futuros posibles? En tercer lugar, y para concluir, cabe plantearse el problema en su dimensión ética, y muy especialmente en relación al proceso de autonomización del plano moral y la subordinación de los valores al plano instrumental en nombre del "realismo", la "eficacia" y el pragmatismo político que caracterizan en gran medida la relación entre política ambiental y desarrollo social tanto en la teoría como en la práctica. Una política democrática que tienda a abarcar el conjunto, en perspectiva de largo plazo, requiere la superación de las contradicciones aparentemente irresolubles entre los requerimientos de la justicia y la igualdad ambientales y sociales. A su vez, en el plano intelectual este desafío requiere una ruptura epistemológica que permita alcanzar niveles más elevados de coordinación interdisciplinaria en la producción de conocimiento científico sobre las relaciones sociedad-naturaleza, un proceso en el que las ciencias sociales latinoamericanas están llamadas a jugar un papel central. 


\section{Referencias}

Alimonda, H., Ed. (2002). Ecología Política. Naturaleza, Sociedad y Utopía. Buenos Aires, Consejo Latinoamericano de Ciencias Sociales, CLACSO.

Allan, J. A. (1998). "Watersheds and problemsheds: Explaining the absence of armed conflict over water in the Middle East." Middle East Review of International Affairs 2(1): 49-51.

Allan, J. A. (1999) Israel and water in the framework of the Arab-Israeli conflict.

Allan, J. A. (2002). The Middle East Water Question. Hydropolitics and the Global Economy. London and New York, Tauris.

Bank Information Center (2011). "Represa Hidroeléctrica Inambari." Disponible en: http://www.bicusa.org/es/Project.10078.aspx.

Barri, F. y N. de Luca (2009). El valor de los servicios ambientales. La Voz del Interior, 15 de mayo de 2009. Córdoba: A8.

Brailovsky, A. E. y D. Foguelman (2007). Memoria Verde. Historia Ecológica de la Argentina. Buenos Aires, Editorial Sudamericana.

Brechin, S. R. y W. Kempton (1994). "Global environmentalism: a challenge to the postmaterialism thesis?" Social Science Quarterly 75(2): 245-269.

Brechin, S. R. y W. Kempton (1997). "Beyond postmaterialist values: national versus individual explanations of global environmentalism." Social Science Quarterly 78(1): 16-20.

Bunker, S. G. (1984). "Modes of extraction, unequal exchange, and the progressive underdevelopment of an extreme periphery: the Brazilian Amazon, 1600-1980." American Journal of Sociology 89(5): 1017-1064. 
Carruthers, D. V., Ed. (2008). Environmental Justice in Latin America. Problems, Promise and Practice. Cambridge, MA, and London, UK, MIT Press.

Chapagain, A. K. y A. Y. Hoekstra (2004). Water Footprints of Nations. The Value of Water Research Report Series. Delft, UNESCO.

Chapagain, A. K. and A. Y. Hoekstra (2004). Water Footprints of Nations. Appendices. The Value of Water Research Report Series. Delft, UNESCO.

Club de Roma (2012). “2012: 40 years Limits to Growth. What Was the Real Message of Limits to Growth?”. Disponible en: http://www.clubofrome. org/.

Cornia, G. A. (2010). "Income Distribution under Latin America's New Left Regimes.” Journal of Human Development and Capabilities 11(1): 85-114.

Crosby, A. W. (1988). Imperialismo ecológico. La expansión biológica de Europa, 900-1900. Barcelona, Editorial Crítica.

De Vries, B. y J. Goudsblom (2002). Mappae Mundi. Humans and their Habitats in a Long-Term Socio-Ecological Perspective. Myths, Maps, and Models. Amsterdam, Amsterdam University Press.

Delgado Wise, R. D. y M. Ortega Breña (2006). "Migration and Imperialism: The Mexican Workforce in the Context of NAFTA." Latin American Perspectives 33(2): 33-45.

Dunlap, R. E. y A. G. Mertig (1997). “Global environmental concern: an anomaly for postmaterialism." Social Science Quarterly 78(1): 24-29.

CEPAL (2009). Social Panorama of Latin America 2008. Santiago de Chile, Comisión Económica Para América Latina y el Caribe. 
Elias, N. (1978). What is Sociology? Londres, Hutchinson.

Parlamento Europeo (2010). European Parliament resolution of 5 May 2010 on a general ban on the use of cyanide mining technologies in the European Union. Luxemburgo, Parlamento Europeo.

Falcon, W. P. y C. Fowler (2002). "Carving up the commons-emergence of a new international regime for germplasm development and transfer." Food Policy 27(3): 197-222.

Farah, I. y L. Vasapollo, Eds. (2011). Vivir Bien: ¿Paradigma no Capitalista? La Paz, Bolivia, Postgrado en Ciencias del Desarrollo de la Universidad Mayor de San Andrés (CIDES-UMSA) y Departamento de Economía de la Universidad de Roma "La Sapienza".

Fischer-Kowalski, M. y H. Haberl, Eds. (2007). Socioecological Transitions and Global Change. Trajectories of Social Metabolism and Land Use. Cheltenham, Gloucestershire, UK, Edward Elgar Publishing.

Gammage, S. (2006). "Exporting People and Recruiting Remittances: A Development Strategy for El Salvador?" Latin American Perspectives 33(6): 75-100.

Gosman, E. (2009). Furia en Brasil: llegan residuos tóxicos clandestinos de Inglaterra. Clarín. Buenos Aires, Grupo Clarín.

Gudynas, E. (2011). "Buen Vivir: Germinando alternativas al desarrollo." América Latina en Movimiento(462): 1-20.

Guha, R. y J. Martínez-Alier (1997). Varieties of Environmentalism. Essays North and South. Londres, Earthscan.

Helfrich, S., Ed. (2002). La Vida en Venta. El Salvador, Fundación Heinrich Böll Editions. 
Hoekstra, A. Y. (2006). The Global Dimension of Water Governance: Nine Reasons for Global Arrangements in order to Cope with Local Water Problems, The Value of Water Research Report Series. Delft, UNESCO.

Hoekstra, A. Y. (2007). Human Appropriation of Natural Capital: Comparing Ecological Footprint and Water Footprint Analysis. The Value of Water Research Report Series. Delft, UNESCO.

Hornborg, A. (1998). "Towards an ecological theory of unequal exchange: articulating world system theory and ecological economics." Ecological Economics 25: 127-136.

Inglehart, R. (1971). "The Silent Revolution in Europe: Intergenerational Change in Post-Industrial Societies." The American Political Science Review 65(4): 991-1017.

Jasanoff, S. (2006). "Biotechnology and Empire: The Global Power of Seeds and Science." Osiris 21(1): 273-292.

Jorgenson, A. K. y B. Clark (2009). "The Economy, Military, and Ecologically Unequal Exchange Relationships in Comparative Perspective: A Panel Study of the Ecological Footprints of Nations, 1975-2000." Social Problems 56(4): 621-646.

Kuecker, G. D. (2007). "Fighting for the Forests: Grassroots Resistance to Mining in Northern Ecuador." Latin American Perspectives 34(2): 94-107.

López-Calva, L. F. y N. C. Lustig, Eds. (2010). Declining Inequality in Latin America. A Decade of Progress? Nueva York, Brookings Institution Press y PNUD.

Martinez-Alier, J. (2002). The Environmentalism of the Poor. A Study of Ecological Conflicts and Valuation. Cheltelham, UK, and Northampton, Ma, USA, Edward Elgar. 
Martínez-Alier, J. y A. Olivares (2003). ¿Quién debe a quién? Deuda externa y deuda ecológica. Barcelona, Editorial Icaria.

Martins, H. (1996). Hegel, Texas e outros Ensaios de Teoria Social. Lisbon, Século XXI.

Martins, H. (1998). 0 deus dos artefatos: sua vida, sua morte. Tecnociência e Cultura. Ensaios sobre o Tempo Presente H. Reis de Araújo. Sao Paulo, Estação Liberdade: 149-168.

Martins, H. (1998). "Risco, incerteza e escatologia. Reflexões sobre o experimentum mundi tecnológico em curso (I).” Episteme 1(1): 99-121.

Martins, H. (1998). "Risco, incerteza e escatologia. Reflexões sobre o experimentum mundi tecnológico em curso (II).” Episteme 1(2): 41-75.

Marx, K. (1985). El Capital. Crítica de la Economía Política. México DF, Siglo XXI.

McNeill, J. (2000). Something new under the Sun. An Environmental History of the Twentieth Century. Londres, Penguin.

Meadows, D. H., D. L. Meadows, J. Randers, y W. W. Behrens III (1972). The Limits to Growth. Washington, D.C., Potomac Associates, New American Library.

Muradian, R., M. O'Connor, y J. Martínez-Alier (2002). “Embodied Pollution in Trade: Estimating the environmental load displacement of Industrialized Countries." Ecological Economics 41(1): 51-67.

Nelson, G. C. y R. D. Robertson (2008). "Green Gold or Green Wash: Environmental Consequences of Biofuels in the Developing World." Review of Agricultural Economics 30(3): 517-529. 
Newell, P. (2009). "Bio-Hegemony: The Political Economy of Agricultural Biotechnology in Argentina." Journal of Latin American Studies 41(1): 27-57.

O'Connor, J. (1998). Natural Causes. Essays in Ecological Marxism. New York, Guilford Press.

OCDE (2010). Tackling Inequalities in Brazil, China, India and South Africa. Paris, OCDE Publishing.

Peritore, N. P. and L. B. Niles (1992). "El surgimiento del cartel biotecnológico.” Revista Mexicana de Sociología 54(2): 101-131.

Pieck, S. K. (2011). "Beyond postdevelopment: civic responses to regional integration in the Amazon." Journal of Cultural Geography 28(1): 179-202.

Redacción La Voz del Interior (2012). La Defensoría le pide a Córdoba que cambie su ley de bosques. La Voz del Interior, 14 de enero de 2012. Córdoba.

Rice, J. (2007). "Ecological Unequal Exchange: Consumption, Equity, and Unsustainable Structural Relationships within the Global Economy." International Journal of Comparative Sociology 48(1): 43-72.

Rice, J. (2007). "Ecological Unequal Exchange: International Trade and Uneven Utilization of Environmental Space in the World System." Social Forces 85(3): 1369-1392.

Rice, J. (2009). "North-South Relations and the Ecological Debt: Asserting a Counter-Hegemonic Discourse." Critical Sociology 35(2).

Roberts, J. T. y B. C. Parks (2007). "Fueling Injustice: Globalization, Ecologically Unequal Exchange and Climate Change." Globalizations 4(2): 193-210. 
Schnaiberg, A. (1980). The Environment: From Surplus to Scarcity. New York, Oxford University Press.

Schnaiberg, A. y K. A. Gould (1994). Environment and Society: The Enduring Conflict. New York, St. Martin's Press.

Shiva, V. (2001). Biopiratería. El saqueo de la naturaleza y el conocimiento. Barcelona, Editorial Icaria.

Sibaud, P. (2012). Opening Pandora's Box. The New Wave of Land Grabbing by the Extracting Industries and the Devastating Impact on Earth. London, The Gaia Foundation: 56.

Simms, A. (2009). Ecological Debt: Global Warming and the Wealth of Nations. London, Pluto Press.

Suárez Salazar, L. y M. Ortega Breña (2007). “The New Pan-American Order: The Crisis and Reconstitution of the U.S. System of Global Domination." Latin American Perspectives 34(1): 102-111.

Taylor, J. (1994). “The challenge of sustainable development." Regulation 17(1): 35-50.

PNUMA. (2011). Decoupling natural resource use and environmental impacts from economic growth, A Report of the Working Group on Decoupling to the International Resource Panel. Paris, PNUMA.

Urkidi Azkarraga, L. (2010). Environmental Justice and the Politics of Scale in Latin American Social Movements against Gold Mining. The Cases of Pascua-Lama in Chile and Marlin in Guatemala. Instituto de Ciencia y Tecnología Ambientales. Barcelona, Universidad Autónoma de Barcelona. Doctorado en Ciencias Ambientales. 
van Dijck, P. y S. den Haak (2007). Construcción Problemática. IIRSA y las Asociaciones Público-Privadas en la Infraestructura Vial. Amsterdam, Centro de Estudios y Documentación Latinoamericanos (CEDLA).

Vecchio, R. (2007). Bioprospecting: Who has rights to nature's cures? The Seattle Times, 12 de enero de 2007, Seattle.

Zhouri, A. y K. Laschefski, Eds. (2010). Desenvolvimento e Conflitos Ambientais. Belo Horizonte, Editora UFMG. 


\section{José Esteban Castro}

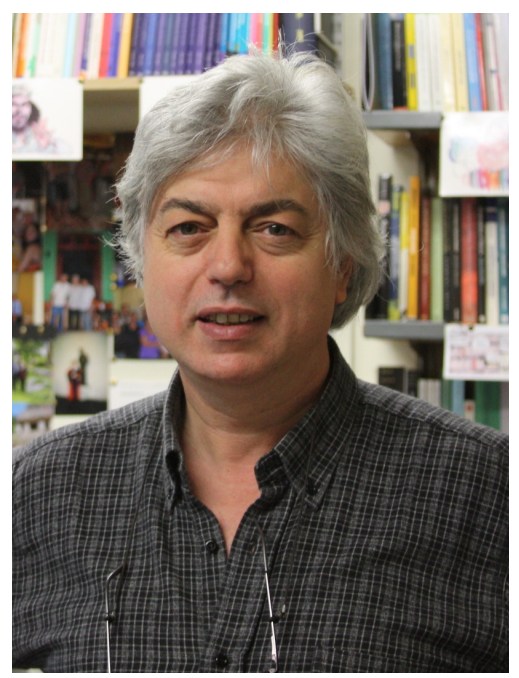

Catedrático (Full Professor) em Sociologia na Universidade de Newcastle, Reino Unido, desde 2005. Previamente foi Pesquisador Principal Associado na Escola de Geografia e Meio Ambiente e no Centro de Estudos Brasileiros da Universidade de Oxford (2001-2004), e Professor em Estudos sobre o Desenvolvimento na London School of Economics and Political Science (2000-2001). Castro tem uma formação interdisciplinar nas ciências sociais: é Licenciado e Professor em Sociologia pela Universidade de Buenos Aires (19831988), estudou Psicologia na mesma Universidade (1984-1990), obteve um Mestrado em Ciências Sociais pela Faculdade Latino-americana de Ciências Sociais (FLACSO) Sede México (1990-1992) e é Doutor em Ciência Política pela Universidade de Oxford (1993-1998). Ele é Membro Correspondente da Academia Mexicana de Ciências. Castro tem realizado tarefas de pesquisa e docência em diversos países, incluindo Argentina, Brasil, Espanha, Colômbia, México, o Reino Unido, e Portugal. Coordena a Rede Internacional WATERLAT-GOBACIT (http://www.waterlat.org), dedicada à pesquisa, a docência e a ação prática em relação à política e a gestão da água e seus serviços. Ele é professor visitante da Universidade Estadual da Paraíba (UEPB) desde 2008. 